AIII0己 I555IB

NAT'L INST, OF STAND \& TECH

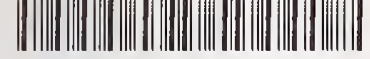

All106 404113

NIST

PUBLICATIONS

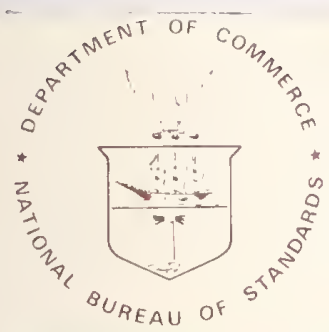

NBS SPECIAL PUBLICATION 674

U.S. DEPARTMENT OF COMMERCE/National Bureau of Standards

\title{
Measurements and Standards for Recycled OHI-IV
}

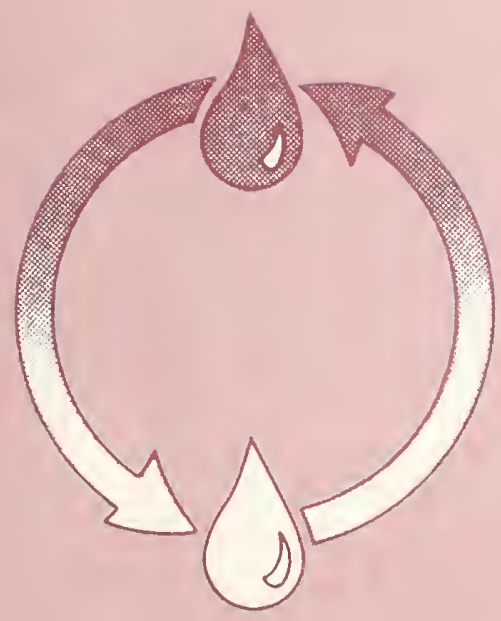




\section{NATIONAL BUREAU OF STANDARDS}

The National Bureau of Standards' was established by an act of Congress on March 3, 1901. The Bureau's overall goal is to strengthen and advance the Nation's science and technology and facilitate their effective application for public benefit. To this end, the Bureau conducts research and provides: (I) a basis for the Nation's physical measurement system, (2) scientific and technological services for industry and government, (3) a technical basis for equity in trade, and (4) technical services to promote public safety. The Bureau's technical work is performed by the National Measurement Laboratory, the National Engineering Laboratory, and the Institute for Computer Sciences and Technology.

THE NATIONAL MEASUREMENT LABORATORY provides the national system of physical and chemical and materials measurement; coordinates the system with measurement systems of other nations and furnishes essential services leading to accurate and uniform physical and chemical measurement throughout the Nation's scientific community, industry, and commerce; conducts materials research leading to improved methods of measurement, standards, and data on the properties of materials needed by industry, commerce, educational institutions, and Government; provides advisory and research services to other Government agencies; develops, produces, and distributes Standard Reference Materials; and provides calibration services. The Laboratory consists of the following centers:

$$
\begin{aligned}
& \text { Absolute Physical Quantities }{ }^{2} \text { - Radiation Research - Chemical Physics - } \\
& \text { Analytical Chemistry - Materials Science }
\end{aligned}
$$

THE NATIONAL ENGINEERING LABORATORY provides technology and technical services to the public and private sectors to address national needs and to solve national problems; conducts research in engineering and applied science in support of these efforts; builds and maintains competence in the necessary disciplines required to carry out this research and technical service; develops engineering data and measurement capabilities; provides engineering measurement traceability services; develops test methods and proposes engineering standards and code changes; develops and proposes new engineering practices; and develops and improves mechanisms to transfer results of its research to the ultimate user. The Laboratory consists of the following centers:

Applied Mathematics - Electronics and Electrical Engineering ${ }^{2}$ - Manufacturing Engineering - Building Technology - Fire Research - Chemical Engineering ${ }^{2}$

THE INSTITUTE FOR COMPUTER SCIENCES AND TECHNOLOGY conducts research and provides scientific and technical services to aid Federal agencies in the selection, acquisition, application, and use of computer technology to improve effectiveness and economy in Government operations in accordance with Public Law 89-306 (40 U.S.C. 759), relevant Executive Orders, and other directives; carries out this mission by managing the Federal Information Processing Standards Program, developing Federal ADP standards guidelines, and managing Federal participation in ADP voluntary standardization activities; provides scientific and technological advisory services and assistance to Federal agencies; and provides the technical foundation for computer-related policies of the Federal Government. The Institute consists of the following centers:

Programming Science and Technology - Computer Systems Engineering.

'Headquarters and Laboratories at Gaithersburg, MD, unless otherwise noted; mailing address Washington, DC 20234.

${ }^{2}$ Some divisions within the center are located at Boulder, CO 80303. 


\section{Measurements and Standards for Recycled Oil-}

Proceedings of a conference held at the National Bureau of Standards

Gaithersburg, Maryland

September 14-16, 1982

Donald A. Becker, Editor

Center for Analytical Chemistry National Measurement Laboratory National Bureau of Standards Washington, DC 20234

Sponsored by:

Recycled Oil Program Office of Recycled Materials National Measurement Laboratory National Bureau of Standards Washington, DC 20234

Co-sponsored by:

ASTM Technical Division P on Recycled Petroleum Products

Association of Petroleum Re-refiners

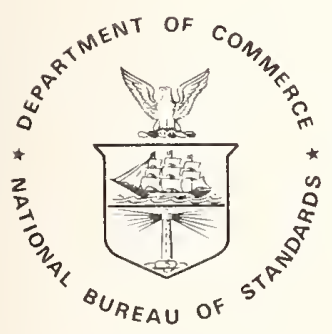

U.S. DEPARTMENT OF COMMERCE, Malcolm Baldrige, Secretary

NATIONAL BUREAU OF STANDARDS, Ernest Ambler, Director

Issued July 1984 
Library of Congress Catalog Card Number: 84-601070

National Bureau of Standards Special Publication 674

Natl. Bur. Stand. (U.S.), Spec. Publ. 674, 314 pages (July 1984)

CODEN: XNBSAV

U.S. GOVERNMENT PRINTING OFFICE

WASHINGTON: 1984

For sale by the Superintendent of Documents, U.S. Government Printing Office, Washington, DC 20402 
On December 22, 1975, President Ford signed into law an act passed by the Congress of the United States entitled "The Energy Policy and Conservation Act of 1975" (Pub1ic Law 94-163). Section 383 of this act states that the National Bureau of Standards (NBS) shall develop test procedures"...for the determination of substantial equivalency of re-refined or otherwise processed used oil... with new oil for a particular end use." Further, NBS is to "...report such procedures to the [Federal Trade] Commission..." as soon as practicable. This fourth NBS conference, held on September 14 through 16, 1982 is part of the NBS response to this legislation.

In additional to usual objectives, this conference was designed to bring together in one place all of the significant work by NBS on the development of test procedures for re-refined lubricating oil. This was done in order to provide a handy reference and compilation of the NBS work. Several papers of non-NBS work of particular relevance were also included.

Certain commercial materials and equipment are identified in this proceedings in order to specify adequately the experimental procedure. In no case does such identification imply recommendation or endorsement by the Naqtional Bureau of Standards, nor does it necessarily imply that the material or equipment indentified is necessarily the best available for the purpose.

This volume, then, essentially completes the efforts of the NBS Recycled 0il Program. During its approximately seven year lifetime, NBS has fulfilled most of the legislative mandates contained in the Energy Policy and Conservation Act of 1975. This work has resulted in over 52 publications in the open literature, as was detailed in the final report of the NBS Office of Recycled Materials (NBS SP 662).

Donald A. Becker

National Bureau of Standards 


\section{ABSTRACT}

This publication is a formal report of the fourth and last Conference on Measurements and Standards for Recycled 011 , held at the National Bureau of Standards on September 14 to $16,1982$. There were five sessions on specific subject areas, with a total of 28 presentations.

This conference was designed to bring together all of the work by NBS and NBS cooperators on the development of test procedures for re-refined lubricating oil. This proceedings contains the entire texts of the various presentations, including figures and tables.

Key Words: Engine oil; hydraulic oil; industrial oil; lubricating oil; oil specifications; petroleum standards; petroleum test methods; recycled oil; re-refined oil; used oil; waste oil. 

Preface.

Abstract

Weicoming Remarks - R. Kammer.

Remarks by the Chairman of ASTM Technical Division P - P. Strigner . . . . . . . . . .

Recent Factors Affecting the 017 Recycling Industry - J. McBain . . . . . . . . . . 5

The California Used $0 i l$ Recycling Program - G. Moskat . . . . . . . . . . . . . . . . .

The Fate of Hazardous Wastes in Used 0i] Recycling - D. Brinkman,

P. Fennelly and N. Suprenant. . . . . . . . . . . . . . . . . . . . . . 13

Analysis of PCB's in 0il: Technique and SRM Development - R. Parris, F. Guenther,

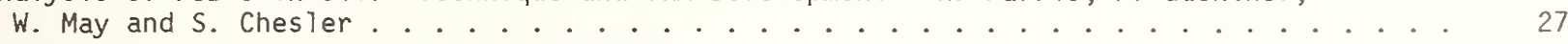

Analysis for PCB's in 0i1: The NBS/ASTM Round Robin - D. Becker. . . . . . . . . . 33

Lube $0 i 1$ Monitoring in the State of California - J. Johnson . . . . . . . . . . . . 43

Revision of the MIL-L-2104C Specification - T. Bowen. . . . . . . . . . . . . . . . . 47

Correlation Aspects of a Virgin and a Re-refined Engine $0 i 1$ Containing the Same Additives -

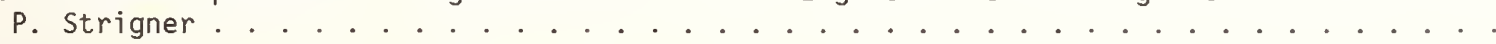

Development of Methodology for Engine Deposit Characterization -

K. Kohl and E. Frame. . . . . . . . . . . . . . . . . . . . . . . . 6]

Development of a Bench Engine Screening Test for Motor 0ils - D. Heath. ......... 75

The ASTM/NBS Basestock Consistency Study - D. Becker. . . . . . . . . . . . . . . . 85

Multiple Regression Analysis: A Look Inside the ASTM/NBS BCS Data - S. Weeks and S. Hsu. . 93

The Consistency of Virgin Basestocks - H. Golinkin. . . . . . . . . . . . . . . . . . . 95

Evaluation of Test Methods for Physical Properties of Re-refined Lubricating Base 0ils -

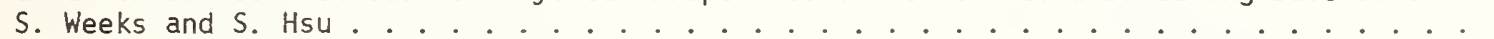

Evaluation of Chemical Property Test Methods for Re-refined Lubricating Base 0ils -

A. Cummings, P. Pei and S. Hsu. . . . . . . . . . . . . . . . . . . . . . . .

Evaluation of Ashing Methods for the Determination of Total Metal Content of Lubricating 0il Basestocks - J. Comeford and S. Hsu . . . . . . . . . . . . . . . . . . .

Development and Use of the Microoxidation Test with Crankcase 0ils - E. Klaus, P. Shah and V. Krishnamachar. . . . . . . . . . . . . . . . . . . . . . 155

Evaluation of a Modified Timken Test for the Characterization of Motor 0ils -

L. Ives, P. Boyer and A. Ruff . . . . . . . . . . . . . . . . . . . . . .

Development of a Step Loading Seizure Test for Engine $0 i 1$ Additive Response -

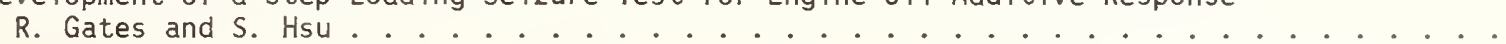

Differential Scanning Calorimetry Test Method for Oxidation Stability of Engine 0ils S. Hsu, A. Cummings and D. Clark. . . . . . . . . . . . . . . . . . . .

Comparative Response of Re-refined and Virgin Lube 0ils to Additives by DSC J. Walker, W. Tsang and L. Szegvary ........................ 
Kinetic Studies for Waste 0iT Demetallization - A. Tarrer, R. Sachhathep, D. Vives and L. Hirth. . . . . . . . . . . . . . . . . . . . . . . . 223

Re-refined Lubricating Base $0 i 1$ Characterization Using Liquid Chromatographic Techniques - P. Pei and S. Hsu. . . . . . . . . . . . . . . . . . . . 241

Evaluation of ASTM D-2007 Method for the Determination of Lubricating $0 i 1$ Composition C. Ku, P. Pej and S. Hsu. . . . . . . . . . . . . . . . . . . . . . .

Test Methods for Total Chlorine in Lubricating Base 0ils - P. Pei, R. Fleming

A Thin-Film Oxygen Uptake Test for the Evaluation of Automotive Lubricants C. Ku and S. Hsu.

Thin-Film 0xidation Test: Relationship Between Composition and Additive Response for Re-refined $0 \mathrm{ils}$ - C. Ku and S. Hsu. . . . . . . . . . . . . . . . . . . 297

NBS Provisional Tests for Re-refined Engine 0iT - D. Becker and S. Hsu. . . . . . . 309 
National Bureau of Standards

Gaithersburg, Maryland USA

September 14-16, 1982

Robert Alvarez

National Bureau of Standards Office of Stand. Ref. Matls.

B1dg. 222, Rm. B311

Washington, DC 20234

Donald A. Becker

National Bureau of Standards

Office of Recycled Matls.

B1dg. 221, Rm. B321

Washington, DC 20234

Anthony S. Bellavia

Pfandler Co.

1000 West Ave.

Rochester, NY 14603

Irving Berkowitz

East Eleventh Street Fuel, Inc.

65-65 Booth Street

Rego Park, NY 11374

Bil? Bider

Franklin Associates

8340 Mission Road, Suite 101

Prairie Village, KS 66206

Fred $\mathrm{Blatz}$

Auto Research Laboratories

6735 S. Harlem Ave.

Chicago, IL 60638

Glenn P. Bone11i

General Waste 0 il Co.

37 Longworth Ave.

Dix Hills, NY 11746

George T. Booth, III

Booth 0 il Co., Inc.

P.0. Box 10112

Buffalo, NY 14210

Thomas C. Bowen

U.S. Army MERADCOM

ATTN: DRDME-GL

Ft. Belvoir, VA 22066

Patrick Brassart

Syndicat Nat'1 Fabricants Raffineurs

44 Rue La Boetic

Paris 8 , France

E. A. Brennan

Brennan Financial Services

16211 Whittier

Whittier, CA 90603
Dennis W. Brinkman

DOE/BETC

P.0. Box 1398

Bartlesville, OK 74005

Anthony Bronson

Lakewood 0 il Service, Inc.

12015 E. Slauson Ave., Suite B

Santa Fe Springs, CA 90670

D. H. Bronson

Lakewood 0 il Service, Inc.

12015 E. S1auson Ave., Suite B

Santa Fe Springs, CA 90670

Evelyn Bronson

Lakewood $0 i 1$ Service, Inc.

12015 E. S1auson Ave., Suite B

P.0. Box 3383

Santa Fe Springs, CA 90670

Sheldon Brontman

Canadian 0 il Company Limited

309 Cherry St.

Toronto, Ontario M5A 3 L3

Douglas M. Cameron

Turbo Manufacturing

Box 5827, Station "L"

Edmonton, Alberta T6C $4 \mathrm{G} 3$

Anthony Cancro

NJ Dept. of Energy

Office of Recycling

101 Commerce Street

Newark, NJ 07102

David Carson

Consolidated Recycling Co., Inc.

8 Commerce Drive

Troy, IN 47588

Paul K. Carson

Consolidated Recycling Co., Inc.

8 Commerce Drive

Troy, IN 47588

Tai S. Chao

Atlantic Richfield Co.

400 E. Sibley Blvd.

Harvey, IL 60426

Jerry Cinq-Mars

Booth 0 il Company, Inc.

P.0. Box 10112

Buffalo, NY 14210 
David B. Clark

National Bureau of Standards

Bldg. 220, Rm. A215

Washington, DC 20234

Jack Comeford

National Bureau of Standards

Bldg. 220, Rm. A215

Washington, DC 20234

Tom Corriveau

American Recovery Co.

Riley Rd.

E. Chicago, IN 46312

Thomas Coyle

National Bureau of Standards

Center for Materials Science

Washington; DC 20234

Bruce Cranford

U.S. DOE

1000 Independence Av., SW

Washington, DC 20585

Arthur L. Cummings

American Sterilizer Company

2424 W. 23rd Street

Erie, PA 16514

George I. Davis

Davis Refining Corp.

P. 0. Box 6089

Tallahassee, FL 32301

Eugene S. Domalski

National Bureau of Standards

Office of Recycled Matls.

Bldg. 220, Rm. B321

Washington, DC 20234

Janise Ehmann

Engineering Science

600 Bancroft Way

Berkeley, CA 94710

J. C. Enslin

S.A. Bureau of Standards

Private Bag $\times 191$

Pretoria, S. Africa 0181

John F. Ferguson, Jr.

Beard Engineering, Inc.

P. 0. Box 3838

Baton Rouge, LA 70821

Edward P. Ferrero

U.S. Dept. of Energy

FE-32; MS-- D-107 (Gtn)

Washington, DC 20545

Dave Fischer

Canadian 0 il Co. Ltd.

309 Cherry St.

Toronto, Ontario M5A 3L3
Ronald F. Fleming

National Bureau of Standards

Bldg. 235, Rm. \# B108

Washington, DC 20234

Donna H. Fothergill

Gulf Canada Ltd.

2489 North Sheridan Way

Sheridan Park, Ontario L5K 1 A8

Richard S. Gates

National Bureau of Standards

Bldg. 220, Rm. A215

Washington, DC 20234

Herbert S. Golinkin

Amoco Chemicals Corp.

P. 0. Box 400

Naperville, IL 60566

Cary Gravatt

National Bureau of Standards

Bldg. 223, Rm. B354

Washington, DC 20234

A. P. Gregg

Lawler Mfg. Inc.

262 Lackland Dr.

Middlesex, NJ 08846

Thomas Harman

Harman Const.

5231 Tow Creek Road

N. Tonawawda, NY 14120

Dan Heath

Franklin Research Center

20th \& Race Streets

Philadelphia, PA 19103

Charles H. Hogue

Lubrizol

29400 Lakeland Blvd.

Wickliffe, OH 44092

John Holuk

Shell Canada

3415 Lakeshore Rd. West

Oakville, Ontario L6J-5L7

Canada

Stephen M. Hsu

National Bureau of Standards

Bldg. 220, Rm. A215

Washington, DC 20234

Gino Iannucci

Texaco Inc.

P. 0. Box 509

Beacon, NY 12508

Earl Jacklin

Warden $0 i 1$ Co. Inc.

187 Humboldt Ave. No.

Minneapolis, MN 55405 
Kenneth J. Jewett

National Bureau of Standards

B1dg. 220, Rm. A215

Washington, DC 20234

C. B. Johnson

Turbo Manufacturing

P.0. Box 5827, Sta. 7

Edmonton, Alberta T5W 1 V9

Canada

James Johnson

Calif. Div. of Measurements Stand.

8500 Fruitridge Road

Sacramento, CA 95826

Watter Johnson

John Deere \& Company

Technical Center

3300 River Drive

Moline, IL 61265

Jennings $H$. Jones

Penn State University

Chemical Engineering Dept.

133 Fenske Laboratory

University Park, PA 16802

Don Jordan

Basic Petroleum Inc.

Refinery Services

13331 Hwy 33

Patterson, CA 95363

Jacob Kalmacoff

HUB $0 i 1$ Company, Ltd.

5805 - 17th Avenue. S.E.

Calgary 23, Alberta

CANADA

Karen B. Kohl

Southwest Res. Inst. AFLRL

6220 Culebra Rd.

San Antonio, TX 78284

Chia-Soon Ku

National Bureau of Standards

Bldg. 220, Rm. A215

Washington, DC 20234

Rong-Sheng Lin

Res. Asso.-Chinese Pet. Corp. National Bureau of Standards

Washington, DC 20234

Russe 11 E. Linnard

Phillips Petroleum Company

256 PLB, PRC

Bartlesville, OK 74004

John A. Lundquist

Quaker State $0 i 1$ Refining Corp.

Research Center, P.0. Box 989

$0 i 1$ City, PA 16301
Thomas J. Manning

Resource Technology, Inc.

6803 W. 64th Street

Shawnee Mission, KS 66202

Denzil Mathews

National Bureau of Standards

Bldg. 220, Rm. A215

Washington, DC 22034

T. Jack Mayer

Sun Tech, Inc.

P. 0. Box 1135

Marcus Hook, PA 19061

James A. McBain

Association of Petroleum Re-Refining

Suite 1111, $2025 \mathrm{~Pa}$., Ave.

Washington, DC 20006

Holly A. McDow

H.A. Associates

6363 San Felipe \#151

Houston, TX 77057

Robert Mehrabian

National Bureau of Standards

Center for Materials Science

Washington, DC 20234

Steven Miller

Ekotek, Inc.

1600 North, 900 West

Salt Lake City, UT 84116

P. E. Mizelle

Cities Service Company

Box 3908, 12PPT

Tutsa, OK 74102

John A. Moore

The 0il Daily

Suite 1010

1301 Pennsylvania Ave., NW

Washington, DC 20004

Kimbal1 L. Morris

AOR CAM-OR, Inc.

2340 S. Tibbs Ave.

P.0. Box 41271

Indianapolis, IN 46241-0271

Gunther Moskat

Calif. Solid Waste Mngmt. Board 1029--9th Street

Sacramento, CA 95814

John P. O'Conne 17

Motor 0ils Refining Company

7601 W. 47th Street

McCook, IL 60525 
Stephen 0dojewski

Waste Resource Associates

2576 Seneca

Niagra Fal1s, NY 14305

T. L. 01 iphant

Witco Chem. Cord.

77 N. Kenda11 Ave.

Bradford, PA 16701

Patrick Pei

National Bureau of Standards

B 1 dg. 220, Rm. A215

Washington, DC 20234

Michae 1 Petruska

U.S. EPA

Hazardous \& Industrial Waste Div.

401 "M" St., SW (WH-565A)

Washington, DC 20460

C. A. Phalen

She 11 Development Company

P. 0. Box 1380

Houston, TK 77001

Richard L. Riedel

The Standard $0 i 1$ Co.

3092 Broadway

Cleveland, $\mathrm{OH} \quad 44115$

James G. Ryder

Bonar-Zimmark, Inc.

Hills Place

London, U.K.

Arman Sachhathep

Dr. A. R. Tarrer

Auburn University

Chemical Engineering Dept.

Auburn, AL 36849

Karen L. Sale

Association of Petroleum Re-Refiners

2025 Penn., Ave., Suite 1111

Washington, DC 20006

E. J. Saunders

Caltex Petroleum Corp.

P. 0. Box 61500

Dallas, TX 75261

L. Robert Sawive11

CAM-OR of Texas, Inc.

(S \& R $0 i 1$ Company)

P.0. Box 35516

Houston, TX 77235

John W. Schulte

Lubrizol Corp.

Wickliffe, OH 44092

G. Darre11 Scruggs

KTI Corp.

221 E. Walnut St.

Pasadena, CA 91006
Morton Sega 1

Petrocon Corp.

Union Street

Modena, PA 19358

Donald J. Smolenski

General Motors Res. Laboratories

Fuels and Lubricants Dept.

Warren, MI 48090-9055

Paul Strigner

Nat1. Res. Council of Canada

Fue1s \& Lubricants Laboratory

Ottawa, Canada K1A OR6

N. F. Surprenant

GCA/Technology Div.

Bedford, MA 01730

Hi iary Tatem

Maryland Environmental Service

60 West Street

Annapolis, MD 21401

H. E. Tiffany

API/Consultant

P. 0. Box 94

Wallingford, PA 19086

Wing Tsang

National Bureau of Standards

Washington, DC 20234

Marcel Veronneau

Environmental Waste Removal, Inc.

130 Freight St.

Waterbury, CT 06702

A. Vidal

Compagnie Francaise de Raffinage

Centre de Recherches

Route Postale u.27

Harfleur, France 76700

W. E. Waddey

Exxon Research and Engr. Co.

P.0. Box 51

Linden, NJ 07036

Frank Wagner

Bres 1 ube Enterprises

P.0. Box 130

Brealau, Ontario NOB 1 MO

James A. Walker

National Bureau of Standards

Chemical Kinetics Div.

Washington, DC 20234

Mark A. Ward

Pennzoil Products Co.

8015 St. Vincent Ave.

P.0. Box 6199

Shreveport, PA 71106 
Stephan J. Weeks

National Bureau of Standards

B1dg. 220, Rm. A215

Washington, DC 20234

Marvin Whisman

Energy Resources Ltd. Partnership

1514 Black Gap Road

Fayetteville, PA 17222

Dana C. Wilson

Association of Petroleum Re-Refiners

2025 Pennsylvania Ave.

Washington, DC 20006

Lowell A. Wilson

Bonar Zimmark Inc.

936 West Fullerton Ave.

Addison, DE 60101

Terrance A. Wilson

Mohawk Lubircants Limited

130 Forester Street

$\mathrm{N}$. Vancouver, British Columbia V7H $2 \mathrm{M} 9$

Canada

Richard J. Windgassen

Amoco 0 il Co.

P. 0. Box 400

Naperville, IL 60540

Keith L. Winegar

Inter Mountain $0 i 1$ Co.

Box 86

Woods Gross, UT 84087

Peter G. Wright

Imperial 0 il Limited

453 Christina St.

P. 0. Box 3022

Sarnia, Ontario N7T 7MI

Yung Chi Wu

National Bureau of Standards

B1dg. 220, Rm. A215

Washington, DC 20234

Harvey Yakowitz

National Bureau of Standards

Office of Recycled Matls.

B1dg. 221, Rm. B321

Washington, DC 20234

John J. Yates

Consultant

320 S. Sunset Ave.

LaGrange, IL 60525 



\section{WELCOMING REMARKS}

Good Morning and welcome to the National Bureau of Standards (NBS). Once again, it is a pleasure for us to be sponsoring this fourth NBS Conference on Measurements and Standards for Recycled 0il. I also wish to publicly acknowledge the cooperation and assistance of the cosponsors, ASTM Technical Division P on Recycled Petroleum Products, and the Association of Petroleum Re-refiners.

As I stand here addressing you, I cannot help but reflect back over the past six years since NBS first became involved with recycled oil, and over the very substantial changes in the outlook for oil recycling which have occured since that time. There has been Congressional legislation eliminating tax differentials and modifying labeling requirements; one major military specification has been changed and you will hear today about modifications to a second specification; the ASTM Technical Division $P$ on Recycled Petroleum Products was formed which has provided a strong alliance between the various industries and with government; and so on. There is no longer a question about "why recycle oil," it is now "which is the best way to recycle oil."

The improvement in acceptance of recycled oil products has also been significant. It is hoped that with the recommended test procedures to be presented on the final day of this conference, this acceptance of quality re-refined lubricating oil will take a further substantial step forward.

I know these improvements did not come easily. Many of you were in the forefront of that fight, and still continue to fight the battle. I believe that NBS and its work on recycled oil has been a help to you in this fight, and I also believe that the set of provisional tests that we are recommending for establishing the consistency of re-refined oil will provide the technical handle necessary for the effective utilization of properly re-refined lubricating oil. It has been a long, hard, complex job, but we are finally close to the end.

As most of you are aware, NBS funding for the Recycled $0 i 1$ Program officially terminates in approximately two weeks. As a consequence, the Recycled $0 i 1$ Program and the Tribochemistry Group has been striving mightily to complete this portion of the program, and to provide the set of provisional test procedures they will report on in this conference.

Thanks again for coming, and we look forward to the contributions you will make to advance the cause of effective oil recycling. 

Technical Division P on Recycled Petroleum Products of ASTM Committee D-2 is once again pleased and honored to be a joint sponsor of this excellent Conference on Measurements and Standards for Recycled 0i1. Clearly though, the NBS and notably two key hard working and dedicated NBS scientists, Mr. Donald Becker and Dr. Stephen Hsu, deserve a lions's share of credit for organizing the conference and indeed presenting a major share of the papers.

It is with a heavy heart that Division $P$ received the news of the closure of the office of Recycled Materials and its Recycled 0 il Program. Both have contributed so much since they were created several years ago and have so much yet to contribute that it seems difficult to envisage the recycling world without their presence. Because Division $P$ was so thoroughly dependent upon the ceaseless and valuable contributions of the NBS Recycled 0il Program, in terms of manpower, direction and laboratory service, the Division may very well suffer, especially in these times of austerity. Who will continue to do the practical and fundamental work that NBS did on re-refined base stocks, used oil fuels, recycled finished products and analytical methods for toxic materials? Who will serve as the focal point for information dissemination and recycled product specifications and test methods?

Let us hope that the membership of Division $P$ is strong and resolute and can make up this 10 s. Let us hope that the APR will take a stronger hand to take up the big slack left by the departure of NBS. Let us hope that the NBS program and as we11 DOE/BETC can be revived even partial1y to continue with their good works. It is understood that lobbying efforts may have some success here.

Thanks, then, Don and Steve and NBS for your outstanding contributions to the efforts of Technical Division P on Recycled Petroleum Products of ASTM Committee D-2. The Division wishes you great success in your present conference and your future activities. The Division also recognizes the outstanding contributions of Dr. Jack Comeford, formeriy of NBS and the past vice-chairman of Division P.

Paul Strigner, Chairman, Technical Division $P$ (ASTM Committee D-2) on Recycled-Petroleum Products 
National Bureau of Standards Special Publication 674. Proceedings, Conference on Measurements and Standards for Recycled 0i1 - IV, held at NBS, Gaithersburg, MD, September 14-16, 1982.

(Issued July 1984).

RECENT FACTORS AFFECTING THE OIL RECYCLING INDUSTRY

James A. McBain

Executive Director

Association of Petroleum Re-Refiners

The topic -- RECENT FACTORS AFFECTING THE OIL RECYCLING INDUSTRY is extremely broad, for more has happened in the past few years that affect this industry than has happened in the previous two decades!

Many of you here are probably involved in much of the technological aspects of oil recycling and may not be aware of the recent history of the industry. In order to appreciate the factors affecting us today and the outlook for the future, a glimpse of the industry's history may provide some comparison with which to view the industry of tomorrow.

$0 i 1$ recycling is not new. It dates back to the early 1900s. The industry and the use of re-refined oil grew rapidly. By the 1960 s the industry contained almost 150 companies re-refining almost 300 million gallons of used oil per year, almost 18 percent of our nation's lubricating needs. By the late 1970 s the industry had dwindled to less than 20 companies producing less than 100 million gallons of re-refined oil per year, or less than 10 percent of our lubricant needs. There are many reasons for the decline of the industry. A few are significant.

FIRST: The use of used oil as a road dust suppressant and as a fuel increased dramatically. This increased competition for used oil reduced the flow of feedstock to re-refiners and led to drastically higher prices for the feedstock they were able to obtain.

SECOND: Overcapacity in the fresh oil market brought lube oil prices down sharply. This prevented re-refiners from passing on increased costs of operation, created financial losses for many, and a shrinking of the industry.

THIRD: The improvement in automotive and lubricant technology required the development of higher levels of re-refining technology. But the industry was already depressed, and few companies could afford the capital expense necessary to upgrade their facilities and keep pace with the developments in the rest of the industry. A few did, of course, but, in general, product quality did not grow as fast as the growth in lubricant technology. This cast a stigma of product inferiority which, although decreasing, still plagues the industry today.

The picture of an industry in change is not unique. It is no more than the process of industrial growth. But in the case of the oil recycling industry, technological growth was stunted by several limiting government actions.

ONE: The Department of Defense eliminated re-refined oil from its procurement list. No matter how good a re-refined oil was, it was not even allowed to qualify under DOD specifications. Since DOD specifications were utilized by virtually all government agencies even at the local level, the entire governmental market was closed to the re-refining industry.

TW0: The Federal excise tax of 6 cents per gallon was imposed unfairly on re-refined lubricants and had to be absorbed by re-refiners.

THREE: The Federal Trade Commission imposed a restrictive labeling rule in 1964 . In essence, the rule required that re-refiners state prominently on the label "Made from previously used oil" which connotated an inferior product.

Since 1978 the picture of the industry has changed dramatically. The Department of Defense has altered its specifications to allow re-refined oil to qualify under military specifications. Re-refined oil has been exempted from the Federal excise tax, and the USED OIL RECYCLING ACT which passed in 1980 eliminated the FTC labeling rule. 
The process of bringing about change in the legislative and regulatory arenas also increased public awareness of used oil recycling. These changes and increased public awareness have already brought about new growth in the industry. As of today, eight new re-refining facilities either have been or are in the process of being built, and more are expected. APR membership alone has almost doubled.

All these legislative and regulatory changes did not come about without some effort on the part of the industry. Through their involvement and commitment to bring about positive change and new growth to the oil recycling industry, the members of APR have made their association a dominant force in the changes that have occurred and are expected to occur in the future.

In 1976, Congress passed the Resource Conservation and Recovery Act. Among other things, that act required the EPA to issue regulations concerning the utilization of used oil. In 1980, the Used 0 il Recycling Act again required EPA to act. Today, almost 9 years since the passage of RCRA, EPA has still failed to propose any regulations in this area. EPA's current target date for used oil regulation is the fall of 1983. However, to most observers this is merely another date that EPA will delay as they see fit. EPA's failure to act in this area frustrates the industry and the Congress as wel1.

Congressman Jim Florio, House sponsor of the Used $0 i 1$ Recyciing Act is taking on the EPA again. He has recentiy introduced HR 6307 which would once again require EPA to act as soon as possible in this area. Mr. Florio has asked for and has received APR support in these efforts.

On another legislative front, it is possible that we will be successful in getting the Congress to refund the NBS Program on Recycled $0 i 1$ for another year. We were successful in getting the House Appropriations Committee to refund one million dollars for the program in FY 1983 . If we are successful in a similar manner in the Senate, this program could continue.

In the area of public education exciting things are happening as well.

FIRST: The Muscular Dystrophy Association has selected used oil collection as one of its campaigns. MDA will urge the public via various media sources to return their used oil to collection centers. Currently they are conducting a test of this program in Texas in cooperation with one of our members, CAM-OR of TEXAS. MDA gets a percentage of the price paid for the used oil that is returned and collected from collection sites participating in the MDA program, which helps to fund their activities. If successful, the MDA program will spread throughout the country. MDA can reach almost 98 percent of the television viewing public. The benefits are obvious, both to MDA and the cause of public education on the issue of oil recycling.

SECOND: The National Association of 0 il Recovery Coordinators has recently decided to join the APR as a separate section of the association. NAORC is made up of government officials responsible for establishing oil recovery programs in their states. The potential for cooperation among the states through NAORC is great. We are hopeful that a coordinated effort between the industry and government officials at all levels will lead to increased oil recovery and enhance the growth of the industry.

THREE: The recent International Conference on used oil recovery in Las Vegas has generated more interest in used oil from a wide spectrum of industrial and private enterprise. The conference drew almost 700 participants, with delegates from over 30 nations in attendance. The next conference will be held in November 1983, again in Las Vegas. We are looking forward to an even higher level of participation from many nations around the world.

Finally, a unique change has occurred within the APR itself. It has opened its membership to a broader representation of the entire oil recycling industry.

If the past three years were positive, the next few years should prove to be even more dramatic. Technology will experience advancement, and re-refining equipment will become more sophisticated. New companies will be entering the field and more of industry will be discovering the hidden asset in the reuse of oil.

Whatever the changes, APR will be involved, actively working on behalf of the industry. For those of you here who are not yet members of the association, I would urge you to seriousiy consider membership. Working together, we can further shape the legislative and regulatory environment in which the entire industry can prosper. 
National Bureau of Standards Special Publication 674. Proceedings, Conference on Measurements and Standards for Recycled 0i1 - IV, held at NBS, Gaithersburg, HD, September 14-16, 1982.

(Issued July 1984).

THE CALIFORNIA USED OIL RECYCLING PROGRAM

\author{
Guenther W. Moskat \\ Used 0 il Recycling \\ State of California \\ Sol id Waste Management Board
}

Used oil in California is classified as a hazardous waste material subject to the regulatory overview of many agencies. Because of its classification as such, used oil is regulated by the State Department of Health Services (DOHS), and subject to manifesting and vehicle registration requirements; the Air Resources Board (ARB), who regulates emission levels and hydrocarbon emissions from processing plants and fuel oil burners; the Regional Water Quality Control Boards who monitor oil disposal operations; the California Highway Patrol, who performs vehicle inspections of the hauling industry; and the State Solid Waste Management Board (SWMB), who regulates used oil recycling activities in the state.

My presentation will focus upon the latter area of used oil recycling, and the program California has developed to effectively monitor the disposition of over 50.6 million gallons of used oil collected and recycled each year in the state. In addition, I will discuss the efforts the state has made to promote the concept of oil recycling through public awareness and marketing activities.

To understand California's used oil efforts, I would like to provide you with a background into how California's oil recycling program got started and the directives issued by the State Legislature to assure the maximum utilization of recovery were undertaken.

As early as 1977, the Legislature enacted the California Used $0 i 1$ Recycling Act. This act basically did 2 things: 1) it prohibited the indiscriminate disposal of used oil, and 2) it required the SWMB to implement a used oil recycling program on or before Jan. 1 , 1979 . Because the SWMB already was engaged in overseeing recycling activities associated with other materials such as metal, aluminum, glass and newsprint, the Board was appointed as the lead agency to carry-out these five functions:

1) adopt rules requiring oil retailers to post signs indicating the location of a nearby used oil collection facility;

2) establish, maintain and publicize a used oil information center to explain laws and regulations governing used $0 i 1$ and to inform holders of quantities of used oil on how and where the used oil may be properly disposed;

3) encourage the establishment of voluntary used oil collection and recycling programs;

4) encourage the procurement of re-refined automotive and industrial oils for all state and $10 \mathrm{cal}$ uses, when prices were found to be competitive with new oils produced for the same purposes; and,

5) adopt rules and regulations governing the operations of all used oil haulers, collection facilities, recyclers and transfer facilities.

I would now like to discuss each of these functions in detail:

First, in order to collect data on the volume of used oil collected and processed each year in the state, the Board was directed to establish rules and regulations governing the operations of all used oil haulers, collection facility operators, transfer facility operators, and recyclers. Included in these regulations is the requirement that all industry members be registered by the Board, provide receipts for a 11 oil transactions, and submit an annual report each February 1 , describing the amounts of oil handled during the calender year. 
Included in the registration process is the requirement that all operators be registered as hazardous waste haulers with the DOHS who, as I mentioned, oversees hazardous waste activities in the state.

As of this time, there are over 130 haulers registered to collect and transport used oil in California. The size of these firms range from simple 1 truck "Mom and Pop" operations to large scale interstate carriers, with fleets of up to 40-50 vehicles.

Along with the hauling industry, there are over 17 recyclers of used oil located in California. This figure includes 7 re-refiners, 1 processor of asphalt, 1 road oil processing plant, and 8 fuel oil processors.

The data which is submitted each year to the Board includes volumetric data, addresses, vehicle license numbers and plant capacities, and these are all maintained by the Board in a computer system. This system was developed in 1980 and incorporates state of the art equipment which the Board feels is necessary to keep pace with the ever increasing activities of the used oil industry.

The Board uses the information kept on the used oil industry to examine areas of the state where used oil collection is not readily available, and presents this data to the industry to maximize recovery efforts in these sometimes isolated areas. The system maintained by the Board is also distributed to neighboring states to assist in identifying used oil trafficking patterns in the western states area.

With its registration system in place, the Board moved to establish a used oil information center, designed to explain laws and regulations governing used oil activities to industry members, the public, and other governmental agencies. In order to effectively provide for easy access to the information center by these various entities, the Board established a toll-free information line for use within the state. As a clearinghouse, the Board receives over 1,400 telephone calls each year regarding questions on the state's used oil program.

In addition to the establishment of its toll-free information line, the Board also maintains a technical assistance line on a non-toll free basis, where individuals may call to receive information on more technical issues related to used oil recycling activities in the state. Approximately 1,500 calls are received on this 1 ine each year.

This successful information system was in response to the second directive of the legislature and is regarded as a vital link in the exchange of important information among persons interested in promoting the concept of used oil recycling in the state.

Having established a monitoring and reporting system for the industry and having developed an information center on used oil regulations, the Board next developed specific regulations dealing with techniques to encourage recycling activities by the public. First in this context was the idea that individuals who purchase new $0 i 1$ would be most likely to need information on the locations of nearby used oil collection stations. By providing this information, it was felt that used oil could be directed towards these centers and eventually recycled instead of being indiscriminantly disposed.

To assist in providing this information to the public, the Board developed regulations which required retail store operators selling over 500 gallons of new oil annually, to post a sign in a readily visible location informing the general public of station locations. Signs were provided to these stores and are available upon request. We found that some stores are doing a good job of posting these signs. Some are doing an adequate job. And unfortunately, some do a rather poor job of posting signs where the oil is displayed.

To provide the retail store operator with a location that can be printed on the signs, the Board developed a directory with the location of over 2,300 collection stations located in the state. The operator merely locates the closest location to his/her business and prints the name on the sign provided by the Board. In order to assure that signs are properly posted as required, the Board has had to periodically inform the retail industry of this requirement. In 1983 , this will become a priority issue with the Board.

Another of the directives the Board was required to pursue under the used oil act, involved the creation of voluntary used oil recycling programs and collection activities. In order to spur on 
interest and participation in used oil recycling by the public, the Board next had to develop a public education and outreach program. To provide a focal point to its public awareness program, the Board adopted an already existing used oil program operated by the California Automobile Association entitled, "Save 0il America, Recycle" or "SOAR" for short. Using the SOAR theme as its public awareness element title, the Board set about obtaining the cooperation of service stations, shops, garages and recycling center operators, who would volunteer to provide their locations as used oil collection points for used oil deposited by do-it-yourself oil changers. The name and location of these centers were used to form the directory of over 2,300 used oi 1 centers made available to the retail store operators previously mentioned, and to the public calling the Board on its tol1-free number. Most of these locations are service stations as well as some recycling centers, al1 80 Sears automotive shops in California and all WoolCo Automotive Centers.

Each collection center is also provided a sign by the Board identifying it as a SOAR "Used 0il Collector". Presently, the Board has proceeded with development of new signs, and has updated its list of participating stations and maintains their location and names of the Board's computer system.

In addition to establishing its voluntary collection system within the state, the Board has developed radio public service announcements and periodic press releases in order to inform the public of the need to recycle used oil. The Board feels that the key to an effective used oil recycling program is the need to provide constant media exposure to the public. Further, continuous communication between the parent agency and the SOAR collection stations is also regarded as extremely important in keeping interest in the program at a high level. As 1983 approaches, the Board will be actively involved in increasing its activities in the area of public awareness.

Thus far, the incentives I have mentioned to encourage public involvement in used oil recycling have dealt primarily with exposure factors such as sign posting at retail outlets, SOAR stations located in communities in the state, and public service announcements. These exposure factors rely wholly on the public's good conscience and do not actually provide monetary or economic incentives to recover the approximately 13 million gallons of used $0 i 1$ estimated to be generated by the do-it-yourself oil changers each year in California.

The Board explored the possibility of a system which allows a credit or "chip" towards purchase of new products whenever used oil is returned to redemption centers. This idea, although extremely difficult to implement, is still being explored by the Board. Already, contact has been made with firms who may be able to assist in this concept.

Basically, the goal of California's oil recycling program is to provide for the maximum recovery of used $0 i 1$ at the least amount of risk to the environment. What has developed is a closed loop system in which retail stores, along with the Board's toll-free line, can direct consumers to the location of a used oil collection station, where it is then collected by certified haulers and taken to a recycler for processing.

The net effect of the used oil program has been the recorded effective recovery of over 50.6 million gallons of used automotive and industrial oils in 1981. This figure is well ahead of projections made in 1977, and this volume represents approximately 51 percent of the total volume of used $0 i 1$ estimated generated each year in the state.

I would now like to list for you the approximate volumes of used oil recycled in 1981 and the end products which they were used for:

- 33.1 million gallons were processed into fuel oil (65\%)

- 6.3 million gallons were sold as a road oil/asphalt (13\%)

- $\quad 4.2$ million gallons were re-refined into motor and industrial $0 i 1 s(8 \%)$

- $\quad 2.6$ million gallons lost in processing (5\%)

- $\quad 3.5$ million gallons were stored in inventory (7\%); and

- 1.0 million gallons went into other uses (2\%)

In addition to these volumes which were recovered and recycled, the Board estimated that over 12.1 million gallons of oil were disposed of both at on and off site disposal facilities in California during the year. Combining this total with the 50.6 million gallons of used oil recycled, the Board estimates that over 62.7 million gallons out of a total 98.4 million gallons were identified in one form or another. 
As the Board coordinates its reporting activities more closely with the DOHS and the ARB in California, it is envisioned that a greater volume of oil will be identified so that recovery efforts in the state can be maximized.

The 50.6 million gallons of used oil recycled in 1981 represents a 14.2 million gallon increase in the volume of $0 i 7$ recycled in 1980 and has been attributed to a host of factors. Perhaps primary in this case has been the increased demand by fuel burners for used oil in the state. Finding it profitable to mix small volumes of used oil with primary stocks of fuel oils, companies in California have steadily created a situation where the street price of used oil has nearly tripled since early 1978. For example, used $0 i l$ prices have jumped from 5-154/gal. in 1978 to as high as 15-454/gal. In 1981, some areas in the state are reporting prices as high as 50-60c/gal. It is estimated that prices and demand will remain high for the foreseeable future.

While the predominance of used oil was processed into fuel oil, it is expected that this trend will be somewhat balanced out in 1982-83, due to the recent start-up of a large re-refinery in Southern California and the proposed start-up of another facility in early 1983 . Both of these operations will be involved in the processing of used oil into lube stocks and are expected to take up a large share of the feedstock supply generated in California each year.

Finally, I would like to address the last topic of my presentation: that of California's attempt to encourage the procurement of products made from re-refined basestocks.

As part of its directive under the used oil recycling act, the SWMB was assigned the task of encouraging the "procurement of re-refined automotive and industrial oils for all state and local uses, whenever such re-refined oils are available at prices competitive with those of new oil produced for the same purpose."1

Since adoption of the Act in 1977, the Board has been sucessful in identifying technologies used by the re-refining industry to produce quality lube products. Much of the data reviewed suggested that these products and technologies match and even exceed quality standards adopted for new oil products. However, although sufficient technological data exists suggesting product reliability and integrity, manufacturers and distributors of re-refined lube products have not reached their potential in marketing their products in California.

The SWMB, in its compilation of annual report data submitted by the used oil industry, has found that only 8 percent of the used $0 i 7$ recycled in 1981 counts towards use in the manufacture of new lube products. Economic constraints, brought on by high prices paid for used oil by fuel oil processors, may have kept the percentage of oils processed into re-refined products at a minimum.

In an attempt to assist the re-refining industry in california in marketing its products, and at the same time meeting its requirements under the used oil recycling act, the SWMB examined the potential for opening the state petroleum procurement market to include the purchase of products made from re-refined sources. It was envisioned that removing procurement barriers might open a new market to re-refined products and that any state procurement would generate enough interest at the private level to initiate purchasing of these types of products statewide.

In its initial examination of the State's procurement policy, it was found that all petroleum products purchased by the state had to have been subjected to a series of technical tests, including actual bench testing of products to determine anti-wear and additive characteristics. In addition, state procurement policy also dictated (1) the satisfactory passage of engine sequence tests by products made from re-refined sources and inclusion of the product on a federal qualifying products test (QPL) and (2) a consistent quality control program backed by laboratory and trained personnel. Previously only 2 products made from re-refined sources have been included on the federal QPL, with no California firm listed. Further, no re-refined oil products were used in state petroleum purchase contracts nor were firms specializing in the production and distribution of these products allowed to bid on state petroleum contracts.

${ }^{\text {TCalifornia }}$ public resources code, section 3465(D) 
In order to respond to increased industry requests to have the state of California initiate the purchase of re-refined oils, the SWMB has begun a process to provide grant monies to a $f i r m(s)$ in California to assist in getting its products placed on the Federal QPL and thus allowing it to be included in the petroleum bid process conducted by the state each year.

While the recipient of grant monies through this grant process will not be assured of a contract to supply the state of California with petroleum products, the recipient will at least be allowed the opportunity to competitively bid on state petroleum contracts under rules and procedures adopted by the State office of Procurement. The Board anticipates this may become a major step in pioneering the widespread use and approval of re-refined oils in California.

As a second step in the process to encourage the use of re-refined products in California, the Board has been examining possible financing options available to individuals interested in construction activities. Although the Board itself does not administer bonds or loans, it has worked with the appropriate state/federal agencies to examine possible financing options and has made this information available to California industries.

The impact of substantially larger volumes of re-refined oils entering the states lubricating market will undoubtedly bring about concerns of how the state will monitor product quality at the retail level. Already the state Department of Food and Agriculture, Measurements and Standards Division, is involved in an enforcement program designed to protect consumers against fradulant product claims. This program oversees oil products derived from virgin and re-refined sources and should well be able to monitor the projected increase in volumes of re-refined oils entering the states marketplace. Jim Johnson from that Department will follow my presentation with a detailed description of California's efforts in product quality control.

I would like to conclude by saying that California's used oil recycling program has been relatively successful in promoting the concept of used oil recovery. Back in 1978 when California's program was first initiated by the legislature, little activity was occurring in recovery efforts. Street prices for used $0 i 1$ were at about a dime per gallon, and over-all recovery figures at about 28 million gallons annually. At the present time volumes and prices have increased dramatically. The Board feels its efforts have had a major influence in the efforts of the industry and public to recover this valuable resource. It is a big disappointment to the state, that just at the time when recovery efforts are beginning to increase both in California and nationally, that the efforts conducted by the NBS Recycled $0 i 1$ Program will be terminated. California has expressed its desire to the administration to keep this important program going, and I only wish our efforts would have been fruitful. Yet despite this setback, I would like to state that the state of California will continue to actively promote the concept of used oil recovery and will strive to continue it's efforts to make used oil recycling a significant part of this country's energy program. 

National Bureau of Standards Special Publication 674. Proceedings, Conference on Measurements and Standards for Recycled 0il - IV, held at NBS, Gaithersburg, MD, September 14-16, 1982. (Issued July 1984).

THE FATE OF HAZARDOUS WASTES IN USED OIL RECYCLING

\author{
Dennis W. Brinkman \\ DOE/BETC, Box 1398 \\ Bartlesville, OK 74003 \\ and \\ Paul Fennelly and Norman Suprenant \\ GCA Corporation \\ 213 Burlington Road \\ Bedford, MA 01730
}

\begin{abstract}
While it is known that used lubricating oils often contain one or more of the EPA priority pollutants, and it can be shown that this contamination frequently is introduced after the oil has been taken out of service, very little documentation exists on what happens to these hazardous species when the used oil is dumped, burned raw, or recycled. GCA Corporation has been working under contract to the U.S. Department of Energy, Office of Industrial Programs to (1) determine which hazardous contaminants tend to show up frequently in used oils, and (2) experimentally demonstrate the fate of these contaminants under number of scenarios. The scenarios under examination include dumping the used oil down a sewer, road oiling, open burning (no controls), reprocessing for fuel, and re-refining for use as lubricating oil basestock using several different methods.
\end{abstract}

Fourteen used oils gathered from around the country were analyzed for priority pollutants and other contaminants. Four of these were combined and the composite spiked with additional contaminants of interest to form a standard oil. The standard oil was then used in the experimental investigations of the various scenarios. In each case a mass balance approach was used to show where each contaminant emerged or was converted to something else. Because chemical analysis of samples is still in progress, the results shown in this paper are not complete and some data may be subject to further verification and possible modification.

\title{
1. Introduction
}

The presence of hazardous materials in used oil is a problem of growing concern. Many contaminants now finding their way into the used oil streams do not originate during the lubricant's use, but are introduced during collection and storage as other substances accidentally or deliberately are blended with the oil. The increasing incidence of significant levels of a wide variety of recognized hazardous species in used $0 i 1^{1}$ present the recycler with the dual problem of preserving worker health during handling and of needing extensive analytical capabilities to monitor the material as it passes through his site.

This study, sponsored by the U.S. Department of Energy, Office of Industrial Programs and described here, documents the hazardous (and some nonhazardous) species found in 14 used oil samples collected from throughout the U.S. in early 1982, and then presents experimental results which determine where each of the species emerges or is destroyed during a variety of typical used oil scenarios. Although chemical analyses of waste streams from some scenarios are still in progress, available data identifying the pathways for certain contaminants are shown for recycling options such as dumping, road oiling and several re-refining methods. Additional data for these and other scenarios, notably combustion, and the implications of the data will be presented in a final report on this study. The final report will also include the results of analyses of additional waste oil samples and a comparison of the result of a sampling and analysis program at a commercial rerefining facility with results of computer simulations of the fate of key contaminants as they pass through the re-refining process.

1Figures in brackets indicate the literature references at the end of this paper. 


\section{Laboratory Analysis of Used 0 ils}

The identification and prioritization of hazardous contaminants in used oil was the first major objective. Contaminant concentration data available in the 1 iterature were combined and weighted with health effects data (using an EPA method for estimating the hazard potential of process and waste streams) [2] to prepare an initial priority list. Since this only considers health effects, corrosivity and flammability were factored in separately. This information helped focus our analysis of actual used oil samples.

To augment the limited database and to provide a meaningful basis for experimentally examining the fate of hazardous and nonhazardous contaminants in used oil during recycling scenarios, samples of waste oil were obtained from various suppliers across the country. Most of the 14 samples analyzed came from organizations engaged in the collection and recycling of used oils. The waste oils were sampled by the suppliers and shipped to GCA in 55-gallon drums for analysis.

The results of the analyses for physical properties, inorganic elements, and trace organics are shown in tables 1,2 , and 3, respectively. As a result of these analyses, oils numbered 1 , 5, 6 , and 10 were blended to provide the base for a "representative" used oil to be studied in the simulations. Based on these analyses and literature citations such as those provided in references [3-4], the following spikes were added to this blended base at a leve] of about 90 ppm: 2,4,6-trichlorophenol, (2) N-nitrosodiphenylamine, and (3) the pesticide, 2,2 bis ( $p$-chlorophenyl) -1,1-dichloroethylene (4-4'-DDE). Polychlorinated biphenyls (PCBs) were also added to the composite 0 il at a level of $40 \mathrm{ppm}$.

The used oil samples were analyzed for 27 elements by Inductively Coupled Argon Plasma Emission Spectrometry (ICAP). The average lead content was $1310 \mu \mathrm{g} / \mathrm{g}$ of oil, a value appreciably lower than values of about $10,000 \mathrm{\mu g} / \mathrm{g}$ reported in studies conducted in the early $1970 \mathrm{~s}$ [5], as would be expected with the declining use of leaded gasoline. Several preparation modes were studied at the outset of this analytical activity (dry ashing at $550{ }^{\circ} \mathrm{C}$ for 24 hours, dry ashing with magnesium nitrate flux, and low temperature plasma ashing), with excellent agreement obtained for almost all elements. The data presented in table 2 were obtained from ICAP analysis of samples prepared by low temperature ashing.

The organic analyses were much more complex than the inorganic analyses. Sample preparation techniques were tailored for each organic species, and an extensive quality control effort was required for compound identification and quantification. The measurement of volatile organic compounds has been particularly troublesome, and is the subject of extensive and current methods development by the EPA [6,7]. The data confirm the presence of chlorinated solvents and volatile organics such as benzene and toluene in most samples of used oil. Polycyclic organic materials (POMs) are also present as anticipated. PCBs at low levels were found in 2 of the 14 samples at detection 1 imits of 0.1 to $0.5 \mu \mathrm{g} / \mathrm{g}$, depending on the level of interferences present.

Correlative comparisons between the presence of specific hazardous materials and more general analytical data are difficult to discern from the data. For example, although sample No. 6 shows reasonable correlation between chlorine content and detected chlorinated solvents (67 percent of chlorine as chlorinated solvents), the amount of chlorine in chlorinated solvents represents only 12 percent of the total measured in sample No. 5. No other source of chlorine was identified by the analytical procedures. Relationships among other factors such as volatile compound content, flash point, ASTM distillation, and total chromatographic organics are similarly obscure. Thus, simple physical tests do not seem to offer much promise as screens for hazardous wastes.

\section{Simulated Disposal/Recycling Scenarios}

Once a uniform "representative" contaminated used oil had been generated by blending and spiking, it was experimentally treated under a variety of conditions intended to simulate disposal or recycling pathways. Each known contaminant was monitored to see where it emerged or was destroyed. Material balances were used to assess pathways and overall recovery rates. Although material balance closure was good-to-excellent in the cause of inorganic elements, recovery and accuracy were appreciably less for many of the organic contaminants, particularly the volatiles. 


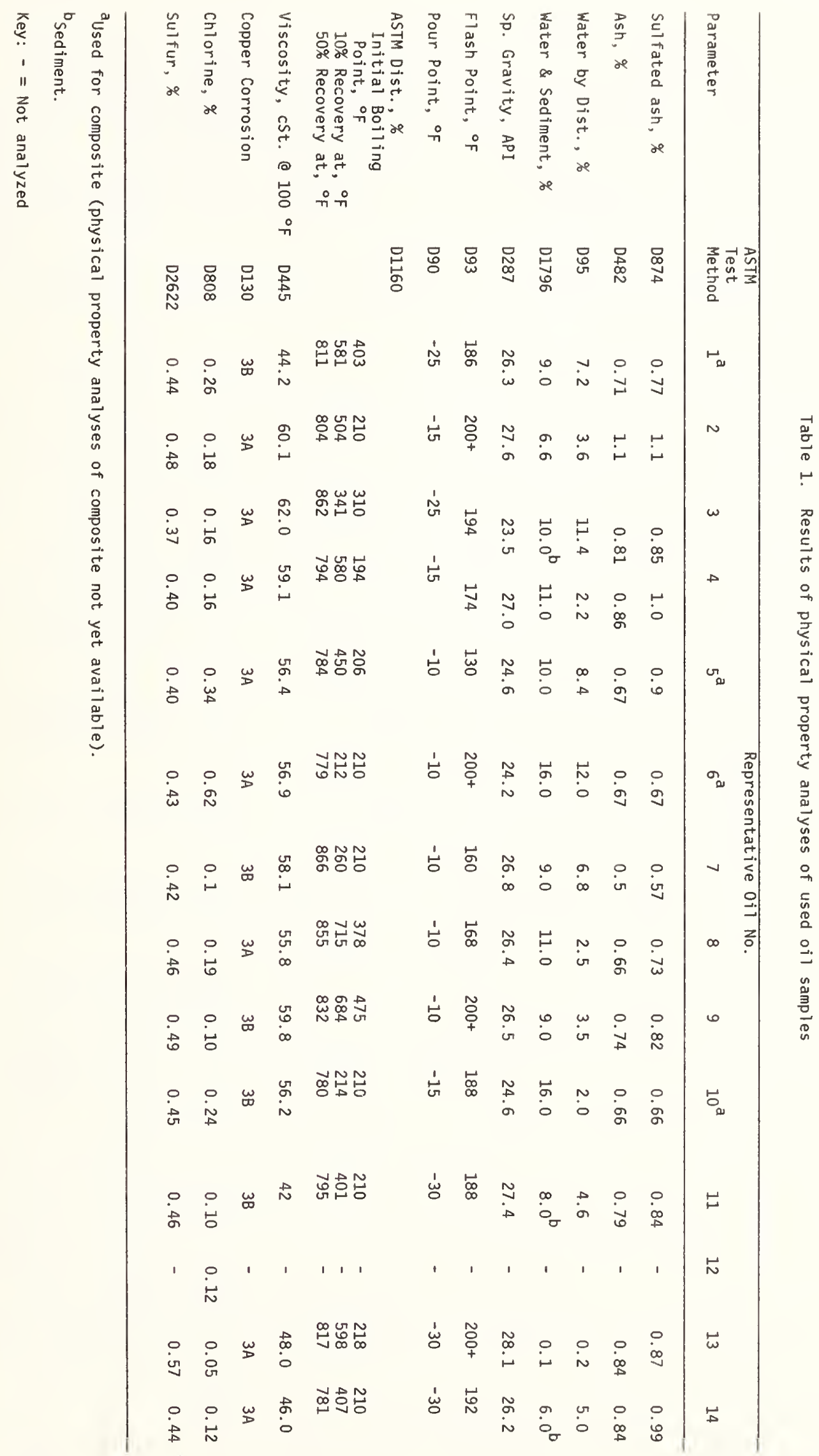




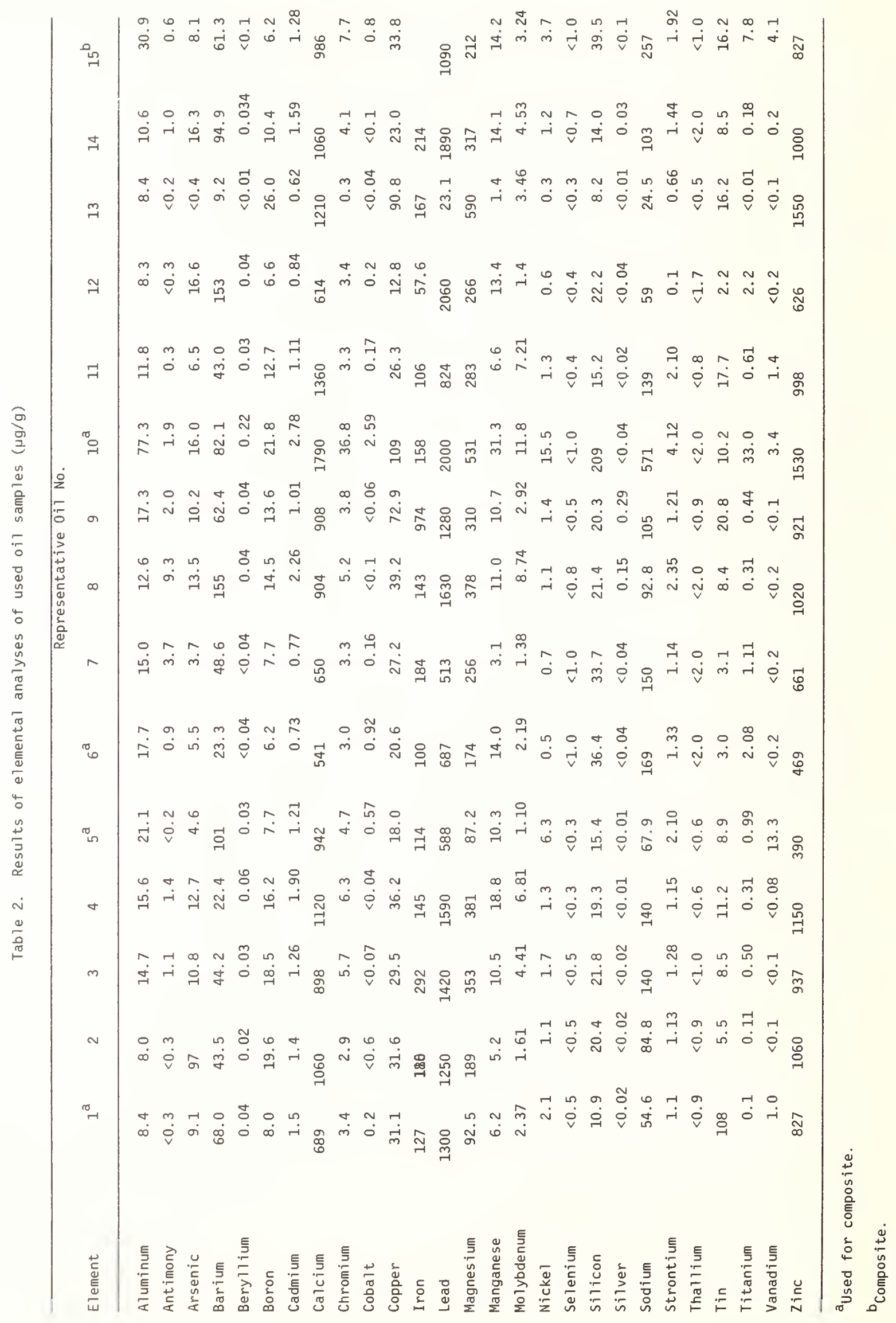




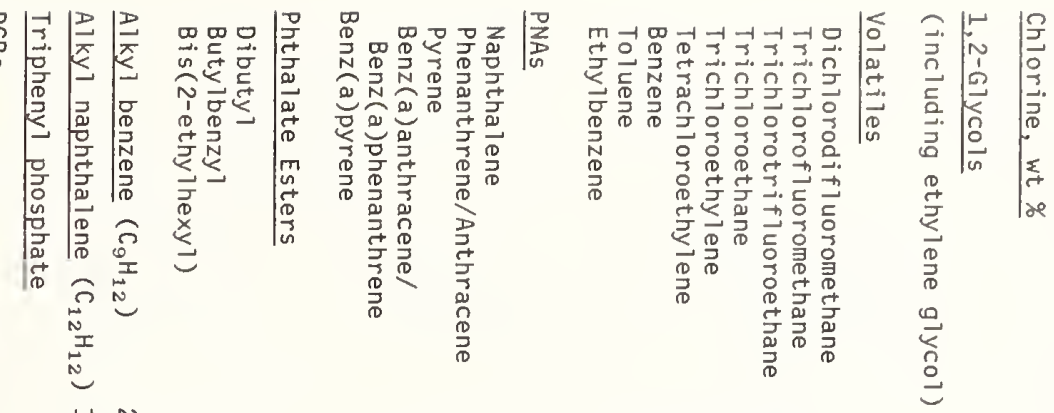

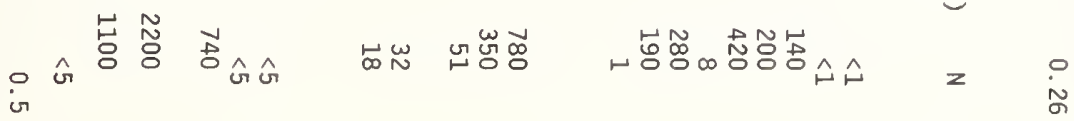

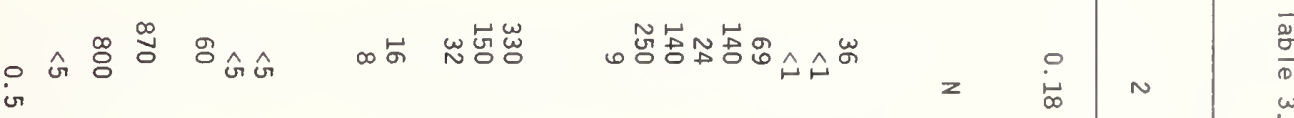

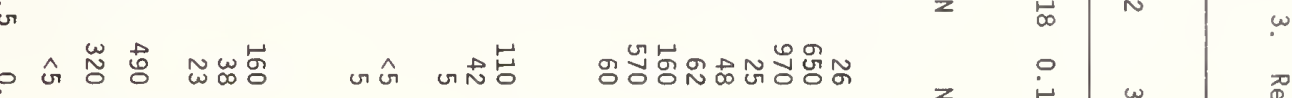

ज G $z$ 宛

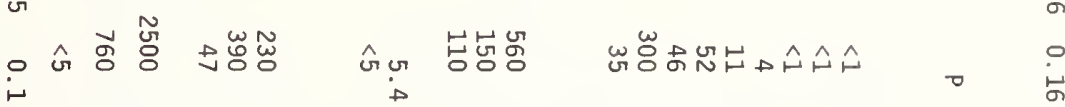

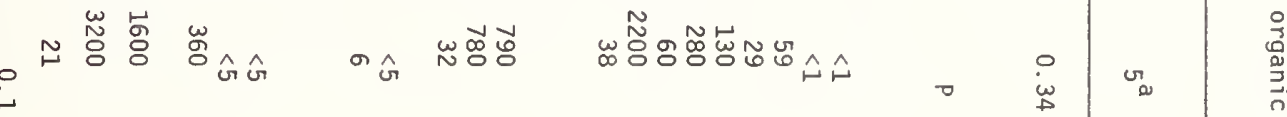

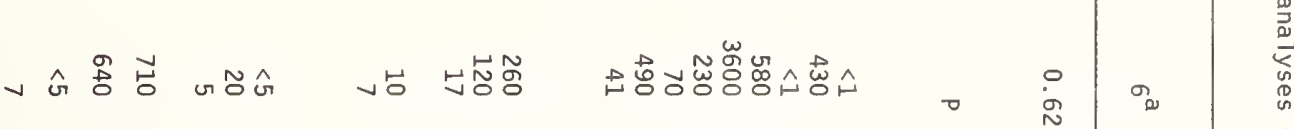

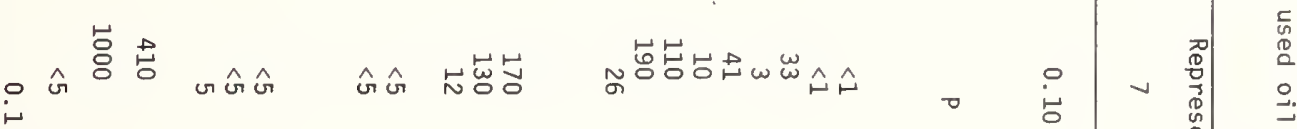

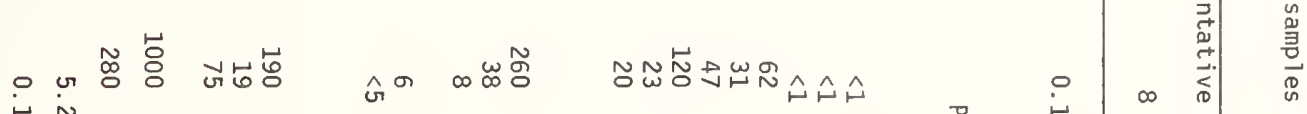

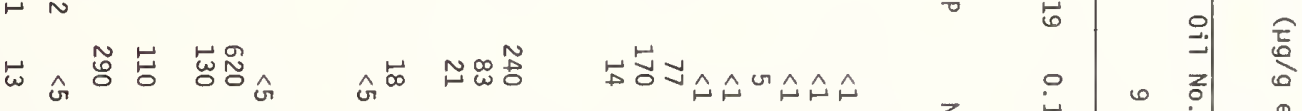

i

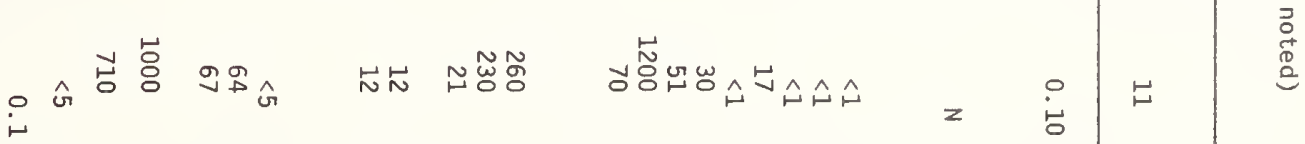

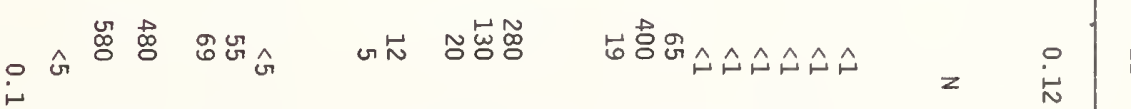

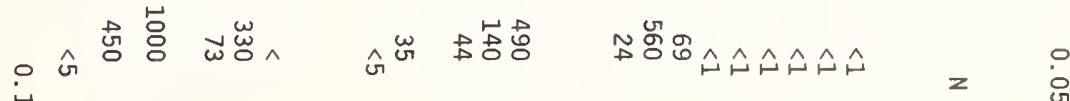

$z$ 宛

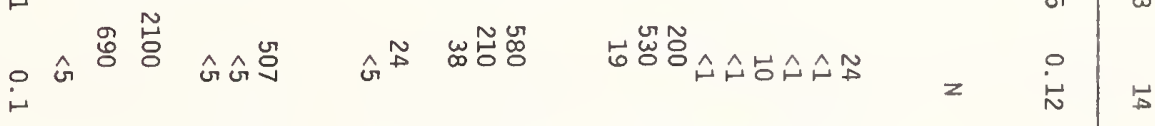

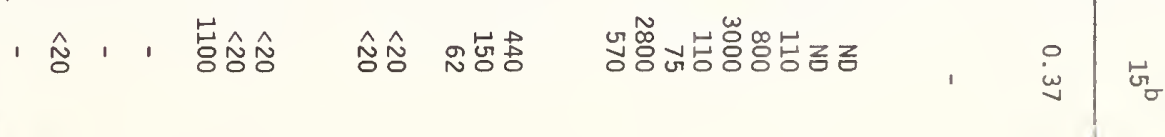




\subsection{Disposal into Sewer Systems}

Based on the results of a recent national survey [8], it is known that a significant portion of used oil generated by individuals who change their own automotive oil ends up in municipal sewer systems. Although oils from other sources, because of the high cost of proper collection and removal, also undoubtedly find their way to the sewer system, discarded automotive oil can account for a major fraction of the sewer system hydrocarbon loading. In at least one location it has been reported that the petroleum in urban runoff resembles used crankcase oil in composition [9]. Treatment processes currently planned for industrial sources of hydrocarbons will, as they come onstream, further accentuate the significance of used lubricating oil as a major source of hydrocarbons in urban runoff.

The concentrations of hydrocarbons in urban source systems have been measured at levels ranging from 1 to $10 \mu \mathrm{g} / \mathrm{g}$ [10]. These levels are slightiy 1 ower but consistent with values of $16 \mu \mathrm{g} / \mathrm{g}$ and $40 \mu \mathrm{g} / \mathrm{g}$ calculated from estimates of the amount of used oil dumped in sewers [8] and other estimates [11] of nationwide flows in combined sewers and storm sewers, respectively, assuming no $10 s 5$ of oil to walls or sediment.

Simulation of the sewer disposal scenario involved laboratory determinations of the distribution of the oil when mixed with water and suspended particulate, followed by analysis of the water fraction. In agreement with other studies [10] most (approximately 90 percent) of the used oil constituents were associated with the particulate matter in the water. Because efficient control technologies for the particulate matter (and free oil) can be implemented at treatment facilities, the constituents in the water soluble fraction were considered to be of major importance for this study.

The water soluble fraction of the representative waste oil consists of a number of organic compounds as shown in table 4. The concentration of these compounds are those resulting from the conditions of laboratory simulation; actual concentrations will be dependent upon sewer loading, dilution and other factors. Assuming the distribution of constituents remains unchanged from that found in the laboratory, and assuming further that the total influent organic loading is as shown in table 4, the discharge of waste lubricants should not prove harmful to the functioning of Publicly Owned Treatment Works (POTWs). Total loadings are well below $100 \mu \mathrm{g} / \mathrm{g}$, a value for the oil and grease content of treatment system influent recommended as an upper 1 imit to prevent serious treatment system degradation [12]. Further, pollutants such as those identified in the laboratory study and shown in table 4 are reportedly effectively treated by POTWs using a variety of secondary and tertiary treatments [13].

Unfortunately, less than 25 percent of the urban population is served by combined sewer systems using effective secondary treatments $[11,14]$. The remaining 75 percent of the urban population is served by storm sewer systems or live in unsewered areas [11]. Storm water discharge from storm sewer systems will generally receive no treatment whatsoever. Because the concentrations of some of the contaminants shown in table 4, notably phenol, exceed EPA suggested concentration goals for stream discharge, sewer disposal of used oil represents a practice which is potentially harmful to the large percentage of the urban population living in areas where storm water control is not practiced and to other populations which are downstream of storm water discharge points.

\subsection{Road 0iling}

Used oil is often applied to rural dirt roads as a dust suppressant during dry summer periods. The fate of constituents in the used oil is dependent upon a multitude of factors relating to soil, meteorology, road traffic, and oil properties. A prior EPA study [15] had reported that only about one percent of the oil applied to dirt roads over extended periods ( $>12$ years) is retained on the road surface. This same study further determined experimentally that approximately 10 percent of the oil is lost through evaporation and that 10-20 percent of the oil is lost through rainfall runoff with most runoff occurring during the first rains following application. Although no data were available it was suggested that other factors such as biodegradation and reentrainment of oil coated particles by road traffic could account for a large fraction of the long term oil transport from the road surface. Direct penetration of 011 beneath the first few millimeters of road surface did not appear to be a major factor. 
Table 4. Contaminant levels in aqueous phase of 1-1 oil/water mixture

\begin{tabular}{|c|c|c|}
\hline \multirow[b]{2}{*}{ Contaminant } & \multicolumn{2}{|c|}{ Sample } \\
\hline & $\begin{array}{c}\text { Composite } \\
\text { oi } 1 \\
(\mu \mathrm{g} / \mathrm{g})\end{array}$ & $\begin{array}{l}\text { Aqueous } \\
\text { phase } \\
(\mathrm{mg} / 1)\end{array}$ \\
\hline \multicolumn{3}{|l|}{ Organics } \\
\hline \multicolumn{3}{|l|}{ Volatiles } \\
\hline $\begin{array}{l}1,1,1 \text {-Trichloroethane } \\
\text { Trichloroethylene } \\
\text { Tetrachloroethylene } \\
\text { Benzene } \\
\text { Toluene }\end{array}$ & $\begin{array}{r}800 \\
3000 \\
110 \\
75 \\
2800\end{array}$ & $\begin{array}{l}<1 \\
<1 \\
<1 \\
<1 \\
<1\end{array}$ \\
\hline \multicolumn{3}{|l|}{ Semivolatiles } \\
\hline $\begin{array}{l}\text { Phenol } \\
2,4,6-T r i c h l o r o p h e n o l \\
\text { N-Nitrosodiphenylamine } \\
\text { Naphthalene } \\
\text { Phenanthrene/Anthracene } \\
\text { Pyrene } \\
\text { Benzo(a)pyrene } \\
\text { Pesticide 4-4'-DDE } \\
\text { PCB (Arochlor 1260) }\end{array}$ & $\begin{array}{r}11 \\
40 \\
116 \\
440 \\
150 \\
62 \\
<10 \\
94 \\
34\end{array}$ & $\begin{array}{r}11.0 \\
2.0 \\
1.0 \\
1.4 \\
<0.1 \\
<0.1 \\
<0.1 \\
0.5 \\
<0.1\end{array}$ \\
\hline \multicolumn{3}{|l|}{ Inorganics } \\
\hline $\begin{array}{l}\text { Arsenic } \\
\text { Barium } \\
\text { Calcium } \\
\text { Chromium } \\
\text { Copper } \\
\text { Iron } \\
\text { Lead } \\
\text { Magnesium } \\
\text { Manganese } \\
\text { Nickel } \\
\text { Sodium } \\
\text { Zinc }\end{array}$ & $\begin{array}{c}8.1 \\
61.4 \\
986 \\
7.7 \\
33.8 \\
214 \\
1090 \\
212 \\
14.2 \\
3.7 \\
257 \\
735\end{array}$ & $\begin{array}{c}<0.03 \\
0.01 \\
3.9 \\
<0.01 \\
<0.01 \\
2.3 \\
<0.02 \\
1.63 \\
0.01 \\
<0.01 \\
58.3 \\
0.26\end{array}$ \\
\hline
\end{tabular}

Our work, which extends the scope of the above study, involves examining the fate of specific constituents, primarily the organics, found in used oil following application to a simulated road bed and exposure to outside weather conditions. Two solids were used to construct the road bed: (1) soil taken from a dirt road maintained by a local community; and (2) the same soil mixed with 5 percent fine clay. 0 il was applied at a suggested level [15] of $0.05 \mathrm{gallons} / \mathrm{ft}^{2}$ [2] and the panel was weathered for 3 days in a ventilated area at approximately $100^{\circ} \mathrm{F}$ to remove most of the volatiles (12 percent loss due to evaporation) before being placed outside for exposure to natural elements. During the month of exposure, rainfall occurred on 8 days with appreciable (greater than $1^{11)}$ rainfall occurring on 2 days.

Rainfall runoff from the bed and that transmitted through the 6 " deep road bed were collected and analyzed. Soil samples from various bed depths were also taken and analyzed for total organics by extraction with methylene chloride followed by gravimetric analysis. (Essentially 100 percent recovery of the applied oil was achieved by the extraction procedure used.) 
The results indicate that in addition to oil lost by evaporation another 3-5 percent is 10 t by runoff. Although measured runoff loss was somewhat less than the 10-20 percent found in the earlier study [15], the observations noted below were quantitatively similar for this and the earlier study. The oil lost through water transmitted through the soil was very small, of the order of 0.04 percent. Almost all of the oil left in the soil was retained within a few millimeters of the surface. The oil concentration measured at the surface was $35,000 \mu \mathrm{g} / \mathrm{g}$; the concentration fell to a value of about $1,000 \mu \mathrm{g} / \mathrm{g}$ at a depth of $1 \mathrm{~cm}$. Below a depth of $1 \mathrm{~cm}$ the organic content of the soil was indistinguishable from the background level of the untreated soil $(\sim 100 \mu \mathrm{g} / \mathrm{g})$.

The used oil constituents in the runoff were associated primarily with soil that was entrained and carried from the surface to the collection vessel. The water-soluble fraction, present at a concentration of only a few mg/liter, represented only a few percent of the oil lost by runoff.

Results of the laboratory analysis of the oil lost by runoff from the test panel are not surprising. The constituents found are similar to those present in the oil (stripped of volatile components), as would be expected if the loss is due primarily to physical processes such as flotation and movement out of the bed of oil coated particulate. The water-soluble compounds found are similar to those shown in table 4 and are largely phenols. Volatile compounds such as the chlorinated hydrocarbons are present only in trace amounts.

\subsection{Burned As Fuel}

Used oil has approximately the same heating value as virgin petroleum fuel (15,000 to 20,000 Btu/lb). Thus, using this lower priced resource as a substitute fuel or fuel extender (blended with virgin fuel) is economically attractive. However, significant uncertainty exists concerning potential air emissions of pollutants and associated operational or maintenance problems [16].

In this study waste oil was burned in two small space heating units (a 250,000 Btu/h airatomizing and a 250,000 Btu/h vaporizing unit) and a larger commercial boiler operating at an input load of 7,000,000 Btu/h. Samples of combustion flue gas were collected and analyzed using EPA recommended procedures.

The larger commercial unit was tested during combustion of a waste automotive lubricating oil. This same oil (Sample No. 14 in tables 1, 2, and 3) was used in one series of tests of the small space heaters; the composite oil blend was then used for a second series of tests of these smaller units. The results of the testing of the boiler show that particulate emissions were roughly twice as high as values normally obtained for similar size units burning No. 6 fuel oil. Further, the elemental lead flue gas loading of about $50 \mathrm{mg} / \mathrm{m}^{3}$ is far greater than the value of $1 \mathrm{mg} / \mathrm{m}^{3}$ or 1 ess that would be emitted from a comparable boiler burning No. 6 fuel oil. At the observed level of flue gas emission the need for air modeling and monitoring studies is indicated to establish the contribution of emissions to ambient levels of lead. The current air quality standard for 1ead [17] is $1.5 \mu \mathrm{g} / \mathrm{m}^{3}$ over a 90-day average. Because of dilution in ambient air, as well as because of the 90-day averaging time, a boiler emitting $50 \mathrm{mg} / \mathrm{m}^{3}$ of lead can meet the air quality standard under proper conditions.

The study of combustion of waste oils in the smalier space heating units gave results consistent with the findings of a recent EPA study [18]. The air-atomizing burner produced far more particulate (approximately $30 x$ ) than the vaporizing burner, with roughly a corresponding increase in the emissions of lead and other trace metals. Lead emissions were measured in the EPA study at $1,600 \mathrm{\mu g} / \mathrm{m}^{3}$ for the vaporizing burner and $141,000 \mu \mathrm{g} / \mathrm{m}^{3}$ for the atomizing burner. The direct introduction of the trace elements into the combustion chamber by the air-atomizing burner is an obvious cause of the higher particulate and elemental emission levels shown by this burner design. The EPA study reported that the vaporizing burner produced slightly more organics than the airatomizing unit and that some of the organic chemicals are potentially hazardous [2]. POMs were particularly prevalent in the vaporizing pot residue. Similar organic analyses are now being conducted at GCA. Emphasis also is being placed on determining how well both units effectively destroy the chlorinated compounds present in the representative oil, or added as spikes, although the detection limits of analysis are not low enough to demonstrate destruction efficiencies greater than 99 percent.

\subsection{Reprocessing to Generate a Fue 1}

With a minimum degree of processing, most used oils can be reprocessed to provide a fuel having properties approaching most specifications for a No. 5 or No. 6 boiler fuel. Up until now, the question of how well this minimal processing also removed hazardous wastes had not been addressed. 
In our studies we simulated (1) gravity settling, (2) centrifugation, (3) filtration and (4) clay contacting using the waste oil composite and the dehydrated waste oil composite as test oils. The simulations, as conducted, indicate that pretreatment steps are of limited value. Gravity settling and filtration were not effective; possibly the samples provided to GCA by the suppliers were essentially feedstocks that had already undergone sedimentation. Some separation of metals, as shown in table 5, was achieved by centrifugation at $10,000 \mathrm{~g}$ and approximately $200^{\circ} \mathrm{F}$, and clay contacting of the dehydrated oil at approximately $200{ }^{\circ} \mathrm{C}$ followed by filtration did achieve some limited removal of components. The high level of removal of certain elements (e.g., aluminum, iron, chromium and nickel) during centrigugation suggests that these elements are present as wear particles of moderately large particle diameter. While simple physical treatments generally did little to enhance the cleanliness of the used lubricating oil we studied, the existence of a number of effective proprietary treatments is not precluded.

\subsection{Re-Refining to Produce Lube $0 i 1 \mathrm{~s}$}

By separately simulating several individual generic process steps, it is possible to estimate the fate of a particular contaminant within any number of specific technologies by combining the steps in the appropriate sequence. Obviously, differences in exact conditions will change the results somewhat, but a good first approximation should be possible from the data provided.

The generic steps investigated are presented in figure 1 . Using the stream numbers provided in this figure, tables 6 and 7 provide a matrix presentation of the fate of some of the hazardous species studied. Table 6 provides quantitative data concerning the distribution of contaminants in the composite oil as it undergoes dehydration and light end removal. As shown in the table,

Table 5. Results of separation by centrifugation, $\mu \mathrm{g} / \mathrm{g}$

\begin{tabular}{lccc}
\hline & Composite oil \\
$(\mu \mathrm{g} / \mathrm{g})$ & $\begin{array}{c}\text { S1udge } \\
(\mu \mathrm{g} / \mathrm{g})\end{array}$ & $\begin{array}{c}\text { Percent } \\
\text { Separation }\end{array}$ \\
\hline Aluminum & 30.9 & 475 & 46 \\
Arsenic & 8.1 & 150 & 56 \\
Barium & 61.4 & 583 & 28 \\
Calcium & 986 & 6170 & 19 \\
Chromium & 7.7 & 151 & 59 \\
Copper & 33.8 & 162 & 14 \\
Iron & 214 & 4260 & 60 \\
Magnesium & 212 & 1080 & 15 \\
Manganese & 14.2 & 91 & 19 \\
Nickel & 3.7 & 162 & 131 \\
Lead & 1090 & 120 & 28 \\
Sodium & 257 & 436 & 5 \\
Zinc & 735 & 4320 & 18
\end{tabular}

$a_{\text {Percent separation }}=\frac{\text { Sludge }(\mu \mathrm{g} / \mathrm{g}) \times 0.03}{\text { Composite oil }(\mu \mathrm{g} / \mathrm{g})} \times 100$

the material balance for the elements is excellent; however, the organic compound closure is much more variable. The elemental material balances, as shown in table 7 , becomes more variable as sludge and multiphase waste streams are included (see Process $C$ ), most likely reflecting problems in sampling rather than analysis. Although data for some waste streams are not yet available, product quality as measured by the removal of trace metals and organic impurities from product streams is considerably enhanced by all of the process combinations shown in figure 1 . Obviously, product quality and process economics, as well as other factors such as the number and hazard of waste streams, must be considered in selecting a re-refining system. 


\section{Comments and Conclusions}

Some interim conclusions based on our analyzes of representative oils and experimental studies of recycling scenarios are presented below. A complete and detailed assessment of all data will be presented upon completion of this ongoing program, with completion now scheduled for February 1983.

\section{1. Contaminant Pathways}

The used oil analyses seem to indicate that many hazardous contaminants are natural contaminants introduced through use, such as lead from leaded gasoline. Another possible example of contamination resulting from use could be POMs formed during gasoline combustion and transferred to the crankcase 011 , as proposed by other investigators [1,19]. In addition to natural sources of contamination, other contaminants such as cleaning solvent and antifreeze are commonplace in used oil, apparently as a result of waste storage and collection procedures. Deliberate addition of other wastes to the oil is also obviously a possibility that has been determined to be a reality in several instances.

Table 6. Results of re-refining scenarios: dehydration and light end removal system

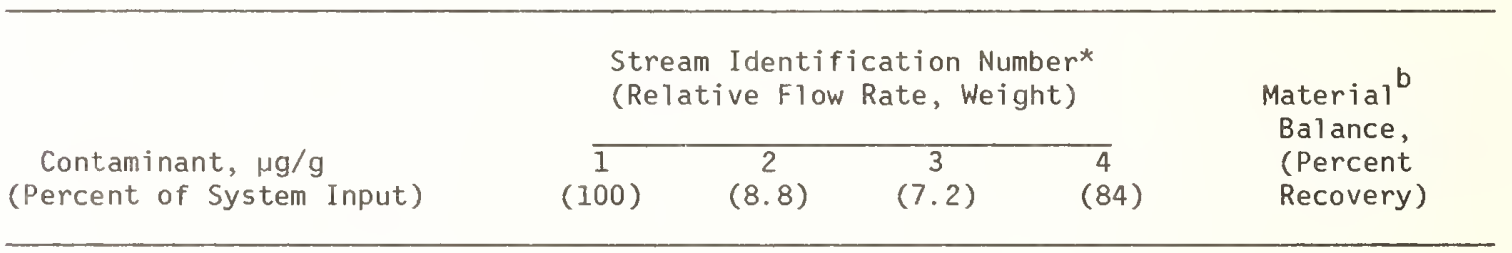

Organics

Volatiles

1,1,1-Trichloroethane

Trichloroethylene

Tetrachloroethylene

Benzene

Toluene

Semivolatiles

Trichloropheno 1

$\mathrm{N}-\mathrm{N}$ itrosodi phenyl amine

Naphthalene

Phenanthrene/Anthracene

Pyrene

Benzo(a)pyrene

Pesticide 4-4'-DDE

PCB (Arochlor 1260)

Inorganics

\section{Arsenic \\ Chromium \\ Copper \\ Iron \\ Magnes ium \\ Lead \\ Zinc}

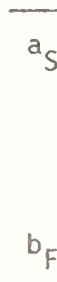

3 Light ends

$\begin{array}{rccrr}800(100) & 140(2) & 6661(60) & <4(-) & 62 \\ 3000(100) & 190(1) & 33780(81) & <4(-) & 82 \\ 110(100) & 30(2) & 1700(111) & <4(-) & 113 \\ 75(100) & 30(4) & 1090(104) & <4(-) & 108 \\ 2800(100) & 150(<1) & 20450(49) & <20(-) & 49\end{array}$

$\begin{array}{rrccr}40(100) & <20(-) & 87(15) & 44(92) & 107 \\ 116(100) & <20(-) & 123(8) & 98(71) & 79 \\ 440(100) & <8(-) & 4190(69) & 54(10) & 79 \\ 150(100) & <8(-) & 82(4) & 260(145) & 149 \\ 62(100) & <8(-) & <13(-) & 28(38) & 38 \\ <10(100) & <8(-) & <13(-) & <10(-) & - \\ 94(100) & <8(-) & <13(-) & 68(61) & 61 \\ 34(100) & <8(-) & <5(-) & 43(106) & 106\end{array}$

$$
\begin{aligned}
& <0.03(-) \\
& <0.01(-) \\
& <0.01(-) \\
& <0.01(-) \\
& <0.02(-) \\
& <0.02(-) \\
& <0.01(-)
\end{aligned}
$$

$<1.0(-)$

$<0.1(-)$

$<0.1(-)$

$<0.3(-)$

$<0.15(-) \quad 239(95)$

$11.5(<1) 1250(96)$

$<0.35(-) \quad 816(93)$
101

104

90

110

95

96

93

Stream identification

I Composite oil

2 Water from dehydration

4 Stock for further processing.

${ }^{b}$ For system material balance $1=2+3+4$ 


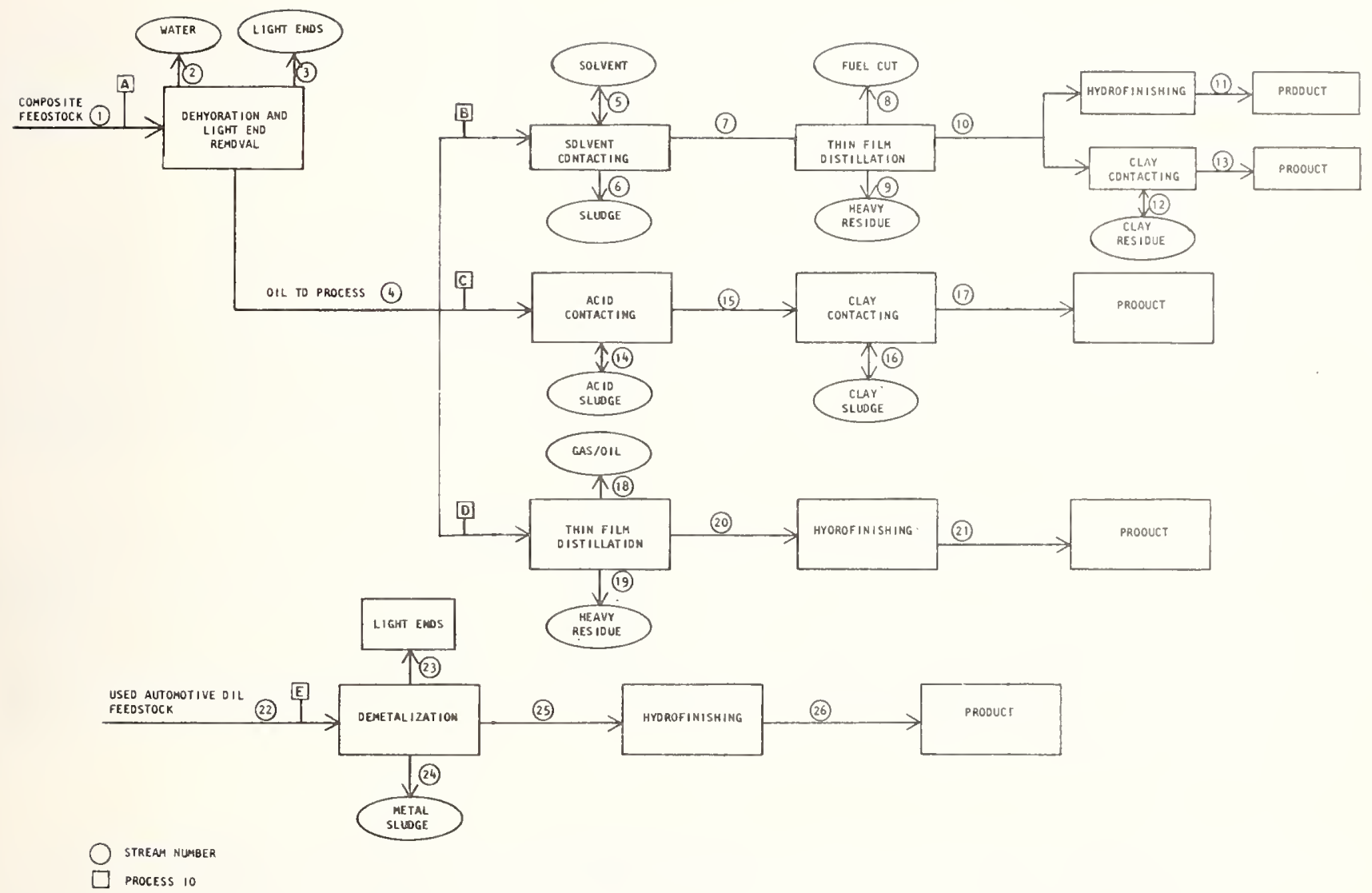

Figure 1. Re-refining to produce lube oils. 
Table 7. Trace element material balances for re-refining processes, percent recovery

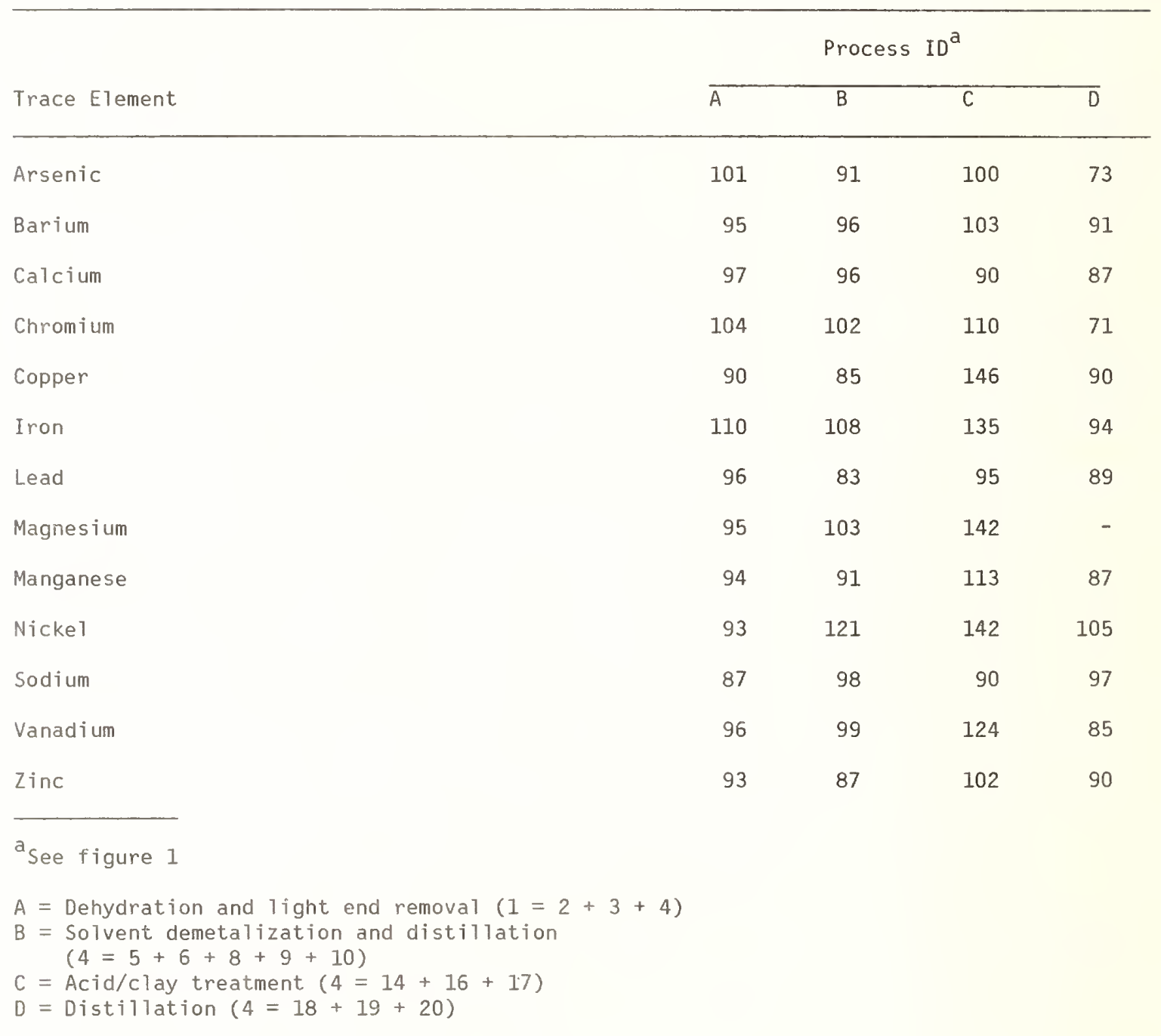

In the case of lead contamination, the obvious approach to decreasing the problem is to continue with the phaseout of leaded gasoline; POM contamination could possibly be reduced by more efficient combustion or the use of a fuel with lower aromatic content but such actions are not likely. However, regulations prohibiting deliberate disposal of hazardous materials in used oil may be useful and necessary.

\subsection{Disposal Assessments}

\subsubsection{Sewage Disposal}

Sewer disposal of used automotive oils is widely practiced, but in locations where sewer discharges are collected and treated there does not appear to be a serious problem. Secondary treatment plants, which handle the wastes of 25 percent of the urban population, are generally effective for contaminants present at measured and reported concentration levels. However, storm sewer or land disposal of the remaining 75 percent of the $0 i 1$ by the urban population not served by secondary treatment systems could lead to problems. 


\subsubsection{Road 0iling}

About 80 percent of the organic material present in used oil is adsorbed onto the top few millimeters of the road surface. About 10 to 20 percent is lost through evaporation and 10 percent lost through rainfall runoff. Over time the primary mechanism for transport of the remaining oil to the environment is through reentrainment of oil-coated dust particles by wind and vehicular traffic.

\subsubsection{Burning as Fuel}

Waste oil produces higher particulate and lead loadings than would burning a No. 6 fuel. This is not unexpected; under proper operating conditions the particulate and lead emissions can comply with existing air quality standards, with compliance based on site specific situations.

\subsubsection{Reprocessing to Fue 1}

Simple physical separation techniques such as gravity settling, filtration and centrifugation do remove some contaminants, notably metals. The maximum percent removal obtained for most metals was in the range of 30 to 50 percent, and was achieved by centrifugation at $10,000 \mathrm{~g}$ and $200{ }^{\circ} \mathrm{F}$ over a 2-hour residence period. The commercial viability of centrifugation under the above conditions is questionable.

\subsubsection{Re-Refining to Lube $0 i 1$}

Re-refining processes involving distillation effectively reduce metal contamination of re-refined oils. Partial demetalization prior to distillation may be useful for reducing coking and equipment fouling. Organic contaminants, notably POMs and PCBs, are more difficult to remove. Hydrotreating destroys PCBs, but does not reduce POM levels. Only moderate concentration reductions of both PCBs and POMs were achieved by the clay finishing and distillation operations conducted in this study. Concentrations of some POMs measured in the re-refined oils prepared in this study appear to be somewhat higher than concentrations reported for unused oils [16, 19]; however, compounds of proven mutagenicity, such as benzo(a)pyrene and benz(a)anthracene, were either not detected or present at low ( $10 \mathrm{ppm})$ levels.

\section{Summary}

The DOE sponsored program at GCA has been designed to determine the fate of constituents in waste oil when subjected to common use and disposal scenarios. Laboratory simulations of these scenarios followed by chemical analysis of product and waste streams are being conducted to determine the disposition of contaminants. To the extent that the laboratory simulation duplicate actual conditions, it will be possible to draw sound conclusions concerning the fate of hazardous compounds and impacts associated with the scenario. A complete and detailed analysis of all data will be forthcoming upon completion of this ongoing program in February 1983.

The work discussed in the report has been supported by the U.S. Department of Energy, 0ffice of Industrial programs. This support and the contribution of members of the used oil recycling industry and the staff of GCA/Technology Division is gratefully appreciated. In particular thanks are due to J. Fitzgerald, M. Hoyt, M. McCabe, D.McGrath, and M. Rennenkamp.

\section{References}

[1] U.S. Environmental Protection Agency. Report to Congress: Listing of Waste 0 i1 as a Hazardous Waste Pursuant to Section (8)(2), Public Law 96-463, SW-909; January 1981.

[2] Baasel, W. D.; McAllister, R. A. ; Kingsbury, G. L. Multimedia environmental goals. Chemical Engineering Progress; October 1980.

[3] Cotton, F. 0.; Whisman, M. L.; Goetzinger, J. W.; Reynolds, J. W. Analysis of 30 used motor oils. Hydrocarbon Research 56(9): 131-140; 1977. 
[4] Nims, J.; Mayo, R.; Boston, L.; Logue, E.; Krueger, J.; and Aho, H. Analysis of waste oil in Maine. Report prepared by State of Maine. Department of Environmental Protection; 1981.

[5] Weinstein, N. J.; Waste oil recycling and disposal. U.S. EPA Report No. 670/2-74-052, PB 236 148; August $1974327 \mathrm{pp}$.

[6] Battelle Columbus Laboratories. Evaluation of methods for analysis of hazardous wastes. Manual for collaborators participating in EPA sponsored interlaboratory study; December 1981.

[7] Arthur D. Little, Inc. Sampling and analysis methods for hazardous waste incineration. Prepared for U.S. Environmental Protection Agency. Industrial Environmental Research Laboratory, Research Triangle Park, NC, under Contract No. 68-02-3111; February 1982.

[8] Gottlieb, M. Analysis of potential used oil recovery from individuals. D0E/BC/10053-21; July 1981.

[9] Whipple, W., Jr.; Hunter, J. V. Petroleum hydrocarbons in urban runoff. Water Resources Bulletin, Volume 15, Number 4; April 1979.

[10] Hunter, J. V.; Sabatino; Gomperts, R.; Mackenzie, M. J. Contribution of urban runoff to hydrocarbon pollution. Journal Water Pollution Contro1, Volume 51, Number 8; August 1979.

[11] U.S. Environmental Protection Agency. Nationwide evaluation of combined sewer overflows and urban stormwater discharges, Volume 1: Executive Summary, EPA-600/2-77-064a; September 1977.

[12] U.S. Environmental Protection Agency. Treatability of oil and grease discharged to PoTWs; EPA-440/1-75-066; Apri1 1975.

[13] U.S. Environmental Protection Agency. Fate of priority pollutants in publicly owned treatment worksं; EPA-440/-80-30; Office of Water and Waste Management; October 1980.

[14] U.S. Environmental Protection Agency. 1978 NEEDS Survey. Cost estimates for construction of publicly-owned wastewater treatment facilities; EPA-430/9-79-001; 1979.

[15] U.S. Environmental Protection Agency. Runoff of oils from rural roads treated to suppress dust; EPA-R2-72-054; October 1972.

[16] Weinstein, N. J. Used oil burned as a fuel. SW-892 (EPA); 1980.

[17] 40 CFR 50.12; National primary and secondary air standards for 1ead. 43 FR 46258; 0ctober 5, 1978.

[18] Hal1, R. E.; Cooke, W. M.; Barbour; R. L. Comparison of air pollutant emissions from vaporizing and air-atomizing waste oil heaters. Presented at 75 th Annual Meeting of the Air Pollution Control Association; New Orleans, Louisiana; June 1982.

[19] Peake, E.; Parker, K. Mutagenicity of used crankcase oils. Polynuclear Aromatic Hydrocarbons. 5th International Symposium; Battelle Press; Columbus, Ohio; October, 1980. 1025-1037. 
National Bureau of Standards Special Publication 674. Proceedings, Conference on Measurements and Standards for Recycled 011 - IV, held at NBS, Gaithersburg, MD, September 14-16, 1982.

(Issued July 1984).

\section{ANALYSIS OF PCBS IN OIL: TECHNIQUE AND SRM DEVELOPMENT}

R. M. Parris, F. R. Guenther, W. E. May, and S. N. Chesler

Organic Analytical Research Division

Center for Analytical Chemistry

National Bureau of Standards

Washington, DC 20234

Polychlorinated biphenyls, PCBs, are toxic, persistent, global environmental contaminants.

PCBs were formulated as complex mixtures of congeners and were manufactured until 1977 in the Unit€d States under the trade name of Aroclor [1]. ${ }^{1}$ These mixtures have been extensively used in this country in high-voltage electrical components and may be introduced into the environment when these components are serviced, repaired or discarded. Since the PCB fluid physically resembles lubricating oils, there have been instances in which PCBs have been added to motor oils being collected for recycling purposes.

An estimated 750 million pounds of PCBs are still in service in the United States [2]. The use, transport and disposal of PCBs is regulated by the Environmental Protection Agency under the auspices of the Toxic Substances Control Act. Cairns and Siegmund recently reviewed the regulatory history and toxicity of PCBs and identified some of the problems of PCB analysis [3].

As we previously reported [4,5], a hybrid technique was developed at NBS for the determination of PCBs in hydrocarbon matrices such as motor oils and transformer fluids. This method first employs preparative-scale high-performance liquid chromatography (HPLC) to remove the major portion of analytical interferences from the oil sample, and then high-resolution capillary gas chromatography for indentification and quantitation of PCB contaminants. This method is less time-consuming and yields more accurate and precise results than many of the methods currently in use. This procedure has been used at NBS in the certification of a Standard Reference Material (SRM 1581)

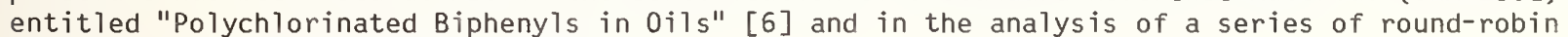
samples for a joint ASTM/NBS study [7].

Heterogeneous samples received for analysis are filtered and/or centrifuged to remove any extraneous materials and water, yielding a homogeneous oil phase suitable for analysis. The appropriate internal standard (IS) are added to the oil which is then injected onto a normal-phase preparative-scale aminosilane HPLC column. Figure 1 shows a typical chromatogram and the conditions used. The PCB-containing fraction of the eluate (previously ascertained from calibration with an appropriate standard PCB mixture showil at the bottom of Fig. 1) is collected. The more polar compounds that would interfere with the analytical determination are not eluted in the volume collected but are retained on the HPLC column. The collected fraction is concentrated by evaporation, if necessary, and an aliquot is then injected onto a nonpolar wall-coated open-tubular (WCOT) gas chromatographic column (See figs. 2 and 3.) The detector signal is integrated and the internal standard calculations are performed by a digital integrator.

Samples of used motor oil containing a wide range on concentrations and types of PCB contamination have been analyzed using this method; both electron capture (ECD) and Hall electrolytic conductivity detection (HECD) have been used. The ECD was found to be more sensitive than the HECD (by two orders of magnitude) and easier to maintain in a non-contaminated state. The HECD has a wider linearity range and is more selective because it responds only to halogenated compounds.

The majority of PCB congeners found in the sample are resolved yielding recognizable patterns of peaks; and thus, peak-by-peak comparisons of the sample chromatogram with chromatograms of commercial PCB mixtures can be made. Any significant non-PCB interference peaks are also readily apparent and can be omitted from the quantitation calculations.

${ }^{1}$ Figures in brackets indicate the literature references at the end of this paper. 


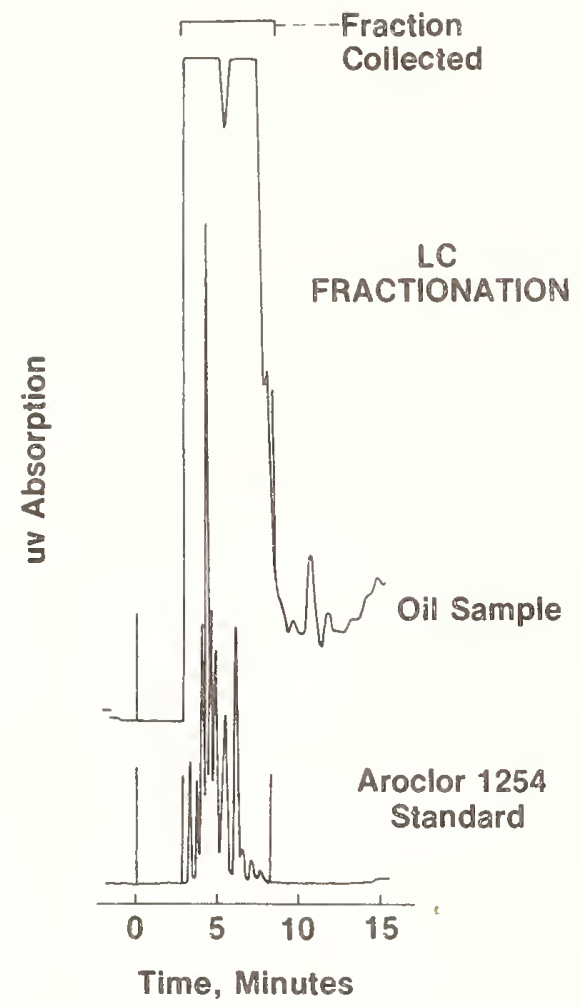

Figure 1. Preparative-scale high performance liquid chromatographic fractionation. Conditions: Column, preparative-scale aminosilane, $7.9 \mathrm{~mm}$ i.d. $x 30 \mathrm{~cm}$; Mobile phase, HPLC grade hexane; Flow rate, $4 \mathrm{~mL} / \mathrm{min}$; Detection, ultraviolet absorption, $254 \mathrm{~nm}$; Sample injected, $100 \mathrm{uL}$.

Since many pure PCB congeners are commercially available, appropriate congeners (i.e., ones not present in significant amounts in the sample being analyzed) can be used as internal standards in quantitative analyses. The choice of using non-occurring PCB congeners as internal standards is nearly ideal, because the PCB congener internal standards exactly mimic the behavior of the analyte throughout the analytical procedure. We have found that with the degree of separation of congeners obtained by using high-resolution GC, the presence of two or more Aroclors can be recognized from the patterns of peaks in the chromatogram and a matrix algebra technique, such as that proposed by Eder [8] can be employed to determine the ratio of the individual Aroclors.

This procedure has been used to certify Standard Reference Material 1581 entitled "Polychlorinated Biphenyls in 0i1" [6] that consists of separate solutions of Aroclor 1242 and Aroclor 1260, each in a virgin motor oil base and a mineral base transformer oil. These solutions were gravimetrically prepared and split into ampoules. The gravimetric values were verified using the methodology described above. Six ampoules from each SRM pool were randomly selected and aliquots were fractionated after the addition of internal standards. These fractions were analyzed in triplicate using a gas chromatograph equipped with an electron capture detector. Analyte calibration factors were generated by analyses of gravimetrically prepared solutions of the Aroclor and internal standards in the appropriate PCB-free diluent oil. Figures 2 and 3 show representative chromatograms with the peaks used for quantitation and the internal standard peaks. The conditions used for these analyses are given in the captions. The gravimetric, analytical (GC), and certified concentration values for this SRM are presented in table 1 . This SRM is designed to be used in calibrating instrumentation and validating methodology for the determination of PCBs in oils. It should be especially useful to analysts in the electrical generation industry and the motor oil recycling industry. 
Aroclor 1242 - Motor Oil

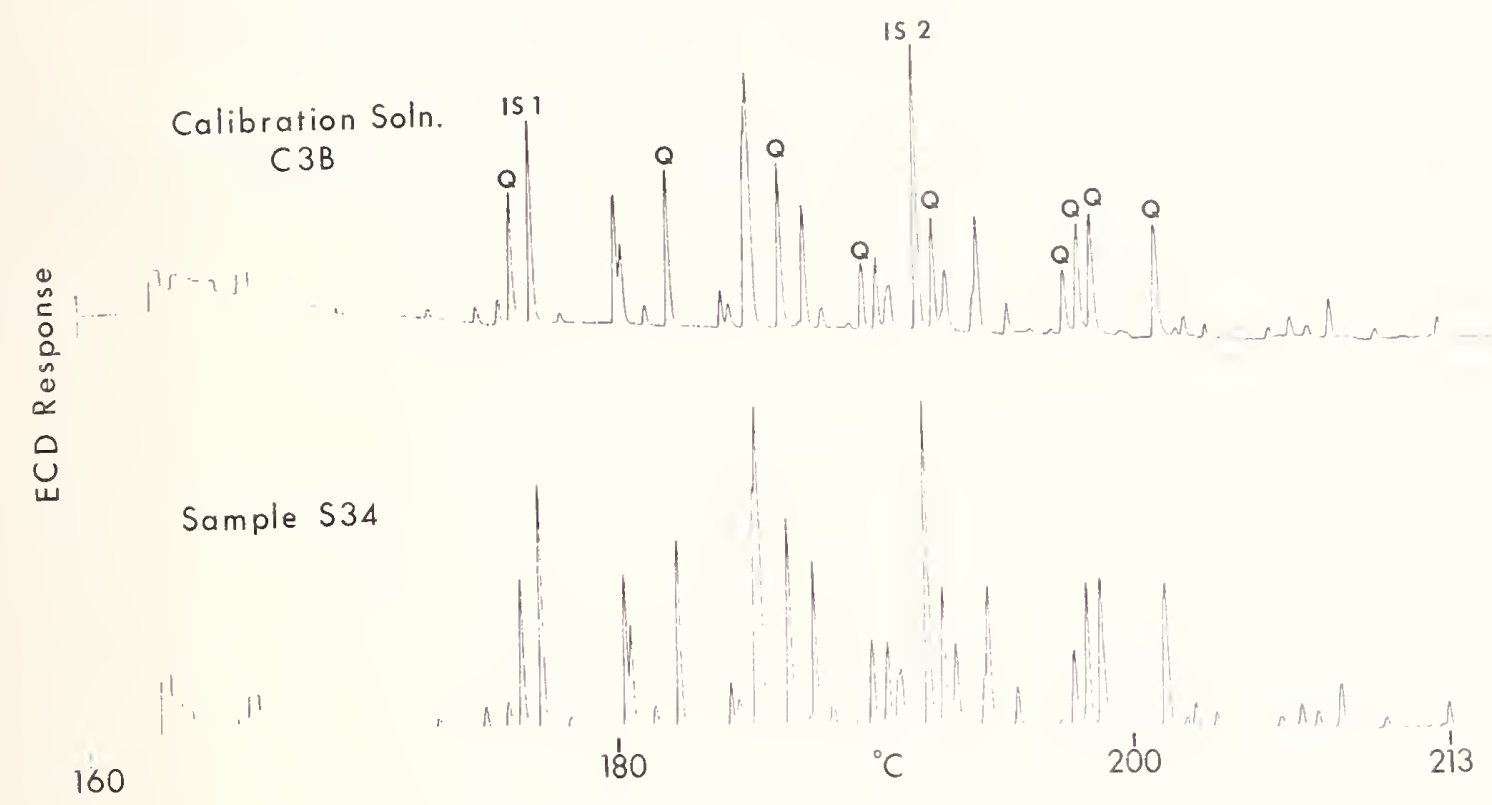

Figure 2. Gas chromatograms of the PCB-containing fractions of: Top: Gravimetrically prepared calibration solution of Aroclor 1242 and 2 internal standards in motor oil. Bottom: SRM sample of "Aroclor 1242 in motor oil" spiked with the 2 internal standards. "Q" designates peaks used for quantitation. "ISI", internal standard 1, was hexachlorobenzene. "IS2", internal standard 2, was a pentachlorobipheny1. Conditions: GC with electron capture detection, $320{ }^{\circ} \mathrm{C}$ (constant current ${ }^{63} \mathrm{Ni}$ ); Column, DB-5 WCOT. $0.25 \mathrm{~mm}$ i.d. $x 30 \mathrm{~m}$; Temperature program, $160{ }^{\circ} \mathrm{C} \rightarrow 230^{\circ} \mathrm{C}$ C $2{ }^{\circ} \mathrm{C} / \mathrm{min}$; Injector temperature, $250^{\circ} \mathrm{C}$; Carrier gas, He, $1.4 \mathrm{~kg} / \mathrm{cm}^{2}$ inlet pressure; sample size $1 \mu \mathrm{L}$; Split 30:1.

Table 1. NBS Standard Reference Material 1581, Polychlorinated biphenyls in oils

\section{Matrix}

Motor $0 i 1$

Motor $0 i 1$

Transformer $0 i 1$

Transformer $0 i 1$

\section{Concentration, $\mu \mathrm{g} / \mathrm{g}$}

Aroclor Type

1242

1260

1242

1260

\section{Calculated $^{\text {a }}$}

$100.00 \pm 0.04^{b}$

$100.00 \pm 0.04$

$99.96 \pm 0.04$

$99.98 \pm 0.04$
Gas Chromatography

$100.1 \pm 1.4^{b}$

$100.7 \pm 2.0$

$100.4 \pm 1.2$

$100.6 \pm 2.7$
Certified

Concentration, $\mu \mathrm{g} / \mathrm{g}$

$$
\begin{aligned}
& 100 \pm 1^{b} \\
& 100 \pm 2 \\
& 100 \pm 1 \\
& 100 \pm 3
\end{aligned}
$$

\footnotetext{
a The calculated concentration is based on the total mass of the Aroclor added to the oil. Uncertainty is given as $95 \%$ confidence 1 imits.
} 
The results of our analyses of 11 samples for an ASTM/NBS collaborative study [7] are 1isted in table 2. Most of these samples were made from pure PCBs added to various types of oils, to provide a range of PCB contamination in terms of Aroclor type and concentration. The oil matrices ranged from a virgin motor oil base to a used lubricating oil that had been collected for recycling purposes. The NBS results for each sample are based on a single fractionation with triplicate GC-ECD analyses.

The method we have described for the analysis of hydrocarbon matrices for PCBs should be easily adaptable to other laboratories because it employs the use of conventional, commercially available instrumentation, columns and detectors. We have found it to give accurate analysis of samples [10].

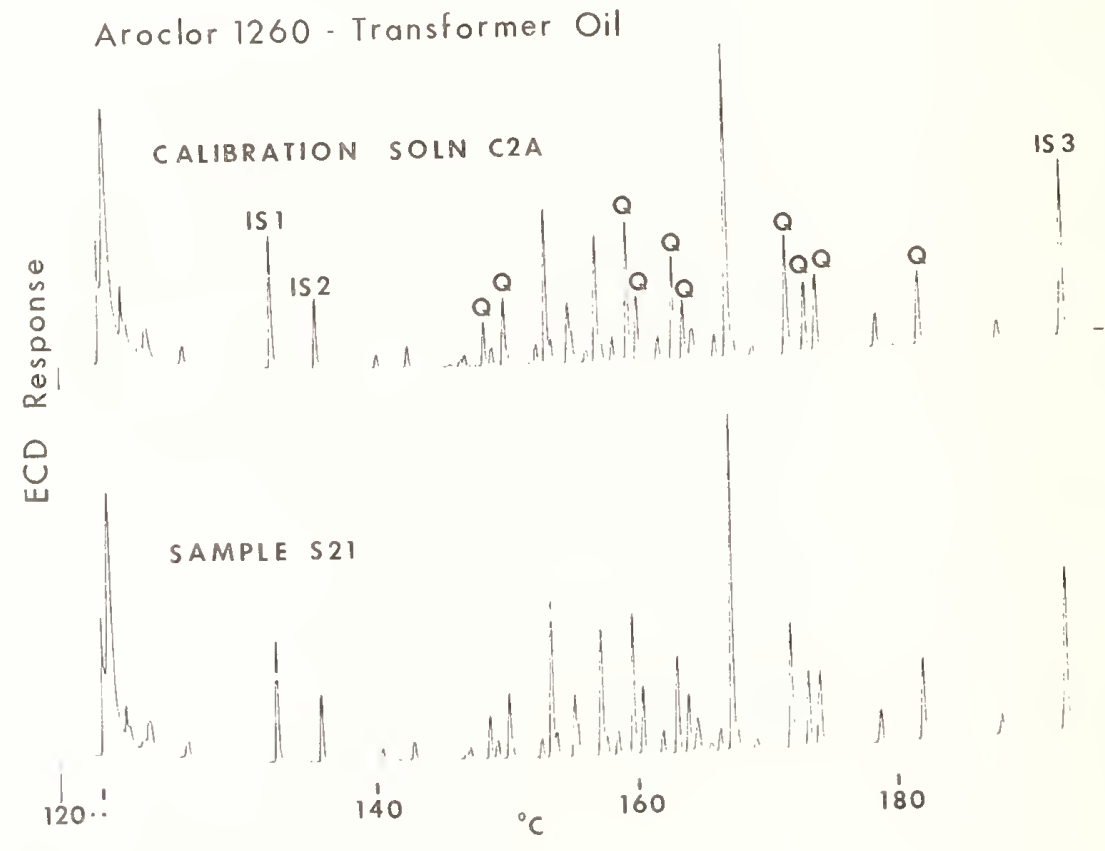

Figure 3. Gas chromatogram of the PCB-containing fractions of: Top: Gravimetrically prepared calibration solution of Arocior 1260 and 3 internal standards in transformer oil. Bottom: SRM sample of "Aroclor 1260 in transformer oil" spiked with 3 internal standards. "Q" designates peaks used for quantitation. "IS1", internal standard 1, was PCB \#21 (Ref. 9), 2,3,4-trichlorobiphenyl. "IS2", internal standard 2, was PCB \#104 2,2',4,6,6'-pentachlorobipheny1. "IS3", internal standard 3, was PCB \#209, decachlorobiphenyl. Conditions: GC with electron capture detection, $300{ }^{\circ} \mathrm{C}$ (constant current ${ }^{63} \mathrm{Ni}$ ); Column, DB-5 SCOT, $0.25 \mathrm{~mm}$ i.d. $\times 30 \mathrm{~m}$; Temperature program, $120{ }^{\circ} \mathrm{C}(1 \mathrm{~min}) \rightarrow 260^{\circ} \mathrm{C}$ (d $4{ }^{\circ} \mathrm{C} / \mathrm{min}$; Injector temperature, $300{ }^{\circ} \mathrm{C}$; Carrier gas, He, $2.8 \mathrm{~kg} / \mathrm{cm}^{2}$ inlet pressure; Sample size, 1 lul; Split 30:1. 
Table 2. NBS-ASTM round robin samples

\begin{tabular}{|c|c|c|c|c|}
\hline Code & Sample & \multicolumn{3}{|c|}{ NBS Results } \\
\hline A & $5.9 \mathrm{ppm}^{\mathrm{b}} \mathrm{A} 1260^{\mathrm{C}} / \mathrm{BC} 7345$ & $6.2 \pm 0.3$ & ppm & A1260 \\
\hline B & $\mathrm{A} 1242 / \mathrm{BC} 7345$ & $41 \pm 1$ & $\mathrm{ppm}$ & A1242 \\
\hline C & $148.3 \mathrm{ppm}$ A1260/BC7345 & $147 \pm 4$ & $\mathrm{ppm}$ & A1260 \\
\hline D & $\mathrm{BC} 7345$ & \multicolumn{3}{|c|}{ N.D. (D.L. <1 ppm Aroclor) } \\
\hline \multirow[t]{2}{*}{$E$} & $\begin{array}{r}41.0 \text { ppm A1242/ } \\
\text { BC7345 }\end{array}$ & $41 \pm 1$ & $\mathrm{ppm}$ & A1242 \\
\hline & 19.9 ppm A1260/ & $19.8 \pm 0.6$ & $\mathrm{ppm}$ & A1260 \\
\hline$F, G$ & Duplicates & \multicolumn{3}{|c|}{ Not Analyzed } \\
\hline $\mathrm{H}$ & $\mathrm{BC} 7227$ & $165 \pm 10$ & $\mathrm{ppm}$ & A1260 \\
\hline I & 96.6 ppm A1254/U05482 & $101.7 \pm 1.6$ & ppm & A1254 \\
\hline \multirow[t]{3}{*}{$\mathrm{J}$} & \multirow[t]{3}{*}{$1: 9^{b} \# 81-335-H / U 05379$} & $25.4 \pm 0.7$ & ppm & A1242 \\
\hline & & \pm 5 & ppm & A1254 \\
\hline & & \pm 3 & $\mathrm{ppm}$ & A1260 \\
\hline k & $\begin{array}{l}\text { 1:4 Additive (Chevron CR-82R 5005)/ } \\
\text { BC7425 }\end{array}$ & No recogniz & $a b l e$ & PCB pattern \\
\hline
\end{tabular}

$a_{1}$ LC fractionation; 3 GC runs

beight/weight

${ }^{C}{ }_{A 1260} \rightarrow$ Aroclor 1260; A1242 $\rightarrow$ Aroclor 1242; A1254 $\rightarrow$ Aroclor 1254

References

1. Hutzinger, 0.; Safe, S; and Zitko, V. The chemistry of PCBs. Cleveland, OH: CRC Press; 1974.

2. Miller, S. The persistent PCB problem. Environ. Sci. Techno1. 16: 98A-99A; 1982.

3. Cairns, T; Siegmund, E. G. PCBs regulatory history and analytical problems. Anal.

Chen. 53: 1183A; 1981.

4. Chesler, S. N.; May, W. E.; White, P. A.; Parris, R. M.; and Guenther, F. R. Determination of polychlorinated biphenyls in waste and lubricating oils, Proc. Joint Conf. on Measurements and Standards for Recycled 0i1/Systems Performance and Durability; 1981 0ct. 23; Gaithersburg, MD. Nat. Bur. Stand. (U.S.) Spec. Pub1. 584; 295-297, 1980 Nov.

5. Chesler, S. N.; Guenther, F. R.; May, W. E.; Parris, R. M. Standard reference materials for accurate analyses of PCBs in oil. ASTM Stand. News 10: 15-20; 1982.

6. National Bureau of Standards Certificate of Analysis, Standard Reference Material 1581. Polychlorinated biphenyls in oils. Office of Standard Reference Materials, National Bureau of Standards, Washington, DC 20234; 1982 June 25.

7. Becker, D. Analyses for PCBs in oil: The ASTM/NBS round robin. Proceedings, Measurements and Standards for Recycled 0i1-IV; Nat. Bur. Stand. (U.S.) Spec. Pub1. 674; 1983. 
8. Eder G. J. Chromatogr. 121: 269-277; 1978.

9. Ballschmiter, K.; Ze11, M. Analysis of polychlorinated biphenyls (PCB) by glass capillary gas chromatography: Composition of technical Aroclor- and Clophen-PCB mixtures. Fresenius Z. Ana1. Chem. 302: 20-31; 1980 .

[10] Certain commercial equipment, instruments, or materials are identified in this paper to specify adequately the experimental procedure. Such indentification does not imply recommendation or endorsement by the National Bureaw of Standards, nor does it imply that the materials or equipment identified are necessarily the best available for the purpose. 
National Bureau of Standards Special Publication 674. Proceedings, Conference on Measurements and Standards for Recycled 0il - IV, held at NBS, Gaithersbura, MD, September 14-16, 1982.

(Issued July 1984).

Analysis for PCB's in 0i1: The NBS/ASTM Round Robin

Donald A. Becker

Recycled 0 il Program

National Bureau of Standards

Washington, DC 20234

\section{Introduction}

Early in 1982, a cooperative effort on the analysis of polychlorinated biphenyls (PCBs) in lubricating oil was initiated by the National Bureau of Standards (NBS) Recycled $0 i 1$ Program and the American Society of Testing and Materials (ASTM), Technical Division P. The primary purpose of this cooperative effort was to help provide the necessary information and data to identify an accurate, relatively simple method for the determination of PCBs in used and re-refined lubricating oils. If identified, such a method could be developed into an ASTM Standard Method. A secondary purpose was to assist oil recyclers to identify an appropriate analytical methodology which could be utilized to obtain reliable PCB analyses in these types of samples. This paper is a further update on the progress and results obtained in this study, and supplements information provided previously at ASTM meetings.

The round robin consisted of eleven samples of oil in sealed glass ampoules which contained one or more of the PCB Aroclors at known (to NBS) concentrations. Seven of these samples (A-G) were made with weighed quantities of the Aroclor(s) dissolved in a virgin lubricating base oil. Since these samples were prepared gravimetrically with high accuracy, they have well known concentrations of $\mathrm{PCB}(\mathrm{s})$. Two duplicate samples were included in the seven. The remaining four samples were: a re-refined base oil with high PCB content $(H)$, two used engine oils containing added PCBs (I,J), and a re-refined base oil containing only an additive package suspected of causing interferences with some PCB analytical methods $(K)$. Sample $J$ was actually a 1:9 dilution of a PCB containing oil sample which had three Aroclors present, 1242, 1254 and 1260 . The dilution was made because of very high PCB concentrations in the original oil, and was made with a PCB-free used engine oil.

The round robin samples as described above were made up and ampouled by the NBS Organic Analytical Research Division. The gas chromatography group analyzed the samples $[1,2]^{1}$. The analysts, though members of the same Division, were not aware of the gravimetric values prior to completion of their analyses. The gravimetric values and the NBS analytical results are given in table 1 . It can be seen from this data that agreement between the two techniques was generally very good.

A total of eighteen laboratories cooperated in this study by supplying analyses of this set of samples using the procedure of their choice. Since one laboratory analyzed the samples by two methods, a total of nineteen sets of result were obtained. In addition, all 1 aboratories were requested to provide a copy of their procedure(s), and most complied although there was a wide discrepancy between the completeness of the information supplied about the various procedures.

The results of the interlaboratory round robin are contained in table 2. This table provides all of the analytical data as well as the gravimetric and NBS results; and the MEAN, STANDARD DEVIATION (of a single measurement; S.D.), and HIGH/LOW values for the non-NBS laboratory analyses. In this table, the values for a sample are contained in a single vertical column, with the letter at the head of the column identifying the specific sample. At the far left are the analyzing laboratory labels, numbers 1 through 18. It should be noted that these 1aboratories are 1 isted in $r a n d o m$ order.

1Figures in brackets indicate the literature references at the end of this paper. 
Table 1. PCBs added and NBS analyses of round robin samples

PCB Concentration (PPM;wt/wt)

\begin{tabular}{|c|c|c|c|c|c|}
\hline Code & $0 i 1^{a}$ & Conc. Added & Aroclor & NBS Value & Aroclor \\
\hline A & BC 7345 & 5.9 & 1260 & $6.2 \pm 0.3$ & 1260 \\
\hline$B(F)$ & BC 7345 & 41.0 & 1242 & $41 \pm 1$ & 1242 \\
\hline C & BC 7345 & 148.3 & 1260 & $147 \pm 4$ & 1260 \\
\hline D & BC 7345 & NONE & - & N.D. ${ }^{C}$ & \\
\hline$E(G)$ & BC 7345 & $\begin{array}{l}41.0 \\
19.9\end{array}$ & $\begin{array}{l}1242 \\
1260\end{array}$ & $\begin{array}{l}41 \pm 1 \\
19.8 \pm 0.6\end{array}$ & $\begin{array}{l}1242 \\
1260\end{array}$ \\
\hline H & BC 7227 & NONE & -- & $165 \pm 10$ & 1260 \\
\hline I & vo 5482 & 96.6 & 1254 & $102 \pm 2$ & 1254 \\
\hline $\mathrm{J}$ & vo 5379 & $\ldots d$ & -- & $\begin{array}{l}25.4 \pm 0.7 \\
48 \pm 5 \\
40 \pm 3\end{array}$ & $\begin{array}{l}1242 \\
1254 \\
1260\end{array}$ \\
\hline
\end{tabular}

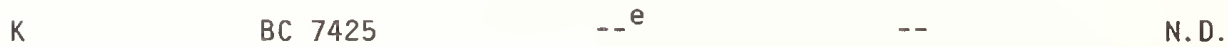

${ }^{a} 0 i l$ identification is as follows: $B C 7345$ is an unused, virgin lube basestock; $B C 7227$ is an unused, re-refined basestock containing a PCB contaminant; BC 7425 is a re-refined lube basestock with $580 \mathrm{ppm}$ total chlorine contaminant, but no PCB contaminant; UO 5482 and U0 5379 are uncleaned, used automotive lube oils.

${ }^{b}$ NBS results based on one LC fractionation with three GC runs per sample. ( \pm values are the standard deviation of a single measurement).

$\mathrm{C}_{\text {N.D. }}=$ Not detected; detection limit is 1 ppm Aroclor.

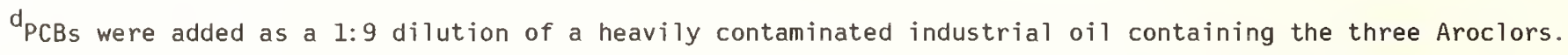

EN PCBs present or added; additive package used which had caused some techniques to give false positives for PCBs. Also, the re-refined base oil used had chlorine present at a relatively high level, but did not contain PCBs. 


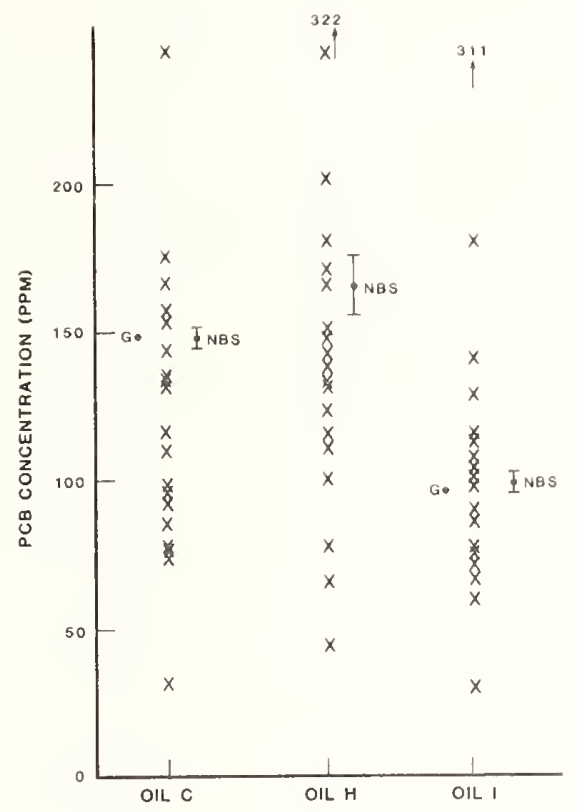

Figure 1. PCB data plot for samples $C, H$ and $I$ ( $G=$ gravimetric value; NBS = NBS value, with estimated uncertainty based on the precision of the three GC runs).

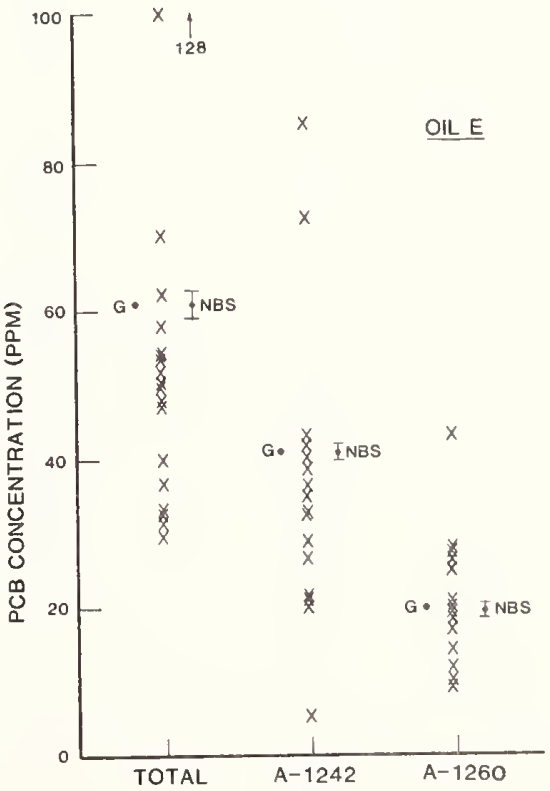

Figure 2. PCB data plot of sample E: total PCB concentration and individual Aroclors ( $G=$ Gravimetric value; NBS = NBS value, with estimated uncertainty based on the precision of the three GC runs.) 
Table 2. Round robin analytical data

PCB Concentration (PPM)

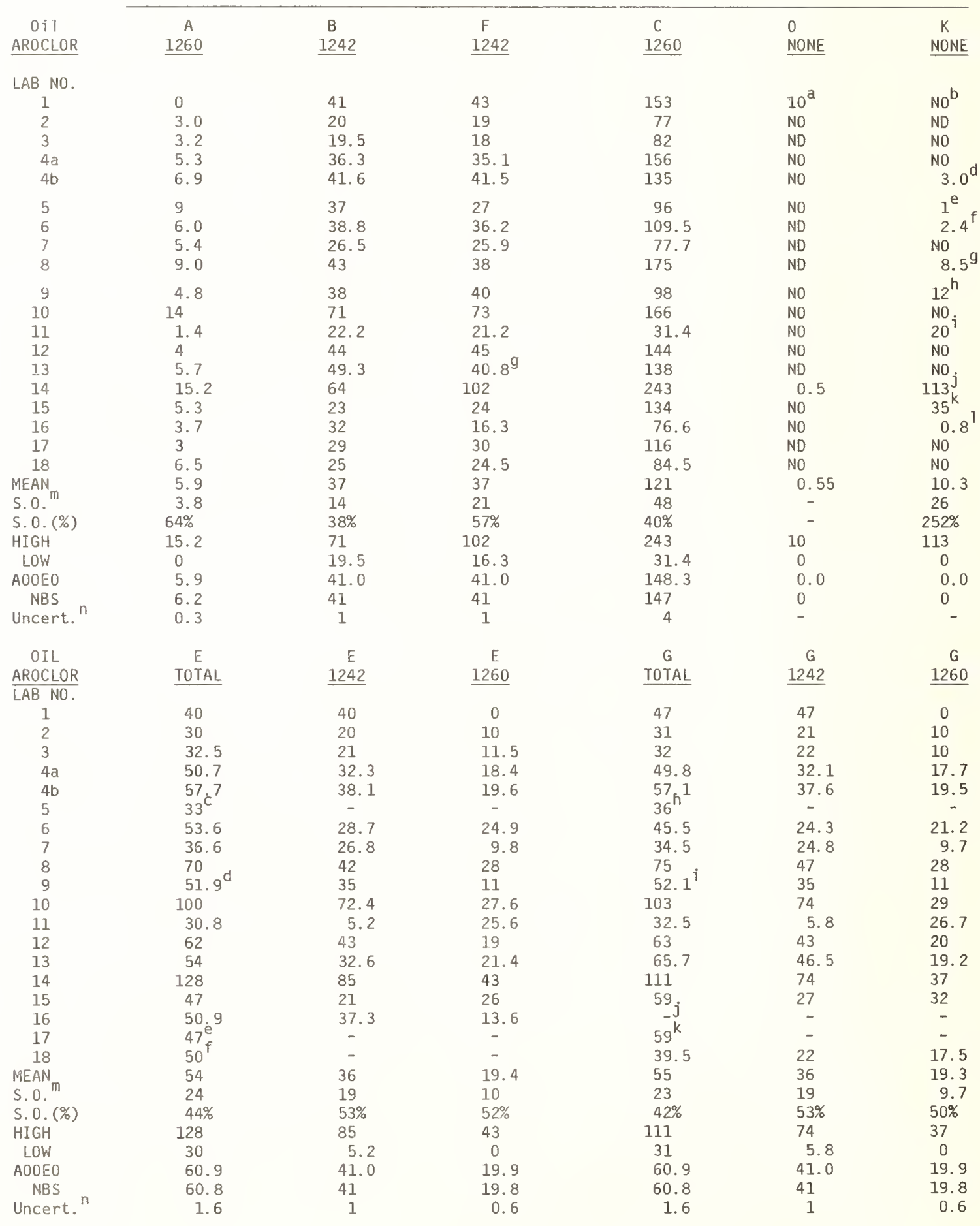


Table 2. (continued)

PCB Concentration (PPM)

\begin{tabular}{|c|c|c|c|c|c|c|}
\hline OIL & $\mathrm{H}$ & I & $\mathrm{J}$ & J & J & $\mathrm{J}$ \\
\hline AROCLOR & $\underline{1260}$ & $\underline{1254}$ & TOTAL & 1242 & 1254 & 1260 \\
\hline$\overline{\mathrm{LAB} \mathrm{N} N \text {. }}$ & & & & & & \\
\hline 1 & 138 & 140 & 156 & 0 & 156 & 0 \\
\hline 2 & 77 & 128 & 94 & 0 & 59 & 35 \\
\hline 3 & 65 & 30 & 137 & 0 & 112 & 25 \\
\hline $4 a$ & 165 & 107 & 143.0 & 41.9 & 76.1 & 25.0 \\
\hline $4 \mathrm{~b}$ & 147 & 97.5 & 129.2 & 41.1 & 66.0 & 22.1 \\
\hline 5 & 150 & $74^{\mathrm{a}}$ & $140^{5}$ & - & - & - \\
\hline 6 & 131.3 & 85.9 & 103.8 & 0 & 0 & 103.8 \\
\hline 7 & 132.1 & 115.4 & 118.3 & 0 & 118.3 & 0 \\
\hline 8 & 200 & 100 & 131 & 31 & 0 & 100 \\
\hline 9 & 110 & 89 & 119 & 25 & 66 & 28 \\
\hline 10 & 179 & 179 & 344 & 10 & 167 & 167 \\
\hline 11 & 43.6 & 75 & 98.3 & 0 & 86 & 12.3 \\
\hline 12 & 170 & 76 & 197 & 24 & 119 & 54 \\
\hline 13 & 123 & 73 & 112 & 32 & 80 & 0 \\
\hline 14 & 322 & 311 & 320 & 106 & 107 & 107 \\
\hline 15 & 242 & 103 & 108 & 0 & 44 & 64 \\
\hline 16 & 116.3 & 60.8 & 42.9 & 0 & 0 & 42.9 \\
\hline 17 & 144 & 114 & 179 & - & - & - \\
\hline 18 & 102 & 67 & $95.5^{c}$ & - & - & - \\
\hline MEAN & 145 & 107 & 146 & 19.4 & 79 & 49 \\
\hline S.D. & 63 & 59 & 74 & 28 & 51 & 48 \\
\hline S.D. (\%) & $43 \%$ & $55 \%$ & $51 \%$ & $144 \%$ & $65 \%$ & $98 \%$ \\
\hline $\mathrm{HIGH}$ & 322 & 311 & 344 & 106 & 167 & 167 \\
\hline LOW & 43.6 & 30 & 42.9 & 0 & 0 & 0 \\
\hline ADDED & - & 96.6 & - & - & - & - \\
\hline NBS & 165 & 102 & 113.4 & 25.4 & 48 & 40 \\
\hline Uncert. ${ }^{n}$ & 10 & 2 & 9 & 0.7 & 5 & 3 \\
\hline
\end{tabular}

adentified as Aroclor 1221.

$b_{\text {ND }}=$ None Detected.

${ }^{C}$ Identified as a mixture of Aroclors 1242 and 1260.

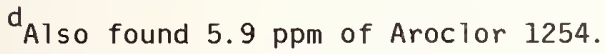

ENo Aroclors identified.

fIdentified as a mixture of Aroclors 1248, 1254 and 1260.

Identified as $28.4 \mathrm{ppm}$ of Aroclor 1242 and $12.7 \mathrm{ppm}$ of Aroclor 1260.

${ }^{h}$ Stated to be a mixture of Aroclors 1242 and 1260.

${ }^{i}$ Also found $6.1 \mathrm{ppm}$ of Aroclor 1254.

${ }^{j}$ Ampoule broken in transit.

ko Aroclors identified.

IIdentified as $0.8 \mathrm{ppm}$ of Aroclor 1254.

${ }^{\mathrm{m}}$ Standard deviation of a single measurement.

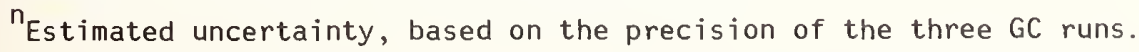

NOTE: Added values are amounts of the Aroclors gravimetrically added to the lubricating oils. 0ils A, B, C, D, E, F, G, and $K$ were clean base oils to which known amounts of PCBs were added. 
A plot of the data for oils $\mathrm{C}, \mathrm{H}$, and I is found in figure 1. It becomes immediately obvious from this figure that there are problems in the analysis of PCBs even at concentrations of 100 ppm and above. Figure 2 shows the same type of plot for the individual Aroclors as well as tne total PCB content for oil $E$. It may be useful to point out that the average uncertainty for the individual Aroclors was $\pm 74 \%$ while for the total PCB content of these oils the average uncertainty was $\pm 48 \%$ (1 sigma). Examination of the data indicates that most of this difference in uncertainty (between total and individual Aroclors) was due to the influence of sample $\mathrm{J}$, a very dirty sample which appeared to cause substantial analytical problems. For most samples, the determination of individual Aroclors increased the uncertainty by only about 10 percent. The lower uncertainty of the total PCB values may result from partial compensation of errors when two or more Arociors were determined in the same sample.

In addition to the data provided above, an attempt was made to ascertain some indication as to the source of the analytical uncertainty utilizing information available from the two sets of duplicates included in the round-robin. These duplicates are samples $B$ and $F$, and samples $E$ and G. In figure 3 , the individual laboratory values for the PCB content of sample B is plotted versus that found for sample $F$, to provide what is called a Youden plot. Since the samples $B$ and $F$ are identical, the "true" value is a point in the center of the figure, marked by an $X$. An examination of the data from the 19 sets of results shows not a symmetrical series of points around the $X$, as would be expected from a true random distribution of errors, but rather a configuration closely approximating a 1 ine at 45 degrees from the origin and passing through the $x$.

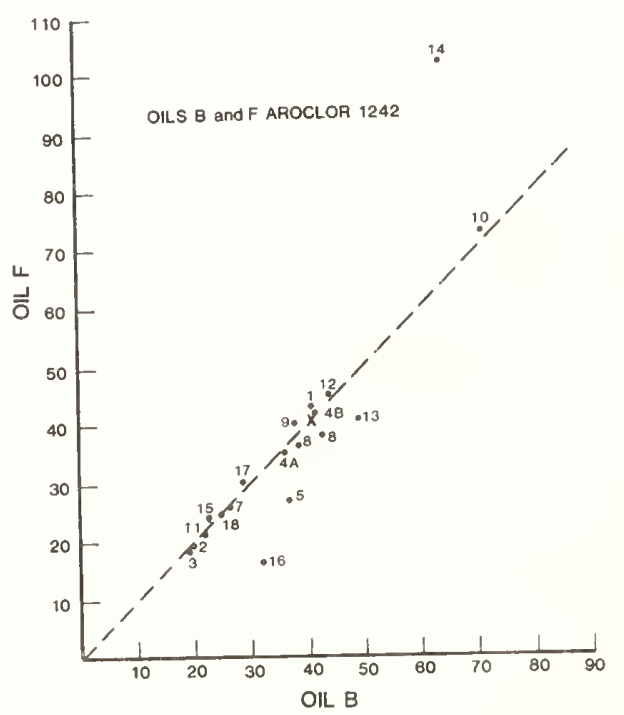

Figure 3. Yopden plot of duplicate sainples for aroclor 1242 content: sample $B$ versus sample $F(X=$ "True" value based on gravimetric data). 
A similar plot is shown in figure 4, for the two duplicate samples $E$ and G. Again, the configuration obtained approximates a straight 1 ine at 45 degrees, passing through the origin and through the $X$.

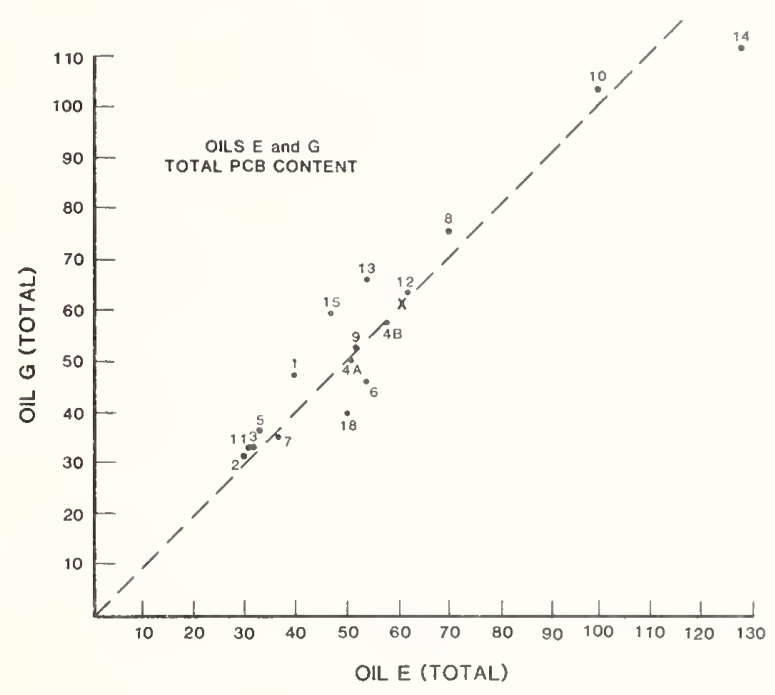

Figure 4. Youden plot of duplicate samples for total PCB content: sample E versus sample $\mathrm{G}$ ( $\mathrm{X}=$ "True" value based on gravinetric data).

The above data and figures can be used to provide some insight into the analytical problems which seem to be causing the rather high uncertainties found in this study. First, the close approximation to a straight 1 ine at a 45 degree angle along with the high repeatibility of most of the laboratories for identical samples, would seem to indicate that the laboratories have reasonably good precision in their analyses. However, the wide variability from the "true" value (the $X$ on the plots) appears to indicate that a substantial problem exists with the standardization and/or quantitation methodology that was utilized. Some information on the analytical techniques used by the laboratories is shown in table 3 .

From the information contained in table 3 , it is seen that all of the participating laboratories used external standards, which may result in different yields between the samples and standards due to differing sample clean-up procedures (column 2 of table 3 ). Examination cf the data shows that, except for the two dirty oil samples ( $I$ and $J$ ), the MEAN value from participating laboratories is less than the amount of PCB added gravimetrically (and later found to be still present by NBS analysts), supporting the concept of uncorrected losses during sample preparation and/or analysis. Also, further discussion with participants revealed that some laboratories analyzed their standards in different matrices than the samples. For example, either of the above difficulties could cause substantial differences between samples and standards, resulting in the observed discrepencies.

In an attempt to evaluate the possibility that congeneric differences between the various standards used might be influencing the quantitation process, samples of their standards were requested from the cooperating laboratories for analysis at NBS. Five laboratories provided such samples, and preliminary analysis of those samples did not indicate any significant differences in isomeric distributions of the Aroclors (less than 5 percent). 
Table 3. Summary of PCB analytical techniques used

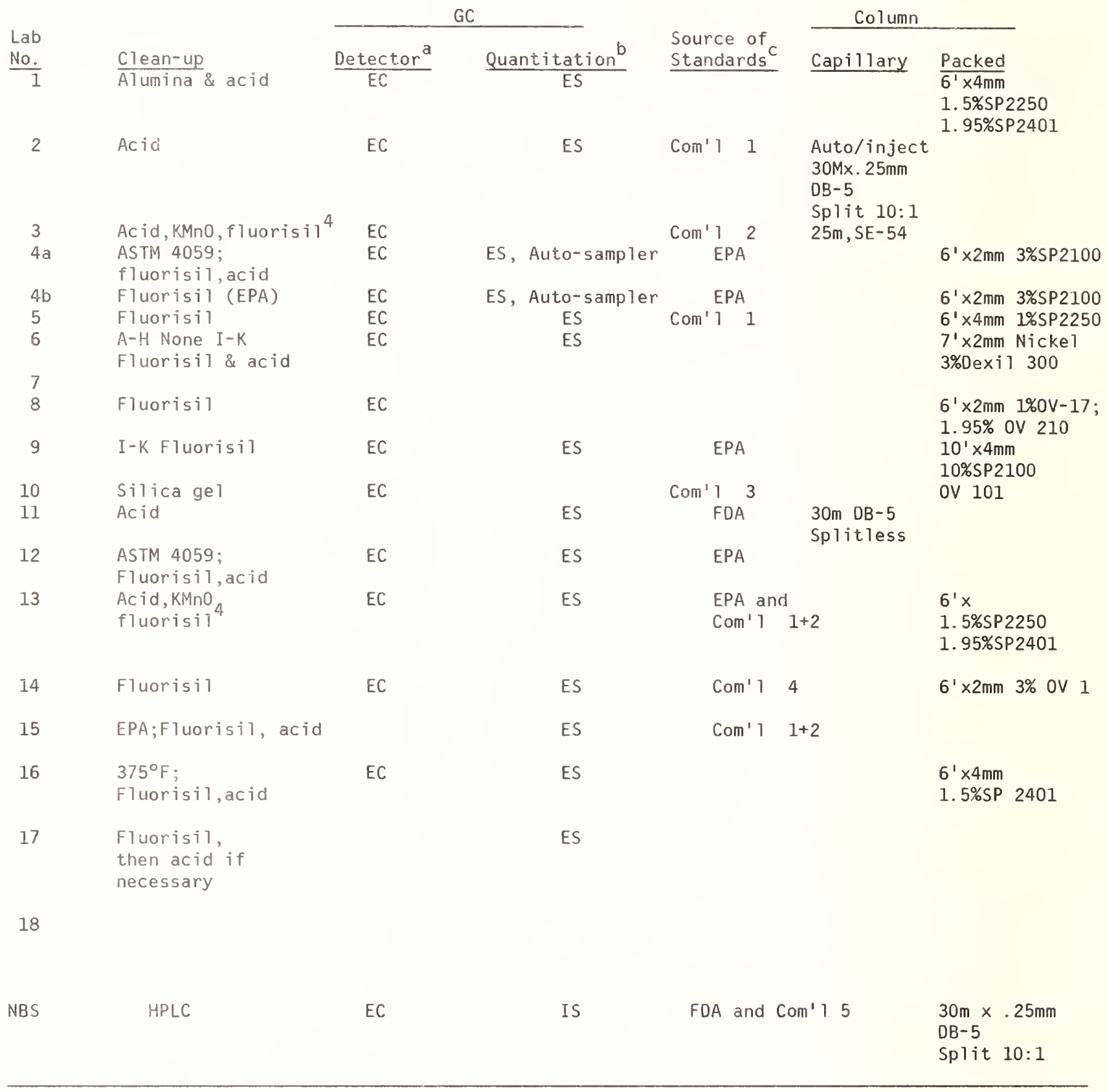

Note: Acid is concentrated $\mathrm{H}_{2} \mathrm{SO}_{4}$

${ }^{a_{E C}}=$ Electron Capture

${ }_{E S}=$ External Standard; IS = Internal Standard

${ }^{C}$ Com' $1^{\prime}=$ Commercial sources, numbered 1 to 5

In conclusion, as a result of this study to date, it appears that there is substantial variability in the analytical results obtained by different laboratories in the analysis of PCBs in petroleum oils. These large uncertainties exist for the analysis of clean lube oil basestocks as well as for the analysis of dirty used and waste oils. Also, it appears that these large uncertainties are related to the quantitation process. It is hoped that further examination of the data and the techniques used will provide additional insight into a method which would be suitable for development into an ASTM PCB standard method for used and recycled oils. 
The author wishes to acknowledge the participation and cooperation of ASTM and the analytical laboratories. In addition, the assistance of the NBS Gas Chromatography Group in the preparation of samples and in their analysis is appreciated.

\section{References}

[1] Parris, R. M.; Guenther, F. R.; May, W. E.; Chesler, S. N. Analysis for PCBs in 0il: Technique and SRM Development. Proceedings, Measurements and Standards for Recycled 0i1-IV, Nat. Bur. Stand. (U.S.) Spec. Pub1. 674; 1983.

[2] Chesler, S.; May, W.; White, P.; Parris, R.; and Guenther, F., eds. Determination of polychlorinated biphenyls in waste and lubricating oil; Proceedings, Joint Conference on Measurements and Standards for Recycled 0il/Systems Performance and Durability; Nat. Bur. Stand. (U.S.) Spec. Pub1. 584; 1980. 

National Bureau of Standards Special Publication 674. Proceedings, Conference on Measurements and Standards for Recycled $0 i 1$ - IV, held at NBS, Gaithersburg, MD, September 14-16, 1982.

(Issued July 1984).

\section{LUBE OIL MONITORING IN THE STATE OF CALIFORNIA}

James N. Johnson

Petroleum Products Program

Division of Measurement Standards

Department of Food and Agriculture

Sacaramento, California 95826

\section{Introduction}

Lubricating oils are a unique commodity to the consumer. Few people, if any, can distinguish between grades or brands by touch, sight or smell. Unlike many other commodities, its sale and delivery into a vehicle is final in the sense that there is no practical way for the motorist to return or exchange the product if dissatisfied. The brand and labeling statements are principal factors in its presentation to the public. Therefore, the interests of the consumer are of primary importance in the assurance of stated quality. This is a vital factor in the monitoring and surveillance of lube oils.

Of equal importance to consumer concerns, is the assurance that the lubricating oil industry competes in a marketplace where equity prevails and where unfair advantage is not gained through misleading and unfair business practices. The California Petroleum Products Program maintains a lubricating oil monitoring program to serve both the consumer and industry alike.

California's presence in the field of petroleum product quality testing is not new. For over fifty years the Petroleum Products Program, through the Department of Food and Agriculture, Division of Measurement Standards, has had the responsibility of maintaining the integrity of a wide variety of automotive petroleum products. Throughout this period of time lubricating oils have been constantly monitored to prevent fraud and misrepresentation. In 1982, this continues to be an important program activity.

The State of California has a large, highly mobile population, accounting for over 10 percent of the nation's consumption in several commodity areas. Gasoline and lubricating oils are no exception. In 1981, sales of gasoline and other motor fuels were 11 billion gallons, while sales of automotive lubricating oils in the same year were approximately 110 million gallons.

Most requirements concerning lubricating oils are contained in the statues of the California Business and Professions Code. Regulations are adopted to clarify, make specific or interpret the statutes. California labeling laws require that the SAE/API engine service classification, S.A.E. viscosity number, brand, name of product and net contents be on all motor oil packages. In addition, the label must state either "the model year for which the oil is generally intended, or the level of service for which it is to be used." The California Legislature has been responsive to needed change and has acted on behalf of industry, consumers and state agencies.

State Petroleum Laboratories are located in Downey (Los Angeles) and Sacramento. Investigative staff work is conducted out of five regional offices that are strategically located throughout the State. Individual county weights and measures departments ( 56 counties) participate in joint enforcement of laws and regulations pertaining to petroleum in varying degrees.

\section{Field Activity}

As a part of the field investigation activity, specially equipped vehicles are used by investigators to covertly purchase motor oils at retail locations for quality and quantity purposes. These vehicles are equipped with a by-pass device which diverts the motor oil sample to a container for analysis purposes. A particular brand and S.A.E. viscosity classification oil is requested and the sample is tagged, labeled and brought to the laboratory for testing. 
The experiences of an undercover motor oil quality program have been unique and varied. In the activity of "playing the part of a consumer motorist" we have been sold crankcase drainings, can drainings, automatic transmission fluid mixtures, wrong S.A.E. viscosity numbers, different brands and grades, and occasionally, nothing at all. In the majority of these instances there was a profit motivation involved and the unscrupulous operator or attendant merely utilized any stock on hand to complete the fraudulent act. In one of the more flagrant cases, an operator filled quart cans of virtually every major brand label in the market with a low quality, SA classification oil. His shelves and cabinets contained 150 refilled quarts of various brand labels; however, they all contained the same oil. Also in inventory were 90 gallons of low quality product stored in bulk for quart can refilling purposes. Several marketing factors have caused these practices to diminish, however, they still do occur occasionally.

Throughout the State, samples of lubricating oil are obtained at virtually all types of retail locations; service stations, auto parts stores, supermarkets, convenience stores and truck stops. Packaged and bulk virgin oils as well as recycled oils are monitored to insure compliance with appropriate advertising, labeling and quality requirements.

Random sampling at both retail and wholesale levels provides the best opportunity to view the broadest market situation. When a problem or violation pattern develops, staff and resources are directed to that specific circumstance. If violations are found that involve off-specification product, appropriate compliance or enforcement measures are utilized. This includes direct court citations, criminal complaints and civil suits. Local prosecutors at the city and county levels have become experienced in handling violations involving consumer and business interests relating to petroleum products. Violations occurring statewide can be referred to the State Attorney General's office. Generally, the California lube oil industry is committed to marketing a range of products that consistently meet existing requirements of law and regulations. Only with a comprehensive quality control program can a high level of compliance to product specification be achieved. In this regard, the industry has made a concerted effort towards that objective.

\section{Laboratory Evaluation of Lubricating $0 i 1 s$}

The Division of Measurement Standards maintains ASTM membership. Most laboratory test methods are ASTM procedures. This involvement assures the maintenance of recognized current ASTM test methods utilized by the industry. Participation within ASTM provides the opportunity to communicate directly with industry, automobile manufacturers, other states and general interest membership. Although our membership has not been of long duration, current and future benefits derived from ASTM membership and participation are of great value to our program activity.

Perhaps the most important aspect of a regulatory monitoring program is the laboratory, where al1 lube oil products found in the marketplace are evaluated. Until recently, the laboratory was relatively basic in nature, performing a variety of physical bench tests to compare various characteristics of a motor oil sample with known "true sample" data. It was relatively easy to determine if an undercover sample of "XYZ S.A.E. 30" was indeed, XYZ S.A.E. 30. Gravity, viscosity, viscosity index, flash point and color generally provided the needed tests for comparison purposes. In some instances, this is still the basis for identification. However, improved equipment and testing procedures have evolved through the years to bring this testing to more sophisticated levels for compliance monitoring. In addition to previous mentioned physical testing, California petroleum laboratories now utilize the infra-red spectrophotometer, cold-cranking simulator, foam test equipment as well as several other necessary lube oil testing procedures. It should be noted that the California State Petroleum Laboratories do not function in a research and development mode. The main purpose of the program activity is to identify off-specification product and subsequently remove it from sale.

When an oil is considered suspect in one or more specification areas, additional testing is necessary for confirmation. For example, a more in depth examination of the additive package contents may be needec to verify the presence of metals. 0ccasionally, samples are sent to commercial laboratories to perform this additional analysis.

Recycled (reclaimed) oils are evaluated in the same manner as virgin oils. Recycled oils, until recent years, had specific labeling requirements distinguishing it from virgin oil. Modern, re-refining processes and technology, coupled with adequate quality control measures, have vastly 
improved the re-refined product image in the marketplace. High quality base stocks and additive packages that are presently available can provide applicable specifications that are appropriate for the rigid lubrication requirements of modern engines.

Within a lube oil monitoring program, several quality factors become apparent. Types of oil, physical qualities and adherence to specifications by the companies that blend and package lubricating oils are examined. While most of the industry observes good quality control procedures, there have been instances of lubricating oils that were offered for sale at retail that had not been subjected to a single test for quality. These particular oils contained metal shavings, impurities, were of various viscosity classifications and generally resembled drainings from engine crankcases. This, of course, is not what is normally found in the marketplace but indicates this type of problem does occur. Before 1965, "reclaimed lubricating oils" carried many negative connotations. Some were real, some imagined. The qualities found in many recycled oils today match virgin oils in equivalence levels. There are several companies in California that incorporate these qualities in the re-refining of lubricating stocks.

Because of favorable climatic conditions, California automobiles may be in service years longer than vehicles driven in other parts of the nation. Recycled as well as virgin oils serve this older generation of automobiles. It is estimated that 5.3 percent of California's over 17.5 million registered vehicles are more than 10 years old. Good lubricating oils certainly contribute to keeping this portion of the vehicle population on the road.

\section{Conclusions}

The Petroleum Program in California is one of flexibility, as priorities must change to meet the challenge of a constantly changing petroleum market. Recent technical developments indicate a need to enhance existing test equipment to focus on vital areas of lube oil quality. As a regulatory function, this is an important aspect in carrying out the laboratory responsibility for enforcement purposes. There is always more that could be done if staff and resources permitted, and I would imagine that is true of most activities in the private sector as well as government. There are plans to expand the lube oil monitoring activity in California. The degree of expansion for the future is dependent upon anticipated needs that would be of benefit to both industry and the consumer.

Industry participation is essential for achieving compliance goals. Quality standards existing in California are consistent with industry goals. Conscious effort on the part of industry to recognize and adopt measures to assure consumers a high quality product maintains the compliance levels necessary for a high volume petroleum products market. 

National Bureau of Standards Special Publication 674: Proceedings, Conference on Measurements and Standards for Recycled 011 - IV, held at NBS, Gaithersburg, MD, September 14-16, 1982.

(Issued JuTy 1984).

\author{
REVISION OF THE MIL-L-2104C SPECIFICATION \\ Thomas C. Bowen \\ U. S. Army MERADCOM \\ Fort Belvoir, VA 22060
}

This paper will present the Army's activities in upgrading Military lubricant specifications to allow the use of re-refined materials. Although primary emphasis will be placed on the proposed revision to specification MIL-L-2104C, I will also provide an update relative to actions taken with other automotive lubricant specifications.

At the time of the last NBS Conference, one document was in effect which provided for the use of re-refined materials. This document, Purchase Description ME-101, was the culmination of the EPA/DOD re-refined oil program addressing engine oils for use in administrative service vehicles. The purchase description became obsolete in January 1980 with the issuance of the MIL-L-46152A specification covering SE/CC quality level engine oils. This specification and the subsequently issued MIL-L-46152B document, formally provided for the qualification and procurement of engine oils formulated with virgin, re-refined or a combination of the two types of basestocks. It should be noted that MIL-L-46152B, dated January 1981, upgraded the performance of administrative service oils to SF/CC quality level and adopted the revised SAE viscosity grading system.

With the successful comp?etion of the work covering engine oils for administrative service vehicles, the Army initiated a second program, to address the use of re-refined materials in lubricants intended for the tactical and combat fleets. The program was patterned after the approach used in the previous effort and in part relied on information generated during the EPA/DOD program. Two re-refined basestocks were selected for evaluation in the MIL-L-2104C program. Table 1 summarizes analyses conducted on the stocks under the 7000 designation. Since stocks from the same manufacturers had been used in the previous program, comparative data generated during the EPA/DOD work are presented. These data are denoted by the 6000 series numbers. The re-refined stocks were treated with an additive system typical of qualified MIL-L-2104C products. Analysis data for the finished oils are presented in table 2. As can be seen, both oils fall within a Grade 30 viscosity classification and have very similar chemical and physical properties.

Table 1. Summary of base stock analyses

\begin{tabular}{|c|c|c|c|c|}
\hline Property & $\frac{\text { Base }}{6694}$ & $\frac{\text { ck A }}{7755}$ & $\frac{\text { Base }}{6696}$ & $\frac{\text { ock B }}{7700}$ \\
\hline Viscosity, cSt & & & & \\
\hline (อ $100^{\circ} \mathrm{C}$ & 7.77 & 8.14 & 8.32 & 9.08 \\
\hline (2) $40^{\circ} \mathrm{C}$ & 53.1 & 57.1 & 60.3 & 68.5 \\
\hline Viscosity Index & 108 & 109 & 105 & 107 \\
\hline Gravity, ${ }^{\circ} \mathrm{API}$ & 30.0 & 30.0 & 29.6 & 29.0 \\
\hline Carbon Residue & 0.06 & 0.13 & 0.05 & 0.15 \\
\hline Pour Point, ${ }^{\circ} \mathrm{C}$ & -9 & -10 & -12 & -3 \\
\hline Flash Point, ${ }^{\circ} \mathrm{C}$ & 196 & 207 & 213 & 224 \\
\hline $\begin{array}{l}\text { Sap. No. } \\
\text { BP Dist. }{ }^{\circ} \mathrm{C}\end{array}$ & 0.35 & 0.30 & 0.24 & 1.33 \\
\hline $1 \%$ & 240 & 292 & 276 & 318 \\
\hline $5 \%$ & 339 & 362 & 371 & 373 \\
\hline $10 \%$ & 377 & 388 & 390 & 394 \\
\hline $50 \%$ & 452 & 485 & 447 & 488 \\
\hline $90 \%$ & 551 & - & 550 & - \\
\hline Residue, M\% & 5 & 14 & 4 & 11 \\
\hline
\end{tabular}


Table 2. Finished oil analyses

\begin{tabular}{llc} 
Property & $0 i 11$ & 0 0i1 2 \\
\cline { 2 - 3 } $\begin{array}{l}\text { Base Stock } \\
\text { Viscosity, cSt }\end{array}$ & $\mathrm{A}$ & $\mathrm{B}$ \\
$\quad 0100^{\circ} \mathrm{C}$ & 10.1 & 11.2 \\
@40 & 76.9 & 92.7 \\
Viscosity Index & 113 & 107 \\
Flash Point, ${ }^{\circ} \mathrm{C}$ & 218 & 223 \\
Pour Point, ${ }^{\circ} \mathrm{C}$ & -10 & -15 \\
TAN & 2.1 & 2.6 \\
TBN & 9.5 & 9.5 \\
Sulfated Ash, \%M & 1.27 & 1.27 \\
Elementa1, \%M & & \\
Ca & 0.21 & 0.20 \\
Mg & 0.09 & 0.09 \\
Zn & 0.13 & 0.13 \\
P & 0.11 & 0.11 \\
S & 0.45 & 0.50
\end{tabular}

The next task in the program involved evaluation of the engine performance characteristics of the finished oils. Since the tactical and combat fleets are predominately diesel powered, emphasis was placed in this area, relying on information generated in the EPA/DOD program to demonstrate the gasoline engine performance of re-refined products. The tests selected were the Caterpillar 1G2, required for qualification of MIL-L-2104C oils, and the Caterpillar 102 test which at the time was proposed to replace the 1-D procedure used for approval testing under the MIL-L-2104C specification. Results of initial testing are summarized in table 3 . As can be seen, $0 i 1$ successfully met the MIL-L-2104C requirements, while oil 2 failed, allowing the formation of deposits well in excess of the limits established by the specification. At this point, a decision was made to reformulate 0 il 2 rather than conduct a retest of the product. This was accomplished by a rebalance of additive components used in the original blend. Table 4 summarizes analytical data for the reformualted product, denoted $0 i 13$, compared with the $0 i 12$ data. The reformulated oil was then subjected to $1 G 2$ and 102 testing. Table 5 summarizes al1 engine performance data generated in the program. As can be seen, $0 i 13$ satisfied the $M I L-L-2104 C, 1 G 2$ test requirement.

Table 3. Initial test results

\begin{tabular}{|c|c|c|c|}
\hline Engine Test & Requirement & $0 i 11$ & $0 i 12$ \\
\hline \multicolumn{4}{|l|}{$1 \mathrm{G} 2$} \\
\hline TGF,\% & 80 MAX & 39 & 34 \\
\hline $\begin{array}{l}\text { WTD } \\
102\end{array}$ & 300 MAX & 172 & 449 \\
\hline TGF,\% & $\begin{array}{l}\text { NRa } \\
\text { NRa }\end{array}$ & $\begin{array}{r}12 \\
244\end{array}$ & NTa \\
\hline
\end{tabular}

ANR - NO REQUIREMENT: NT - NOT TESTED

Table 4. Analysis reformulated oil

$\begin{array}{lcc}\text { Property } & 0 i 12 & 0 i 13 \\ \text { TAN } & 2.6 & 2.2 \\ \text { TBN } & 9.5 & 11.9 \\ \text { SULFATED ASH, \%M } & 1.27 & 1.46 \\ \text { Elementa1, \%M } & & \\ \text { CA } & 0.20 & 0.30 \\ \text { MG } & 0.09 & 0.08 \\ \text { ZN } & 0.13 & 0.14 \\ \text { P } & 0.11 & 0.12\end{array}$


Table 5. Engine test results

\begin{tabular}{|c|c|c|c|c|}
\hline Engine Test & $\begin{array}{c}2104 \mathrm{C} \\
\text { Requirement } \\
\end{array}$ & $\underline{0} \mathbf{1 1} 1$ & 0112 & 0 i1 3 \\
\hline \multicolumn{5}{|l|}{$1 \mathrm{G} 2$} \\
\hline $\begin{array}{l}\text { TGF, \% } \\
\text { WTD }\end{array}$ & $\begin{array}{r}80 \text { MAX } \\
300 \text { MAX }\end{array}$ & $\begin{array}{r}39 \\
172\end{array}$ & $\begin{array}{r}34 \\
449\end{array}$ & $\begin{array}{r}53 \\
232\end{array}$ \\
\hline 1D2 & & & & \\
\hline $\begin{array}{l}\text { TGF, \% } \\
\text { WTD }\end{array}$ & $\begin{array}{l}\text { NRa } \\
\text { NRa }\end{array}$ & $\begin{array}{r}12 \\
244\end{array}$ & $\begin{array}{l}\text { NTa } \\
\text { NTa }\end{array}$ & $\begin{array}{r}25 \\
111\end{array}$ \\
\hline
\end{tabular}

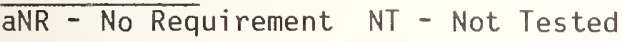

From the results obtained during the program the following conclusions were drawn:

1) It is possible to formulate engine oils containing re-refined material which will meet the performance requirements of the MIL-L-2104C specification.

2) The performance characteristics of finished lubricants formulated using different rerefined base stocks and identical additive treatments can vary significantly.

3) To verify the performance characteristics of finished oils containing re-refined materials, it will be necessary to maintain current qualification procedures which require products to be tested against all specification performance requirements.

Based on these conclusions, it was recommended that:

1) When amended or revised, restrictions on the use of re-refined materials should be removed from the MIL-L-2104 specification.

2) The methodology used for incorporating re-refined materials into the MIL-L-46152 specification be employed under the MIL-L-2104 document.

The aforementioned recommendations have been adopted. As many of you are aware, the MIL-L-2104 specification is currently under revision. The proposed "D" specification will allow use of re-refined basestock and provisions for sampling of basestocks have been incorporated. As with other Military engine oil specification, property requirements have been established to define lubricant grade and provide a general control of low-temperature handling and product volitility. A series of engine dynamometer tests will be used to define lubricant performance characteristics. In addition, the proposed specification will include several transmission performance tests. This 1 ater aspect was necessitated because of the Military's use of MIL-L-2104 oil in power transmission application. It is expected that the MIL-L-2104D specification will be issued in early 1983.

This concludes my remarks concerning the MIL-L-2104 specification, however, I would 1ike to take this opportunity to advise you of action taken in regard to the MIL-L-46167 Arctic engine oil and the MIL-L-2105 gear lubricant specifications. The Arctic engine oil specification is currently being updated. As a portion of this effort, it is proposed to allow the use of re-refined materials in formulating products qualified under the revised specification. It is anticipated that the MIL-L-46167A document will be issued in the latter portion of this year.

In regard to the MIL-L-2105 gear lubricant, a demonstration program investigating the use of re-refined base stocks is in progress. This effort follows the approach used in the previously discussed engine oil programs. In brief summary, a re-refined virgin base stock combination will be formulated with an additive system used in qualified MIL-L-2105B lubricants. The finished product will then be tested against the specification requirements. Based on the results of these tests, a decision will be made regarding the use of re-refined material under a future amendment or revision of the specification.

To summarize, re-refined products are allowed for use under one engine oil specification, MIL-L-46152B, and will be allowed for use under the soon to be issued MIL-L-2104D and MIL-L-46167A documents. In addition, a program is in progress addressing the use of these materials in military gear lubricants defined by the MIL-L-2105B specification. 
National Bureau of Standards Special Publication 674. Proceedings, Conference on Measurements and Standards for Recycled 011 - IV, held at NBS, Gaithersburg, MD, September 14-16, 1982.

(Issued July 1984).

CORRELATION ASPECTS OF A VIRGIN AND A RE-REFINED ENGINE OIL CONTAINING THE SAME ADDITIVES

$$
\text { P. L. Strigner }
$$

National Research Council of Canada Division of Mechanical Engineering ottawa, CANADA K1A 0R6

\section{Introduction}

Over a three year period commencing early in 1979, Environment Canada and the National Research Council of Canada carried out comprehensive comparative testing of a re-refined-base and a virginbase automotive engine oil, both containing the same additive package, i.e., the only difference between the two being the base oil. Both oils were formulated to meet API service classification SE and SAE viscosity classification 20 - 40 requirements. The virgin-base engine oil, being a commercial formulation, was regarded as the reference oil while the re-refined-base engine oil, being an "experimental" formulation, was assessed for its potential use as a viable engine oi] based on its comparative performance to the virgin-base engine oil. The ultimate objective of the exercise, supplemented by future testing of other formulations, was to determine the suitability of re-refined-base engine oils for use in government vehicles. reports:

The test program comprised four distinct parts preceding the compilation and presentation of

1) Laboratory bench testing and analyses of the base and finished oils.

2) Evaluation of the finished oils in engine sequence tests.

3) Field operation and monitoring of eight police patrol vehicles, four using the re-refined engine oil and four using the virgin engine oil, over their normal fleet lifetimes of $100,000 \mathrm{~km}$.

4) Examination and rating of the eight field vehicle engines upon completion of the field test period.

A paper was presented by Armstrong and Strigner at the 1982 SAE International Fuels and Lubricants Meeting and Exposition, October 18-21, 1982, Toronto, Canada describing the test program and giving results and conclusions[1] $]^{1}$. The following is an abstract of the paper:

A field test and laboratory analysis program, including the four SE engine tests, was carried out to evaluate the comparative performance characteristics of a virgin and an acid/clay re-refined API-SE/SAE 20W-40 automotive engine lubricating oil under selected operating conditions. The two oils had the same additive package. Eight new police patrol cars, four on virgin and four on re-refined oi], were run in 1979/ 80 under normal fleet operation and maintenance practices for $100,000 \mathrm{~km}$. The fleet oil change interval was $5000 \mathrm{~km}$. A11 engines were disassembled and rated at the end of their fleet service. There were no oil related problems. Engine vehicle parts showed normal wear and deposits. Some small differences, however, were noted in the used oil properties, engine sequence tests and field engine ratings. In general, both oils operated satisfactorily and were considered substantially equivalent.

Additional data are presented in a number of anci]lary reports [2-5]. This present report covers correlation aspects not covered in the reports already issued and, indeed food for thought because

1Figures in brackets indicate the literature references at the end of this paper. 
not al1 aspects could be dealt with. Correlation aspects include comparisons and possible correlations notably among the engine sequence test data; between sequence and field test data; among laboratory, sequence and field test data; and between laboratory bench test and analytical data.

\section{Base 0il Characteristics}

The reference virgin base oil was neutral oil obtained by solvent refining of Western Canadian crude. It has been widely used as a base oil for engine oils. The re-refined base oil was obtained by conventional acid/clay treatment in Western Canada principally of used engine oil drainings. Some of the major physical and chemical properties are given in table Al of the appendix. Marked differences are noted in viscosity index, total sulphur, total nitrogen, total chlorine and emulsibility. The high viscosity index of the re-refined oil may be due to a trace of VI improver from the used $0 i 1$, although it is interesting to note that the re-refined oil does have a markedly lower level of low VI, single ring saturates than the virgin base oil (table A2, appendix). Total chlorine and emulsibility in the re-refined base oil are also due to trace used oil residues.

Table A2 in the Appendix shows hydrocarbon types analyses by two techniques. Considering differences in technique, agreement is quite good. Hydrocarbon types/levels seem to be similar in the two base stocks except for the higher polars level in the re-refined oil (probably due to trace residues from used $0 i 1$ ) and differences in the paraffinic hydrocarbons, the virgin oil having a higher single ring cyclo-paraffin content, but a lower noncyclo-paraffin content.

Table $A 3$ in the appendix, shows boiling ranges by simulated distillation. By and large the re-refined base oil has a slightly lower overall boiling range than the virgin base oil ( 310 to $585{ }^{\circ} \mathrm{C}$ vs 340 to $600{ }^{\circ} \mathrm{C}$ ).

\section{Finished 0il Characteristics (Excluding Engine Tests)}

Some of the principal fintshed oil properties (excluding engine tests) in comparison with limits from specification MIL-L-46152A, the U.S. Army specification covering API SE and SAE $20 W-40$ oi1, are given in table A4 of the appendix. As shown, the properties of the two oils are quite comparable, meeting the limits from MIL-L-46152A.

\section{Engine Sequence Test Data}

Engine sequence data for four engine tests along with limits from API service classification SE are given in table A5 of the appendix. Only the L-38 and Sequence III D tests were performed as specified for the SE additive package used in the two oils. Sequences II C and V-C which were also specified were not done owing to supersedure by the II $D$ and $V-D$ tests and the testing 1 aboratory's inability to carry out the former from lack of parts. In summary, then, SE tests L-38, II D, III D and $V-D$ were performed on the two finished engine oils. The virgin and re-refined oils were tested back-to-back in the same engine to minimize the effects of engine influence between tests.

Variations in performance between the two $0 i 1 \mathrm{~s}$ as well as some failures to meet 1 imits were observed. These are noted in table A5.

5. Field Test and Data

Field testing was accomplished in eight Royal Canadian Mounted Police (RCMP) sedans. Details are as follows:

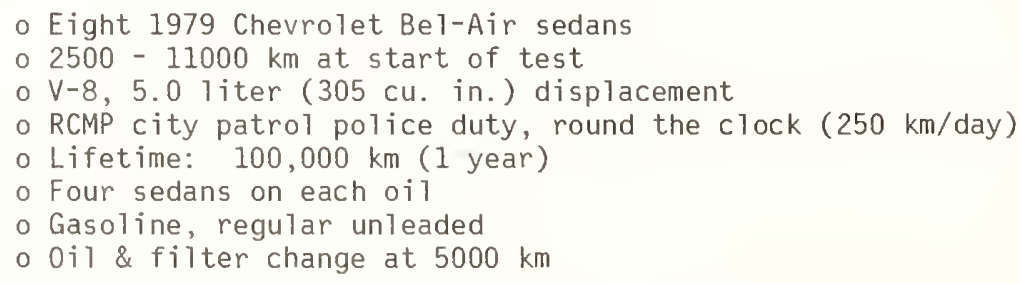

No oil related problems were encountered during the field trails. One vehicle, however, was removed prematurely from service due to an accident that did not involve the engine. Engine parts from this engine, nevertheless, were examined and considered part of the overal1 data as the kilometreage accumulation on it was high. Individual parts examination data are not recorded here because of the large volume. Instead, only summaries are presented in the comparison/correlation 
aspects tables, and references to individual data [1] made as required. General data in summarized form giving average kilometres and oil change data for the two groups of vehicles are given in table A6 of the appendix. While oil change intervals were set at $5000 \mathrm{~km}$, in practice these were difficult to maintain. In the extreme, there were some changes at $3000 \mathrm{~km}$ and others at $8000 \mathrm{~km}$. The overall average, as shown in table $\mathrm{A} 6$, is higher for the engines on re-refined oil. Correspondingly, these engines required on the average more oil top-up in the longer interval. On the average then, re-refined oil staying longer in the engine was more heavily stressed than virgin oil.

Table A7 in the appendix shows average used oil analysis data for the two oil types. As shown there are differences between properties of the two oils, generally such that the average re-refined oil values are higher. Except for the average viscosity values which are markedly higher for the re-refined oil, the higher average re-refined oil values tend to be accounted for by the longer average oil change interval for this oil in the test vehicles. Individual averages for each of the vehicles also show these trends. The markedly higher viscosity increase of the re-refined oil is believed to be due to the proportionately higher loss of light ends from the re-refined oil (table 1).

Table 1. Field test used oil viscosity vs boiling range vs oxidation

Car

Engine Kilometres

0il Kilometres

Viscosity Inc. (d $100^{\circ} \mathrm{C}$, cSt. Viscosity Inc. ¿ $40^{\circ} \mathrm{C}$, cSt. IR Oxid. Prod. Inc., abs/cm IR Nitr. Prod. Inc., abs/cm

Boiling Range, ${ }^{\circ} \mathrm{F}$,

IBP
$5 \%$
$10 \%$
$50 \%$

\begin{tabular}{|c|c|c|c|c|c|c|c|}
\hline \multicolumn{2}{|c|}{ Virgin } & Engine & ji & \multicolumn{2}{|c|}{ Re-Refined } & \multirow{2}{*}{$\frac{\text { Engine }}{\text { Used }}$} & \multirow{2}{*}{$\frac{0 i 1}{\text { Used }}$} \\
\hline New & Used & Used & Used & New & Used & & \\
\hline - & 215 & 217 & Avg. & - & 214 & 216 & \\
\hline - & 30846 & 11593 & - & - & 30947 & 14701 & - \\
\hline - & 3282 & 5983 & 5081 & - & 6586 & 7700 & 5463 \\
\hline - & -1.3 & 1.2 & 1.1 & - & 2.4 & 2.7 & 2.0 \\
\hline - & 3.6 & 23.2 & 14.7 & - & 38.7 & 43.9 & 29.5 \\
\hline - & 3.8 & 9.8 & 12.2 & - & 17.4 & 25.9 & 15.7 \\
\hline - & 2.6 & 9.0 & 7.4 & - & 4.1 & 15.7 & 8.6 \\
\hline
\end{tabular}

$\begin{array}{llllllll}646 & 656 & 685 & - & 585 & 641 & 648 & - \\ 702 & 701 & 734 & - & 626 & 699 & 727 & - \\ 725 & 720 & 755 & - & 707 & 719 & 752 & - \\ 835 & 818 & 856 & - & 806 & 810 & 841 & -\end{array}$

Individual average viscosity increases for the eight vehicles are also a funotion of oil change interval, but there is a clear difference in the level of the increases based on oil type which tends to be explained by the evaporation of light ends of the re-refined oil thus thickening it up. The evaporated light ends of the re-refined oil are not fuel diluents, but light lubricating oil fractions. Table A1 shows that the fuel dilution level of the re-refined base oil, both by ASTM D322 and D3525, was substantially the same as that of virgin base oil.

\section{Correlation Aspects}

Correlation and possible correlations are presented in a number of tables followed by comments.

a) Comparative average engine rust data from the sequence II D test, field test and 1 aboratory beaker test (ASTM D665/A on base oils only) are presented in table 2 .

Table 2. Engine rust $(10=$ clean $)$

\begin{tabular}{|c|c|c|c|c|}
\hline & Test & Virgin & Re-Refined & Limit \\
\hline $\begin{array}{l}\text { Avg. Engine Rust } \\
\text { Overal1 } \\
\text { Lab Rust Test }\end{array}$ & $\begin{array}{l}\text { IID } \\
\text { Field } \\
(D 665 / A)\end{array}$ & $\begin{array}{l}8.43 \\
9.5 \\
3 \mathrm{Hr} . \mathrm{F}\end{array}$ & $\begin{array}{l}8.55 \\
9.5 \\
<6 \mathrm{Hr} . \mathrm{F}\end{array}$ & $\begin{array}{l}8.5 \mathrm{~min} \\
- \\
-\end{array}$ \\
\hline
\end{tabular}

an Base 0i1s, hrs to "F" or failure. 
Clearly the field rust ratings are identical for the two oils, the overall average engine rust of 9.5 for the two oils having been obtained from individual ratings of the four engines of 9.3 to 9.6 for the virgin engine $0 i 1$ and 9.4 to 9.6 for the four engines on re-refined engine oil.

Furthermore, individual push rod and valve lifter rust ratings ranged from 9.7 to 9.8 for all eight engines. Correlation with the average re-refined II D engine rust rating is good owing to the pass rating but only fair with the virgin oil rating which is a marginal failure. It is interesting to speculate whether possible trace rust inhibitor present in the re-refined base oil (note D665/A rust results) gave the re-refined engine oil a marginally better performance in the II $D$ test. The incidence of pitted cam lobes was also higher in the virgin engine vehicles (10 vs 2).

b) Comparative engine sludge data from three engine tests, L-38, II D and V-D, and field test are presented in table 3 .

Table 3. Engine sludge $(10=C l e a n)$

\begin{tabular}{|c|c|c|c|c|c|}
\hline & & Test & Virgin & Re-refined & Limit \\
\hline Avg. Engine Sludge & & III D & 9.3 & 9.6 & $9.2 \mathrm{~min}$ \\
\hline Avg. Engine Sludge & & $V-D$ & 9.7 & 9.6 & $9.2 \mathrm{~min}$ \\
\hline Avg. Engine Sludge & (Overa11) & Field & 9.3 & 9.2 & - \\
\hline Avg. Engine Sludge & & $L-38$ & 9.8 & 9.8 & - \\
\hline
\end{tabular}

Al1 results are in substantial agreement. They all have shown low sludge levels and more or less equivalent average results for the two oil types. Both III D and V-D results meet requirements. The closely agreeing overall average field results are confirmed by close agreement among average individual engine sludge ratings and individual rocker arm cover, valve deck and oil pan ratings. Generally, sludge ratings of individual engines exposed to virgin engine oil were indistinguishable from those exposed to re-refined oil.

c) Comparative oil viscosity change data from the III D and L-38 engine tests, and field test are presented in table 4. In all tests, including all eight engines in the field test, the re-refined oil showed higher viscosity after use, except 64 hrs in the III $D$ when the virgin oil thickened to a gel while the re-refined oil did not. The virgin oil is judged to have thickened to a gel after 64 hrs. due to oxidation. The tendency for the re-refined oil to show generally a higher viscosity increase than the virgin oil in the three tests (apart from the $64 \mathrm{hr}$ III $\mathrm{D}$ test) is believed to be due not to oxidation, but to loss of light ends of the base oil (table I).

For comparison some bench oxidation test data are given. These are ASTM D943, the turbine oil oxidation stability test, (TOST) and two experimental tests being studied by NBS, i.e., modified RBOT [6] and DSC [7], differential scanning calorimetry test. All show good results for both engine oils, the TOST giving the virgin oil a slightly better rating, while the other two tests favoring the re-refined oil.

Table 4. Viscosity change, $\%$, and bench oxidation test data

\begin{tabular}{|c|c|c|c|c|}
\hline Characteristic & Test & Virgin & Re-refined & Limit \\
\hline \multicolumn{5}{|l|}{ Viscosity Change (\%) } \\
\hline After $40^{\text {hrs }}\left(40^{\circ} \mathrm{C}\right)$ & I I I D & 47 & 62 & $375 \max$ \\
\hline$" \quad 64 \operatorname{hrs}\left(40^{\circ} \mathrm{C}\right)$ & I I I D & $>1000$ & 113 & - \\
\hline Avg. $40^{\circ} \mathrm{C}$ & Field & 13.5 & 27.7 & - \\
\hline$" 100{ }^{\circ} \mathrm{C}$ & Field & 5.5 & 12.7 & - \\
\hline fter 40 hrs $\left(40^{\circ} \mathrm{C}\right)$ & $L-38$ & -5.8 & -1.3 & - \\
\hline$" \quad 40 \mathrm{hrs}\left(100^{\circ} \mathrm{C}\right)$ & $L-38$ & -55.7 & -35.2 & - \\
\hline fied RBOT break point (min) & $\operatorname{NBS}[6]$ & 186 & 222 & - \\
\hline $\begin{array}{l}\text { hrs to TAN inc. of } 2 \\
\text { NBS[7] }\end{array}$ & 0943 & 1596 & 1512 & - \\
\hline set Temp., ${ }^{\circ} \mathrm{C}$ & & 253 & 259 & - \\
\hline duction time, minutes & & 29 & 42 & - \\
\hline
\end{tabular}


d) Comparative engine varnish data from the L-38, III $D$ and $V$-D engine tests, and field test are presented in table 5. The re-refined oil showed less varnish in the III-D test, but more varnish in the V-D test. Both oils behaved similarly in the L-38 test. While piston skirt, piston land and cylinder wall varnish ratings were similar for the two oils in the field test, the virgin oil engines showed less varnish on the rocker arms and timing gear covers. The virgin oil appeared to show less varnish under less severe (i.e., lower V-D operating temperature) conditions, while the re-refined oil appeared to fare better under the more severe conditions of the III D test. It should be noted though that the virgin oil gelled after 64 hrs of operation in the III D and probably contributed in the gelled condition to added piston skirt varnish and ring sticking. Correlation of some of these data seem tenuous particularly field versus III D data on the virgin oil; the III D 64 hr test, considering the gelling of the virgin oil, would appear to have given invalid results for correlation with the field data. There are suggestions of some correlations between $V-D$ and overall field engine varnish ratings though, the virgin oil appearing marginally better.

Table 5. Engine Varnish $(10=$ Clean $)$

\begin{tabular}{|c|c|c|c|c|}
\hline Varnish & Test & Virgin & Re-refined & $\underline{\text { Limit }}$ \\
\hline Piston skirt varnish & I I D & 8.7 & 9.6 & $9.2 \mathrm{~min}$ \\
\hline Piston skirt varnish & $V-D$ & 7.0 & 6.7 & $6.4 \mathrm{~min}$ \\
\hline Piston skirt varnish (average) & Field & 7.0 & 7.1 & - \\
\hline Piston skirt varnish & $L-38$ & 9.5 & 9.65 & - \\
\hline Engine varnish (average) & $V-D$ & 6.8 & 5.5 & $6.3 \mathrm{~min}$ \\
\hline Engine varnish " & $L-38$ & 9.7 & 9.8 & - \\
\hline Engine varnish (overal1) & Field & 6.9 & 6.3 & - \\
\hline $0 i 1$ ring 1 and deposit & III D & 6.7 & 8.0 & $4.0 \mathrm{~min}$ \\
\hline Onset temn ${ }^{\circ} \mathrm{c}$ & NBS[7] & & & \\
\hline Onset temp. ${ }^{\circ} \mathrm{C}$ & & 253 & 259 & - \\
\hline Induction time, minutes & & 29 & 42 & - \\
\hline Piston land varnish & Field & 2.0 & 2.3 & - \\
\hline TOST, hrs to TAN inc. of 2 & D943 & 1596 & 1512 & - \\
\hline Modified RBOT break point (min) & NBS $[6]$ & 186 & 222 & - \\
\hline
\end{tabular}

Considering the bench tests as well, it would appear that the TOST lines up with V-D and field data in favoring the virgin engine oil, while the modified RBOT \& DSC line up with III D in favoring the re-refined oil.

e) Comparative cam and lifter wear data are given in table 6. While the oils differ markedly in their performances in the III $D$ and $V$-D tests, their performances are not analagous. The virgin engine oil performed better in the III D but worse in the $V-D$ test. Their performances were substantially the same, on the average, in the field test. NBS in the modified Timken test found substantially no difference in the performances of the two oils while indicating good anti-wear characteristics.

Table 6. Cam and lifter wear and timken bench test data

\begin{tabular}{|c|c|c|c|c|}
\hline & Test & Virgin & $\underline{\text { Re-refined }}$ & Limit \\
\hline \multicolumn{5}{|l|}{ Cam Plus Lifter, $\mu m$} \\
\hline Average & I I D & 58.4 & 112 & $102 \max$ \\
\hline Maximum & III D & 101.6 & 173 & $254 \max$ \\
\hline Avg. Lifter Wear & Field & 15.25 & 15.85 & - \\
\hline \multicolumn{5}{|l|}{ Cam Lobe, $\mu m$} \\
\hline Average & $V-D$ & 17.8 & 10.2 & - \\
\hline Maximum & $V-D$ & 22.9 & 12.7 & - \\
\hline \multirow{2}{*}{$\begin{array}{c}\text { Average } \\
\operatorname{LCC}^{\mathrm{a}} \text { (Newtons) }\end{array}$} & Field & 24.8 & 24.1 & - \\
\hline & $\begin{array}{l}\text { NBS }[8] \\
\text { Timken }\end{array}$ & 540 & 495 & - \\
\hline
\end{tabular}

a Load Carrying Capacity 


\section{Conclusions}

Good correlations were observed for both oils between field trial rusting and the sequence II $D$ test, between field trial sludging and the L-38, III $D$ and $V-D$ sludge results, and among oil thickening data from various tests. Correlations between field and engine tests in respect to wear and varnish formation were somewhat mixed. Some good correlations were observed between 1 aboratory and field data and between laboratory and engine test data.

\section{References}

[1] Armstrong, J.; Strigner P. L. A field and laboratory comparison of a re-refined and a virgin automotive engine 0i1. SAE paper 821239. Presented at Toronto, Canada; 0ctober 18-21, 1982.

[2] Armstrong, J. Field test of a re-refined automobile engine oil in RCMP vehicles. Nat. Bur. Stand. (U.S.) Spec. Pub1. 584; 1979 October.

[3] Strigner P. L.; Moroz G.; Sabourin R.; Burton G.; and Bailey T. Comparative engine and laboratory test data for a re-refined and a virgin automotive engine oil. Report No. MP-80; Division of Mechanical Engineering; National Research Council Canada.

[4] Frame, E. A.; Koh1, K. B. Characterization and evaluation of re-refined engine lubricating oi1. Interim Report AFLRL No. 152. U.S. Army Fuels and Lubricants Research Laboratory; Southwest Research Institute, San Antonio, TX.

[5] Hawthorne, H. H.; Lowe, J. Comparison of spent automotive engine oils by ferrography. LTR-WE-26; National Research Council Canada; Division of Mechanical Engineering, Vancouver, B.C., Canada; December 1981.

[6] Becker, D. A. NBS research on re-refined engine oil tests. Used 0i1, The Hidden Asset. Proceedings of the fourth international conference on used oil recovery and reuse; Association of Petroleum Re-refiners; 1981 September 28-October 1. Las Vegas, Nevada.

[7] Walker, J.; Tsang, W.; Szegvary, L. Comparative response of re-refined and virgin lub oils to additives by DSC. Proceedings, Measurements and Standards for Recycled 0i1-IV, Nat. Bur. Stand. (U.S.) Spec. Pub1. 674; 1983.

[8] Ives, L.; Boyer, P.; Ruff, W. Evaluation of wear behavior using a modified ASTM D2782 timken test. Proceedings, Measurements and Standards for Recycled 0il-IV, Nat. Bur. Stand. (U.S.) Spec. Pub1. 674; 1983. 
Table Al. Some base oil properties

\begin{tabular}{|c|c|c|}
\hline & Virgin & Re-refined \\
\hline Color (D1500) & L1. 0 & L3.0 \\
\hline API Gravity & 29.7 & 29.6 \\
\hline Flash Point, ${ }^{\circ} \mathrm{F}$ (D92) & 421 & 421 \\
\hline Viscosity, @ $100^{\circ} \mathrm{C}$, cSt & 7.30 & 7.51 \\
\hline Viscosity Index & 95 & 104 \\
\hline $\mathrm{N}$-Penane Insolubles, \% $\mathrm{W}$. & .000 & .001 \\
\hline $\begin{array}{l}\text { Ramsbottom Carbon Residue, \% } w . \\
\text { Emulsibility Characteristics (D1401), } 60 \text { min, } \mathrm{mL}\end{array}$ & 0.09 & 0.17 \\
\hline 011 & 39 & 37 \\
\hline Water & 38 & 29 \\
\hline Emulsion & 3 & 14 \\
\hline Ash (D482), \% W. & .000 & .002 \\
\hline Total Sulphur, \% w. & 0.09 & .19 \\
\hline Total Nitrogen, PPM & 45 & 5 \\
\hline Total Chlorine, PPM & 0.2 & 18.6 \\
\hline Strong Acid No. & $\mathrm{NiT}$ & $\mathrm{Ni} 1$ \\
\hline Total Acid No (D664) & 0.02 & 0.10 \\
\hline Total Base No. (D664) & 0.02 & 0.00 \\
\hline $\begin{array}{l}\text { Sap. No. (D94) } \\
\text { DiTution }\end{array}$ & 0.18 & 0.25 \\
\hline D322, \% w. & 0.6 & 0.4 \\
\hline D3525, \% w. & 0.02 & 0.03 \\
\hline Iron & $<1$ & 1 \\
\hline Silicon & $<5$ & $<5$ \\
\hline Zinc & $<1$ & 2 \\
\hline Calcium & $<10$ & $<10$ \\
\hline Barium & $<10$ & $<10$ \\
\hline Others ${ }^{a}$ & $<1$ & $<1$ \\
\hline
\end{tabular}

${ }^{\mathrm{a}} \mathrm{Cu}, \mathrm{Pb}, \mathrm{Al}, \mathrm{Cr}, \mathrm{Mg}, \mathrm{Ni}, \mathrm{Li}, \mathrm{Na}, \mathrm{Mn}$ (Each is <1).

Table A2. Hydrocarbon types in base oils by 1 iquid chromotography (D2007)

HC Types, \% W.

Saturates

Aromatics

Polars

\section{Virgin}

77.7

21.4

0.9 $\underline{\text { Re-Refined }}$

75.4

22.6

2. 0

by mass spectroscopy (D2786-71 (76))

Saturates, \% W.

Paraffins
1-Ring
2-Ring
3 to 6 Ring
Mono Aromatics
TOTALS

Virgin

13.2

27.4

16.8

19.4

$\frac{2.9}{79.7}$

\section{$\underline{\text { Re-Refined }}$}

21.3

19.0

15.2

22. 1

$\frac{1.2}{78.8}$ 
by mass spectroscopy (03239-76)

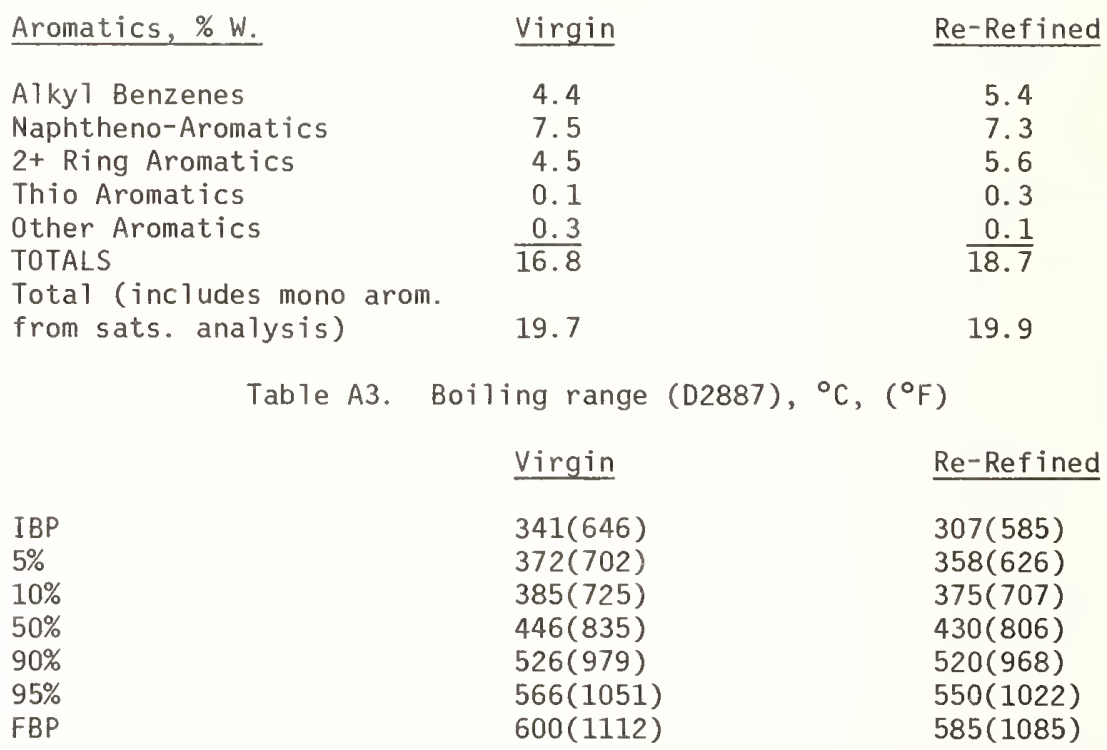

Table A4. Finished oil properties versus specification limits

Virgin

Viscosity e $100^{\circ} \mathrm{C}, \mathrm{cSt}$.

Viscosity $0-18{ }^{\circ} \mathrm{C}$ ( CCS ), P

V I

Pour Point, ${ }^{\circ} \mathrm{C},\left({ }^{\circ} \mathrm{F}\right)$

Flash Point, ${ }^{\circ} \mathrm{C},\left({ }^{\circ} \mathrm{F}\right)$

Phosphorus, \% W.

Rams. Carb. Res., \% W.

Sulf. Res., \% W.

Total Acid No. (D664)

Total Base No. (D664)

Lithium, PPM

Calcium, PPM

Zinc, PPM

13.71
69.5
128
$-32(-26)$
$229(444)$
.132
1.07
1.04
2.5
5.7
2.3
2200
1390

Table A5. Engine sequence test data

BWL, mg

Avg. Engine Rust

No. of Stuck Lifters

Virgin

31.5

\section{Re-Refined}

13.92

55

132

$-34(-29)$

$227(441)$

.137

1.14

1.08

2.5

5.7

0.0

2200

1380
MIL-L-46152A

$12.5-16.3$

25- 100

REPORT

$-23 \max (-9)$

$215 \max (419)$

$.14 \max$

REPORT

REPORT

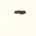

$-$

-

$-$

$\underline{\mathrm{L}-38 \text { test }}$

$\underline{\text { Re-refined }} \underline{\underline{L}-38}$

22.4

$40 \max$

II D sequence test

\begin{tabular}{|c|c|c|}
\hline Virgin & Re-Refined & II D \\
\hline $8.43^{a}$ & 8.55 & $8.5 \mathrm{Mi}$ \\
\hline$\overline{\mathrm{NONE}}$ & NONE & NONE \\
\hline
\end{tabular}




\section{D sequence test}

\section{Virgin}

Viscosity Inc. C $40^{\circ} \mathrm{C}, \%$ After 40 Hours

After 64 Hours

Avg. Eng. Ratings e 64 Hours Sludge

0 il Ring Land Deposits

No. of Lifters Stuck

No. of Rings Stuck

Scuffing and Wear e 64 Hours Cam or Lifter Scuffing

Cam Plus Lifter Wear, $\mu \mathrm{m}$ Average

Maximum

0 il Consumption, Liters
47

$<1000$
9.3
$\frac{8.7}{6.7}$
NONE
$\underline{O N E}$
NONE
58.4
101.6
5.60

Piston Skirt Varnish

Virgin

Avg. Engine S7udge

Avg. Engine Varnish

Avg. Piston Skirt Varnish

0 il Screen Clogging, \%

Oil Ring Clogging, \%

No. of Compressor Rings Stuck

Cam Wear, $\mu \mathrm{m}$

Average

Maximum

$\overline{a_{\text {Failures }}}$ are underlined.

\footnotetext{
Failures are underlined.
}

$\underline{\text { Re-refined }}$

62

113

9.6

9.6

8. 0

NONE

NONE

NONE

$\frac{112}{173}$

5.37

$\underline{V-D}$ seguence test

II D

375 Max.

9. 2 Min.

9. 1 Min.

4. $0 \mathrm{Min}$.

NONE

NONE

NONE

102 Max.

254 Max.

6. 03 Max.

$\underline{V-D}$

9.7
6.8
7.0
0
0
NONE

17.8
22.9

9.6

$\frac{5.5}{6.7}$

6.7

0
0

NONE

10.2

12.7

$9.2 \mathrm{Min}$.

$6.3 \mathrm{Min}$.

6. 4 Min.

10.0 Min.

10.0 Min. NONE

REPORT

REPORT

Table A6. Field test - Km and oil change data ${ }^{a}$

$\begin{array}{lll} & \text { Virgin } & \text { Re-refined } \\ \text { Total Test, Km (Avg) } & 92000 & 89000 \\ \text { Avg. 0il Change Interval, Km } & 5081 & 5463 \\ \text { Avg. Top Up, L/0i1 Change } & 0.75 & 0.90\end{array}$

avg. of 4 cars on each oil. 
Table A7. Field test - used oil analysis ${ }^{a}$

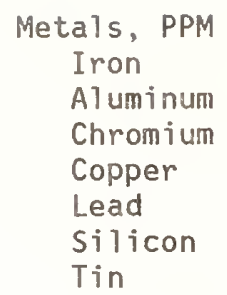

$\bar{a}$ Avg. of 4 cars on each oil. Some new oil data in parenthesis.

\section{Virgin}

34

13

3

3

159

10

$<5$

$221(229)$

$0.6(0.4)$

$3.9(2.5)$

$0.8(5.7)$

0.1

0.74

0.35

0.40

14.7

1. 1

12.2

7.4 $\underline{\text { Re-refined }}$

36

16

4

3

177

12

$<5$

220(217)

$0.6(0.6)$

4. $3(2.5)$

$0.9(5.7)$

0.1

0.81

0.36

0.45

29.5

2.0

15.7

8.6 
National Bureau of Standards Special Publication 674. Proceedings, Conference on Measurements and Standards for Recycled 0i1 - IV, held at NBS, Gaithersburg, MD, September 14-16, 1982.

(Issued July 1984).

\title{
DEVELOPMENT OF METHODOLOGY FOR ENGINE DEPOSIT CHARACTERIZATION
}

\author{
K. B. Kohl and E. A. Frame
}

U.S. Army Fuels and Lubricants Research Laboratory Southwest Research Institute San Antonio, Texas

\section{Introduction}

More than two billion gallons of lubricating oils are used each year in the United States. Approximately 50 percent of this total is consumed or otherwise lost during use [1] $]^{1}$. The remaining one billion gallons per year of used lubricating oil are a significant and valuable resource. With proper re-refining treatment, used oil can be utilized as a fuel, or, more importantly, it can be reused as a lubricant or lubricant basestock. The U.S. government has enacted important legislation in recent years to encourage the utilization of this valuable natural resource [2].

In December 1975, the Energy Policy and Conservation Act (Public Law 94-163) was passed. This act instructed the National Bureau of Standards (NBS) to develop test procedures to determine the potential "substantial equivalency" of recycled oil products to virgin oil products. NBS was required to transmit these test procedures to the Federal Trade Commission (FTC) for its use in developing trade regulation rules.

The Resource Conservation and Recovery Act (PL-94-580) of 1976 called for a review of Federal government specifications to allow for the purchase of products containing recycled materials. The U.S. Army responded to this by conducting research on the feasibility of making military engine oils from re-refined basestocks, which resulted in the revision of engine oil specification MIL-L-46152 to eliminate restrictions on re-refined oil use. Finally, the Model (SLates) Used Oil Recycling Act of 1980 (PL-96-463) assists states in establishing control over used oil disposal.

The current NBS-Army program was initiated to obtain an additional data base on the comparative performance of re-refined and virgin oils, and to investigate the potential "substantial equivalency" of re-refined and virgin oils. A portion of the program included the development of an engine deposit removal, recovery, and analys is methodology, which was used to compare engine deposits derived from virgin and re-refined engine oils.

\section{Development of Deposit Removal and Analysis Methodology Using}

$$
\text { 2. 3-L Engine Parts }
$$

Development of methodology for the removal and recovery of engine deposits initially focused on solvent removal of deposits from Sequence VD engine parts. The recovered deposits were then analyzed by a variety of instrumental and chemical techniques.

The cam baffle from a 2.3-L engine was selected for initial deposit removal because it was simple to wash and contained a reasonable amount of deposit. The entire cam baffle was sequentially washed with the following series of solvents of increasing polarity or solvency power:
1) Heptane
2) Toluene $(T)$
3) Methanol (M)
4) Acetone (A)
5) TAM combination (equal volumes)
6) Methylene chloride

TFigures in brackets indicate the literature references at the end of this paper. 
Since the engine part surfaces are wetted with engine oil, it was decided to remove this oil separately from the deposits to simplify the analysis of the deposits. Heptane was chosen to remove this $0 i 1$ and any other readily soluble, low-polarity or low-molecular weight material. Toluene was chosen to dissolve the more polar or the higher molecular weight asphaltene materials. The increasingly polar methanol, acetone, and TAM (equal volumes of toluene/acetone/methanol) dissolved the more resinous, high-molecular weight deposits.

A final wash with methylene chloride removed the small amount of deposit remaining after the TAM washing. The solvent from each collected wash was removed using a vacuum rotary evaporator. The collected deposit fractions were then analyzed for molecular weight and elemental content as shown in table 1. While this washing procedure removed the deposit, it was judged to be rather difficult and too complex. It also allowed possible contamination of fractions with insoluble matter loosened by the solvents. Thus, a modified procedure was developed which resulted in deposit removal from the engine part with a solvent mixture of equal volume parts of toluene/acetone/methanol (TAM). The TAM mixture completely removed all deposits found on the cam baffle, rocker cover, oil pump pickup tube and screen, and the front seal housing of the 2.3-L engine. This procedure was adopted to simplify the washing and filtration process and minimize contamination of fractions with insoluble matter. The TAM washings were filtered to remove any suspended insoluble or metaliic particulate matter. The TAM solvent was removed with a rotary evaporator, and the soluble deposit was recovered and weighed. The collected deposit was then subsequently extracted with $n$-heptane, toluene, and finally, TAM. Each of these fractions was then recovered using solvent removal by the vacuum rotary evaporator. The recovered individual deposit fractions were then analyzed as shown in table 2. Next, the deposits from 2.3-L engine pistons were removed and recovered. The piston skirt, oil rings and oil ring grooves were washed with TAM. The resulting deposit was extracted with heptane, toluene, and TAM as before. Finally, the piston crown, compression rings, lands and grooves were washed with $\mathrm{N}, \mathrm{N}$-dimethylformamide (DMF). Based on the work of Harris, et al. [3], DMF was selected as a more effective varnish removal solvent than TAM. The DMF washings were filtered through a Whatman No. 541 filter to remove any suspended insoluble or metallic particulate matter. DMF was removed using a vacuum rotary evaporator, and the recovered deposit was solvent extracted with sequential washes of heptane, toluene, TAM, and DMF. The analyses of the piston area deposit fractions are presented in table 3.

Table 1. 2.3 L engine cam baffle deposit analysis

\begin{tabular}{|c|c|c|c|c|c|c|c|}
\hline \multirow[b]{2}{*}{ Deposit Fraction ${ }^{a}$} & \multirow{2}{*}{$\begin{array}{l}\text { Wt\% of } \\
\text { Recovered } \\
\text { Soluble } \\
\text { Mat' } 1 \\
\end{array}$} & \multicolumn{6}{|c|}{ Data for Specific Soluble Fractions } \\
\hline & & $\begin{array}{l}\text { Avg } \\
\text { Mol Wt }\end{array}$ & $\% \mathrm{~S}$ & $\% \mathrm{~N}$ & $\begin{array}{r}\mathrm{C} / \mathrm{H} \\
\text { Ratio } \\
\end{array}$ & $\% \mathrm{C}$ & $\% \mathrm{H}$ \\
\hline Heptane Soluble & 72 & 420 & 2.0 & 1.0 & 6.7 & 83.4 & 12.5 \\
\hline Toluene Soluble & 15 & 900 & 4.4 & 6.0 & 8.8 & 67.8 & 7.7 \\
\hline Methanol Soluble & 5 & 800 & 3.9 & 7.0 & 8.7 & 59.9 & 6.9 \\
\hline Acetone Soluble & 7 & 1300 & 2.5 & 5.0 & $9.2 \mathrm{~b}$ & 63.9 & 6.9 \\
\hline TAM Soluble & 1 & 950 & 0.4 & 3.0 & IS $^{\mathrm{b}}$ & IS & IS \\
\hline Methylene & & & & & & & \\
\hline Chloride Soluble & $<1$ & 1.150 & IS & 4.0 & IS & IS & IS \\
\hline
\end{tabular}

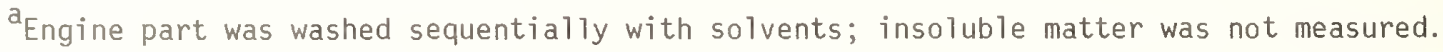

${ }^{b_{I S}}=$ Insufficient sample.
} 
Table 2. 2.3-L engine deposit analysis

\begin{tabular}{|c|c|c|c|c|c|c|c|}
\hline \multirow[b]{2}{*}{ Deposit Fraction $^{a}$} & \multirow{2}{*}{$\begin{array}{c}\text { Wt\% of } \\
\text { Recovered } \\
\text { Soluble } \\
\text { Mat'l } \\
\end{array}$} & \multicolumn{6}{|c|}{ Data for Specific Soluble Fractions } \\
\hline & & $\begin{array}{l}\text { Avg } \\
\text { Mol Wt }\end{array}$ & $\% \mathrm{~S}$ & $\% \mathrm{~N}$ & $\begin{array}{c}\mathrm{C} / \mathrm{H} \\
\text { Ratio } \\
\end{array}$ & $\% \mathrm{C}$ & $\% \mathrm{H}$ \\
\hline \multicolumn{8}{|c|}{ Rocker Arm Cover } \\
\hline Heptane Soluble & 69 & 420 & 1.1 & 1.0 & 6.7 & 82.9 & 12.3 \\
\hline Toluene Soluble & 19 & 770 & 1.8 & 3.0 & 9.1 & 67.9 & 7.5 \\
\hline TAM Soluble & 12 & 1470 & 1.9 & 3.0 & 9.2 & 62.3 & 6.8 \\
\hline \multicolumn{8}{|c|}{ 0il Pump Tube } \\
\hline Heptane Soluble & 59 & 400 & 1.2 & 1.0 & 6.8 & 81.7 & 12.0 \\
\hline Toluene Soluble & 31 & 635 & 1.4 & 3.0 & 8.6 & 68.4 & 8.0 \\
\hline TAM Soluble & 10 & 1625 & 1.4 & 5.0 & 9.9 & 60.8 & 6.2 \\
\hline \multicolumn{8}{|c|}{ 0il Pump Screen } \\
\hline Heptane Soluble & 78 & 400 & 1.0 & 1.0 & 6.8 & 80.3 & 11.8 \\
\hline Toluene Soluble & 10 & 560 & 1.5 & 2.0 & 8.3 & 70.4 & 8.4 \\
\hline TAM Soluble & 12 & 1900 & 2.0 & 3.0 & 9.7 & 60.5 & 6.2 \\
\hline \multicolumn{8}{|c|}{ Timing Gear Cover } \\
\hline Heptane Soluble & 54 & 410 & IS $^{b}$ & 1.0 & 6.8 & 81.7 & 12.0 \\
\hline Toluene Soluble & 27 & 610 & IS & 2.7 & 8.9 & 68.8 & 7.7 \\
\hline TAM Soluble & 19 & IS & IS & 2.4 & 7.3 & 61.7 & 8.4 \\
\hline
\end{tabular}

\footnotetext{
aDeposit was removed, then exacted sequentially with solvents.

$\mathrm{b}_{\text {IS }}=$ Insufficient sample Insoluble matter was not measured.
}

Table 3. 2.3-L engine deposit analysis for piston area

\begin{tabular}{|c|c|c|c|c|c|c|c|}
\hline \multirow[b]{2}{*}{ Deposit Fraction ${ }^{a}$} & \multirow{2}{*}{$\begin{array}{c}\text { Wt\% of } \\
\text { Recovered } \\
\text { Soluble } \\
\text { Mat'l } \\
\end{array}$} & \multicolumn{6}{|c|}{ Data for Specific Soluble Fractions } \\
\hline & & $\begin{array}{l}\text { Avg } \\
\text { Mol Wt }\end{array}$ & $\% \mathrm{~S}$ & $\% \mathrm{~N}$ & $\begin{array}{r}\mathrm{C} / \mathrm{H} \\
\text { Ratio } \\
\end{array}$ & $\% \mathrm{C}$ & $\% \mathrm{H}$ \\
\hline & Pist & Skirt, & Rings & Groo & & & \\
\hline $\begin{array}{l}\text { Heptane Soluble } \\
\text { Toluene Soluble } \\
\text { TAM Soluble }\end{array}$ & $\begin{array}{l}70 \\
18 \\
12\end{array}$ & $\begin{array}{l}390 \\
450 \\
570\end{array}$ & $\begin{array}{l}0.0 \\
0.7 \\
1.7\end{array}$ & $\begin{array}{l}0.2 \\
0.7 \\
1.7\end{array}$ & $\begin{array}{l}6.5 \\
8.5 \\
8.3\end{array}$ & $\begin{array}{l}83.7 \\
73.3 \\
61.8\end{array}$ & $\begin{array}{r}12.8 \\
8.6 \\
7.4\end{array}$ \\
\hline
\end{tabular}

\section{Piston Crown, Compression Rings and Grooves}

$\begin{array}{lccccrrr}\text { Heptane Soluble } & 47 & 380 & 0.0 & 0.4 & 6.8 & 83.1 & 12.3 \\ \text { Toluene Soluble } & 20 & 440 & 0.6 & 2.1 & 9.0 & 72.4 & 8.1 \\ \text { TAM Soluble } & 33 & 860 & 0.7 \text { b } & 2.6 & 11.4 & 64.4 & 5.6 \\ \text { OMF Soluble } & 1 & \mathrm{a} & \mathrm{IS}^{\mathrm{C}} & 2.4 & 11.9 & 61.5 & 5.2\end{array}$

\footnotetext{
${ }^{a}$ Beyond scope of method for DMF soluble.

${ }^{b_{I S}}$ = Insufficient sample Insoluble matter was not measured.
} 
While the data presented in tables 1 and 3 were obtained primarily to aid in methodology development, some interesting trends concerning the chemistry of Sequence VD deposits were revealed. As expected, by using increasingly polar solvents, the extracted deposit materials were separated by polarity and complexity. It is of interest to note that deposits from the lower temperature engine areas such as oil pump screen and rocker arm cover had higher molecular weight polar deposits and had higher nitrogen and sulfur contents than the deposits from the higher temperature piston areas. This could be due to thermal cracking of large molecules in the higher temperature piston areas.

Based on the 2.3-L engine deposit analysis work, a deposit removal, recovery, and analysis methodology was finalized. This methodology is described in detail in the following section.

\section{Finalized Deposit Methodology}

\subsection{Piston Deposit Removal Procedure}

The piston deposits are removed in three steps. A mixture of TAM and DMF is used to wash the piston, which removes essentially all deposits. The first step is to remove deposits from piston skirts, oil rings, and oil ring grooves with the wash mixture. Secondly, the piston crown, compression ring, land, and groove deposits are removed. The third step is to remove deposits from the undercrown portion of the piston. Figure 1 illustrates the piston wash areas. Washing the parts in this order allows good separation of deposits from the separate areas of the piston, as the wash is never allowed to flow across unwashed areas. The mixture of TAM and DMF allows simultaneous removal of both oily deposits and high molecular-weight polar residues. Insoluble materials are also removed, suspended in the wash mixture.

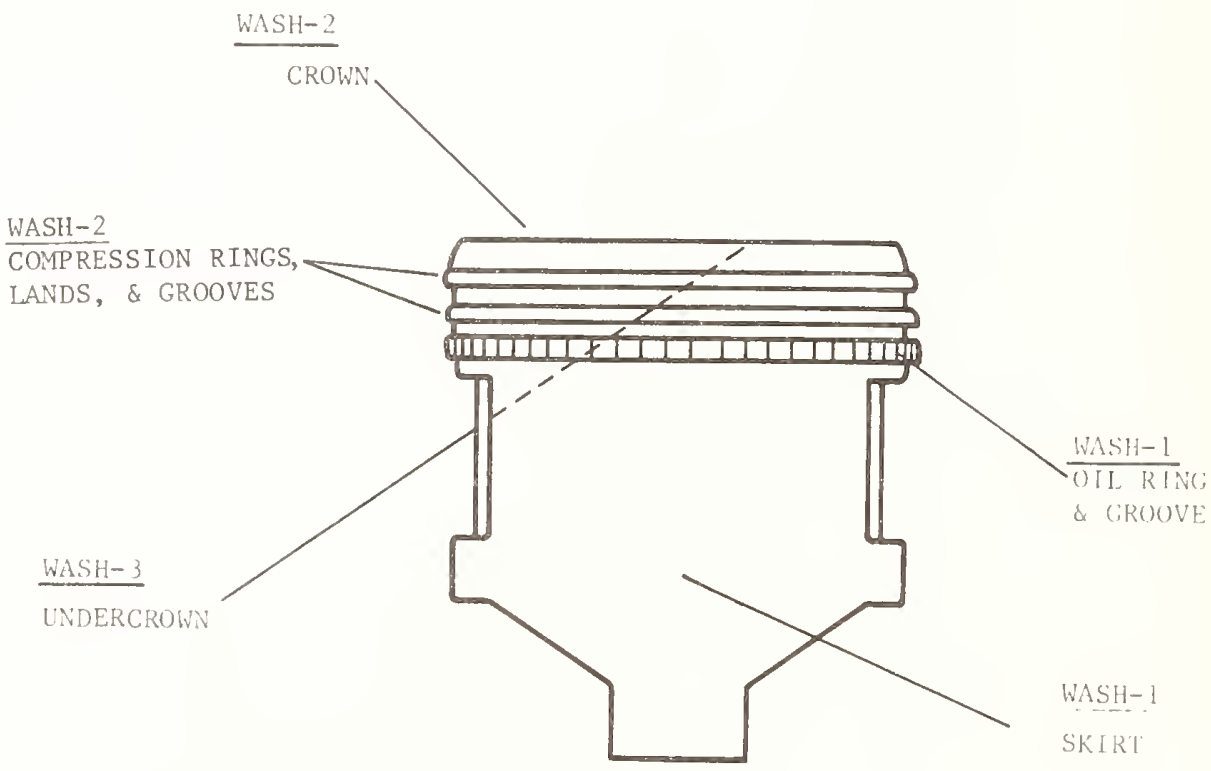

Figure 1. Piston wash areas. 


\subsection{Piston Deposit Recovery Procedure}

Washes from the three different areas of the piston are collected separately and subjected to a recovery procedure. A flow chart illustrating the engine part washing and deposit recovery procedure is shown in figure 2 .

The recovery procedure involves filtering through a Whatman No. 541 filter, then evaporating the TAM/DMF wash mixture for a given piston area on a vacuum rotary evaporator. The residue remaining in the evaporator is then agitated with heptane, in order to remove oils and nonpolar materials. The heptane solution is filtered through a Whatman No. 43 filter and heptane is evaporated off with the rotary evaporator, producing the heptane-soluble fraction of the deposits.

The wash residue is then agitated with toluene in order to remove asphaltenes, and the toluene solution filtered through the Whatman No. 43 filter and evaporated to produce a toluene-soluble fraction. The same procedure is followed with TAM in order to isolate resins in a TAM-soluble fraction, and with DMF to solubilize high-molecular weight polar residues. Each solvent wash is continued until the solvent coming through the filter appears colorless. No more than 41 ters of TAM/DMF mixture, no more than 2 liters of the other solvents were used. The residue remaining in the No. 541 filter used to filter the original TAM/DMF part washing mixture for the piston area, and the No. 43 filter used to filter solution during fractionation, form the insoluble residue fractions. These fractions are composed of metals and insoluble carbonaceous materials.

\subsection{Analysis of Deposits}

Once obtained, fractions may be subjected to any analyses desired. AFLRL analyzed each deposit fraction from each of the three piston areas for carbon, hydrogen, nitrogen, sulfur, and qualitative elemental content. An infrared scan was made on each fraction, and on soluble fractions, molecular weights were determined. Quantitative elemental analysis was performed on insoluble fractions.

An infrared spectrum was obtained for each deposit fraction using a Beckman Microlab 620 MX Computing Spectrophotometer. When the fraction was a solid material, spectra were obtained using a $13-\mathrm{mm} \mathrm{KBr}$ pellet formed in a vacuum die. For fluid fractions, spectra were obtained using a demountable window holder. A small drop of the fraction was placed between NaCl windows in the holder, and the resulting thin film was scanned.

Special attention was given to absorption bands around $1710 \mathrm{~cm}^{-1}, 1640 \mathrm{~cm}^{-1}$, and $1550 \mathrm{~cm}^{-1}$, as these give evidence of oxidation and nitration. The band near $1710 \mathrm{~cm}^{-1}$ is due to the carboxyl group $(C=0)$; bands near $1640 \mathrm{~cm}^{-1}$ to nitro compounds, and bands near $1550 \mathrm{~cm}^{-1}$ to carboxylate salts and nitro compounds. Typical spectra for representative fractions are shown in figure 3 . Each of these fractions shows a fairly large absorption near $1710 \mathrm{~cm}^{-1}$, showing oxidation. The infrared spectra were used to note the presence or absence of absorption due to oxidation and nitration in fractions and to observe trends. Due to small sample sizes and varied methods of sample preparation from fraction to fraction, no quantitative work was attempted on these samples.

An EDAX International EXAM (Elemental X-ray Analysis of Materials) System and an EDAX model 707B Energy Dispersive X-ray Analyzer were used to make sulfur determinations and qualitative elemental determinations. Sulfur was determined by dissolving fractions in TAM or DMF and comparing with sulfur standards in these solvents. Qualitative elemental analysis was performed directly on fractions using no solvents.

Carbon and hydrogen analysis was performed according to ASTM D 3178 Carbon and Hydrogen in the Analysis Sample of Coal and Coke. Nitrogen was determined using an Antek instrument based on the chemiluminescence principle. Molecular weight was determined by vapor osmometry, using chloroform or DMF as the solvent. Since samples must be dissolved for this method, molecular weight determinations were not made on insoluble fractions.

\subsection{Briquetting Method Development}

To better define insoluble residues in engine deposits, a briquetting method has been developed for determining elemental content. This method employs an energy-dispersive $X$-ray fluorescence spectrometer. An advantage of energy-dispersive X-ray fluorescence analysis is the ability to simultaneously analyze for virtually every element with an atomic number greater than that of sodium. The method may not be used to analyze for $C, N$, or 0 . 


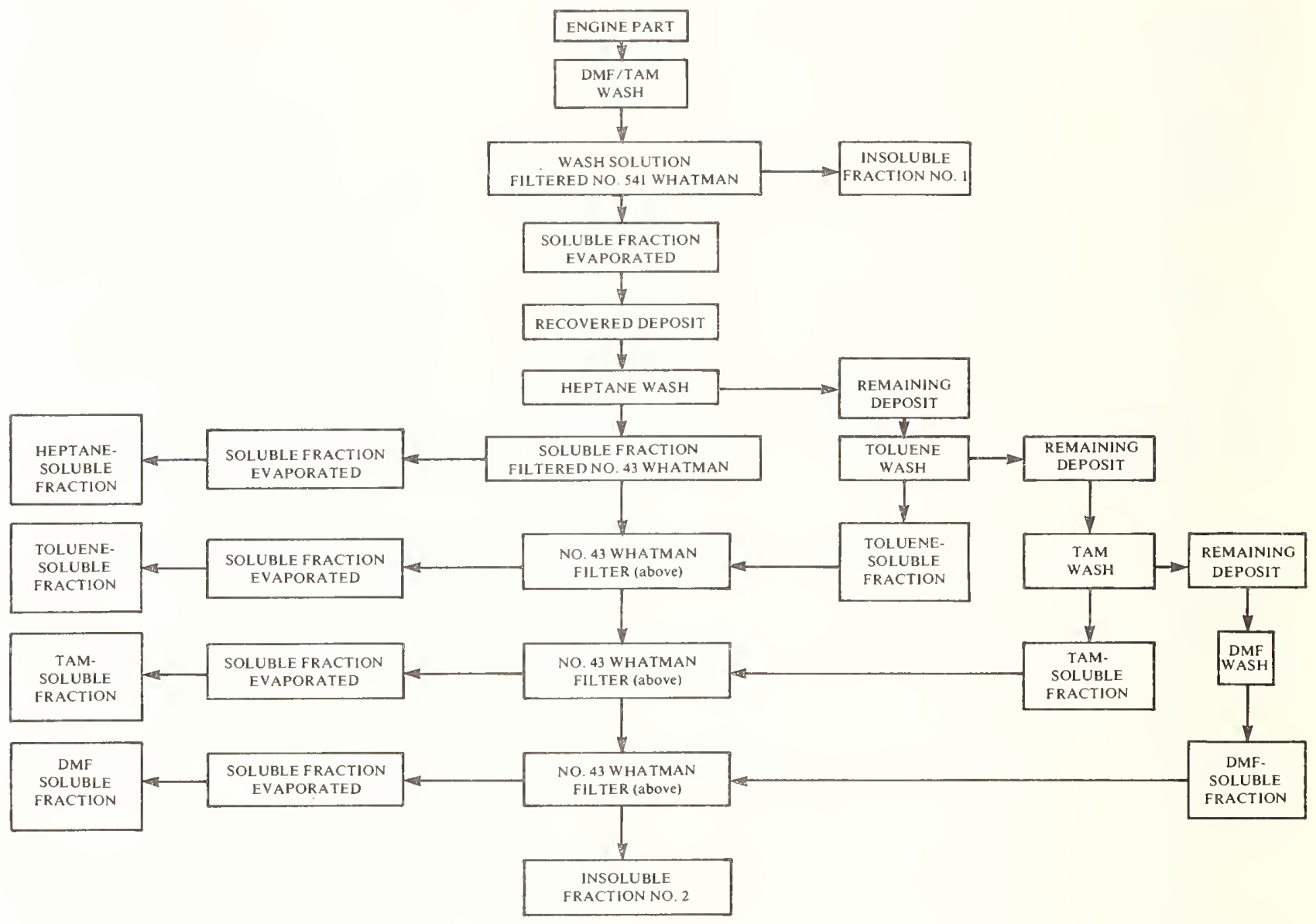

Figure 2. Engine part washing and deposit recovery procedure.

The briquetting method requires the mixing of a ground engine deposit residue with a plasticizing binder followed by pressing into a sample pellet and X-ray fluorescence analysis of the pellets. The briquetting method was chosen as a means of analyzing samples which cannot be put into solution without the errors involved in loose powder analysis, in which a reproducible measurement is difficult to obtain.

Preparation of sample involves a preliminary grinding with a mortar and pestle to ensure a reasonably homogeneous sample. This is followed by grinding a mixture of Somar-mix additive and sample, in approximately a 4:1 ratio, in a vibrating ball mill grinder. The Somar-mix is an organic, chemically inert substance which will not chemically react with sample materials or introduce any interfering $x$-ray spectra. The lubricious and abrasive constituents in the mix intermix with the sample during comminution, uniformly reduce sample size, and produce a homogeneous blend. The additive also serves as a briquetting agent, forming materials into "plasticized" sample pellets which are firmly bonded together to uniform densities and which have smooth, unblemished surface finishes for statistically reproducible results and minimized intensity variations. Pellets are formed using compressible aluminum X-ray pellet cups in a 1.25-in mold assembly. In order to avoid thin, brittle pellets due to the small sample size used, the pellet cup is first filled two-thirds full with Somar-mix and lightly pressed. The sample and Somar-mix mixture is then placed on the pellet, and the sample is pressed at 25000 pounds total load on a hydraulic press. The resulting pellet is about $3 / 16$ in thick with a smooth, highly plasticized surface. 


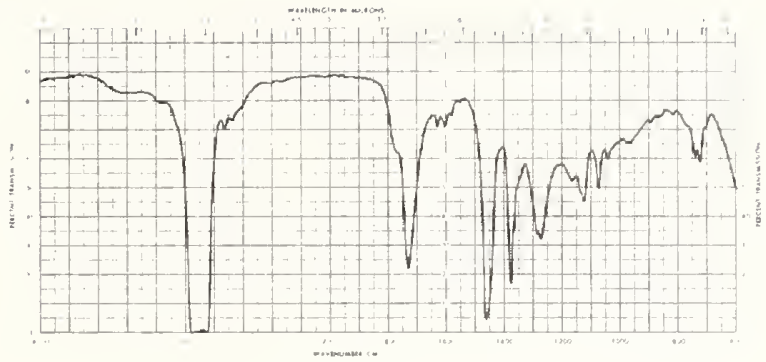

a. Heptane Fraction

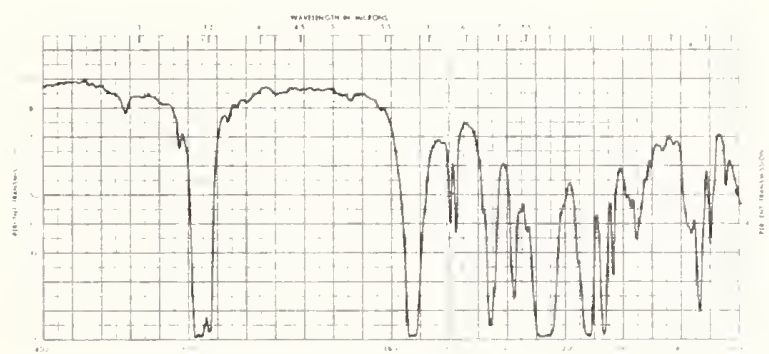

b. Toluene Fraction

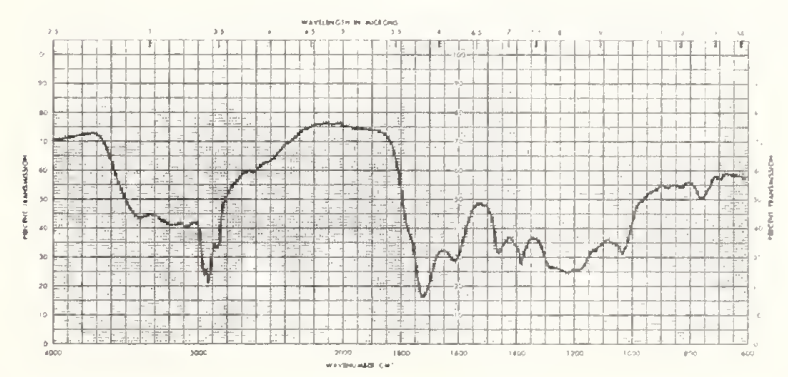

c. TAM Fraction

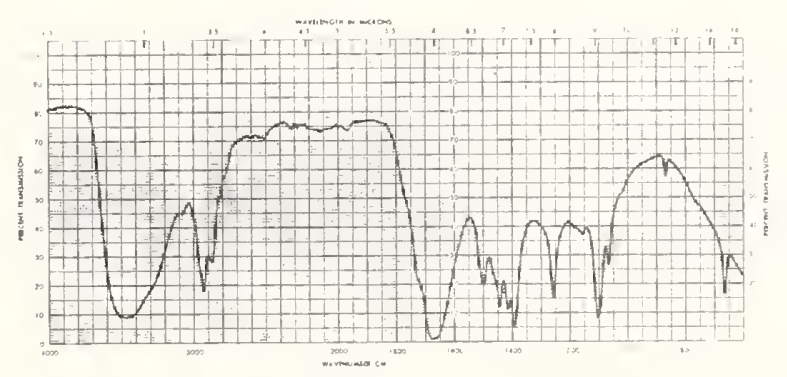

d. DMF Fraction

Figure 3. Representative IR spectra. 
In the $X$-ray spectrochemical analysis of powdered materials, factors such as matrix composition, interelement effects, absorption, and enhancement play important roles in the analytical accuracy of elemental determinations. In order to treat these factors, an XRF regression program has been used in analysis of the samples. Standards were prepared using metal oxides or metal hydroxides in similar proportions to those observed in qualitative examination of the deposits. Interelement effects and matrix composition can be taken into account in the SRF regression program and concentration versus counts per second calibration curves formed for each element observed. Samples may be analyzed, and their counts per second entered in the program to produce weight percent data.

The previously described deposit analysis methodology has been used to examine and compare laboratory- and field-derived engine deposits for both virgin and re-refined engine oils [4]. Typical results are shown in the appendix. These results were obtained in a comparison of RCMP vehicles using re-refined and virgin basestock oils and in a comparison of Sequence III D tests using both oils [5]. This work suggested that deposits from the virgin and re-refined engine oils were very similar.

\section{Summary and Conclusions}

The following Summary and Conclusions are drawn from this work:

- A methodology was developed for the removal, recovery and analysis of engine deposits.

- Deposits were characterized based on their solubility using a variety of analytical techniques.

- To aid in characterizing insoluble fractions, a briquetting method for XRF elemental analyses was developed.

- The methodology has been used to examine deposits from virgin and re-refined engine oils derived from both field and 1 ab tests (AFLRL-152). This work suggested that deposits from virgin and re-refined engine oils were very similar.

\section{References}

[1] Kimba11, V. S. Waste oil recovery and disposa1. Noyes Data Corporation; 1975.

[2] Kaufman, H. B. Recent used oil legislation. Proceedings of workshop on measurements and standards for recycled oil; Nat. Bur. Stand. (U.S.) Spec. Publ. 488; 1977.

[3] Harris, S. W.; Eggerding, D. W.; and Udelhofen, J. H. Analysis of the PV-1 test via used oils. ASLE Preprint No. 80-AM-1B-2. Presented at the ASLE Annual Meeting; 1980 May 5-8; Anaheim, CA.

[4] Frame, E. A.; and Koh1, K. B. Characterization and evaluation of re-refined engine lubricating 0i1. Interim Report AFLRL No. 152, AD A118573, prepared by U. S. Army Fuels and Lubricants Research Laboratory, San Antonio; TX; December 1981.

[5] Armstrong, J. A.; and Strigner, P. L. A field and laboratory comparison of Re-refined and virgin automotive engine oil. SAE Paper No. 821239. Presented at Toronto Fuels and Lubricants Meeting; October 1982. 


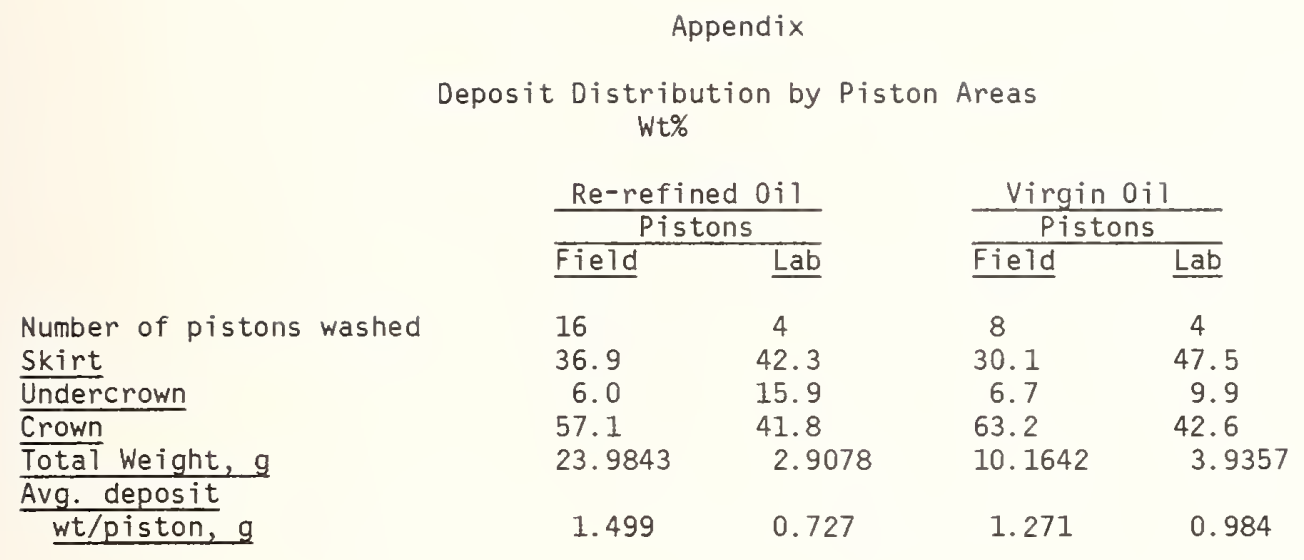

Fraction

Heptane

Toluene

TAM

DMF

TOTAL
Deposit Distribution by Piston Area and Fraction Solvent, Wt\%

\begin{tabular}{|c|c|c|}
\hline Skirt & Undercrown & Crown \\
\hline e-refined & Re-refined & Re-refined \\
\hline Field Lab & $\overline{\text { Field Lab }}$ & Field Lab \\
\hline
\end{tabular}

$\begin{array}{rrrrrr}56 & 74 & 18 & 72 & 5 & 70 \\ 10 & 2 & 19 & 8 & 8 & 4 \\ 17 & 1 & 16 & 11 & 50 & 3 \\ 17 & 22 & 48 & 9 & 37 & 24 \\ 100 & 100 & 100 & 100 & 100 & 100\end{array}$



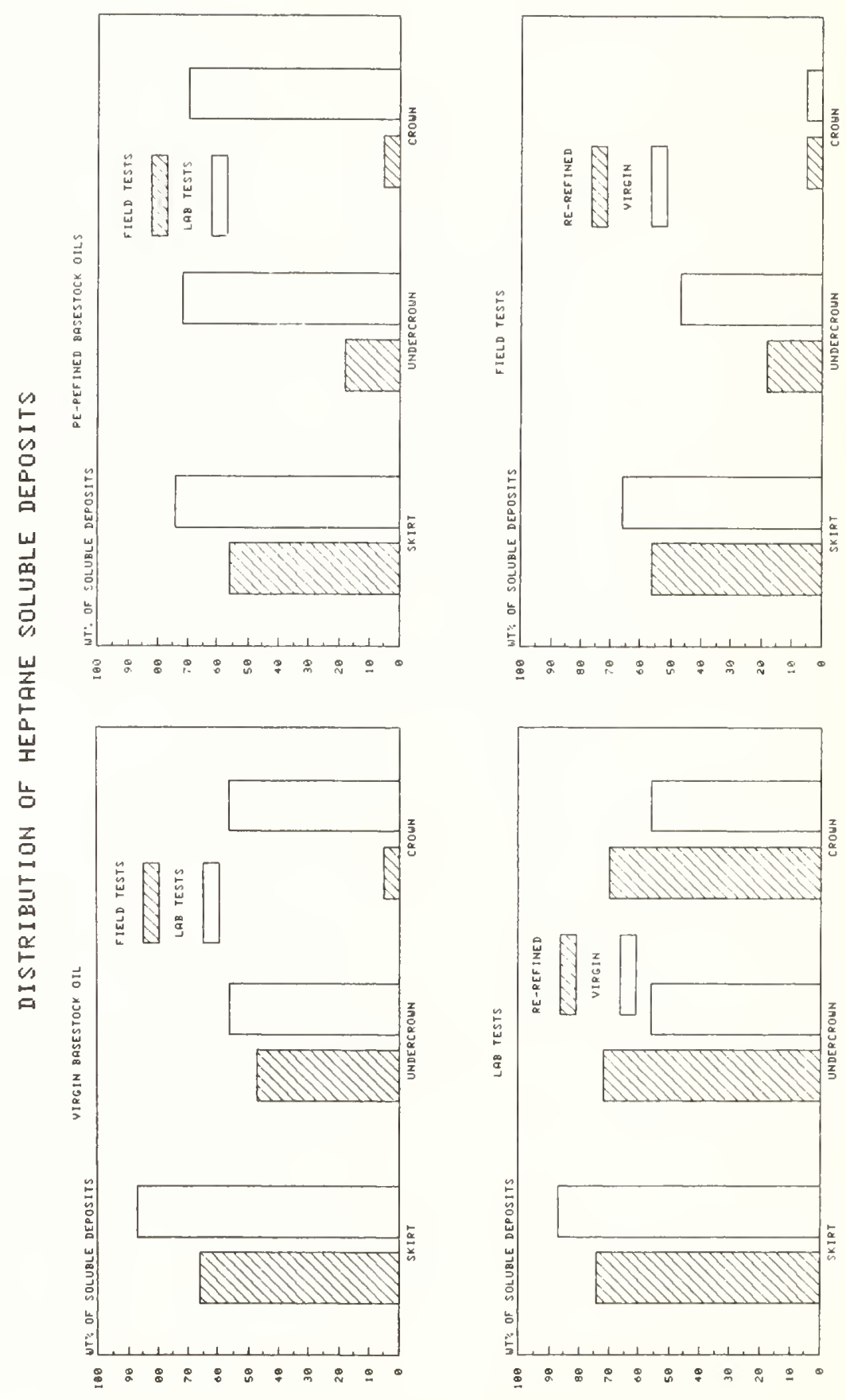

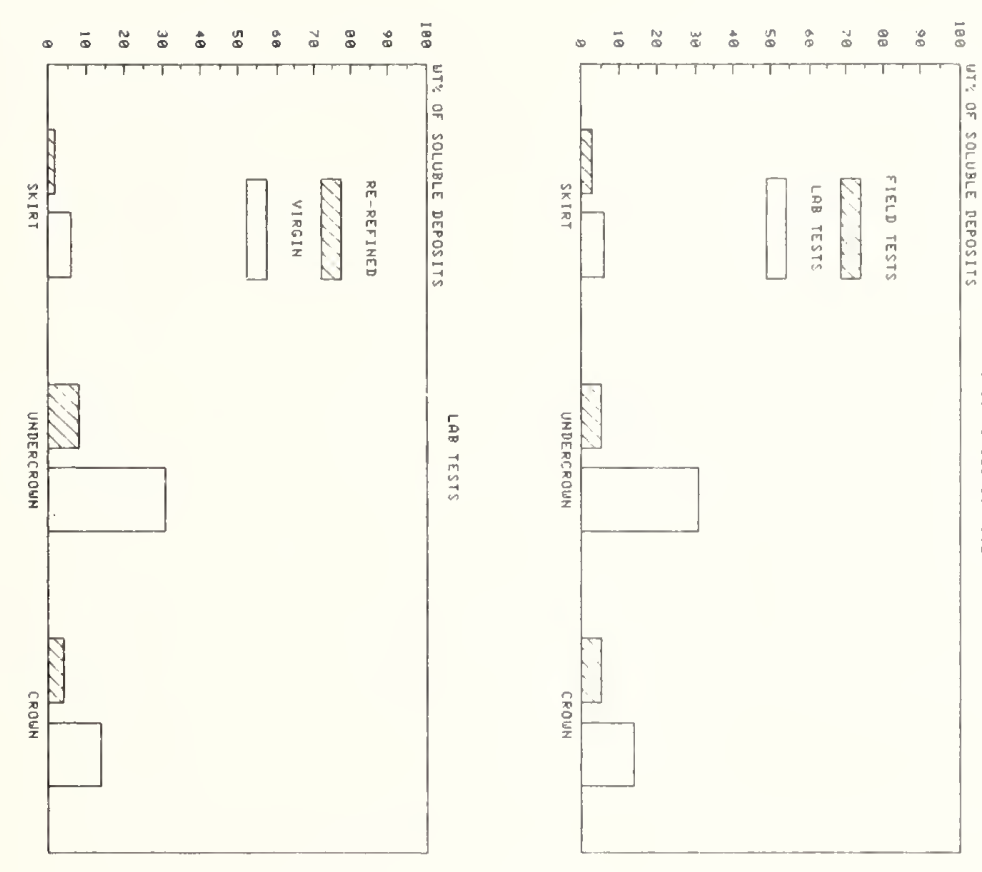

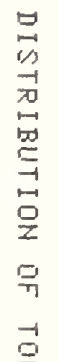
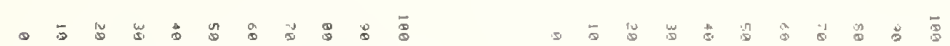

章
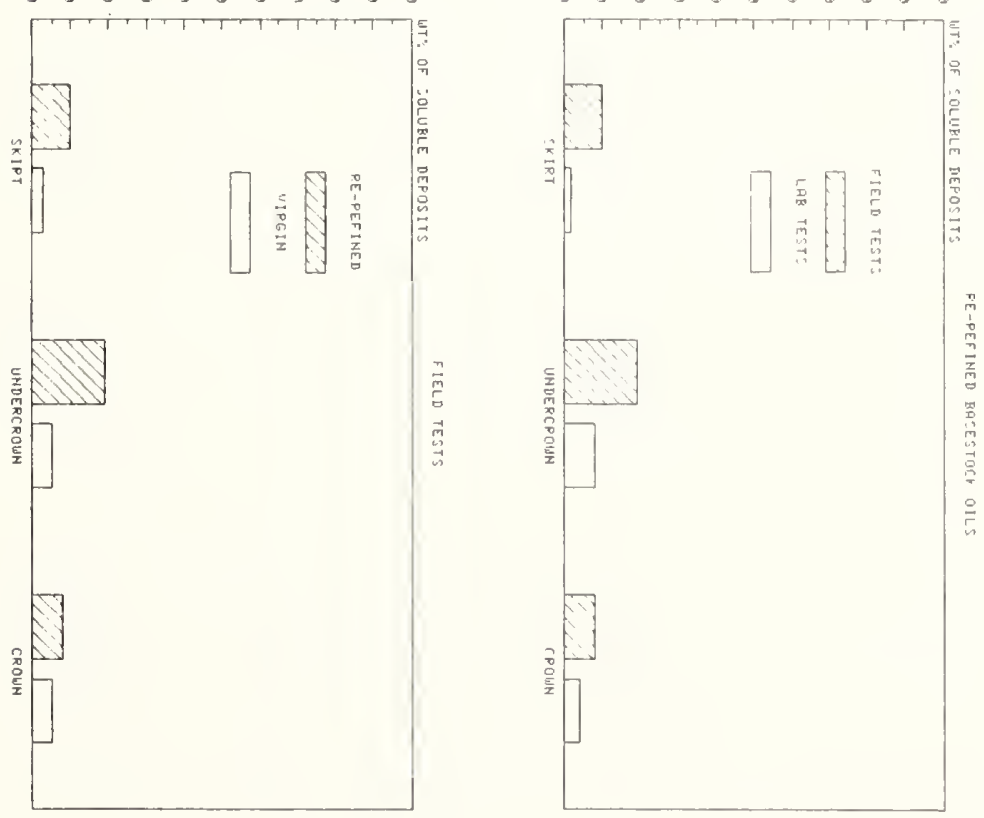


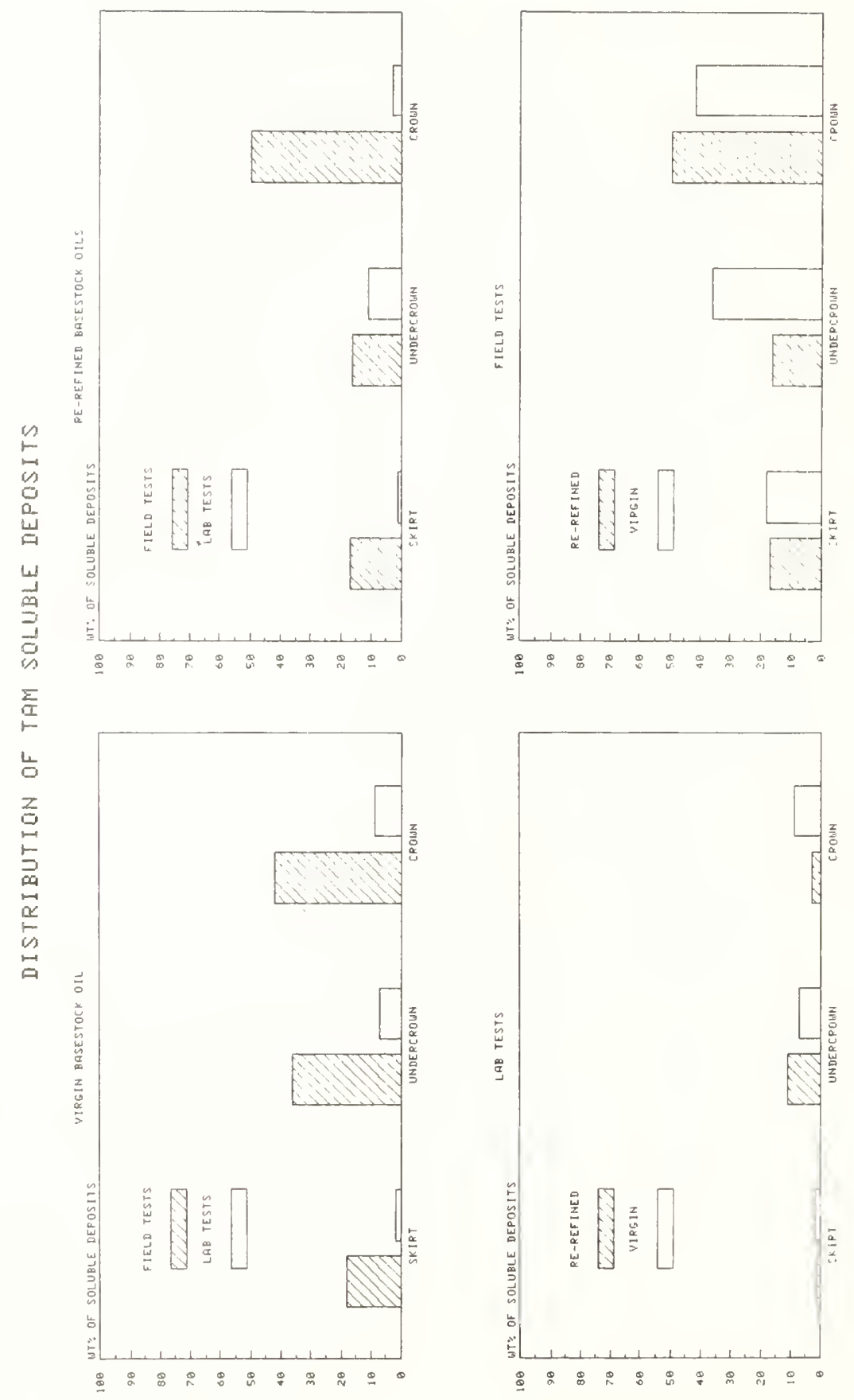



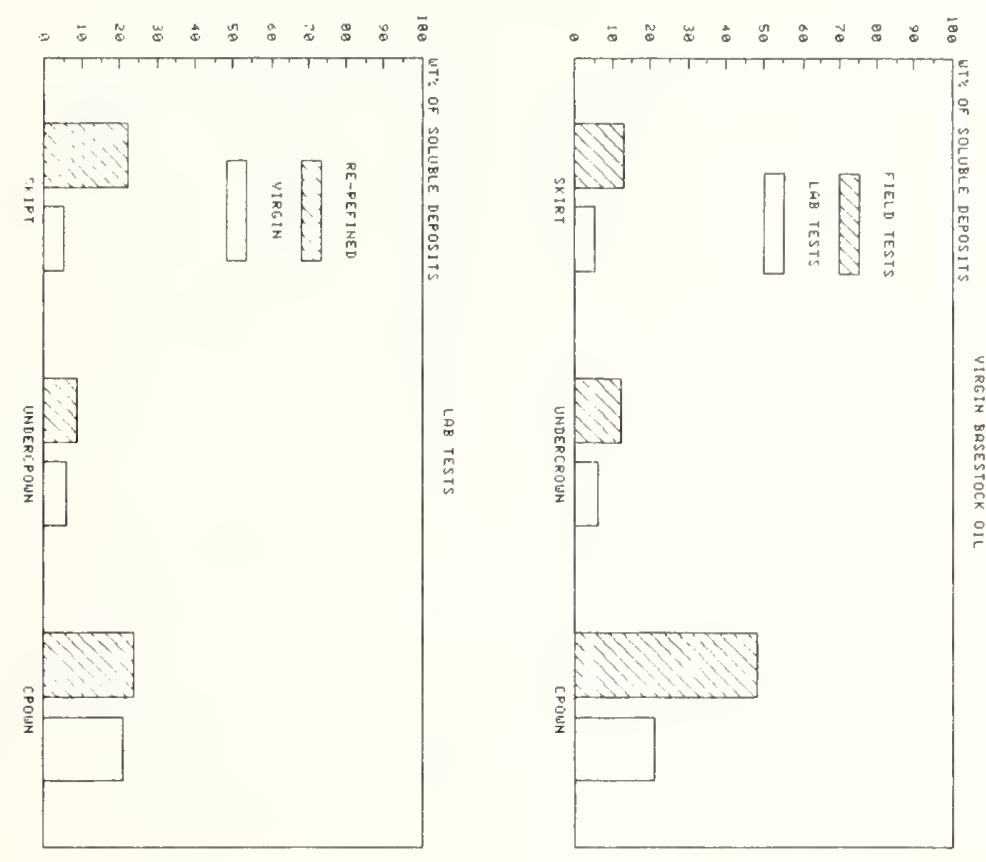

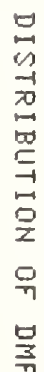
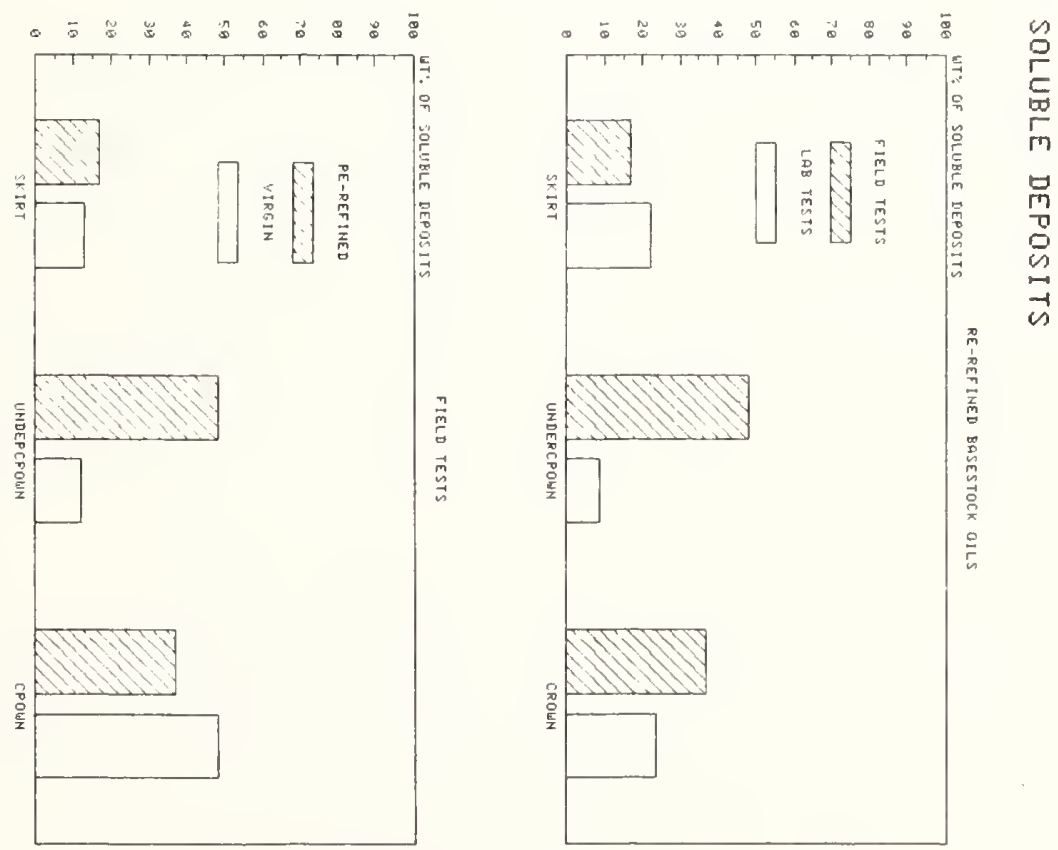

National Bureau of Standards Special Publication 674. Proceedings, Conference on Measurements and Standards for Recycled 0iT - IV, held at NBS, Gaithersburg, MD, September 14-16, 1982.

(Issued JuTy 1984).

\section{DEVELOPMENT OF A BENCH ENGINE SCREENING TEST FOR MOTOR OILS}

\section{Daniel Heath}

Franklin Research Center

20 th and Race Streets

Philadelphia, PA 19103

1. Introduction

This presentation is a status report of a cooperative project funded by the U.S. Army MERADCOM, NBS, and the Franklin Research Center. The initial phase of the project, the feasibility

demonstration, will be completed within the next several weeks. The theme of this conference was so in line with our project that we planned this presentation knowing that the initial test results might not be in-hand for today.

Our title, when the terms are explained, denotes the general concept which we are pursuing: specifically, to provide a screening tool for the Sequence $V$-D Test, and which may later be adapted to the other multicylinder and single cylinder oil specification engine tests.

\section{Background}

To explain the concept I have chosen the following definitions:

- Bench Test - involving process simulation often by way of glassware and a simplified mechanical simulation, configured to produce results at low cost.

o Screening Engine Test - a downgraded version of the full scale test which produces results at moderate cost.

- Bench Engine Screening Test - utilizing a small slave engine to simulate the test process in conjunction with actual engine hardware separate from the slave engine, all under especially precise control, with versatility (explained later) and relatively low cost.

From Bench Engine Screening Test we form the acronym BEST; and for the Sequence V-D rendition we assign the name BEST-5.

\section{Need}

Very quickly one thinks of the high cost, extended length factors and often the limited availability of Sequence test facilities. Beyond that the sometimes questionable precision of the tests is troublesome. Wear prediction in quantitative terms has been difficult. The mainstream industry develops engine oils by reformulating up to the requirements of new military specifications and industry classifications via a relatively high volume of testing to qualify in all of the Sequence tests.

In the recycled oil business, quality control and basestock influence are the concerns which in the usual repetitive engine test context would translate into prohibitive costs.

\section{Objectives}

The sponsors of this work, therefore, agreed on the following objectives for the BEST-5:

- a nonproprietary test available to all;

o good correlation to the $V-D$ test; 
o good precision;

o short duration (48 hours?); and

- low cost (approximately $\$ 1000$ in routine use).

In general, the test was to be adaptable, at least conceptually, to predict L-38, Sequence IID, and IIID performance either individually or in "combined" concurrent operation. The combined test, BEST-C, we conceive would run to completion in 48 hours and might cost about $\$ 2500$.

\section{Concept}

Figure 1 summarizes the concept. The slave engine duplicates the essential combustion and cylinder conditions only as a source of "live" blowby which can be precisely metered to selected motored components of the Sequence test engine with speed/load/heat/ cooling and test oil conditions astutely selected to provide the cooling desired severity and precision. Depicted in the lower half of Figure 1 is the BEST-C concept with the four individual "prime" engine hardware subassemblies concurrently being served by the one slave engine.

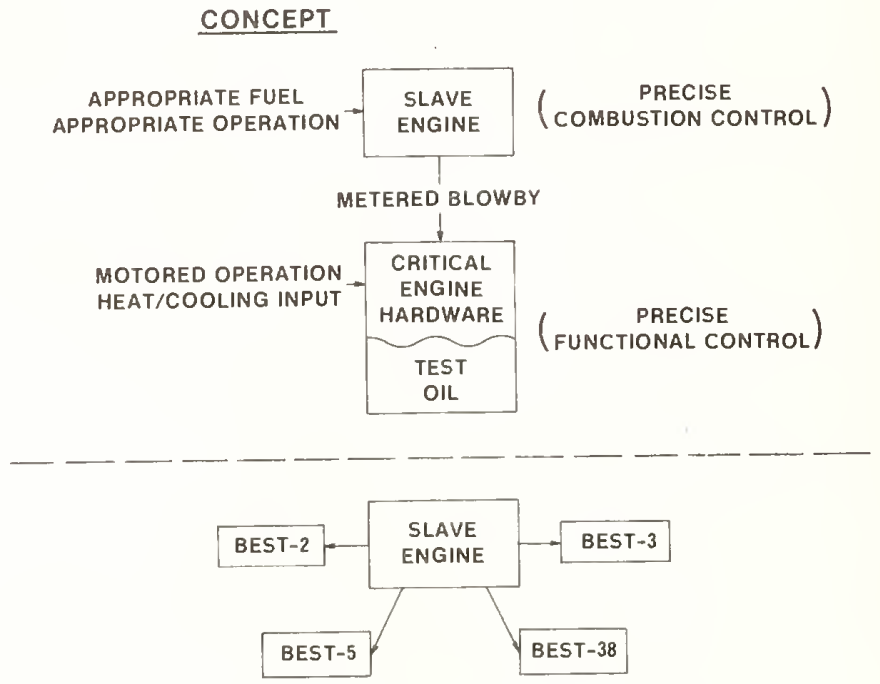

Figure 1. Concept

Let me say that we recognize the limitations of this concept, the foremost one being that crankcase blowby is undoubtedly of a different character and constituency than is ring-zone blowby which interfaces directly with the test oil in the Sequence tests, whereas, under our concept only the crankcase blowby is metered out to the test oil/hardware section or sections.

In answer to that concern, we are prepared to use fast sampling valve techniques at the cylinder wall to obtain the more reactive blowby species if our results suggest the need. $0 \mathrm{n}$ the other hand, we certainly recognize the advantages of this concept. As regards the slave engine, we are able to concentrate on combustion specifics rather than agglomerate interrelated conditions throughout the engine, since the test does not reside in the engine. Relative to the slave engine we are able to:

o control combustion, not net engine output;

- control quality of blowby, not quantity;

o operate at steady state, not cyclic; and

o preserve engine function rather than degrade the engine along with test oil. 
With regards to the test hardware, we are able to:

- accentuate severe conditions without conventional constraints;

- control all severity inputs; and

o design for ultimate precision control.

The significance of these points is better appreciated within the specific context of the Sequence V-D Test.

\section{Sequence V-D Operational Analysis}

Figure 2 lists operational parameters and features of the Sequence V-D Test. As the V-D test was developed cooperatively in the ASTM PV-1 Task Force and then has been groomed to the present time, we have learned much about its functionality. Without the time constraints we have today, one could give a bit of a discourse at each point listed in the figure. Suffice to say that we have at least directional knowledge of the severity influences involved. Figure 3 summarizes the primary effects under the headings of wear, siudge and varnish. We recognize the temperature-speed transition as a severe boundary lubrication exercise for the camshaft with the listed factors representing a sustained stress which tests the wear protection offered by the oil. Sludge severity has been shown in ASTM cooperative work to be dependent on the deep cycling temperature effects. Varnish severity is easily obtained using the $V-D$ cycle without having an apparent especially limiting parameter associated with it.

SEQUENCE V-D TEST

OPERATIONAL ANALYSIS

[SLUDGE-VARNISH-CAM/FOLLOWER WEAR]

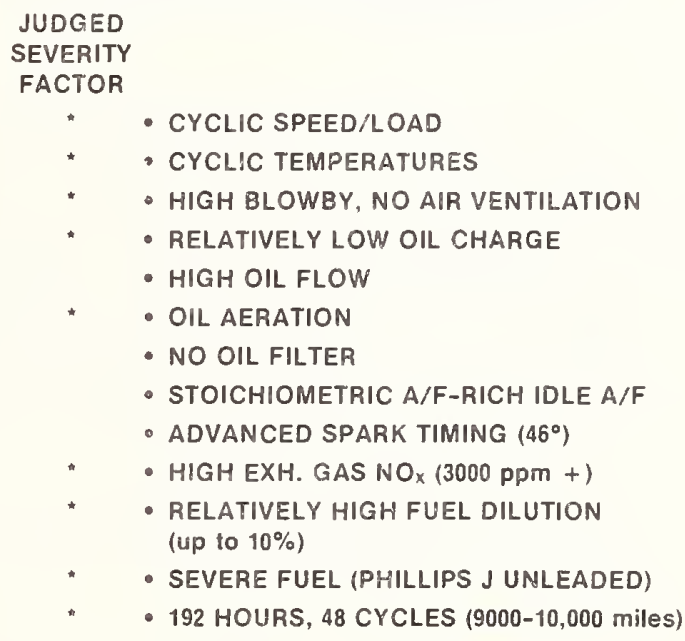

Figure 2. Sequence $V-D$ test operational analysis

Having then analyzed the full scale Sequence V-D Test, we configured the BEST-5 to accentuate the severe conditions in steady-state operation.

\section{BEST-5 Operating Regime}

Figure 4 describes the configuration. The slave engine is an Onan RCK-MS (2 cylinder, opposed, liquid cooled, 50 CID) operated constantly at governor controlled 1800 rpm and moderate power output. The engine is coupled directly to an alternator which controls the engine load at a moderate level, via manual adjustment to predetermined constant absolute intake manifold pressure and exhaust backpressure. This is a control technique with which we have become familiar in fuel economy testing of oils. The technique reasonably well assures a constant energy input to the engine. Obviously, the air/ fuel ratio must also be controlled. The coolant and oil temperatures as shown in figure 4 were selected to resemble the most severe of the three stages of Sequence $V-D$ operation (Stage I: high blowby, low temperature - favoring both $\mathrm{NO}_{\mathrm{x}}$ and aldehyde formation). 


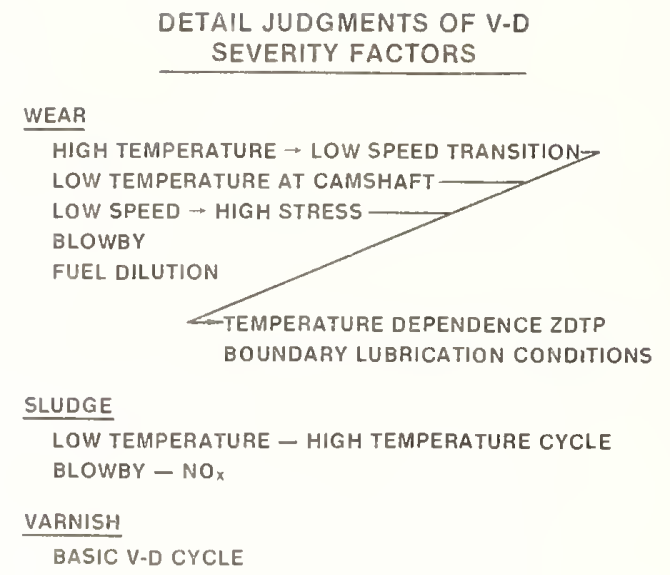

Figure 3. Detail judgments of $V-D$ severity factors

Only a precisely regulated, small amount of the slave engine crankcase blowby is metered to the test oil sump. Perhaps the most significant feature here is that the blowby gas is metered directly into the inlet of the primary oil pump. Obviously this gas produces oil aeration. The primary oil pump is driven by a variable speed motor and consequently is utilized to control oil pressure. The primary pump oil inlet is directly from the sump in which the two pumps are totally immersed and the cylinder head is partially immersed. The outlet of the primary oil pump feeds the inlet of the secondary pump which is modified to prevent any internal bypass. The function of the secondary pump is to constantly circulate the oil under high pressure (120 psi) and high turbulent flow, through either the hot or cold bath heat exchanger. The operation is set up to recirculate the oil rapidly, making several passes through the exchanger before flowing on into the main pressure gallery of the cylinder head. The oil gravity feeds from the cylinder head valve deck back to the sump.

The camshaft of the complete lash cylinder head assembly is motored at a constant 375 rpm. The hydraulic lash adjusters are modified via a solid mechanical adjustment to hold the valves slightly open rather than reaching full closure when the follower is on the base circle of the cam lobe.

The 40 gallon hot and cold reservoirs, containing hydraulic oil, pump constantly, looping through the hot and cold bath exchangers respectively. Consequently, we have test oil on the tube side exchanging heat with the hydraulic process control fluid (hydraulic oil) on the shell side. The dual 3-way spool valve is hydraulically actuated to direct the test oil flow either to the hot bath or cold bath exchanger in a 2-stage, 1 hour cycle (30 minutes hot, 30 minutes cold). 0ne bath exchanger is always stagnant and acts as a soak chamber to "process" the test oil under full 120 psi system pressure.

To summarize the operating regime, the slave engine operates constantiy to supply a surplus of severe blowby. A precise quantity of the blowby is constantly metered into the test oil system to generate a severe yet controlled oil aeration process. Primary and secondary oil pumps circulate the aerated oil under high pressure and high flow turbulence conditions through the bath exchangers providing simultaneous hot and cold conditions. The oil performs all lubricating functions for the operating cylinder head at severe low/high temperatures and a constant severe low cam speed.

\section{BEST-5 Severity Bases}

Figure 5 summarizes the conditions which favor the success of this regime in duplicating actual Sequence $V-D$ test operation. Most of the points I have already discussed either in relation to the $V-D$ test itself or the BEST-5 regime. Two points, however, deserve explanation. First, the 
apparently unconventional concept of aerating the test oil is really not unprecedented. The Sequence $V-D$ test itself was plagued by this phenomenon in its early development, and in its present form the aeration factor is held to tolerable limits (since there is no direct control over the factor). The Sequence $V-C$ test in the author's experience was also known to generate a low level of oil aeration. Categorically, then, the employment of this mechanism may be considered within the realm of realistic engine oil degradation chemistry. Secondly, implementation of simultaneous cool and hot cylinder wall/combustion chamber environments offers a further means of duplicating in two days what the $V-D$ engine undergoes in eight days. This flexibility is afforded by the distinctly separate coolant jacket configuration of the Onan RCK-MS 2 cylinder opposed engine, i.e., one cylinder can be operated at high temperature while the other is maintained at a lower temperature with the blowby from both mixing in the crankcase prior to being metered to the outside test oil sump. A similar scenario could deal with the concept of using two air-fuel ratios. The author's experience in the development of the Sequence $V-D$ test wherein exhaust gas carbon monoxide levels were carefully studied justifies these considerations.

\section{BEST-5 OPERATING REGIME}

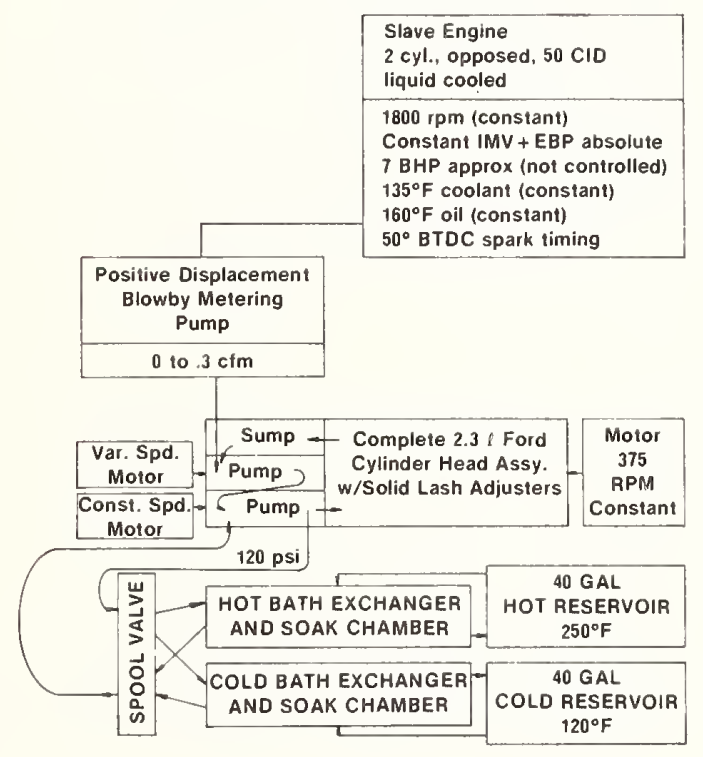

Figure 4. BEST-5 operating regime.

\section{BEST-5 Precision Basis}

Figure 6 summarizes the precision features. In each itemized category the full scale engine test, the Sequence $V-D$, functions without precise parameter control and the BEST-5, by the design of its operating regime, is able to function with either no natural variations involved or under precise direct control.

\section{BEST-5 Operating Conditions}

Having developed the concept to this point, we can now examine in figure 7 the operating conditions chosen for the initial feasibility study. Forty-eight one-hour cycles comprise the test. Stages I and II are each 30 minutes in duration. For development puposes many other parameters, such as oil flow rates, coolant flow rates and temperature gradients, will be examined. Certain parameters such as ignition timing, not shown in figure 7 , will be controlled at levels compatible with the overall balance (interdependence) of the system. 


\section{BEST-5 SEVERITY BASIS}

- CONSTANT LOW SPEED CAMSHAFT OPERATION (375 rpm)

- CYCLIC HIGH-LOW TEMPERATURES $\left(250-120^{\circ} \mathrm{F}\right)$

- blowby aerating test oil (PRECISEly CONTROLLED)

- HIGH PRESSURE, HIGH TURBULENCE BLOWBY-OIL INTERFACE

- BLOWBY FROM LOW TEMP HIGH NOX ENGINE

- BLOWBY FROM PHILLIPS "J" TEST FUEL

- DUAL PHASE OIL ENVIRONMENT (ALWAYS HOT AND COLD)

- SMALL TEST OIL CHARGE, NO FRESH OIL ADDED

- incReased Continuous and PEAK VALVE SPRING LOAD (VALVES DO NOT CLOSE)

- AIR FUEL RATIO STOICHIOMETRIC AND RICH

AT SAME TIME (VIA 2 CYL. ENGINE WITH 2

CARBURETORS AND COMMON CRANKCASE)

- CYLINDER WALL TEMPERATURES HIGH AND

LOW AT SAME TIME (VIA 2 CYL. OPPOSED

ENGINE WITH SEPARATE COOLANT JACKETS)

Figure 5. BEST-5 severity basis.

\section{BEST-5 PRECISION BASIS}

- NO TRANSIENT SPEEDS (ENGINE OR CAMSHAFT)

- PRECISION SPEED CONTROL OF CAMSHAFT

- No LASH ADJUSTER VARIATION (VALVES DO NOT CLOSE)

- VALVE guides WELL LUBRICATED (NO SEALS)

- NO OIL CONSUMPTION

- OIL TEMPERATURES CYCLED PRECISELY (BATH CONCEPT)

- NO BLOWBY VARIATION TO TEST OIL (METERED)

- BLOWBY GENERATED VIA CONSTANT COMBUSTION (NO BREAKIN EFFECTS)

- OIL FLOW CONDITIONS CONTROLLED

Figure 6. BEST-5 precision basis. 


\section{BEST-5 OPERATING CONDITIONS}

TOTAL TEST LENGTH: 48 HOURS, 48 CYCLES

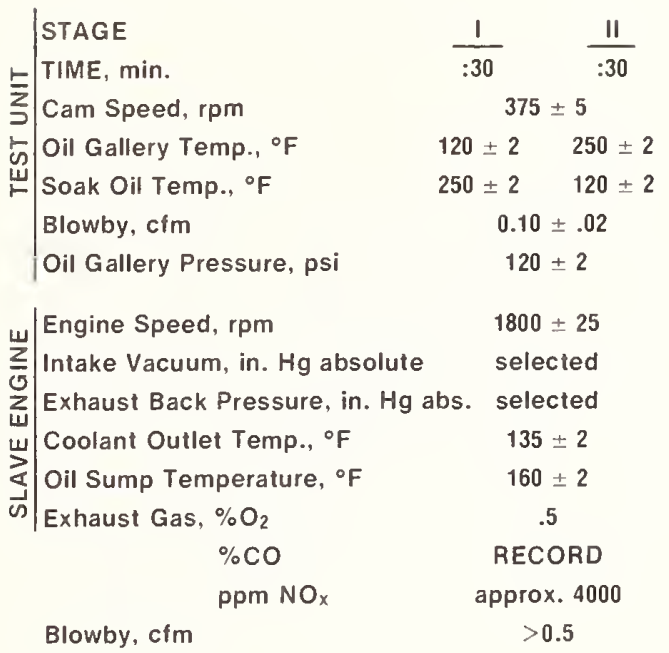

Figure 7. BEST-5 operating conditions.

\section{BEST-5 Rig Configuration}

The mobile BEST-5 test rig is presently fully assembled at the Franklin Research Center engine test laboratory and receiving its final service connections (electrical, exhaust, and cooling) figures 8, 9, and 10 depict the physical layout of components. The inclined cylinder head/sump assembly is encased and insulated to minimize ambient temperature effects. The overall bench is approximately $6 \mathrm{ft}$. long by $3 \mathrm{ft}$. wide and $5 \mathrm{ft}$. high. As indicated in the figures, the bench is on wheels and has a self contained fuel supply. Figures 8 , 9, and 10 as overlay drawings progressively highlight the systems functions.

\section{Test Result Format}

Figure 11 summarizes the manner in which sequence $V-D$ test results are paralleled. Use of the 2. 3 litre Ford rocker arm cover permits exact duplication of some rating areas. The wear results in their entirety are identical to those of the $V-D$ test. The BEST-5 sump configuration offers similarity to the sump of the $V-D$ engine. A piston skirt varnish rating as obtained in the $V-D$ test is obviously not available. However, we intend to explore whether a correlation may exist between cam bearing varnish deposits and piston skirt varnish.

In order to enhance the rating accuracy we are incorporating removable rating surfaces for varnish and sludge deposits. These modules, by design, have deposit depth or comparative varnish intensity pockets to help eliminate some of the subjectiveness of the traditional deposits rating methods.

\section{Final Procedure Development}

Within the next few weeks we anticipate shakedown operation to begin and by this November to:

- establish significant severity

- evaluate 2 Seq. V-D reference oils

- adjust the operating conditions as needed 
o show a similar performance ranking as in the $V-D$

- demonstrate the precision with 3 repeat tests

- evaluate other $V-D$ reference oils.

Completion of these items is expected by the end of the year.

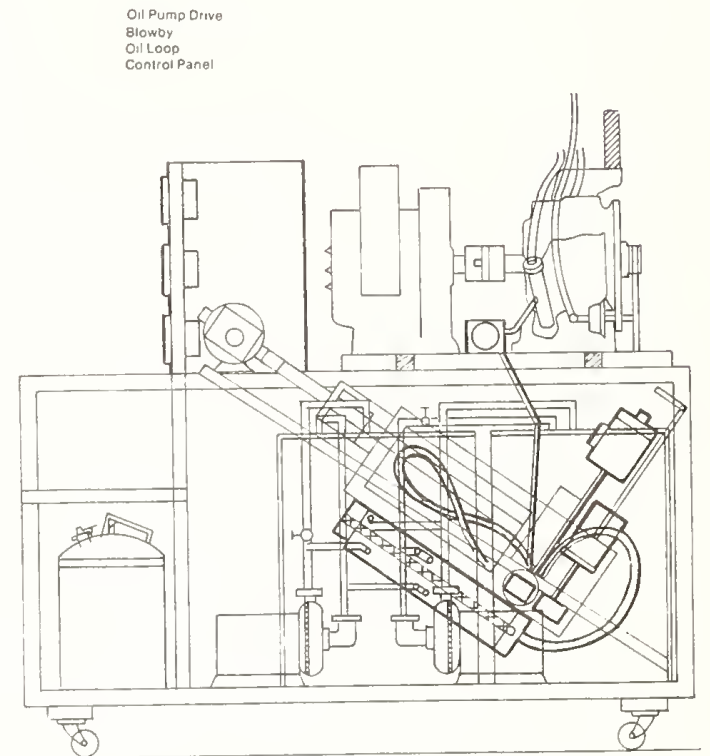

Figure 8. Bench engine screening test for motor oil under Development at Franklin Research Center.

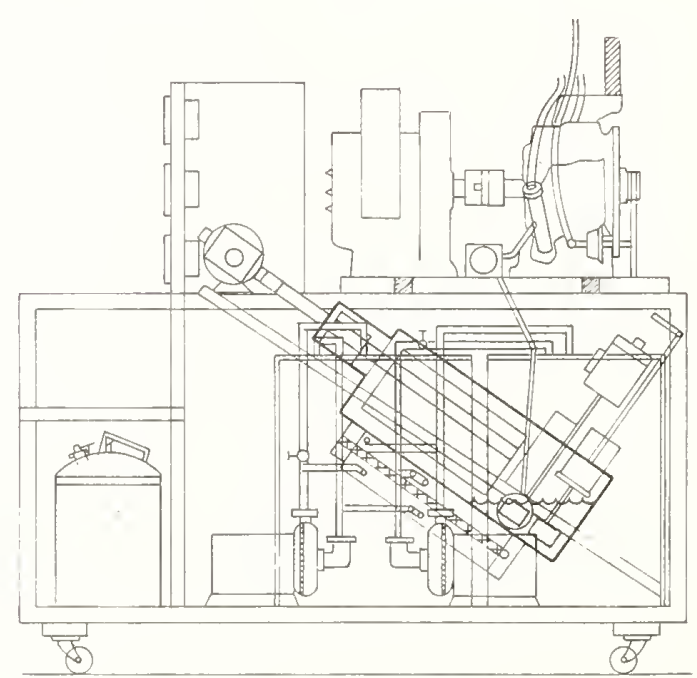

Figure 9. Bench engine screening test for motor oil under development at franklin research center 


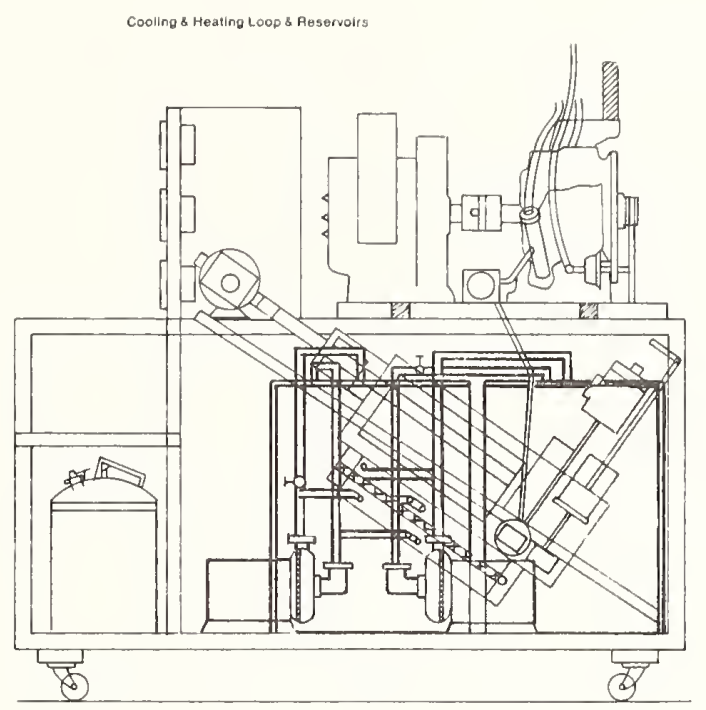

Figure 10. Bench engine screening test for motor oil under development at franklin research center.

\section{BEST-5 TEST RESULT FORMAT}
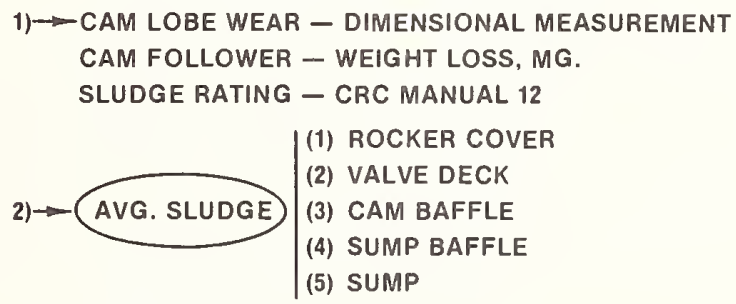

VARNISH RATING - CRC MANUAL 9

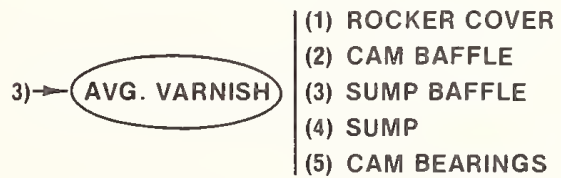

[ALL EXCEPT CAM BEARINGS DESIGNED WITH SPECIAL MODULE SURFACES WHICH ARE SELF-INDICATING FOR BOTH VARNISH AND SLUDGE DEPOSITS

[CAM BEARINGS MAY SHOW CORRELATION WWITH PISTON SKIRT VARNISH OF V-D

Figure 11. Test result format. 

National Bureau of Standards Special Publication 674. Proceedings, Conference on Measurements and Standards for Recycled 011 - IV, held at NBS, Gaithersburg, MD, September 14-16, 1982.

(Issued Ju1y 1984).

The ASTM/NBS Basestock Consistency Study

Donald A. Becker

Recycled 0 il Program

Nationa 1 Bureau of Standards

Washington, DC 20234

The ASTM/NBS Basestock Consistency Study was initiated in 1980 and completed in 1983. It's purpose was to help provide the technical data base required for the NBS Recycled $0 i 1$ Program. In the study, six re-refined and four virgin lubricating oil basestocks were obtained monthly from different manufacturers. These oils, along with control samples, were characterized by 14 cooperating laboratories with over 50 different tests yielding over 65 different values per oil sample. The results and data analyses are compiled in a 500 page report, and are thought to be the most comprehensive ever obtained on lubricating oil basestocks.

\section{Introduction}

Early in the National Bureau of Standards (NBS) work on recycled oil, it became clear that the most important requirement for assuring the quality of re-refined engine oil was the development of a set of test procedures capable of monitoring the consistency and additive response of a re-refined oil basestock. These procedures would help assure a consistent product between qualifications of the formulated oil through use of the ASTM (American Society of Testing and Materials) engine sequence tests.

To help provide the technical data base necessary to develop and select this proposed set of test procedures, a study was needed which would provide lube oil basestock characterization data on re-refined and virgin oils over a substantial period of time. Therefore, in 1979, NBS proposed to ASTM Technical Division $P$ that a cooperative basestock consistency study be initiated. In this study, as many tests as possible would be used to extensively characterize monthly production samples for both commercial re-refining companies and virgin oil refiners. This effort was approved by ASTM in June of 1979.

The ASTM/NBS Basestock Consistency Study (BCS) was initiated in early 1980, when six commercial U.S. re-refined oil producers and four virgin oil producers began submitting monthly samples of their regular production basestock for analysis by a group of 14 cooperating analytical

laboratories. These ten suppliers had been selected as representing the widest variety and most important types of automotive lubricant basestocks available at that time. The monthly production samples were provided to NBS in 55-gallon drums. NBS then thoroughly mixed the drums, subdivided the samples and coded them before transfering them in groups each month to the analyzing laboratories.

Each group of samples sent to an analytical laboratory had a control sample in it, identified only with a code number in a similar way as the samples. This control sample was part of a five-drum batch of virgin oil that had been thoroughly homogenized in a large vat before shipment to NBS. The control sample was added to provide a means to monitor the consistency of the analyzing laboratory for a particular test procedure. The 14 cooperating laboratories analyzed the samples using over 50 different chemical, physical and performance tests, providing more than 65 different characteristics on each sample. It should also be noted that one particular laboratory analyzed all of the oil samples for that particular test, in order to eliminate the interlaboratory variability from the test results. In a few cases, a second laboratory repeated the test on the complete set of samples.

In addition to the monthly production samples of 55-gallon drums from each manufacturer, NBS obtained 5-galion cans of oil from each manufacturer in the middle of each month. The purpose of these 5-gallon samples was to have them available for further evaluation of the 55-gallon monthly oil samples, in case the analytical results showed that a particular sample was extremely different from previous samples from that same manufacturer. Since the analytical results would only be obtained well after the time of production, the determination of whether an outlier was really a 
momentary outlier or occurred over a substantial period of time could only be determined with samples already taken. To date, analysis of these middle samples has not been found necessary.

The data contained in the report of this study is a compilation of the results from these tests on 13 monthly production samples from each oi1, 116 samples, representing 65 re-refined oils from six producers (one ceased operation during the study) and 51 virgin oils from four producers. With the addition of 16 control oil samples, a total of 132 oil samples were analyzed. The data has been statistically evaluated, and for many of the tests the results have been graphed using one or more techniques, in order to better visualize the relative consistency of the oils and/or test data. All of this information has been published in a 500 page report [1] ${ }^{1}$. The table of contents of the report and the list of cooperating analytical laboratories are contained as appendices to this paper. Also included as an appendix is the data and statistical plots for one test, Refractive Index (ASTM D 1218). This will provide the reader with an example of the treatment afforded each of the tests included in this study.

\section{Conclusions}

The data generated in this study provides the technical information and data necessary to establish the consistency of re-refined lubricating oil. It is thought to be the most comprehensive data ever obtained on either virgin or re-refined lubricating basestocks, and has been used extensively by NBS in the evaluation of tests for re-refined oil basestock consistency [2]. In addition, these stocks of oils have provided a number of re-refined oils for use by ASTM technical committees as samples of re-refined oils for round-robin studies of individual test procedures.

Grateful acknowledgement is made to all of the manufacturers, analysis laboratories, and coordinators have contributed so much to this study. The work of the NBS Tribochemistry Group for the logistics and data evaluation is particularly appreciated. It is hoped that all of the tremendous effort represented here will be useful to many people for multiple purposes.

\section{References}

[1]. Weeks, S. J., Becker, D. A., Hsu, S. M. ASTM/NBS basestock consistency study data, NBSIR 83-2707, Nat. Bur. Stand. (U.S.) Washington, DC 20234; 1983. (Also to be published as NBS Special Publication 661 and DOE Report No. DOE/BC/10749).

[2]. Becker, D. A., Hsu, S. M. NBS provisional tests for re-refined engine oil, Proceedings, Measurements and Standards for Recycled 0i1-IV, Nat. Bur. of Stand. (U.S.) Spec. Pub1. 674; 1983.

$\overline{1}$ Figures in brackets indicate literature references at the end of paper. 
TABLE OF CONTEITS

Foreword (ivational Bureau of Standards)

Page

Foreword (merican Society for Testing and Materials)-.........

1. THE ASTM/NBS SASESTOCK CONSISTENCY STUDY

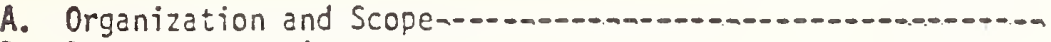

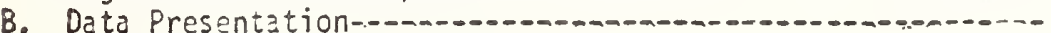

11. RHEOLOGY

A. Kinematic Viscosity at $40{ }^{\circ} \mathrm{C}$ and $100{ }^{\circ} \mathrm{C}$

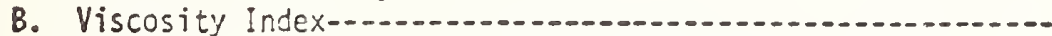

C. Low-Temperature Viscosity by Brookfield Viscometer-.......

D. Apparent Viscosity by Cold Cranking Simulator-.............

E. Critical Starting Temperature by Cold Cranking Simulator--

F. Borderline Pumping Temperature by Mini-rotary Viscometry--

III. PHYSICAL PROPERTIES-

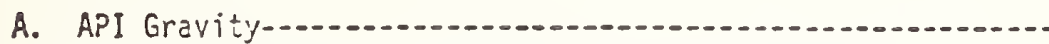

B. Boiling Rança Distribftion by Gas Chroriatocraphy...........

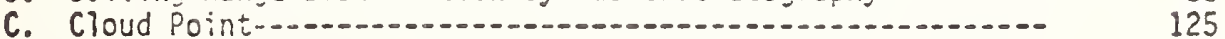

D. Pour Pcint-_....... 128

E. Color-1... 131

F. Fire Point-.....

G. Flash Point-_. 140

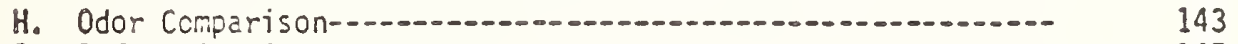

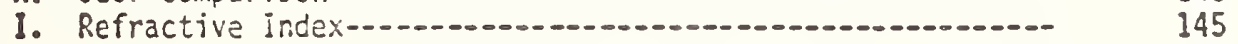

IV. CHEMICAL PROPERTIES-_...

A. Carbonyl, Nitrates, Tertiary Carbon and P-0-C Ábscrption

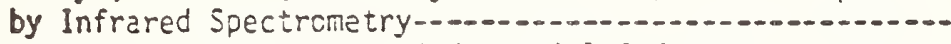

B. Carbonyl and Nitrates by Differential Inirared

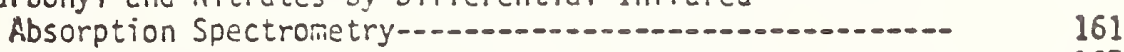

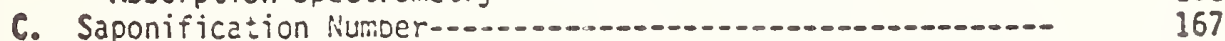

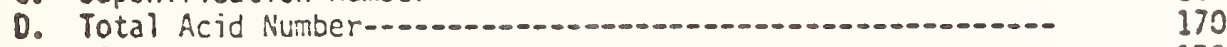

E. Nitrogen-1..... 173

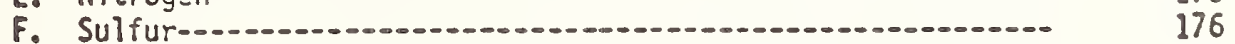

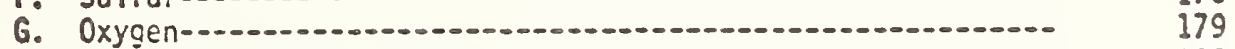

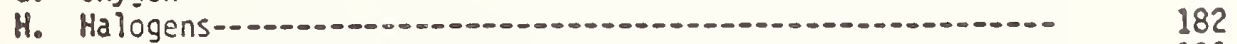

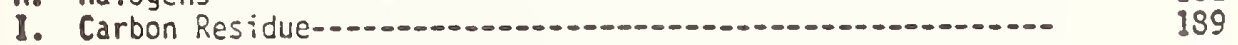

J. Water-........... 192

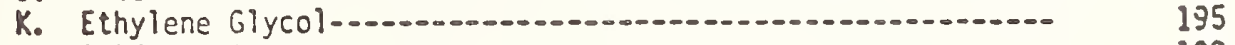

L. Suliated Ash-..._. 198

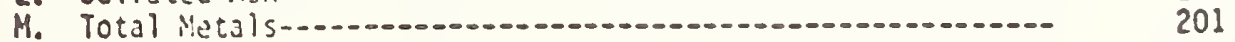

N. Metals-15.0. 204

0. Silicon-1..... 216 


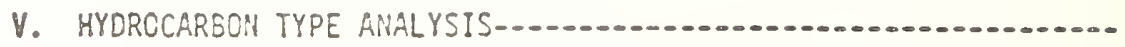

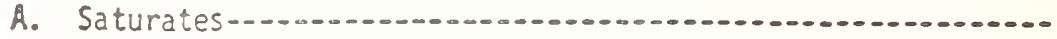

B. Aromatics by LC, TLC, UV, MS, and Extrection-...............

1. Monoaromatics-.............................................

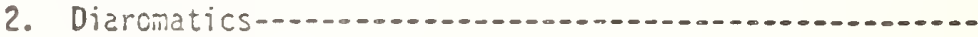

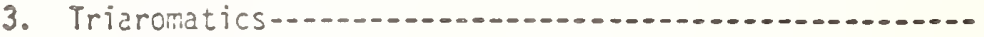

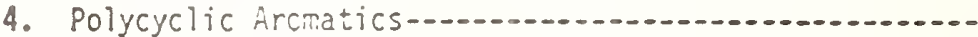

5. Poiycyclic Arcmatics and Polars-_........................

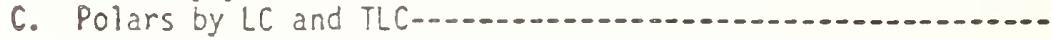

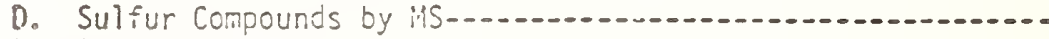

E. Isoprenoid Ratio by nmr-...........................................

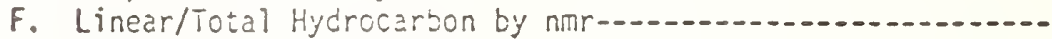

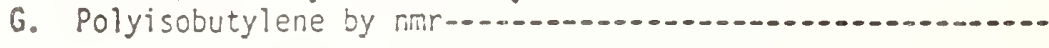

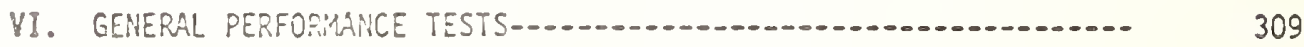

A. Demulsibility-......................................... 310

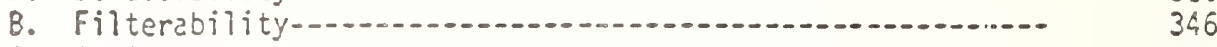

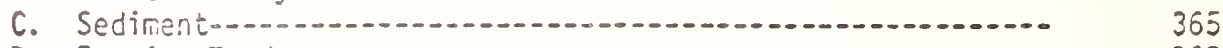

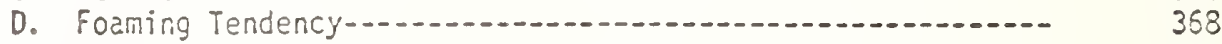

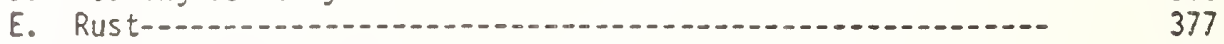

F. High Iemperature Copper Corrosion-........................ 383

G. CD/SE Additive Compatability-.............................. 384

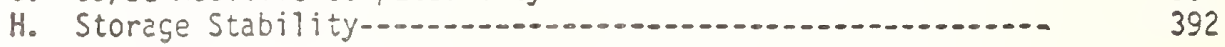

VII. OXIDATIOH AIID WEAR BENCH TEST PERFOR'HANCE.................... 402

A. Rotary Bomb Oxidation Test (REOT) -...................... 403

B. Turbine 0ii Oxidetion Stability Test (TOST).............. 409

C. Antioxidant Capacity-................................ 412

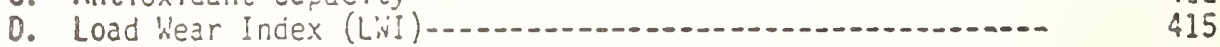

E. Differential Scanning Calorimetry-....................... 418

F. Lubricant Themal Oxidation Test (LUSTOT) -................ 427

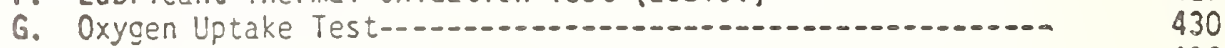

H. Sequence III Simulator-..................................... 436

APPENDIX I Sample Numbering System and Data Table for Repeated Samples-.-.-...................... 439

APPENDIX II Test ":ethods and Sumaries-..................... 449 APPENDI $\ddot{x}$ III Additional Data................................... 489

ACKYONL EDGEMENT-_. . . . . 


$$
\begin{aligned}
& \text { Cooperating Laboratories } \\
& \text { ASTM/NiS 3ase Stcek Corsistency Study }
\end{aligned}
$$

Bartlesville Energy Mechical Center Chevron USA Filmite Oil Corporation Gulf Reserrch ard Development Cozoration. Lubrizol Corporation Meradcor (U.S. Army)

Mobil Research and Developuent Corgozation Motor Oils Refining Corpany National 3ureau of StardardsNatioral Reseazch Courcil of carada: Savast, Inc. Shell Research Itd. (Thornton) Suntech Group Texaco, Inc. 
Appendix III

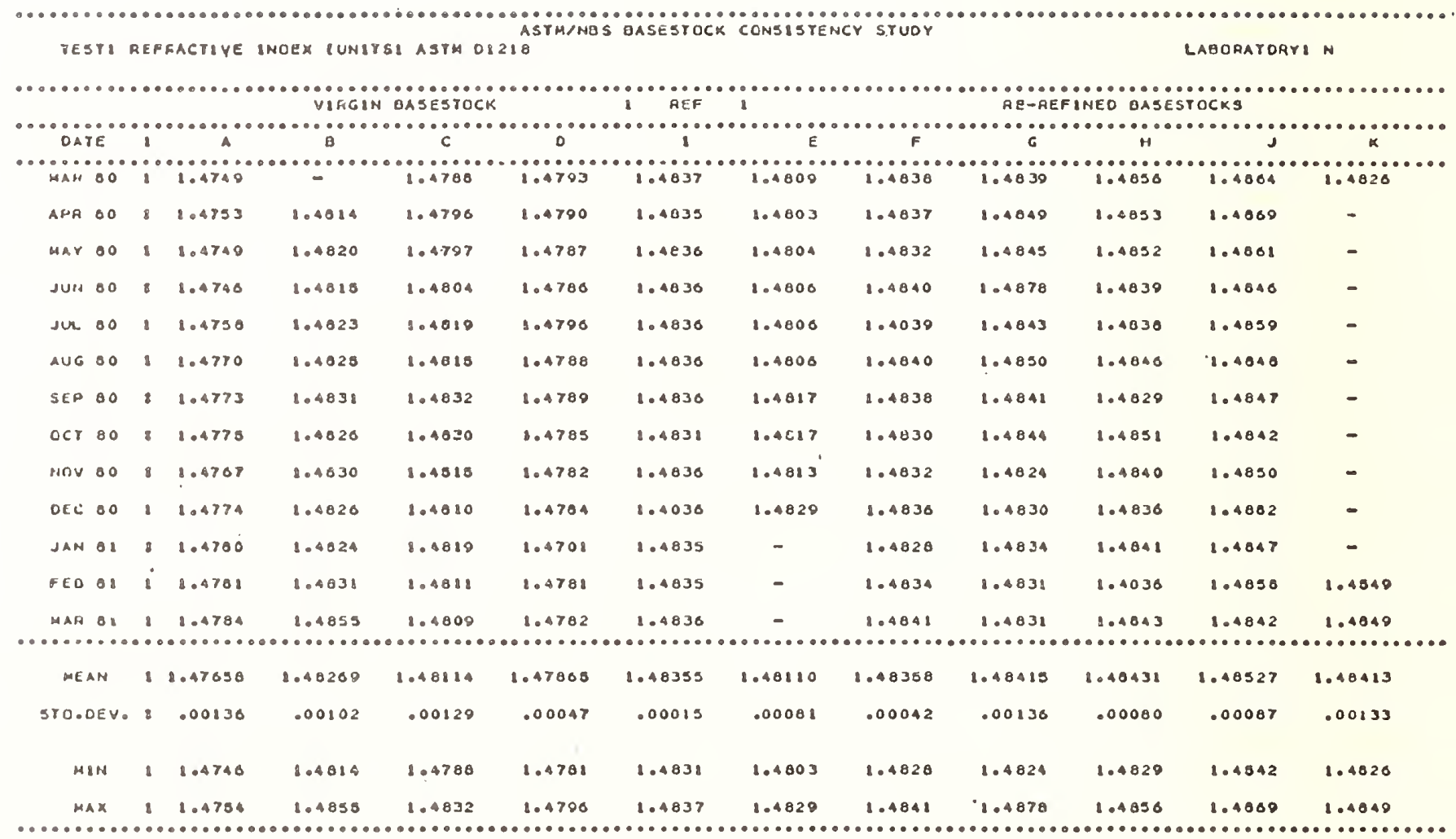


REFRACTIVE INDEX

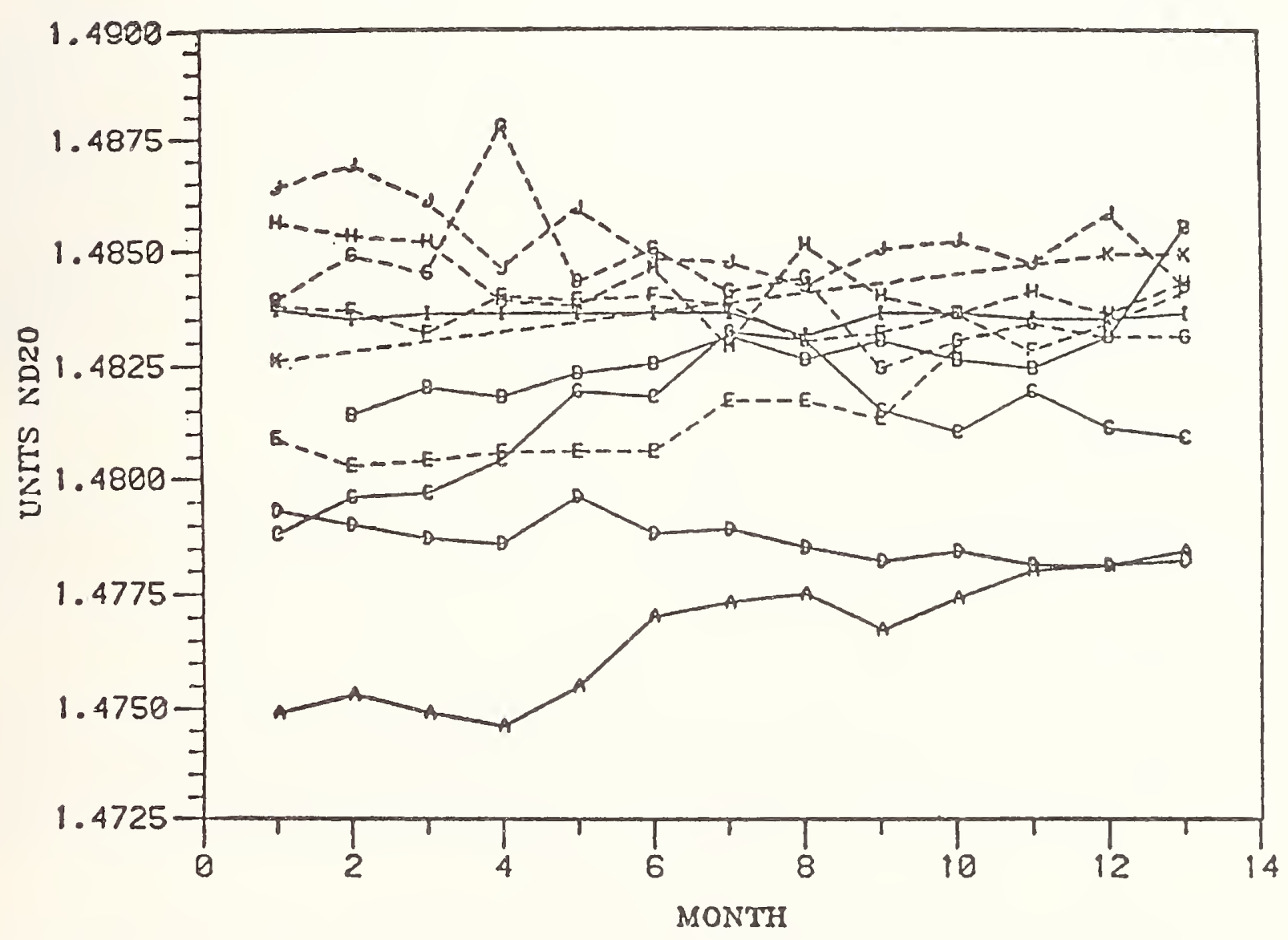


REFRACTIVE INDEX

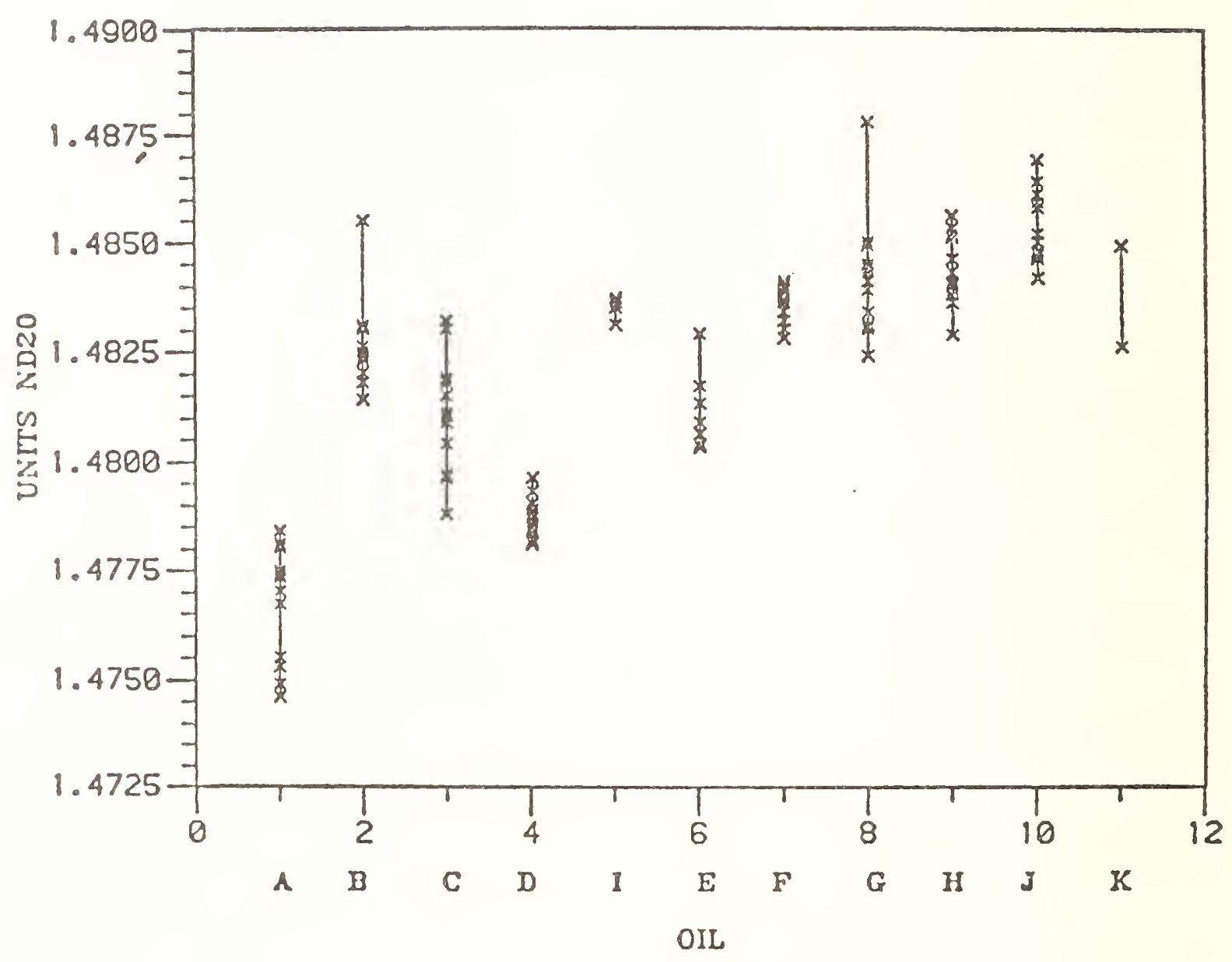


National Bureau of Standards Special Publication 674. Procesdings, Conference on Measurements and Standards for Recycled 0il - IV, held at NBS, Gaithersburg, MD, September 14-16, 1982.

(Issued July 1984).

MULTIPLE REGRESSION ANALYSIS: A LOOK INSIDE THE ASTM/NBS BCS DATA

S. J. Weeks and S. M. Hsu

Chemical Stability and Tribology Group

National Bureau of Standards

Washington, DC 20234

\section{ABSTRACT}

The ASTM/NBS Basestock Consistency Study was designed to assess the consistency of re-refined lubricating basestocks. Historically, the quality of a lubricant is defined by the ASTM engine sequence tests. For virgin base oils, the crude source and refining process are required to remain constant for quality control of the finished product. Concerns arose over the variability of the base oil when used oils were used as the feedstock for re-refining. These concerns necessitated a new evaluation of the consistency criteria for re-refined oils.

The goal of the BCS work was to assess the consistency of re-refined base oils in comparison to corresponding characteristics of virgin base oils. The BCS compiled data of samples submitted monthly from four virgin and six re-refined base oil products. These samples were analyzed over a 13 month period by 14 cooperative laboratories. Over 55 tests were performed on 132. samples. Many tests had multiple data entries and some tests were performed by more than one laboratory. The test data and preliminary statistical information can be found in references [1] and [2] ${ }^{1}$. The tests were grouped into six categories: (1) rheology; (2) physical properties; (3) chemical properties; (4) hydrocarbon type analyses; (5) general performance tests, and (6) oxidation and wear bench tests. Statistical methods were used to evaluate the significance of the BCS data.

Assessment of re-refined base oils in comparison to virgin base oils required that data sets be examined both separately and jointly. Therefore, both univariate and multivariate statistical methods were used. The BCS data were examined for features such as location, dispersion, randomness, distribution, collinearity, outliers, leverage points, and nonlinearity $[3,4]$. These results showed the average values of re-refined base $0 i 1$ properties and indicated how much these values could be expected to vary in production over an extended period.

The descriptive univariate statistics determined the mean, dispersion, range, and distribution characteristics of the individual test results. Deviations from test means, time sequences, and distribution plots (vs. base oil producer) were subsequently generated for purposes of intercomparison. Bivariate analysis (e.g., cross correlation coefficient) was used to identify highly correlated test results so that the data could be reduced to a set of linearly independent test methods. Multivariate analysis (e.g., principal component analysis) was used to further investigate test interdependencies.

Sample consistency was evaluated using graphical analysis (deviation from mean plots), extreme value selection by statistical stripping methods, rank-sum analysis and cluster analysis. Using these statistical methods, criteria for identifying inconsistent samples were developed. Finally, the correlation of the performance test results with the base oil characteristics was investigated using multiple linear regression analysis $[3,4]$. Transformations of variables were used whenever appropriate to normalize variable distributions, to investigate nonlinear effects, and to enhance the explanatory power of the regression model.

\section{References}

[1] Becker, D. A.; Hsu, S. M.; Weeks, S. J. Lubricating oil basestock data and analysis: Based on the ASTM-NBS basestock consistency study; DOE Report No. DOE/BC/107949-2; U.S. Department of Energy 1983.

IFigures in brackets indicate the literatures references at the end of this paper. 
[2] Weeks, S. J.; Becker, D.A.; Hsu, S. M. ASTM/NBS basestock consistency study data, NBS Spec. Publ 661; 1983.

[3] Weeks, S. J.; Hsu, S. M. Development of consistency criteria for recycled lubricating oil basestocks (submitted for publication).

[4] Weeks, S. J.; Hsu, S. M. A critical assessment of lubricating basestock parameters for quality and consistency, ACS, Division of Petroleum Chemistry Symposium Preprint, 188th National ACS Meeting, August 26-31, 1984, Philadelphia, PA. 
National Bureau of Standards Special Publication 674. Proceedings, Conference on Measurements and Standards for Recycled 0i1 - IV, held at NBS, Gaithersburg, MD, September 14-16, 1982.

(Issued July 1984).

\section{THE CONSISTENCY OF VIRGIN BASESTOCKS}

Herbert S. Golinkin

Amoco Chemicals Corporation

P. O. Box 400

Naperville, Illinois 60566

The two main areas of concern in discerning the equivalency of re-refined and virgin lubricants are the establishment of criteria for evaluating re-refined and virgin basestocks, and the determination of variances that can be tolerated. As a supplier of additives to the lubricant industry, Amoco Chemicals Corporation receives many basestock samples each year. This paper will attempt to show the limits of variability observed for six broad viscosity grades of virgin basestocks over a seven-year period. Certain trends over this period are indicated. Single basestock variability from three suppliers will also be examined.

\section{Introduction}

The primary areas of concerns in establishing the equivalency of re-refined and virgin lubricants are the determination of criteria for evaluating equivalency, and the variances in these criteria that can be tolerated. A major step in the acceptance of re-refined lubricants was the issuance of MIL-L-46152B which allows the use of re-refined basestocks. This specification requires that certain properties of the basestocks be stated for both re-refined and virgin materials used in a formulation. These properties are expected to be consistent over the four-year life of the LRI approval.

As a supplier of additives to the lubricant industry, Amoco receives fifty to one hundred basestock samples per year. In addition to the LRI required inspections (table 1), analyses are conducted which help formulate finished lubricants (table 2). This paper will attempt to show the limits of variability in these various properties for six broad viscosity grades of virgin basestocks as observed over a seven-year period, 1975 through 1981.

\section{Experimental}

The inspections required by the LRI (table 1 ) have been obtained by the methods described in the MIL-L-46152B specification. Those not falling under the specification were obtained as indicated in table 2. The mass spectroscopic analysis for hydrocarbon type sees only the volatile portion of the basestock. This is approximately the same part that is observed in the simulated distillation. Up to $250 \mathrm{~N}$, the entire basestock is examined. Some of the heavier base stocks are completely volatilized, but progressively less material is observed. For these the hydrocarbon type analysis is more of a fingerprint than a quantitative distribution.

\section{Results}

The neutral basestocks have been divided into six broad categories by viscosity grade (table 3). Over the seven-year period, 222 samples that fall into these six categories were analyzed. To depict the trends of the nineteen variables for each basestock, over 4000 pieces of data are needed. In order to simplify the presentation, industry trends are shown in figures 1 through 19.0 One year averages for each variable were determined within each category, and standard deviations for these averages obtained. A range of two standard deviations was plotted for each year, and an envelope drawn about the seven ranges. These curves show the variability observed for a given parameter, and the trend, if any, over the seven-year period. This method gives rise to 114 graphs depicting trends for basestock properties within the industry. The wide range of variation apparent in each parameter is the result of differences in basestocks between suppliers. It should not be taken as a measure of the ability to control the quality of any single product. The gyrations of the envelopes from year to year are due, in part, to sampling variations. Not all suppliers' products were sampled at the same frequency, nor were they all sampled each year. Although indicating the typical properties of basestocks that can be expected, these curves do not indicate the ability of individual 
suppliers to control the quality of basestocks with respect to these characeristics. To fill this gap, table 4 shows the mean values and standard deviations for nominal $100 \mathrm{~N}$ basestocks from three refiners.

Table 1. Lubricant review intitute requirements

\begin{tabular}{|c|c|c|}
\hline • & Viscosities at $40^{\circ} \mathrm{C}$ and $100^{\circ} \mathrm{C}$ & 0445 \\
\hline - & Viscosity Index & D2270 \\
\hline - & API Gravity & 0287 \\
\hline - & Pour Point & D97 \\
\hline - & Carbon Residue & D524 \\
\hline - & Chlorine & $x$-ray fluorescence \\
\hline • & Sulfur & 02622 \\
\hline - & Color & D1500 \\
\hline • & Sulfated Ash & D874 \\
\hline • & Total Acid Number & D664 \\
\hline . & Saponification Number & D94 \\
\hline 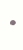 & Nitrogen & D3228 \\
\hline & Boiling Point Distribution & D2887 \\
\hline & $1 \%$ point & \\
\hline & $5 \%$ point & \\
\hline & $10 \%$ point & \\
\hline & $50 \%$ point & \\
\hline & $90 \%$ point & \\
\hline
\end{tabular}

Table 2. Basestock characterizations

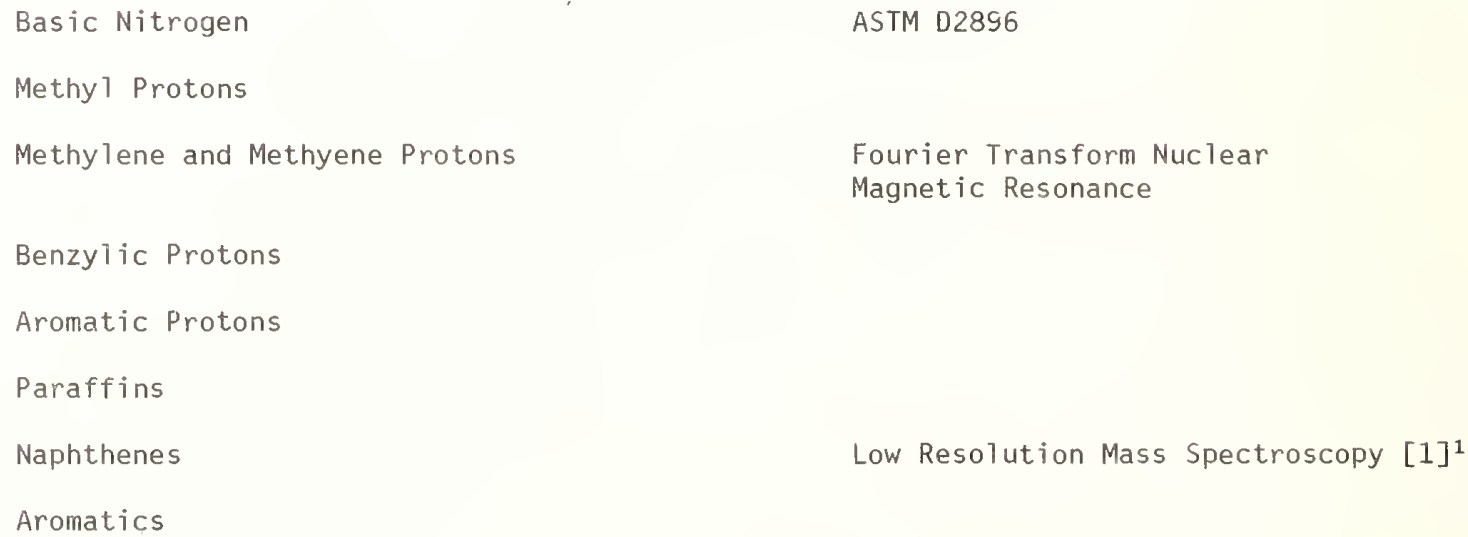

\footnotetext{
${ }^{1}$ Figures in brackets indicate the literature references at the end of this paper.
} 
Table 3. Viscosity classification

Nominal Viscosity
Classification

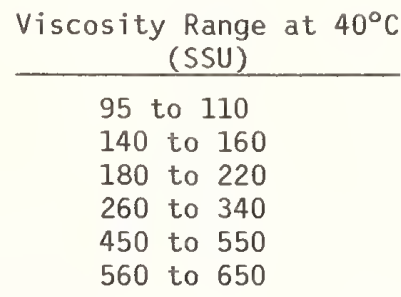

Table 4. Consistency of $95-110 \mathrm{~N}$ basestocks ${ }^{\mathrm{a}}$

Company
Viscosity, cSt
$40^{\circ} \mathrm{C}$
$100^{\circ} \mathrm{C}$
Viscosity Index
API Gravity
Rambottom
Carbon, \%
Sulfated Ash, \%
Nitrogen, ppm
Basic Nitrogen, ppm
Bromatic
Sulfur, ppm
Proton Distribution, \%
Mistilation Points, ${ }^{\circ} \mathrm{F}$

Hydrocarbon Distribution, \% Paraffins

Naphthenes

Aromatics

\section{A}

20.93

0.89

4.07

0.12

88

8

31.8

0.4

0.043

0.046

0.003

0.009

37

18

30

13

3934

1795

606

31

643

26

753

7

29.0

0.7

64.9

1.3

4.8

0.7

1. 2

0.3

26.5

3.3

54.8

4.7

18.6

2.2
B

C

21. 70

20. 18

0.61

2. 12

4.20

0.26

0.11

102

94

32.6

32.5

0.4

0.6

0.064

0.071

0.013

0.018

12

10

11

11

146

161

605

13

658

13

760

10

30.1

1.4

1. 2

65.8

1.2

1.1

3. 4

4.8

0.7

0.9

1. 3

0.7

0.2

28. 7

3.3

25.8

3.8

53.2

5. 3

61.1

5. 7

13. 1

18. 1

3. 3

a The first number is the value of the property, the second number is the standard deviation of that value. 


\section{Discussion}

The viscosities at $40{ }^{\circ} \mathrm{C}$ (fig. 1) and $100{ }^{\circ} \mathrm{C}$ ( fig. 2), are the most constant of the properties observed. Since these are the basis upon which gas oil cuts are made to produce lubricant basestocks, this constancy is not surprising. It is controlled by the refining process and not the crude feed.

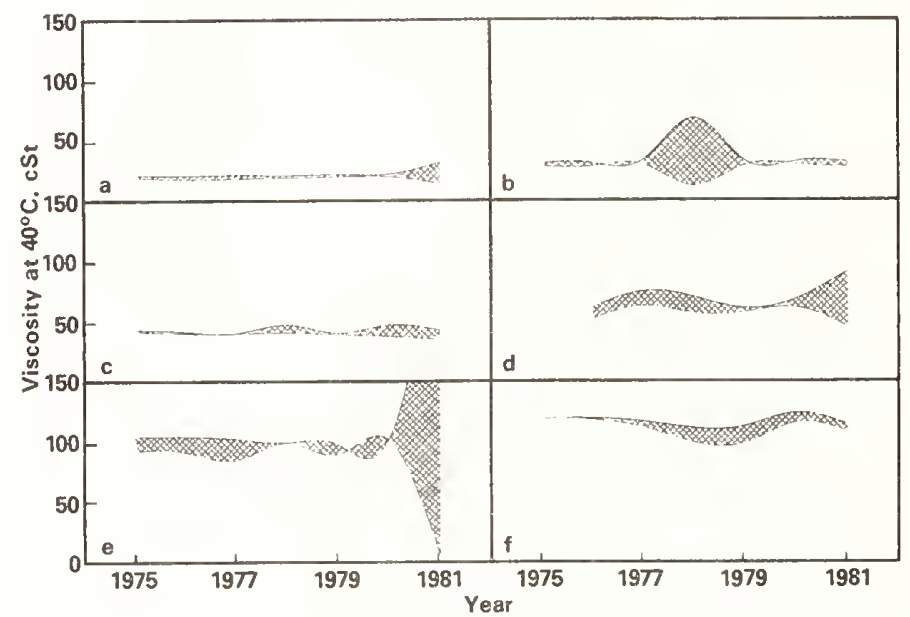

Figure 1. Kinematic viscosity a $40{ }^{\circ} \mathrm{C}$, cSt. a) $100 \mathrm{~N}$; b) $150 \mathrm{~N}$; c) $200 \mathrm{~N}$; d) $300 \mathrm{~N}$; e) $500 \mathrm{~N}$; f) $600 \mathrm{~N}$.

The viscosity index depends upon both the refining process and the crude feedstock. Higher viscosity indices have been associated with higher paraffin content, but the correlation coefficient between these properties is only 0.2. The breadth of VI values for the $100 \mathrm{~N}$ and $150 \mathrm{~N}$ basestocks (fig. 3) can be attributed in part to small errors in viscosity determination. An error in the $100{ }^{\circ} \mathrm{C}$ viscosity of a $100 \mathrm{~N}$ basestock can alter the observed viscosity index by six units (table 5).

API gravity is shown in figure 4. Except for the $150 \mathrm{~N}$ and $200 \mathrm{~N}$ categories, there has been a slight trend toward reduction of the API gravity with time. This may indicate a reduction in the extent to which the gas oil cuts are further refined either by solvent extraction or hydrotreating.

The Ramsbottom carbon, shown in figure 5, appears to have reached peak levels between 1978 and 1980. Sulfated ash has been determined only since the inauguration of MIL-L-46152B in 1979 . The data (fig. 6) indicate a definite reduction in metals content over the three-year period paralleling the Ramsbottom carbon trend. However, there is no direct correlation between these properties (correlation coefficient $=-0.06$ ).

Nitrogen levels shown in figure 7 undergo fairly large fluctuations with time which can be due to variations in crude or to the extent of hydrotreating and solvent extraction. Basic nitrogen (fig. 8 ) is the TBN of the basestock expressed as nitrogen ( 1 TBN $=250 \mathrm{ppm} \mathrm{N}$ ). This assumes that the basicity is due only to compounds such as amines, pyridenes, quinolines and the like.

The increased use of sour crude in refining operations in recent years is expected to result in higher levels of sulfur in the finished product. Figure 9 shows that this expectation is unrealized. Only the $300 \mathrm{Ns}$ show such a trend, although a hint of increasing sulfur levels is afforded by the 600Ns since 1978 . 


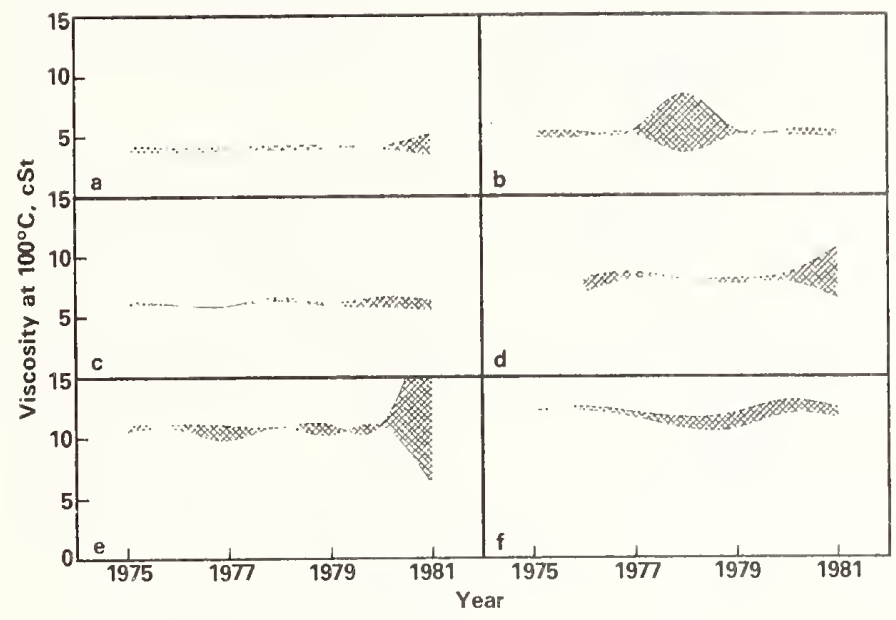

Figure 2. Kinematic viscosity at $100{ }^{\circ} \mathrm{C}$, cSt. a) $100 \mathrm{~N}$; b) $150 \mathrm{~N}$; c) $200 \mathrm{~N}$; d) $300 \mathrm{~N}$; e) $500 \mathrm{~N}$; f) $600 \mathrm{~N}$.

The one percent, 5 percent, and 50 percent distillation points are displayed in figures 10 through 12. The heavier neutrals show increasing front end volatility since 1979 , but the midpoint has remained fairly constant.

Nuclear magnetic resonance provides an intimate view of the molecular environment. Figure 13 shows a constant level of methyl protons independent of the viscosity grade. Except for the $600 \mathrm{Ns}$, the methylene and methyne (fig. 14) and benzylic (fig. 15) proton levels are also constant. The aromatic protons (fig. 16) show a slight increase with time (most noticeable for the 150 , 500, and 600 neutrals), but smaller than the variability in that property.

The hydrocarbon type analysis demonstrates a steady trend toward increasing levels of paraffins (fig. 17), accompanied by a decreasing level of naphthenes (fig. 18). The aromatics content is virtually flat (fig. 19). Hydrotreating increases naphthenic levels which implies that hydrotreating may be coming less important.

The trends observed with the basestocks we receive can be taken as industry wide trends only if the samples are representative of existing production at the time. Since these samples extend over a large number of refiners, there is no reason to doubt that these trends are real.

The data in table 4, which is limited to three refiners, shows the control that is maintained over individual products. In each case, the variation is smaller than indicated by figures 1 through 19. In terms of the LRI inspections, there appears to be very little to differentiate the products from these companies except for the lower sulfur content in Company C's product. However, Company C's product is higher in naphthenes and lower in aromatics than the other two.

\section{Conclusions}

On an industry wide basis, various trends in basestock properties are apparent over the seven-year period between 1975 and 1981. However, the wide range encompassed for each of these properties approximates the magnitude of the observed change. Only the reduction in sulfated ash during the period $1979-1982$ is larger than the breadth of values for any given year. A close look at single products by refiner might be expected to reduce the breadth of property values, and emphasize the observed trends. However, for three nominal $100 \mathrm{~N}$ basestocks, the variability in product is quite small. 


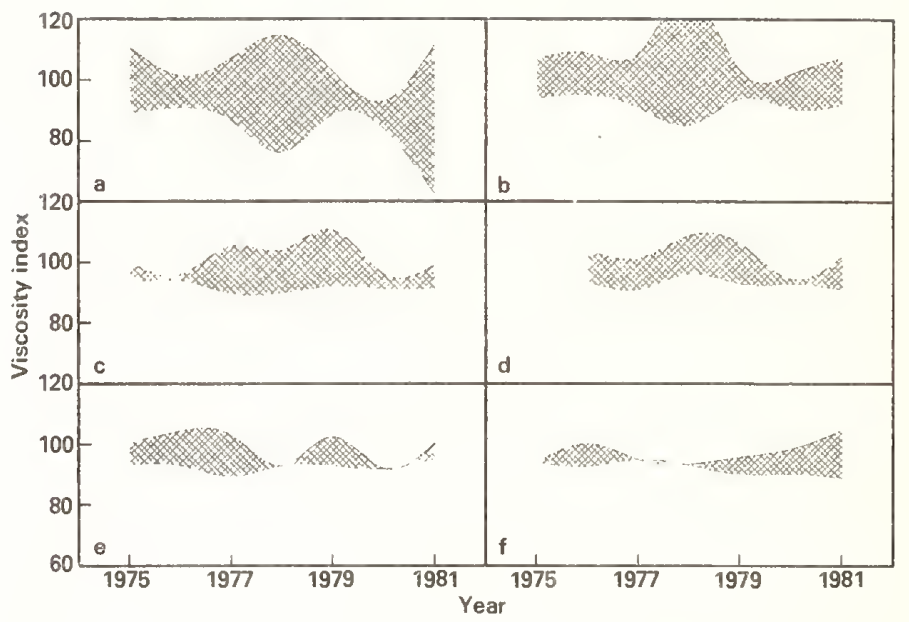

Figure 3. Viscosity index. a) $100 \mathrm{~N}$; b) $150 \mathrm{~N}$; c) $200 \mathrm{~N}$; d) $300 \mathrm{~N}$; 3) $500 \mathrm{~N}$; f) $600 \mathrm{~N}$.

Table 5. Viscosity index of a $100 \mathrm{~N}$ basestock (Viscosity at $40^{\circ} \mathrm{C}=19.19 \mathrm{cSt}$ )

\section{Viscosity at $100^{\circ} \mathrm{C}$, cSt}

3.95

3.91

3.87
Viscosity Index

100

94

88

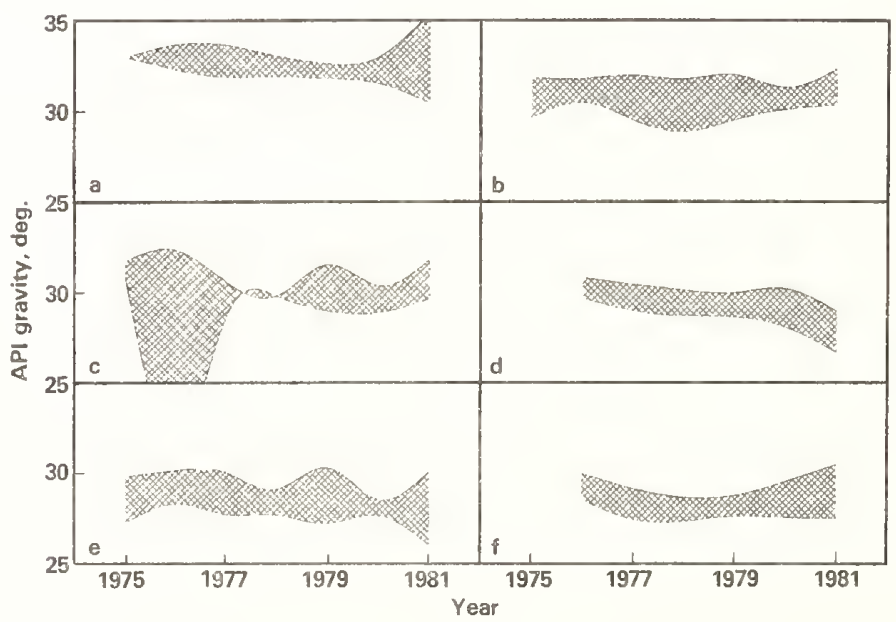

Figure 4. API gravity. a) $100 \mathrm{~N}$; b) $150 \mathrm{~N}$; c) $200 \mathrm{~N}$; d) $300 \mathrm{~N}$; e) $500 \mathrm{~N}$; f) $600 \mathrm{~N}$. 


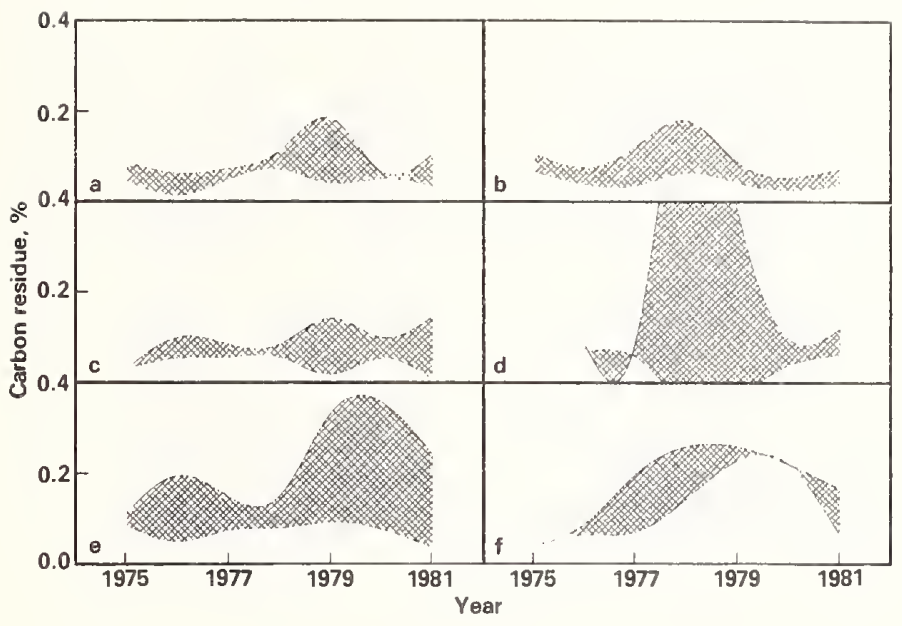

Figure 5. Ramsbotton carbon, \%. a) $100 \mathrm{~N}$; b) $150 \mathrm{~N}$; c) $200 \mathrm{~N}$; d) $300 \mathrm{~N}$; 3) $500 \mathrm{~N}$; f) $600 \mathrm{~N}$.

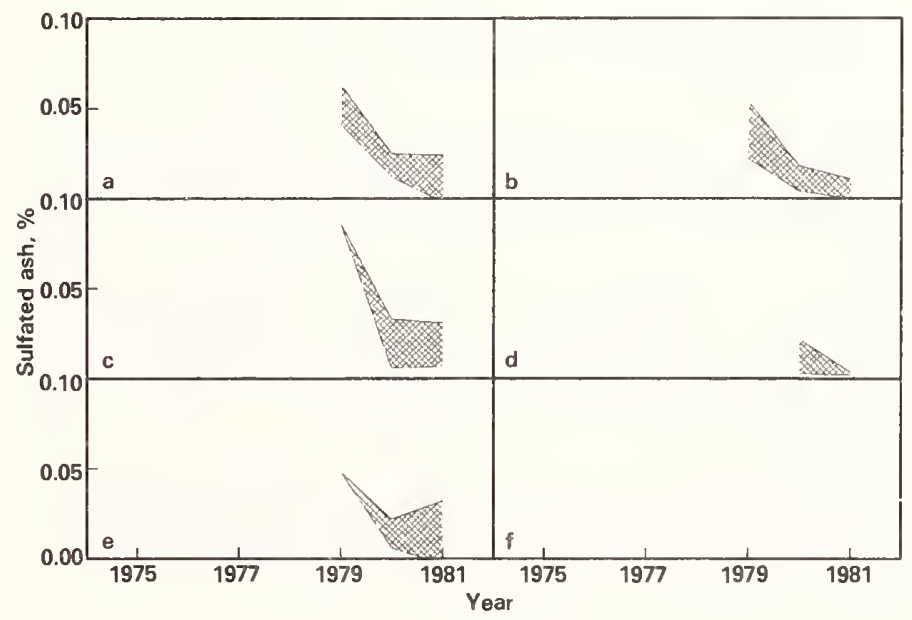

Figure 6. Sulfated ash \%. a) $100 \mathrm{~N}$; b) $150 \mathrm{~N}$; c) $200 \mathrm{~N}$; d) $300 \mathrm{~N}$; e) $500 \mathrm{~N}$; f) $600 \mathrm{~N}$. 


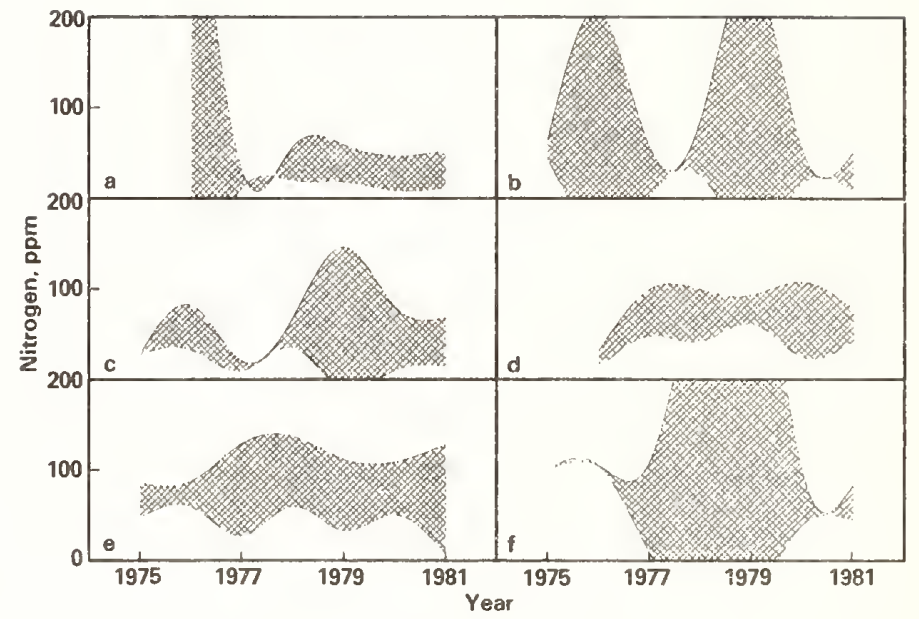

Figure 7. Nitrogen, ppm. a) $100 \mathrm{~N}$; b) $150 \mathrm{~N}$; c) $200 \mathrm{~N}$; d) $300 \mathrm{~N}$; e) $500 \mathrm{~N}$; f) $600 \mathrm{~N}$.

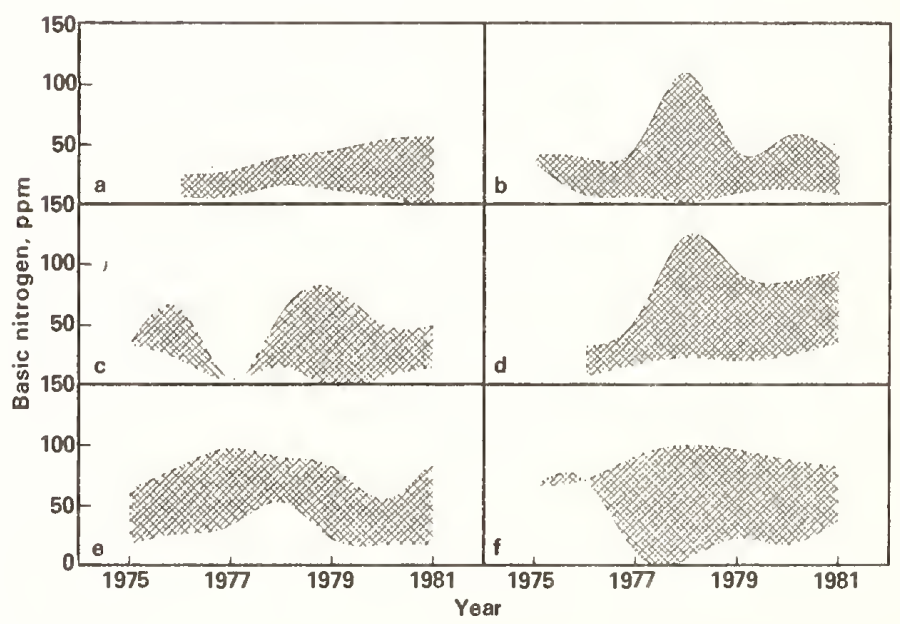

Figure 8. Basic nitrogen, ppm. a) $100 \mathrm{~N}$; b) $150 \mathrm{~N}$; c) $200 \mathrm{~N}$; d) $300 \mathrm{~N}$; e) $500 \mathrm{~N}$; f) $600 \mathrm{~N}$. 


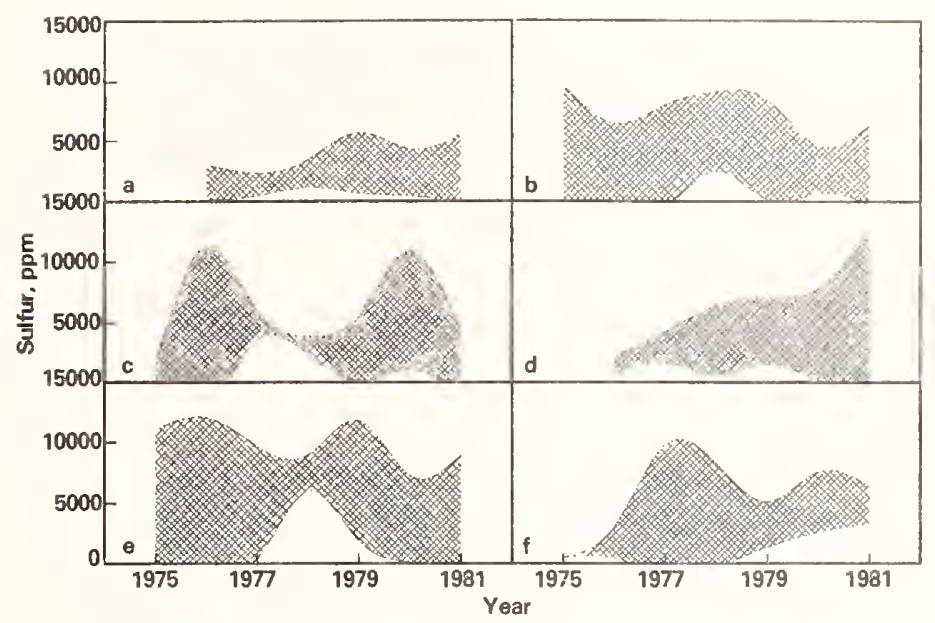

Figure 9. Sulfur, ppm. a) $100 \mathrm{~N}$; b) $150 \mathrm{~N}$; c) $200 \mathrm{~N}$; d) $300 \mathrm{~N}$; e) $500 \mathrm{~N}$; f) $600 \mathrm{~N}$.

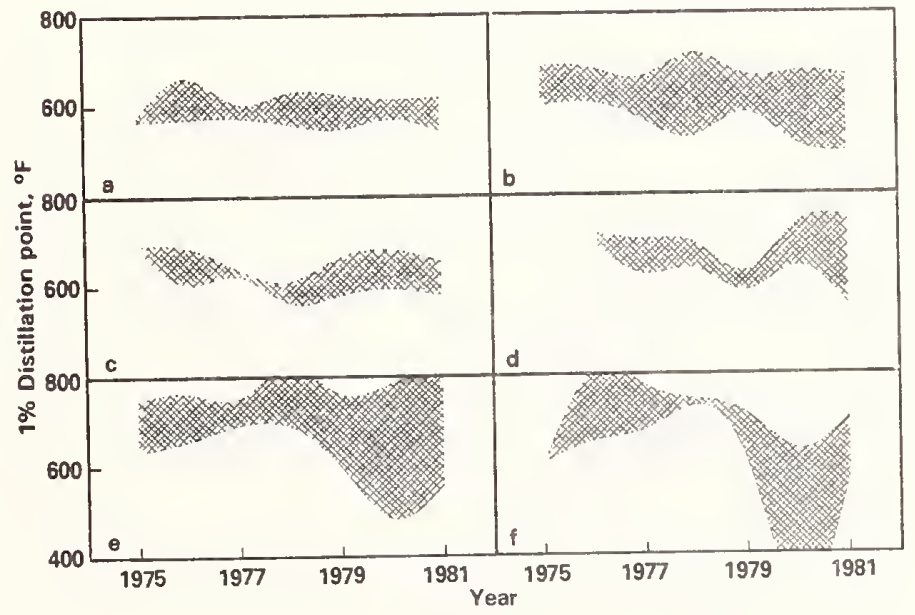

Figure 10. $1 \%$ distillation point, ${ }^{\circ} \mathrm{F}$. a) $100 \mathrm{~N}$; b) $150 \mathrm{~N}$; c) $200 \mathrm{~N}$; d) $300 \mathrm{~N}$; e) $500 \mathrm{~N}$; f) $600 \mathrm{~N}$. 


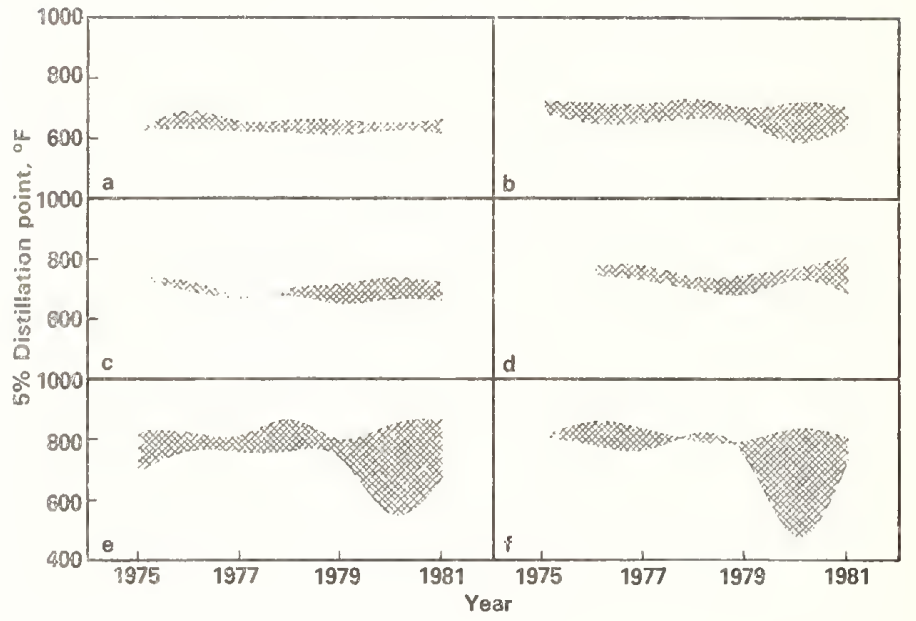

Figure $11.5 \%$ distillation point, ${ }^{\circ} \mathrm{F}$. a) $100 \mathrm{~N}$; b) $150 \mathrm{~N}$; c) $200 \mathrm{~N}$; d) $300 \mathrm{~N}$; e) $500 \mathrm{~N}$; f) $600 \mathrm{~N}$.

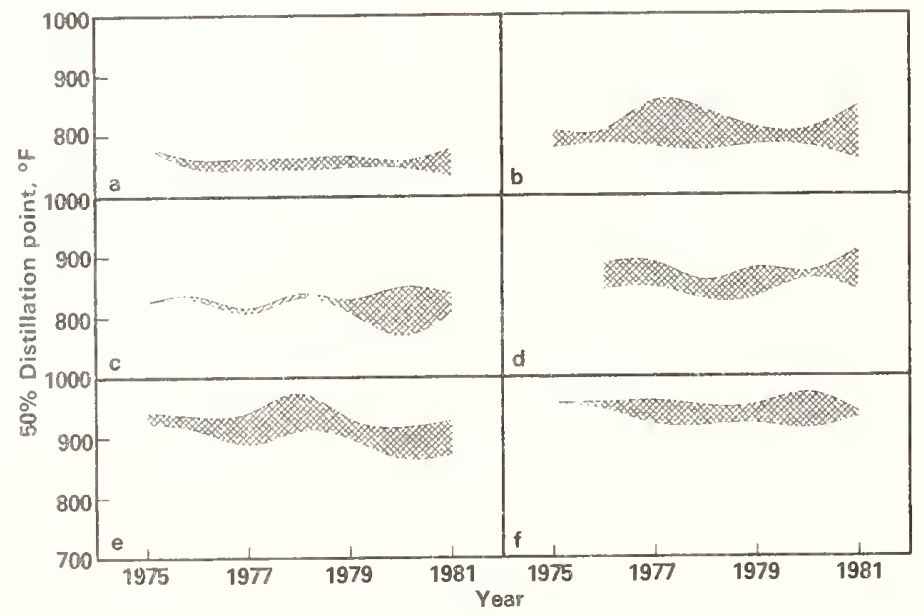

Figure 12. $50 \%$ distillation point, ${ }^{\circ} \mathrm{F}$. a) $100 \mathrm{~N}$; b) $150 \mathrm{~N}$; c) $200 \mathrm{~N}$; d) $300 \mathrm{~N}$; e) $500 \mathrm{~N}$; f) $600 \mathrm{~N}$. 


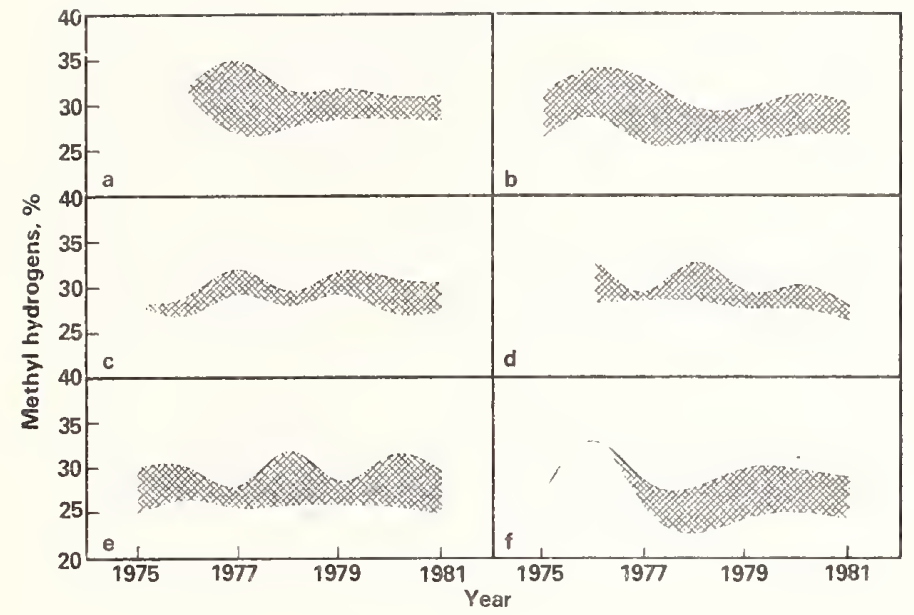

Figure 13. Methyl hydrogens, \%. a) $100 \mathrm{~N}$; b) $150 \mathrm{~N}$; c) $200 \mathrm{~N}$; d) $300 \mathrm{~N}$; e) $500 \mathrm{~N}$; f) $600 \mathrm{~N}$.

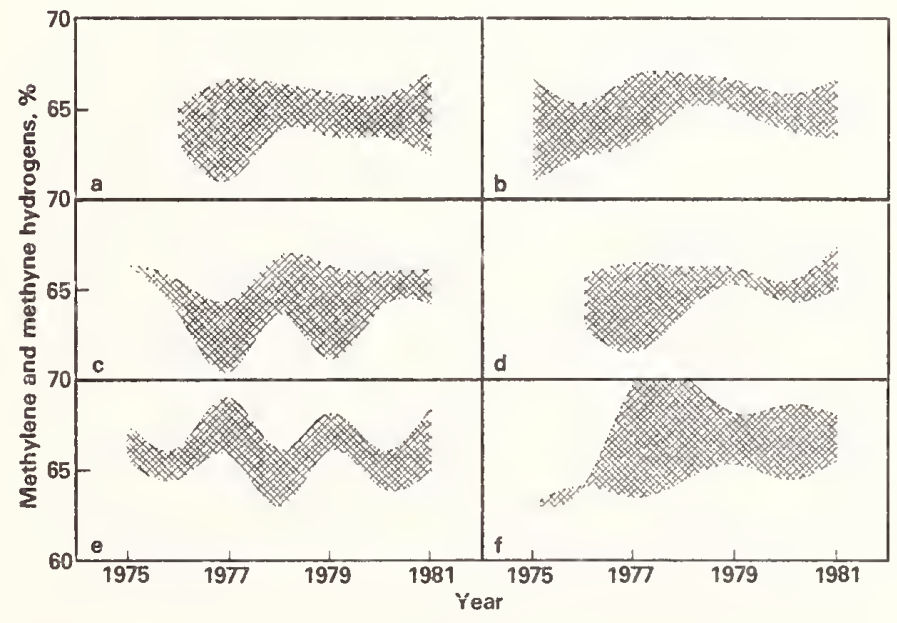

Figure 14. Methylene and methyne hydrogens, \%. a) $100 \mathrm{~N}$; b) $150 \mathrm{~N}$; c) $200 \mathrm{~N}$; d) $300 \mathrm{~N}$; e) $500 \mathrm{~N}$; f) $600 \mathrm{~N}$. 


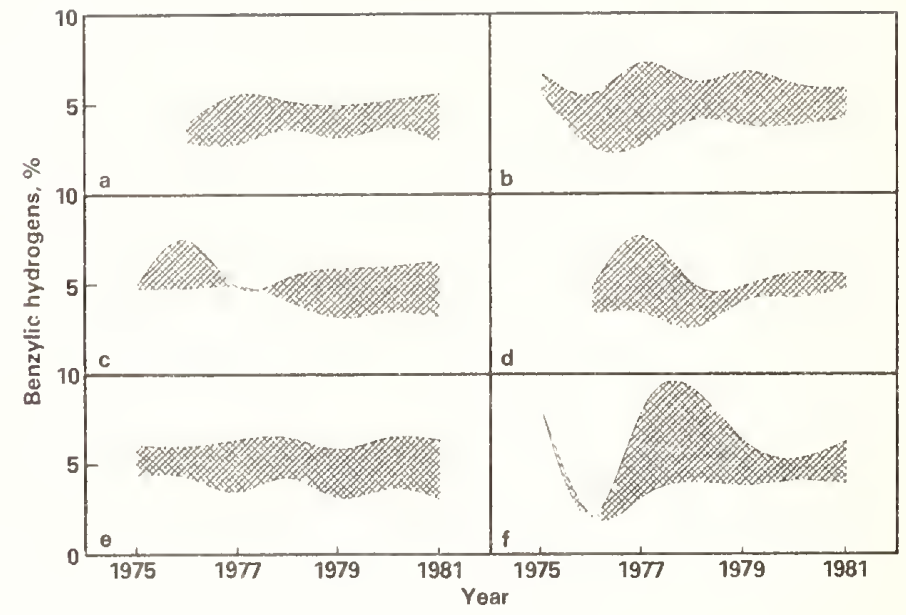

Figure 15. Benzylic hydrogens, \%. a) $100 \mathrm{~N}$; b) $150 \mathrm{~N}$; c) $200 \mathrm{~N}$; d) $300 \mathrm{~N}$; e) $500 \mathrm{~N}$; f) $600 \mathrm{~N}$.

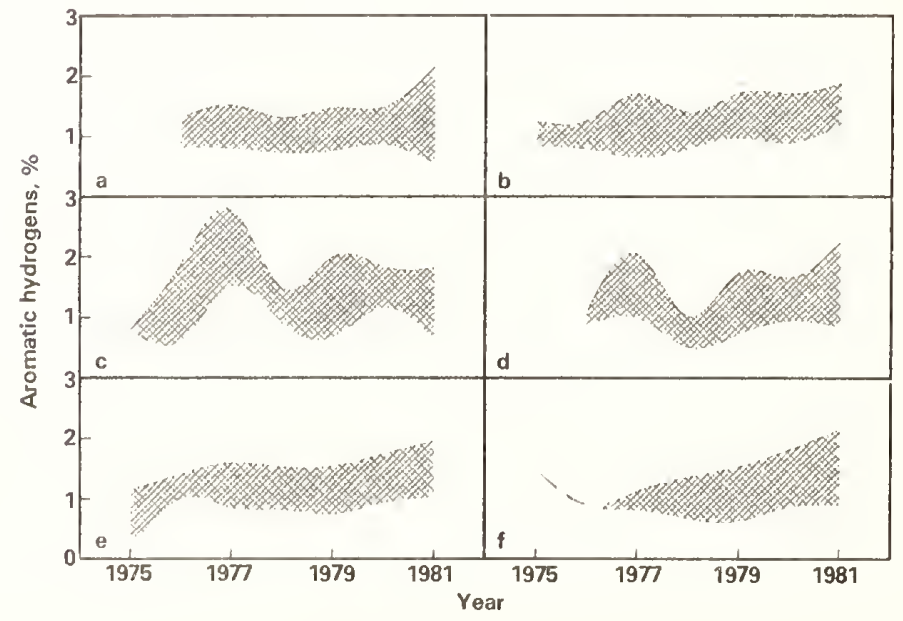

Figure 16. Aromatic hydrogens, \%. a) $100 \mathrm{~N}$; b) $150 \mathrm{~N}$; c) $200 \mathrm{~N}$; d) $300 \mathrm{~N}$; e) $500 \mathrm{~N}$; f) $600 \mathrm{~N}$. 


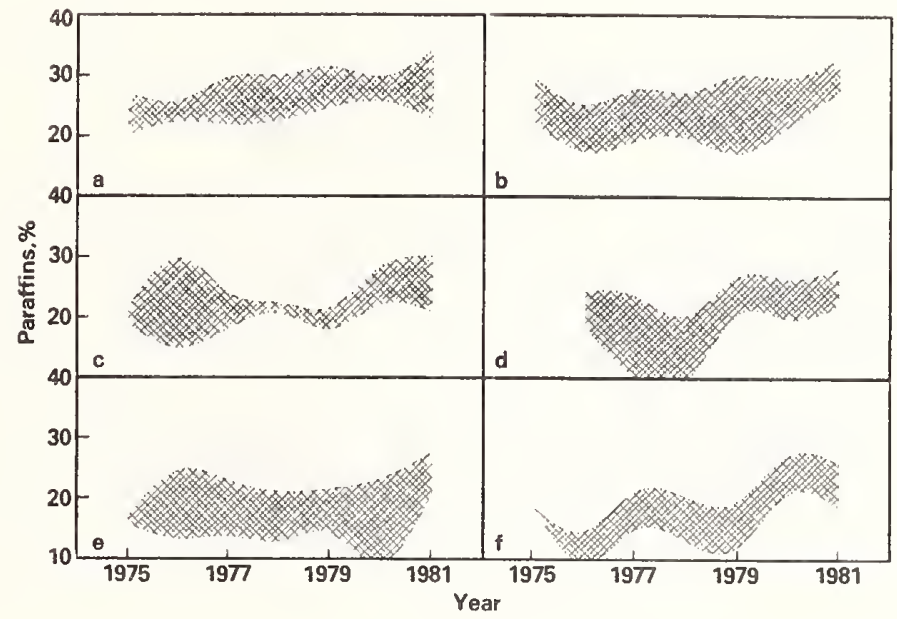

Figure 17. Paraffins, \%. a) $100 \mathrm{~N}$; b) $150 \mathrm{~N}$; c) $200 \mathrm{~N}$; d) $300 \mathrm{~N}$; e) $500 \mathrm{~N}$; f) $600 \mathrm{~N}$.

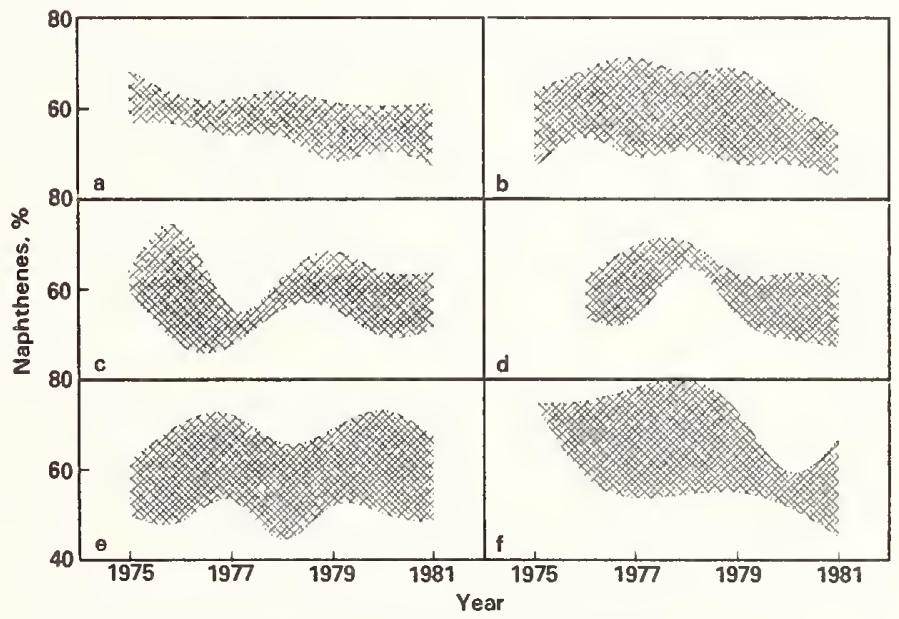

Figure 18. Napthenes, \%. a) $100 \mathrm{~N}$; b) $150 \mathrm{~N}$; c) $200 \mathrm{~N}$; d) $300 \mathrm{~N}$; e) $500 \mathrm{~N}$; f) $600 \mathrm{~N}$. 


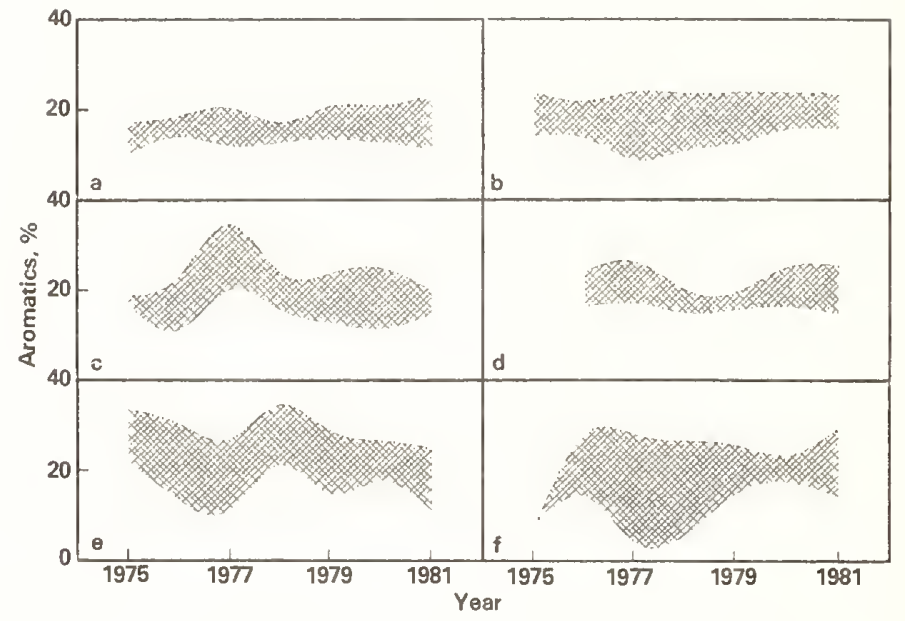

Figure 19. Aromatics, \%. a) $100 \mathrm{~N}$; b) $150 \mathrm{~N}$; c) $200 \mathrm{~N}$; d) $300 \mathrm{~N}$; e) $500 \mathrm{~N}$; f) $600 \mathrm{~N}$.

\section{References}

[1] Robinson, C. J. Analytical Chemistry 43: 1425; 1971.

The author would like to thank Amoco Chemicals Corporation for permission to publish this paper. 
National Bureau of Standards Special Pubiication 674. Proceedings, Conference on Measurements and Standards for Recycied 0i1 - IV, heid at NES, Gaithersburg, MD, September 14-16, 1982.

(Issued Juiy 1984).

\title{
EVALUATION OF TEST METHODS FOR PHYSICAL PROPERTIES OF RE-REFINED LUBRICATING BASE OILS
}

\author{
S. J. Weeks and S. M. Hsu \\ Tribochemistry Group \\ Materials Chemistry Division \\ National Bureau of Standards \\ Washington, DC 20234
}

\begin{abstract}
ASTM standard test methods for determining physical characteristics of lubricating oil basestocks were selected, applied to re-refined base oils, and the results evaluated. The test methods evaluated were: color, viscosity, pour point, API gravity, density, flash point, boiling range distribution by gas chromatography, and refractive index. In addition, some properties derived from the above measurements were calculated. These included viscosity index, carbon distribution and structural group analysis by the $n-d-M$ method, average molecular weight, and the viscosity-gravity constant. The evaluated test procedures were applied to most of the currently existing, commercially-available re-refined base oils. All of these standard test procedures except three were found to be acceptable when used with re-refined base oils. Modifications to the density, boiling range distribution and refractive index test methods were developed which made them acceptable for use with re-refined base oils. These modifications are described.
\end{abstract}

\section{Introduction}

Physical property measurements are routinely performed on lubricating oil basestocks to assure quality control. In the past, virgin oil refiners controlled the feedstock source as well as the refining process to ensure product quality. For re-refined base oils, it is needed to establish (1) the applicability of available test methods to these oils, and (2) the range limits for physical property measurements of these products.

Although much emphasis has been placed on oil recycling over the past decade, prior to the National Bureau of Standards (NBS) work a systematic effort to establish the applicability of physical property test methods to re-refined base oils had not been made. A series of base oils and test methods were selected to provide this data, with the oils representing most of the current re-refining process technologies in the U.S. at this time. A total of ten re-refined basestocks was obtained for this study.

The American Society for Testing and Materials (ASTM), Committee D-2 on Petroleum Products, has developed methods [1] ${ }^{1}$ for the determination of color, viscosity, viscosity index, pour point, API gravity, density, escimation of molecular weight, boiling range distribution by gas chromatography, flash point, calculation of structural group analysis by the $n-d-M$ method, calculation of the viscosity-gravity constant, and refractive index. Some of the above properties are derived from the test measurements. Some or all of these physical properties can provide guidelines [2] for the evaluation of quality control and of possible contamination by indicating the following physical characteristics: appearance, flow, mass, volatility and composition.

The test methods selected were applied to ten re-refined oils. These oils are described in table 1. The methods and their results were evaluated with respect to their practicality, effects of potential impurities or contaminants, and precision. Modifications of the boiling range distribution by gas chromatography and refractive index test methods were made. 0ne test, a digital density test method, was developed at NBS and a modified version has recently been adopted as an ASTM test procedure. These test procedures were then established [3] as being applicable to re-refined lubricating oil basestocks. The set of oils given in table 1 comprise the oils for which the tests methods were evaluated. The test methods and data are presented in tables 2 and 3 . The derived properties are given in tables 4 and 5 . In the following sections each test method is discussed separately.

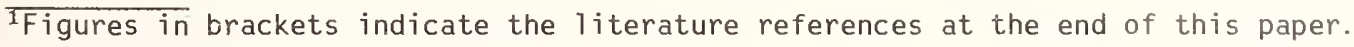


Table 1. Feedstock source and processing technologies of the ten re-refined base oils

\begin{tabular}{|c|c|c|c|}
\hline Dil ID & Viscosity Grade & Processing Technology & $\begin{array}{l}\text { Feedstock Source } \\
\text { Geographical Area }\end{array}$ \\
\hline RA & $200 \mathrm{~N}$ & $\begin{array}{l}\text { Pretreat/Vac.dist./ } \\
\text { Clay finish }\end{array}$ & Mid-West (US) \\
\hline RB & $250 \mathrm{~N}$ & Clay treat & Southwest \\
\hline $\mathrm{RC}$ & $350 \mathrm{~N}$ & Acid/Clay & Southeast \\
\hline RD & $300 N$ & Acid/Clay & West Coast \\
\hline RE & $400 \mathrm{~N}$ & $\begin{array}{l}\text { Caustic Pretreat/ } \\
\text { Vac. dist. }\end{array}$ & Northeast \\
\hline RF & $350 \mathrm{~N}$ & Acid/Clay & South \\
\hline RG & $300 \mathrm{~N}$ & Acid/Clay & Northwest \\
\hline RH & $250 \mathrm{~N}$ & Acid/Clay & Canada \\
\hline RI & $350 \mathrm{~N}$ & Acid/Clay & West Coast \\
\hline RJ & $200 \mathrm{~N}$ & Acid/Clay & Northeast \\
\hline
\end{tabular}

Table 2. Physical property values of the re-refined oils

\begin{tabular}{|c|c|c|c|c|c|c|c|c|c|}
\hline $\begin{array}{c}\text { Sample } \\
\text { Code }\end{array}$ & $\begin{array}{l}\text { K.Vis. } \\
40^{\circ} \mathrm{C} \\
\text { (cSt) }\end{array}$ & $\begin{array}{l}\text { K.Vis. } \\
100{ }^{\circ} \mathrm{C} \\
\text { (cSt) }\end{array}$ & $\begin{array}{c}\text { VI } \\
\text { (units) }\end{array}$ & $\begin{array}{c}N_{D}^{20} \\
\text { (units) } \\
\end{array}$ & $\begin{array}{c}\text { Color } \\
\text { (units) }\end{array}$ & $\begin{array}{l}\text { API } \\
\text { Gravity } \\
\left({ }^{\circ} \mathrm{API}\right)\end{array}$ & $\begin{array}{l}\text { Density } \\
\text { at } 20{ }^{\circ} \mathrm{C} \\
\mathrm{(kg}-\mathrm{m}^{-3} \\
\end{array}$ & $\begin{array}{l}\text { Pour } \\
\text { Point } \\
\left({ }^{\circ} \mathrm{C}\right) \\
\end{array}$ & $\begin{array}{l}\text { Flash } \\
\text { Point } \\
\left({ }^{\circ} \mathrm{C}\right) \\
\end{array}$ \\
\hline K & 81.91 & 9.4 .5 & 90 & 1.48810 & 5.5 & 28.9 & 833.55 & -11 & 241 \\
\hline L & 57.71 & 8.10 & 108 & 1.48328 & 6.5 & 29.8 & 874.21 & -8 & 201 \\
\hline$M$ & 73.46 & 9.36 & 104 & 1.48486 & 6.5 & 29.4 & 878.02 & -10 & 215 \\
\hline$N$ & 60.26 & 8.35 & 108 & 1.48422 & 5.0 & 29.7 & 875.95 & -13 & 203 \\
\hline 0 & 48.20 & 6.80 & 94 & 1.48626 & 4.5 & 29.1 & 878.99 & -8 & 218 \\
\hline$P$ & 78.66 & 9.92 & 106 & 1.48526 & 4.5 & 29.1 & 878.17 & -10 & 226 \\
\hline Q & 66.56 & 8.85 & 106 & 1.48547 & 6.5 & 29.4 & 879.08 & -10 & 203 \\
\hline$R$ & 52.71 & 7.39 & 100 & 1.48254 & 3.0 & 29.8 & 874.81 & -11 & 200 \\
\hline$S$ & 79.46 & 9.95 & 105 & 1.48556 & 5.5 & 28.9 & 880.18 & -8 & 211 \\
\hline$T$ & 41.45 & 6.38 & 102 & 1.48671 & 8.0 & 28.7 & 881.14 & -15 & 174 \\
\hline
\end{tabular}




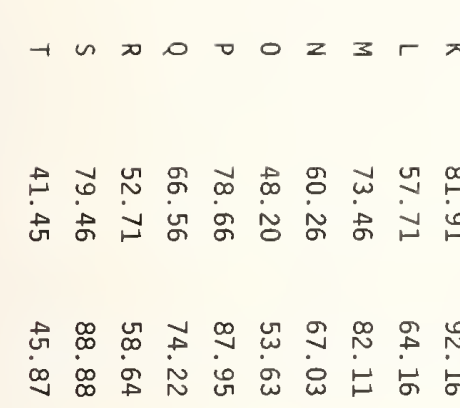

ब 6 ○

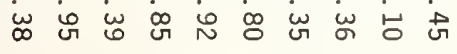
の ڤ if $N$ in

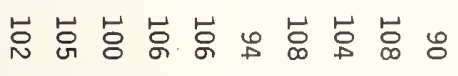

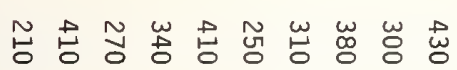

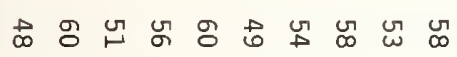

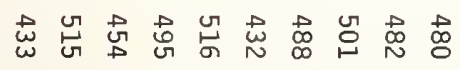

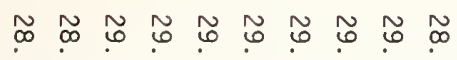

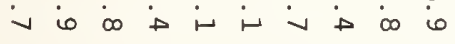

0.00000000

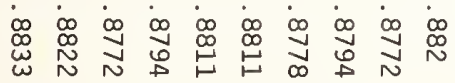

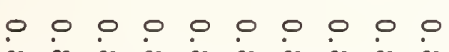
少

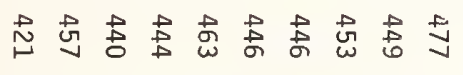

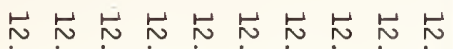

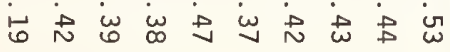

紊獣

\&

ه

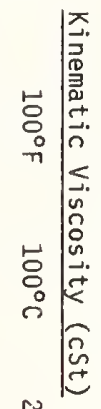

莫

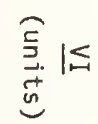

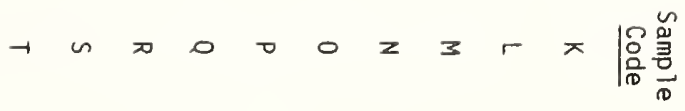

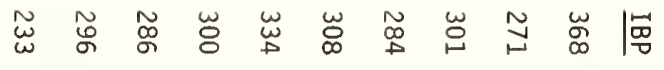

怘

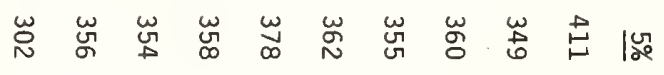

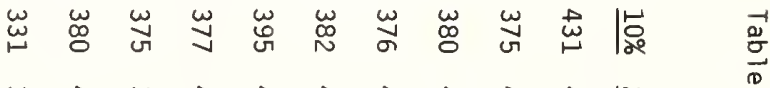

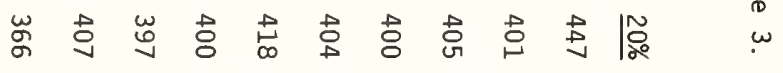

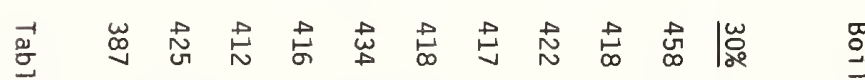

落|

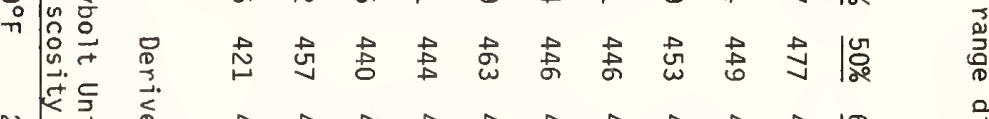

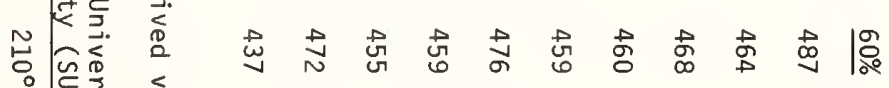

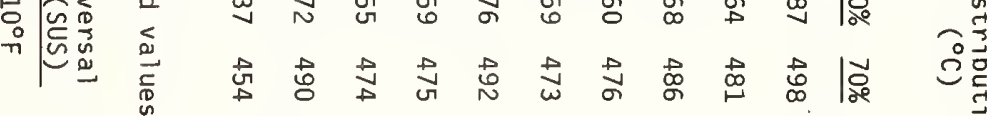

言|

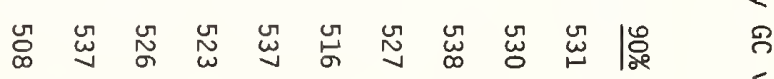

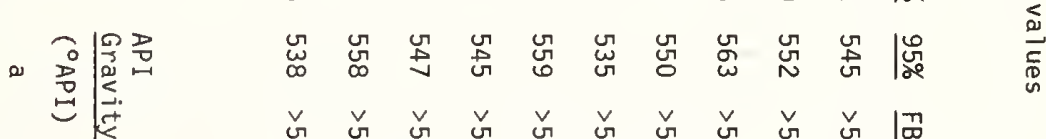

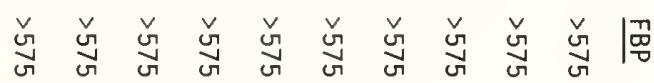

$\stackrel{2}{2}$

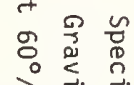

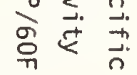

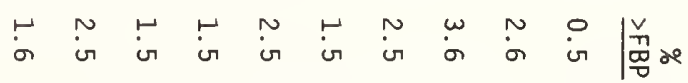

昘

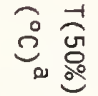


Table 5. Carbon distribution ${ }^{a}$ and structural group analysis ${ }^{b}$ by the $n-d-M$ method

\begin{tabular}{|c|c|c|c|c|c|c|c|}
\hline $\begin{array}{l}\text { Sample } \\
\text { Code }\end{array}$ & $\% \mathrm{C}_{\mathrm{A}}$ & $\% \mathrm{C}_{\mathrm{R}}$ & $\% \mathrm{C}_{\mathrm{N}}$ & $\% c_{p}$ & $\mathrm{R}_{\mathrm{A}}$ & $\mathrm{R}_{\mathrm{T}}$ & $\mathrm{R}_{\mathrm{N}}$ \\
\hline K & 7.77 & 34.91 & 27.14 & 65.09 & 0.449 & 2.511 & 2.063 \\
\hline$L$ & 5.97 & 31.88 & 25.92 & 68.12 & 0.346 & 2.274 & 1.928 \\
\hline M & 5.78 & 32.54 & 26.75 & 67.46 & 0.349 & 2.433 & 2.084 \\
\hline$N$ & 6.29 & 31.99 & 25.76 & 68.01 & 0.369 & 2. 311 & 1.941 \\
\hline 0 & 8.59 & 35.31 & 26.72 & 64.69 & 0.446 & 2.250 & 1.804 \\
\hline$P$ & 6.14 & 31.90 & 25.76 & 68.10 & 0.381 & 2.466 & 2.085 \\
\hline Q & 6.19 & 33.13 & 26.94 & 66.87 & 0.369 & 2.451 & 2.082 \\
\hline$R$ & 4.79 & 34.15 & 29.36 & 65.85 & 0.263 & 2.294 & 2.031 \\
\hline S & 5.31 & 33.22 & 27.91 & 66.78 & 0.330 & 2.579 & 2. 249 \\
\hline $\mathrm{T}$ & 7.95 & 36.40 & 28.45 & 63.50 & 0.414 & 2. 335 & 1.921 \\
\hline
\end{tabular}

${ }^{a}$ Composition expressed in terms of carbon distribution as the percentage of the total number of carbon atoms that are present in: aromatic ring structures $\left(\% C_{A}\right)$; naphthene ring structures $\left(\% \mathrm{C}_{N}\right)$; total ring structure $\left(\mathrm{C}_{\mathrm{R}}\right)$; and paraffin chains $\left(\%_{\mathrm{p}}\right)$.

${ }^{b}$ Composition expressed in terms of the proportion of: aromatic rings $\left(R_{A}\right)$; naphthene rings $\left(R_{N}\right)$; total rings $\left(R_{T}\right)$; and paraffin chains $\left(C_{p}\right)$ that would comprise a hypothetical mean

\section{Color}

Color is an appearance characteristic. It is a three-dimensional property in terms of brightness, hue, and saturation. Color has both physical and psychological meaning.

Color is often indicative of the degree of refining. After a color range has been established for a particular grade of lubricating oil, color provides a quick visual test for uniformity and possible contamination. However, oils with different composition can appear to have the same color. Therefore, color is not a sufficient test by itself to judge product quality. Re-refined oils may contain higher levels of oxygenated compounds, which are generally somewhat darker in color.

The method selected to evaluate the color of re-refined base oils was ASTM D1500, "ASTM Color of Petroleum Products (ASTM color scale)" [1]. This is a well established test method for the evaluation of virgin lubricating oils.

\subsection{Physical Basis}

In the establishment of this test method many years ago, the color of lubricating oils was determined by comparison with 16 glass standards developed by Hellige Inc., in accordance with specifications by NBS [4]. The spacing between the color standards is intended to be perceptually uniform. These standards for the ASTM color scale were selected by comparing 49 oil samples by the substitution method using a photoelectric colorimeter with tristimulus filters. The one-dimensional color scale that was constructed cannot be applied to all oils, but by choosing color standards that correspond to the average color of an oil, difficulties introduced by off-color oils are minimized. 
The colorimeter used for ASTM D1500 is a color comparator. The sample is placed in a standard jar and visually compared to standards until the operator obtains a color match. The results are indicated on a scale from 0.5 to 8.0, with the letter "L" indicating the sample is lighter than a recorded color standard, if no exact match is found.

\subsection{Evaluation}

Test method ASTM D1500 required no modifications for the measurement of color in the re-refined oils selected. The data for the ten re-refined base oils are given in table 2 . No sample required dilution to determine its color. The range of color observed was L3.0 to 8.0 with an average of L5.5. The data are an average of a minimum of three measurements over an eight-month period, during which no change in color was observed due to exposure to the atmosphere or normal room 1 ighting. All data were within the ASTM 01500 precision limits [3]. ASTM D1500 provides a valid, rapid and low-cost test procedure, which is applicable to re-refined base oils.

\section{Viscosity}

Viscosity is a flow characteristic. It is a measure of a liquid's internal resistance to flow of one liquid layer in relation to another at a given temperature. Viscosity varies inversely with temperature--the viscosity-temperature relationship depends on chemical composition, and is described by the viscosity index (VI). VI is an arbitrary number calculated from the viscosities of oils at $40^{\circ}$ and $100{ }^{\circ} \mathrm{C}$. For oils of similar kinematic viscosity, the higher the viscosity index, the smaller is the effect of temperature on its kinematic viscosity.

Viscosity is often the first consideration in the selection of a lubricating oil for the protection of moving surfaces. The load carrying capacity of a lubricant depends largely upon viscosity. Viscosity is generally the most important controlling property for the refining, blending, and applications selection of lubricating oils. Engine lubricants are classified into individual grades of oil according to their viscosity. The SAE (Society of Automotive Engineers) classification is commonly used for this purpose [5]. This classification provides a useful guide to the selection of the proper viscosity oil for the intended use under different temperature ranges.

Viscosity is an important parameter for base oil manufacturing since it represents the molecular weight range of different "cuts" from a distillation unit.

The test methods selected for evaluation with re-refined oils were: ASTM D445, "Kinematic Viscosity of Transparent and Opaque Liquids (and the calculation of Dynamic Viscosity)," and ASTM D2270, "Calculating Viscosity Index from Kinematic Viscosity at $40{ }^{\circ} \mathrm{C}$ and $100{ }^{\circ} \mathrm{C} "$ [1]. The precision data in 0445 were obtained using five mineral oils covering the kinematic viscosity range from 3 to $1200 \mathrm{cSt}$ at temperatures from 38 to $99{ }^{\circ} \mathrm{C}$. These tests are used to measure the viscosity characteristics of virgin lubricating oils.

\section{1. Physical Basis}

Viscosity, $\eta$, is defined by Newton's 1aw, which states $[6,7]$ that at a given point in a fluid, the shearing stress, $S$, is directly proportional to the rate of shear, $R$ :

$$
S=\eta R \text {. }
$$

The viscosity of a Newtonian oil changes with temperature but not normally with shear rate, unless specific additives--which may not be shear stable--are included to modify the viscosity-temperature characteristics [8]. Thus for base oils, the rate of flow of the oil through a capillary is directly proportional to the pressure applied. The relation is given for capillary tubes by the Poiseuille equation:

$$
\eta=\left(\frac{\pi P r^{4}}{8 V \ell}\right) t
$$

where $P$ is the pressure, $r$ is the radius of the tube, 2 is the length of the tube, and $V$ is the volume of liquid flowing in time $t[6,7]$. 
The viscosity is measured, for most practical purposes, by timing the flow of a fixed amount of oi] through a calibrated glass capillary tube under gravitational force at a standard temperature. This is the kinematic viscosity of the oil, and is generally given in units of centistokes (cSt), $\mathrm{cm}^{2} \cdot \mathrm{s}^{-1}$. Kinematic viscosity, which is defined as viscosity divided by density, can be converted into dynamic viscosity by multiplying by the density at the specified temperature. The units then are given in Poise $(P): \mathrm{g} \cdot \mathrm{cm}^{-1} \cdot \mathrm{s}^{-1}$.

This test and procedure is applicable to liquid petroleum products, both transparent and opaque, and is intended for application to liquids for which the shear stress and shear rates are proportional [1]. At the test temperatures, lubricating oil basestocks satisfy this criterion and may be considered "Newtonian Fluids."

In the kinematic viscosity method, ASTM D445, the "time is measured in seconds for a fixed volume of liquid to flow under gravity through the capillary of a calibrated viscometer under a reproducible driving head and at a closely controlled temperature. The kinematic viscosity is the product of the measured flow time and the calibration constant of the viscometer" [1].

\subsection{Evaluation}

ASTM D445 did not required any test procedural modifications for evaluation with re-refined basestocks. The data are listed in table 2 for the ten re-refined basestocks. All values are an average of at least three sets of values measured over at least a six month period. The range of these values is from 40 to $82 \mathrm{cSt}$, with an average of $64 \mathrm{cSt}$.

The precision listed in D445 is for "clean, transparent oils." A11 oils appeared to be homogeneous and free of suspended matter. A study using centrifugation performed on used oils [9] showed the magnitude of the effect of particles did not affect viscosity measurements within the repeatability limits of the test procedures. Transparency was not a problem, since no difficulties were encountered in determining the position of the meniscus as the oils flowed through the capillary viscometer. All data were within the precision of the D445 test method [3].

ASTM 0445 provides a precise, rapid and low-cost test procedure for the measurement of kinematic viscosity in re-refined base oils.

\section{3. Derived Properties}

Measurement of viscosity index (VI) is very important for basestocks because of the relationship between VI and composition. Modern refining techniques and the use of additives allow oils to be produced with high VI's with most crude sources. Viscosity index can be used for quality control on the re-refining processes to indicate hydrocarbon composition.

In addition to VI, several other viscosity parameters can be calculated or estimated. Kinematic viscosity at a temperature different from the test temperatures can be calculated using ASTM D341, "Viscosity-Temperature Charts for Liquid Petroleum Products" [1]. If desired, the Saybolt viscosity, which is often used in manufacturing processes, can be calculated from the kinematic viscosity using ASTM method D2161, "Conversion of Kinematic Viscosity to Saybolt Universal Viscosity or Saybolt Furol Viscosity." An estimation of the mean molecular weight of petroleum oils from kinematic viscosity measurements can be calculated by ASTM D2502, "Estimation of Molecular Weight of Petroleum 0ils from Viscosity Measurements." These derived properties are listed in table 4 for reference.

The viscosity index, VI, compares the rate of change of viscosity with temperature of the sample with the rates of change of two types of oil having the highest and lowest viscosity indices at the time (1929) when the viscosity index scale was first introduced. A standard paraffinic oil was given a VI of 100 , and a standard naphthenic oil a VI of 0 . Equations were developed for the relationships of kinematic viscosities at two temperatures and the VI scale for oils with VI between 0 and 100. In 1964, ASTM adopted an extension to the tables, and an equation for oils with VI's greater than 100.

ASTM D2270, "Calculating Viscosity Index from Kinematic Viscosity at 40 and $100{ }^{\circ} \mathrm{C}$," gives procedures to calculate VI for oils with a VI up to and including 100, and for oils with a VI greater than 100 .

ASTM D2270 is an appropriate method for re-refined basestocks. 


\section{Pour Point}

Pour point is a low-temperature flow characteristic. It is defined as the lowest temperatur. at which an oil is observed to flow under controlled cooling. Low-temperature fluidity depends ol the type of feedstock, method of refining, and the presence of pour point depressant additives.

The pour point is a guide to, and not an exact measure of, the temperature at which flow ceases under the service conditions of a specific system. Because in practice, the size and shape of the container, the pressure of oil, and the physical structure of the solidified oil all influence the tendency of the oil to flow $[8,10]$, pour point will therefore only give an estimation of the amount of oil flow to the bearings at low temperatures, which is critical to the prevention of bearing failure and minimization of engine wear during and immediately after the motor is started [11]. In service, the oxidation stability of the oil, as well as the tendencies of the oil to polymerize and to form oil-insoluble products, will also affect the low temperature fluidity [12,13]. Determinination of pour point is of value for: quality control, storage planning, indicating low-temperature fluidity, determining efficiency of the dewaxing process, and indicating presence of pour point depressant, viscosity index improver and fuel or water contamination, in the re-refining process. Pour point cannot be used to predict: low-temperature pumpability or cold weather startability.

ASTM D97, "Pour Point of Petroleum 0ils," was selected as the method to evaluate lowtemperature flow characteristics of re-refined basestocks, and is the method generally used for lubricating oil basestocks.

\subsection{Physical Basis}

Lubricating oils contain straight-chain paraffin molecules which tend to form wax crystals at moderately low temperatures. Branched chain paraffins, naphthenes, and aromatics show less of a tendency to form crystals and may actually congeal. The temperature at which a lattice of wax crystals forms trapping the liquid, or the entire body of oil congeals, thus preventing flow under gravity, is the pour point. The pour point of wax-containing oils can be reduced by addition of pour point depressants which inhibit the growth of wax crystals.

Pour point by D97 is determined by initially heating the sample in a standard test jar containing a thermometer, and then cooling the sample at a specified rate and procedure while examining the sample for flow characteristics at specified intervals. The lowest temperature at which movement is observed is recorded as the pour point.

\subsection{Evaluation}

Petroleum oils contain components with a wide range of molecular sizes and configurations. The pour point is, therefore, difficult to determine precisely because the transition from liquid to solid is a gradual one, with the oils becoming more or less plastic solids or supercooled 1iquids when cooled to sufficiently low temperatures. Also, the pour point of some oils may be affected by their previous thermal history. In fact, pour point reversion may occur.

The ASTM D97 test procedure ASTM D97 was found to be time-consuming. In addition, some experimental conditions were hard to reproduce exactly. Experimental conditions which lacked precise control were: amount of sample disturbance, cooling rate, and determination of solidification. However, no modification of 197 was necessary for the measurement of pour point on re-refined oils. Data on measurements of re-refined basestocks by this test are presented in table 2 . The range of values for these base oils is from -8 to $-18{ }^{\circ} \mathrm{C}$, with an average of $-10{ }^{\circ} \mathrm{C}$. The precision of the method is within that stated for virgin oil basestocks [3].

ASTM D97, "Pour Point of Petroleum 0ils," has been evaluated with re-refined oil basestocks and has been found to be an acceptable test procedure for the measurement of the pour point of re-refined oil basestocks [3].

\section{API Gravity and Density}

Density is a measure of molecular mass and is a fundamental physical property. It is the mass of a unit volume of material at any given temperature. API gravity is a special function of relative density. The relative density is ratioed to the density of water at a specific temperature. 
The determination of density is necessary for the conversion of measured volumes to volumes at the standard temperature of $15^{\circ} \mathrm{C}$ or $60{ }^{\circ} \mathrm{F}$. Tables are available for these conversions [14]. This is of great economic importance in commerce.

Density by itself is an uncertain indicator of the quality of lubricating base oils. However, it can be used in conjunction with other properties to give approximate hydrocarbon composition, and therefore, provide quality control information.

The viscosity-gravity constant (VGC) is one function which has been correlated with the paraffinic content of base oils. Table 4 lists the VGC value for the ten re-refined oils as calculated from ASTM D2501, "Calculation of Viscosity-Gravity Constant (VGC) of Petroleum 0ils" [1].

Two techniques were selected for evaluation with re-refined oils: (1) the hydrometer technique using either ASTM D287, "API Gravity of Crude Petroleum and Petroleum Products (Hydrometer Method)" or ASTM D1298, "Density, Relative Density (Specific Gravity) or API Gravity of Crude Petroleum and Liquid Products by Hydrometer Method," and (2) the digital density meter technique, using ASTM D4052, "Density and Relative Density of Liquids by Digital Density Meter."

\subsection{Physical Basis}

The hydrometer methods are based on the principle that the depth of immersion of a body floating in a liquid is inversely proportional to the density of the liquid. The floating body is a hydrometer that has appropriate graduations. When temperature equilibrium is reached, the hydrometer scale is read and the temperature recorded.

The digital density meter is based on an electronic measurement of frequency. A sample is introduced into an oscillating sample tube. A change in oscillating frequency is caused by the change in the mass of the tube. This frequency change is measured electronically and used in conjunction with calibration data to determine the density of the sample.

\subsection{Modifications}

The NBS procedure for measuring density with a digital density meter was developed prior to the adoption of test method D4052 by ASTM. It differs from the ASTM method in calibration and data calculation procedures $[3,15]$. First, in addition to distilled water, the NBS procedure used xylene as a calibration standard instead of air, since xylene has a density similar to that of lubricating oil basestocks. Second, the instrument was calibrated daily. Third, air samples were run in between each fluid as a check on cleanliness of the oscillator tube. Fourth, a calibrated thermistor was used instead of a thermometer to provide electronic temperature measurements good to 0.001 degree Celsius. Fifth, because of the difficulty in setting temperatures accurately and precisely, density measurements were made slightly above and below the desired temperature, and the density value was interpolated. And last, the density measurement process was microprocessor-controlled.

No modifications were necessary for the hydrometer methods.

\subsection{Evaluation}

The data collected are presented in tables 2 and 6 . Table 6 contains: (A) the interpolated density values, (B) observed density values measured as close as possible to $20{ }^{\circ} \mathrm{C}$ (within $0.1{ }^{\circ} \mathrm{C}$ of $20^{\circ} \mathrm{C}$ ), (C) the differences between these two values, (D) an API gravity value calculated from the interpolated density value, (E) a measured API gravity value, and (F) the difference between the measured and calculated API gravities. No difficulties were encountered in either the density or gravity measurements due to re-refined oil samples [3]. The precision of the NBS digital density system is $3 \times 10^{-\mathrm{s}}$. All data are within the ASTM precision statements and agree wel1 with each other. The density measured by the NBS digital density meter procedure is more precise, uses less sample, and is over an order of magnitude more sensitive than the hydrometer methods.

ASTM test methods D287, D1298, and 04052 are acceptable for the measurement of density of re-refined oils. 
Table 6. Density at $20^{\circ} \mathrm{C}$ and API gravity

(A)

5 Place

Interpolated

Sample

Code

$\left(\mathrm{kg}-\mathrm{M}^{-3}\right)$
(B)

5 Place

Observed

$\mathrm{d}_{20}^{\prime}$

$\left(\mathrm{kg}^{20} \mathrm{M}^{-3}\right)$

(C)

(D)

(E)

(F)

Calculated

from $d_{20}$

$d_{20}-d_{20}^{\prime}$

${ }^{\circ}$ API $\sigma$

$\left({ }^{\circ} A P I\right)-\left({ }^{\circ} A P I\right)$

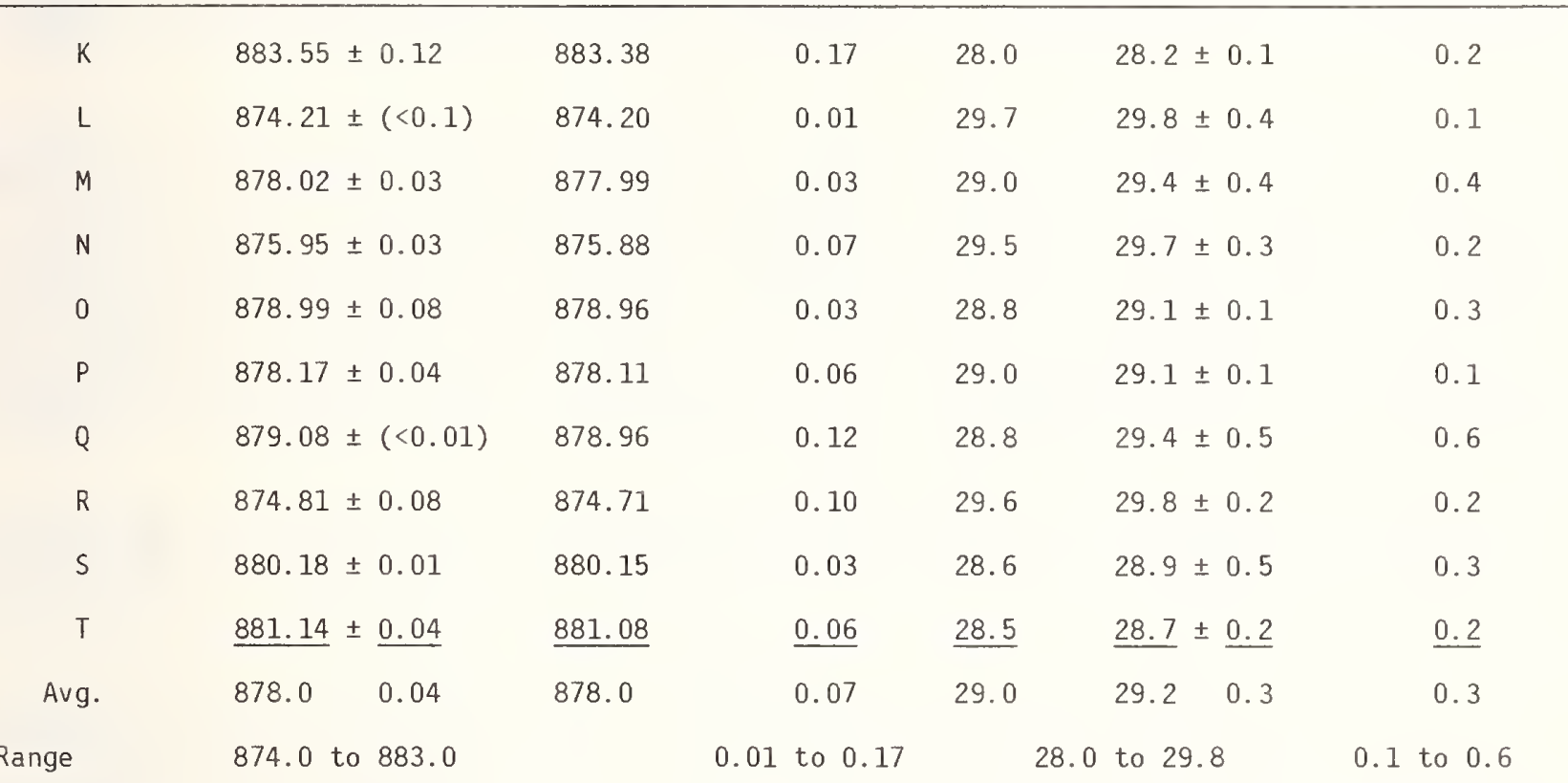

6. Flash Point

Flash point is a volatility characteristic. It is one measurement of the flammability hazard of a material. The flash point is the lowest temperature to which an oil must be heated, under specified conditions, to give off sufficient vapor to form a mixture with air which will ignite in the presence of an open flame.

Flash point is used in shipping and safety regulations to define "flammable" and "combustible" materials. Flash point should be considered relative to the temperatures to which a basestock will be subjected in storage, transportation, and use. Normally, lubricating oil basestocks present no hazards in these respects. Flash point is only one of a number of properties which must be considered in assessing the overall flammability hazard of a material.

Flash point can also indicate oil volatility. For lubricating oil basestocks this may be related to oil consumption at operating conditions. It can also indicate the possible presence of highly volatile and flammable materials in a relatively nonvolatile or nonflammable material. This may be fuel or solvent contamination of the lubricating oil basestock.

ASTM D92, "Flash and Fire Points by Cleveland Open Cup," was selected [3] as the test method to evaluate for use with re-refined lubricating oil basestocks. ASTM D93, "Flash Point by PenskyMartens Closed Tester, " should be used when it is desired to determine the possible presence of small but significant concentrations of lower flash point substances which may escape detection by ASTM D92. Use of ASTM D93 was not necessary for the base oils selected in this study. ASTM D92 is the method generally used for flash point measurements on virgin lubricating oil basestocks.

\subsection{Physical Basis}

Flash point measures the response of the sample to heat and flame under controlled laboratory conditions. As the name implies, only momentary combustion occurs. This distinguishes it from fire 
point, which is a higher temperature at which vapor is generated at a sufficient rate to sustain combustion. Combustion is possible only when the ratio of fuel vapor to air (oxidant) lies between certain limits [2]. A fuel mixture too lean or rich will not burn.

In ASTM D92, a test cup is filled to a specified level with the sample. The temperature is increased rapidly at first and then at a slow, constant rate as the flash point is approached. At specific intervals a small test flame is passed across the cup. The lowest temperature at which application of the test flame causes the vapors above the surface of the liquid to ignite is taken as the flash point.

\subsection{Evaluation}

No modifications of ASTM D92 were necessary for use with re-refined lubricating oil basestocks. However, see below for special conditions. The data for the ten re-refined base oils are given in table 2. The range of these values is 170 to $250^{\circ} \mathrm{C}$, with an average of $210{ }^{\circ} \mathrm{C}$. 0 ne oil, which has a significantly lower flash point, is a minimally re-refined oil not intended for automotive use.

During the test evaluation, it was noted that the rate of heating and the air drafts were difficult to control. As a result, special precautions concerning the fume hood and its draft were necessary [3]. Darkened laboratory conditions were generally necessary to observe the true flash point and not confuse it with a bluish halo that sometimes surrounds the test flame.

No data point fell outside of the ASTM 092 reproducibility 1 imits of $17{ }^{\circ} \mathrm{C}$ or the repeatability limits of $8^{\circ} \mathrm{C}$. ASTM D92 can be used without modification to measure the flash point of re-refined lubricating oil basestocks.

\section{Boiling Range Distribution by Gas Chromatography}

(GCBRD)

Boiling range distribution by gas chromatography (GC) is a simulated distillation. As such it is a measure of the volatility characteristics of an oil. A gas chromatographic method provides good precision, time and sample efficiency, and more detailed information than can be achieved using conventional ASTM distillation methods.

Distillation is one of the principal processes used to separate petroleum products. Process control and specification testing can be accomplished with the boiling range distribution by the GC method. GCBRD results have been compared and correlated to a number of distillation tests [7,18]. GCBRD by ASTM 02887 has been found to agree closely with the volume percent data given by ASTM D2892, "Distillation of Crude Petroleum (15 Theoretical Plate Column)."

Volatility characteristics are important for a number of reasons including oil consumption, flammability, and performance. One study has used GCBRD to evaluate these parameters [19]. Front end volatility can also serve as a check on contamination and processing conditions.

ASTM D2887, "Boiling Range Distribution of Petroleum Fractions by Gas Chromatography" is the method usualiy used for lubricating oils and was selected as the method for evaluation with re-refined oils [3].

\subsection{Procedure}

In the GCBRD method, a sample is introduced into a gas chromatographic column, which separates hydrocarbons in boiling point order. The column temperature is raised at a reproducible rate and the area under the chromatogram is recorded throughout the run. Boiling temperatures are assigned to the time axis from a calibration curve, obtained under the same conditions by running a known mixture of hydrocarbons covering the boiling range expected in the sample. From these data, the boiling range distribution may be obtained and tabulated as "percent off" vs boiling point.

\subsection{Modifications}

The scope section of ASTM D2887 states the method is applicable to petroleum products with a final boiling point ( $F B P=99.5$ percent off) of $538^{\circ} \mathrm{C}$ or lower at atmospheric pressure. However, al1 the re-refined oils in this study have FBP $>538{ }^{\circ} \mathrm{C}$. Also, ASTM D2887 provides only guidelines for the chromatographic method and resulting data analysis. 
The modifications given in this section do not conflict with ASTM 02887, but merely extend its upper range and define the procedure used in this laboratory [3]. The main modifications were the use of a baseline subtraction technique, on-column injection and a standard with higher boiling components.

In the method developed, the sample was injected onto the GC column within the oven wall. Typically, a $0.2 \mu \mathrm{L}$ sample was injected using the solvent flush technique. The oven was programmed to increase the temperature from 50 to $380^{\circ} \mathrm{C}$ at a rate of $10^{\circ} \mathrm{C} / \mathrm{min}$. Typically, a ten-minute isothermal hold at the final oven temperature would ensure a return to baseline, indicating elution of the entire sample. Glass columns packed with SP2100, 0V101 or Dexi1 300 were used [3,20].

A calibration standard and a baseline were run each day prior to sample analysis. The calibration standard contained normal hydrocarbons, $C_{5}-C_{44}$. In addition, control samples (e.g. ASTM D2887 Reference Gas 0i1) were run periodically.

The data analysis consisted of a point-to-point calibration (as opposed to a curve fitting program) with an extrapolation to $575{ }^{\circ} \mathrm{C}$ and a report of percent off $>575{ }^{\circ} \mathrm{C}$. This procedure was felt to be a reasonable limit for extrapolation beyond the boiling point of the $C_{44}$ standard. Area time slices were taken every 5 seconds over the entire chromatogram. The baseline was subtracted from the sample data and the retention times compared to the latest calibration curve for the boiling range distribution report.

\subsection{Evaluation}

The data are presented in table 3 and in graphical form in figure 1 . Good precision was obtained for values from 2 percent to 98 percent boiled off. Baseline definition, in general, had to be examined to obtain precise results in the Initial Boiling Point (IBP) and FBP ranges [3]. Table 7 gives the ranges and averages for the re-refined base oils at 2, 50 , and 90 percent off.

The repeatability in general is within the ASTM D2887 precision statement. More detailed discussion of the precision on the IBP and FBP is presented in reference [3].

The IBP values in table 3 suggest a qualitative correspondence with the flash point data in table 2. Thus, both measurements are good indicators of the light ends volatility in a lubricating base $0 i 1$.

Figure 1 shows graphically the boiling point for the ten re-refined oils used in this study. Eight of the ten oils are fairly tightly grouped with 90 percent of the oil (as defined by 5-95 percent points) having a boiling range between 170 and $205{ }^{\circ} \mathrm{C}$ in the region between 350 to $560{ }^{\circ} \mathrm{C}$. These are, in general, slightly broad boiling ranges when compared to virgin lubricating base oils of the same viscosity. Again, the minimally re-refined oil (oil T) stands out from the other oils, having the lowest and broadest boiling point curve. 0il $\mathrm{K}$ has the narrowest boiling range.

The modified version of ASTM 02887 has been evaluated and is acceptable for use with re-refined lubricating base oils.

\section{Refractive Index}

Refractive index is a compositional characteristic. It is the ratio of the velocity of light of a specified wavelength in air to its velocity in the substance under examination. Refractive index is a fundamental physical property which can be used in conjunction with other properties to characterize pure hydrocarbons and their mixtures. It is sensitive to composition, and therefore may be used in quality control for testing the composition uniformity of the product. A general rule for petroleum products of equivalent molecular weight is that paraffins have relatively low refractive indices, aromatics have relatively high indices, and naphthenes have intermediate indices.

ASTM 01218, "Refractive Index and Refractive Dispersion of Hydrocarbon Liquids" was selected for evaluation with re-refined base oils. The carbon atom distribution and ring content of olefin-free petroleum oils can be calculated from the measurement of refractive index, density, molecular weight and sulfur by ASTM D3238, "Calculation of Carbon Distribution and Structural Group Analysis of Petroleum $0 i 1 \mathrm{~s}$ by the $n-d-M$ method." These values have been calculated and are included in table 5 for reference. No evaluation was made in the accuracy of the composition analysis by the $n-d-M$ method. 


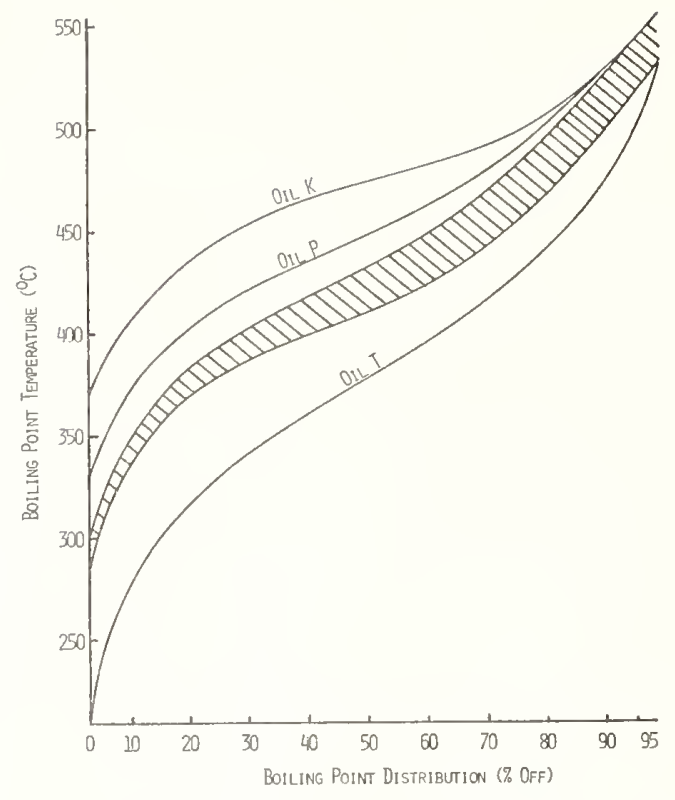

Figure 1. Boiling point distribution curves for ten re-refined lubricating base oils (seven of the ten oils have distributions grouped within the shaded area of the plot).

Table 7. Summary of test results for re-refined oils

Test

Color

[ASTM Color Units]

Pour Point

$\left[{ }^{\circ} \mathrm{C}\right]$

Viscosity, $40{ }^{\circ} \mathrm{C}$ [cSt]

$$
100{ }^{\circ} \mathrm{C}
$$

VI [units]

Flash Point

$\left[{ }^{\circ} \mathrm{C}\right]$

API Gravity

[ ${ }^{\circ} \mathrm{API}$ ]

Density at $20{ }^{\circ} \mathrm{C}$

$\left[\mathrm{kg}-\mathrm{dm}^{-3}\right]$

Refractive Index

$\mathrm{N}_{\mathrm{D}}^{20}$ at $20^{\circ} \mathrm{C}$ [units]

Boiling Range Distribution

by Gas Chromatography, $2 \%$

\section{$\underline{\text { Range }}$}

L3. 0-8. 0

-8 to -18

$40-82$

$6-10$

90-108

$170-250$

$29.8-28.7$

$0.874-0.884$

1. $482-1.489$

268-387

$\begin{array}{ll}50 \% & 421-477 \\ 90 \% & 508-538\end{array}$
Average

L5. 5

$-10$

64

8.5

102

210

29.2

9.878

1. 485
D1218 (modified)

Test Method

ASTM D1500

D97

D445

D445

D2270

D92

D287 or 01298

D4052 (modified)

02887 (modified)
327

450

527 


\subsection{Physical Basis}

The refractive index is a measure of the extent to which various substances cause a decrease in the speed of light as compared with its speed in air or vacuum. It may be defined as the sine of the angle of incidence divided by the sine of the angle of refraction, as light passes from air into the substance. This is the relative index of refraction. The absolute refractive index in vacuum may be obtained by multiplying this value by 1.00027 , which is the absolute refractive index of air. The numerical value of refractive index varies inversely with both wavelength and temperature. It is also a function of pressure, chemical composition, physico-chemical constitution, homogeneity, purity, and physical state [16].

\subsection{Modifications}

ASTM 01218 states that is is not applicable within the accuracy stated for oils having colors darker than ASTM Color No. 4. All oils except one in our test set were darker than ASTM Color No. 4. Although D1218 does not explicitly state that measurements are to be made in the transmission mode, this is assumed. The modification made was simply to use the reflectance mode.

The refractive index for hydrocarbon liquids is generally measured at $20{ }^{\circ} \mathrm{C}$ using the wavelength of the sodium $D$ lines $(589 \mathrm{~nm})$ and is expressed as $\mathrm{n}_{\mathrm{D}}^{20}$. It is measured by the criticai angle method with a precision refractometer. The instrument is calibrated befcre each use with a solid reference standard and certified liquid standards. Simply, a drop of liquid is placed on a prism face and allowed to reach temperature equilibrium. The lamp and the stage are adjusted so that the cross hairs intersect at the dividing line and the reading is recorded.

\subsection{Evaluation}

The data for refractive index are shown in tables 2 and 8 . The range for these values is from 1.482 to 1.489 units using an average of at least 5 measurements, which are within the repeatability-$6 \times 10^{-5}$ units--1isted in D1218. Table 8 shows measurements taken in the transmittance (T) and reflectance $(R)$ modes by two operators. Also included on table 8 is the reproducibility between operators and the ASTM color of the oils. In the reflectance mode, the reproducibility is $\pm 3 \times$ $10^{-5}$ units; whereas, in the transmittance mode, the reproducibility was significantly worse, $\pm 20 \times$ $10^{-5}$. The diffuse 1 ine observed in the transmittance mode forces the operator to make a "best guess" at where the dividing line is; whereas, the distinctly sharper edge in the reflectance mode allowed the cross hairs to be aligned readily with the dividing line. Color was not a significant factor when the reflectance mode was used. As a result of the above there was a definite bias between the two modes of operation. The transmittance values were less than the reflectance mode values.

Table 8. Comparison of refractive index data

\begin{tabular}{|c|c|c|c|c|c|c|c|c|}
\hline \multirow{2}{*}{$\begin{array}{c}\text { Sample } \\
\text { Code }\end{array}$} & \multicolumn{2}{|c|}{ Operator 1} & \multicolumn{2}{|c|}{ Operator 2} & \multicolumn{2}{|c|}{ Reproducibility } & \multicolumn{2}{|r|}{ Color } \\
\hline & $\mathrm{T}_{1}$ & $\mathrm{R}_{1}$ & $T_{2}$ & $\mathrm{R}_{2}$ & $T_{2}-T_{1} \times 10^{5}$ & $R_{2}-R_{1} \times 10^{5}$ & (ASTM & Color Units) \\
\hline K & 1.48796 & 1.48810 & 1.48810 & 1.48810 & +14 & 0 & & 5.5 \\
\hline $\mathrm{L}$ & 318 & 327 & 321 & 328 & +3 & +1 & & 6.5 \\
\hline$M$ & 469 & 485 & 480 & 486 & +11 & +1 & & 6.5 \\
\hline N & 410 & 423 & 415 & 420 & +5 & -3 & & 5.0 \\
\hline 0 & 616 & 625 & 616 & 627 & 0 & +2 & & 4.5 \\
\hline $\mathbf{P}$ & 518 & 525 & 521 & 527 & +3 & +2 & & 4.5 \\
\hline $\mathrm{Q}$ & 535 & 547 & 539 & 549 & +4 & +2 & & 6.5 \\
\hline $\mathrm{R}$ & 244 & 253 & 252 & 255 & +8 & +2 & & 3.0 \\
\hline$S$ & 554 & 558 & 546 & 556 & -8 & -2 & & 5.5 \\
\hline $\mathrm{T}$ & 664 & 672 & 645 & 670 & -19 & -2 & & 8.0 \\
\hline
\end{tabular}

$T=$ Transmission mode

$R=$ Reflectance mode 
Refractive index is a fundamental, simple, precise, and accurate test requiring only a few drops of sample. Measurements can be made readily and precisely on light and dark colored rerefined lubricating base oils. ASTM D1218 is an acceptable method for use with re-refined oils when used in the reflectance mode.

\section{Conclusion}

Existing ASTM standard test methods can be used, with modifications as mentioned above, for the measurement of physical properties of re-refined lubricating oil basestocks. The oils selected for the test set used in the evaluations described in this study included samples representing most commercially re-refined basestocks existing in the U.S. at that time. Table 7 summarizes the data on these samples. The work conducted in this study demonstrates that the evaluated methods can be applied to re-refined oils within the precision statements listed in the ASTM methods.

The authors greatly appreciated the laboratory work performed by Hilary B. Nottingham, Wing Leung, Ying Leung, and others. Also discussions with other members of the Tribochemistry Group were much appreciated.

\section{References}

[1] Annual Book of ASTM Standards Parts 23, 24, and 25. Petroleum Products and Lubricants, American Society for Testing and Materials; Philadelphia, PA; 1981.

[2] Boldt, K.; Ha11, B. R., eds. Significance of tests for petroleum products; ASTM STP 73; ASTM, Philadelphia, PA; 1977.

[3] Weeks, S.; Hsu, S. Physical properties of re-refined lubricating oil basestocks, Nat. Bur. Stand. (U.S.) NBSIR; to be published.

[4] Judd, D. B.; Plaza, L.; Belknap, M. A suggested relocation and respacing of the union colorimeter scale for lubricating oil and petroleum, J. Res. Nat. Bur. Stand. (U.S.) 44: 559; 1950.

[5] SAE Handbook. Society of Automotive Engineers; Warrendale, PA; 1977.

[6] Zuidema, H. H. Performance of lubricating oils. New York: Reinhold Publishing Corp.; 1952.

[7] Bondi, A. Physical chemistry of lubricating oils. New York: Reinhold Publishing Corp.; 1951.

[8] Allinson, J. P. ed. Criteria for quality of petroleum products, England: Applied Science Pubiishers Ltd.; 1973.

[9] Becker, D. A.; Comeford, J. J., eds. Recycled oil program: Phase 1-Test Rrocedures for Recycled 0 il Used as Burner Fuel. Nat. Bur. Stand. (U.S.) Tech. Note 1130; 1980.

[10] Georgi, C. W. Motor oils and engine lubrication. New York: Reinhold Publishing Corp.; 1950.

[11] Davis, G. H. B.; Zimmer, J. C. Science of pecroleum IV. London: Oxford University Press; 1938.

[12] Becker, D. A., ed. Joint conference on measurements and standards for recycled oil/Systems performance and durability; Nat. Bur. Stand. (U.S.) Spec. Pub1. 584; 1980, 141.

[13] Symposium on the relationship between engine oil viscosity and engine performance SAE, Inc.; Warrendale, PA; 1977.

[14] Petroleum measurement tables ASTM; Philadelphia, PA; 1980.

[15] Whetstone, J. R.; Cameron, J. M.; Carrol1, C. L. ; Gallagher, W. L. Density and therma] expansion coefficients of petroleums, Nat. Bur. Stand. (U.S.) NBSIR; September 1978. 
[16] Tilton, L. W.; Taylor, J. K. Refractive index measurement, in Analytical methods in chemical analysis, Vol. 1. New York, NY: Academic Press Inc.; 1960.

[17] Calculation of physical properties of petroleum products from gas chromatographic analyses, STP 577; ASTM; Philadelphia, PA; 1975.

[18] Green, L. E. Chromatograph gives boiling point. Hydrocarbon Processing: $205 ; 1976$.

[19] Stavinoha, L. L.; Eichelberger, J. R.; Lestz, S. J.; Tyler, J. C. Lubricant volatility related to two cycle diesel engine piston ring/cylinder 1iner wear, ASLE 38; 11-22; 1982.

[20] Certain commercial equipment, instruments, or materials are identified in this paper in order to adequately specify the experimental procedure. Such identification does not imply recommendation or endorsement by the National Bureau of Standards nor does it imply that the materials or equipment identified are necessarily the best available for the purpose. 

National Bureau of Standards Special Publication 674. Proceedings, Conference on Measurements and Standards for Recycled 0i1 - IV, held at NBS, Gaithersburg, MD, September 14-16, 1982. (Issued July 1984).

\title{
EVALUATION OF CHEMICAL PROPERTY TEST METHODS FOR RE-REFINED LUBRICATING BASE OILS
}

\author{
A.L. Cummings ${ }^{1}$, P. Pei, and S.M. Hsu \\ Chemical Stability \& Tribology Group \\ Nationa] Bureau of Standards \\ Washington, DC 20234
}

\begin{abstract}
Several standard test methods measuring chemical properties of lubricants were evaluated for use on re-refined lubricating basestocks. The methods evaluated included total acid number (TAN), total base number (TBN), total nitrogen, basic nitrogen, saponification number, and water. Except for the TAN and basic nitrogen test methods, some modifications were necessary for the test methods when applied to re-refined base oils. The evaluation and the modifications for each test method are described.
\end{abstract}

\section{Introduction}

Measurement of particular chemical characteristics of re-refined lubricating base stocks can provide a basis for monitoring quality consistency, as well as detecting or identifying potentially beneficial or deleterious components. Although standardized test methods are available for determining the chemical characteristics of virgin lubricants, few have been tested and evaluated for use with re-refined lubricating base oils.

The Energy Policy and Conservation Act of 1976 (Public Law 94-163) requires the National Bureau of Standards (NBS) to develop test procedures for the characterization of re-refined lubricating oils. This report summarizes the NBS experience with test methods for six chemical properties: total acid number (TAN), total base number (TBN), total nitrogen, basic nitrogen, saponification number, and water content.

The American Society for Testing and Materials (ASTM), Committee D-2 on Petroleum Products, has developed methods for the determination of TAN [1] ${ }^{2}, \operatorname{TBN}$ [1-2], tota] nitrogen [3], water [4], and saponification number [5]. The Universal $0 i 1$ Products Company has published standard methods for the determination of nitrogen [6-7]. Precision statements are given in the standards for certain applications, but re-refined base oils were apparently not considered in the generation of these statements.

The evaluation of the test methods proceeded in several stages. First, standardized test methods currently in use for virgin lubricants were selected for investigation as indicated above. Then, these methods were tested with re-refined lubricants, and the results examined in terms of accuracy, precision, and/or sensitivity. If necessary, these procedures were modified for use with re-refined oils. Finally, the modified procedures were applied to selected re-refined base stocks to demonstrate the ability of the modifications to provide adequate accuracy and precision.

Re-refined basestocks from major re-refining technologies were used to evaluate these test procedures. A total of ten re-refined lubricating base stocks were obtained from current $U . S$. re-refiners. Brief descriptions of these re-refined base oils are shown in table 1 . In the following sections, each of the chemical property test methods are evaluated for use with re-refined oils.

TPresent address: American Sterilizer Company, Erie, PA 16512.

2 Figure in brackets indicate the literature references at the end of this paper. 
Table 1. Source and processing technologies of the re-refined base oils

\begin{tabular}{|c|c|c|c|}
\hline i] ID & Viscosity Grade & Processing Technology & Geographical Area \\
\hline RA & $200 \mathrm{~N}$ & $\begin{array}{l}\text { Pretreat/Vac. dist./ } \\
\text { Clay finish }\end{array}$ & Mid-West (US) \\
\hline RB & $250 N$ & Clay treat & Southwest \\
\hline RC & $350 \mathrm{~N}$ & Acid/Clay & Southwest \\
\hline RD & $300 N$ & Acid/Clay & West Coast \\
\hline RD & $400 N$ & $\begin{array}{l}\text { Caustic Pretreat/ } \\
\text { Vac. dist. }\end{array}$ & Northeast \\
\hline RF & $350 N$ & Acid/Clay & South \\
\hline RG & $300 \mathrm{~N}$ & Acid/Clay & Northwest \\
\hline RH & $250 N$ & Acid/Clay & Canada \\
\hline RI & $350 \mathrm{~N}$ & Acid/Clay & West Coast \\
\hline RJ & $200 N$ & Acid/Clay & Northeast \\
\hline
\end{tabular}

\section{Total Acid Number (TAN)}

The Total Acid Number (TAN) is a measure of the acidic components in an oil. Since acidic constituents in an engine lubricating oil may be detrimental to the stability or performance of a lubricant, it is important to be able to determine their concentration. For re-refined base stocks, the measurement of TAN has additional significance. Since used engine oil often contains large amounts of acidic compounds formed as a result of oxidative degradation, the TAN of base stocks after re-refining may reflect the effectiveness of the re-refining process in removing oxidized acidic components of the feedstocks.

ASTM Standard Test Method D-664, "Neutralization Number by Potentiometric Titration" [1], provides a procedure for the determination of TAN in virgin lubricating oils. Re-refined lubricants were not used in the ASTM cooperative test development program of ASTM D-664.

\subsection{Chemical Basis}

The acidic compounds in oils can be neutralized by reaction with a strong base. The relative strength of an acid is an expression of the degree to which an acid can be neutralized under a given set of conditions. Strong acids react rapidly and completely with strong bases. Weak acids do not react as readily. The relative acidity of the entire reaction solution, especially the solvent, determines how strong a weak acid must be to react quantitatively with a strong base.

ASTM D-664 employs a weakly acidic solvent mixture of toluene, isopropanol, and water, in the ratio 500:495:5. In this solvent system, potassium hydroxide is a strong base and will titrate strong and weak acids which might be present in the oil sample and be soluble in this solvent system. The method uses a glass electrode to monitor the course of the titration. The titration endpoint is the point at which sufficient basic titrant has been added to neutralize all strong and weak acids. That point is recognized by the inflection point of the electrode potential vs. titrant volume curve. In the absence of a clearly defined inflection point, an arbitrary reference electrode potential from a standard buffer solution is taken as the endpoint potentia] [2]. The TAN value is expressed as the number of milligrams of potassium hydroxide required to neutralize the acids in one gram of oil to that end point potential.

\subsection{Evaluation}

In order to measure the low acid levels found in re-refined oils, the concentration of the potassium hydroxide titrant was reduced from $0.1 \mathrm{~N}$, as prescribed by ASTM D-664, to $0.04 \mathrm{~N}$. This change improved the precision and sensitivity of the method on titrations of $20 \mathrm{~g}$ samples of oil. This change is not considered to be a modification, since it is an optional part of the ASTM D-664 method. 
The TAN results of ten re-refined base oils were measured using ASTM D-664 in triplicate, and the results are shown in table 2. The TAN ranged from 0.08 to 1.69 , which is within the range of stated D-664 applicability (0.05 to 250). No modifications were made in applying the method to re-refined base oils. Repeatability is within ASTM D-664 guidelines of $6 \%$ of the mean.

Table 2. Total acid number and total base number of re-refined base oils ${ }^{a}$

\begin{tabular}{|c|c|c|c|c|}
\hline 0i1 & $\operatorname{TAN}(D-664)$ & Repeatability,\% & $\begin{array}{r}\text { TBN, mg KOH/g } \\
\text { (modified } \mathrm{D}-2896 \text { ) } \\
\end{array}$ & $\%$ Deviation \\
\hline N & 0.187 & 6 & 0.0115 & 8 \\
\hline$P$ & 0.081 & 6 & 0.0063 & 16 \\
\hline Q & 0.180 & 2 & 0.0085 & 32 \\
\hline$R$ & 0.145 & 6 & 0.0520 & 4 \\
\hline S & 0.109 & 6 & 0.0215 & 14 \\
\hline$T$ & 0.105 & 6 & 0.0050 & 160 \\
\hline$U$ & 0.810 & 2 & 0.0020 & 200 \\
\hline v & 0.136 & 6 & 0.0025 & 120 \\
\hline$W$ & 0.285 & 4 & 0.0095 & 32 \\
\hline$x$ & 1.69 & 4 & 0.003 & 66 \\
\hline
\end{tabular}

${ }^{a}$ TAN values determined in triplicate, using $0.04 \mathrm{~N}$ potassium hydroxide.

\subsection{Conclusion}

In ASTM D-664, the TAN titration curves can be used to measure the strong and weak acids separately in an oil. For re-refined base oils no strong acids were detected, so applicability of this part of the procedure could not be specifically evaluated. However, based on our experience and historical usage, no difficulties should be encountered in the measurement of strong acid components. No problems were encountered in determination of weak acid components.

\section{Total Base Number (TBN)}

The Total Base Number (TBN) is a measure of the amount of the basic components present in an oil. Most engine oils are formulated with an excess of basic additives to control the buildup of acidic species during use. In addition to these overbase additives, other additives such as inhibitors, detergents, and dispersants with basic functionality are sometimes added to improve lubricant stability and performance. Since re-refined oils are processed from used, formulated lubricating oils, a measure of the basic constituents may be useful.

ASTM has two methods for the determination of TBN in petroleum products. ASTM D-664, "Neutralization Number by Potentiometric Titration" [1], includes a TBN procedure. ASTM D-2896, "Total Base Number of Petroleum Products by Potentiometric Perchloric Acid Titration" [2], employs an acid titrant and titrating solvent stronger than those in the D-664 TBN procedure. Consequently, D-2896 detects weaker bases which are not measured by the D-664 test.

In the development of the precision statements for ASTM D-2896, test samples used were formulated oils, additive concentrates, and used oils. TBN of these samples ranged from 2.9 to 99 [2]. Lubricating base oils were not included. 


\section{1. Chemical Basis}

The basic compounds in a lubricating oil can be neutralized by reaction with a strong acid. The D-2896 procedure is a non-aqueous acid/base titration method. An oil sample is dissolved in a mixture--dry glacial acid and chlorobenzene--and titrated potentiometrically with a solution of perchloric acid in glacial acetic acid. The endpoint of the titration is the inflection point in a plot of the electrode potential difference vs. volume of titrant. The Total Base Number (TBN) is "the quantity of perchloric acid, expressed in terms of the equivalent number of milligrams of potassium hydroxide, that is required to neutralize all basic constituents present in one gram of [oil] sample" [2].

In those cases where the titration inflection points are obscure, a "back-titration" procedure is recommended: An excess of perchloric acid is first added to bring the electrode potential well beyond the neutralization point, and then the solution is titrated back through the endpoint with a solution of sodium acetate in glacial acetic acid. The inflection point in this case is very sharp, and the TBN can be calculated from the difference in perchloric acid and sodium acetate equivalents.

\subsection{Evaluation}

The TBN of a re-refined basestock is typically less than $0.05 \mathrm{mg} \mathrm{KOH} / \mathrm{gram}$ oil. ASTM D-664 is not applicable for this concentration range, hence, D-2896 was used. In order to measure such 10 w base levels, the concentration of the perchloric acid titrant was reduced from $0.1 \mathrm{~N}$, as prescribed by ASTM D-2896, to $0.005 \mathrm{~N}$. This change improved the precision and sensitivity of the method on titrations of $10 \mathrm{~g}$ oil samples. Since direct titration of re-refined oils often produced poorly-defined endpoints, the "back-titration" procedure, as described in D-2895, was employed routine 1y.

Table 2 summarizes the results of the modified 02896 TBN tests for ten re-refined base oils. The applicable range of base number by $0-2896$ for virgin oils as stated in the method is 5.5 to 13.5 $\mathrm{mg} \mathrm{KOH/g}$. The values in table 2 range from 0.002 to $0.05 \mathrm{mg} \mathrm{KOH/g}$ for the ten re-refined base oils. From the percent relative deviation, the detection limit for the method is approximately 0.05 ( $4 \%$ relative deviation vs. the 5\% relative deviation specified by the method for 5.5 to 13.5 TBN). Levels down to 0.01 TBN appear to be possible with up to $30 \%$ relative deviation. Be1ow 0.01 TBN, the relative deviation from the mean becomes quite large. Without the modification described above, precision of the D-2896 probably cannot be extended down to 0.05 TBN. Since the intended use of the method is to monitor excess contamination, it is felt that the method as modified, extending the lower limit from 5.5 to $0.05 \mathrm{TBN}$, is acceptable.

To test the accuracy of the method, known quantities of base compounds were added to 10 grams of a re-refined base $0 i 1$, and the resulting solutions titrated. Table 3 indicates a recovery error of 2 percent or less, the recovery errors representing less than 0.005 TBN units in each case.

Table 3. Recovery of basic compounds in 10 grams re-refined oil by D-2896 TBN method.

\begin{tabular}{|c|c|c|c|}
\hline Base & $\begin{array}{l}\text { Found } \\
\text { TBN } \\
\end{array}$ & $\%$ Recovery & $\begin{array}{c}\text { TBN } \\
\text { Error } \\
\end{array}$ \\
\hline THAM $^{\mathrm{a}}$ & 0.246 & $100.8 \pm 0.7$ & +0.002 \\
\hline Pyridine & 0.106 & $99.8 \pm 0.7$ & -0.0002 \\
\hline$A D 5015^{b}$ & 0.188 & $98 \pm 2$ & -0.004 \\
\hline
\end{tabular}

\footnotetext{
a Tris(hydroxymethy 1)amino-methane.

A commercial, sucinimide dispersant additive.
}

\subsection{Conclusion}

As modified, ASTM D-2896 can be used to determine TBN in re-refined oils down to about 0.05 TBN with a accuracy of about \pm 0.005 to \pm 0.01 . The recommended modification is to reduce the perchloric acid titrant from $0.1 \mathrm{~N}$ to $0.005 \mathrm{~N}$, for samples with low TBN values. 


\section{Total Nitrogen}

ASTM D-3228, "Total Nitrogen in Lubricating $0 i 1 s$ and Fuel 0ils by Modified Kjeldahl Method" [3], is applicable in the determination of down to 0.03 percent ( $300 \mathrm{ppm}$ ) nitrogen in lubricating oils. However, most base oils contain much lower concentrations of nitrogen. A test method, UOP Method 384 [7], and other sources [8-10], describe procedures by which nitrogen-containing compounds can be extracted from oils to extend the effective sensitivity of the normal Kjeldahl method to about 0.0002 percent (2 ppm) nitrogen. The UOP 384 test method was the basic guide for our experimental work; however, in this report all modifications are presented in terms of deviations from the ASTM D-3228 procedure.

\subsection{Chemical Basis}

In the Kjeldahl method, organically-bound nitrogen in the oil is reduced to ammonium sulfate by sulfuric acid digestion. The hydrocarbon material is simultaneously converted to carbon dioxide and water. The ammonium sulfate is then converted to ammonia which is trapped in an aqueous boric acid solution, and this solution is then titrated quantitatively with a standard acid. Nitrogen in most compounds can be detected this way; exceptions are when the nitrogen is bound, as in the nitro- or azo- forms. It should be noted that the overall recovery of nitrogen from a sample can be affected by the temperature at which digestion is performed [10].

Quantitative extraction of nitrogen-containing compounds from petroleum oils can be accomplished with concentrated sulfuric acid [9]. Since sulfuric acid is the digestion reagent in the Kjeldahl procedure, the nitrogen-containing extract can be used directly in the Kjeldahl procedure. The separation is clean, since the sulfuric acid phase is considerably more dense than the petroleum phase.

\subsection{Evaluation}

As discussed briefly above, the D-3228 procedure was modified to use sulfuric acid extraction in order to obtain the required sensitivity. The procedural points by which the modified procedure differs from ASTM D-3228 is shown in table 4. The most important modifications are the monitoring of the digestion temperature and the extraction procedure. The acid extraction of re-refined oils generally produces a viscous black substance in the acid phase. The phase boundary can be detected by transmission of light through the petroleum phase near the phase boundary. The digestion step generally required several hours and frequent additions of $5 \mathrm{ml}$ quantities of acid. With careful attention to digestion temperature, determinations were repeatable to $\pm 2 \mathrm{ppm}$.

Table 4. Differences between ASTM D-3228 Kjeldahl method and NBS modification

Parameter
Sample Size
Digestion Temperature
Digestion Time at
Specified Temperature

Acid Extraction

Acid Volumes $(\mathrm{ml})$

Catalysts:

$$
\begin{aligned}
& \mathrm{K}_{2} \mathrm{SO}_{4} \\
& \mathrm{HgO}^{\mathrm{CuSO}_{4}}
\end{aligned}
$$

$$
\begin{gathered}
\frac{\text { ASTM D-3228 }}{1 \text { to } 15 \mathrm{~g}} \\
\text { not specified }
\end{gathered}
$$

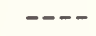

none

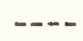

$9.9 \mathrm{~g}$

$0.41 \mathrm{~g}$

$0.08 \mathrm{~g}$

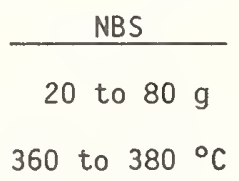

1 hour

yes

5 , then 5

$25 \mathrm{~g}$

$1.1 \mathrm{~g}$ 
Thirteen re-refined base oils were tested for total nitrogen content by this modified method, and the values are given in table 5. Nitrogen contents ranged from 9 to $76 \mathrm{ppm}$. This range is below the stated applicable range of the ASTM D-3228 method of 300 to 1000 ppm with a repeatability of $100 \mathrm{ppm}$.

Table 5. Total nitrogen content of re-refined base oils by modified extraction Kjeldahl method

\begin{tabular}{|c|c|c|}
\hline 011 & $\begin{array}{c}\text { Total Nitrogen } \\
\mu \mathrm{g} \mathrm{N} / \mathrm{g} 0 \mathrm{il} \\
\end{array}$ & $\begin{array}{l}\text { Repeatability } \\
\mu \mathrm{N} / \mathrm{g} 0 i 1 \\
\end{array}$ \\
\hline $\mathrm{N}$ & 47 & 2.0 \\
\hline 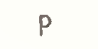 & 9 & 2.2 \\
\hline Q & 18 & 0.7 \\
\hline $\mathrm{R}$ & 17 & 1.3 \\
\hline$S$ & 21 & 2.3 \\
\hline $\mathrm{T}$ & 9 & 1.3 \\
\hline U & 20 & 3.0 \\
\hline V & 13 & 1.2 \\
\hline$W$ & 28 & 1.0 \\
\hline$x$ & 24 & 0.8 \\
\hline$Y$ & 76 & 0.6 \\
\hline Z & 48 & 1.4 \\
\hline M & 9 & 0.2 \\
\hline Mean & 26 & 1.4 \\
\hline Range & 9 to 76 & 0.2 to 3.0 \\
\hline
\end{tabular}

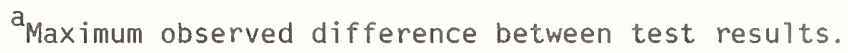

Duplicate and triplicate tests of 15 to $60 \mathrm{~g}$ oil samples typically repeated within 2 ppm nitrogen (table 5). Accurate recovery was demonstrated by determining the nitrogen content of a blend of a base oil with a typical automotive lubricant additive package of known nitrogen content. Recovery was quantitative.

The sensitivity of the test is approximately $2 \mathrm{ppm}$ nitrogen, based on results from two virgin oil samples. However, the detection limit, as well as precision and accuracy, may be impaired if the reagents used in all steps of the procedure are not sufficiently free of nitrogen $[8,9]$.

This modified test procedure determines total Kjeldahl nitrogen in re-refined base oils. It is, however, a time-consuming process. The acid extraction step can be tedious and difficult, but accurate results can be obtained.

\subsection{Alternative Method}

An instrumental, total nitrogen method is currently being evaluated by ASTM Committee D-2, Research and Development Division III [11]. In this method, organically-bound nitrogen is oxidized in a furnace to nitric oxide, which later reacts with ozone and is detected by chemiluminescence. 
The method is rapid, simple to perform, and capable of detecting less than 1 ppm nitrogen in petroleum liquids. ASTM cooperative tests have been completed, and the method is in the process of being considered for final approval as a standard test method.

To get an indication of the suitability of this method for use with re-refined oils, three oils, selected to cover the range encountered, were tested by this method. The results, shown in table 6 , suggest that this method provides total nitrogen determinations in re-refined oils which are equivalent to results obtained using the modified Kjeldahl procedure. Further testing, perhaps after the chemiluminescence method is adopted officially by ASTM, would establish this correspondence more firmly.

Table 6. Comparison of combustion/chemiluminescence nitrogen determination and modified Kjeldahl

$\begin{array}{ccc}0 i 1 & \begin{array}{r}\text { Tota1 } \\ \text { Kjeldah1 }\end{array} & \begin{array}{c}\text { Nitrogen, ppm } \\ \text { Chemilum. a }\end{array} \\ Z & 9 & 10 \\ Y & 48 & 46 \\ Y & 76 & 74\end{array}$

a Data furnished by U.S. Army MERADCOM.

\subsection{Conclusion}

The ASTM D-3228 total nitrogen method as modified can be used to obtain total nitrogen values in re-refined oils. In addition, the ASTM chemiluminescent method also appears to provide a useful method for obtaining total nitrogen values for re-refined oils.

\section{Basic Nitrogen}

Characterization of nitrogen compounds by basicity can be significant. In many cases, the greater the basicity--i.e., the availability of electrons at the nitrogen atom--the more reactive the compound will be. For re-refined oils, the determinations of basic nitrogen can serve a quality assurance purpose by detecting basic nitrogen-containing additives which may not have been removed during re-refining.

There is no existing ASTM method for the determination of basic nitrogen in 1ubricants. The Universal $0 i 1$ Products Company (UOP) has developed a basic nitrogen method [6] which is very similar to ASTM D-2896, the TBN method discussed previous7y. The chemical basis of this basic nitrogen method, UOP 269, is the same as ASTM D-2896. A major difference between the methods is the assumption by which the results are calculated. In the UOP basic nitrogen method, all bases titrated are assumed to contain nitrogen. The results are then expressed as micrograms of nitrogen per gram of $0 i 1$, assuming one mole nitrogen per mole of base titrated.

\section{1. Evaluation}

As the discussion of total base number results applies to basic nitrogen, it will not be repeated here. The results of those tests were recomputed as basic nitrogen and are given in tables 7 and 8 . Expressed as ppm nitrogen, the results suggest that there are very low levels of basic nitrogen-containing molecules present in re-refined base oils. Typical test repeatability is 1 to 2 ppm. The detection limit appears to be about 1 ppm. Basic nitrogen in these re-refined oils ranges from about 1 to $15 \mathrm{ppm}$. The precision appears to be a few percent at nitrogen contents above 15 ppm. The accuracy of the method appears to be excellent. Tests performed on model compounds suggest good recovery, as shown in table 8 . For the purpose of monitoring basic nitrogen contaminants, the method appears to be acceptable. 
Table 7. Basic nitrogen determination in re-refined oils (solvent: chlorobenzene)

$\begin{array}{lcc}\text { 0i1 } & \text { Basic Nitrogen } & \\ \text { N } & \text { Std. Dev. }(1 \sigma) \\ \text { P } 0 i 1 & 0.9 \\ \text { Q } & 2.3 & 1.1 \\ \text { R } & 1.6 & 1.7 \\ \text { S } & 1.1 & 1.8 \\ \text { T } & 14.9 & 0.8 \\ \text { U } & 5.0 & 3 \\ \text { V } & 3 & 0.5 \\ \text { W } & 0.4 & 0.7 \\ \text { X } & 0.7 & 1.1\end{array}$

Table 8. Recovery of model basic nitrogen compounds in 10 grams re-refined oil

\begin{tabular}{|c|c|c|c|}
\hline Compound & $\begin{array}{l}\text { Recovery } \\
\text { ug Nitrogen }\end{array}$ & $\%$ Recovery & $\begin{array}{c}\text { Error } \\
\mu \mathrm{N} \text { Nitrogen } \\
\text { per g } 0 i 1\end{array}$ \\
\hline THAM $^{a}$ & 615 & $100.8 \pm 0.7$ & +0.5 \\
\hline Pyridine & 265 & $99.8 \pm 0.7$ & -.05 \\
\hline$A D 5015^{b}$ & 470 & $98 \pm 2$ & -0.9 \\
\hline
\end{tabular}

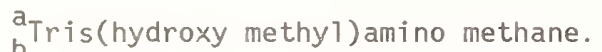

A commercial succinimide dispersant additive.

One potentially significant difference between the ASTM D-2896 and the UOP 269 procedures is the choice of organic solvent. ASTM D-2896 uses chlorobenzene, whereas UOP 269 prescribes toluene. To decide if the choice of solvent affected the basic nitrogen analysis of re-refined oils, several tests were performed with each solvent. The results of triplicate analyses of four re-refined base oils are shown in table 9. There appears to be no consistent difference in results between toluene and chlorobenzene. The observed differences are all within the range of experimental uncertainty. Thus, for the purposes of this test, toluene and chlorobenzene are equivalent solvents.

Table 9. Comparison on chlorobenzene and toluene as solvents in basic nitrogen tests

\begin{tabular}{|c|c|c|c|}
\hline $0 i 1$ & Chlorobenzene & Toluene & Difference \\
\hline$N$ & 3.7 & 2.3 & 1.4 \\
\hline T & 2.4 & 2.8 & -0.4 \\
\hline $\mathrm{R}$ & 15.7 & 14.7 & 1.0 \\
\hline$x$ & 1.2 & 1.6 & -0.4 \\
\hline
\end{tabular}




\title{
5.2. Conclusions
}

As modified, the D-2896 test procedure can be used to measure the basic nitrogen concentrations in re-refined oils.

\section{Saponification Number}

Saponification number is intended to be a measure of the ester-containing constituents of an oil. Potentially, these include esters of fatty acids and ester-based additives. Presence of a large amount of fatty acids in re-refined base oils might suggest incomplete removal of contaminants. ASTM Standard Test Method D-94 [5] provides a procedure for measuring the saponification number in petroleum products. It is applied typically to determining ester additives in new industrial oils.

\subsection{Chemical Basis}

In the ASTM Standard Test Method D-94, "Saponification Number of Petroleum Products" [5], an oil sample is dissolved in methylethylketone (MEK). The solution is heated with a known amount of alcoholic (ethyl alcohol; ETOH) potassium hydroxide which reacts with saponifiable materials in the sample. The excess alkali is then titrated with standard acid and the saponification number is calculated in terms of the milligrams of $\mathrm{KOH}$ consumed per gram of oil sample.

The principal chemical reactions which constitute the ASTM D-94 saponification number test are given in figure 1. Esters, reactions [1] and [2], are typically the object of saponification number tests. Reactions [3] and [5] therefore represent possible interferences and sources of erroneous interpretation due to nitrogen compounds. Reaction [3] has the effect of increasing the apparent saponification number, whereas reaction 5 has the opposite effect. Since re-refined base oils generally have much higher acid numbers than base numbers, reaction 3 might be of greater concern than reaction 5 .

Some compounds of sulfur, phosphorus, the halogens, and other elements which are sometimes found in petroleum products, consume alkali or acids and may affect saponification number test results. The D-94 saponification number is a measure of a potentially wide range of compounds. Saponification number may prove to be a useful screening tool for consistency, however, further analysis (by other methods) will be required to accurately interpret the results. Some practical problems with this test are shown in table 10.

Table 10. Saponification number. Practical Problems with ASTM D94

1. Dark-colored oils can obscure endpoint.

2. Weak acid salts can obscure endpoint.

3. $\mathrm{CO}_{2}$ absorption could cause premature endpoint.

4. Acids in oil may be titrated.

5. Bases in oil may be titrated.

\author{
Eliminate By \\ 1 Potentiometric titration \\ 2 Use Excess $\mathrm{HCl}$, purge with $\mathrm{N}_{2}$, titrate $w / \mathrm{KOH}$ \\ $1,2,3,5 \quad$ Method of Swan, et a1. [12]
}

If an "ester number" is desired, other procedures would have to be developed to remove or correct for acidic, basic, and other potential interferences. Simple adjustment using standard TAN and TBN results is not advisable, because TAN, TBN, and saponification number may overlap in an unpredictable way. Also each of these test procedures employs a different solvent system, so that the acid and base equivalents are not necessarily transferrable. 


\subsection{Evaluation}

The color of the oil can be a major problem when using this test method. Intense oil color can impair detection of the endpoint of a colorimetric titration. As a result, the repeatability could suffer. In an attempt to extend the detection limit of D-94 to oils having saponification numbers below 1, two modifications were examined. First, the sample size was increased to $40 \mathrm{~g}$. However, some of the darker oils could not be analyzed in $40 \mathrm{~g}$ quantities because their dark color hampered detection of the colorimetric titration end-point. For the second modification, a sample size of 20 grams or less was taken and a more dilute titrant $(0.1 \mathrm{~N})$ was used.

Table 11 shows results of the modified D-94 procedure (using the $0.1 \mathrm{~N}$ titrant) on the ten re-refined test oils. The values range from 0.06 to 3.15 . The ASTM D-94 method states an applicability range of 1 to $200 \mathrm{mg} \mathrm{KOH} / \mathrm{g}$ with a precision of \pm 0.25 units at $1 \mathrm{mg} \mathrm{KOH} / \mathrm{g} \mathrm{of} \mathrm{sample.}$ The repeatability of the modified D-94 is shown in table 12 . The test was performed over a period of ten months at a saponification level of $0.15 \mathrm{mg} \mathrm{KoH} / \mathrm{g}$. The precision is acceptable according to D-94 standards.

\section{3. Conclusions}

As modified, the ASTM D-94 test procedure can be used to determine the saponification number of re-refined base oils. The recommended modification is to use a standard acid titrant at the $0.1 \mathrm{~N}$ concentration. At higher values of the saponification number the D-94 method can be used without modification.

A. Reflux with base $(\mathrm{KOH})$ in MEK and Et $\mathrm{OH}$

$$
\begin{aligned}
& \text { 1) } \mathrm{R}^{\prime} \mathrm{COOR}+\mathrm{KOH} \rightarrow \mathrm{R}^{\prime} \mathrm{COO}-\mathrm{K}^{+}+\mathrm{ROH} \\
& \text { 2) } \mathrm{R}^{\prime} \mathrm{COO}-\mathrm{CH}_{2}+\mathrm{KOH} \rightarrow \mathrm{R}^{\prime} \mathrm{COO}^{-} \mathrm{K}^{+}+\mathrm{HO}^{-} \mathrm{CH}_{2} \\
& \text { 3) } \mathrm{RCOOH}+\mathrm{KOH} \rightarrow \mathrm{RCOO}{ }^{-} \mathrm{K}^{+}+\mathrm{H}_{2} \mathrm{O}
\end{aligned}
$$

B. Titrate excess base with acid ( $\mathrm{HCl}$ )
4) $\mathrm{KOH}+\mathrm{HCl} \rightarrow \mathrm{KCl}+\mathrm{H}_{2} \mathrm{O}$
5) $\mathrm{R}-\mathrm{N}+\mathrm{HCl} \rightarrow \mathrm{R}-\mathrm{N}: \mathrm{H}^{+} \mathrm{Cl}^{-}$

Figure 1. Saponification number reactions.

Table 11. Evaluation of the modified Saponification number for re-refined base oils

\begin{tabular}{cr}
$0 i 1$ Code & $\begin{array}{r}\text { Saponificatio } \\
\mathrm{mg} \mathrm{KOH} /\end{array}$ \\
\cline { 2 - 2 } A & 0.09 \\
B & 0.61 \\
C & 0.36 \\
D & 1.46 \\
E & 3.15 \\
F & 0.06 \\
G & 0.23 \\
H & 0.17 \\
I & 0.24 \\
J & 1.03
\end{tabular}




\section{Water}

Water in oil can cause corrosion of engine parts. In re-refined base oils, if there is residual dispersant additive present, the water content could be much higher than predicted by solubility. ASTM standard test method D-1744, "Water in Liquid Petroleum Products by Karl Fischer Reagent" [4], provides a procedure for determining 50 to $1000 \mathrm{ppm}$ water in 1 iquid petroleum products. Base oils typically contain 50 to 150 ppm water.

\subsection{Chemical Basis}

In the Karl Fischer reaction, water reacts with iodine and sulfur dioxide to produce iodic acid and sulfur trioxide. Efficient reaction is achieved only in the presence of a complexing agent, like pyridine, and a protolytic solvent, such as methanol, which help remove sulfur trioxide from the system [13]. The titration endpoint of the Karl Fischer reagent is determined

electrometrically. After all the water has reacted, iodine is free to react at a polarized electrode to form iodide ions. The resultant current signals the endpoint.

Any substance that reacts with iodine or interferes with the electrode reaction will cause errors in the Karl Fischer determination of water. Some substances which react with iodine include free alkali, oxidizing and reducing agents, mercaptans, and certain nitrogenous substances. Fouling

Table 12. Repeat test data on oil "A" from the modified saponification number test

Saponification Number $\mathrm{mg} \mathrm{KOH} / \mathrm{g}$

0.16

0.17

0.14

0.17

0.14

0.09

0.23

0.13

0.15

0.15

0.15

0.14

0.12

0.15

0.20

Mean

0.15

Std. Deviation ( $1 \sigma)$

0.03 
of electrodes can occur if the oil contains substances such as polyisobutylene, which does rot dissolve in the Karl Fischer reaction solution. These substances can coat the electrode surface, physically interfering with the electrode reaction.

\subsection{Evaluation}

In testing over 75 re-refined baseoil samples, 30 to $400 \mathrm{mg}$ water per gram of oil was determined with good repeatability. These results suggest that the D-1744 procedure is applicable to the determination of water in most re-refined base stocks. Five of the oils were not titrable because a waxy substance separated from the solution and coated the electrodes, which made endpoint detection impossible. This problem was then further examined.

As a result of the above problems with some re-refined oils, modifications were evaluated in sample size, endpoint conditions, and the method for endpoint interpretation. To summarize, the sample volume and endpoint conditions differed from those prescribed by ASTM 0-1744 as follows. Sample volume was $15 \mathrm{ml}$, rather than the $50 \mathrm{ml}$ suggested by $\mathrm{D}-1744$, since the 1 arger volume sometimes resulted in an unstabie endpoint. Also, an azeotropic distillation step was used for some oils. These modifications are discussed more fully below.

The endpoint conditions were also modified in this evaluation. The endpoint current prescribed in D-1744, Section 7.1.1 is $1 \mu \mathrm{A}$. However, for most modern commercial titrators, $1 \mu \mathrm{A}$ is a negligible current. A better endpoint current is $30 \mu \mathrm{A}$, and that value was used during this evaluation.

The volume of titrant required to titrate the water in a sample was determined by a method different from that given in D-1744. Because the Karl Fischer titration endpoint is unstable, a certain "baseline" rate of reagent consumption is required to maintain the endpoint current at $30 \mu A$ in the absence of a sample. An automatic titrator can be set to maintain the endpoint current at 30 $\mu A$ and the reagent volume dispensed can be recorded as a function of time on a strip chart. In use, the "baseline" reagent consumption is recorded until a test specimen is introduced into the reaction solution. Upon introduction of a specimen, reagent is dispensed rapidly until the water from the specimen is consumed, whereupon the "baseline" reagent dispensing rate is again observed. The reagent volume represented by the distance between extrapolated baselines before and after specimen introduction is thus the volume required to titrate the test specimen. This procedure avoids some potential errors which can occur when the D-1744 "dead-stop" procedure is used. It also requires less attention from the operator prior to introduction of the sample.

An azeotropic distillation step was added to the procedure to facilitate water determinations in those oils that cause electrode fouling, when tested in the normal procedure. Water from the oil is transferred to the Karl Fischer reaction flask as a vapor-phase azeotrope with toluene. The sample is mixed with dry toluene in a round-bottom flask. Nitrogen is bubbled through the toluene and oil solution to aid the transfer. As the solution is heated to a maximum of $100^{\circ} \mathrm{C}$, the nitrogen carries the water-toluene azeotrope vapors up through a glass tube and into the Karl Fischer reaction solution, where the water reacts with Karl Fischer reagent.

The azeotropic distillation procedure has several advantages over the direct $0-1744$ titration procedure. Consumption of Karl Fischer reagents and titration solvents is reduced, there is 1 ess downtime between samples, and many possible chemical and physical interferences are avoided.

General considerations for use of the Karl Fischer test are also noted as follows. Best repeatability was obtained when fresh Karl Fischer solvent was used for each sample titrated. Titrations of second and third samples in the same aliquot of soivent did not repeat consistently the results of the first titrations in many cases.

Table 13 lists results of the D-1744 moisture determinations of the 10 re-refined base oils. Water contents ranged from 40 to $219 \mathrm{ppm}$. Uncertainty of the determinations is about $\pm 5 \mathrm{ppm}$, expressed as a standard deviation of at least three measurements. (For example, four tests of an $0 i 1$ yielded results of $96,88,84$, and $92 \mathrm{ppm}$. The average is 90 with a standard deviation of 5 ppm.) This is well within the stated repeatability of D-1744, 11 ppm of water. 
Table 13. Moisture content of re-refined base oils

\begin{tabular}{|c|c|}
\hline $0 i 1$ & $\mu \mathrm{g} \mathrm{H}_{2} \mathrm{O} / \mathrm{g} \mathrm{Oi}$ \\
\hline $\mathrm{N}$ & 88 \\
\hline P & 56 \\
\hline Q & 87 \\
\hline$R$ & 108 \\
\hline$S$ & 57 \\
\hline $\mathrm{T}$ & 90 \\
\hline$U$ & 91 \\
\hline V & 40 \\
\hline W & 75 \\
\hline$x$ & 219 \\
\hline
\end{tabular}

Accurate recovery of water was demonstrated by titrations of pure water before and afier additions of oil to the Karl Fischer reaction solution. Results differed by 5 percent or less. Tests which included the azeotropic distillation step demonstrated similar repeatability as shown in table 14.

Table 14. Repeatability of azeotropic Karl Fisher titration

$\underline{0 i 1}$

RB007

VB5090
Moisture Content

$$
\underline{\mu g ~} \mathrm{H}_{2} \mathrm{O} / \mathrm{g} \mathrm{Oi} 1
$$

123

118

110

31

28

41
Average

114
Std. Dev. $(1 \sigma)$

6

7

\subsection{Conclusions}

The Karl Fischer titration method for water, ASTM D-1744, has been found to be acceptable for the determination of water in re-refined oils with the modifications as described above.

\section{Summary}

Six existing standard test methods were evaluated for the determination of the chemical properties of ten re-refined base oils typical of those commercially available in the United States. These test methods include: TAN, TBN, nitrogen, basic nitrogen, saponification number, and water content in base oils. All of the test methods except TAN and basic nitrogen required some modification. Most of the modifications were necessary to extend the detection limit to lower ranges. Practical lower detection limits, for each of these characteristics are as follows: total acid number, 0.1 units; total base number, 0.05 unit; total nitrogen, $50 \mathrm{ppm}$; basic nitrogen, 15 ppm; saponification number, 0.1 unit; and water, $20 \mathrm{ppm}$. These test procedures, as modified, were found acceptable to monitor the chemical properties of re-refined base oils. 


\section{References}

[1] ASTM D-664 Test for Neutralization Number by Potentiometric Titration, Annual Book of ASTM Standards, part 23.

[2] ASTM D-2896 Test for Total Base Number of Petroleum Products by Potentiometric Perchloric Acid Titration, Annual Book of ASTM Standards, part 24.

[3] ASTM D-3228-79 Test for Total Nitrogen in Lubricating 0i1s by Modified Kjeldah1 Method, Annual Book of ASTM Standards, part 25.

[4] ASTM D-1744-64 Test for Water in Liquid Petroleum Products by Karl Fischer Reagent, Annual Book of ASTM Standards, part 24.

[5] ASTM D-94-71 Test for Saponification Number of Petroleum Products, Annual Book of ASTM Standards, part 23.

[6] UOP 259-70T, Nitrogen Bases in Hydrocarbons by Potentiometric Titration, Universal 0i1 Products Company, Des Plaines, IL, 1970.

[7] UOP 384-76, Nitrogen in Petroleum Distillates and Heavy $0 i 1$ by Acid Extraction or Direct Kjeldahl Procedures, Universal 0 il Products Company, Des Plaines, IL, 1976.

[8] Nobe1, E.D., "Determination of Trace Kjeldahl Nitrogen in Petroleum Stock," Ana1. Chem. 27, (9), 1413-1416 (1955).

[9] Milner, 0.I., Zahner, R.J., Hepner, L.S., and Cowe11, W.H., "Determination of Trace Quantities of Nitrogen in Petroleum Fractions," Anal. Chem., 30 (9), 1528-1530 (1958).

[10] Lake, G.R., McCutchan, P., VanMeter, R., and Neel, J.C., "Effects of Digestion Temperature on Kjeldahl Analyses," Anal. Chem., 23 (11), 1634-1638 (1951).

[11] "A Method for Determining Nitrogen in Hydrocarbons by Oxidative Combustion, Chemiluminescence Detection," Working Document for ASTM Committee D2-RDD IIIC (1981).

[12] Swann, W. B., Zahner, R. J., and Milner, 0. I., "Improved Saponification Number Determination by Use of Ion Exchange," Ana1. Chem., 30 (11), 1830-1833 (1958).

[13] Mitche11, J. and Smith, D. M., "Aquametry," Interscience, New York, 1948. 
National Bureau of Standards Special Publication 674. Proceedings, Conference on Measurements and Standards for Recycled 0il - IV, held at NBS, Gaithersburg, MD, September 14-16, 1982. (Issued July 1984).

\section{EVALUATION OF ASHING METHODS FOR THE DETERMINATION OF TOTAL METAL CONTENT OF LUBRICATING OIL BASESTOCKS}

J. J. Comeford and S. M. Hsu

Chemical Stability and Tribology Group

Inorganic Materials Division

National Bureau of Standards

Washington, DC 20234

Ash from a petroleum oil is the residue, free of carbonaceous material, remaining after burning and ignition in air at a specified high temperature. Ash content of a re-refined oil provides a method for the determination of total metals resulting from wear or additive metals remaining after re-refining.

Three ashing methods were evaluated for metal retention to ensure that the ash value reflects an oil's total metal content, including such metals as magnesium and lead which are volatile under the ashing conditions. The sulfated ash method (ASTM 0874) was found to have good metal retention properties, and was modified to improve its precision in the low ash range.

The sulfated ash content of ten re-refined basestocks, representing products from most of the major U.S. re-refiners, ranged from 0.005 percent of 0.017 percent. The majority of the virgin stocks measured had ash values below 0.005 percent.

\section{Introduction}

Ash from a petroleum oil may be defined as the residue, free from carbonaceous material, remaining after burning and ignition in air at a specified high temperature of the sample [1] ${ }^{1}$. The ash content of a lubricating base oil indicates the relative amount of ash-forming elements remaining after refining. Therefore, it also reflects the degree and effectiveness of the refining process in removing these elements. In the case of re-refined lubricating base oils, ash content could indicate the amount of residual additive metals after the re-refining process. In addition, an indication of wear metals or other ash-forming elements acquired in use and remaining after re-refining may be obtained also. High levels of these metals, indicated by high ash values, may suggest deficiencies in the re-refining of the oil. The presence of large amounts of these metals may affect the oil performance. Ash content, therefore, to some extent reflects the contaminant level of the oil.

Ashing techniques have been applied to a wide range of organic materials to determine their inorganic components; e.g., the mineral contents of foods and biological specimens [2,3]. Ashing of a sample involves the use of heat--ignition and burning--or chemical means to remove carbonaceous material, leaving an inorganic residue comprised generally of the oxides of the metals. In this study only ashing techniques applicable to petroleum lubricating oils are evaluated.

The ash content of petroleum oils is an indication of the amount of inorganic matter present in the oil. In a virgin crude oil these may be naturally-occurring elements s'dch as chromium, nickel, vanadium, and sodium [4]. Nickel and chromium, which occur in the form of volatile organo-metallic complexes in the oil, may be lost easily during the initial ignition step. To avoid this loss, a wet ashing or predigestion step may be used. Replacing the ignition step by digestion in a strong chemical agent such as fuming sulfuric acid removes the hydrocarbon components while reducing the loss of volatile metals. These naturally-occurring metals are not present in significant quantities in refined base oils.

1Figures in brackets indicate the literature references at the end of this paper. 
In the case of re-refined oils, three additional sources of ash precursors may be present, depending upon the completeness of re-refining: residual additives, wear metals, or contaminants. Additive metals, including those in the fuel, may be lead, calcium, zinc, magnesium, and silicon. Wear metals resulting from engine components are primarily iron, aluminum, and copper. Silicon and iron may result from contaminants such as dirt or rust. Analytical results of metals in various oils are given in tables 1-3.

In formulated oils, ash is used to monitor additive content when metal-based additives are employed. These additives may contain compounds of zinc, calcium, silicon, and magnesium [5].

In table 1 the metal content of a typical re-refining feedstock (used oil) is given, as well as that of a re-refined base oil. Metal contents of virgin basestocks are generally below the detectable limits for conventional atomic absorption spectroscopy--in these cases less than 1 to 5 $\mu \mathrm{g} / \mathrm{g}^{--}$as indicated in table 1 . Of the elements 1 isted in table 2 and summarized in table 3 , barium, calcium, and zinc are commonly associated with additives present in the oil. Successful re-refining of the oils listed in the table is indicated by the removal of essentially all of the wear and additive metals, compared with the feedstock values shown in table 1 .

Given the wide range of elements as summarized in table 3 , and the possibility of volatile compounds, it is important that the ashing conditions minimize the loss of the metals that may be present in re-refined oils. Temperature, chemical composition of the ash, and the ashing procedure itself will affect metal retention.

\section{Ashing Methods}

Ashing of petroleum oils may be accomplished in several ways $[2,6-8]$. A weighed sample of approximately $50 \mathrm{~g}$, placed in a refractory dish such as porcelain or Vycor, is ignited and burned. The sample may require heating to maintain the burning. The carbonaceous material remaining is driven off by heating the sample to a constant weight in a furnace at $775{ }^{\circ} \mathrm{C}$, this temperature having been found to produce an ash of repeatable composition. Metals present in the sample are converted to their oxides by this method. Since the oxides of certain metals such as lead are volatile or decompose at this temperature, the ash may be treated with sulfuric acid (sulfation) after ignition to convert the less stable oxides to sulfates and hence lower metals 10ss [3,4]. The melting points for the oxides and sulfates of elements likely to be found in re-refined oils are shown in table 4 [9]. For most of the elements of concern, both oxides and sulfates are stable at the ashing temperature, $775{ }^{\circ} \mathrm{C}$. However, the sulfates of iron and zinc are unstable at the ashing temperature and decompose to the more stable oxides. In the case of lead in the regular ashing method, D482, a number of oxides are produced, most of which decompose below $775{ }^{\circ} \mathrm{C}$. Hence, conversion to the sulfate results in reduction of lead loss and a stable ash of constant composition.

Only ashing methods applicable to petroleum derived lubricating oil basestocks were evaluated in this study. The methods were examined for precision, repeatability, and accuracy with respect to both virgin and re-refined base oils. Three ashing methods--D482 (IP 4) ash, ASTM D874-79 (IP 163/78) sulfated ash, and a wet ashing procedure--were studied [1].

The ASTM D482 ash method involves burning a weighed sample and subsequent ignition of the carbonaceous residue in a muffle furnace at $775{ }^{\circ} \mathrm{C}$ to constant weight. The ASTM D874 sulfated ash method involves burning the weighed sample until only ash and carbon remain. The residue is then treated with concentrated sulfuric acid, $\mathrm{H}_{2} \mathrm{SO}_{4}$, and heated in a furnace at $775{ }^{\circ} \mathrm{C}$ until oxidation of the carbon is complete. The sample is re-treated with dilute sulfuric acid (1:1) and heated at $775^{\circ} \mathrm{C}$ to constant weight. In the third method, wet ashing, an initial sample, weighing $50 \mathrm{~g}$ or more is destroyed with strong oxidizing agents, and taken to dryness. The sample is then placed in a muffle furnace at $550^{\circ} \mathrm{C}$ and heated to constant weight.

D482 is intended to measure ash-forming materials in petroleum products free from ash-forming additives. A lower limit of applicability is not stated, although precisions are given to 0.001 percent ash [1]. D874, sulfated ash, was developed for use in measuring additive metal concentrations of compounded oils with a minimum ash of 0.005 percent [1]. A majority of the re-refined and virgin base oils tested yielded ash values below the stated minimum level for method D874 as shown in table 5. Therefore, the applicability of these methods in the low ash range--i.e., below 0.005 percent--was examined. 
Table 1. Metal analysis for used and based oils

\begin{tabular}{|c|c|c|c|}
\hline Element $(\mu \mathrm{g} / \mathrm{g})$ & Used $0 i 1$ [11] & ${\underline{\text { Re-Refined } 0 i 1^{a}}}^{\mathrm{a}}$ & $\underline{V i r g i n}^{0}{ }^{b}$ \\
\hline Barium & 260 & $<0.5$ & $<0.5$ \\
\hline Calcium & 1431 & $2.5 \pm 0.1$ & $<0.2$ \\
\hline Magnesi um & 227 & $0.78^{C}$ & ND \\
\hline Sodium & 764 & $0.42^{d}$ & $0.02^{d}$ \\
\hline Zinc & 860 & $2.3 \pm 0.9$ & $<0.2$ \\
\hline Aluminum & 10 & ND & ND \\
\hline Chromium & 7 & ND & ND \\
\hline Copper & 41 & ND & ND \\
\hline Iron & 129 & $10.5 \pm 1.1$ & 1.1 \\
\hline Lead & 4890 & $1.4 \pm 0.2$ & $<1$ \\
\hline Silicon & 38 & $<5$ & $<5$ \\
\hline
\end{tabular}

ND - Not determined.

aAS, T. Rains, Average of forty determinations (AAS = Atomic absorption spectroscopy).

bAS,

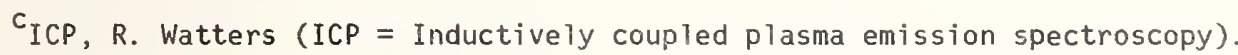

$\mathrm{d}_{\text {NAA, }}$ R. Fleming $($ NAA $=$ Neutron activation analysis $)$.

Table 2. Metal content of re-refined base oils ${ }^{a}$

$\begin{array}{lcccccc}\text { Sample } & \underline{\mathrm{Ba}} & \underline{\mathrm{Ca}} & \underline{\mathrm{Fe}} & \underline{\mathrm{Pb}} & \underline{\mathrm{Si}} & \underline{\mathrm{Zn}} \\ \mathrm{RA} & <0.5 & 0.23 & <0.5 & 2.3 & <5 & 9.4 \\ \mathrm{RB} & <0.5 & 1.8 & 0.7 & 1 & <5 & 0.7 \\ \mathrm{RC} & <0.5 & 2.5 & 9.5 & 1 & <5 & 1.9 \\ \mathrm{RE} & <0.5 & 10 & 0.6 & 2.7 & <5 & 41 \\ \mathrm{RF} & <0.5 & 0.6 & <0.5 & <1 & <5 & <0.2 \\ \mathrm{RG} & <0.5 & <0.2 & 2.9 & <1 & <5 & <0.2 \\ \mathrm{RH} & 0.5 & 0.47 & 1.4 & <1 & <5 & <0.2\end{array}$

atomic absorption spectroscopy. 
Table 3. Range of metal concentrations for re-refined base oils ${ }^{a}$

$\begin{array}{lcc}\text { Element } & \text { Maximum }(\mu \mathrm{g} / \mathrm{g}) & \text { Minimum }(\mu \mathrm{g} / \mathrm{g}) \\ \text { Barium } & <0.5 & <0.5 \\ \text { Calcium } & 13 & <0.2 \\ \text { Iron } & 10.5 & 0.2 \\ \text { Lead } & 2.5 & <1 \\ \text { Magnesium } & 0.78 & 0.18 \\ \text { Zinc } & 41 & <0.2\end{array}$

${ }^{\text {aAS, T. Rains. }}$

Table 4. Melting points for oxides and sulfates, ${ }^{\circ} \mathrm{C}$

\begin{tabular}{|c|c|c|c|c|c|}
\hline \multirow[t]{2}{*}{ Element } & \multicolumn{2}{|c|}{$0 x i d e$} & \multicolumn{3}{|c|}{ Sulfate } \\
\hline & Compound & Melting Point & Compound & Melt & ing Point \\
\hline Barium & $\mathrm{BaO}$ & $1923^{\circ}$ & $\mathrm{BaSO}_{4}$ & & $1580^{\circ}$ \\
\hline Calcium & $\mathrm{CaO}$ & $2565^{\circ}$ & $\mathrm{CaSO}_{4}$ & & $1450^{\circ}$ \\
\hline Iron & $\mathrm{Fe}_{2} \mathrm{O}_{3}$ & $1565^{\circ}$ & $\mathrm{Fe}_{2}\left(\mathrm{SO}_{4}\right)_{3}$ & dec. & $480^{\circ}$ \\
\hline \multirow[t]{4}{*}{ Lead } & $\mathrm{Pb} 0$ & $880^{\circ}$ & $\mathrm{PbSO}_{4}$ & & $1170^{\circ}$ \\
\hline & $\mathrm{PbO}_{2}$ & $290^{\circ b}$ & & & \\
\hline & $\mathrm{Pb}_{2} \mathrm{O}_{3}$ & $370^{\circ}$ & & & \\
\hline & $\mathrm{Pb}_{3} \mathrm{O}_{4}$ & $500^{\circ}$ & & & \\
\hline Magnesium & $\mathrm{MgO}$ & $2800^{\circ}$ & $\mathrm{MgSO}_{4}$ & dec. & $1124^{\circ}$ \\
\hline silicon & $\mathrm{SiO}_{2}$ & $1600^{\circ}$ & $\mathrm{SiO}_{2}$ & & $1600^{\circ}$ \\
\hline Zinc & $\mathrm{ZnO}$ & $1975^{\circ}$ & $\mathrm{ZnSO}_{4}$ & dec. & $600^{\circ}$ \\
\hline
\end{tabular}

${ }^{a}$ CRC Handbook of Chemistry and Physics, $49^{\text {th }}$ ed.

$b_{\text {dec. }}=$ decomposes. 
Table 5. Sulfated ash values for lubricating base oils Method $0874 M^{a}$

\begin{tabular}{|c|c|c|c|c|}
\hline Sample & $n$ & Ash \% ( $\bar{x})$ & $\mathrm{s}$ & RSD \\
\hline RA & 3 & 0.0039 & 0.0002 & 5 \\
\hline RB & 3 & 0.0012 & 0.0006 & 5 \\
\hline $\mathrm{RC}$ & 3 & 0.0066 & 0.0001 & 1 \\
\hline $\mathrm{RD}$ & 2 & 0.0183 & 0.0008 & 5 \\
\hline RE & 3 & 0.0170 & 0.0003 & 2 \\
\hline RF & 3 & 0.0005 & 0.0001 & 17 \\
\hline RG & 2 & 0.0030 & 0.0004 & 14 \\
\hline $\mathrm{RH}$ & 3 & 0.0046 & 0.0009 & 19 \\
\hline RI & 2 & 0.0019 & 0.0002 & 10 \\
\hline RJ & 3 & 0.0022 & 0.0012 & 55 \\
\hline RK & 3 & 0.0043 & 0.0010 & 23 \\
\hline RL & 3 & 0.0025 & 0.0002 & 9 \\
\hline VA & 2 & $0.0000^{b}$ & -- & -- \\
\hline VB & 3 & 0.0000 & --- & -- \\
\hline VC & 3 & 0.0000 & -- & -- \\
\hline VD & 3 & 0.0005 & 0.0001 & 23 \\
\hline VE & 3 & 0.0000 & --- & -- \\
\hline VF & 3 & 0.0000 & --- & -- \\
\hline VG & 3 & 0.0038 & 0.0012 & 30 \\
\hline
\end{tabular}

Method D874 modified by using Vycor crucibles and constant cooling time.

Weights of ash of less time than $0.2 \mathrm{mg}$ or $0.004 \%$ were taken as zero.

The possible loss of metals, such as lead and magnesium, through volatilization during ashing required an evaluation of the degree of metal retention for these methods. Clearly, loss of significant amounts of metals during ashing would reduce the usefulness of the method as an indicator of metal-containing compounds. The regular ash method, D482, was found to be less satisfactory than D874 due to the loss of lead and magnesium during ashing. The sulfated ash, D874, was found to provide a satisfactory measurement of the ash-forming elements, including lead and magnesium, down to 0.004 percent total ash. 
D874 was modified to improve its precision in the low ash range. These modifications consisted of the use of Vycor dishes for ashing and a constant cooling time after removal of the sample from the muffle furnace. The modified sulfated ash method, distinguished here as D874M, was found to improve results with re-refined lubricating base oils (see Section 5, below).

\section{Evaluation of Ashing Method Precision}

Precision of ASTM test methods is defined in terms of repeatability and reproducibility of the method. Repeatability is the amount of difference between successive test results, obtained by the same apparatus and operator under identical test conditions, that would be exceeded only in one case in 20. Reproducibility is the difference between two, single and independent results, obtained by different operators working in different, laboratories on identical test material which would, in the long run, in the normal and correct operation of the test exceed only one case in 20.

Several factors may affect the precision of ashing methods. For example, the relative precision of the method tends to decrease with the value of the ash content. Ash contents of basestocks are generally low, and in some instances fall below the published lower limit for a given method. Also, design parameters of the methods--e.g., the way the ash samples are weighed--will affect the precision. An additional variable is the type of metallic element(s) present in the oil. Elements which may be lost easily through volatilization during the ashing process will increase the variability of the results, hence, lowering the precision.

The first factor, low levels of ash, is discussed here. Section 4 addresses the problem of metal loss in various methods. Modifications to D874, sulfated ash, designed to improve the low-level precision are discussed in Section 6.

Since the ash content for re-refined basestocks often falls below the stated ranges for the methods, it was necessary to evaluate the precision in the low range. ASTM method D482, "Ash from Petroleum Products," has no stated lower limit, and is intended for products that are free from added ash-forming additives. The test method states that it has a repeatability of 0.003 percent ash in the range 0.001-0.79 percent ash. ASTM D874, "Sulfated Ash from Lubricating 0ils and Additives," has a stated lower limit of applicability of 0.005 percent ash. It is intended for additive-containing oils, and, at levels below 0.02 percent ash, is restricted to oils containing ashless additives. The "wet ashing" technique, which employs strong oxidizing agents, is not an ASTM method and has no established lower limit of precision.

A re-refined base $0 i 1$, RB, was selected to determine the repeatability of the methods. Metal analyses by means of AAS showed low levels of metals in the indicated amounts: calcium, $1.2 \mu \mathrm{g} / \mathrm{g}$; zinc, $0.5 \mu \mathrm{g} / \mathrm{g}$; iron, $0.8 \mu \mathrm{g} / \mathrm{g}$; and 1ead, less than $0.1 \mu \mathrm{g} / \mathrm{g}$. Silicon was found to be less than 5 $\mu \mathrm{g} / \mathrm{g}$. Therefore, a low ash value was anticipated. Multiple determinations of the ash level of RB by the various methods being evaluated were made. The data are given in table 6.

For method D482, al1 values obtained fell within the stated precision for the method. However, Operator C's values were at the lower limit of applicability and B's were below the limit of applicability. All values for sulfated ash, D874, fell below the stated lower limit for the method. Since the metal content of RB0023 is relatively low, as mentioned above, fluctuations in the low ash range shown in table 6 are not due to metal loss but to method design, as will be discussed in Section 6.

Precision daca for method 0874 on ash values below 0.02 percent was originally developed by ASTM using platinum crucibles. Table 7 compares for ash values obtained using the modified sulfated ash (fused silica crucibles) with values obtained using platinum. The observed repeatability for both types of crucibles is within the limits called for in the precision statement of 0874. Although the results with platinum show somewhat improved repeatability, their use is not recommended due to the 1 imited avajlability of large (120-150 ml capacity) crucibles and the possibility or damage to the platinum if phosphorus is present [1]. 
Table 6. Precision of ashing methods for a re-refined basestock, RC

\begin{tabular}{|c|c|c|c|c|c|c|}
\hline Method & Operator & $\underline{n}$ & $\underline{\bar{x}(\%)}$ & $\underline{S(\%)}$ & $\operatorname{RSD}(S / X) \times 100$ & $\begin{array}{c}\text { Reproducibilit } \\
\text { as stated in } \\
\text { method }(\%) \\
\end{array}$ \\
\hline \multirow[t]{3}{*}{ D482 } & A & 3 & 0.0027 & 0.0007 & 27 & .005 at $.001 \%$ \\
\hline & B & 2 & 0.0005 & 0.0003 & 64 & \\
\hline & $c^{a}$ & 2 & 0.0011 & 0.0003 & 27 & \\
\hline \multirow[t]{2}{*}{ D874 } & A & 3 & 0.0036 & 0.001 & 30 & 0.002 at 0.005 \\
\hline & B & 3 & 0.0017 & 0.0006 & 36 & \\
\hline Wet Ash & B & 4 & 0.0044 & 0.0014 & 32 & \\
\hline D874M & $c^{a}$ & 3 & 0.0022 & 0.0002 & 8 & \\
\hline
\end{tabular}

${ }^{\mathrm{a}}$ Constant cooling time with Vycor dish.

4. Evaluation of Ashing Method Metal Retention

The three ashing methods for petroleum oils were evaluated for metal loss using both single element additions and multiple element additions to the oils. Single element studies were limited to lead, since of the more volatile elements, lead is more likely to be found in re-refined oils $[2,5,9]$. The multi-element studies were done using typical chemical forms of the elements used in additives to evaluate possible interactions to form more volatile compounds; e.g., reactions to form volatile phosphorous compounds.

\subsection{Single Element Additions}

The method of standard additions was used to evaluate lead recovery. The method involves addition of known amounts of a standard solution of a lead compound to the oil sample and determination of the weight of the resulting ash. Since the ash level will now be in the applicable range for the analysis method, this procedure eliminates the problems associated with analyses of samples with low ash values. The ashing method used was ASTM D874M, sulfated ash, modified to improve its precision in the low ash range (percent ash <0.02) (see Section 5).

Known amounts of lead in a "standard" solution were added to a very low ash re-refined base oi1. The standard solution was prepared from SRM 2059b, lead cyclohexanebutyrate, which contains $36.65 \pm 0.065$ percent lead by weight. The solution was made up to approximateiy $1000 \mu \mathrm{g} / \mathrm{g}$ of $\mathrm{Pb}$ in low ash Conostan base oil. Equivalent amounts of the standard lead solution were added to the base oil and the sample ashed. Three different levels of added lead were used with multiple determinations at each level. 
The experimental results are found in table 8 . If we assume complete conversion of the ash to $\mathrm{PbSO}_{4}$, the percent lead may be calculated from the slope of a plot of $\mathrm{mg} \mathrm{Pb}$ added vs mg ash obtained. The ratio lead/lead sulfate is the gravimetric factor converting lead sulfate to lead. The slope from figure 1 equals the milligrams of ash divided by the milligrams of lead, 9.4/7.0. The percent lead equals $9.4 / 7.0$ times the gravimetric factor, lead/lead sulfate, times 100, or 92 percent.

Table 7. Comparison of precisions for sulfated ash using platinum and Vycor crucibles

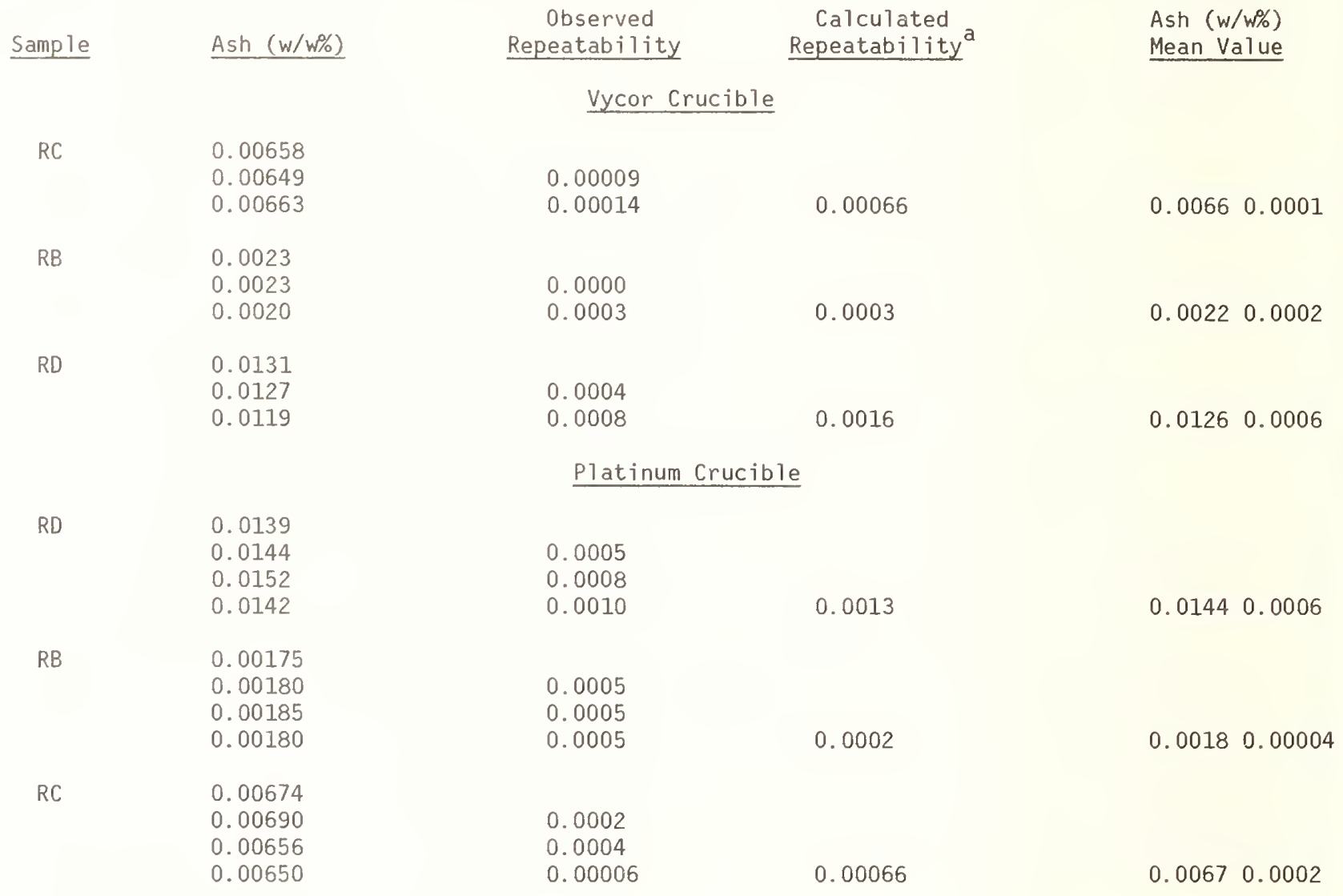

\footnotetext{
${ }^{a}$ Calculated repeatability $=0.047 \times{ }^{0.85}$ where $x$ is mean of two consecutive determinations under identical conditions.

${ }^{\mathrm{b}}$ Calculated reproducibility $=0.189 \times{ }^{0.85}$ where $\times$ is mean of two test results under different conditions. For RB0042 calculated repeatability $0.0049 \%$.
}

\subsection{Multiple Element Additions}

The possibility of synergistic effects (e.g., increases in the loss of certain elements) arising from the additive compound type was investigated using multi-element additions to the base oil. Losses could arise, for example, through the formation of volatile phosphorus or sulfur compounds by reactions with the additive zinc dithiophosphate. By including elements known to be non-volatile, such as iron and calcium, the analytical recovery of the procedure can be checked.

Known amounts of iron, lead, zinc, calcium, and magnesium compounds were added to an ashless 0i1. The chemical compounds used for the zinc, calcium, and magnesium additions are typical of commercial additives, and thus closely approximate possible residual additives which may be present in certain re-refined oils. 
The metal-containing compounds used were SRM 1079b, tris(1-pheny1-1,3-butanediono) iron(III), (\%Fe: 10.45 \pm 0.04 ); SRM 1059b, lead cyclohexanebutyrate, (\% Pb: $36.65 \pm 0.06$ ); zinc dithiophosphate, (\% Zn: 9); calcium phenate, (\%Ca: 9); and magnesium sulfonate, (\%Mg: 9.4). A stock solution containing the five elements was prepared and the amounts indicated in Appendix A ("mg added") were added to $50 \mathrm{~g}$ samples of metal-free base $0 i 1$ (Conostan 85). Two concentration levels were employed: approximately $1.8 \mathrm{mg}$ per $50 \mathrm{~g}$ of sample ("high level"), and approximately $0.18 \mathrm{mg}$ per $50 \mathrm{~g}$ of oil ("low leve1").

Table 8 . Lead retention in sulfated ash-method of additions ${ }^{a}$

\begin{tabular}{lrr}
$\mathrm{Pb}(\mathrm{mg})$ & Sample weight $(0 i 1+\mathrm{Pb}$ compound, $\mathrm{g})$ & $\frac{\text { Ash }(\mathrm{mg})}{1.99}$ \\
\cline { 2 - 3 } 1.99 & 50.0614 & 2.36 \\
2.00 & 50.0231 & 2.42 \\
3.98 & 50.0147 & 2.49 \\
3.98 & & 4.36 \\
5.97 & 50.0686 & 4.70 \\
5.97 & 50.4450 & 7.87 \\
5.97 & & 8.74
\end{tabular}

ash method was D874M (see text).

Percent lead $=(\mathrm{mg} \mathrm{Ash} / \mathrm{mg}$ lead) $($ at. wt. 1ead/mol. wt. 1ead sulfate $) \times 100$.

Samples were run in duplicate. The resulting ashes were dissolved and analyzed using atomic absorption spectroscopy. The results are found in Appendix $A$ and are summarized in table 9 for lead. Considering the problems attendant in the recovery and determination of small amounts of metal ( $0.1 \mathrm{mg}$ ), the agreement is quite good. Generally, iron and calcium were in good agreement, and since no loss of these elements was anticipated, these elements provided a check in the analytical method. For the wet ashing method, one sample each gave very high iron (178 percent) and high zinc (129 percent) recoveries, indicating an analytical problem for these particular samples.

The samples at low levels $(0.2 \mathrm{mg})$ of metal addition presented a difficult analytical problem, especially in the case of lead, where only 9 percent was recovered by method D874 (see table 9). At the $1.8 \mathrm{mg}$ level of lead addition, recovery was 50 percent--still somewhat 1 ower than the 92 percent obtained by the method of additions. The 92 percent value should be taken as the more accurate one due to the problems in direct analysis of the ash. The primary problem is the formation of a lead glass which attaches very strongly to the vycor and cannot be quantitatively removed.

\subsection{Evaluation of Overall Metal Retention}

The results of the multielement additions can be summarized as follows: 
Method

D482

D874M

Wet ash
Result

Complete retention of $\mathrm{Fe}, \mathrm{Zn}$, and $\mathrm{Ca}$ Good retention of $\mathrm{Mg}$ ( 80 percent) Very low retention of $\mathrm{Pb}$ (32 percent)

Complete retention of $\mathrm{Fe}, \mathrm{Zn}$, and $\mathrm{Ca}$ Good retention of $\mathrm{Mg}$ ( 80 percent)

Good retention of $\mathrm{Pb}$ (92 percent) (standard additions)

Complete retention of $\mathrm{Fe}, \mathrm{Zn}$, and $\mathrm{Ca}$ Good retention of $\mathrm{Mg}$ ( 80 percent)

Good retention of $\mathrm{Pb}$ ( 86 percent) (multielement addition)

Table 9. Summary of lead recoveries in ash methods. Ash analysis by atomic absorption spectroscopy

Method

Doping Procedure

Conc. $(\mathrm{mg} / 50 \mathrm{~g}$ oil)

Lead Recovery(\%)

D482

Multielement
Multielement Addition

1.8

0.18

1.8

0.18

$2,4,6$

655.0

329.0

Wet

Ashing
$0 门$ W022

Used 0i1 W011

Multielement

Multielement

Standard Additions

Multielement

1.8

0.18

86.0

81.0

\footnotetext{
$a_{D}$. A. Becker and J. J. Comeford, Recycled 0 il Program: Phase 1 - Test Procedures for Recycled 0 il Used as Burner Fuel. NBS Tech Note 1130, August 1980.

D482 appears unsatisfactory for oils which may contain lead. The 0874 and wet ashing methods would appear satisfactory, both methods offering considerable improvement over D482. However, there was not 100 percent retention of the lead or magnesium. Except for the method of additions, lead recoveries in these experiments may be low, due to fusion of the lead salts with the vycor crucible. The method of additions would appear to be the most accurate method, eliminating the problems associated with analysis of small amounts of ash. Based on this procedure, ASTM D874 gives a lead retention of 92 percent, a satisfactory level of recovery.
}

\subsection{Metal Speciation in Ash}

Composition of the ash is important for several reasons. The method of standard additions, used to evaluate lead retention in method 0874 , assumes the lead present in the ash is in the form of lead sulfate. Thus, variations in composition of the ash will affect the precision of the method. Moreover, if the composition of the ash is known, a material balance can be made by calculating the amount of ash expected from the metal concentrations present in the base oil. 


\subsubsection{Phase Identification}

$X$-ray powder diffraction techniques were used to identify the crystalline phase of five ash samples. Samples were removed from the porcelain crucibles by scraping. Due to the small sample sizes and the difficulty in obtaining a homogeneous or representative sample from the crucibles, the phase identifications must be considered tentative. Only lead and magnesium were investigated, since of the elements present, they are the ones most likely to be lost. Identification for sample $B$ is tentative due to the smal1 amount (10.6 $\mathrm{mg}$ ) of sample. The results are summarized:

\begin{tabular}{|c|c|c|c|}
\hline Code & Sample & Method & Phase Identified \\
\hline A. & $\mathrm{A}(\mathrm{Pb}$ added $)$ & Wet ash $550{ }^{\circ} \mathrm{C}$ & $\mathrm{PbSO}_{4}+\mathrm{Pb}_{2}\left(\mathrm{SO}_{4}\right) \mathrm{O}$ \\
\hline B. & VIII' (Pb added) & D874 & $\mathrm{PbSO}_{4}+$ possible minor phase \\
\hline c. & $I^{\prime}$ (Mg added) & $\mathrm{D} 874$ & $\mathrm{MgSO}_{4} \cdot 6 \mathrm{H}_{2} \mathrm{O}$ \\
\hline D. & XIV (Mg added) & Wet ash $550^{\circ} \mathrm{C}$ & $\mathrm{MgSO}_{4} \cdot 6 \mathrm{H}_{2} \mathrm{O}$ \\
\hline$E$ & $I X^{\prime}$ (Mg added) & D482 & MgO \\
\hline
\end{tabular}

The $x$-ray results tend to confirm that the major phase produced in the sulfated ash method (D874) is sulfate, as shown by samples $A$ and $B$. Thus, the assumption needed to use the method of standard additions appears to be a good one.

\subsubsection{Mass Balance Comparisons}

A comparison was made of observed and calculated sulfated ashes, based on actual metal contents of the oils. A high degree of correlation between the analyzed metals would indicate the method reflects the metal content of the oil.

The metal concentrations determined for the oils are 1isted in table 3 . For this comparison, complete conversion of the metals to the salts was assumed. The compounds formed for the analyzed metals are $\mathrm{BaSO}_{4}, \mathrm{CaSO}_{4}, \mathrm{Fe}_{2} \mathrm{O}_{3}, \mathrm{MgSO}_{4}, \mathrm{SiO}_{2}$, and $\mathrm{ZnO}$. The comparison between the calculated sulfated ash and the measured ash is shown in table 10 . Since all ash-forming materials were not determined in the initial oil sample, a comparison of actual values was not feasible. Instead, the samples were ranked by percent of ash. The order of this ranking, as shown in table 10, indicates a reasonable correlation between the calculated and observed values.

\section{Recommended Ashing Method: Modified Sulfated Ash}

In table 11 values of regular ash, D482, and sulfated ash, D874M, are compared. As anticipated, since the sulfates are heavier than the oxides, the 0874 values are the same or higher than the 0482 values. The higher values for 0874 indicate a greater sensitivity for the metals present. However, since all of these re-refined oils contain very low metal contents as determined by atomic absorption spectroscopy--generally in the 1 to $10 \mu \mathrm{g} / \mathrm{g}$ range--both methods give approximately the same relative ranking of ash values for the oils. At considerably higher metal concentrations, especially for oils containing 1ead, the 0874 method reflects more accurately the metal concentration.

Therefore, the sulfated ash method, D874, was modified to provide improved accuracy and precision for the determination of ash in the low range. The sulfated ash method was selected because of its better retention of metals such as lead. The modifications were directed at improving the repeatability of the method, stated to be 0.0005 percent at the lower 1 imit of 0.005 percent. 


\subsection{Modifications}

The modifications consisted of a change from porcelain to Vycor crucibles, and a constant cooling time for the samples after removal from the furnace. Since the majority of samples measured had ash weights of less than $1 \mathrm{mg}(0.002 \%$ ash), the ASTM method calls for successive heatings of the sample until successive weights differ by no more than $1.0 \mathrm{mg}$. In order to tighten this criterion (i.e., improve the repeatability of the measurement), $100 \mathrm{ml}$ Vycor dishes were used in place of porcelain crucibles. After removal of the samples from the $775^{\circ} \mathrm{C}$ furnace, the samples were cooled for 45 minutes in a desiccator, transferred to a second desiccator for an additional 15 minutes, and then weighed on a semi-micro analytical balance. The criterion for consistency of weight was set at $0.5 \mathrm{mg}$ for consecutive heatings in the furnace.

These changes aided in reducing weight variations due to temperature-humidity fluctuations. Also, the number of heating cycles needed to meet the new constant weight criterion of $0.5 \mathrm{mg}$ was reduced significantly. The repeatability obtained with these modifications are shown as $D 874 M$ in table 6. Based on these results, the changes have resulted in improved reproducibility at low ash levels.

Table 10. Comparison of observed and calculated sulfated ash

\begin{tabular}{|c|c|c|c|c|}
\hline Sample & Ash \% (D874M) & Rank & Calculated Ash(\%) & Rank \\
\hline RE & 0.017 & 1 & 0.009 & 1 \\
\hline RG & 0.0068 & 2 & 0.0004 & 5 \\
\hline $\mathrm{RC}$ & 0.0066 & 3 & 0.0024 & 2 \\
\hline $\mathrm{RH}$ & 0.0046 & 4 & 0.0004 & 6 \\
\hline RA & 0.0039 & 5 & 0.0016 & 3 \\
\hline $\mathrm{RB}$ & 0.0022 & 6 & 0.0008 & 4 \\
\hline RI & 0.0019 & 7 & 0.0004 & 7 \\
\hline
\end{tabular}

Table 11. Comparison of D482 and D874M ash values (\%)

$\underline{\text { Sample }} \underline{\text { D482 }} \underline{\text { Rank }} \underline{\text { D874M }} \underline{\text { Rank }}$

\begin{tabular}{|c|c|c|c|c|}
\hline RA & 0.0039 & 4 & 0.0038 & 5 \\
\hline RB & 0.0011 & 6 & 0.0022 & 6 \\
\hline $\mathrm{RC}$ & 0.0056 & 3 & 0.0066 & 3 \\
\hline RE & 0.017 & 1 & 0.0170 & 1 \\
\hline RF & 0.00010 & 7 & 0.0005 & 7 \\
\hline$R G$ & 0.0057 & 2 & 0.0068 & 2 \\
\hline RH & 0.0013 & 5 & 0.0046 & 4 \\
\hline
\end{tabular}


Table 12. Metal retention - multielement additions

Method

D482

D874

Wet ash
Result

Complete retention of $\mathrm{Fe}, \mathrm{Zn}$, and $\mathrm{Ca}$

Good retention of $\mathrm{Mg}(80 \%)$

Very low retention of $\mathrm{Pb}(32 \%)$

Complete retention of $\mathrm{Fe}, \mathrm{Zn}$, and $\mathrm{Ca}$

Good retention of $\mathrm{Mg}(80 \%)$

Good retention of $\mathrm{Pb}(92 \%)$

(standard additions)

Complete retention of $\mathrm{Fe}, \mathrm{Zn}$, and $\mathrm{Ca}$

Good retention of $\mathrm{Mg}(80 \%)$

Good retention of $\mathrm{Pb}(86 \%)$

(multielement addition)

In this report the designation, D874M, is used to distinguish the modified method from the published $D 874$ method.

\section{Summary}

Regular ash, ASTM D482; sulfated ash, ASTM D874; and wet ashing methods have been evaluated for applicability to re-refined lubricating base oils. The sulfated ash method was modified to improve repeatability, and is designated here as D874M. A set of 10 re-refined base oils, representing current production of the major re-refiners, was employed in the evaluation. The observed ranges and means for the re-refined base stocks were for $0482,0.0001$ to 0.017 percent, $\bar{x}=0.0046$ percent (see table 10); and for the modified sulfated ash, D874M, 0.005 to 0.017 percent, $\bar{X}=0.0056$ percent (see table 1).

Based on the metal retention studies, there appears to be no significant advantage to wet ashing over D874M. There are several disadvantages to the wet ashing which tend to make it non-routine for the large ( $50 \mathrm{~g}$ or more) samples required. In particular, the use of strong oxidizing agents with large petroleum samples can lead to explosive conditions and should be attempted only with extensive safety precautions.

Regular ash, D482, the least time-consuming method, does not reflect volatile metal oil components such as lead. A comparison of the $D 482$ and D874M ash methods for re-refined base stocks containing only trace amounts of metals (10 $\mu \mathrm{g} / \mathrm{g}$ or less) indicated no significant difference (see table 11). For ash-forming impurities, such as metals at higher concentrations, D874M would reflect the metal content more accurately.

The authors would like to express the appreciation to $C$. Hubbard and $S$. Carmel for the X-ray analysis and $\mathrm{T}$. Rains for the atomic absorption analysis of the ash samples. 


\section{References}

[1] 1981 Annual Book of ASTM Standards, Part 23, Petroleum Products and Lubricants, American Society for Testing and Materials, Philadelphia, PA, 1981.

[2] T. T. Goursuch, Analyst (London) Radiochemical Investigations on the Recovery for Analysis of Trace Elements, 84, 135-73 (1959). (Also: T.T. Gorsuch, The Destruction of Organic Matter, Pergamon Press (New York) 1970.)

[3] M. Feinberg and C. Ducauze, High Temperature Dry Ashing of Foods for Atomic Absorption Spectrometric Determination of Lead, Cadmium, and Copper, Anal. Chem. 52, 209-11 (1980).

[4] 0. I. Milner, J. R. Glass, J. P. Kirchner and A. N. Yurick, Determination of Trace Metals in Crudes and Other Petroleum 0i1s, Anal. Chem. 24, 1728-32 (1952).

[5] C. V. Smalheer, Additives, Interdisciplinary approach to Liquid Lubricant Technology. NASA SP-318, P. M. Ku, ed. Sept., 1972.

[6] T. T. Goursuch, Dissolution of Organic Materials, Accuracy in Trace Analysis, Vol. 1, P.D. Lefleur, Ed., U.S. Dept. of Commerce, 1976.

[7] R. A. Hofstader, 0. I. Milner and J. H. Rumme1s, eds., Chapter 10, Lead, Analyses of Petroleum for Trace Metals, Advances in Chemistry, Series 156, American Chemical Society, Washington, D.C., 1976 .

[8] V. Valkovic, Trace Elements in Petroleum, The Petroleum Publishing Co., Tulsa, 0K, 1978, pp. 210-14.

[9] CRC Handbook of Chemistry and Physics, 49th ed., Chemical Rubber Co. Cleveland, Ohio, 1968.

[10] M. L. Whisman, et a1. BERCRI-76/4 Waste Lubricating $0 i 1$ Research: Part 4 . A Summary of Composition Variations Among 30 used Lubricating 0ils Selected for Seasonal and Geographical Significance, October 1976.

[11] D. A. Becker and J. J. Comeford, "Recycled 0il Program: Phase One--Test Procedures for Recycled $0 i 1$ Used as Burner Fuel", NBS Technical Note 1130, August 1980. 
Appendix A. Multielement retention during ashing ${ }^{a}$

Method

\section{$\underline{\mathrm{D} 482}$}

mg added

mg recovered

$\%$ recovery

mg added

$\mathrm{mg}$ recovered

$\%$ recovery

Avg. "high level"

$\%$ recovery

mg added

mg recovered

$\%$ recovery

mg added

mg recovered

$\%$ recovery

Avg. "Low level"

$\%$ recovery

Fe

$\underline{\mathrm{Pb}}$

$\underline{Z n}$

$\underline{\mathrm{Ca}}$

Mg

$\underline{0874}$

mg added

mg recovered

$\%$ recovery

mg added

mg recovered

$\%$ recovery

Avg. "High level"

$\%$ recovery

mg added

mg recovered

$\%$ recovery

mg added

mg recovered

$\%$ recovery

Avg. "low level"

$\%$ recovery

Wet Ashing

XXI I I

mg added

mg recovered

$\%$ recovery

XXVI

mg added

mg recovered

$\%$ recovery
1.8

1.7

94

100

0.16

0.15

94

0.16

0. 15

94

94

1.8

1.5

83

1.6

1.5

94

1.8

0.48

27

32

0.18

0.038

21

0.18

0.031

17

1.9

121

1. 9

2. 2

116

118

0.16

0.19

119

0.16

0.14

87

19

103

1. 8

0.9

50

1.9

1. 6

84

1. 7

0.9

1. 6

1. 9

84

88

0.16

0.14

87

0. 16

0. 15

94

90

51

0.17

0.01

5.9

0.18

0.02

11

84

0.16

0.16

100

0. 16

0.16

100

9

100

1. 9

1.9

100

0.17

0.16

94

0.17

0.15

88

91

78

0.16

0.15

94

0.16

0.099

62

$\begin{array}{rr}1.7 & 1.6 \\ 1.7 & 1.4 \\ 100 & 87\end{array}$

100

87

$0.17 \quad 0.16$

100

0.13

81

0.18

0.16

0.18

0.13

100

81

100

81

$\begin{array}{cc}1.8 & 1.8 \\ 1.9 & 0.67 \\ 106 & 37\end{array}$

1.7

206

1.8

150
1.8

83

1.9

1.7

86
1.7

1.8

2. 0

111
1. 8

1.7

1.2

71 
Appendix A - (continued)

Avg. "High level"

$\%$ recovery

XXIV

mg added

mg recovered

$\%$ recovery

XXI I

mg added

$\mathrm{mg}$ recovered

$\%$ recovery

Avg. "Low Tevel"

$\%$ recovery

100

0.16

0.16

100

0.15

83

0.18
0.18
100

0.20

0.16

80

0.23

128

0.16

0.21

131

0.16

89

0.20

0.15

75

0.18

0.16

89

A Ashes analyzed using AAS, T. Rains.
81

129

82

91 
National Bureau of Standards Special Publication 674. Proceedings, Conference on Measurements and Standards for Recycled 0il - IV, held at NBS, Gaithersburg, MD, September 14-16, 1982.

(Issued July 1984).

\section{DEVELOPMENT AND USE OF THE MICROOXIDATION TEST WITH CRANKCASE OILS}

\section{E. E. K1aus, P. Shah and V. Krishnamachar}

Department of Chemical Engineering

The Pennsylvania State University

University Park, PA 16802

1. Introduction

The Penn State microoxidation test has been used to evaluate a wide variety of mineral oil and synthetic lubricants. Techniques have been developed to use this test to study basestocks and finished formulations under bulk system and concentrated contact conditions. The microoxidation test also has been modified and adapted for use with re-refined and virgin base oils. This paper covers three specific projects. First, a modified microoxidation evaluation using steel and copper catalyst test cups has been used to provide a comparison of virgin and re-refined base oils. Second, conventional microoxidation tests have been used to evaluate fractions separated chromatographically from virgin and re-refined base oils. Some factions were produced by gravity percolation through a silica gel _column and others by an HPLC separation on a column with packing similar to that from the gravity system. Third, a set of microoxidation test conditions have been developed to give good correlation with formulated mineral oil lubricants in the $3 \mathrm{C}$ and $3 \mathrm{D}$ engine sequence test.

\section{Test Procedures}

The microoxidation test procedures have been described by several investigators [1-3]. ${ }^{1}$ In conventional tests the fluid is held in a steel cup. However, for this work catalyst cups were made from copper, babbitt, and aluminum as well as steel to show the effects of metal type on oxidation rate and products. The typical tests in this study used a $40 \mu \ell$ sample. After the test the sample was diluted with tetrahydrofuran and analyzed by gel permeation chromatography (GPC). The analyses of the oxidation products using the refractive index curve from GPC is shown on figure 1 for a superrefined mineral oil base stock. Curve 1 represents the superrefined mineral oil feed to the microreactor and as such produces the total area to be distributed among the products of the reaction. Curve 2 is generated from a sample of the lubricant that has been subjected to the microoxidation test procedure using nitrogen instead of air as the circulating gas to give a minimum value for evaporation loss. The loss under oxidizing conditions is always somewhat higher than under nitrogen because some of the primary oxidation products are more volatile than the starting material. The difference in evaporation loss between nitrogen and air is minimized by the rapid secondary oxidation reactions that result in polymerization and reduced volatility. Curve 3 shows the overall oxidized oil. The area under curve 1 not accounted for by the area under curve 3 is the evaporation and the deposit left on the metal catalyst test cup. The deposit (sludge and varnish) is obtained by the weight gain of the catalyst test cup during the test. This value is determined by weighings on a microbalance. Curve 4 represents the unreacted superrefined mineral oil separated from the oxidized product. For this purpose an aliquot of the oxidation product represented by Curve 3 is percolated through clay in a hexane solvent to remove the oxidized material. Hexane is removed from the eluent and the unreacted material run in the GPC. The area between curves 3 and 4 represent the oxidized material generated by the test. This material is reported in two categories as indicated by the lines on figure 1. The area indicated by the horizontal lines is oxidation product in the same molecular weight range as the base oil. The cross-hatched section is the oxidized material of higher molecular weight than the base oil. The material in this high molecular weight range originally came from the area between Curves 1 and 4 . A careful examination of Curves 3 and 4 indicate that there is no oxidized product representing the lower molecular weight fraction of the base oil. That is, most of the oxidized product in the molecular weight range of the base oil could be at least a dimer of the primary oxidation product. This type of analytical procedure has been used for both base oils and finished formulations. Finished formulations contain inhibitors that are lower than or the same as the base oil in molecular weight. These additives may contribute to evaporation losses. Polymeric VI improvers and dispersants tend to have much higher molecular weights than the basestock. The same system of analysis is used for the finished formulations as for the base oil.

${ }^{1}$ Figures in brackets indicate the 1 iterature references at the end of this paper. 


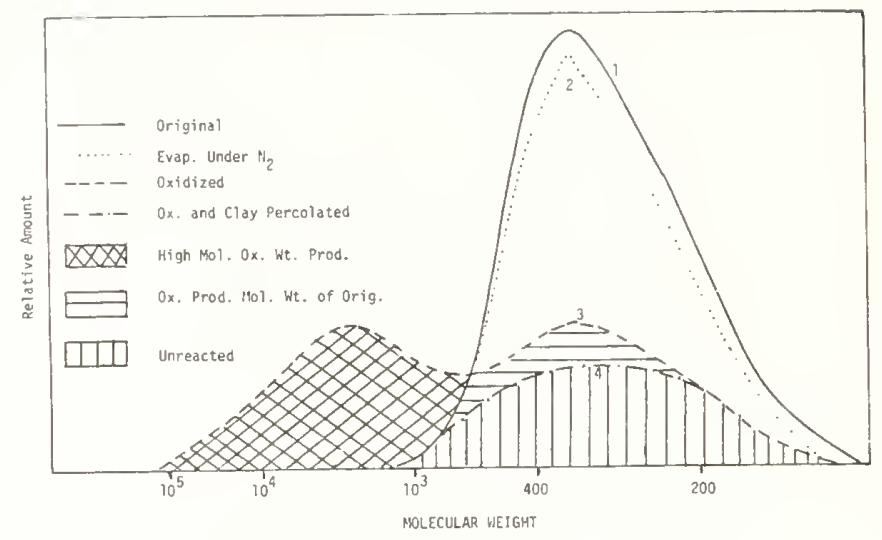

Figure 1. Sample of analysis of oxidized superrefined mineral oils using gel permeation chromatography with a refractive index detector.

Test Conditions: $225^{\circ} \mathrm{C}$; $40 \mu \ell$; steel catalyst; 30 minutes; evaporation test under nitrogen; oxidation test using air.

\section{Basestock-Metal Systems}

A superrefined mineral oil was used as a model basestock in this study of the effects of metals on oxidation. The metals used include a low carbon steel, aluminum, a copper-tin babbitt, and copper. It has been demonstrated previously that mineral oil oxidation in a thin film on a metal surface can be conducted without oxygen diffusion limitation. Under these conditions the oxidation follows a first-order rate until more than 75 percent of the mineral oil feed has been reacted. This relationship can be illustrated by a series of tests at $225^{\circ} \mathrm{C}$ as shown on figure 2 . These data show that metals have significant effects on the oxidation rate. Steel and aluminum show a consistent rate curve for the oxidation through 75 percent oxidation of the base oil. The oxidation rate curve for copper and babbitt show what appears to be a change in rate with test time. The rate appears to change significantly as metal-fluid interaction takes place. Data on figure 3 show a comparison of the behavior of copper test cups with a series of tests in which $2000 \mathrm{ppm}$ soluble copper is added as copper naphthenate. It can be seen that the soluble copper naphthenate on a steel catalyst shows the final oxidation rate similar to that obtained with the copper catalyst. That is, corrosion products generated in the test run on the copper specimen behave in the same way as the copper naphthenate added to the white oil. The data show that iron accelerates the oxidation rate compared with aluminum, while copper and a copper containing babbitt show a substantial rate reduction.

The effects of metal catalysts on the condensation polymerization product from oxidation are shown in figure 4. These data show that the amount of condensation polymerization on each metal catalyst follows the amount of primary oxidation on the same metal. This relationship indicates that the subsequent condensation polymerization reaction is much faster than the primary oxidation reaction. A better comparison of high molecular weight product formation can be obtained from a comparison at the same level of oxidation rather than the same oxidation time. These data are shown on table 1. The oxidation on copper takes 4 to 5 times as long as that on the other metals to produce the same amount of oxidation. Under this comparison copper produces the most high molecular weight material followed by iron and then aluminum and babbitt. Careful data analysis shows that the high molecular weight product produced on copper is higher than that of the original base oil, but not as high as that produced on a steel catalyst. 
Table 1. Comparison of high molecular weight product formation on different metals at equal amounts of degradation

Microoxidation test conditions include: superrefined mineral oil $7828,40 \mu l$, and $225{ }^{\circ} \mathrm{C}$

$\begin{array}{ccccr}\text { Metal } & \begin{array}{c}\text { Time } \\ \text { Min. }\end{array} & \begin{array}{c}\text { Unreacted } \\ \text { Wt. \% }\end{array} & \begin{array}{l}\text { Wt. \% Oxidized Product } \\ \text { Original } \\ \text { Mol. Wt. }\end{array} & \begin{array}{r}\text { Higher } \\ \text { Mo1. Wt. }\end{array} \\ \text { Fe } & 7.7 & 57 & 30 & 6.5 \\ \text { A1 } & 8.5 & 57 & 29 & 6.5 \\ \text { Babbitt } & 10 & 57 & 21 & 15.4 \\ \text { Cu } & 40 & 57 & 13 & \end{array}$

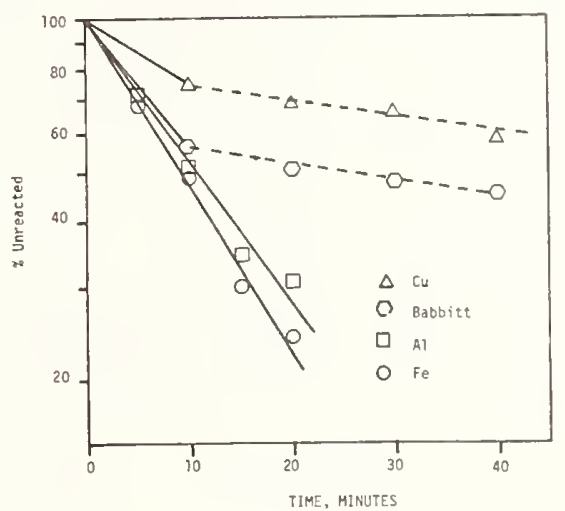

Figure 2. Oxidative degradation of a superrefined mineral oil, PRL7828, on different metals. Microoxidation test conditions include: $40 \mu \ell$ and $225^{\circ} \mathrm{C}$.

A complete analysis of oxidized products from base oils and formulated base oils containing a typical level of zinc dialkyldithiophosphate ( $0.15 \%$ phosphorus) is shown on table 2 . These data are shown for steel, aluminum and copper with a superrefined mineral oil, a good quality virgin basestock, a well re-refined stock and a second re-refined stock. A careful analysis of these oxidation data show that all of the fully formulated base oils also have the same oxidation characteristics as the base oils alone when the test is conducted on the copper catalyst. Severe oxidation takes place with the base oils on the steel catalyst. These data suggest that copper corrosion products are effective as oxidation inhibitors like zinc dialkyldithiophosphate.

Data are presented in table 3 to show the effect of 2000 ppm of copper as copper naphthenate on a superrefined base oil. The oxidation stability of the superrefined mineral oil system on steel is as good as a formulated superrefined mineral oil containing the equivalent of 0.15 percent phosphorus as zinc dialkyldithiophosphate, plus 0.5 percent of phenyl alpha naphthylamine. These data indicate that the use of a soluble copper salt can provide oxidative stability equal to an effective automotive additive package.

One of the goals of this study is the evaluation of basestock quality. In general, the quality of a virgin base oil is related to the response of the base $0 i 1$ to an inhibitor package. The presence of polar impurities and "natural inhibitors" tends to reduce the effectiveness of a synthetic inhibitor package. A superrefined mineral oil basestock which shows excellent additive response because the natural inhibitors have been removed shows little or no oxidation protection when evaluated neat. This same trend is shown by poly alpha olefinic (PAO) synthetic hydrocarbons 
and organic acid esters. One measure of basestock quality is suggested by the relative oxidation behavior on steel and copper catalysts. The oxidation characteristics of the base oil on the steel catalyst indicate the amount of natural and or synthetic inhibitors presert. The better basestocks show the higher levels of oxidation. Oxidation of the basestock on copper gives the equivalent of the behavior of a well formulated oil with excellent oxidation protection. The ratio of the oxidation rates or the ratio of the amount of unreacted base oil after tests with steel and copper catalysts should provide a measure of base oil quality. The ratio of unreacted base oil in an oxidation test on copper to the unreacted base oil on steel for the same test time and temperature has been used to rate a series of virgin and rerefined base oils. The data from table 2 show examples of these base oils. The highest ratio on this scale represents the best quality base oil.

These data show that this quality ratio is highest for the superrefined mineral oil. The values for the conventionally refined virgin basestock and NBS 5100 re-refined oil are about the same. The second re-refined base oil NBS 5101 shows a low quality ratio indicating in this case that the refining technique probably left some of the original additives, as well as some oxidized products in the re-refined base oil. The same general quality index could be obtained for base oils using a second series of microoxidation tests. The fully formulated base oil could be compared with the base oil above on a steel catalyst. This comparison would produce the same quality index, but does require an additive package. The choice of a common additive package would present some problems based on the notion that additives should be tailored to basestock composition.

Table 2. Additive response of several base oils as a function of metal catalysts

Microoxidation test conditions: $225^{\circ} \mathrm{C}, 30 \mathrm{~min}, 40 \mu \ell$

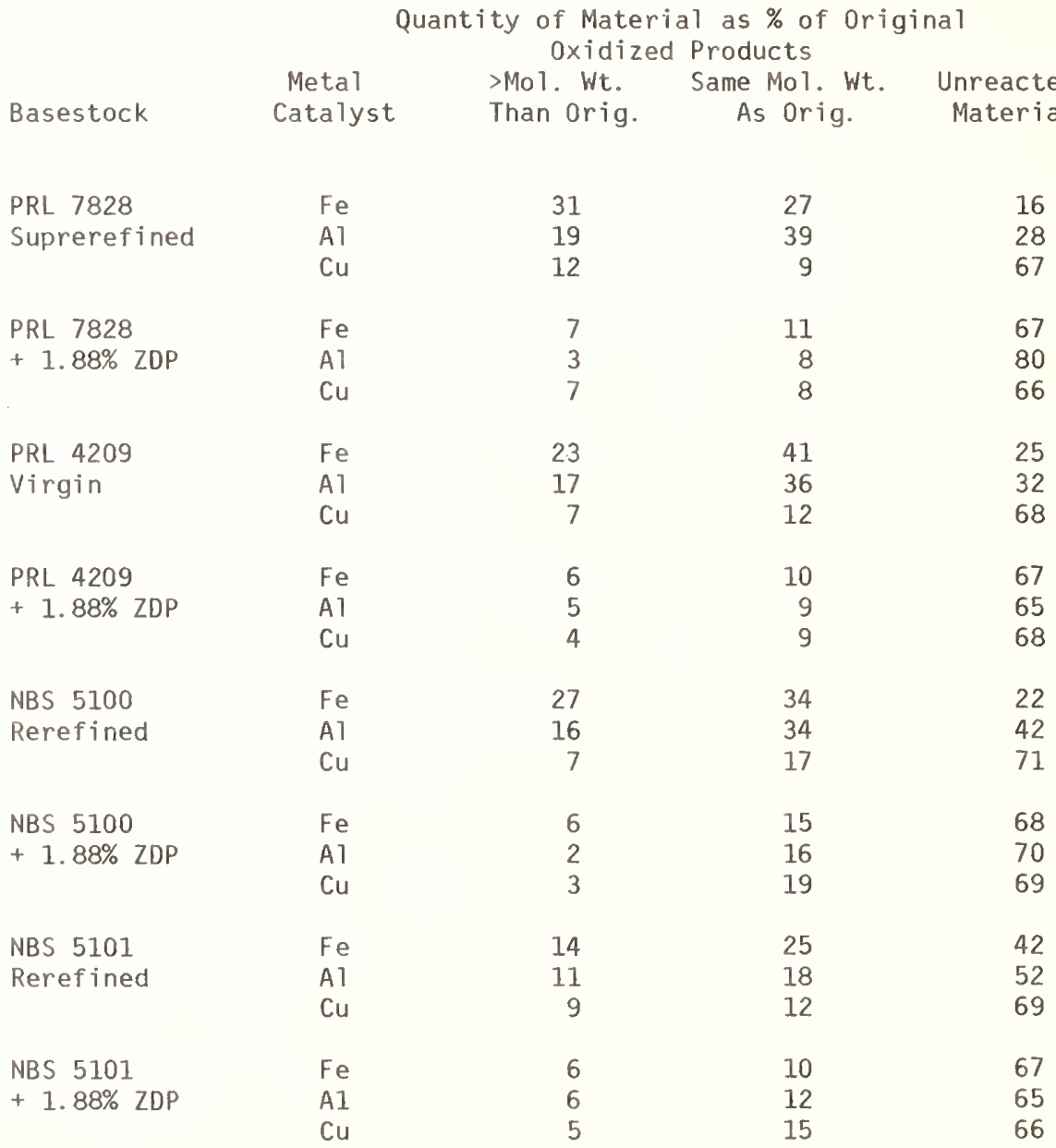




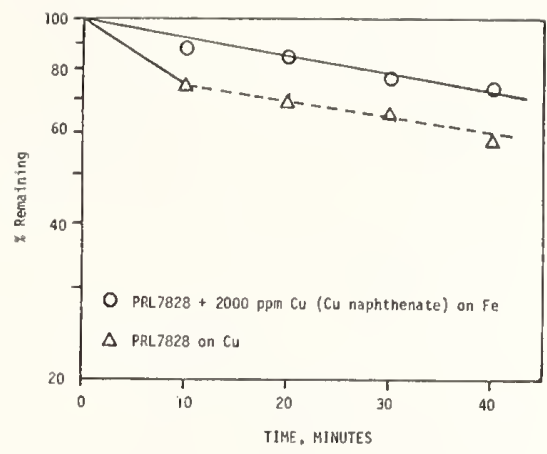

Figure 3. Comparative effects of copper catalyst and soluble copper naphthenate on the oxidative degradation of a superrefined mineral oil, PRL7828. Microoxidation test conditions include: $40 \mu \ell$ and $225^{\circ} \mathrm{C}$.

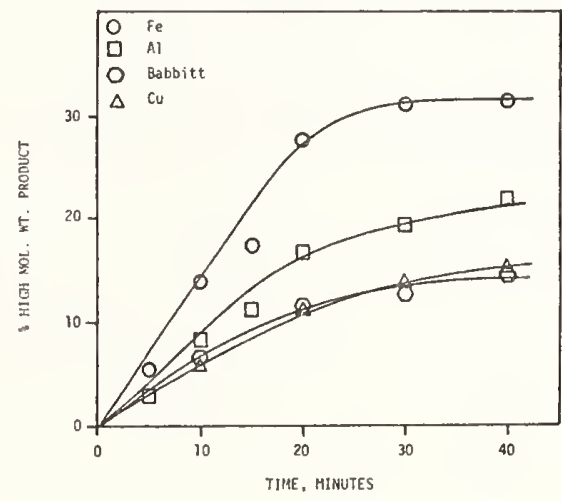

Figure 4. Effect of metal catalyst on the formation of high molecular weight products from the oxidation of superrefined mineral oils, PRL7828. Microoxidation test conditions include: $40 \mu l$ and $225^{\circ} \mathrm{C}$.

Table 3. Comparative data for a conventional automotive inhibitor package and copper naphthenate in a superrefined mineral oil, PRL 7828

Microoxidation test conditions: $225^{\circ} \mathrm{C}, 30 \mathrm{~min}, 40 \mu \mathrm{l}$

Quantity of Material as \% of Original Oxidized Products

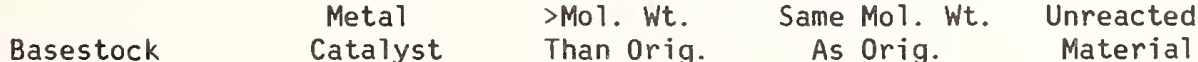

PRL 7828

$\begin{array}{lrrr}\mathrm{Fe} & 31 & 27 & 16 \\ \mathrm{Al} & 19 & 39 & 28 \\ \mathrm{Cu} & 12 & 9 & 67\end{array}$

PRL 7828

$\mathrm{Fe}$

$+2.0 \%$ Cu Nap.

Al

1

$\begin{array}{ll}7 & 81\end{array}$

$\mathrm{Cu}$

$3 \quad 80$

PRL 7828

$\mathrm{Fe}$

A

$+1.88 \%$ ZDP

A1

$\mathrm{Cu}$

5
3
11

81

84

$+0.5 \%$ PAN

1

11

82

2.0 Cu Nap. $=2000 \mathrm{ppm}$ Soluble Cu 
The relative values for such a rating system are tabulated as follows:

Quality Ratio

$\begin{array}{lll}\text { PRL } 7828 & \text { Superrefined mineral oil } & 4.2 \\ \text { PRL } 4209 & \text { Conventionally refined mineral oil } & 2.7 \\ \text { NBS } 5100 & \text { Re-refined base oil } & 3.2 \\ \text { NBS } 5101 & \text { Re-refined base oil } & 1.6\end{array}$

4. Basestock Component Analysis

Another view of base oil quality can be obtained by chromatographic separation of the base oil into several fractions. The Tribochemistry Group at the National Bureau of Standards used two different chromatographic processes to separate a series of virgin and re-refined base oils into fractions that could be catagorized as (1) saturates, (2) aromatic, and (3) polar. The first set of samples was obtained from a gravity percolation of the base oil through a silica gel type adsorbent. The saturate fraction was the percolate. The aromatic fraction was washed from the column with pentane. The third fraction containing polar natural inhibitors, inhibitors and oxidation products was washed from the column with acetone. All three fractions from each oil were evaluated in the microoxidation test for 30 minutes at $225^{\circ} \mathrm{C}$ as shown in table 4 .

Table 4. Oxidative stability of chromatographic fractions of base oils

0 ils were separated by a gravity chromatographic process by NBS; oxidative test conditions: $40 \mu \ell, 225{ }^{\circ} \mathrm{C}, 30 \mathrm{~min}$, on steel

$\begin{array}{llrl} & >\text { Mol. Wt. } & \text { Same Mol. Wt. } & \\ \text { Fluid Fraction } & \text { Than Orig. } & \text { as Orig. } & \text { Evaporation }\end{array}$

$>$ Mol. Wt.
Than Orig.

uid Fraction

$\begin{array}{lll}1^{\mathrm{a}} & \text { RB07276 } & 12.58 \\ 2^{\mathrm{b}} & \text { RB07277 } & 8.35 \\ 3^{\mathrm{C}} & \text { RB07275 } & 7.35\end{array}$

$1^{\mathrm{a}} \quad$ VB07279

14.37

12.75

9.18

14.68

18.46

13.26

13.19

7.20

$3^{\mathrm{c}} \quad$ Corrected $^{\mathrm{d}}$

RE-REFINED OIL X

$\begin{array}{lll}53.80 & 31.90 & 1.72 \\ 52.36 & 37.88 & 1.41 \\ 66.67 & 25.41 & 0.57\end{array}$

VIRGIN OIL Y

$\begin{array}{lll}60.37 & 24.13 & 1.13 \\ 63.38 & 23.49 & 0.38 \\ 36.40 & 52.46 & 1.96 \\ 58.19 & 24.00 & 3.13\end{array}$

VIRGIN OIL Z

$\begin{array}{lll}64.14 & 16.85 & 0.55 \\ 74.48 & 12.26 & 0.26 \\ 25.96 & 59.76 & 1.09 \\ 53.54 & 17.00 & 2.25\end{array}$

\footnotetext{
${ }^{a}$ Fraction 1 is the saturates fraction eluted without solvent.

${ }^{b}$ Fraction 2 is the aromatic fraction eluted with pentane.

${ }^{c}$ Fraction 3 is the polar fraction eluted with acetone.

$d_{\text {These fractions were corrected by calculating the components on an }}$ acetone free basis.
} 
The saturates fraction would be similar to a superrefined mineral oil. The best quality on this basis would be the fraction that produces the highest level of oxidation on a steel catalyst. Virgin oil $Z$ shows the best properties as a base oil from the point of view of additive response, while re-refined oil $X$ shows the least desirable base oil properties. The pentane fractions would contain aromatics and other slightly polar compounds. These materials fall in the natural inhibitor class and show a lower level of oxidation than the saturates from the same base oils. The acetone fractions of oils $Y$ and $Z$ showed a very high level of volatile material which is not typical of a virgin base oil, but appears in the GPC analysis where acetone would be expected to elute. The corrected acetone fractions shown in table 4 are the GPC analysis for the oxidized fractions corrected to produce the same evaporation loss as the other fractions of the same base oil. For the two virgin base oils the acetone fraction should contain polar impurities containing sulfur, nitrogen and oxygen. The high level of deposits and high molecular weight products indicate that this fraction contains some partially oxidized material along with natural inhibitors. The acetone fraction of the re-refined base oil $X$ shows the best stability of these acetone fractions. The behavior of the saturates fraction and the acetone fraction on base oil $x$ indicates that the re-refining process probably did not remove all of the inhibitors of the original additive package.

A second set of base oils was separated by the National Bureau of Standards using HPLC with gradient elution. The three fractions from the HPLC separation correspond to those taken by gravity elution chromatography. These fractions of virgin and re-refined base oils were evaluated in the microoxidation test under the same conditions used with the gravity chromatography samples. The behavior of the HPLC fractions is given on table 5 . All of the saturates from the HPLC separation show a consistent difference from the saturates of the gravity separation. The evaporation loss in al1 cases is excessive suggesting solvent contamination. The higher molecular weight and deposit fractions of the saturated fractions are higher than predicted from the gravity separations. If the data are corrected for excessive evaporation, the high molecular weight and deposit fractions appear to be even higher. These data suggest solvent dilution and accelerated oxidation due to the solvent. The aromatic and polar fractions from HPLC compare with the same fractions from the gravity separations. The comparison of virgin and re-refined base oil fractions show some general trends that follow expected behavior. However, solvent or other contamination problems limit the analysis of the two sets of samples available from these separation techniques. The data presented here suggest that with proper contamination control fractions separated from base oils can be studied and their oxidation properties defined with the Penn State microoxidation test. The real advantage with this oxidation and analysis system is the very small samples required which does fit well with the separation capability of HPLC.

\section{Microoxidation Test - 3D Engine Sequence Correlation}

The microoxidation test has also been used to evaluate finished automotive lubricants. The goal of this study was the development of test conditions which simulate the iubricant degradation found in $3 C$ and 30 engine sequence testing. Viscosity increase and deposits which cause failure in $3 C$ and 30 engine sequence tests result from severe oxidative degradation of the lubricant. The most severe conditions in these engine tests occur in the piston ring-cylinder area. There are indications that temperatures in the range of 175 to $250{ }^{\circ} \mathrm{C}$ exist in the lubricant in this part of the system [4].

Oxidation behavior of automotive lubricants has been found to follow an Ahrrenius type temperature-oxidation rate relationship. Studies in the microoxidation test where oxygen diffusion problems have been eliminated show the typical activation energy for the reaction to be on the order of $25+5$ kilocalaries per gram mole. Based on this information the oxidation rate of a typical crankcáse oil would be expected to double for approximately every $12.5{ }^{\circ} \mathrm{C}$ increase in temperature. In the temperature range of 175 to $250{ }^{\circ} \mathrm{C}$ this relationship appears to apply for a variety of commercial and experimental automotive lubricant formulations. Based on these preliminary studies test conditions have been chosen for the evaluation of crankcase lubricants to simulate engine severity in the $3 \mathrm{C}$ and $3 \mathrm{D}$ tests. The microoxidation test conditions include a low carbon steel catalyst and a $40 \mu \mathrm{\mu}$ sample. The test time at $200{ }^{\circ} \mathrm{C}$ is 2 hours, while the test time at $225{ }^{\circ} \mathrm{C}$ is 30 minutes. The two sets of test conditions should indicate differences between the relative oxidation rates due to distinctive additive packages. These test conditions emphasize the formation of high molecular weight products which contribute to viscosity increase.

The evaluation of engine tests also places a heavy emphasis on deposits in the engine. The 40 $\mu \ell$ microoxidation tests give some indication of deposits by measuring the weight gain of the steel catalyst after the test. The deposits from these tests tend to be low enough to be only slightly above the minimum weight change detected by a microbalance. A second microoxidation test has been developed and used to emphasize the deposit forming tendencies of crankcase oils. In order to increase the amount of deposits for ease of gravimetric determination, the test was increased in severity over the microoxidation tests used to determine the liquid products of oxidation. Deposit 
tests using the microoxidation test with a low carbon steel catalyst were run with a $20 \mu \ell$ test sample at 225 and $250{ }^{\circ} \mathrm{C}$ for extended time periods to determine the deposit formation as a function of time. All of these tests give a characteristic behavior as shown in figure 5 . The deposit builds up slowly during the early part of the test. This induction period type of behavior is followed by a more rapid rise in deposit formation. Finally, the deposit level reaches an asymptote in the region of 25 to 40 percent of the initial charge because all of the 1 ubricant has been converted into deposit or lost by evaporation from the test cup. The length of time when the deposit formation is low and the portion of the curve approaching the asymptote would provide a relative behavior value is of interest in this study. This portion of the deposit curve is generated by a $20 \mu l$ test of 60 minute duration at $225^{\circ} \mathrm{C}$. A test of equivalent severity at $200{ }^{\circ} \mathrm{C}$ would take four hours, while a test time of equivalent severity at $250{ }^{\circ} \mathrm{C}$ would be 15 minutes. For convenience the 60 minute test at $225^{\circ} \mathrm{C}$ was chosen.

Table 5. 0xidative stability of chromatographic fractions of base oils 0 i1s were separated by an HPLC process by NBS; oxidative test conditions: $40 \mu \ell, 225^{\circ} \mathrm{C}, 30 \mathrm{~min}$, on steel

Fluid Fraction

1 SATURATE

2 AROMATIC

3 POLAR

1

SATURATE

2 AROMATIC

3 POLAR

1

SATURATE

2 AROMATIC

3 POLAR

1

2

3

SATURATE

AROMATIC

POLAR

1 SATURATE

2 AROMATIC

3 POLAR

$>$ Mol. Wt. Same Mol. Wt.

Than Orig. as Orig. Evaporation Deposit

RE-REFINED OIL RB0042

$\begin{array}{lll}40.74 & 38.43 & 4.16 \\ 66.78 & 19.18 & 0.31 \\ 65.79 & 26.88 & 0.89\end{array}$

RE-REFINED OIL RB0033

20.93

15.07

5.92

17.45

11.18

6.61

19.84

18.67

18.08

15.14

14.71

Insufficient sample for check runs

$\begin{array}{lll}46.51 & 30.18 & 2.38 \\ 65.07 & 19.32 & 0.54 \\ 86.06 & 8.02 & 1.25\end{array}$

RE-REFINED OIL RB5109

$\begin{array}{lll}20.75 & 59.02 & 2.78 \\ 56.58 & 17.35 & 4.89 \\ 73.55 & 13.92 & 0.92\end{array}$

VIRGIN OIL VB5167

$\begin{array}{lll}37.65 & 38.15 & 4.36\end{array}$

60.84

19.82

0.773

61.26

17.21

3.45

VIRGIN BASE OIL VB5078

$\begin{array}{lll}47.57 & 37.29 & 2.51 \\ 67.65 & 17.64 & 0.77\end{array}$

0.77 
The only analytical tool required for the deposit test is a mjcrobalance. For the conventional microoxidation test gel permeation chromatography is the key analytical device. For complete analysis there are a number of techniques required in addition to careful control of the sample dilution. The analytical procedure used for base oils and formulated crankcase oils is shown in figure 1 and has been described in the section on procedure.

For the data shown on figure 1, it has been assumed that molecular size is the only separational characteristic in the gel permeation chromatography. However, some recent work shows that there is an adsorption delay for very polar materials of relatively large molecular weight range which is inappropriate for the actual molecular size. The one test method that would appear to solve this problem of relative molecular weight is the pentane insoluble test conventionally used with bulk oxidation tests to determine the high molecular weight viscosity builders formed during oxidation.

A modified microoxidation test was designed to incorporate a pentane insoluble determination. The same philosophy was used in the evaluation of this test method as that used when it was desired to evaluate the oxidized material in the same molecular weight as the original charge to the microoxidation test. This technique comprises the separation of the 40 micro liter oxidized sample into two aliquot parts of 20 micro liters each. The one aliquot is analyzed directly in gel permeation chromatography to show the chromatogram indicative of the oxidized materials. The second aliquot is treated to remove the pentane insolubles. After the removal of the pentane insolubles this material is then analyzed by gel permeation chromatography and the difference between the two chromatograms is measured. The difference in the area between the two chromatograms is taken to represent the pentane insolubles. In the case of a base oil the pentane insolubles can be removed by simply using pentane as the solvent. In the case of a formulated oil the presence of detergents and dispersants makes the pentane precepitation virtually impossible on a quantitative basis. In this case, it is necessary to add a coagulant to overcome the effect of the detergent and dispersant. The same coagulant specified in the ASTM test technique was used. The major problem was in the determination of a logical quantity of coagulant to be used in the pentane precipitation of 20 micro liters of test oil. When the concentration specified in the ASTM procedure was used in all of the pentane involved in the pentane precipitation of the 20 micro 1 iters a minor problem developed. The coagulant shows up in the gel permeation chromatographic curve somewhere near the peak of the original base oil and close to the low molecular weight end of the pentane insolubles. Since the difference in the two chromatograms was measured directly, this caused some concern about the precision of the pentane insoluble measurement. A procedure has been developed using the pentane with coagulant at a concentration level that appears to measure ali of the pentane insolubles without confusing the area due to the coagulant in the analysis. The two different coagulant concentrations are illustrated in figures 6 and 7 . The lower coagulant concentration level has been used for the analytical tests presented in the following correlations.

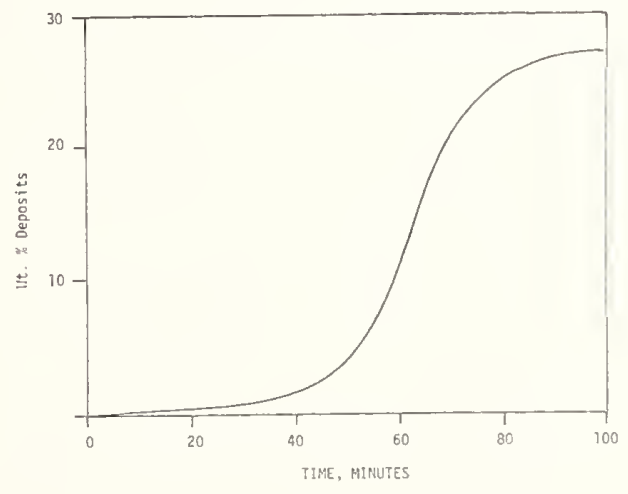

Figure 5. Typical curve for deposit formation as a function of time for a fully formulated automotive crankcase oil. Microoxidation test conditions: $20 \mu \ell, 225^{\circ} \mathrm{C}$, Fe catalyst.

A series of ASTM $3 C$ and 30 reference oils were obtained from the National Bureau of Standards for use in developing an engine sequence-microoxidation test correlation. The reference oils are rated by the hours to failure in the $3 \mathrm{C}$ or 30 sequence engine tests. The behavior of the reference 
oils in the microoxidation test at 200 and $225{ }^{\circ} \mathrm{C}$ are shown on tables 6 and 7 . The percent of oxidized product with a higher molecular weight than the original oil was used to judge the relative viscosity increase of the lubricant. The two sets of test conditions were chosen to be about equal in severity based on the Arrhenius type relationship of reaction rate and temperature. The trends noted in high molecular weight oxidation product show some correlation with engine test performance. The measurement of high molecular weight products formed on oxidation was further refined by the use of the pentane insoluble evaluation of the microoxidation product. These values are shown on Table 8. The use of pentane insoluble oxidation products as a measure of oil degradation shows a much better agreement with performance in the engine tests. The two oils that appear to be better in the pentane insolubles from the microoxidation test than in engine performance are NBS 5017 (16 hour 3C) and NBS 7044 (24 hour 3D).

All mineral oil oxidations conducted thus far show the same general trend for the oxidized products. The reaction to form the primary oxidation product is the slowest reaction. Subsequent reactions of the primary oxidation product to form condensation polymers are much more rapid. The rate of reaction and final molecular weight of these products vary over a moderate range due to additive package. In some cases a smaller amount of high molecular weight product will produce sludge and varnish rather than high molecular weight liquid products. Deposit tests have been conducted on the reference lubricants as shown on table 8 . The two lubricants that show lower than anticipated high molecular weight oxidation products show excessive amounts of deposit formation. Deposits above were considered for comparison with $3 \mathrm{C}$ and $3 \mathrm{D}$ engine tests. On this basis, correlation looks good with a few exceptions. The principal lack of correlation is in the case of NBS 7048 (16 hours in 3D) where deposit tests look very good. Deposits for NBS 5019 and NBS 7045 also appear to be slightly higher than anticipated for the engine performance. These two oils show an unusual trend in the microoxidation test. Both oils have a substantial quantity of a polymeric VI improver which appears to decrease in molecular weight in the microoxidation tests. This behavior could make the overall fluid look better than anticipated from the oxidation products of the base oil.

Table 6. Comparison of $3 \mathrm{C}$ reference oils in the microoxidation test

Data based on GPC curves for the original and oxidized sample

40 He samples were used with a low carbon steel catalyst

\begin{tabular}{|c|c|c|c|c|c|}
\hline Conditions & \multicolumn{2}{|c|}{$\begin{array}{l}\text { Test Fluid } \\
\text { NBS No.(Hrs.) }\end{array}$} & $\begin{array}{l}\text { Oxidized Prod. } \\
>\text { Mol. Wt. than } \\
\text { Original }\end{array}$ & $\begin{array}{l}\text { Oxidized and } \\
\text { Unreacted Mat. } \\
\text { at Orig. Mol. Wt. }\end{array}$ & $\begin{array}{c}\text { Evaporat } \\
\text { Loss }\end{array}$ \\
\hline \multirow[t]{5}{*}{$200^{\circ} \mathrm{C}, 2$ Hrs. } & 5021 & (16) & 21.8 & 51.2 & 27.0 \\
\hline & 5017 & $(16)$ & 10.8 & 43.4 & 45.9 \\
\hline & 5016 & (32) & 16.5 & 48.8 & 34.7 \\
\hline & 5014 & $(40)$ & 2.9 & 71.7 & 25.4 \\
\hline & 5019 & $(64)$ & 7.6 & 51.5 & 40.8 \\
\hline \multirow{5}{*}{$225^{\circ} \mathrm{C}, 30$ Min. } & 5021 & (16) & 22.5 & 52.3 & 25.2 \\
\hline & 5017 & $(16)$ & 13.3 & 58.2 & 28.5 \\
\hline & 5016 & $(32)$ & 11.2 & 52.6 & 36.2 \\
\hline & 5014 & $(40)$ & 3.7 & 70.6 & 25.7 \\
\hline & 5019 & $(64)$ & 13.8 & 58.3 & 27.9 \\
\hline
\end{tabular}


Table 7. Comparison of 30 reference oils in the microoxidation test

Data based on GPC curves for the original and oxidized sample

$40 \mu \ell$ samples were used with a low carbon steel catalyst

\begin{tabular}{|c|c|c|c|c|c|}
\hline Conditions & \multicolumn{2}{|c|}{ Test Fluid } & $\begin{array}{l}\text { Oxidized Prod. } \\
\text { >Mol. Wt. than } \\
\text { Original }\end{array}$ & $\begin{array}{l}\text { Oxidized and } \\
\text { Unreacted Material } \\
\text { At Original Mol. Wt. }\end{array}$ & $\begin{array}{l}\text { Evaporation } \\
\text { Loss }\end{array}$ \\
\hline \multirow[t]{5}{*}{$200{ }^{\circ} \mathrm{C}, 2 \mathrm{Hrs}}$. & 7048 & (16) & 7.4 & 72.4 & 20.2 \\
\hline & 7044 & (24) & 4.5 & 58.6 & 36.9 \\
\hline & 7046 & $(40)$ & 13.6 & 55.1 & 31.3 \\
\hline & 7047 & (56) & 11.1 & 59.1 & 29.8 \\
\hline & 7045 & (64) & 6.3 & 65.0 & 28.7 \\
\hline \multirow[t]{5}{*}{$225^{\circ} \mathrm{C}, 30 \mathrm{Min}}$. & 7048 & (16) & 10.1 & 73.7 & 16.2 \\
\hline & 7044 & (24) & 8.0 & 63.9 & 28.1 \\
\hline & 7046 & $(40)$ & 15.9 & 53.1 & 31.0 \\
\hline & 7047 & (56) & 11.3 & 64.6 & 24.1 \\
\hline & 7045 & (64) & 8.4 & 63.7 & 27.9 \\
\hline
\end{tabular}

6. Conclusions

A combination of pentane insolubles data (column $A$ in table 8 ) with the deposit test results (column B in table 8) yields a measure of "total solids" ( $A+B)$ generated, which appears to provide good agreement with the $3 C$ and 30 engine test ratings for the ASTM reference oils evaluated. This combination of tests can be conducted in simple equipment in tests of short duration to provide chemical information, as well as measured values which provide some correlation to the results form $3 C$ and 30 engine sequence tests.

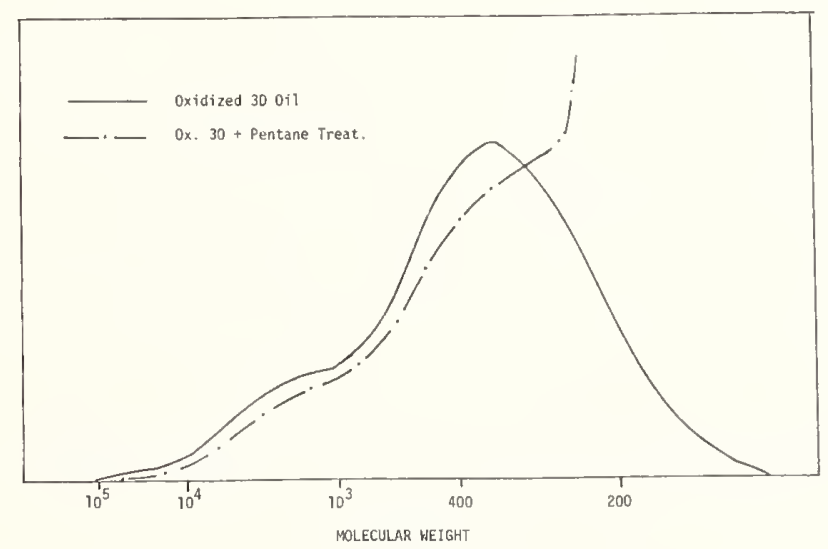

Figure 6. Modified pentane insoluble procedure for the microoxidation test, high coagulant concentration. Microoxidation test conditions: $225^{\circ} \mathrm{C}$, 40 minutes, steel catalyst, $40 \mu \ell$ pentane insoluble procedure: mod. ASTM method, $4 \mu \ell$ of $5 \%$ coagulant in pentane. 
Such a combination test evaluation would appear to provide a useful quaitity control test for monitoring formulated engine oils. For research and development, this combination provides a powerful screening tool for formulation studies involving base oils and additives for high performance crankcase oils.

Table 8. Deposit and pentane insolubles formation for several $3 \mathrm{C}$ and 30 reference oils

A11 tests were carried out on a low carbon steel catalyst at $225^{\circ} \mathrm{C}$

Microoxidation tests for pentane insolubles were

30 minutes and those for deposits were 60 minutes.

\begin{tabular}{|c|c|c|c|c|}
\hline \multicolumn{2}{|c|}{$\begin{array}{l}\text { Test Fluid } \\
\text { NBS No. }\end{array}$} & \multirow{2}{*}{$\begin{array}{c}\text { A } \\
\text { Pentane Insoiubles } \\
\text { Weight } \% \text { Charge }(40 \mu \ell)^{b} \\
\text { ASTM-3C-REFERENCE 0ILS }\end{array}$} & \multirow[t]{2}{*}{$\begin{array}{c}\text { B } \\
\text { Deposit } \\
\text { Weight \% Charge }(20 \mu \ell)\end{array}$} & \multirow[t]{2}{*}{$\begin{array}{l}\text { A\&B } \\
\text { Total } \\
\text { Solids }\end{array}$} \\
\hline & & & & \\
\hline 5021 & $(16)^{a}$ & 15.8 & 15.6 & 31.4 \\
\hline 5017 & $(16)$ & 4.8 & 17.4 & 22.2 \\
\hline 5016 & $(32)$ & 7.4 & 9.7 & 17.1 \\
\hline 5014 & $(40)$ & 3.0 & 7.7 & 10.7 \\
\hline 5019 & (64) & 4.4 & 8.3. & 12.7 \\
\hline & & ASTM-3D-REFERENCE OILS & & \\
\hline 7048 & (16) & 14.3 & 3.9 & 18.2 \\
\hline 7044 & (24) & 3.9 & 17.1 & 21.0 \\
\hline 7046 & $(40)$ & 8.0 & 10.9 & 18.9 \\
\hline 7047 & $(56)$ & 2.2 & 5.5 & 7.7 \\
\hline 7045 & (54) & 2.7 & 9.1 & 11.8 \\
\hline
\end{tabular}

${ }^{a}$ Values in parentheses are the hours to failure in the $3 C$ and 30 engine tests.

${ }^{b}$ Based on a deposit density of $0.875 \mathrm{gcm}^{-3}$.

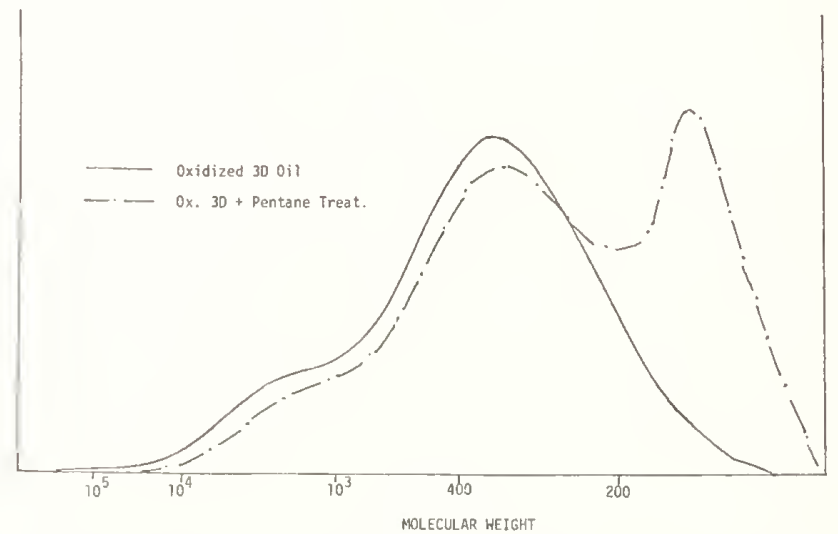

Figure 7. Modified pentane insoluble procedure for the microoxidation test (low-coagulant concentration). Microoxidation test conditions: $225{ }^{\circ} \mathrm{C}$, 40 minutes, steel catalyst, $40 \mu \ell$ pentane insoluble procedure: mod. ASTM method, $4 \mu \mathrm{r}$ of $0.25 \%$ coagulant in pentane. 
The Penn State microoxidation test also provides an effective method for the evaluation of base oils. The method can be used to establish additive response directly or by means of the relative behavior of the base oil on steel and copper catalyst test cups. This same general technique can also be used on fractions of base oil separated to illustrate various component types such as saturated hydrocarbons, aromatics and polar components.

This work was supported by Grant No. NB80NADA1037 from the National Bureau of Standards. The authors also wish to express their appreciation to Dr. S. M. P. Hsu at the NBS for his cooperation in supplying samples and background information for some of the work reported here.

\section{References}

[1] Cvitkovic, E.; Klaus, E. E; Lockwood, F. A thin film test for measurement of the oxidation and evaporation of ester-type lubricants ASLE Trans. 22 395; 1979.

[2] Lockwood, F.; Klaus, E. E. Ester oxidation-the effect of an iron surface ASLE Trans. 25(2): $236-44 ; 1982$.

[3] Lahijani, J.; Lockwood, F. E.; Klaus, E. E. The influence of metals on sludge formation ASLE Trans. 25 (1): 25-32; 1982

[4] Stewart, R. M.; Selby, T. W. The relationship between oil viscosity and engine performance--a literature search ASTM STP 621: 1-19; SAE Warrendale, PA; 1977. 

National Bureau of Standards Special Publication 674. Proceedinas, Conference on Measurements and Standards for Recycled 0il - IV, held at NBS, Gaithersburg, MD, September 14-16, 1982.

(Issued July 1984).

\title{
EVALUATION OF A MODIFIED TIMKEN TEST FOR THE CHARACTERIZATION OF MOTOR OILS
}

L. K. Ives, P. A. Boyer, and A. W. Ruff

\author{
Metallurgy Division \\ National Bureau of Standards \\ Washington, DC 20234
}

\begin{abstract}
A modified version of the Timken ${ }^{1}$ method, ASTM D2782, for the determination of the load carrying capacity of lubricating fluids is described and evaluated. The modified method differs from the standard method primarily in that a very small volume of oil $(0.2 \mathrm{ml})$ is used. The evaluation procedure consisted of applying the modified Timken method to a series of IIID engine sequence test reference oils having known performance characteristics. Good correlation was obtained between the modified Timken test results and documented IIID engine sequence test cam plus lifter wear values. A similar correspondence was also found for VD engine sequence test reference oils. Good correlation with service data was obtained when the modified Timken method was applied to Royal Canadian Mounted Police Field Trial 0ils. Results are also presented on the application of the method to commercial SF motor oils and to the determination of additive response of re-refined base oils.
\end{abstract}

\section{Introduction}

Effective control of cam and follower wear is recognized as one of the critical functions of a motor oil. The recently established IIID and VD engine sequence tests cite specific limits on wear for one or both of these components. These limits must not be exceeded if the oil is to meet performance requirements for American Petroleum Institute (API) Service Classification SF. Because of the considerable expense involved and the time consuming nature of engine sequence tests, the development of simple laboratory tests to assist in the motor oil formulation process and for batch-to-batch quality control purposes is highly desirable. Unfortunately, the detailed physical and chemical characteristics of a formulated motor oil that are responsible for control of wear are not well known. Nor has the nature of the wear process been fully described when a lubricant fails to provide adequate wear protection. Thus, there is limited guidance for the design of a suitable laboratory test to measure the wear properties of motor oils. On the basis of the known conditions of load, temperature and sliding speed it is, however, generally expected that the contact conditions at the cam and follower will intermittently fall in the boundary lubrication regime. One measure of a lubricant's performance under boundary conditions is given by its load carrying capacity. When a lubricant's load carrying capacity is exceeded, a condition of severe wear (variously referred to as scoring, seizure, scuffing or galling) may occur. A number of bench tests have been used to measure the load carrying capacity of lubricating oils. Among these are three ASTM methods [1] $]^{2}$, D3233 (pin and V-block), D2783 (four-bal1), and D2782 (Timken method). This investigation is concerned with an evaluation of a modified version of the last mentioned method, the Timken method. The modified Timken method has been reported [2] to predict with surprisingly good accuracy the performance of a motor oil in the IIIC engine sequence test.

The evaluation procedure consisted of applying the modified Timken method to a series of six available IIID engine sequence test reference oils. ${ }^{3}$ The load carrying capacity obtained for each oil was then compared to the documented cam plus lifter wear values which had been determined in IIID engine sequence tests [3]. To establish further the validity of the test method, the

Identification of commercial products and names is made in this report solely for the purpose of adequately describing the tests involved.

${ }^{2}$ Figures in brackets indicate the literature references at the end of this paper.

3Provided by ASTM Test Monitoring Center (TMC), Pittsburgh, PA. 
evaluation procedure was extended to include three VD reference oils $5^{4}$, two RCMP (Royal Canadian Mounted Police) field trial oils [4] and three commercial SF motor oils. As an application, the modified Timken test was employed to examine the additive response of three re-refined base oils. Results of these evaluative tests and measurements will be presented together with a detailed outline of the test procedure. Some preliminary results on the evaluation of this test method have been presented previously [5]. It should be noted that Gates and Hsu [6] have developed a similar test method utilizing the four-ball test machine.

\section{Modified Method Compared to Standard Timken Method}

The essential conditions and parameters for ASTM D2782, "Measurement of Extreme-Pressure Properties of Lubricating Fluids (Timken Method), " are compared in table 1 with the corresponding quantities for the modified test. The standard Timken method employs a rectangular block of carburized and hardened steel which is forced against a rotating ring of a similar steel in the configuration illustrated in figure la. The object of the test is to determine the maximum load that the lubricant can sustain without failure during the 10 min test period. Failure is understood to mean a condition of severe wear which is described as seizure or scoring. The maximum pass load is referred to as the OK load or more generally as the load carrying capacity of the lubricant according to this test.

Table 1. Comparison of standard timken method and modified method

\section{ASTM D2782 \\ Modified Test}

Quantity of $0 i 1$

$0 i 1$ Temperature

Break-In

Load Increments ${ }^{a}$

Continuous Flow ( 0.1 to $2.31 / \mathrm{min}$ )

$37.8^{\circ} \pm 2.8^{\circ} \mathrm{C}$

$30 \leq @ 6.7 \mathrm{~N}$

$45 \mathrm{~N}(\geq 135 \mathrm{~N})$

$27 \mathrm{~N}(<135 \mathrm{~N})$

Test Duration

Speed

$10 \mathrm{~min}$.

$800 \mathrm{rpm}$

Ring

Carburized AISI 8720

Block

Carburized AISI 4320
Wet with 0 il

$(0.2 \mathrm{ml})$

Room Temp.

(s ame)

$4.5 N$

5 min.

(s ame)

(same)

(same)

a Load applied to lever arm. Load applied to specimen is a factor of 10 larger.

The minimum load at which failure is observed is also recorded and the contact pressure may be calculated if desired. The contact pressure is determined by the width of the wear scar produced in the test at the maximum pass load. Load values are reported in units of weight applied to the lever arm. The actual load applied to the block is ten times the reported value plus an additional increment of approximately $67 \mathrm{~N}^{\mathrm{S}}$ which is due to the weight of the lever arm and pan assembly. In this investigation only the total load applied to the block will be reported unless otherwise noted.

${ }^{4}$ Provided by ASTM Test Monitoring Center (TMC), Pittsburgh, Pa.

${ }^{5} \mathrm{~A} 11$ force (load) values are expressed in Newtons $(N)$ where $1 \mathrm{~N}=0.2251 \mathrm{~b}$. 

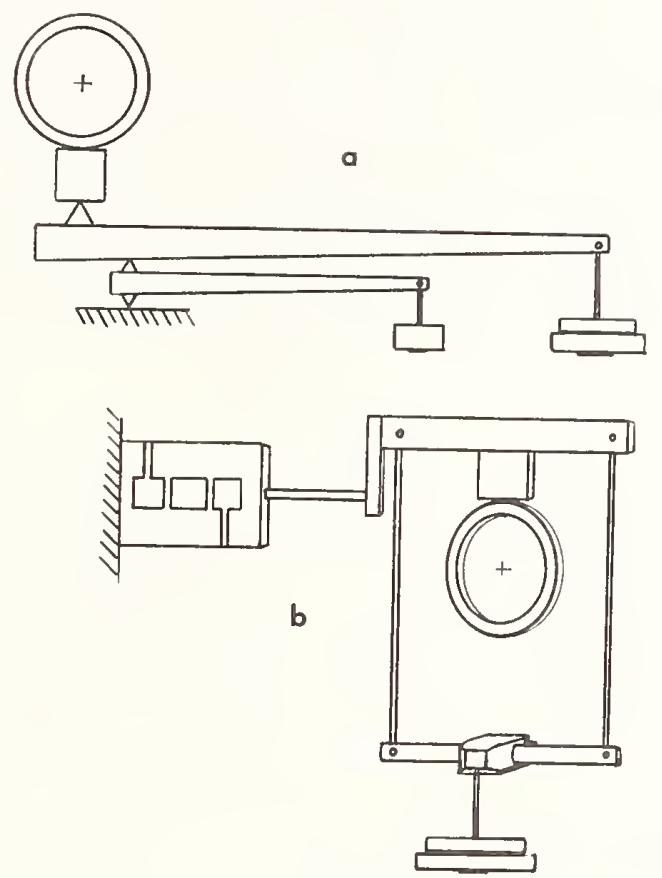

Figure 1. Schematic drawing of specimen and load application assembly of a) Timken machine and b) Falex \#1, ring and block machine.

The most important difference between the standard Timken method and the modified test concerns the quantity of oil employed to lubricate the block and ring specimens during the test. As indicated in table 1 , the standard method requires a continuous flow of oil from a 21 iter reservoir that is maintained at a temperature of $37.8 \pm 2.8{ }^{\circ} \mathrm{C}$. In the modified test the specimen contact surfaces are only "wet" with $0.2 \mathrm{ml}$ of $0 i 1$ at the beginning of the test. No additional oil is supplied. The reasons for employing a volume of $0.2 \mathrm{ml}$ will be considered in later discussion.

Other differences noted in table 1 concern the duration of the test and the load increment employed. Test duration in the modified test was fixed at 5 min compared to 10 min for the standard method. The effect of varying the test duration was not investigated in detail, however, available results, as might be expected, indicated that a shorter duration would within limits 1 ead to an increased load carrying capacity. At loads far in excess of the load carrying capacity determined at $5 \mathrm{~min}$, failure occurred on application of the load so that test time would not be a factor under these circumstances. Selection of a longer duration was found to reduce the determined load carrying capacity.

Choice of load increment depends both on the sensitivity of the test and the required discrimination among oils. It was found in several cases that increasing the 10 ad by $45 \mathrm{~N} 1 \mathrm{ed}$ from a condition of consistent passes to consistent failures; that is, the minimum failure load was $45 \mathrm{~N}$ higher than the maximum pass load. This, however, was not always true as is indicated by the results which are presented in the following section. For this study, $45 \mathrm{~N}$ was chosen as the 10 ad increment. 
The test machine prescribed for conducting ASTM 02782 is the so-called Timken machine. The Timken machine was not employed in the present investigation. Instead, a friction and wear testing machine manufactured by the Faville-LeVally Corporation, the Falex \#1, machine was used. The designs of the Timken and the Falex \# 1 machines are shown schematically in figure 1 . Both machines employ the same block and ring test specimens but differ with respect to the mechanism by which the load is applied to the block. For the case of the Timken machine the block is positioned below the ring while for the Falex \#l machine it is located above. This may affect the manner in which oil is accumulated in the contact region, potentially resulting in a difference in performance between the two machines. Also, the Falex \#l machine is equipped with a strain gage type load cell to indicate friction force, an important feature with respect to the present investigation since friction response was used to determine failure. A similar load cell could, however, be adapted to the Timken machine without apparent difficulty.

\section{Test Procedure}

A brief outline of the modified Timken test procedure is presented below. Some further details can be found in ASTM D2782 and the operators manual for the test machine that is employed.

- Clean Specimens --- Ultrasonically agitate in hexane for 5 min (repeat 3 times) and then ultrasonically agitate in acetone for $5 \mathrm{~min}$. Heat specimens to $60^{\circ} \mathrm{C}$ in the test oil and follow with a rinse in hexane. The latter step was adopted because it was found to reduce data scatter.

- Prepare test machine -... Flush all components and parts with hexane to remove residual oil from previous tests which might come into contact with the test specimens.

- Mount Specimens and apply oil--- $0 i 1(0.2 \mathrm{ml})$ is applied to the slowly rotating ring with an appropriate syringe and hypodermic needle.

- Break-in --- Increase ring rotational speed to $800 \mathrm{rpm}$ and apply run-in $10 \mathrm{ad}$ of $67 \mathrm{~N}$ for $30 \mathrm{~s}$.

- Run Test -- Apply test load and terminate test after 5 min or sooner if failure occurs.

Tests described in this investigation were carried out in air at room temperature $\left(22^{\circ} \pm 2{ }^{\circ} \mathrm{C}\right)$ at the ambient relative humidity which was in the range from 45 percent to 65 percent.

\section{Some Consequences of the Modified Method}

A list and brief discussion of several of the most significant consequences either resulting from or anticipated to result from the test modification are given below.

- Debris is not effectively flushed from the contact region;

- increased contact temperature;

- 0 il degradation effects enhanced;

o only small amount of oil required for evaluation;

o cleanup between tests is simplified; and

- specimen contamination more critical.

During run-in a significant quantity of wear debris is generated. This debris rapidly flushed away in the standard Timken method to be caught by the filter screen, by the optional magnetic trap when one is used, or simply may not find its way back to the contact region because it is not in the fraction of circulating oil that actually passes through the contact. In the modified test, debris is not flushed away but may continue to pass through the contact region. 
The flow of $0 i 1$ at $37.8 \pm 2.8^{\circ} \mathrm{C}$ that affords specimen cooling in the standard method is not present in the modified test. Thus the contact temperature may rise to considerably higher values enhancing oil degradation and oxidation as well as its reaction with the steel specimen surfaces. As a result, boundary film lubrication properties may be affected. In addition, oil that has been degraded is not replaced and important anti-oxident or other components may become depleted during the test.

A practical consequence of the modified procedure concerns the need for only a small quantity of oil. A few milliliters of oil are sufficient for evaluation, although as was mentioned earlier, a larger quantity is desirable for specimen preparation purposes.

Clean up between tests with different oils is greatly simplified. With the standard method it is necessary to remove previous test $0 i 1$ from the reservoir, pump and other parts of the oil circulating system. In the modified test, only the components assuciated with the specimen mounting mechanism need to be cleaned. On the other hand, considerably greater care must be exercised in cleaning the specimens themselves. Contaminants on improperly or ineffectively cleaned specimens are not flushed away and diluted in a large volume of oil as is the case with the standard method.

\section{Results}

\subsection{Friction Behavior and Determination of Failure}

A typical friction force record from a modified Timken test is shown in figure 2 . Following the initial $30 \mathrm{~s}$ break-in period at $67 \mathrm{~N}$, a large spike is observed corresponding to the application of the principal test load, $720 \mathrm{~N}$ in this example. Subsequently, the friction force remains relatively constant, rising slightly to a value which corresponds to a friction coefficient of 0.12. A friction coefficient of this magnitude is characteristic of a condition of boundary lubrication. Near the end of the test a marked drop in friction is observed followed by a sharp rise which indicates failure.

Despite reference to the initial $30 \mathrm{~s}$ period at $67 \mathrm{~N}$ as a break-in period, examination of block wear scars indicated that a major portion of the break-in process occurred during application of the principle test load. At $67 \mathrm{~N}$ after $30 \mathrm{~s}$ the block wear scar was a slightily polished band with most of the original grinding marks still present. This might be expected considering the small size of the break-in load. Thus the large spike in friction force which occurs on application of the principle test load is associated with break-in. The reason for the drop in friction force which precedes failure in the example shown is not understood. It was only observed for "wel1" formulated oils. In the example shown in figure 2, the oil used (76A-1) was a reference cil that passed the IIID engine sequence test for SF classification.

During the course of this investigation it was found that the friction force trace gave a sensitive and accurate indication of failure. Even in several cases where visual examination of the block wear scar with the unaided eye --- the method specified in ASTM 02782 -.- did not provide evidence of failure, confirmation of the failure that was indicated by the friction force trace was obtained by more critical examination of the surface by optical or scanning electron microscopy. Thus, the friction force trace was adopted as the means of determining failure in this investigation.

Friction force traces could, in general, be categorized as belonging to one of four different types. These are shown in figure 3. Type $A$ has already been discussed and, as mentioned, was observed only for well formulated ojls, although the other types of curves ( $B$, $C$ and $D$ ) were also observed for these oils. Base oils and oils that had received only minimal formulation often exhibited a type $B$ curve but $C$ and $D$ were also obtained. The type D curve is associated with failure on initial application of the principal test load. This type of failure could usually be produced by application of a load considerably higher than the load carrying capacity of the lubricant; however, it was not limited to that condition.

\subsection{Effect of 0 il Volume}

Figure 4 shows the effect on load carrying capacity of employing three different volumes of 0 i $1,0.20,0.035$, and $0.025 \mathrm{ml}$. The oil in this example, 76A-1, as previously indicated is a IIID engine sequence test reference oil meeting IIID requirements for SF classification. In figure 4 , pass and fail tests for each oil volume are enumerated at the indicated 1oads. For $0.2 \mathrm{~m} 1 .$, five 
consecutive failures were obtained at $675 \mathrm{~N}$ and five consecutive passes occurred at $630 \mathrm{~N}$. Thus a load carrying capacity of $630 \mathrm{~N}$ is indicated. When the volume of oil applied to the test specimen was reduced to $0.035 \mathrm{ml}$, failures predominated until the load was reduced to $450 \mathrm{~N}$. Similarly, a further reduction in oil volume to $0.025 \mathrm{ml}$ resulted in an additional decrease in load carrying capacity to about $180 \mathrm{~N}$, a value that was characteristic of base oils. A volume of $0.025 \mathrm{ml}$ of oil still represents a significant quantity of oil in terms of film thickness. For a ring surface area of $\sim 20 \mathrm{~cm}^{2}$, the nominal $\mathrm{film}$ thickness is $13 \mu \mathrm{m}$. This can be compared with the original surface roughness of $0.5-0.8 \mu \mathrm{m} R$ for the blocks and rings. It may be hypothesized that the reduction in load carrying capacity with test oil volume was associated with a decrease in the quantity of additives needed for effective boundary lubrication rather than too little oil to cover the surface. It should also be noted that when an oil volume much in excess of $0.20 \mathrm{ml}$ was employed there was a tendency for droplets to be lost from the system.

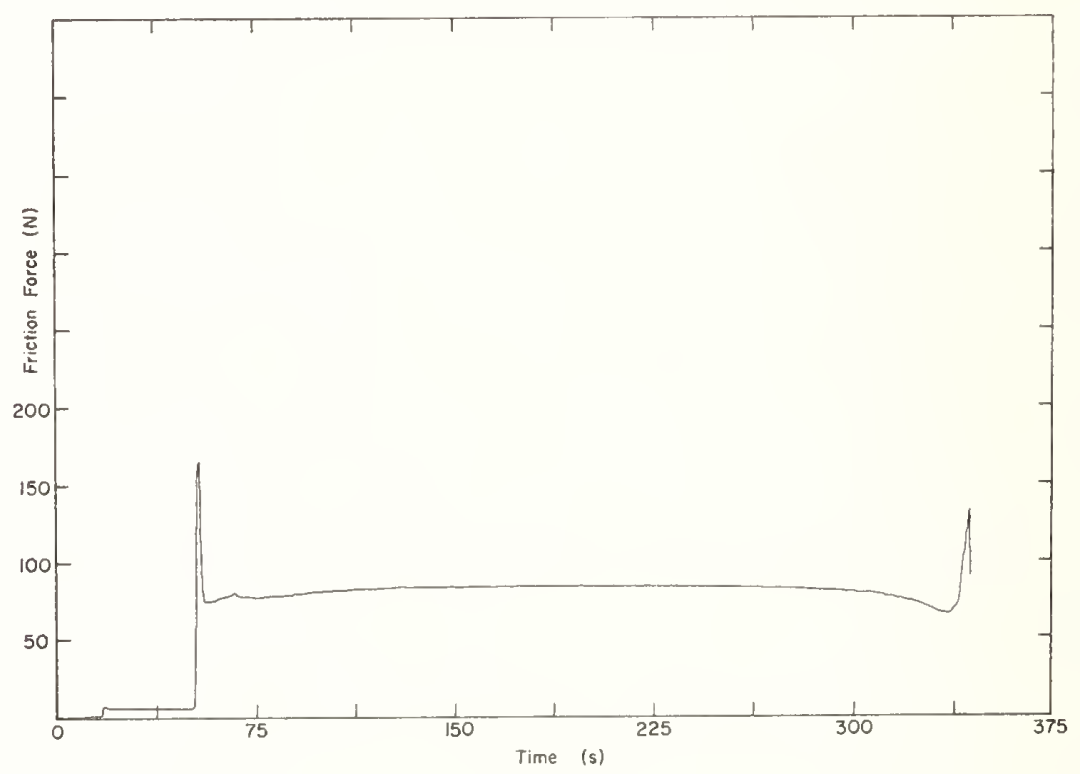

Figure 2. Typical friction force trace from modified Timken test. Thirty second break-in at $67 \mathrm{~N}$ and test at principal load of $720 \mathrm{~N}$ are shown. Large initial spike corresponds to application of principal load. Test was terminated when friction force was observed to rise sharply. Test oil was a IIID engine sequence test reference $0 i 1,76 \mathrm{~A}-I$.

\subsection{Results on IIID Reference 0ils}

Results obtained on six IIID reference oils are shown in figure 5 . For each oil an initial test was carried out at a load of $450 \mathrm{~N}$, additional tests were conducted at $90 \mathrm{~N}$ intervals above or below $450 \mathrm{~N}$, depending on whether the initial test was a pass or failure, until the approximate pass-fail range was located. (The initial results outside the pass-fail range are not shown in fig. 5.) Tests were then carried out at $45 \mathrm{~N}$ load increments until five consecutive failures and five 
consecutive passes were obtained to bound the pass-fail region. This procedure which requires a large number of tests (a minimum of 10 tests per oil) was adopted in order to obtain information on the statistical characteristics of the modified Timken method. The maximum load at which five consecutive passes were obtained is then referred to as the maximum pass load, i.e., the load carrying capacity of the oil according to this test method. Similarly, the minimum load at which five consecutive failures were obtained is referred to as the minimum failure load. Clearly, using these definitions, if a larger number of tests had been used at each load increment, a smaller maximum pass load and larger minimum failure load might have been assigned. The opposite affect might have occurred if fewer tests had been carried out at each increment. Utilizing five tests per load increment, it can be seen in figure 5 that for two oils, $76 \mathrm{~A}-1$ and $77 \mathrm{~B}-1$, the spread between the maximum pass load and minimum failure load is one load increment, i.e., $45 \mathrm{~N}$. For three of the six oils the spread is $135 \mathrm{~N}$ and for the remaining oil it is $90 \mathrm{~N}$.

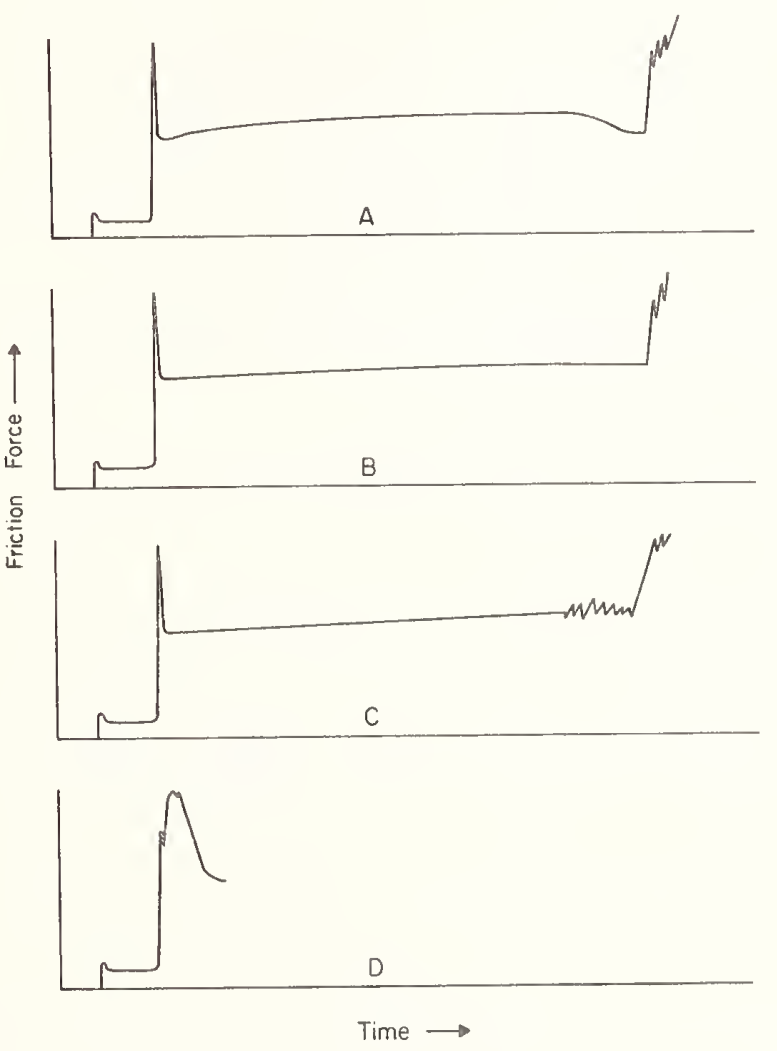

Figure 3. Characteristic types of friction force failure traces.

The test results presented in figure 5 are summarized in figure 6 . The maximum pass load, the mixed pass-fail region and the minimum fail load are indicated for each oil. In addition, cam plus lifter wear results obtained in IIID sequence tests are shown [3]. According to load carrying capacity, the oils fall into two distinct groups. $0 \mathrm{ils} 76 \mathrm{~A}-1,75 \mathrm{~B}-1$ and $79 \mathrm{~A}$ are similar and have maximum pass loads equal to or above $585 \mathrm{~N}$. 0 ils $72 \mathrm{~A}, 77 \mathrm{~B}-1$, and $77 \mathrm{C}$ are similar to each other but have minimum fail loads equal to or less than $405 \mathrm{~N}$, with considerably lower maximum pass loads. Dashed lines indicate the $585 \mathrm{~N}$ and $405 \mathrm{~N}$ load levels in figure 6 . The oils are grouped in an identical way according to cam plus lifter wear data. 0i1s 76A-1, 75B-1, and 79A exhibit approximately the same wear performance with average wear values well below the $102 \mu \mathrm{m} 1 \mathrm{imit}$ required to pass the IIID test for SE and SF service. Likewise, 72A, 77B-1 and 77C gave wear values exceeding the acceptable limit by a wide margin. 


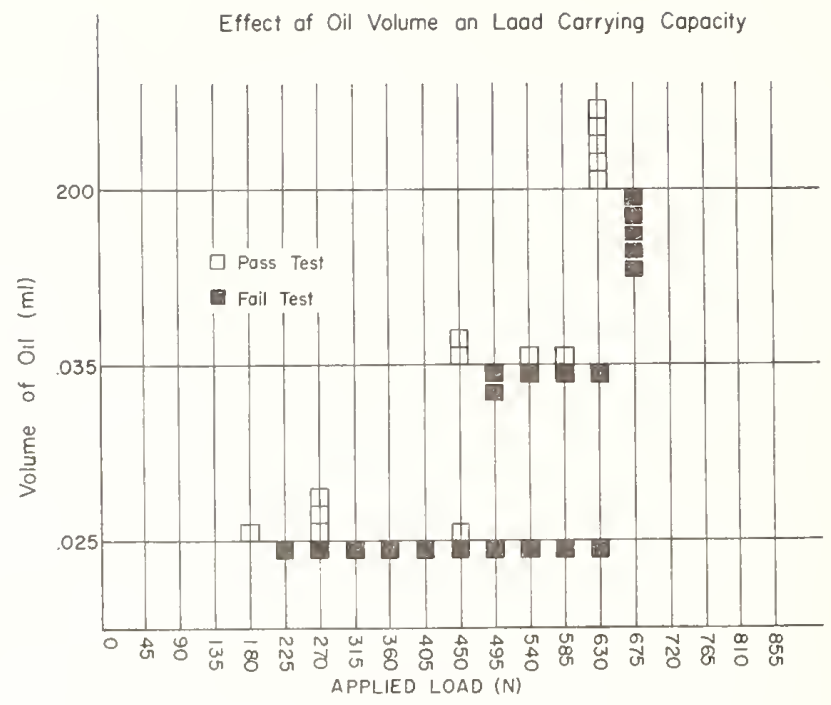

Figure 4. Influence of oil volume on load carrying capacity. Test oil was IIID engine sequence test reference oil $76 \mathrm{~A}-1$. This oil meets IIID requirements for SF classification.

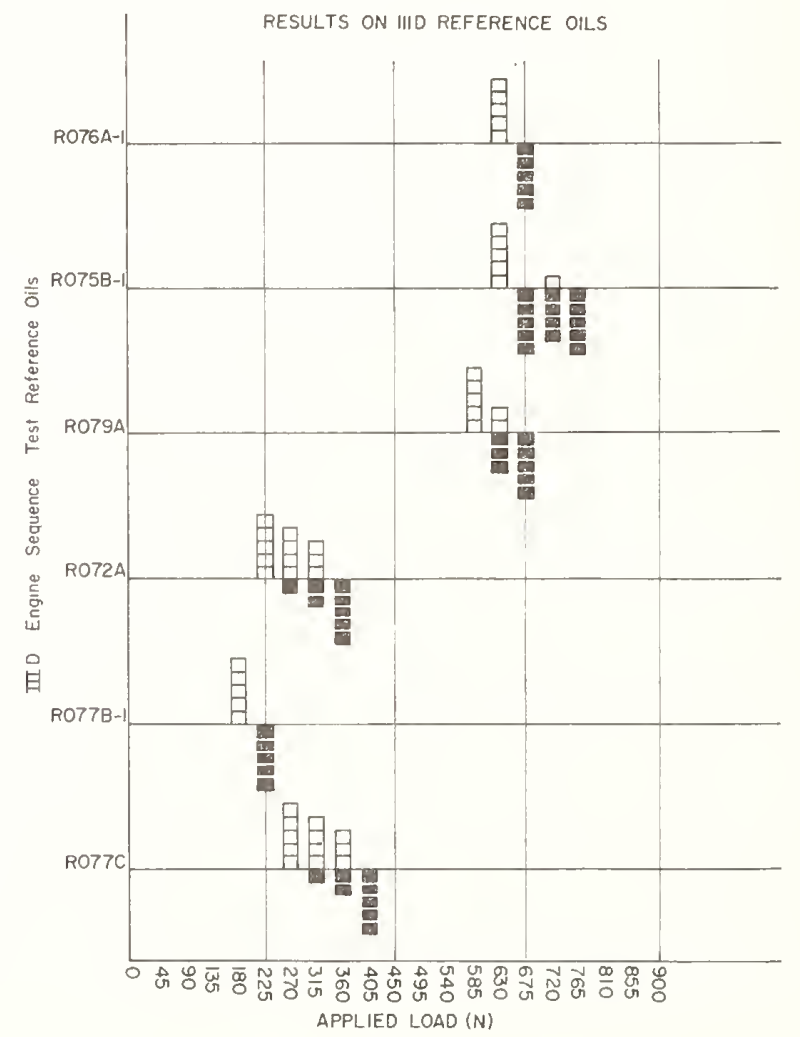

Figure 5. Modified Timken test results on six IIID engine sequence test oils. $\square$ indicates pass test and denotes a failure. For each oil, five consecutive passes determines the maximum pass load and five consecutive failures indicates the minimum failure load. 


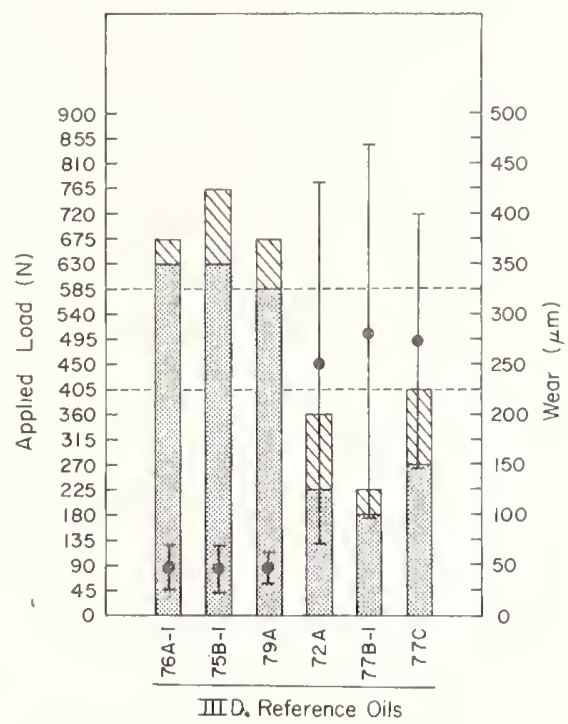

Figure 6. Load carrying capacity results on six IIID engine sequence test reference oils are shown. The hatched region corresponds to the load range where both pass and failure tests were obtained. At higher loads only failures were obtained while at lower loads in the shaded region only passes occurred. Cam plus lifter wear results from IIID engine sequence tests are plotted.

\subsection{RCMP and Commercial SF 0ils}

Two additional oils for which IIID engine sequence test data were availabie were examined. These are the RCMP oils which were subject to extensive field and laboratory evaluation. Detailed results of that study are presented elsewhere in these Proceedings

[4]. One RCMP oil was a virgin base oil product while the other was a re-refined base oil. Both oils were formulated with the same additive package at the same concentration to meet requirements for the SE classification. Field tests in RCMP patrol cars indicated that the performance of the oils was essentially similar in that type of service. Some differences were noted, however, in laboratory evaluations [4]. Load carrying capacity results obtained with the modified Timken test are shown in figure 7. Both oils have maximum pass loads somewhat below that obtained for the "low wear" IIID reference oils shown in figure 6. Of the two RCMP oils the re-refined oil is 10 west at 495 N. Correspondingly, the cam plus lifter wear for this oil determined in the IIID engine sequence test [4] is high with a value of $112 \mu \mathrm{m}$, which is slightly above the required SE limit of $102 \mu \mathrm{m}$. Because the cam plus lifter wear produced by this oil is so close to the limit, its load carrying capacity at $495 \mathrm{~N}$ may provide a good estimate of the threshold load carrying capacity that should be attained by an oil that is formulated to pass the IIID sequence test cam plus $7 i f t e r$ wear requirements for SE and/or SF qualification. The load level at $495 \mathrm{~N}$ is indicated by a dashed line in figure 7. It may be noted that $495 \mathrm{~N}$ is midway between the limits of $585 \mathrm{~N}$ and $405 \mathrm{~N}$ shown in figure 6 . 
Test results for three additional oils are shown in figure 7 . These oils were purchased from retail suppliers. Each was labeled as being an SAE $10 \mathrm{~W}-40$ oil which exceeded or met SF requirements. $A$ and $B$ were major brand name motor oils while $C$ carried the name of a local retail trade establishment. As indicated in figure 7 all three oils exhibit load carrying capacities above the threshold load carrying capacity level of $495 \mathrm{~N}$ just discussed.

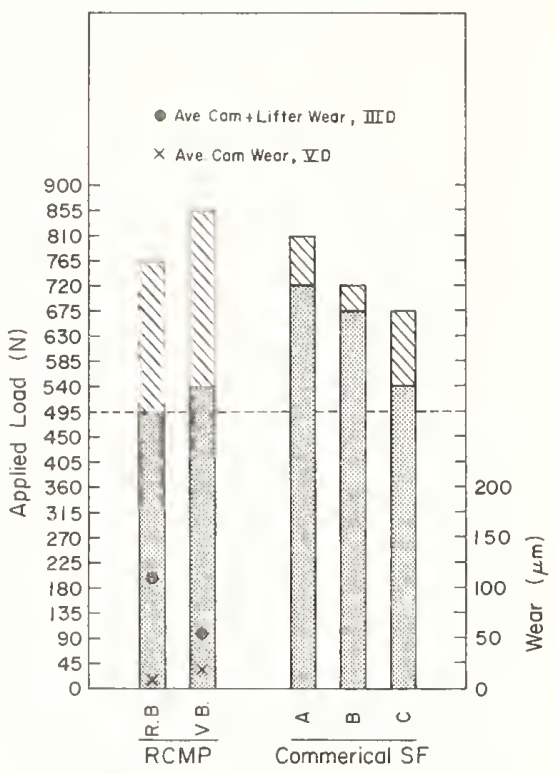

Figure 7. Load carrying capacity results on RCMP field trial and commercial SF motor oils. In the hatched range both passes and failures were obtained. At high loads only failures were obtained and at lower loads in the shaded region only passes occurred.

\subsection{VD Reference $0 i 1 \mathrm{~s}$}

While the IIID sequence test is performed under conditions of continuous high load and high temperature, the VD test stresses cyclical operation at low to moderate temperatures. In order to successfully pass the VD sequence test for the SF Classification, among other requirements, the average cam wear must not exceed $25 \mu \mathrm{m}$. Follower wear is not specified. Results on three VD reference $0 i 1 s$ are shown in figure 8 . Good correlation is indicated between load carrying capacity determined by the modified Timken test and VD cam wear results [7]. Average cam wear values for oils 913 and 916 are both approximately $14 \mu \mathrm{m}$, well below the $25 \mu \mathrm{m}$ limit. The load carrying capacity for these oils falls in the same range as the low wear IIID oils. The average cam wear for oil 915 is more than double the limit and the load carrying capacity is correspondingly quite low.

VD cam wear values were also documented for the two RCMP oils. These data are plotted in figure 7. In both cases the wear value is below the $25 \mu \mathrm{m} 1 \mathrm{imit}$; however, in contrast to the IIID wear results, the virgin base oil performs somewhat more poorly than the re-refined base oil (also contrary to the load carrying capacity behavior). 


\subsection{Additive Response of Base 0 i1s}

As an application, the modified Timken method was employed to examine the additive response of three re-refined base oils. The re-refined base oils were selected arbitrarily. Each was furnished by a different re-refiner and was generated from used oil collected by the individual re-refiner. The same additive package was used to treat each oil. A suitable treatment level according to the supplier of the additive package was $8 \mathrm{wt} \%$. Each of the re-refined base oils was tested at three additive concentrations, 4,6 , and 8 wt\%. The results are shown in figure 9 . With respect to the load carrying capacity of $495 \mathrm{~N}$ which we have determined is the minimum value for an oil to meet the IIID engine sequence test cam plus lifter wear limit for SE and SF qualification, 6 wt\% appears to be an adequate concentration in each case. At a concentration of 8 wt\%, the re-refined oils yield load carrying capacities that are comparable with those obtained for the low wear IIID reference oils shown in figure 6 and the premium motor oils, $A$ and $B$, shown in figure 7 . On the other hand, a concentration of 4 wt\% was not adequate to provide a load carrying capacity of $495 \mathrm{~N}$ for any of the re-refined base oils.

\section{Discussion}

The load carrying capacity results on IIID engine sequence test reference oils obtained with the modified Timken method exhibit a consistent correlation with reported cam plus lifter wear results. The inverse relationship between load carrying capacity and cam plus lifter wear is as would be expected. That is, high load carrying capacity corresponds to low wear and low load carrying capacity is consistent with high wear. Results on the well characterized RCMP oils, on commercial SF motor oils and on VD reference oils also show equally good correlation. It may therefore be concluded that the modified Timken method is a potentially useful laboratory test for predicting the cam and follower wear behavior of motor oils.

It may be anticipated that the modified Timken method could be used to select an appropriate additive package and to determine the concentration of the package that is necessary to achieve cam and follower wear values below the limits specified in the IIID and VD engine sequence test for SE and SF qualification. The test might also be used for quality control purposes to monitor the consistency of different batches of formulated motor oils. This application could be of considerable importance under circumstances where refinery feed stock and product is subject to variations which might influence additive response.

The extent to which the modified Timken test may actually be used for the applications suggested above will depend on individual requirements for test sensitivity, precision and accuracy. With respect to precision and accuracy it may be noted that in some of the examples presented there is a relatively sharp demarcation between the maximum pass and minimum failure loads while in other cases there is a large separation. It is thought that this is at least in part due to intrinsic characteristics of the oils themselves. However some of the variation is undoubtedly caused by differences in test conditions. For example, differences in humidity, temperature, rotational speed, specimen alignment, and specimen cleanliness may be considered. Perhaps the most serious source of uncertainty rests with the block and ring test specimens. Differences in metallurgy and surface finish can have a pronounced effect on test behavior [5]. To minimize these effects, which can contribute to both systematic and random errors, specimens from a single production run must be employed and random selection procedures used.

It should also be emphasized that load carrying capacity is not a property of the oil but is a quantity determined under the conditions of a given test method. Thus not only would different test procedures lead to a different load carrying capacity value but using a Timken machine, for example, rather than the Falex \#1 machine employed here could pesult in different values. Therefore, it is important that a calibration procedure be carried out using an appropriate set of reference oils, perhaps the engine sequence test reference oils, following the procedure of this investigation.

A measure of the test sensitivity is indicated by the additive response experiments on three re-refined base oils. A relatively wide separation was obtained between load carrying capacities determined at concentrations of 4,6 , and 8 wt\% additive package. Interpolation of the results shown in figure 9 suggests that discrimination at a 1 wt\% additive concentration interval can be achieved. Discrimination will, of course, depend not only on careful control of test conditions but also on the additive response characteristics of the given base $0 i 1$ and the additive itself. 


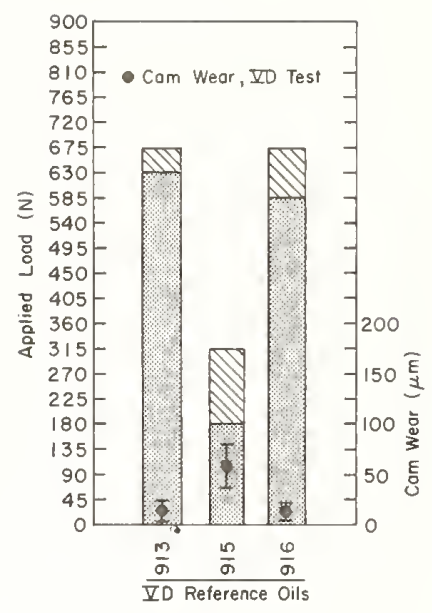

Figure 8. Load carrying capacity results on VD engine sequence test reference oils. In the hatched region both passes and failures were obtained. At higher loads only failures were obtained and at lower loads in the shaded region only passes occurred.

Finaliy, it should be recognized that the correlation that has been demonstrated to exist between load carrying capacity and cam and follower wear was empirically derived. Formulated o might be devised which exhibit a high load carrying capacity and at the same time result in excessive cam and lifter wear. The lubricant properties stressed in the modified Timken test a not necessarily those that control cam and lifter wear. The sliding conditions, environment an metallurgy of the cam and follower were not simulated in the modified Timken method. The valid of the correlation relationship with respect to a base oil-additive system differing from those studied here would have to be established through appropriate testing; or better, through a fundamental understanding of wear mechanisms and the lubricant properties that control boundary lubrication behavior.

\section{Conclusions}

1. The modified Timken method described here is an uncomplicated test which is straight forward to conduct in practice.

2. Load carrying capacity results on six IIID engine sequence test reference oils show: correlation with cam and follower wear values for those oils. High load carrying cal corresponds to low cam plus lifter wear; low load carrying capacity corresponds to $h$ cam plus 1 ifter wear. 


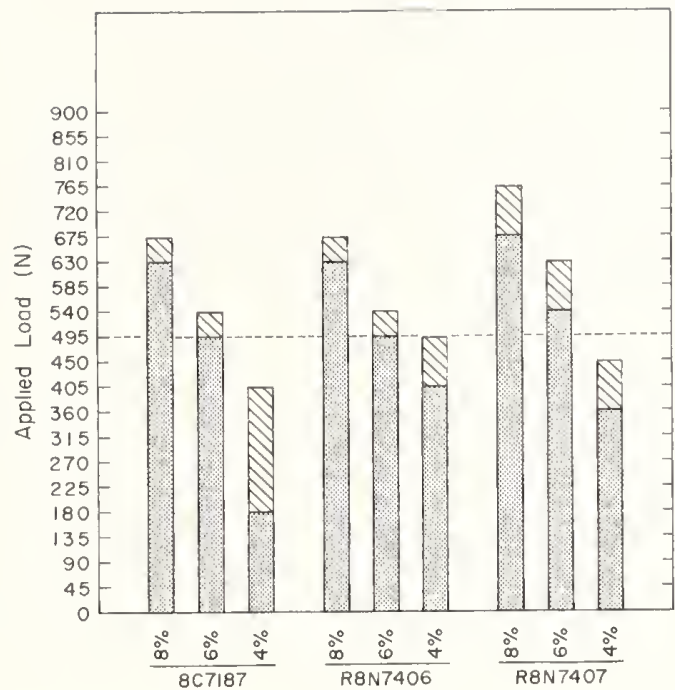

Figure 9. Additive response behavior of three different re-refined base oils as determined by load carrying capacity is indicated. The same additive package was used for each oil. $495 \mathrm{~N}$ (dashed line) is the load carrying capacity which, according to results in this investigation, should be exceeded if an oil is to meet IIID engine sequence test requirements for cam lifter wear.

3. IIID reference oils can be used to calibrate the modified Timken method for application to oils having unknown cam plus follower wear. (The extent to which the calibration will be applicable to base oil-additive systems differing markedly from the IIID oils has not been evaluated. )

4. A correlation relationship between load carrying capacity and wear, similar to that obtained for IIID reference oils, was found to hold for three VD reference oils.

5. The modified Timken test can be employed to determine the additive response of base oils.

The authors wish to thank Donald Becker for his support and many valuable discussions. Support of the NBS Office of Recycled Materials is gratefully acknowledged.

\section{References}

[1] 1980 Annual Book of ASTM Standards. Parts 24 and 25. American Society for Testing Materials, Philadelphia; PA; 1980.

[2] Didot, F. E. Suntech Corporation private communication.

[3] ASTM IIID surveillance panel reports; 1981. 
[4] Strigner, P. L. Correlation aspects of a virgin and a re-refined engine oil containing the same additive. Proceedings, Measurements and Standards for Recycled 0il-Iv; Natl. Bur. Stand. (U.S.) Spec. Publ. 674; 1983.

[5] Ives; L. K. Boyer, P. Pin and V-Block and ring and block bench wear tests for engine oil evaluation. Joint Conference on Measurements and Standards for Recylced 0i1/Systems Performance and Durability; 1979 Oct. Nat. Bur. Stand. (U.S.) 584; 1980; 245-259.

[6] Gates; R. S. Hsu; S. M. Development of an oxidation-wear coupled test for the evaluation of lubricants; ASME/ASLE 1982 Lubrication Conference; 1982 Oct. 5-7; Washington, DC. ASLE paper No. $82-L C-I D-2$.

[7] ASTM VD surveillance panel reports, 1981. 
National Bureau of Standards Special Publication 674. Proceedings, Conference on Measurements and Standards for Recycled Di1 - IV, held at NBS, Gaithersburg, MD, September 14-16, 1982.

(Issued July 1984).

\title{
DEVELOPMENT OF A STEP LOADING SEIZURE TEST FOR ENGINE OIL ADDITIVE RESPONSE
}

\author{
R. S. Gates and S. M. Hsu \\ Chemical Stability \& Tribology Group \\ Inorganic Materials Division \\ National Bureau of Standards \\ Washington, DC 20234
}

Additive response measures the effect of base oils on the performance of an additive or combination of additives. This study is concerned with measuring the effect of basestock composition on antiwear performance of oils with an SE/CC additive package.

A step loading seizure test procedure using a four-ball wear tester was developed to measure the antiwear additive response of eighteen base oils. The procedures examined were: a step loading seizure test, and a thin film step loading seizure test with six microliters sample volume. The latter procedure combines oxidation and wear in a single test. Both test procedures have been shown to relate to engine wear experience. The conventional ( $10 \mathrm{~m} 1$ ) step loading seizure test procedure was found capable of measuring additive response only at very low additive concentrations. The micro-sample step loading seizure test procedure was able to measure differences in additive response among the base oils at the normal treat rate of 8.0 percent (wt.) additive package.

\section{Introduction}

Additive response is a measure of the extent of improvement in performance due to the addition of an additive or mixture of additives to a lubricating base oils for a particular application. This improvement in performance due to additives may be affected by such factors as additive concentration, the presence of other additives, test severity, and the composition of the base oil $[1-3]^{1}$. This study is concerned with the development of a wear test to measure the effect of base oil composition on the antiwear performance of oils with an automotive engine oil additive package.

Recently, two bench wear test procedures using a four-ball wear tester were developed to simulate and evaluate the wear prevention capabilities of motor oils in engine sequence IIID [4,5]. Results from these procedures were shown to correlate with engine sequence IIID wear results. In addition, the bench tests are short, inexpensive, and precise. In this study, we will examine both tests to determine if they can be used to measure the additive response on wear due to the base oil composition differences.

\subsection{Effect of Base 0il-Additive Interaction on Wear}

Antiwear additives are thought to reduce metal-metal contact in highly loaded contacts through the formation of a protective surface film. Initially, polar molecules are adsorbed onto the metal surface. Subsequent surface chemical and mechanical interactions may then result in the formation of a more tenacious protective film. This film can be removed through desorption, mechanical rubbing, cavitation, or thermal excitation. As the film is removed, a new film is formed and eventually an equilibrium is established between the film formation and film removal processes.

One of the controlling steps in the antiwear mechanism is the adsorption of the polar species onto the metal surface. Other polar molecules in the oil solution may interfere with this process by competing for the available surface active sites. An example of this preferential additive adsorption is shown in table 1 . Constant condition wear tests with chemical wear debris analyses were performed on a base oil blended with two different surface active additives. The base fluid alone produces a large wear scar of $0.76 \mathrm{~mm}$ (test 1 ). Wear debris is largely composed of iron and iron oxide particles with relatively little organic iron. When $2.25 \%$ Triscresyl phosphate (TCP) antiwear additive is blended with the base oil (test 2) the wear scar is significantly smaller.

1Figures in brackets indicate the literature references at the end of this paper. 
Less total iron is recovered in the wear debris which still consists largely of iron and iron oxide particles. 0ctadecyl bromide has a very different effect as seen in test 3 . The corrosive nature of this additive is reflected in the large wear scar and the higher proportion of organometal ic iron to inorganic iron in the wear debris. When both additives are present (test 4) a small wear scar is produced and iron in the wear debris is largely in the inorganic forms. This demonstrates the ability of the TCP to mask out the effects of the second surface active additive, 0ctadecyl Bromide. There may be many others cases where a surface active molecule competes with and reduces the effectiveness of other surface active molecules.

Table 1. Effect of preferential additive adsorption

\begin{tabular}{|c|c|c|c|c|}
\hline \multirow[b]{2}{*}{ Formulation } & \multirow{3}{*}{$\frac{\underset{\mathrm{mm}}{\text { Wear Scar Diameter }}}{0.76}$} & \multicolumn{3}{|c|}{$\begin{array}{l}\text { Iron Recovered in } \\
\text { Wear Debris in } \mu \mathrm{g} \text { as } \\
\end{array}$} \\
\hline & & $\begin{array}{l}\text { Organic } \\
\text { Iron } \\
\end{array}$ & Iron & $\begin{array}{l}\text { Iron } \\
\text { Oxide }\end{array}$ \\
\hline 1) Base Fluid & & 36 & 54 & 192 \\
\hline $\begin{array}{c}\text { 2) Base Fluid + } 2.15 \% \\
\operatorname{TCP}(A)\end{array}$ & 0.60 & 14 & 26 & 78 \\
\hline $\begin{array}{l}\text { 3) Base Fluid + } 2.25 \% \\
\mathrm{C}_{18} \text { Bromide (B) }\end{array}$ & 0.90 & 106 & 120 & 120 \\
\hline 4) Base Fluid + (A) + (B) & 0.55 & 12 & 27 & 27 \\
\hline
\end{tabular}

Lubricating base oils are composed of complex mixtures of paraffins, naphthenes, aromatics, and heteroatomic compounds containing sulfur, nitrogen, and oxygen. Some of these compounds in the oil mixture are polar and may affect antiwear additive response by competing for the surface active sites. Evidence of the polar compounds interacting with additives and affecting antiwear additive performance is demonstrated in figure 1. In this case the polar constituents of a base oil were isolated using liquid chromatographic techniques. Constant condition wear tests were conducted on the purified base oil reconstituted with selected quantities of the polar fraction. When all the polar molecules were removed from the base oil, relatively large wear scars (0.64mm) were obtained. Addition of small amounts $(0.1 \%$ ) of polars reduced the wear scars to $0.56 \mathrm{~mm}$. Apparently, some surface active polar constituents in the base oil were able to reduce wear. When this test was repeated with base oil blended with $0.5 \%$ antiwear additive a different result was obtained. For the case where no polar molecules are present in the purified base oil, very small wear scars were produced. When a small amount of polar fraction was added, wear scars increased significantly suggesting antagonistic interaction between the polar molecules in the base oil and the antiwear additive. Therefore, the antiwear additive is most effective when no polar molecules are present, and addition of small quantities of polar molecules isolated from the base oil interfered with the overall antiwear effectiveness of the additive.

With this model, the antiwear mechanism is strongly surface adsorption related. Therefore, the additive response in wear could be traced to the interference of the surface active molecules in base oils that compete for the surface active sites. Such compounds may be found in the polar fraction of base oils in the form of organic acids, sulfur compounds, nitrogen containing aromatic compounds, and many others. Additive response may therefore be related to the quantity and nature of particular polar molecular structures present in a particular base oil.

Determination of molecular structures of polar species in complex mixtures such as lubricating base oils is very difficult. An economical, well controlled laboratory test is needed for extensive additive response testing to establish a data base. Lubricating base oils that provide different additive response can then be studied in more detail to determine the molecular structures which affect the performance of an additive.

The purpose of this study is to develop a wear test procedure that can be used to measure antiwear additive response among different base oils. 


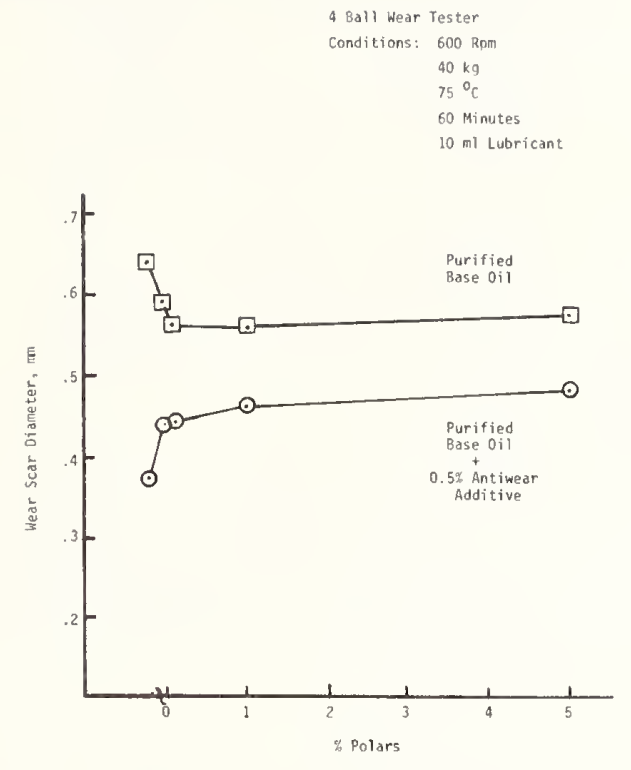

Figure 1. Effects on wear of polar fraction from a re-refined base oil.

\section{Experimental}

\subsection{Apparatus and Equipment}

Testing was carried out using a Falex No.6 four-ball wear tester and a Roxana four-ball wear tester. Ten ml oil step loading seizure tests were conducted using the Falex No. 6 wear tester, while six microliter oil step loading seizure tests were run on the Roxana four-ball apparatus. In both cases, friction was monitored during the test using an electronic force transducer whose output was displayed on a strip chart recorder.

Test specimens were $12.7 \mathrm{~mm}$ (0.5 in) diameter AISI E52100 steel Grade 25 EP (Extra Polish) bal1s. The Rockwell C hardness of the balls was between 64 and 66 .

\subsection{Sample Preparation}

Specimens were cleaned prior to each test in successive rinses of hexane and acetone (ACS Grade) in an ultrasonic bath, wiped with a clean tissue, and dried with a stream of nitrogen gas. The test cup and top ball assembly was cleaned and prepared in the same manner without the use of the ultrasonic bath.

For this study, a commercial SE detergent-inhibitor additive package was used. Al1 mixtures of base oil and additive package were prepared in 100 gram quantities to ensure sufficient sanile for testing. To ensure homogeneity, samples were mixed with a magnetic stirrer at $\sim 75{ }^{\circ} \mathrm{C}$ for $60^{\circ}$ minutes. Each sample was weighed, blended, and stored in the same container to prevent contamination.

\subsection{Reference 0 ils}

Bench test procedures are screened using the ASTM sequence IIID engine reference oils. The reference oils have an extensive engine test data base and are used to qualify engine test stands for the IIID test. In turn, valve train wear results from the IIID engine test have been found to correlate with valve train wear observed in field tests $[6,7]$. 
Based on the engine wear results, the reference oils can be ranked as high wear or low wear oils. The same reference oils were run in the step loading seizure test using a four-ball wear tester. The performance of the oils in the IIID test was then compared with performance in the bench tests to determine the degree of correlation.

\subsection{Test Procedures and Correlation}

Two test procedures were examined in detail after initial screening based on previous work $[4,5]$. They are:
1) step loading seizure test (ten milliliter oil sample)
2) Thin film step loading seizure test (six microliter oil sample)

These two bench test procedures determine the antiwear characteristics of lubricants in a similar manner but under different environments.

The step loading seizure test (SLST) measures the load carrying capability of a lubricant. The test is run at constant speed (600 Rpm) with the load increased by nine kg (20 1b) every five minutes. A typical friction trace for a step loading seizure test, given in figure 2 , shows the incremental increase in friction associated with the load increases. At some point during the test the lubricant fails to protect the surface adequately and severe wear occurs accompanied by a large increase in friction (point $A$ in figure 2). The load at which this occurs is defined as the seizure load.

Earlier studies [4,5] have shown that the SLST test correlated with engine wear data. Summary results on the eight reference oils are shown in table 2. The data indicate that the low wear reference oils have higher seizure loads than the high wear reference oil. Repeatability of the 10 $\mathrm{ml}$ step loading seizure test on the IIID reference oils was approximately $\pm 13 \mathrm{~kg}$.

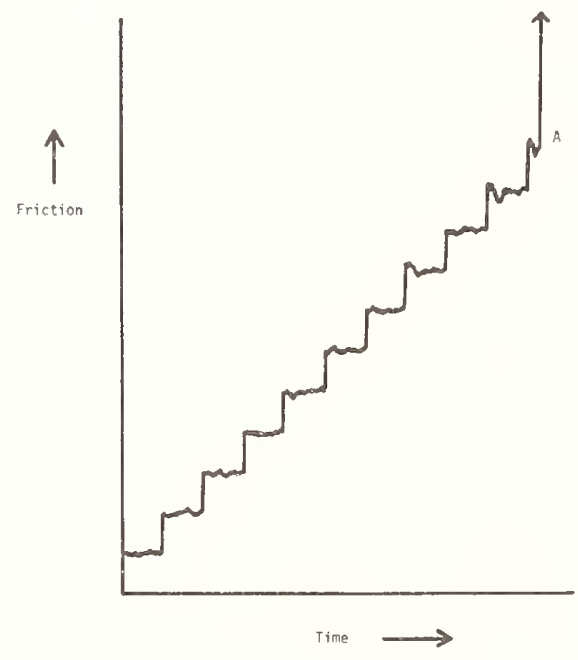

Figure 2. A typical step loading seizure test friction trace. 
Table 2. Correlation between the step loading seizure test results and engine test data

\begin{tabular}{lccc}
$\begin{array}{c}\text { Reference } \\
\text { 0ils }\end{array}$ & $\begin{array}{c}\text { IIID Wear } \\
\text { Rating }\end{array}$ & $\begin{array}{c}10 \mathrm{ml} \text { SLST } \\
\text { Seizure Load, } \mathrm{kg}\end{array}$ & $\begin{array}{c}\text { Micro Sample SLST } \\
\text { Seizure Load, } \mathrm{kg}\end{array}$ \\
\cline { 2 - 4 } $76 \mathrm{~A}-1$ & Low & 200 & 240 \\
$75 \mathrm{~B}-1$ & Low & 209 & 210 \\
$81 \mathrm{~A}$ & Low & 227 & 240 \\
$79 \mathrm{~A}$ & Low & 218 & 188 \\
$73 \mathrm{~B}-1$ & High & 127 & 128 \\
$77 \mathrm{~B}$ & High & 168 & 128 \\
$77 \mathrm{C}$ & High & 132 & 135 \\
$72 \mathrm{~A}-1$ & High & 132 & 120
\end{tabular}

Table 3. Crude source and processing technologies of the seventeen base oil set

\section{$\underline{0 i 1 \quad \text { ID }}$}

A

B

c

D

E

F

G

H

I

J

K

L

M

N

0

$\mathrm{P}$

Q

\section{Viscosity Grade}

$200 \mathrm{~N}$

$250 N$

$350 \mathrm{~N}$

$300 \mathrm{~N}$

$400 \mathrm{~N}$

$350 N$

$300 \mathrm{~N}$

$250 \mathrm{~N}$

$350 \mathrm{~N}$

$200 \mathrm{~N}$

$150 \mathrm{~N}$

$600 \mathrm{~N}$

$50: 50$

$150 \mathrm{~N} / 600 \mathrm{~N}$

$210 \mathrm{~N}$

$270 N$

$210 \mathrm{~N}$

$110 \mathrm{~N}$
Processing Technology

Pretreat/Vac. dist./

Clay finish

Clay treat

Acid/Clay

Acid/Clay

Caustic Pretreat/

Vac. dist.

Acid/Clay

Acid/Clay

Acid/Clay

Acid/Clay

Acid/Clay

Solvent extraction

Solvent extraction

Solvent extraction

Solvent extraction

Solvent extraction

Solvent extraction

Solvent extraction
Crude Source Geographical Area

Mid-West (US)

Southwest

Southwest

West Coast

Northeast

South

Northwest

Canada

West Coast

Northeast

Mid-East

Mid-East

Canada

Mid-Continent

Mid-East

Mid-Continent

Mid-Continent 
The thin film step loading seizure test also distinguishes between the reference oils on the basis of seizure load. This test however, uses only a thin film of lubricant and contains a much larger component of oxidation than the conventional test. The thin film step loading seizure test is run at 400 RPM with $15 \mathrm{~kg}$ load increases every 30 seconds under a controlled flowing atmosphere of $0.25 \mathrm{~L} / \mathrm{min}$ dry air.

The results of testing using the eight reference oils, given in table 2, show that the seizure load of the low wear reference oils is significantly higher than the high wear reference oils. Repeatability of the micro-sample step loading seizure test on the IIID reference oils is approximately $\pm 15 \mathrm{~kg}$.

\section{Results and Discussion}

Seven virgin (VB) and ten re-refined (RB) base oils constituted the base oil set used for additive response testing. These oils were selected because they represent a cross section of available processing technologies, crude sources, and viscosity grades as shown in table 3 . They have been extensively characterized and large quantities are available for testing.

\subsection{Step Loading Seizure Test}

Initially, ten ml step loading seizure tests were conducted on the set of base oils blended with 8.0 percent additive package. Results from these tests are given in table 4 and figure 3 . Average seizure loads are presented graphically in figure 3 in order of increasing seizure load. The shaded histograms represent re-refined oils, and the unshaded areas represent virgin oils. The approximate repeatability of the test $( \pm 13 \mathrm{~kg}$ ) obtalned with the reference oils, is overlaid on oil $C$ as an aid to interpreting the degree of separation of the oils. Seizure loads for most of the oils were high except $0 i 1 \mathrm{G}$. For most oils, seizure loads exceeded the $299 \mathrm{~kg}$ (660 1b) seizure 1oad $1 \mathrm{imit}$ of the equipment. This indicates that the test procedure (speed, load, duration) is not severe enough to properly distinguish performance difference among all the base oils at 8.0 percent additive package. There may or may not be a difference in base oil additive response using this procedure, however, the equipment limitation does not allow for a comparison. Further testing with an increase in test severity is desirable. Three base oils with different amounts of polar constituents were selected and blended to study the interaction of additive level and test severity in this test. Arbitrary virgin and re-refined base oils and a super-refined white oil were chosen for testing. All three base oils have similar viscosities.

Results from ten $\mathrm{ml}$ step loading seizure tests on the three base oils at various concentrations of additive package are shown in figure 4. The superrefined paraffin, virgin, and re-refined oils al1 show responses to the additive package. At 0.5 percent additive level, there is a significant difference among the three base oils in terms of antiwear behavior. The order of the base oils: white oil > virgin $\gg$ re-refined also coincides with our interference model.

Table 4. Additive response test results based on $10 \mathrm{ml}$ SLST with 8.0 percent additive package

\begin{tabular}{c} 
Base \\
\hline A \\
B \\
C \\
D \\
E \\
F \\
G \\
H \\
I \\
J \\
K \\
L \\
M \\
N \\
O \\
P \\
Q
\end{tabular}

\begin{tabular}{c}
$\begin{array}{c}\text { Seizure Load } \\
\mathrm{kg}\end{array}$ \\
\hline$>299$ \\
299 \\
272 \\
$>299$ \\
$>299$ \\
$>299$ \\
$168^{\alpha}$ \\
$>299$ \\
$>299$ \\
263 \\
$>299$ \\
254 \\
$>299$ \\
290 \\
$>299$ \\
$>299$ \\
$>299$
\end{tabular}

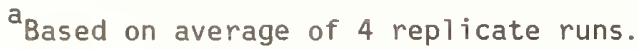




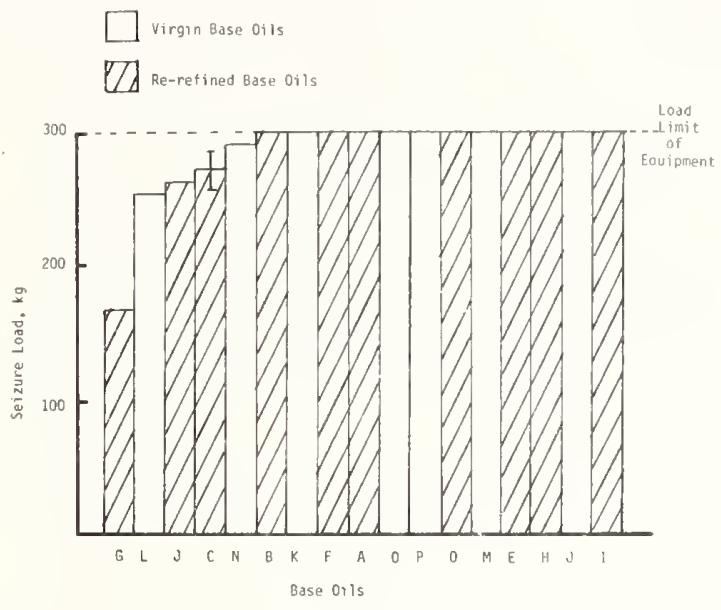

Figure 3. Additive response of the seventeen base oil set at 8.0 percent additive package (10 ml SLST).

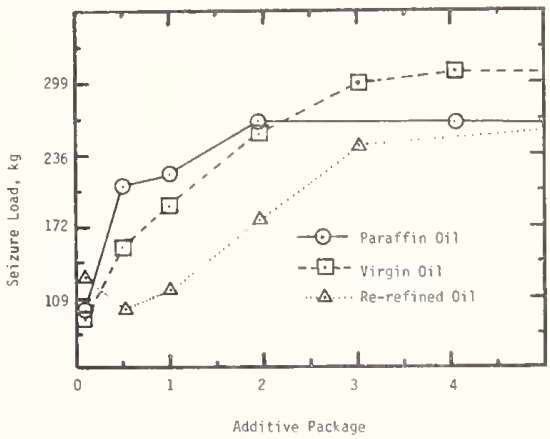

Figure 4. Effect of additive package concentration on seizure load: $10 \mathrm{ml}$ SLST. 
Since there appeared to be a performance difference between the base oils at 0.5 percentage additive package, testing was expanded to the entire set of base oils at this additive package concentration. Results from ten $\mathrm{ml}$ step loading seizure tests conducted on these blends are given in table 5. Average seizure loads, presented in order of increasing seizure load, are presented in figure 5. All base oil-additive package blends gave relatively low seizure load values, ranging from $91 \mathrm{~kg}(200 \mathrm{lbs})$ to $181 \mathrm{~kg}(400 \mathrm{lbs})$. After accounting for the test precision, the antiwear characteristic differences observed due to base oil differences are significant.

Table 5. Additive response test results based on $10 \mathrm{ml} \mathrm{SLST}$ with 0.5 percent additive package

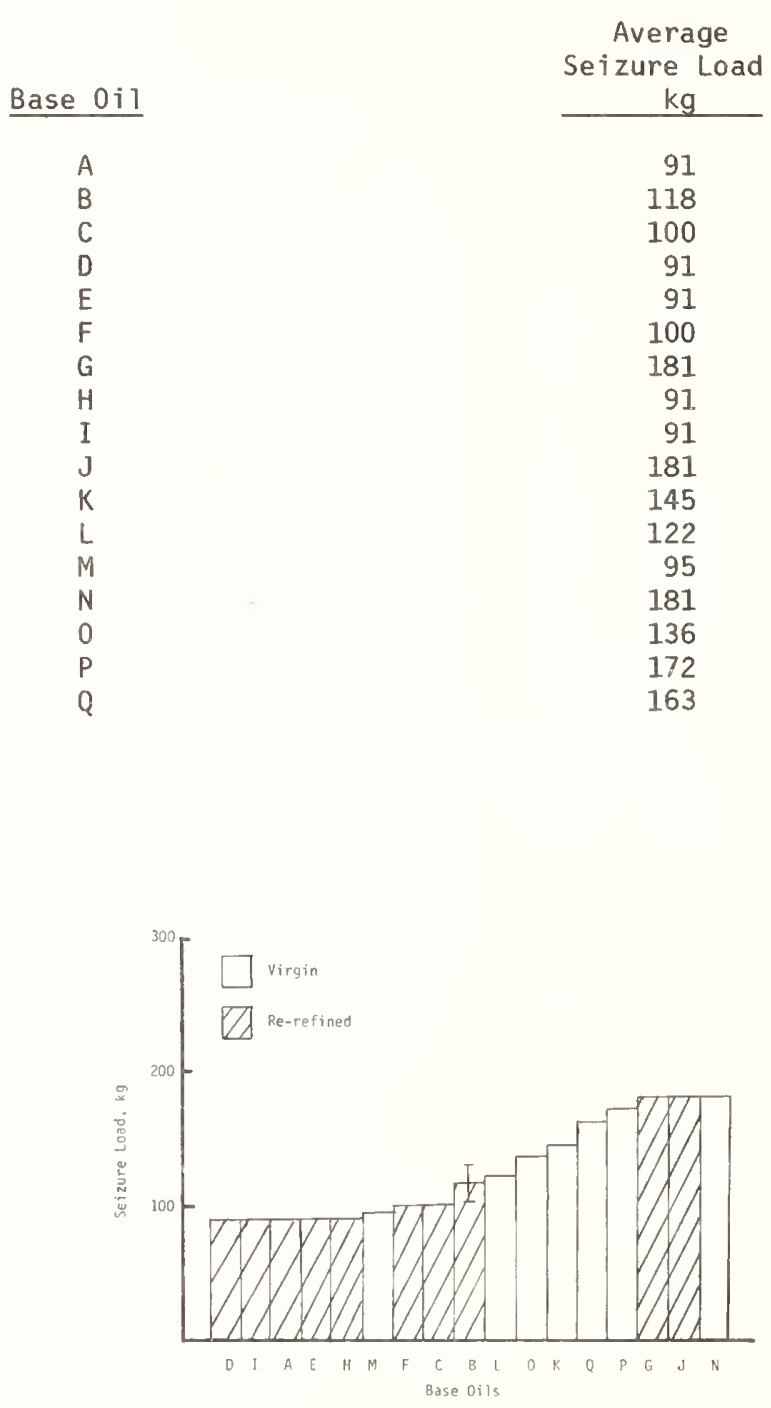

Figure 5. Additive response of the seventeen base oil set at 0.5 percent additive package. 
From these studies, two trends may be evident. In both figure 3 and figure 5 , differences in antiwear additive response are observed. These differences are primarily due to the base oil compositional variation. The second observation is that there is no discernable trend between re-refined and virgin base oils. Correlation between the polar content and wear did not show any significant cause and effect relationships. Also, the ranking of the oils appears to be test method dependent. Further testing by other methods may elucidate this trend.

\subsection{Micro Sample Step Loading Seizure Test}

$10 \mathrm{ml}$ step loading seizure tests on 8.0 percent additive package blends indicated that the test procedure was not able to discern the base oil influence at that particular additive package concentration. Relative test severity was increased by decreasing the additive package concentration. Another method of increasing test severity is to adjust the test conditions. A second, thin film micro sample, step loading seizure test was developed which combines oxidation and wear in a single test and requires only six microliters of sample [5]. The test is more severe since it stresses the oil under oxidizing conditions.

Micro sample step loading seizure tests were conducted using the 8.0 percent additive package blends. Results from these tests are given in table 6 and presented graphically in order of increasing seizure load in figure 6. Seizure loads ranged from a low of $150 \mathrm{~kg}$ to a high of over $285 \mathrm{~kg}$ (load limit of equipment). The difference of base oil response to the same additives are again observed. Since the test has a demonstrated correlation to IIID wear ranking, the results would appear to be satisfactory for the purpose of measuring the base oil antiwear additive response.

To cross check the test procedure with the interference model discussed previously, three base oils with varying degree of polar content (paraffinic white oil, virgin base oil, and a re-refined base oil) were used at various additive levels. Results are shown in figure 7 . Significant base oil additive response differences are observed at 1 percent and 8 percent additive treat. However, the ranking of the oils does not conform to the interference model based on polar content.

If we take the maximum difference among the base oils under one set of test conditions and rank the base oils in percentiles, we can compare the various base oil rankings for different test methods and test conditions. Table 7 shown the percentile ranking of the seventeen base oils. It is apparent that different base oils respond to the same additive package differently under different test procedures and test conditions. There is no universal ranking of base oils with respect to wear.

Among the three test procedures investigated, only the micro sample thin film SLST test procedure shows engine test wear correlation, and at the same time, has shown significant base oil effects at full additive package concentration.

In the final analysis, the results obtained in this study may be consistent with the interference mode1. After all, different molecular structures have different effects. In a surface adsorption competition model, a very minor constituent may dominate the surface chemistry. Therefore, a simple measure such as polar content without taking into account the molecular structural parameters may not produce consistent ranking of base oils.

\section{Summary}

Two step loading seizure test procedures have been studied with respect to determining base oil additive response. The following conclusions can be drawn:

1) Significant base oil additive responses to wear were observed as measured by the two step loading seizure tests.

2) An interference model explaining the mechanisms of base oil additive response was developed and found consistent with the results. 
Table 6. Additive response results based on micro sample SLST with 8.0 percent additive package

\section{Base 0i]}

\section{A}

B

C

D

E

G

G

I

J

K

L

M

N

0

$P$

\begin{tabular}{c}
$\begin{array}{c}\text { Average }^{a} \\
\text { Seizure Load } \\
\text { kg }\end{array}$ \\
\hline 240 \\
270 \\
233 \\
255 \\
225 \\
270 \\
190 \\
255 \\
$>285$ \\
150 \\
188 \\
248 \\
225 \\
233 \\
225 \\
203 \\
180
\end{tabular}

${ }^{a}$ Based on average of at least 2 runs.

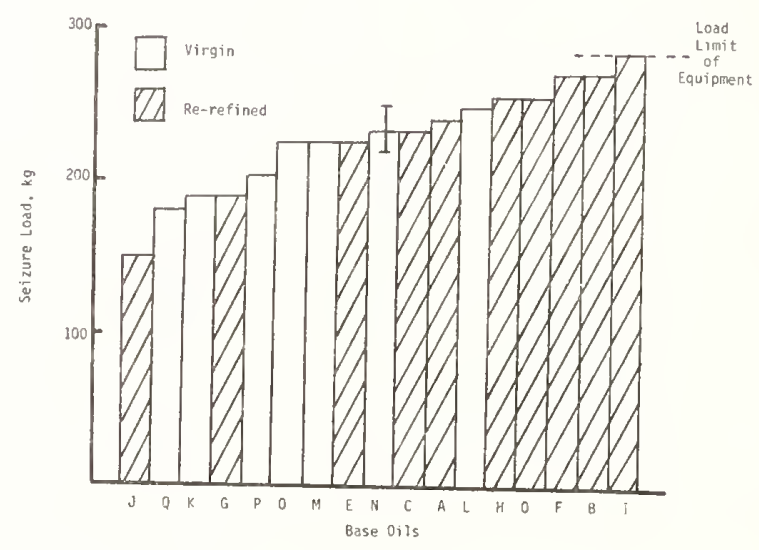

Figure 6. Additive response of the seventeen base oil set at 8.0 percent additive package. (Micro-sample SLST).

3) Different base oils exhibited different additive responses under different conditions of the step loading seizure tests.

4) There is no generic difference between re-refined and virgin base oils in terms of anti-wear additive response as measured in these tests. Each oil has to be judged on its own merit. 


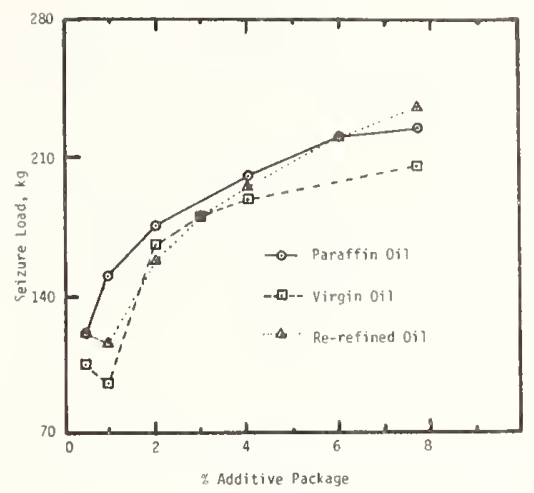

Figure 7. Micro-sample SLST concentration study effect of additive package concentration on seizure load: Micro sample SLST.

Certain commercial equipment, instruments, or materials are identified in this paper in order to adequately specify the experimental procedure. Such identification does not imply recommendation or endorsement by the National Bureau of Standards, nor does it imply that the materials or equipment identified are necessarily the best available for the purpose.

Table 7. Comparison of base oil additive response ranking in different test procedures: percentile

$10 \mathrm{~m} 7 \mathrm{SLST}$

$8 \%$

Base
$0 i 1$

$A$
$B$
$C$
$D$
$E$
$F$
$G$
$H$
$I$
$J$
$K$
$L$
$M$
$N$
$O$
$P$
$Q$
Additive

Package

100

100

79

100

100

100

1

100

100

73

100

66

100

93

100

100

100
Micro Sample SLST

$0.5 \%$

Additive

Package

1
30
10
1
1
10
100
1
1
100
60
34
4
100
50
90
80

1

30

1

10

100

1
1

100

60

34
4

00

50

80
$8 \%$

Additive Package

Ranking: 1 Lowest $100=$ Highest 
Table 8. Comparison of base oil additive response ranking in different test procedures: Quartile

10 m1 SLST

$\begin{array}{rcc} & 8 \% & 0.5 \% \\ \text { Base } & \text { Additive } & \text { Additive } \\ 0 i 1 & \text { Package } & \text { Package }\end{array}$

$\begin{array}{ll}A & A \\ B & A \\ C & A \\ D & A \\ E & A \\ F & A \\ G & D \\ H & A \\ I & A \\ J & B \\ K & A \\ \text { L } & B \\ M & A \\ N & A \\ O & A \\ P & A \\ \text { Q } & A\end{array}$

Micro Sample SLST

$$
\begin{gathered}
8 \% \\
\text { Additive } \\
\text { Package }
\end{gathered}
$$

\begin{tabular}{|c|c|}
\hline D & \\
\hline C & \\
\hline$D$ & \\
\hline D & \\
\hline D & \\
\hline D & . \\
\hline A & \\
\hline D & \\
\hline D & \\
\hline A & \\
\hline B & \\
\hline C & \\
\hline D & \\
\hline A & \\
\hline B & \\
\hline $\bar{A}$ & \\
\hline A & \\
\hline
\end{tabular}

Ranking: $\quad D=$ Lowest

$$
A=\text { Highest }
$$

\section{References}

[1] Rounds, R. G. Some factors affecting the decomposition of three commercial zinc organodithrophosphates. ASLE Transactions 18 (2): 79-80; 1973.

[2] Misra, A. K.; Mehrotra, A. K. ; Srivastava, R. D. Antiwear characteristics of additives: synergistic and adverse effects. Wear $31 ; 345-357 ; 1975$.

[3] Willermet, P. A.; Mahone, L. R.; Haas, C. M. The effects of antioxidant reactions on the wear behavior of a zinc dialkyldithiophosphate. ASLE Transactions 23 (3): 225-231; 1980.

[4] Gates, R. S.; Hsu, S. M. Development of a four-ball wear test procedure to evaluate automotive Tubricating oils. Preprint No 82-AM-6A-4. Presented at the ASL annual meeting held at Cincinnati, Ohio. 1982 May 10-13.

[5] Gates, R. S.; Hsu, S. M. Development of an oxidation-wear coupled test for the evaluation of Tubricants. ASLE Preprint No 82-LC-D-2. Presented at the ASME/ASLE Lubrication Conference in Washington, D.C. 1982 0ct. 5-7.

[6] Rodgers, J. J.; Kabe1, R. H. A revised sequence IIIC engine oil test. SAE Paper No. 780259; Society of Automotive Engineers; 1979.

[7] Graff, W. P., Jr.; Roberts, C. E. ; Lepisto, D. R. New lubricant test procedures for gasoline engines from the viewpoint of an independent research laboratory. Lubr. Eng. 36 (4): 201-214; 1980. 
National Bureau of Standards Special Publication 674. Proceedings, Conference on Measurements and Standards for Recycled 011 - IV, held at NBS, Gaithersburg, MD, September 14-16, 1982. (Issued July 1984).

\title{
DIFFERENTIAL SCANNING CALORIMETRY TEST METHOD FOR OXIDATION STABILITY OF ENGINE OILS
}

S. M. Hsu, A. L. Cummings, and D. B. Clark

\author{
Tribochemistry Group \\ Materials Chemistry Division \\ National Bureau of Standards \\ Washington, D.C. 20234
}

\section{ABSTRACT}

A laboratory bench test has been developed which measures oxidation stability of automotive crankcase lubricants under simulated engine conditions. The test employs a high-pressure, differential scanning calorimeter (DSC) to measure oxidation induction times in thin-film oil samples at $175^{\circ} \mathrm{C}$ in $3.6 \mathrm{MPa}$ oxygen. Engine chemistry is simulated by mixing the oil sample with oil-soluble metal naphthanates and oxidized nitrated gasoline. The DSC test ranks the relative oxidation stability of seven ASTM engine sequence IIID reference oils in the same order as the engine test does. The bench test requires less than an hour's time to perform, uses only $1 \mathrm{mg}$ of sample, with an average 6 percent repeatability. Details of method development are discussed elsewhere ${ }^{1}$. A copy of the paper is included as an appendix to this abstract.

${ }^{1}$ Evaluation of automotive crankcase lubricants by differential scanning calorimetry. SAE SP 526 Base 0ils for Automotive Lubricants; SAE, Warrendale, PA, 1982. 


\title{
Evaluation of Automotive Crankcase Lubricants by Differential Scanning Calorimetry
}

\author{
S. M. Hsu, A. L. Cummings, \\ and D. B. Clark \\ Materials Chemistry Div. \\ National Bureau of Standards \\ Washington, DC
}

\section{ABSTRACT}

A LABORATORY BENCH TEST has been deveioped to examine the uxidation stability of crankcase lubricants using a high pressure power-

compensation differential scanning calorimeter (DSC). Oxidation induction time measured at $175{ }^{\circ} \mathrm{C}$ and $3.62 \mathrm{MPa}$ ( $525 \mathrm{psia}$ ) oxygen pressure was used to rank eight ASTM sequence IIID engine test stand reference oils. The DSC result correlated with the viscosity increase tendencies of the reference oils as determined by the engine tests. The new test method is rapid and requires only microliter sample size for testing with good precision. The method employs a mixture of soluble metal catalysts consisting of lead, iron, copper, manganese, and $\operatorname{tin}(82 \%, 7 \%, 4 \%, 3.5 \%, 3.5 \%)$ together with a synthetic oxidized high-boiling gasoline fraction. This combination was found necessary to simulate some of the engine conditions and chemistry.

Laboratory tests which could assess the performance of lubricants in engines have long been sought. Such tests could be used by lubricant developers to screen lubricants and lubricant formulations, to aid development of products and processes, and to minimize the expenses for engine tests. This paper reports the development of a differential scanning calorimeter test method to evaluate the oxidation stability of lubricants under the ASTM Sequence IIID engine test conditions.

- OIL DEGRADATION MECHANISMS AND ENGINE CHEMISTRY

In order to correlate laboratory bench test results to engine test data, a test must provide oil degradation pathways similar to those that occur under service situations.

*Numbers in parentheses designate references at end of paper.

Publication of the National Bureau of Standards. Not subject to Copyright.
The general mechanisms of oil degradation in gasoline engines have been reviewed recently by Hsu [1]*. Briefly, the engine can be viewed as two chemical reactors in series: the piston ring-cylinder liner area and the oil sump. In the piston ring-liner area, a thin film of oil is subjected to high temperatures, high shear stress, hot combustion gases, and freshly worn metal surfaces. It has been suggested that antioxidant additives are primarily consumed in this area [2] and the precursors to most engine deposits are found here [3-9]. In the second reactor, the oil sump temperatures are relatively low (climatic to $100{ }^{\circ} \mathrm{C}$ in field tests, up to $150{ }^{\circ} \mathrm{C}$ for sequence IIID engine test). Here the oil mixes with reaction products from the first reactor as well as with other contaminants, such as blow-by gases, fuel, water, and dust. Subsequent reactions form sludge and varnish.

Fuel components and blow-by gases (encountered in the first reactor) have been suggested to be the major contributors to oil degradation and deposit formation. Examination of the chemical composition of varnish and sludge deposits $[10,11]$ bears evidence of fuel components, such as fuel additives, lead salts, and lead scavengers. 0lefins and aromatics from fuels have been identified as active components in deposit formation [3-8]. Nitrogen oxides $\left(\mathrm{NO}_{x}\right)$ in combustion gases are also important reactants $[3,9]$. Spindt [12] operated an engine in a nitrogen-free atmosphere and obtained essentially clean pistons. These studies suggest that in developing a test procedure, one should consider the effect of fuel components and nitration products on oil degradation.

Metals also play an important role in engine oil degradation. Used oil analys is reveals the presence of many metals from engine wear as well as from oil and gasoline additives [13]. Engine sludge contains significant amounts of lead, zinc, and iron [10]. Several investigators [14-17] have reported catalysis 
of oil degradation by metals, but the mechanism of catalysis, i.e., whether heterogeneous or homogeneous, is not clear. The importance of metals, however, is generally recognized.

Metals (such as copper and/or iron) are used in most bench oxidation tests.

To simulate engine chemistry, we combined a "synthetic sucl catalyst" and a "soluble metal catalyst" mixture with formulated oil [18.] The synthetic fuel catalyst contains many of the reactants identified in engine blow-by: fuel hydrocarbons (especially olefins and aromatics), oxidized fuel, nitrated fuel, and fuel additives. A modified procedure based on safety considerations for preparing the fuel catalyst, largely based on the work of Verly [19] and Forbes [20], is described in detail in the experimental section of this paper. Gasoline is oxidized in the presence of nitrogen dioxide, then neutralized with sodium bicarbonate.

The soluble metal catalyst consists of lead, copper, iron, manganese, and stannous naphthanates $(82 \%, 7 \%, 4 \%, 3.5 \%, 3.5 \%$, respectively). The particular metal combination and concentration was based on averaged results of used oil analysis [21].

\section{DIFFERENTIAL SCANNING CALORIMETRY}

Differential scanning calorimetry (DSC) has been used to study oxidation inhibitors, effect of oil composition on stability, and oil oxidation kinetics [22-26]. A thin film of oil is placed on a metal pan and heated. Either the oxidation onset temperature (temperature-scanning mode) or the oxidation induction time (isothermal mode) can be measured. The DSC detects heat generated or consumed by thermal events (reactions, phase transition, etc.) occurring in a sample. If several events occur simultaneously (some might be exothermic, some endothermic), the net sum of the heats is measured.

oxidation of hydrocarbon mixtures such as lubricants is primarily an exothermic process. At high temperatures evaporation of the oil (an endothermic process) can be significant. This evaporation affects the magnitude and shape of the DSC exotherm directly resulting in imprecise determination of the oxidation onset. Elevated pressure reduces volatility and thus reduces the evaporation interference. High oxygen pressure also minimizes the mass transfer interference by slow oxygen diffusion rates on rapid oil oxidation processes. Thus high pressure increases the DSC peak magnitude and onset sharpness of the DSC signal. For these reasons DSC studies of oil degradation have been performed under high pressure $[22,25$, 27].

The DSC induction time method measures the time required for oxidation of the oil sample to begin and produce a strong exothermal DSC signal. The induction time can be thought of in terms of the time during which the aduitives inhititing the oxidation processes are consumed. As long as the antioxidant additives are functioning, DSC detects no changes in heat evolution rate and the flat straight induction period trace results (Figure 1).

Increasing oxygen pressure increases the magnitude of the thermal peak, but reduces the induction time. High pressure improves the symmetry of the peak shape by reducing the heat loss through evaporation. At higher oxygen pressures, increased oxygen availability increases oil oxidation rates by increasing the oxygen concentration and the oxygen diffusion rate into the oil. Induction times are reduced because antioxidants deplete faster. Increasing temperature also improves peak magnitude, but reduces induction time due to faster oxidation rate.

\section{EXPERIMENTAL}

\section{HIGH PRESSURE MODIFICATION}

A commercial power-compensation DSC was used. The equipment was designed without the high pressure capability, so the cell supplied with the unit was modified to operate at internal pressures of up to $7 \mathrm{MPa}$. These modifications were required to: (1) contain the pressure and (2) eliminate signal instability at elevated pressures.

Figure 2 illustrates the modifications made to the DSC cell to contain high pressures. The existing commercial DSC cell (DSC cell body and cell cover) is at the center of Figure 2a. A detailed internal schematic diagram of the DSC cell is shown in Figure 3 . Rubber "0-rings" were used to form a gas-tight seal between the cell body and cover. A clamping device was designed to hold the cell body and cover together against a designed pressure of $14.0 \mathrm{MPa}$. The device consisted of $2 \mathrm{~cm}$ thick aluminum plates ("top plate" and "bottom plate," Fig. 2a) joined by four tie rods at four corners. This clamping device or pressure reinforcement was anchored to the exiting DSC platform by several clear plastic support rings. Pressure test of up to $7 \mathrm{MPa}$ showed no gas leaks.

Severe instability in the DSC signal occurred when the unit was operated at pressures above $1 \mathrm{MPa}$. The instability was apparently caused by turbulent flow and convective heat transfer at and above the sample pans in the DSC cell. This hypothesis was reinforced when the unit was operated near ambient pressures and no instability in signals was observed. Three modifications of the existing cell were required to eliminate the DSC signal instability at elevated pressures: (1) the domeshaped cavities in the cell cover above the sample and reference chambers (Figure 3) were filled with glass wool to minimize the effects of flow turbulence and heat convection on temperature; (2) a needle valve and flow meter 
were installed downstream of the sample and reference cells in the gas line to balance the gas flow rates through the two chambers. This would maintain the same flow rate of gas through the two cell chambers; and (3) the aluminum baffles (dashed line, Figure 3) were removed from the sample and reference cavities of the cell to minimize eddies in the flow pattern. These combined measures produced a stable baseline at elevated pressures. Typical peak-to-peak noise levels are less than 0.03 $\mathrm{mcal} / \mathrm{s}$.

\section{TEST PROCEDURES}

The test consists of catalyzed isothermal oxidation of an oil specimen in a differential scanning calorimeter. A small specimen (0.9 mg) of a mixture of oil and liquid catalyst is oxidized at $175{ }^{\circ} \mathrm{C}$ in a gold pan in oxygen at a pressure of $3.62 \mathrm{MPa}$ ( $525 \mathrm{psia}$ ). The selection of the test condition will be discussed in detail in a later section. To bring the specimen to the test temperature in the shortest possible time, the sample is heated at a rate of 160 degrees/min to $140{ }^{\circ} \mathrm{C}$, then at 80 degrees/min until the test temperature is reached. A typical thermogram (rate of heat detected vs time) is shown in Figure 1. The oxidation induction time is determined by the intersection of the slope of the exotherm with the base line. The induction time probably marks the time when the antioxidant additives are depleted, i.e., the point at which rapid, autocatalytic oxidation of the oil begins.

The total time required to heat from room temperature to the test temperature is about one minute. This constant time was neglected in computing the oxidation induction time.

\section{CATALYST PREPARATION}

The soluble metal catalyst is a mixture of commercial metal naphthanate preparations mixed in the following proportions: $8 \mathrm{~g}$ lead, $0.69 \mathrm{~g}$ copper, $0.41 \mathrm{~g}$ iron, $0.35 \mathrm{~g}$ manganese, and $0.35 \mathrm{~g}$ tin naphthanates. The fuel catalyst is a neutralized, oxidized, and nitrated gasoline fraction prepared from ASTM Sequence VD gasoline by the procedure developed by $\mathrm{Ku}$ [18]. One hundred grams of the high boiling fraction of the fuel (boiling point greater than $150{ }^{\circ} \mathrm{C}$ at $5 \mathrm{~cm} \mathrm{Hg}$ vacuum) was oxidized with air and nitric dioxide for 72 hours at $125{ }^{\circ} \mathrm{C}$ in an open glass tube. (Caution: proper safety precautions should be exercised in oxidizing flammable liquids such as gasoline.) The product, which had a total acid number (TAN) of about 15, was neutralized with sodium bicarbonate until the TAN was 2 . The neutralized product was used as the "synthetic fuel catalyst."

\section{REFERENCE OILS}

To maintain test precision in standardized engine dynamometer tests, the ASTM test monitoring board set up an engine test reference qualification system. The system is based on a set of reference oils whose field performance experience has been established. Periodically, a coded reference oil sample is sent to each testing facility to compare its engine test. results to the known performance. These oils, therefore, are constantly being tested in engine tests and the test results are statistically significant.

Eight ASTM Engine Sequence IIID Reference 0ils were obtained from the ASTM Engine Test Monitoring Center. The oxidation stability of the oils is measured in terms of time to 375 percent viscosity increase in the IIID test. These times ranged from 16 hours to 64 hours. Four of the reference oils are SAE 30, two are $10 W-30$, and two are $10 W-40$. Prior to testing in the DSC, oil was mixed with 3 volume percent soluble metal catalyst and 3 volume percent synthetic fuel catalyst.

\section{RESULTS AND DISCUSSIONS}

The eight ASTM Engine Sequence IIID reference oils were used to develop the DSC procedure, to assess the effects of various parameters such as different catalysts, temperature, and pressure combinations, and to demonstrate correlation with engine test results. The following sections describe the test procedure development and the engine test correlation.

Effects of Temperature and Pressure-Walker and Tsang [25] studied the effects of temperature and pressure on oxidation induction time of various lubricants and found that for uncatalyzed lubricant oxidation, a pressure of 3.5 $\mathrm{MPa}$ was required to produce clear, sharp exotherm peaks. Therefore, the initial conditions were set at about $3.6 \mathrm{MPa}$ oxygen pressure and the isothermal test temperature was adjusted to determine an optimum temperature for the ASTM IIID engine test reference oils. The objective was to select a temperature at which the induction times for all the reference oils are within a range of 5 to 45 minutes. Table 1 shows the results of DSC tests at four temperatures. At $165^{\circ} \mathrm{C}$, the induction time of the most stable oil (76A) was too long. At $193{ }^{\circ} \mathrm{C}$, induction times were too short. At $183^{\circ} \mathrm{C}$, oils of different stability could be distinguished, but the separation, for example between oils $77 \mathrm{~B}-1$ and $72 \mathrm{~A}-1$, was not significant within the test precision. The best separation and range based on test precision was obtained at $175{ }^{\circ} \mathrm{C}$.

Effects of Metal Surfaces and Oxidized Fuel Catalyst--In addition to oxygen and high temperatures, oil in an engine encounters combustion products and metals which can react with the oil or catalyze its degradation. 
Table 2 demonstrates the effects of various metal surfaces and fuel components on DSC induction times using five IIID engine test reference oils. Test results without fuel components on an aluminum surface, a noncatalytic metal, showed differences in stability of oils, but the relative ranking of the reference oils ( 1 being most stable) did not correspond to the IIID engine test results. When these oils were tested on cold-rolled steel surface, a known catalyst, the oxidation induction times were shorter than on aluminum, but the relative ranking of the reference oils still did not match the engine test results. When the oxidized fuel fraction catalyst and the mixed metal catalysts were added to the oil and the oils tested on a gold surface, both the range of the induction times and oxidation stability ranking of the reference oils corresponded to engine test experience. Apparently the catalyst package containing the fuel and metal mixtures provided some critical reaction pathways which simulated the engine chemistry. Statistical analysis of the data in Table 2 with respect to the correlation coefficients and the tail significance also suggested that the mixed fuel and metal catalyst package is the most significant case (correlation coefficient of 0.98 ).

Effects of Water--Water is also present in engine blow-by gases and the oil sump and can contribute to oil degradation and sludge formation. To test the effects of water on the DSC induction time, one percent water was added to mixtures of IIID reference oils and liquid catalyst package. Table 3 shows that water has variable effect on DSC induction time. It increases the induction time of one oil (76A) but has little effect on others. Mixtures containing one percent water were unstable, sometimes forming a white precipitate within 15 minutes after mixing. Repeatability of DSC results was impaired by addition of water with no improvement in correlation with IIID engine test results. Therefore, water was not included in the final DSC test procedure.

Engine Test Correlation--Final DSC test conditions and catalyst concentration were set at $175{ }^{\circ} \mathrm{C}, 3.62 \mathrm{MPa}$ oxygen pressure with three volume percent of the soluble metal mixtures and three volume percent of the synthetic oxidized fuel fraction. Eight ASTM engine sequence IIID reference oils were tested.

The DSC thermograms of these reference oils are condensed in Figure 4, All reference oils have very sharply defined peaks and the induction times can be easily determined. As shown in Figure 4 , the peaks tend to cluster into three groups: (A) reference oil 76A; (B) oils 73B-1, 79A, 81A, and 758-1; (C) oils 77C, $77 B-1$, and $72 A-1$. $01172 A-1$ is almost identical to oil $77 \mathrm{C}$ and therefore is not shown in Figure 4 to avoid clutter. $0 i 176 \mathrm{~A}$ is the most oxidatively stable and followed by group $B$ and $C$ oils. There is a clear separation on induction between group B ("pass") oils and group C ("fail") oils.

Comparing the DSC oxidation induction times with sequence IIID engine test results in Table 4, there appears to be an almost linear dependence between DSC induction times and IIID viscosity increase break-point hours. The correlation reported here provides insight into the mechanism of oil degradation in engines. This verifies that oxidized fuel components and metal catalysts are important participants in oil degradation chemistry in the sequence IIID engine test as suggested by previous workers [1-12]. The correlation provides an attractive alternative for research and quality control of lubricants using DSC. Test Precision--Precision of the DSC induction time data at the test conditions is good. The standard deviations in Table 4 average about six percent of the observed induction time with the maximum deviation at about ten percent.

Potential sources of variance in the DSC test results include instability of catalysts, instability of mixtures of catalysts and oil, and inhomogeneous mixing of the oil and catalysts. The metal catalyst mixture and the fuel catalyst have been stored in argon atmosphere in amber vials for over eleven months with no apparent change in activity. Batch-tobatch variations of the fuel catalysts prepared from the same batch of gasoline show no significant effects. Different gasoline batches, however, do require adjustments in the oxidation conditions to maintain the test precision. Standard reference fuel catalyst materials will be available for calibration [28].

\section{CONCLUSIONS}

A bench test has been developed which correlates with the IIID engine sequence test visosity break point. The correlation is accomplished by simulation of the chemical environment of the engine. The test results, which measure presumably antioxidant degradation time, suggest that antioxidant lifetime is a major factor in oil service life.

The test procedure is rapid, repeatable, and requires only microliter quantities of oil. Potential applications of the procedure range from basic research to quality control.

\section{ACKNOWLEDGMENTS}

The authors wish to thank Dr. Chia-Soon Ku who developed and prepared the oxidized fuel catalyst and soluble metal catalyst for this study. The data supplied by Mr. J. Walker and $\mathrm{Dr}$. W. Tsang of the Chemical Kinetics Division, Center for Chemical Physics, NBS, are sincerely appreciated. The generous support from the Recycled $0 i 1$ Program, Office of Recycled Materials, National Bureau of Standards, is also acknowledged. 


\section{REFERENCES}

[1] Hsu, S. M., "Engine Oil Evaluation Through Bench Testing," Proc. Joint Conf. Meas. Standards Recycled 0i1/Syst. Perf. Durability, NBS SP 584, pp. 191-204 (1980).

[2] Korcek, S., Mahoney, L. R., Johnson, M.D., and Otto, K., "Antioxidant Consumption and Oxidative Degradation of Lubricants," ibid., pp. 227-235.

[3] Spilners, I. J., and Hedenburg, J. F., "Effect of Fuel and Lubricant Composition on Engine Deposit Formation," Preprints ACS Div. Petrol. Chem., 26, 632-639 (March 1981).

[4] Geyer, J. , "The mechanism of deposit formation and control in gasoline engines," Preprints ACS Div. Petrol. Chem., 14, A15A23 (1969).

[5] Williams, A. L., "Lacquer precursor from a paraffinic lubricant traced by Carbon 14," ibid, A7-A12.

[6] Vineyard, B. D., and Coran, A. Y., "Gasoline engine deposit: I. Blow-by collection and identification of deposit precursors," ibid., A25-A32.

[7] Coran, A. Y., and Vineyard, B. D., "Gasoline engine deposit: II. Sludge binder," ibid., A35-A44.

[8] Dimitroff, E., Moffit, J. V., and Quillian, R. D., "Aromatic Compounds in Fuels Identified as Main Precursors of Engine Varnish," SAE J., 77, 52-58 (1969).

[9] Anderson, D. J., "Mechanism of Engine Deposit and Wear. A Progress Report," Jap. Petrol. Inst. Meeting, Tokyo, Japan (Oct. 1968).

[10] Dimitroff, E., and Quillian, R. D., "Low Temperature Engine Sludge--What?--Where?-How?," Internat. Auto. Eng. Cong. SAE Paper No. 650255, Detroit (Jan. 1965).

[11] Dimitroff, E., Moffit, J. V. and Qui]lian, R. D., "Why, What, and How: Engine Varnish," ASME Trans. J. Lubr. Tech., pp. 406-410 (July 1969)

[12] Spindt, R. S., Wolfe, C. L., and Stevens, D. R., "Nitrogen Oxides, Combustion, and Engine Deposits," SAE Trans., 64, 797-811 (1956).

[13] Schwarz, C. F., "Used 0il Analysis: Past, Present, and Future," Proc. Joint Conf. Meas. Standards Recycled 0il/Syst. Perf. Durabi]ity, NBS SP 584, pp. 167-171 (1980).

[14] Klaus, E. E., and Tweksbury, E. J., "Microcorrosion Studies with Functional Fluids," Lubr. Eng., 29, 205-211 (1973).

[15] Bondi, A. , Physical' Chemistry of Lubricating 0 ils, Rheinhold Publishing Corp., New York (1951), p. 302.

[16] Ceci1, R., "High Temperature Thickening of Motor 0i1s," J. Inst. Petrol., 59, 201-210 (1973).

[17] Lockwood, F., and Klaus, E. E., "Ester Oxidation--The Effect of an Iron Surface," ASLE Preprint No. 81-AM-30-2 (1981).
[18] Ku, C.-S., and Hsu, S. M., "A Thin-Film Oxygen Uptake Test for Evaluation of Automotive Crankcase Lubricants," paper presented at the ASLE/ASME Lubrication Conference, October 5-7, Washington, D.C. (1982).

[19] Verly, G. M., "Lubricating 011 Detergency Testing," U.S. Patent 3,044-860 (July 17, 1962).

[20] Forbes, E. S., and Wood, J. M., "Development of a Bench Detergency Test for Automotive 0ils and Its Correlation with the MS Sequence $V$ Engine Test," I\&EC Prod. R\&D, 8, 48-54 (1969).

[21] Hotten, B. W., and King, J. M., "Lubricating 0 il Additive Composition," U.S. Patent 4032462 (June 28, 1977).

[22] Noel, F., "The Characterization of Lube $0 \mathrm{ils}$ and Fuel $0 \mathrm{ils}$ by DSC Analysis," $\mathrm{J}$. Inst. Petrol., 57, 354-358 (1971).

[23] Noe 1, F., and Cranton, G. E., "Application of Scanning Calorimetry to Petroleum Oxidation Studies," Analytical Calorimetry, 3. Plenum Press, New York (1974), Eds. $\bar{R}$. S. Porter and J. F. Johnson, pp. 305320.

[24] Cranton, G. E., "Composition and Oxidation of Petroleum Fractions," Thermochim. Acta, 14, 201-208 (1976).

[25] Waiker, J. A., and Tsang, W., "Characterization of Lubricating Oils by Differential Scanning Calorimetry," SAE Tech. Paper 801383 (Oct. 1980).

[26] Wesolowski, M., "Thermal Analysis of Petroleum Products," Thermochim. Acta, 46, 21-45 (1981).

[27] Levy, P. F., Nieuweboer, G., and Semanski, L. C. "Pressure Differential Scanning Calorimetry," Thermochim. Acta, 1, 429-439 (1970)

[28] The fue] catalyst will be issued as Standard Reference Material 1817 with certified stability data by the Office of Standard Reference Materials, National Bureau of Standards, Washington, D.C. 20234. 
Table 1

Effect of Temperature on DSC Induction Times

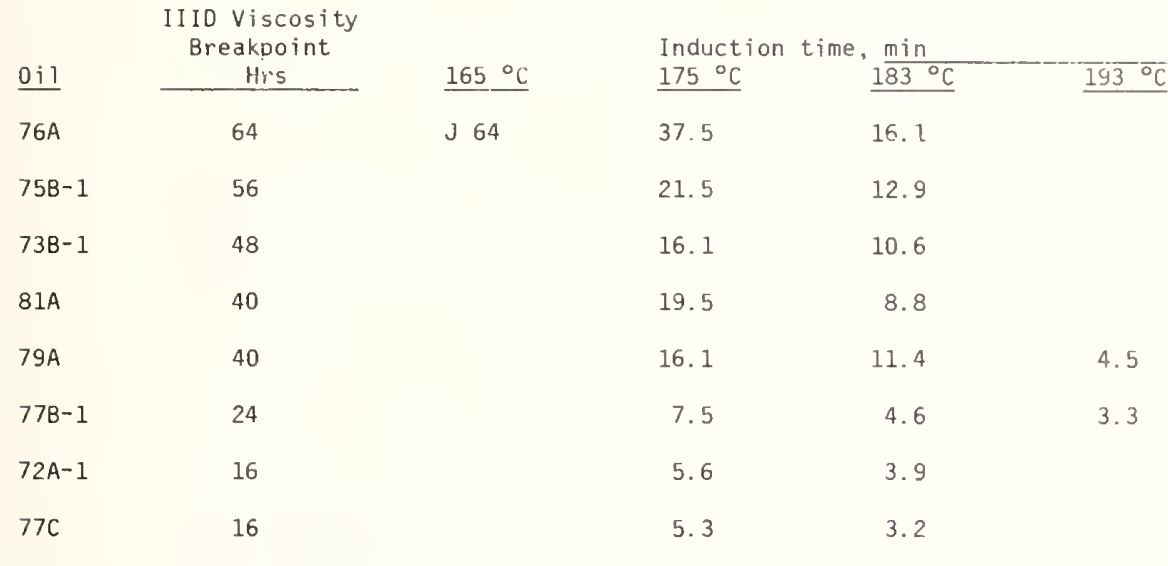

Operating conditions: $3.6 \mathrm{MPa}$ oxygen pressure

$3 \%$ (volume) soluble metal catalysts

$3 \%$ (volume) oxidized fuel component catalyst

Gold sample pan

Table 2

Effects of Metals and Liquid Catalyst on DSC Tests of IIID 0 ils

Oils $\frac{\text { IIID }}{\text { Hrs. Rank }}$

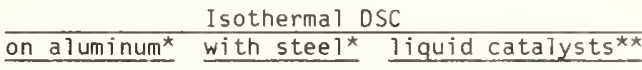

$t_{\text {ind, rank }} t_{\text {ind, rank }} t_{\text {ind, rank }}$ min.

$\begin{array}{lllllllll}76 \mathrm{~A} & 64 & 1 & 47 & 1 & 29 & 1 & 16 & 1 \\ 75 \mathrm{~B}-1 & 56 & 2 & 22 & 4 & 16 & 2 & 13 & 2 \\ 79 \mathrm{~A} & 40 & 3 & 30 & 2 & 11 & 4 & 11 & 3 \\ 77 \mathrm{~B}-1 & 24 & 4 & 30 & 2 & 15 & 3 & 5 & 4 \\ 72 \mathrm{~A}-1 & 16 & 5 & 20 & 5 & 9 & 5 & 4 & 5\end{array}$

*data furnished by $\mathrm{J}$. Walker and Tsang; $3.5 \mathrm{MPa}$ oxygen, $185^{\circ} \mathrm{C}$

$\star \star 3 \%$ (volume) soluble metal catalysts

$3 \%$ (volume) oxidized fuel component catalysts

at $3.6 \mathrm{MPa}$ oxygen, $183^{\circ} \mathrm{C}$, on gold surface 
Table 3

Effect of Water on DSC Tests of IIID Reference 0ils

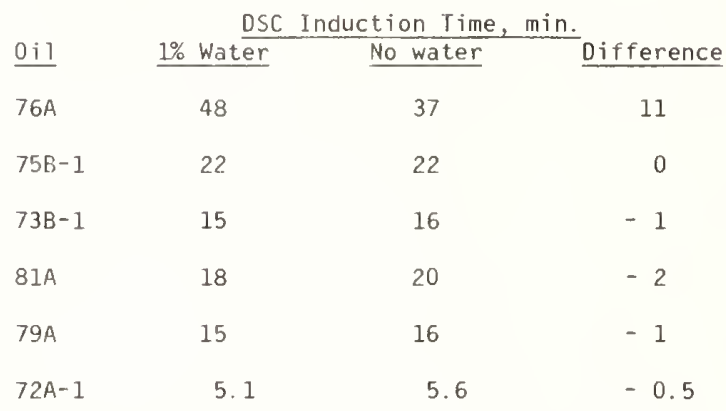
Operating conditions: $3 \%$ (volume) soluble metal catalysts $3 \%$ (volume) oxidized fuel component catalyst, $3.6 \mathrm{MPa}$ oxygen, $175^{\circ} \mathrm{C}$, on gold surface

Table 4

Comparison of 0xidation Induction Time with IIIO Viscosity Increase

\begin{tabular}{|c|c|c|c|c|}
\hline 0i1 & $\begin{array}{l}\text { SAE } \\
\text { Grade }\end{array}$ & $\begin{array}{l}\text { IIID } \\
\text { Hrs. } \\
\end{array}$ & $\begin{array}{l}\text { SE } \\
\text { Status } \\
\end{array}$ & $\begin{array}{l}\text { DSC* } \\
\text { Induction } \\
\text { time, min. }\end{array}$ \\
\hline $76 A$ & $10 W-40$ & 64 & Pass & \pm 2 \\
\hline $75 B-1$ & $10 w-30$ & 56 & Pass & \pm 2 \\
\hline $73 B-1$ & 30 & 48 & 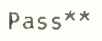 & \pm 1 \\
\hline $81 \mathrm{~A}$ & 30 & 40 & Pass & \pm 1 \\
\hline $79 A$ & $10 W-30$ & 40 & Pass & \pm 1 \\
\hline $77 B-1$ & $10 W-40$ & 24 & Fail & $7.5 \pm 0.4$ \\
\hline $77 \mathrm{C}$ & 30 & 16 & Fail & $5.3 \pm 0.2$ \\
\hline $72 A-1$ & 30 & 16 & Fail & $5.6 \pm 0.2$ \\
\hline
\end{tabular}

\footnotetext{
${ }^{*}$ At $175{ }^{\circ} \mathrm{C}, 3.62 \mathrm{MPa}$ oxygen, with $3 \%$ (vol.) soluble metal catalysts $3 \%$ (vol.) oxidized fuel component catalysts; uncertainty is standard deviation of three measurements.

**Passed viscosity criterion, but failed wear criterion.
} 


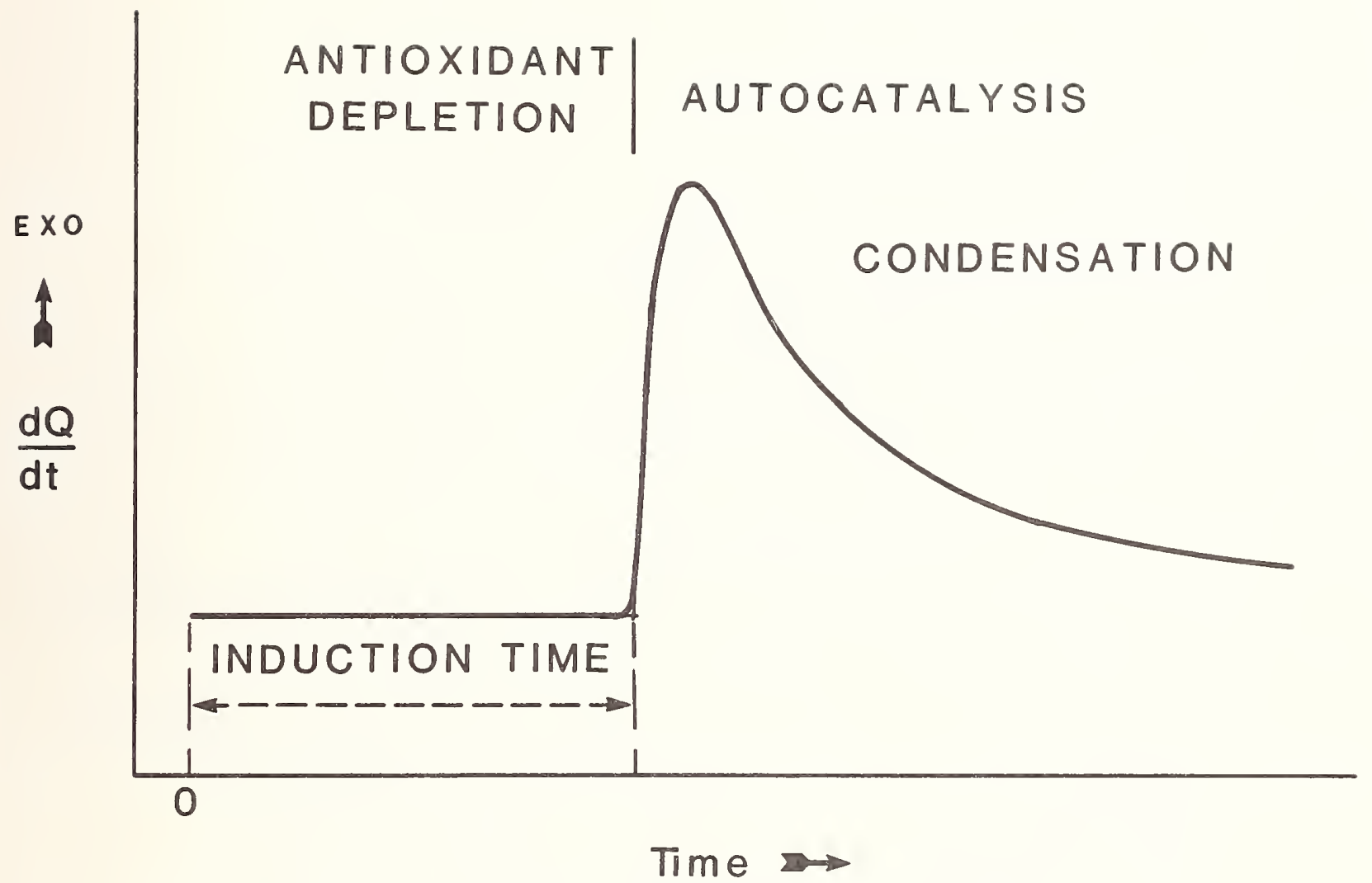




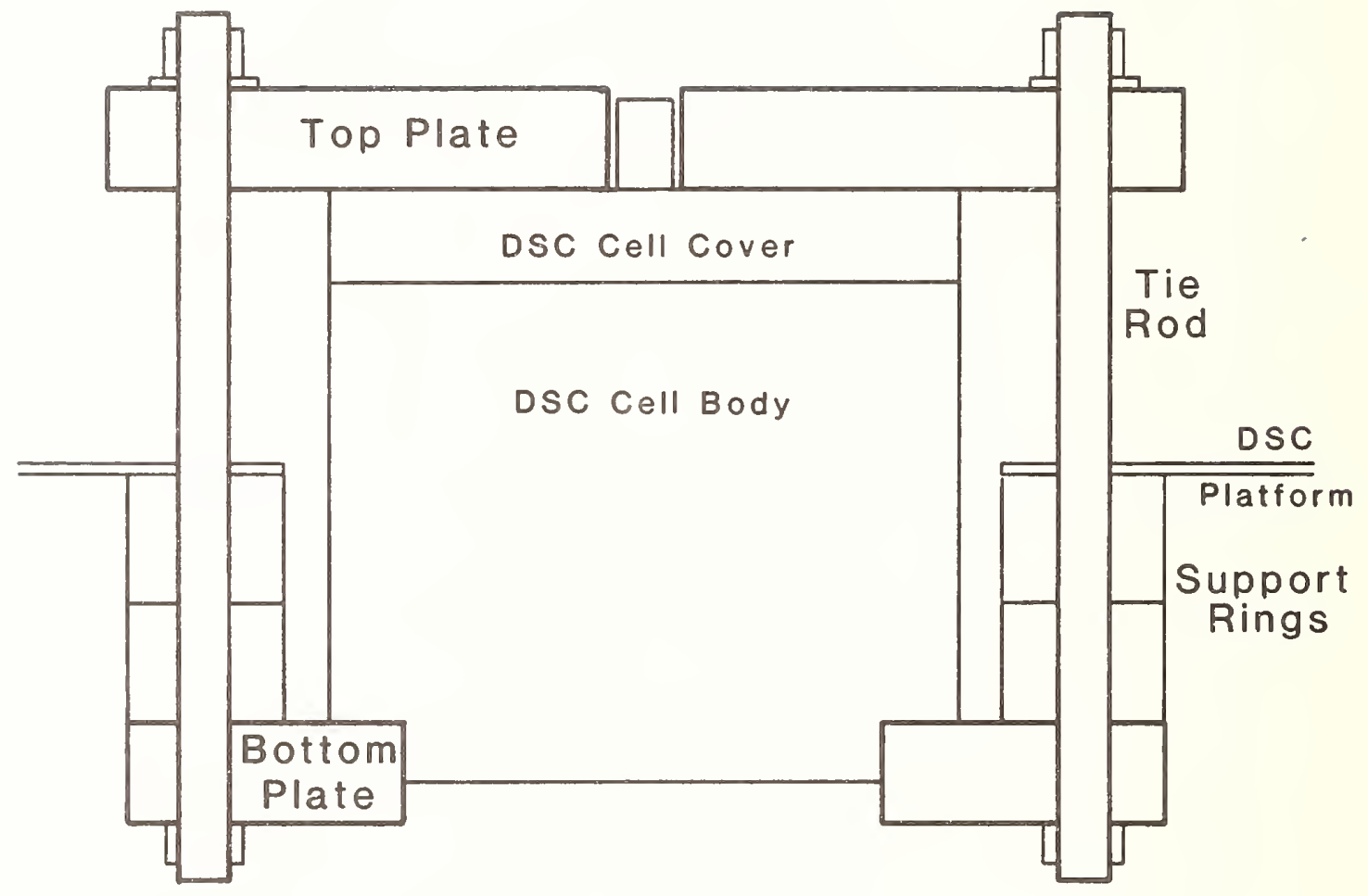

Figure 2. DSC High Pressure Cell

(a) Vertical section 


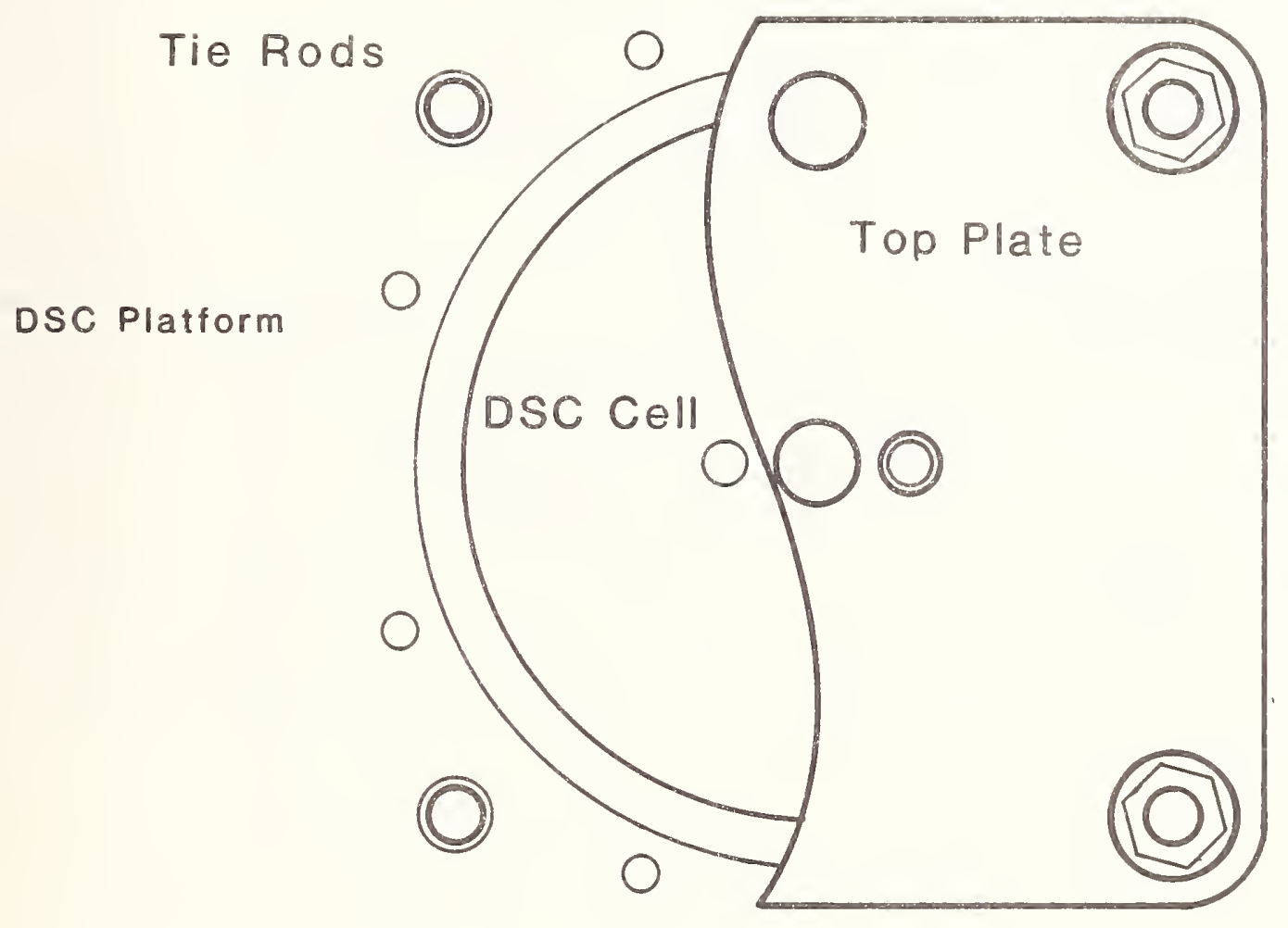

Figure 2. DSC High Pressure Cell

(b) Top view 

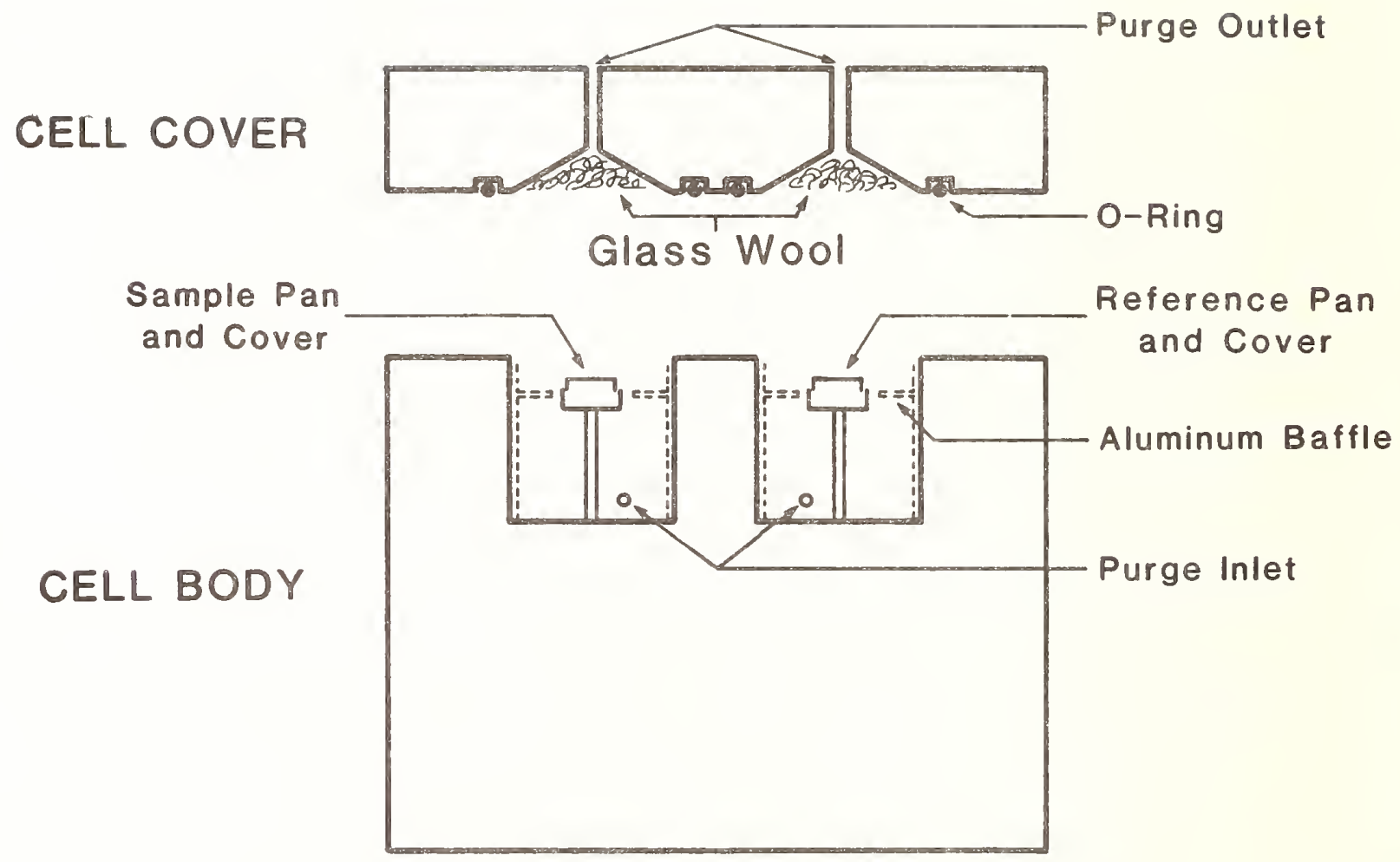

Figure 3. DSC cell and cover, vertical section 


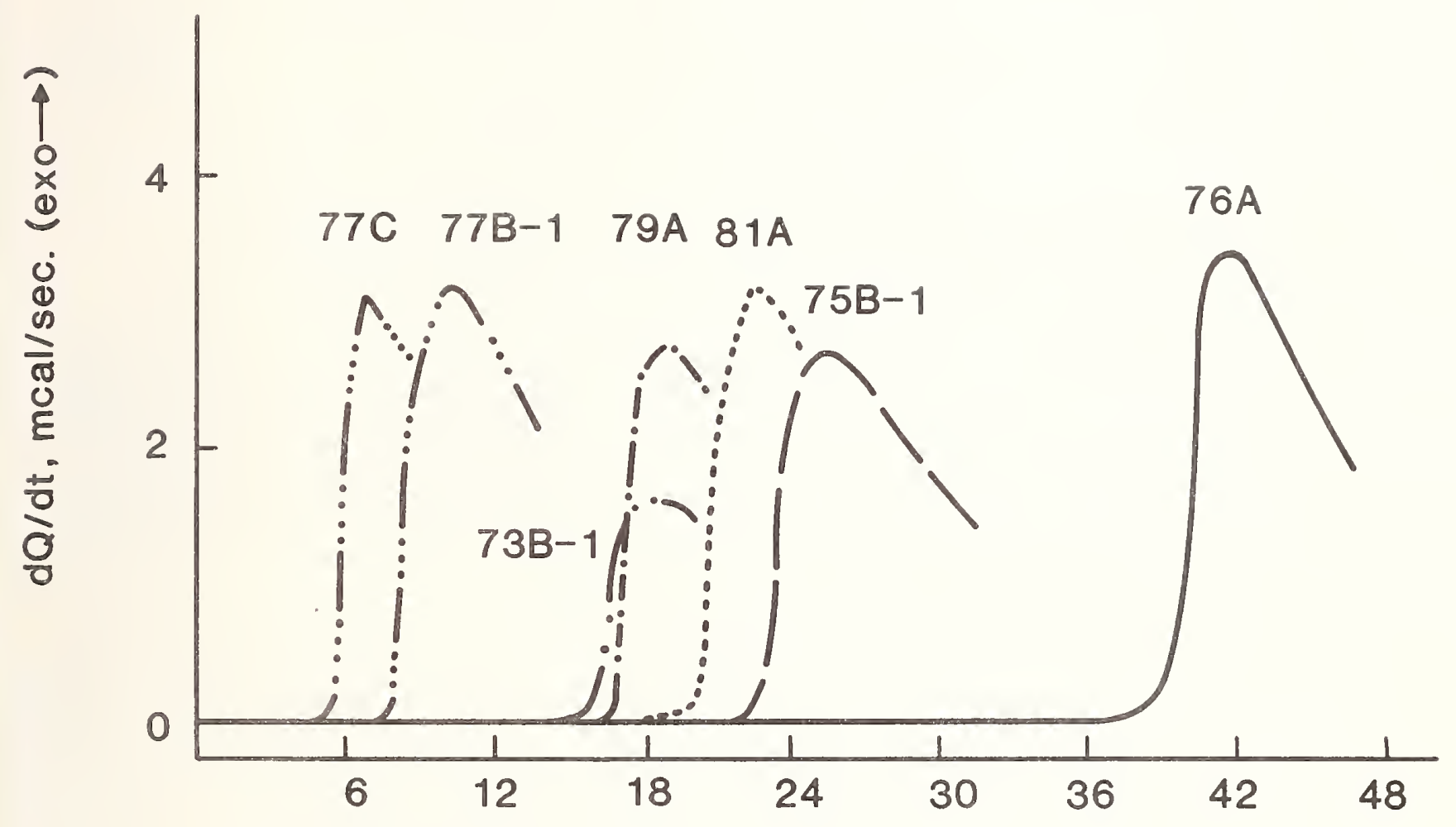

Time, $\min$

Figure 4. DSC thermograms of IIID reference oils 


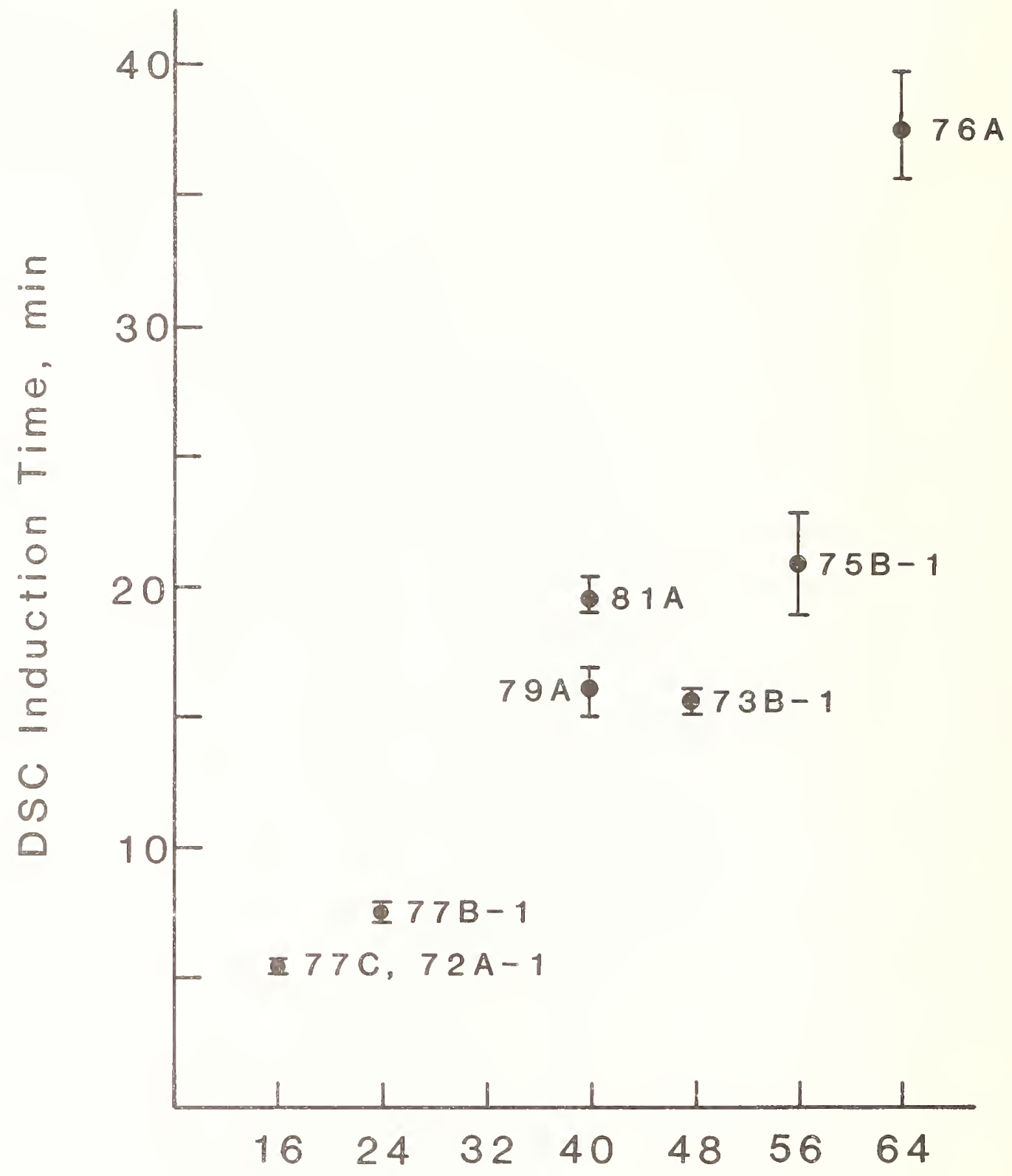

IIID Viscosity Break Point, hrs

Figure 5. Correlation of DSC induction time and IIID viscosity break time 
National Bureau of Standards Special Publication 674. Proceedings, Conference on Measurement and Standards for Recycled 0il - IV, held at NBS, Gaithersburg, MD, September 14-16, 1982. (Issued July 1984).

\section{COMPARATIVE RESPONSE OF RE-REFINED AND VIRGIN LUBE OILS TO ADDITIVES BY DSC}

J. A. Walker, W. Tsang, L. Szegvary

National Bureau of Standards

Chemical Kinetics Division

Washington, DC 20234

Earlier studies have demonstrated the capability of high pressure differential scanning calorimetry (HPDSC) for determining the propensity towards autoxidation of lubricating oils. This report is an extension of previous work and is focused on the following issues:

a) The consistency of basestocks produced over the course of a year, with special reference to the similarities and differences between re-refined and virgin basestocks.

b) The effect of the various components in the additive mixture on the intensity and time of response.

c) The response of various fractions of the basestocks to a particular additive.

d) The response of basestocks to different additive packages.

Our results are consistent with the assumption that differences between virgin and rerefined basestocks are no larger than those between virgin basestocks. Appropriate additives can overcome such differences. The variation in oxidative properties for samples of virgin and re-refined basestocks prepared over a period of time were similar. The polar and aromatic fractions in basestocks contain the active constituents that interact with the antioxidant. With respect to additives, both detergents and dispersants have effects on autoxidation properties. Addition of calcium sulfonate results in a dramatic increase in heat effects and serves to increase the sensitivity of the method.

\section{Introduction}

In earlier communications $[1,2]^{1}$ we have demonstrated the use of High Pressure Differential Scanning Calorimetry (HPDSC) as a sensitive probe for the oxidative stability of automotive lubricating oils. With high pressures of air or oxygen in both scanning and isothermal modes, differences between and among virgin and recycled base oils as well as formulated oils can be precisely determined. For the base oils, differences between re-refined and virgin basestocks can be easily established through examinations of the scanning thermograms. With respect to the formulated oils, more quantitative measures of oxidative stability can be established through measurements of induction times in isothermal experiments than for onset temperatures in scanning runs. In this paper we apply this methodology to the solution of questions dealing with the consistency and long term stability of basestocks, the response of basestocks to a variety of additive packages, the effect of the various components in the additive mixture on the intensity and time of response and the response of various components of the basestock towards a particular additive.

The work that will be described is part of the Recycled $0 i 1$ Program in the Office of Recycled Materials at the National Bureau of Standards. This work responds to the legislative mandates of the Energy Policy and Conservation Act of 1975 [5] and has as one of its aims the establishment of the scientific and technical basis for the characterization of recycled petroleum products. A major part of this program during the past year has dealt with the consistency of basestocks. Over a period of 13 months, samples from re-refiners and virgin oil refiners were subject to a variety of tests. The present report represents our contribution to this project. Noe 1 and Cranton [6,7] have demonstrated the effect of anti-oxidant concentration on oxidative stability, and from studies on the separate fractions of basestocks suggested that the aromatic portion (also containing various sulfur compounds) appeared to have natural antioxidant properties. The present paper is based on

\footnotetext{
1Figures in brackets indicate the literature references at the end of this paper.
} 
the HPDSC analyses on formulated lube oils (basestock plus additive package). It is well known that additives play a dominant role in the performance of lubricating oils. The present study can, therefore, be expected to shed some light on the nature of additive--basestock interaction.

\section{Experimental}

All experiments were carried out with a Dupont ${ }^{2} 990$ Thermal Analyzer and 910 High Pressure Differential Scanning Calorimeter [4]. The procedure and rationale are described in detail in earlier publications [1-3]. Briefly, approximately 1 milligram of oil is placed in an open aluminum pan with an empty pan as a reference. The oxidation onset temperature is determined by programmed scanning at a constant heating rate $\left(20^{\circ} \mathrm{C} / \mathrm{min}\right)$ and $700 \mathrm{KPa}$ air pressure until a sharp rise in signal is observed. 0xidation induction time is determined at an isothermal temperature $\left(185^{\circ} \mathrm{C}\right.$ and 3.4 $\mathrm{MPa}$ oxygen) and is the time at which a sharp rise in signal is observed. In both cases the linear portion of the curve is extrapolated to the baseline. The total heat of the reaction can also be determined, by allowing the induction time curve to return to the baseline, then measuring the area under the curve, and using the sample mass with a calibration constant.

A11 additives used in these studies were from commercial manufacturers and were supplied through the Recycled $0 i 1$ Program at NBS. The base oil fractions were supplied by the Tribochemistry Group at NBS and were prepared by high pressure liquid chromatography (HPLC). The eluents were saturated, aromatic and polar fractions. The former represented the largest component. A fixed amount of additive ( $7.7 \%$ by wt.) was added to each of the fractions, and the onset temperatures and induction times determined.

\section{Results and Discussion}

\subsection{Consistency Tests}

Over a period of 13 months, 132 oil samples (65 virgin and 67 re-refined) were evaluated for oxidative stability. These represented contributions from ten companies and were delivered at the rate of one per month from each source. Primary interest was focussed on the variations between samples from the same manufacturers. Experiments were carried out in the scanning mode in the absence and presence (7.7\%) of the additive package made available to us by the Recycled 0il Program. As expected, the additive increased the onset temperature by $40-60^{\circ} \mathrm{C}$. However, as noted earlier, the most sensitive determinations are from induction time measurements at the same treat-level (7. $7 \%$ ). This will be the focus of our discussion. As an indication of the sensitivity of the method, we show in table 1 typical results of induction time and onset temperature measurements for ASTM formulated reference oils. On this basis it appears that a 4 percent standard deviation (10) in induction time measurements is achievable. This test was next evaluated with respect to two oils which had undergone fleet and engine testing. Results of the ASTM IIID Engine Sequence Test, which were obtained on the re-refined and virgin oils used in the Environment Canada/RCMP Fleet Test, are presented in table 2, with DSC induction time data. Equal concentrations of the same additive package were blended with each oil. Both oils satisfactorily completed the fleet test as well as the engine sequence tests for the API SE Service Classification. However, only the re-refined oil passed the more severe SF engine test requirements. These oils are also clearly differentiated by DSC induction time measurements, which show a greater oxidative stability for the re-refined oil (42 min) than for the virgin oil $(30 \mathrm{~min})$. We make no claims that these tests simulate directly what occurs in an engine. However, the above data does indicate some correlation of DSC data with performance testing and provides some indication of time scales for the HP DSC method.

All the results using this method on the basestock consistency study samples are summarized in figures 1 and 2 and table 3 . In terms of individual suppliers, we summarize in table 4 induction time measurements listed according to refiners. One can see that there is considerable variation in the basestocks. However, our results give no indication of any greater variability in re-refined basestocks in comparison to virgin basestocks whether considered all together or in terms of samples from single suppliers.

\footnotetext{
${ }^{2}$ Certain commercial materials and equipment are identified in this paper in order to specify adequately the experimental procedure. In no case does such identification imply recommendation or endorsement by the National Bureau of Standards, nor does it imply the material or equipment identified is necessarily the best available for the purpose.
} 
Table 1. Repeatability

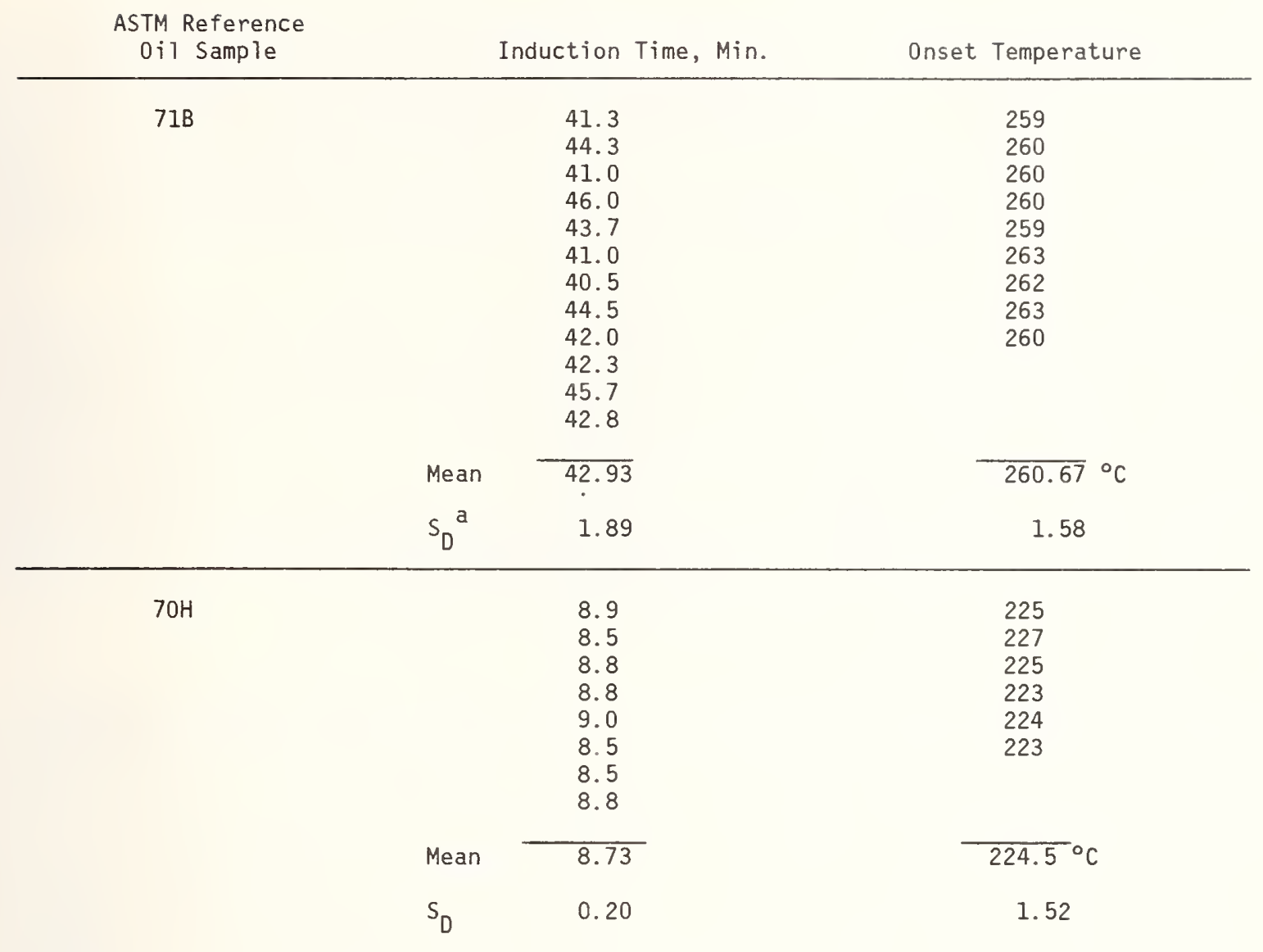

$\mathrm{a}_{\mathrm{S}}=$ Standard Deviation $(1 \sigma)$

Table 2. DSC and engine test results from environment canada/RCMP fleet test ${ }^{\mathrm{a}}$

oil Sample Onset $T$, ${ }^{\circ} \mathrm{C}$ Induction Time, Min Engine Test Results, Hours ${ }^{b} \mathrm{C}$

Re-refined 0 il

\begin{tabular}{|c|c|c|c|c|c|c|}
\hline $\begin{array}{l}\text { Quart Can (1) } \\
\text { Quart Can (2) } \\
\text { Test Drum }\end{array}$ & $\begin{array}{l}259 \pm 0.5^{d} \\
260 \pm 0 \\
258 \pm 0.5 \\
\end{array}$ & $\begin{array}{l}41.5 \pm 0.5 \\
43.3 \pm 0.8 \\
40.6 \pm 0.1 \\
\end{array}$ & $\begin{array}{c}\text { Pass } \\
" 1 \\
"\end{array}$ & $\begin{array}{c}40(\underset{11}{\text { (I) }}) \\
" 1\end{array}$ & $\begin{array}{c}\text { Pass } \\
" 1 \\
11\end{array}$ & $64\left(\begin{array}{c}\text { SE } \\
11\end{array}\right.$ \\
\hline Average & $259 \pm 1^{e}$ & $41.8 \pm 1.4$ & & & & \\
\hline
\end{tabular}

\section{Virgin $0 i 1$}

$\begin{array}{ll}\text { Quart Can (1) } & 252 \pm 0 \\ \text { Quart Can (2) } & 253 \pm 0 \\ \text { Test Drum } & 254 \pm 0 \\ & \text { Average } \\ & 253 \pm 1\end{array}$

$29.3 \pm 0.7$
$29.5 \pm 0.5$

$28.0 \pm 0$

Pass 40(SE) Faị 64(SE)

$28.9 \pm 0.8$

a Both oils satisfactorily completed fleet test.

Both oils met the design criteria for that additive package (MIL-L-46152A;

pass at 40 hours).

Cime to $375 \%$ viscosity increase.

Al1 data are average of two determinations.

$\mathrm{e}_{ \pm} \mathrm{values}$ for averages are standard deviations $(1 \sigma)$. 


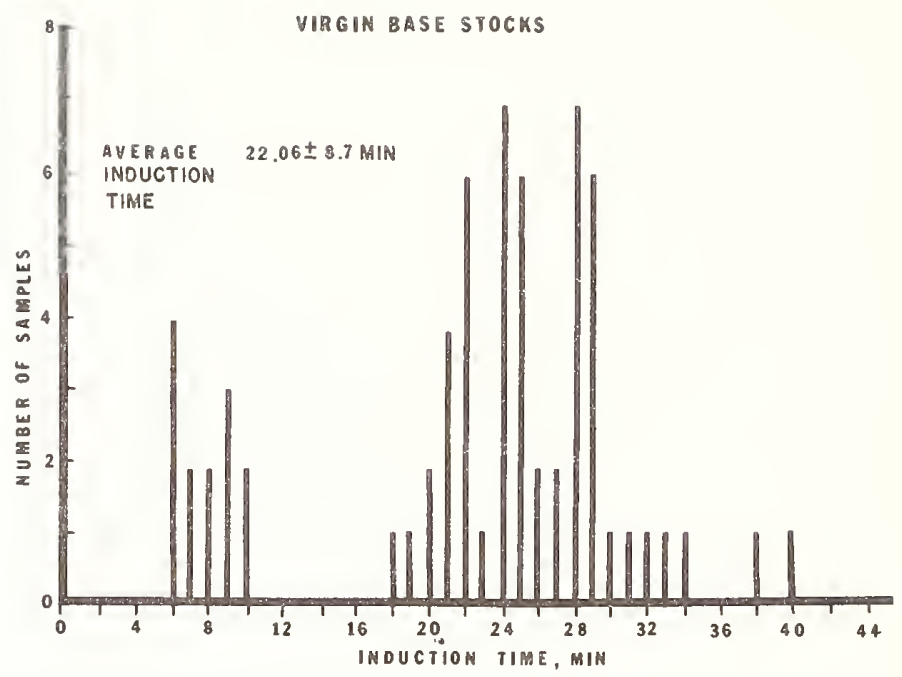

Figure 1. Summary of induction time data for virgin basestocks used in consistency study.

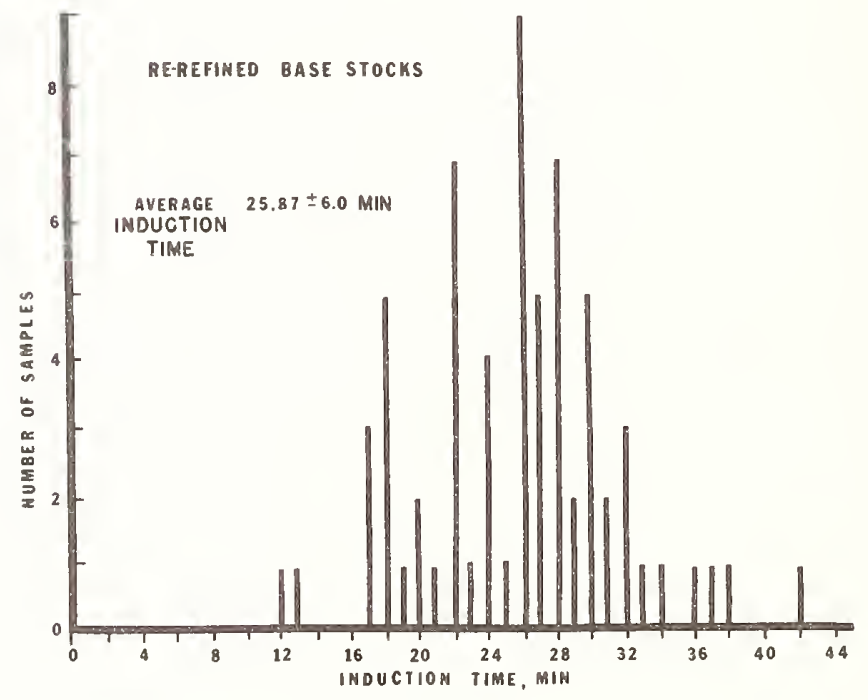

Figure 2. Summary of induction time data for re-refined basestocks used in consistency study. 
We have also carried out studies with three additional additive packages supplied by other manufacturers. Five virgin and 4 re-refined oils were included in this study and the results are summarized in table 5 . These results appear to confirm that there are additive packages that are more suitable for virgin basestocks than for re-refined basestocks, and vice-versa. Indeed, the present results are in accordance with the concept that there are additive packages that are particularly suited for each basestock. This is especially noticeable in the case of one of the virgin basestocks, which was always a persistent deviant in the earlier consistency tests. It was found that with the new additive packages, the HPDSC results were brought closer to those of the other oils.

Data on the long term stability of several formulated oil samples used in the consistency testing are summarized in table 6. It should be noted that, in general, the base oils appear to be stable [over the 13 month period] in the sense that induction time measurements made immediately after adding the additive mixture and at later intervals yield very reproducible values. This appeared to be the case for all the treated base oils (with the additive used in the consistency tests) except for the one virgin basestock that gave persistently low induction times during the study. The evidence is clear that for this oil there is a slow reaction between the additive and base oil which decreases the HPDSC results. It is noteworthy that this virgin oil showed somewhat larger variability in the consistency tests. Over all, the present study suggests the usefulness of the High Pressure Differential Scanning Calorimetry technique as a means of moritoring lubricating base oils.

\subsection{Response of Base 0i1 Fractions to Additives}

Figures 3, 4, and 5 represent data on the effect when the consistency study additive package is added to various lube oil fractions derived from a re-refined basestock. The fractions consisted of a saturated fraction containing mostly paraffinic and naphthenic compounds (fig. 3), an aromatic fraction containing 1 and 2 ringed aromatics and alkyl substituted aromatics (fig. 4), and a polar fraction with organic nitrogen, sulfur and nitrogen compounds as well as the polynuclear aromatics (fig. 5). It can be seen that the results from the scanning and isothermal experiments are consistent with the assumption that the non-paraffinic fraction of the basestock contain components that are capable of deactivating the added inhibitor. This is particularly striking in the case of the polar fraction where scanning thermograms with and without additives are virtually identical. In the isothermal experiment, figure 6 , there is in fact no induction time for the polar fraction. In the absence of inhibitors the contrast between the scanning thermograms of the paraffinic and the aromatic and polar fractions is indicative of self-inhibition in the latter. This has been suggested previously by Cranton [8]. Thus, this base oil obviously contains components that are self-inhibiting but which also appear to deactivate added inhibitors. This is indicative of the very complex interactions that occur during the oxidative degradation process. In this sense, it appears that the scientifically interesting chemistry which takes place during autoxidation, actually primarily occurs in the aromatic and polar fractions. Of course, this effect is finally seen in the complete lube oil sample.

Table 3. Summary of basestock consistency study data

\section{Virgin}

$$
22.1 \pm 8.7
$$$$
193.6 \pm 7.1
$$

$250.5 \pm 2.5$

$80 \%$
Re-Refined

$$
25.9 \pm 6.0
$$

$213.0 \pm 5.9$

$256.7 \pm 2.6$

(4) Percent of samples (basestock + add. pkg.) with induction time $>16$ min. 
Table 4. Summary of basestock consistency data induction time, min

\begin{tabular}{|c|c|c|c|c|c|c|c|c|c|c|c|}
\hline Month & $A$ & B & C & D & $I^{a}$ & $\mathrm{E}$ & $F$ & $G$ & $H$ & $\mathrm{~J}$ & K \\
\hline March & 10 & & 24 & 28 & $\begin{array}{l}24 \\
24\end{array}$ & 28 & 26 & 20 & 22 & 31 & 21 \\
\hline April & 10 & 24 & 26 & 28 & 27 & 26 & 29 & 17 & 28 & 18 & \\
\hline May & 9 & 29 & 29 & 32 & 30 & 30 & 28 & 18 & 22 & 28 & \\
\hline June & 9 & 25 & 37 & 31 & 28 & 27 & $\begin{array}{l}32 \\
30 \\
34\end{array}$ & 12 & 18 & 32 & \\
\hline July & 7 & 22 & 21 & 28 & 25 & 32 & 22 & 19 & 24 & 28 & \\
\hline August & 6 & 24 & 22 & 22 & 25 & 33 & 26 & 13 & 26 & 30 & \\
\hline September & 8 & 22 & 21 & 28 & 29 & 31 & 27 & 20 & 24 & 29 & \\
\hline October & 6 & 22 & 25 & 29 & 29 & 27 & 26 & 22 & 27 & 26 & \\
\hline November & 7 & 21 & 20 & 25 & 24 & 30 & 38 & 18 & 22 & 27 & \\
\hline December & 6 & 22 & 23 & 28 & 24 & 26 & 26 & 18 & 23 & 26 & \\
\hline January & 6 & 19 & 18 & 28 & 26 & & 37 & 17 & 25 & 42 & \\
\hline February & 8 & 21 & 20 & 29 & 25 & & 30 & 28 & 36 & 22 & 22 \\
\hline March & 9 & 27 & 40 & 33 & 34 & 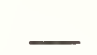 & 38 & 17 & 24 & 28 & 24 \\
\hline Mean & 7.7 & 23.2 & 25.1 & 28.4 & 26.7 & 29.0 & 29.9 & 18.5 & 24.7 & 28.2 & 22.3 \\
\hline Std. Dev. & 1.5 & 2.8 & 6.6 & 2.8 & 3.0 & 2.5 & 4.9 & 3.9 & 4.2 & 5.6 & 1.5 \\
\hline
\end{tabular}

\footnotetext{
airgin basestock I was a blind control, with all samples coming from a single large sample.

Table 5. Induction time data (4 commercial additive packages)
} Pkg. $\begin{array}{lllll}A(7.7 \text { wt. \% }) & B(10.8 \text { vol. \% } & C(7.4 \text { vol. \% }) & D(7.45 \text { vol. \% })\end{array}$ Pkg.
Pkg. $\mathrm{Pkg}$. 0xidative Induction Time, Min

\section{Re-refined Basestock}

BC7346
BC7347
BC7352

29

$30 \quad 15$

1814

$\begin{array}{ll}14 & 58 \\ 20 & 54 \\ 18 & 26 \\ 18 & 52\end{array}$

\section{Virgin Basestock}

\section{BC7348}

BC7349

BC7350

BC7351

BC7354 
Table 6. Long term stability of basestock mixtures

Sample $+7.7 \%$

Additive Pkg.
Initial Induction

Time, Min
Induction Time

Nov. 80 , Min
Time Difference, Month

\section{Virgin Basestock}

(Company A)

$\begin{array}{lrll}\text { BC7168 } & 10 & 7.3 & 7 \\ \text { BC7168 (New Mixture Nov. ' } 80 \text { ) } & -- & 10 & 5 \\ \text { BC7230 } & 9 & 6.2 & 4 \\ \text { BC7242 } & 9 & 5.4 & 2 \\ \text { BC7263 } & 6 & 5.3 & \end{array}$

(Company B)

BC7202

24

23.2

6

Re-refined Basestock

$\begin{array}{ll}\text { BC7187 } & 26 \\ \text { BC7204 } & 25.5\end{array}$

BC7204

26.5

30.4

28

26

BC7227

8.2

8.7

17

ASTM Ref.
$(70 H-I I I C)$

.

30

7
6
5

\subsection{Response of Base 0ils to Additive Components}

When zinc-dialkyldithiophosphate (ZDDP) was added directly to base oils, the isothermal experiments yielded signals that were much weaker than when the total additive package was used (fig. 7 ). In order to check this phenomenon we made a mixture of $1 \%$ (wt.) ZDDP + $2 \%$ (wt.) of calcium sulfonate (detergent) and a light, white paraffin oil and compared the results with just $3 \%$ ZDDP in the paraffin oil. The difference in response between the oils would then obviously be due to the presence of the detergent, calcium sulfonate. Addition of the detergent reduced the induction time by 10 minutes, as can be seen in figure 8 . Also, the heat generated is close to an order of magnitude larger. More systematically, one virgin and one re-refined base oil were treated with 1\% ZDDP and from 0.25 to $2 \%$ calcium sulfonate. The results are summarized in table 7 , and demonstrate the continued increase in heat until the maximum amount was added. The effects on the induction time are also included. For the two base oils shown, there is a small but significant increase in induction time with detergent concentration. There is some evidence that the numbers may be approaching a maximum. On the other hand, with paraffin oil induction time is reduced. Also included are data on various other detergents and dispersants. The change in induction times is presumably a manifestation of the higher order interactions and represent the type of synergism that is often discussed as "additive response". The inverse effect for the paraffin oil is indicative of another complexity of the phenomena.

Nevertheless, the large increase in heat output is of considerable interest in terms of its relationship to the autoxidation process. If one assumes that the detergent is acting in its designated role, then these observations suggest solubilization of reactive species leading to a higher level of reactivity. However, for the present purposes, the retardation of autoxidation, this is an undesirable quality. Since additives clearly improve lubricating oil performance, there is an obvious inconsistency. We suspect that this is an example of the well known "catastrophic" nature of lubricant failure. In other words, once "failure" begins the subsequent chemistry is immaterial. Furthermore, this "failure" must occur under very low percentage conversion. On this basis, the choice of onset temperature and induction time as markers for the consistency of lubricating oils appears to be justified. It is in accord with our earlier conclusion (1) that there is no correlation between the measured heat of reaction and the quality of a lubricating oil.

It should also be noted that all of the above is based on ZDDP as the antioxidant. We have also carried out additional experiments with calcium phenate as the anti-oxidant. The results are summarized in tables 8 and 9 , and no particular difficulties were experienced in obtaining sufficient heat of reaction for induction time determinations. As before, the onset temperatures 


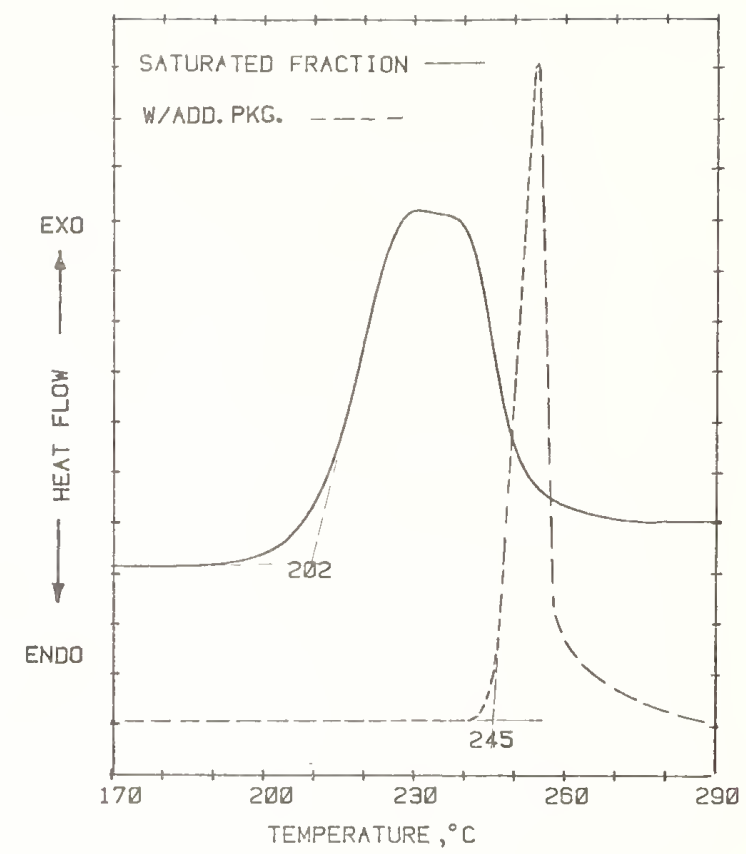

Figure 3. Temperature scanning thermograms of saturated fraction from re-refined oil with and without additive package "A".

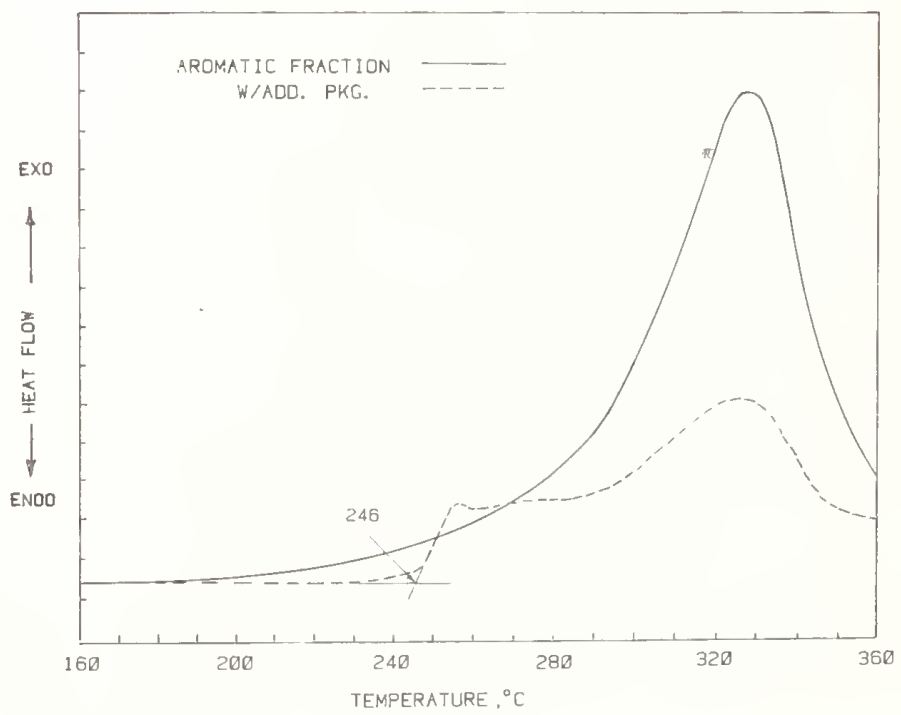

Figure 4. Temperature scanning thermograms of aromatic fraction from re-refined oil with and withoug additive package " $A$ ". 


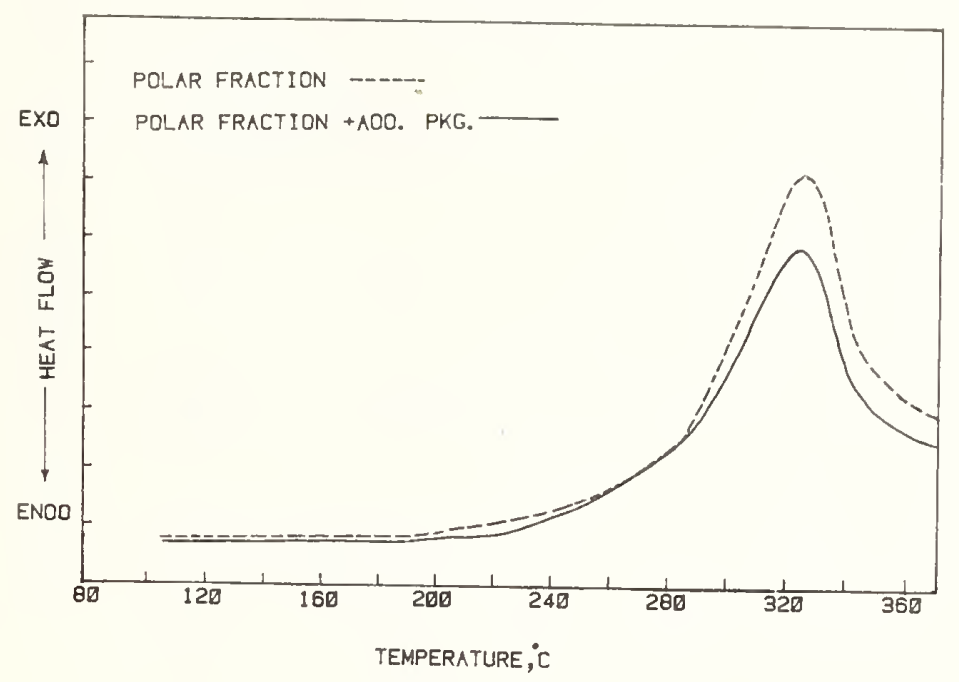

Figure 5. Temperature scanning thermograms of polar fraction from re-refined oil with and without additive package " $A$ ".

are not particularly informative (table 8). They do show, together with the induction time determinations, that at the recommended levels the numbers are close to those used in the consistency tests. Of special interest is the observation that the virgin basestock, which was an obvious outrider in the consistency tests, responded much better to the calcium phenate antioxidant and is now brought much closer to the range of other virgin basestocks. However, the effect on the paraffin oil sample is strikingly different from that caused by the original ZDDP additive package. Similarly, when the calcium sulfonate detergent is mixed with the calcium phenate antioxidant, one notes a decrease in induction time as opposed to the increase when ZDDP is the antioxidant. All of these effects are indicative of the high degree of specificity for the additive/base oil interactions. The important point in all these observations is that HPDSC provides a convenient and precise means of quantifying such effects.

\section{Conclusions}

From the results of the High Pressure Differential Scanning Calorimetric test, it appears that the variations in autoxidative propensity of re-refined basestocks are no worse than those for virgin basestocks. There are, however, sufficient differences in physico-chemical properties such that certain additive packages will provide a substantially more satisfactory service with one type of base oil. Information has been obtained with respect to the finer details of the additive basestock interaction. In particular, the crucial reaction is clearly between the more polar constituents of the basestock and the inhibitor. Detergents have the direct effect of markedly increasing the heat of reaction during isothermal experiments. This is supportive of the assumption that the key steps in the mechanism for autoxidative degradation of lubricating oils occur during the initiating stages. Synergistic effects arising from interactions involving detergents have been observed. They are clearly specific to the system in question. Pending a more detailed understanding of the molecular nature of the complex interactions during the degradation of a lubricant, HPDSC appears to be a valuable tool for monitoring the relative response of lubricants to additives. 


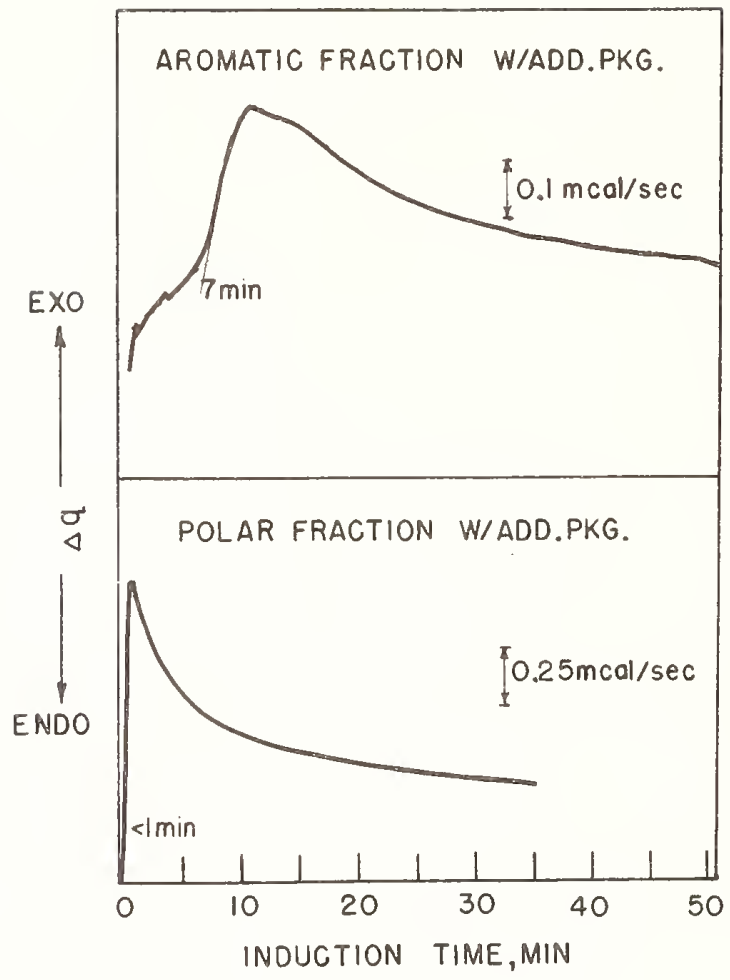

Figure 6. Induction time thermograms of aromatic and polar fractions with additive package " $A$ ".

Table 7. Synergistic effects of some lubricating oil additives

Sample Additives

Induction

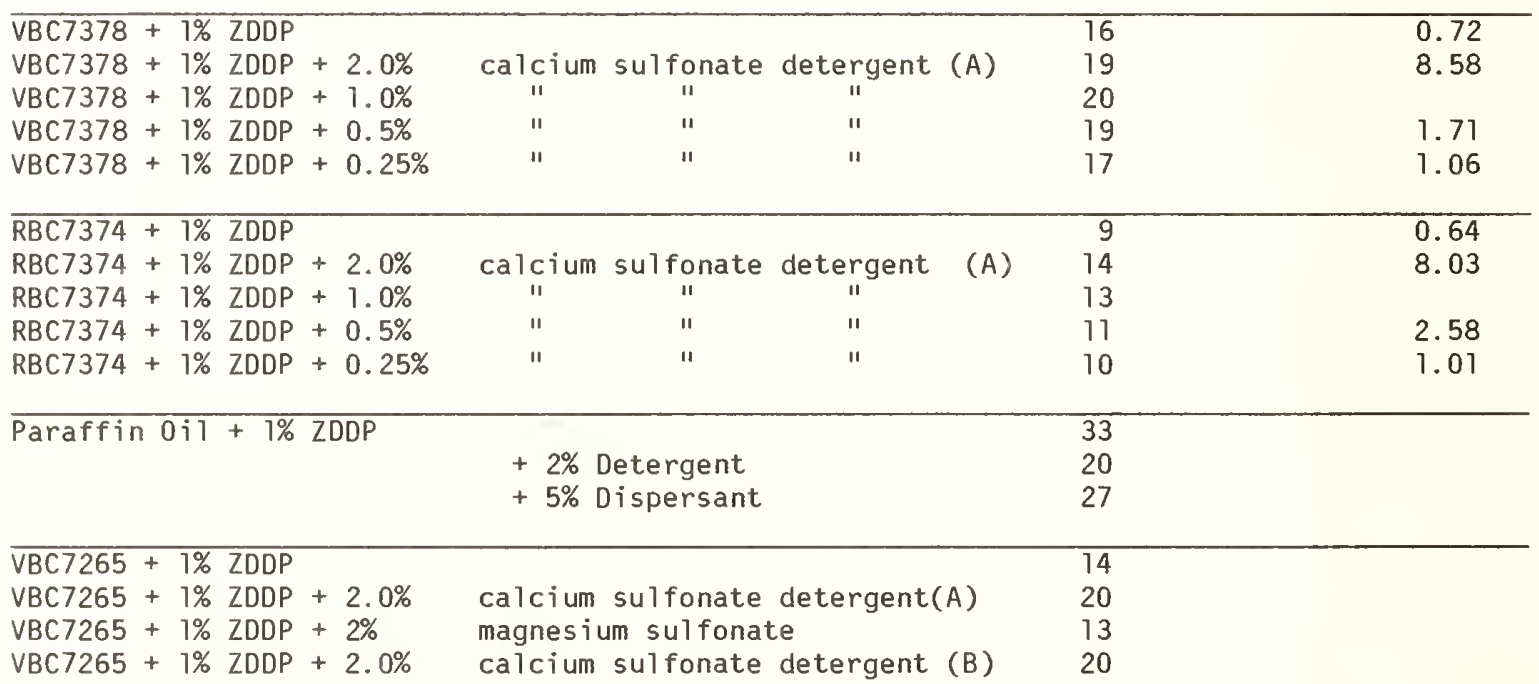




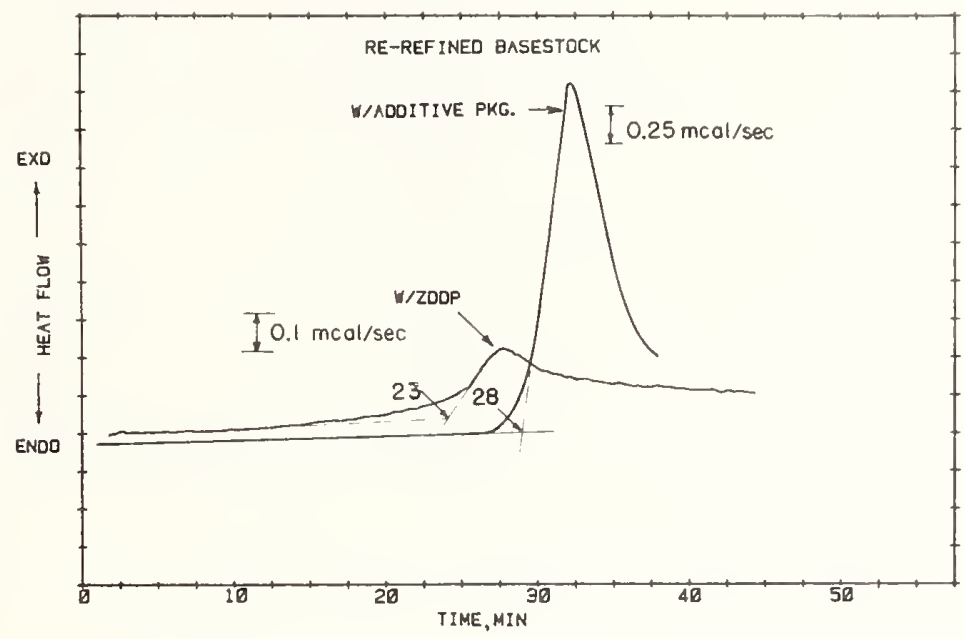

Figure 7. Comparison of the signal magnitude of a base oil with 1\% (wt.) ZDDP and additive package " $A$ ".

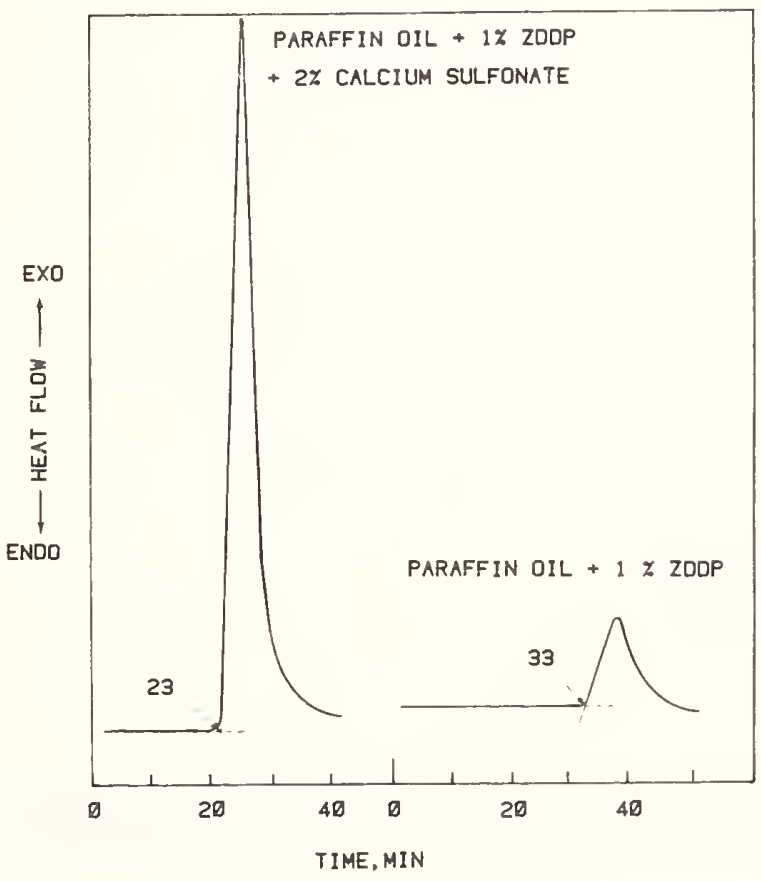

Figure 8. Comparison of signal magnitude of a paraffin light oil contining 1\% (wt.) ZDDP with a paraffin light oil containing $1 \%$ (wt.) ZDDP plus $2 \%$ (wt.) calcium sulfonate detergent. 
Table 8. Oxidation onset temperature results for ZDDP and calcium phenate antioxidants

Additive $\mathrm{Pkg}$. (A)

$7.7 \%$ by wt.
Calcium Phenate

(Antioxidant) $2 \%$ by $w t$.
Calcium phenate $2 \%$ by wt.

Calcium sulfonate $2 \%$ by wt. (Detergent)

\begin{tabular}{|c|c|c|c|}
\hline Re-Refined Basestocks & \multicolumn{3}{|c|}{ Oxidative 0 nset Temperature, ${ }^{\circ} \mathrm{C}$} \\
\hline$\overline{\mathrm{BC} 7346}$ & 258 & 260 & 259 \\
\hline BC7347 & 257 & 260 & 259 \\
\hline BC7352 & 261 & 262 & 261 \\
\hline BC7353 & 258 & 261 & 256 \\
\hline \multicolumn{4}{|l|}{ Virgin Basestocks } \\
\hline$\overline{\mathrm{BC} 7348}$ & 244 & 257 & 252 \\
\hline $\mathrm{BC} 7349$ & 249 & 253 & 249 \\
\hline $\mathrm{BC} 7350$ & 250 & 250 & 246 \\
\hline BC7351 & 254 & 256 & 254 \\
\hline BC7354 & 253 & 249 & 252 \\
\hline Heating Rate & \multicolumn{3}{|c|}{$20^{\circ} \mathrm{C} / \mathrm{min}$} \\
\hline Purge Gas & \multicolumn{3}{|c|}{ Air 3} \\
\hline Flow Rate & \multicolumn{3}{|c|}{$100 \mathrm{~cm}^{3} / \mathrm{min}$} \\
\hline Pressure & \multicolumn{3}{|c|}{$700 \mathrm{KPa}(100 \mathrm{psig})$} \\
\hline
\end{tabular}

Table 9. Induction time results for ZDDP and calcium phenate antioxidants

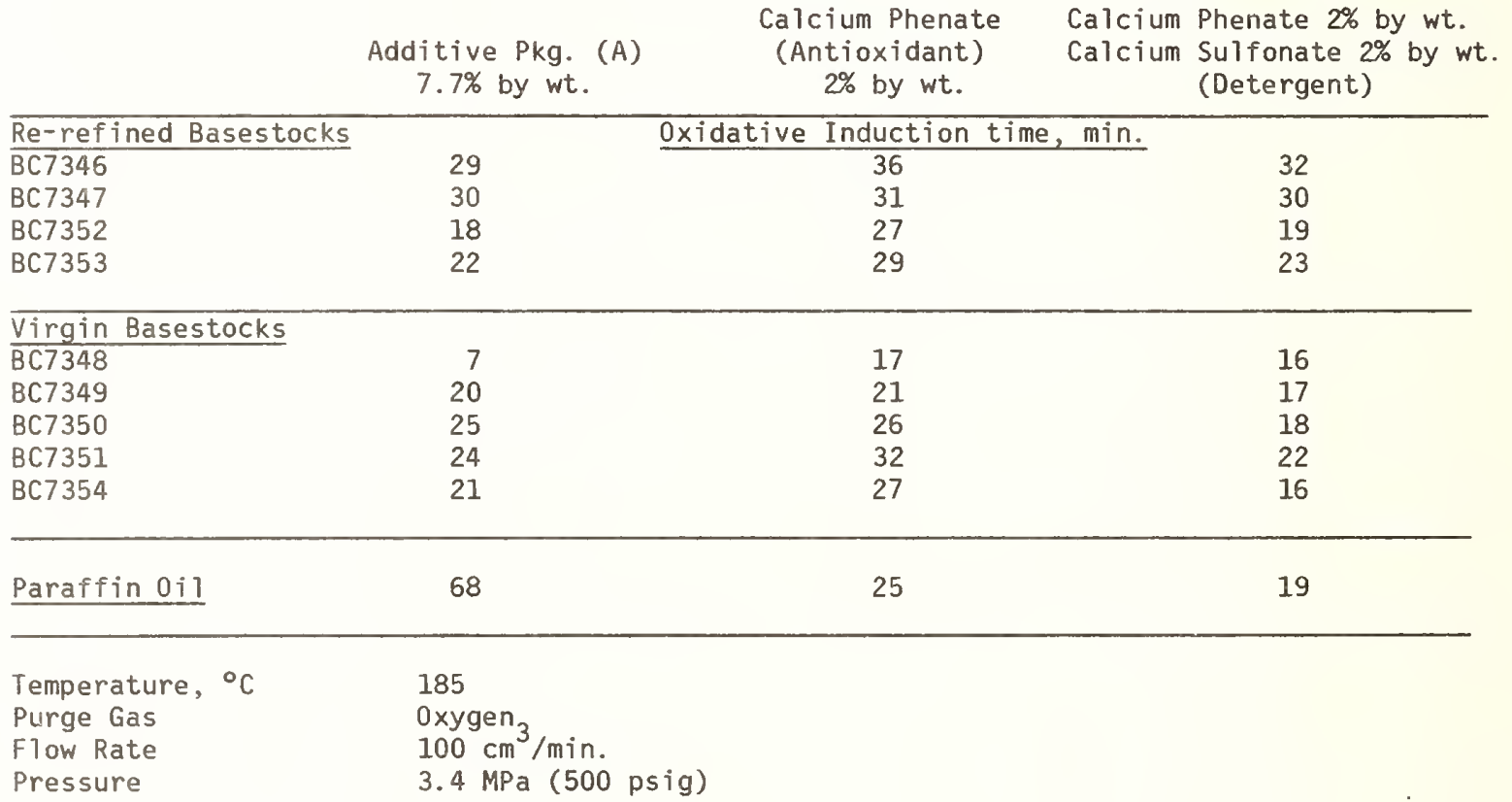

We would like to express our appreciation to $\mathrm{Mr}$. Donald Becker and the Recycled 0 il Program their generous support. In addition, we would like to thank the members of the Tribiochemistry Group for supplying the samples and additives and Dr. Patrick Pei for the basestock fractions. 


\section{References}

[1] Walker, J. A. and Tsang, W., Joint Conference on Measurements and Standards for Recycled 0i1/Systems Performance and Durability October 23-26, 1979, Nat. Bur. Stand. (U.S.) Spec. Publ. $584 ; 1980$.

[2] Walker, J. A. and Tsang, W., SAE Technical Paper Series 801385 , Fuel and Lubricant, Baltimore, Maryland, 1980.

[3] Walker, J. A. and Tsang, W., Proceedings of the Tenth NATAS Conference, Boston, Massachusetts, 1980 , p 291.

[4] Levy, P. F., Nievweboer, G. and Semanski, L. C., Thermochimica Acta, 1, 429-439 (1970).

[5] Energy Policy and Conservation Act of 1975 [P.L. 94-163, Section 383; 42 U.S.C. 6363(C)1].

[6] Noel, F. and Cranton, F. E., Analytical Calorimetry, Vol. 3, R. S. Porter and J. F. Johnson, ed. New York: Plenum Publishing Co.; New York, 1974. 305.

[7] Noel, F., J. Inst. Petro1., 57: 354-358; 1971.

[8] Cranton, G. E., Thermochemica Acta, 14: 201-208; 1976. 
National Bureau of Standards Special Publication 674. Proceedings, Conference on Measurements and Standards for Recycled 0il - IV, held at NBS, Gaithersburg, MD, September 14-16, 1982, (Issued July 1984).

\section{KINETIC STUDIES FOR WASTE OIL DEMETALLIZATION}

A. R. Tarrer, R. Sachhathep, D. L. Vives, and L. J. Hirth

Chemical Engineering Department

Auburn University

Al abama 36849

\section{Introduction}

Research in waste oil re-refining was begun at Auburn University in January 1982. Major emphasis was placed on the development of kinetic parameters for demetallization using dibasic ammonium phosphate (DAP). In addition, studies were conducted in the area of hydrogenation accompanied by demetalization of waste oil using three types of guard catalysts. Thermal demetallization was also briefly investigated.

The data obtained in the laboratory was used in the design fabrication and operation of a small re-refining unit recently started up in the Auburn area. Currently, the final product is a high quality fuel oil obtained at a capacity of 200,000 gallons/year. Future plans entail the addition of hydrotreating unit for the production of a high quality lube oil basestock.

The experimental findings at Auburn will be of aid in the characterization of waste oils in terms of kinetic behavior and the prediction of operative parameters for their processing.

\section{Experimentai}

\subsection{Equipment:}

Reactions were carried out in microreactors (tubing bomb reactors) constructed of 316 seamless stainless steel, 3/4" O.D. with 0.065 inch wall thickness. Two types of microreactors were used. The first was sealed at both ends with Swagelok caps and had no provisions for charging the reactor with gases (fig. 1). The second type of reactor was sealed on one end with a Swagelok cap and the other end was fitted with Swagelok reducing unions connected to a Swagelok fine-metering valve (fig. 2). The valve was used for pressurizing the reactor contents with gases. The internal volume of these reactors amounted to $46.3 \mathrm{~cm}^{3}$.

Reaction temperatures were maintained at the desired values by immersing the microreactors in a fluidized bath. Techne Inc. SBL-2D fluidized baths equipped with Techne TC-4D temperature controllers were used to maintain temperatures within $+2{ }^{\circ} \mathrm{C}$. The reactors were agitated at $850 \mathrm{r}$. $p$.m. by using a variable speed motor equipped with crankshaft, bushing, couplings and extension rods (fig. $3)$.

Other equipment employed were porcelain and vycor crucibles ( $50 \mathrm{ml}$ capacity), bunsen burners with tripod stand and wire gauze and a high temperature muffle furnace (Sybron/ Thermolyne). Dehydration of samples was accomplished with the use of a Rotovapor-R, Fisher Scientific \#9-548-151 (1979).

Experiments were performed using several batches of waste oil obtained randomiy from service stations and individual car owners. Reagents included dibasic ammonium phosphate ( $99.5 \%$ pure), MCB Co., A.C.S. certified, and sulfuric acid (95\%-98\% purity), Fisher Scientific Co., A.C.S. certified. In the hydrogenation studies the guard catalysts, nitrogen gas and hydrogen gas, Alabama 0xygen Co. Inc. were employed. 


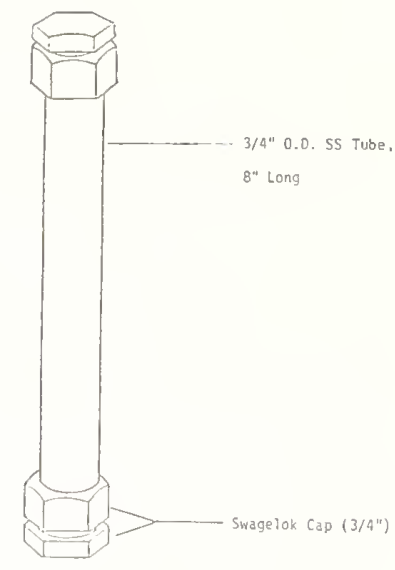

Figure 1. Microreactor used for demetallization reactions

\subsection{Procedure:}

\subsubsection{Reactions with Dibasic Ammonium Phosphate (DAP)}

Carefulty weighed samples of $30 \mathrm{~g}$ of dehydrated $0 i 1$ and the required amount of DAP were placed in the reactor. To these, just enough distilled water was added to yield a saturated solution of the DAP. The addition of DAP and $\mathrm{H}_{2} \mathrm{O}$ separately, rather than in the form of a saturated solution, was made to improve experimental accuracy. The $\mathrm{H}_{2} \mathrm{O}$ was required as a reactant in the proposed reaction stoichiometry. To provide mixing, two steel balls were added. The tubing bomb was then sealed and the reaction was carried out in the fluidized sand bath. The speed of agitation was maintained at 850 r.p.m. Reaction temperatures were varied between 250 and $400{ }^{\circ} \mathrm{F}$.

At the end of the reaction, the shaft was removed from the fluidized bed and the reactor was cooled. The products were then carefully removed and centrifuged for 30 minutes at $3500 \mathrm{r}$. $p$.m. The supernatent oil was decanted into a flask and dehydrated in the rotovap under vacuum ( $5 \mathrm{~m} . \mathrm{m}$. $\mathrm{Hg}$ ) at $60^{\circ} \mathrm{C}$. This was determined to be a low enough temperature to avoid any further reaction of remaining traces of DAP with the 017 . The dehydrated product was finally filtered and ashed in accordance with ASTM procedures D-482 and D-874 for ash and sulfated ash respectively.

\subsubsection{Hydrogenation Studies}

The second type of microreactor (fig. 2) was used in these reactions. The reactor was charged with $15 \mathrm{~g}$ of $0 i 1$ and $1.5 \mathrm{~g}$ of the powdered guard catalyst. If an increased product volume was required, two tubing bombs were charged and run simultaneously. The reactor contents were purged with hydrogen and then pressurized. Hydrogen pressures were varied between 50 psig and 1250 psig. In some cases, nitrogen gas was used to provide an inert atmosphere. Reaction temperatures were varied between $200{ }^{\circ} \mathrm{C}$ and $400{ }^{\circ} \mathrm{C}$.

The procedure for carrying out the reaction after charging the reactor was the same as that described for the DAP reactions. At the end of the reaction, the tubing bomb was cooled and the product gases were released. The product was filtered and analyzed for ash and sulfated ash as needed. 


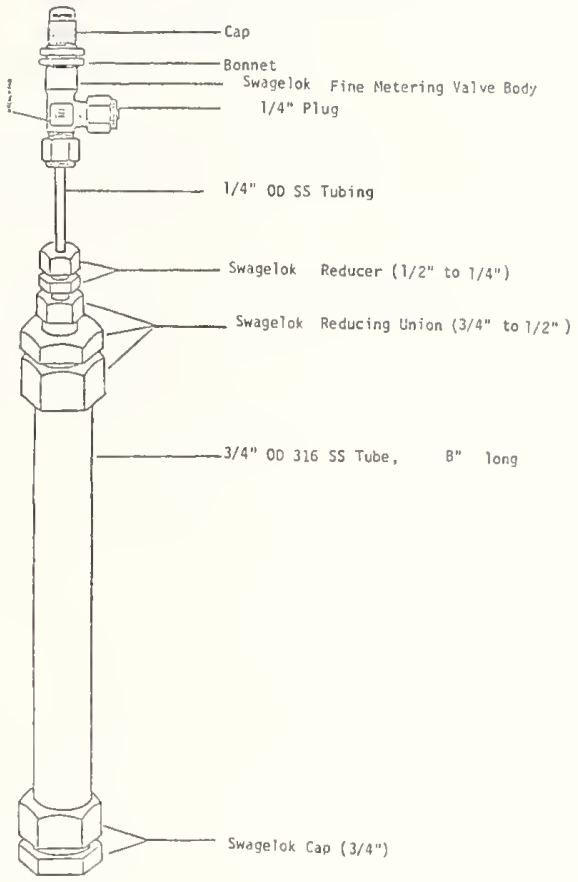

Figure 2. Microreactor used for hydrogenation studies

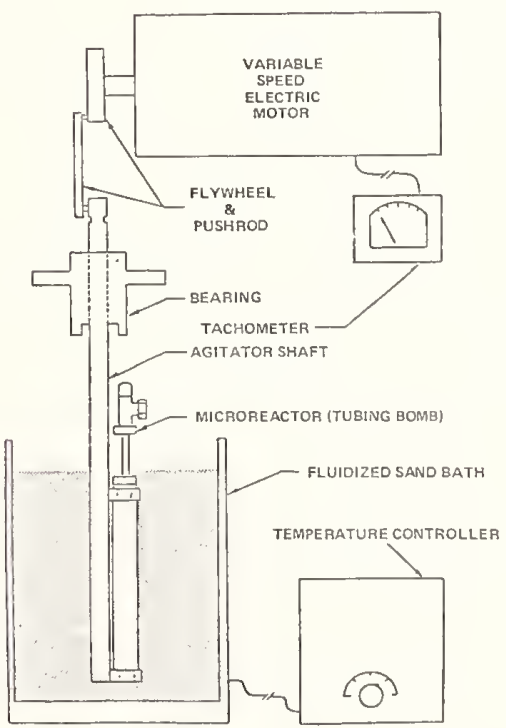

Figure 3. Reaction system employed in hydrogen and demetallization studies 


\section{Kinetic Modeling}

For simplicity of treatment it was assumed that all metallic components within waste oils react with DAP in the same manner as does lead oxide. Thus, the ash content of the waste oils was hypothetically attributed to lead oxide. Based on the stoichiometry of the reaction between lead oxide and DAP, a kinetic model for demetallization of waste oil was proposed and tested. The stoichiometric equation is a follows:

$$
2\left(\mathrm{NH}_{4}\right)_{2} \mathrm{HPO}_{4}+3 \mathrm{PbO}+\mathrm{H}_{2} \mathrm{O} \rightarrow 4 \mathrm{NH}_{4} \mathrm{OH}+\mathrm{Pb}_{3}\left(\mathrm{PO}_{4}\right)_{2}
$$

The following kinetic models were proposed:

\subsection{Pseudo First Order Reaction}

The rate of decrease in ash content can be represented as follows:

$$
-r_{A}=\frac{-d C_{A}}{d t}=k_{1} C_{A} C_{B}
$$

where, $C_{A}=$ weight $\%$ ash

$$
\begin{aligned}
& C_{B}=\text { DAP concentration (wt\%) } \\
& r_{A}=\frac{d C_{A}}{d t}=\text { rate of disappearance of ash with respect to time }(\% / m i n)
\end{aligned}
$$

Assuming that DAP is present in enough excess that its concentration remains virtually constant during the reaction, equation (1) can be rewritten as,

$$
-\frac{d C_{A}}{d t}=k_{1} C_{A} C_{B 0}=k_{1}^{\prime} C_{A}
$$

where,

$$
\begin{aligned}
& C_{B O}=\text { initial DAP concentration (wt \%) } \\
& k_{1}^{\prime}=k_{1} C_{B O}
\end{aligned}
$$

Rearranging equation (2) and integrating,

$$
\begin{gathered}
\frac{d C_{A}}{C_{A}}=-k_{1}^{\prime} d t \\
\ln \left(C_{A} / C_{A 0}\right)=-k_{1} t
\end{gathered}
$$

A plot of $\ln \left(C_{A} / C_{A 0}\right)$ versus $t$ should yield a straight line with a slope of $-k_{1}^{\prime}$.

\subsection{Pseudo Second Order Reaction}

The rate of decrease in ash content is,

$$
-r_{A}=-\frac{d C_{A}}{d t}=k_{2} C_{A}^{2} C_{B O}^{2}
$$

Provided DAP is in excess and its concentration remains approximately constant during the reaction,

$$
-r_{A}=k_{2}^{\prime} C_{A}^{2}
$$

where,

$$
k_{2}^{\prime}=k_{2} c_{B 0}^{2}
$$


Combining equations 4.1 and 4.2 , and integrating,

Combining equations 4.1 and 4.2 , and integrating,

$$
\frac{d C_{A}}{c_{A}^{2}}=-k_{2}^{\prime} d t
$$

and,

$$
\frac{1}{C_{A}}-\frac{1}{C_{A 0}}=k_{2}^{\prime} t
$$

A plot of $1 / C_{A}$ versus $t$ should yield a straight line with a slope of $k_{2}^{\prime}$ and an intercept of $1 / C_{A 0}$.

Since the re-refining unit in the Auburn area incorporates a reactor configuration that closely approximates a constant stirred tank reactor (c.s.t.r.) (fig. 4) this reactor configuration wil1 be discussed here. For a c.s.t.r. reactor a material balance on ash yields,

$$
\begin{gathered}
\text { Input-output-depletion (due to reaction) }=0 \\
\qquad Q C_{A O}-Q C_{A f}-V\left(-r_{A}\right)=0
\end{gathered}
$$

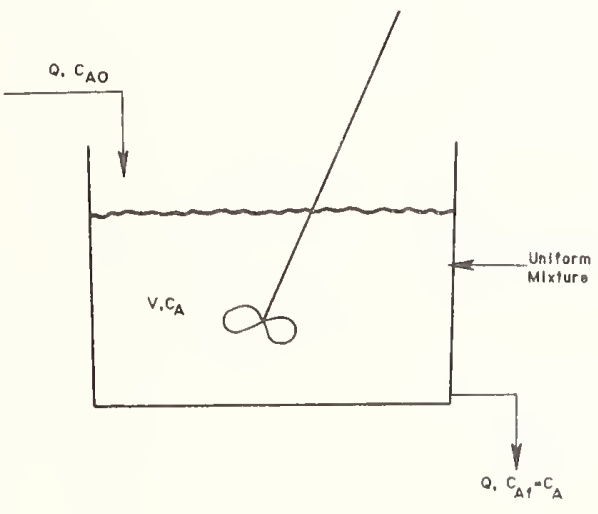

Figure 4. Constant stirred tank reactor configuration

where,

$$
\begin{aligned}
& C_{A 0}=\text { initial ash weight } \% \\
& C_{A f}=\text { final ash weight } \% \\
& Q=\text { flow-rate of input and product streams (gal/min.) } \\
& V=\text { reactor volume (gal.) } \\
& -r_{A}=-\frac{d C_{A}}{d t}=\text { rate of disappearance of ash }
\end{aligned}
$$

For the pseudo first order case, substituting eq. 2 in eq. 4, 


$$
\begin{aligned}
& Q C_{A O}-Q C_{A f}-V\left(k_{1}^{\prime} C_{A f}\right)=0 \\
& \frac{Q}{V}\left(C_{A O}-C_{A f}\right)=k_{1}^{\prime} C_{A f}
\end{aligned}
$$

Defining the residence time within the reactor as $\tau=V / Q$ (min.) and substituting we have,

$$
\frac{1}{\tau}=\frac{k_{1}^{\prime} C_{A f}}{C_{A 0}{ }^{-C} C_{A f}} \text { or } \tau=\frac{C_{A 0}-C_{A f}}{k_{1}^{\prime} C_{A f}}
$$

Similarly for the Pseudo second order case,

$$
\tau=\frac{C_{A 0}{ }^{-C_{A f}}}{k_{2}^{\prime} C_{A f}^{2}}
$$

Thus, if $C_{A f}$ is fixed and $k_{2}^{\prime}$ is evaluated experimentally, the value of $\tau$ can be easily determined.

From Arrhenius' law it is known that the rate constant of a reaction is related to the reaction temperature as follows:

$$
k=k_{0} e^{-E / R T}
$$

or,

$$
-\ln k=\ln k_{0}+\frac{E}{R T}
$$

where

$$
\begin{aligned}
& k_{0}=\text { frequency factor (same units as } \mathrm{k} \text { ) } \\
& E=\text { activation energy }(\mathrm{cal} . / \mathrm{g} \text { mole) } \\
& T=\text { reaction temperature }\left({ }^{\circ} \mathrm{K}\right)
\end{aligned}
$$

It is known that for the first order model,

$$
\mathrm{k}_{1}^{\prime}=\mathrm{k}_{1} \mathrm{C}_{\mathrm{BO}}
$$

Substituting equation (10) above,

$$
\begin{aligned}
k_{1}^{\prime} & =k_{10} e^{-E / R T} C_{B 0} \\
-\ln k_{1}^{\prime} & =-\ln \left(k_{10} C_{B 0}\right)+\frac{E}{R T}
\end{aligned}
$$

Thus, a plot of - In $k_{1}^{\prime}$ versus $1 / T$ should result in a straight 1 ine with a slope of $E / R$ and an intercept of -1 n $\left(k_{10} C_{B 0}\right)$.

\section{Results and Discussion}

\subsection{DAP Treatment}

It was found that different batches of oil exhibit varying kinetic behavior. Certain batches of waste oil showed first or second order kinetics whereas others did not conform to any simple reaction order. Unless otherwise specified, three times the required stoichiometric amount of DAP was used in all the reactions. This was done to provide a safety factor for demetallization at the Auburn re-refinery and hence was extended to laboratory studies for consistency. DAP concentration is accounted for in the theoretical treatment. 


\subsubsection{First Order Reaction}

The first order plots at different reaction temperatures are shown in figure 5 for one batch of oil investigated. The original ash content was 1.192 percent. Reaction temperatures were $300{ }^{\circ} \mathrm{F}$, $315^{\circ} \mathrm{F}, 330^{\circ} \mathrm{F}, 360^{\circ} \mathrm{F}$ and $390^{\circ} \mathrm{F}$. Three times the required stoichiometric amount of DAP ( $1.83 \%$ ) was used in these reactions. As can be seen, the data fits first order kinetics very well although the behavior at $330^{\circ} \mathrm{F}$ was unexpected.

Figure 6 depicts the corresponding Arrhenius plot for the reactions discussed above. A 1 east squares regression technique was used to fit these data points. From this method the slope and intercept of the line were found to be 4320.26 and -5.935 respectively. The values of $k$ ' obtained from the slopes of the plots in figure 5 are tabulated in table 1 . These values are compared to values obtained from least squares regression. Standard deviations and variances are also 1 isted.

Table 1. Values of $k^{\prime}$ determined from slopes of first order plots for waste oil batch 1 compared to results calculated from least squares regression

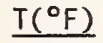

300

315

330

360

390

From Slopes
$k^{\prime}\left(\min ^{1}\right)$

0.0147

0.0179

0.0171

0.0276

0.0436

$$
\text { Least Squares }
$$

$k^{\prime}\left(\min ^{-1}\right)$

.0135

.0165

.0199

.0285

.0400

\section{Standard \\ Deviation}

.0012

.0014

.0028

.0009

.0036
Variance

$1.4 \times 10^{-6}$

$2 \times 10^{-6}$

$7.8 \times 10^{-6}$

$8 \times 10^{-7}$

1. $3 \times 10^{-5}$

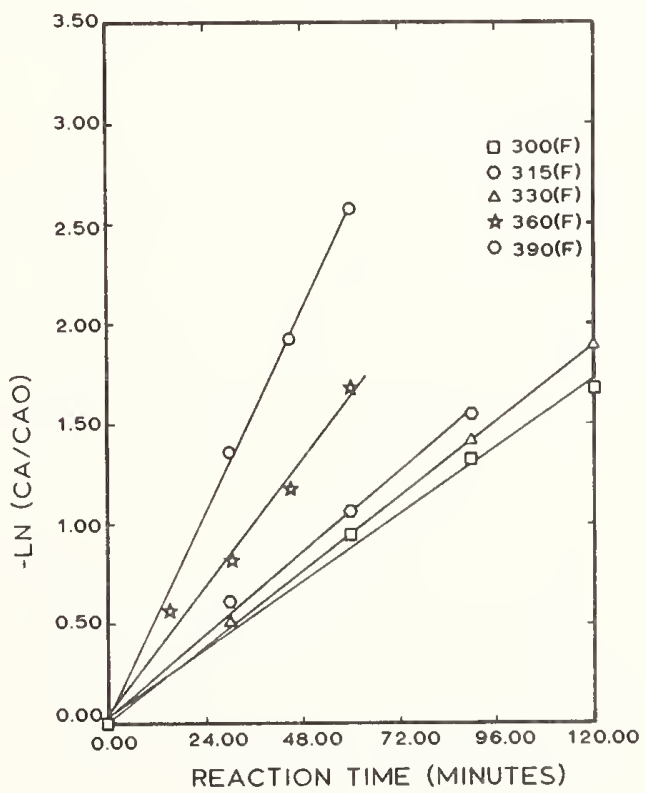

Figure 5. - $L N(C A / C A O)$ versus time for various reaction temperatures Waste 0 il Batch \#1

$\mathrm{CAO}=1.192 \mathrm{Wt} . \% \mathrm{ASH}$

$\mathrm{CBO}=1.83 \mathrm{Wt} . \%$ DAP

Agitation Speed $=850$ RPM 
From equation (12),

$$
\frac{E}{R}=4320.26 ; \quad E=8600 \text { calories } / g \text { mole }
$$

and $-\operatorname{In}\left(k_{10} C_{B 0}\right)=-5.93496$

$$
\begin{aligned}
k_{10} C_{B 0} & =378.02 \\
C_{B 0} & =1.83 \% \\
k_{10} & =378.02 / 1.83=206.57\left(\mathrm{~min}^{-1}\right)
\end{aligned}
$$

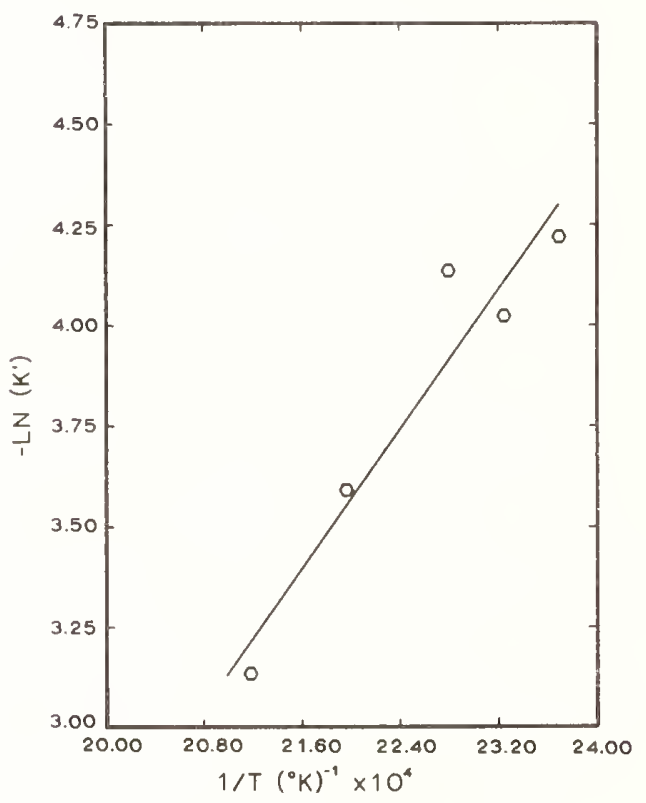

Figure 6. $-L N\left(K^{\prime}\right)$ versus 1/T: Arrhenius plot for waste oil batch \#1 (first order kinetics)

Substituting the above results in equation (12a),

$$
k_{1}^{\prime}=206.57 C_{B 0} e^{-4320 / T+273}
$$

For first order reaction in a c.s.t.r. reactor,

$$
\tau=\frac{C_{A 0}-C_{A f}}{k_{1}^{\prime} C_{A f}}
$$

The value of $C_{A f}$ must be fixed at the desired value of weight percent ash. In this case, $C_{A f}=0.1 \%$

$$
C_{A 0}=1.192 \% \text { (from experiment) }
$$

The required residence time for a given reaction temperature can easily be determined from equation (A) and equation (8). For example, if it is desired to know the required residence time at a reaction temperature of $400^{\circ} \mathrm{F}$ and a DAP concentration of three times the required stoichiometric amount (1.83\%) it can be done as follows: 


$$
\begin{gathered}
T=400{ }^{\circ} \mathrm{F}=204.44{ }^{\circ} \mathrm{C} \\
C_{B 0}=1.83 \%
\end{gathered}
$$

Substituting in equation (A),

$$
\begin{aligned}
k_{1}^{\prime} & =206.57(1.83) \mathrm{e}^{-4320 /(204.44+273)} \\
& =0.044 \mathrm{~min}^{-1}
\end{aligned}
$$

Substituting in equation ( 8 ),

$$
\tau=\frac{1.192-0.1}{(0.044)(0.1)}=248.18 \mathrm{~min} .=4.1 \text { hours }
$$

Since the value of 4.1 hours is too high it must be reduced by increasing the temperature and/or DAP concentration. If the maximum allowable residence time is 60 minutes the required temperature at $z$ DAP concentration of 1.83 percent and conversely the required DAP concentration at a temperature of, say, $400^{\circ} \mathrm{F}$ are easily calculable as follows:

a) $\mathrm{C}_{\mathrm{BO}}=1.83 \%, \tau=60 \mathrm{~min}$.

$$
\begin{aligned}
& \text { From equation (8), } k_{1}^{\prime}=\frac{C_{A 0}-C_{A f}}{\tau C_{A f}} \\
& k_{1}^{\prime}=\frac{1.192-0.1}{(60)(0.1)}=0.182 \mathrm{~min}^{-1}
\end{aligned}
$$

Substituting in equation $(A)$,

$$
\begin{gathered}
0.182=206.57(1.83) \mathrm{e}^{-4320 / \mathrm{T}+273} \\
\mathrm{~T}=293^{\circ} \mathrm{C}=559^{\circ} \mathrm{F}
\end{gathered}
$$

b) $\mathrm{T}=400{ }^{\circ} \mathrm{F}=204.44{ }^{\circ} \mathrm{C}, \tau=60 \mathrm{~min}$.

$$
k_{1}^{\prime}=0.182 \mathrm{~min}^{-1}
$$

Substituting in equation $(A)$,

$$
\text { therefore } \quad \begin{aligned}
0.182 & =206.57\left(C_{B 0}\right) \mathrm{e}^{-4320 /(204.44+273)} \\
C_{B O} & =7.5 \%
\end{aligned}
$$

A range of values of $C_{B 0}$ and $T$ required to yield 0.1 percent final ash at a residence time of 60 min., for a c.s.t.r. reactor, are tabulated in table 2. These values are compared to similar results obtained for the second batch of waste oil. The final decision as to what values should be used depends on economic considerations.

\subsubsection{Second Order Reaction}

A second batch of oil (1.495\% original ash percent) that was studied was found to exhibit second order kinetics. The second order plots for reactions at $330^{\circ} \mathrm{F}, 360^{\circ} \mathrm{F}$ and $380^{\circ} \mathrm{F}$ are shown in figure 7. Three times the required stoichiometric amount of DAP (1.69 weight percent) was used. The corresponding Arrhenius plot is shown in figure 8. Using least squares regression, the values of the slope and intercept were found to be 15686.70 and -31.791 respectively. Table 3 depicts values of $k^{\prime}$ calculated from the slopes of the plots in figure 7 . These values are compared to those calculated from the least squares technique and standard deviations and variances are listed.

$$
\frac{E}{R}=15687, E=31170 \mathrm{cal} / \mathrm{g} \mathrm{mole}
$$


and,

$$
\begin{gathered}
-\ln \left(k_{20} C_{B 0}^{2}\right)=-31.791 \\
k_{20} c_{B 0}^{2}=6.407 \times 10^{13} \\
k_{2}^{1}=k_{20} C_{B 0}^{2} e^{-E / R T}=6.407 \times 10^{13} e^{-15687 / T}
\end{gathered}
$$

Table 2. Reaction temperature versus initial DAP concentration required to yield a final ash content of $0.1 \%$ for waste $0 i 1$ batches 1 and 2, using a residence time of 60 minutes in a c.s.t.r. reactor

Batch 1 1st Order Kinetics ( $\left.C_{A 0}=1.192 \%\right)$

$T\left({ }^{\circ} \mathrm{F}\right)$

560

530

500

470

440

410

380

350

- $\mathrm{C}_{\mathrm{BO}}(\%$ DAP $)$

1.811

2.282

2.917

3.790

5.010

6.751

9.294

13. 102
Batch 2 2nd Order Kinetics $\left(\mathrm{C}_{\mathrm{AO}}=1.495 \%\right)$ $\mathrm{C}_{\mathrm{BO}}(\% \mathrm{DAP})$
0.331

0.507

0.792

1.274

2.114

3.634

6.493

12. 110

Table 3. Values of $k^{\prime}$ determined from slopes of second order plots for waste oil batch 2 compared to results calculated from least squares regression.

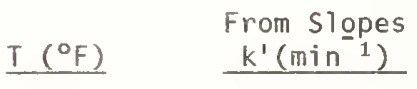

300

330

360
0.0171

0.0820

0.1490

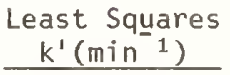

0.0188

0.0659

0.1690
Standard

Deviation

.0017

.0161

.0200
Yariance

$2.90 \times 10^{-6}$

$2.59 \times 10^{-4}$

$4.00 \times 10^{-4}$ 


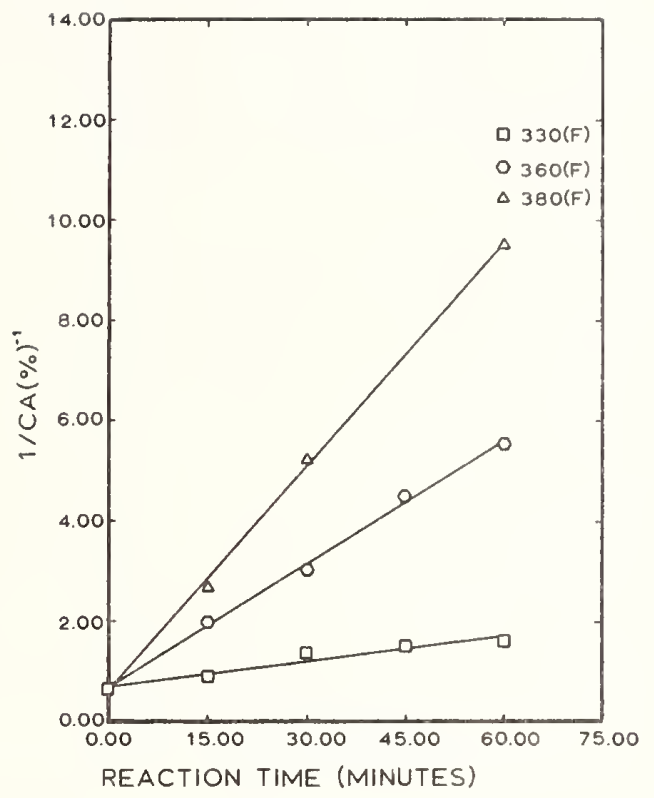

Figure 7. 1/CA versus time for various reaction temperatures Waste 0 il Batch \#2 $\mathrm{CAO}=1.495 \mathrm{Wt} . \% \mathrm{ASH}$ $\mathrm{CBO}=1.495 \mathrm{Wt} . \%$ DAP

Agitation Speed $=850$ RPM

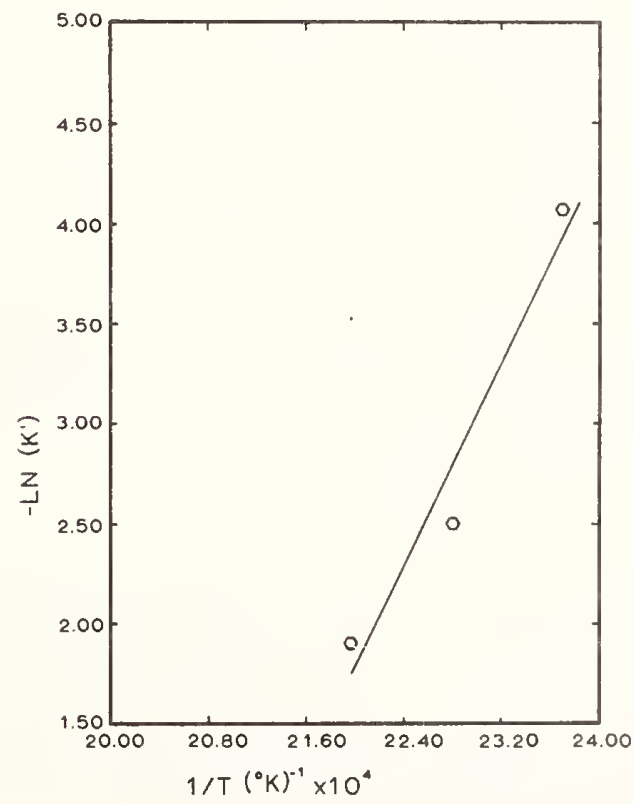

Figure 8. - LN $\left(K^{\prime}\right)$ versus 1/T: Arrhenius plot for waste oil batch \#2 (second order kinetics) 
For c.s.t.r. reactors,

$$
\text { From equation (8), } \quad \tau=\frac{C_{A 0}-C_{A f}}{k_{2}^{\prime} C_{A f}^{2}}
$$

If $\tau$ is fixed at $60 \mathrm{~min} \& C_{B 0}=1.69 \%$

$$
k_{2}^{\prime}=\frac{1.495-0.1}{(0.1)^{2}(60)}=2.325(\% / \mathrm{min})
$$

So to achieve a final ash content of 0.1 percent under these conditions the temperature must be as follows:

$$
\begin{gathered}
k_{2}^{\prime}=2.325=6.407 \times 10^{13} \mathrm{e}^{-15687 / \mathrm{T}+273} \\
T=233.89^{\circ} \mathrm{C}=453.01{ }^{\circ} \mathrm{F}
\end{gathered}
$$

Conversely, if $\tau$ is fixed at $60 \mathrm{~min}$ and $T=400{ }^{\circ} \mathrm{F}$,

$$
\begin{aligned}
k_{20} C_{B 0}^{2} & =6.407 \times 10^{13} \\
k_{20}(1.69)^{2} & =6.407 \times 10^{13} \\
k_{20} & =2.243 \times 10^{13} \\
k_{2}^{\prime} 2.325 & =\left(2.243 \times 10^{13}\right) C_{B 0}^{2} e^{-15687 /(204.44+273)} \\
C_{B 0} & =4.390 \%
\end{aligned}
$$

Thus, in order to have a residence time of 60 minutes at a temperature of $400^{\circ} \mathrm{F}, \mathrm{C}_{\mathrm{B} 0}$ must be 4.39 percent in order to yield a final ash.percent of 0.1 . A range of values of $T$ and $C_{B O}$ required to yield an ash value of 0.1 percent at a residence time of 60 minutes are tabulated in table 2. Comparison is made to similar values obtained for the first batch of oil. From the proposed kinetic model it is known that for pseudo second order kinetics,

$$
k^{\prime}=k C_{B O}^{2}
$$

Figure 9 shows a plot of $k^{\prime}$ versus $C_{B 0}^{2}$. These results were obtained experimentally by varying $C_{B 0}$ at a fixed reaction temperature of $380^{\circ} \mathrm{F}$. The values of $k$ ' were obtained from the slopes of the plots of $1 / C_{A}$ versus $t$ for each value of $C_{B 0}$. As can be seen, the relationship between $k^{\prime}$ and $C_{B O}^{2}$ is linear, thus verifying the proposed kinetic model.

Table 4 shows the response of a third batch of oil to DAP treatment at $330{ }^{\circ} \mathrm{F}$ and $360^{\circ} \mathrm{F}$. In each case the ash content drops substantially within 15 minutes of reaction time beyond which there is no significant change. Due to the inherent complexity of kinetic behavior in this case no attempt at characterization has yet been made. However, detailed investigation will be pursued in the future.

\subsection{Hydrogenation Studies}

Although hydrogenation studies at Auburn are still in the preliminary stages some interesting results have been obtained thus far. A fourth batch of waste 0 il $(0.88 \%$ ash) was used for hydrogenation studies. Unless otherwise specified, the agitation speed was maintained at 850 r.p.m. in all cases. Shown in figure 10 are the results of studies conducted at 600 psig hydrogen partial pressure and various reaction temperatures. The reaction time was held constant at 15 minutes. A high hydrogenation activity catalyst (Catalyst 1) was used. The weight of catalyst used was 10 percent of the weight of oil charged into the reactor. The plot of weight percent ash versus reaction temperature indicates that there is a steady decline in ash content with increase in reaction temperature. Thus, complete demetallization can be achieved above a reaction temperature of $360{ }^{\circ} \mathrm{C}$ with a hydrogen partial pressure of $600 \mathrm{psig}$ and a reaction time of 15 minutes. 
Figure 11 shows a plot of kinematic viscosity (centistokes) versus reaction temperature for the reactions discussed above. As expected, the viscosities decreased with increase in reaction temperature. In order to study the effect of hydrogen partial pressure on viscosity, a series of reactions were carried out at $400{ }^{\circ} \mathrm{C}$, a catalyst loading of 10 percent by weight and a reaction time of 15 minutes. Catalyst 1 was used and hydrogen partial pressures were varied between 0 and $600 \mathrm{psig}$. The plot of viscosity versus hydrogen partial pressure is presented in figure 12 . Contrary to what was expected, the viscosities were observed to increase with increase in hydrogen partial pressure. This effect is not presently understood but will be further studied in the future.

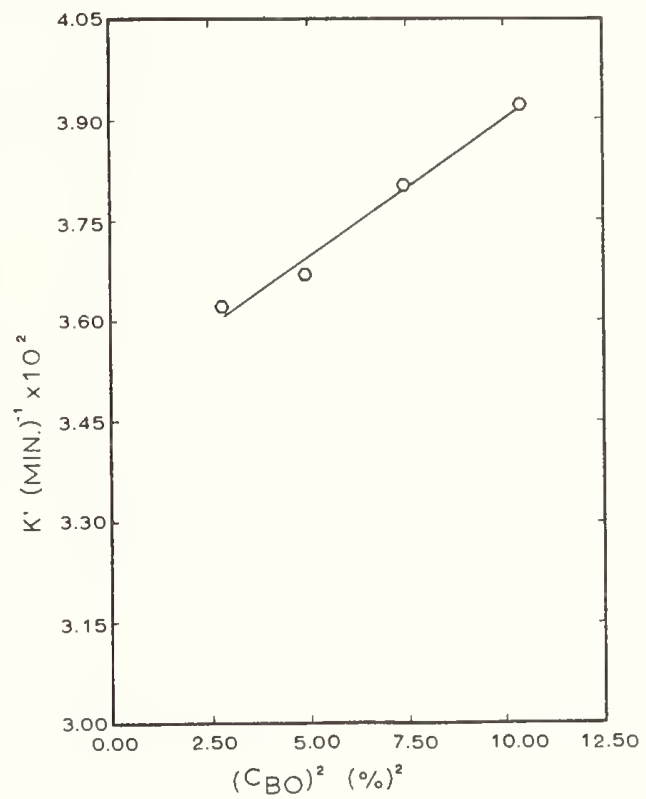

Figure 9. $K^{\prime}$ versus $(C B O)^{2}$ : test of a linear relationship between $K^{\prime}$ and $(\mathrm{CBO})^{2}$ for waste $0 i 1$ batch $\# 2, \mathrm{CAO}=1.495$ weight \% ASH

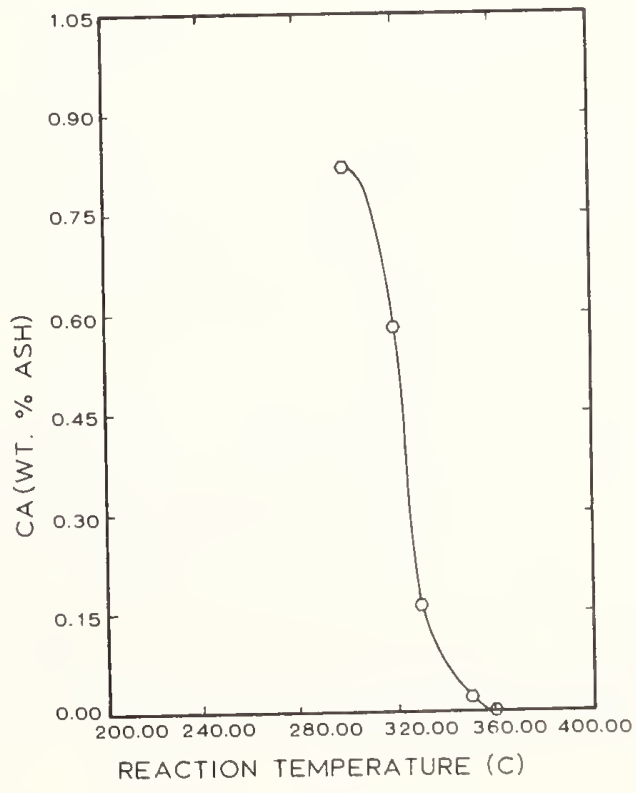

Figure 10. Weight \% ASH versus reaction temperature. Reaction conditions: 600 psig $H 2$ pressure, 10 wt. \% catalyst loading, $15 \mathrm{~min}$., 850 rpm; original ash $=0.88 \%$ 
Table 4. Sulfated ash versus reaction time at $330^{\circ} \mathrm{F}$ and $360^{\circ} \mathrm{F}$ for waste oil batch 3. $C_{A 0}=1.608 \%$ (Sulfated ash); $C_{B O}=1.81 \%$ DAP; Agitation Speed $=850$ r.p.m.

A. $330^{\circ} \mathrm{F}$

$$
\underline{t(\min )}
$$$$
0
$$

30

45

60

B $360^{\circ} \mathrm{F}$
$C_{A}(\%$ Sulfated Ash $)$
1.608
0.337
0.356
0.388
0.341

$C_{A}(\%$ Sulfated Ash)
1. 608
0.153
0.099
0.163
0.151

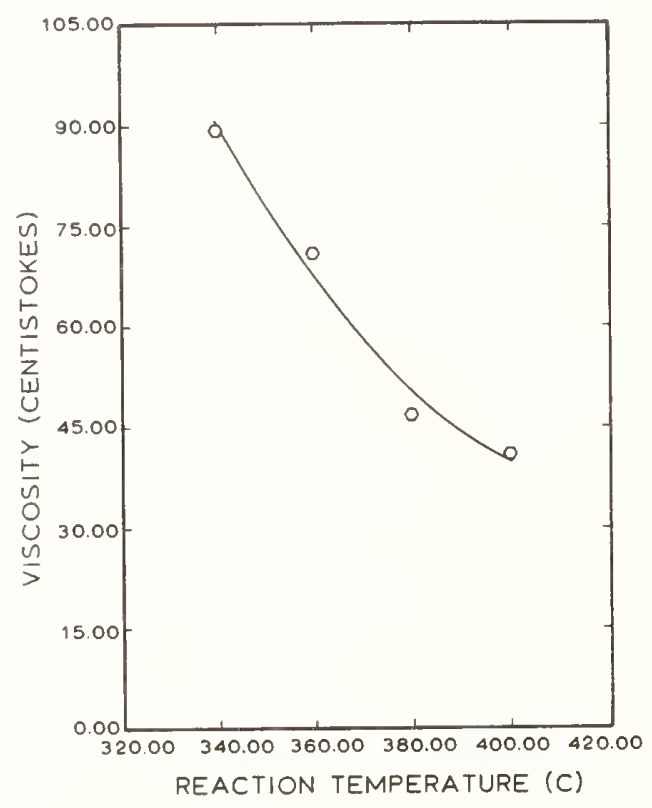

Figure 11. Viscosity versus reaction temperature. Reaction conditions: 600 psig H2 pressure, 10 Wt. \% catalyst loading, 15 minutes, $850 \mathrm{rpm}$, original ash $=0.88 \mathrm{Wt}$. \%. 
For the purpose of studying the demetallization ability of Catalyst 1 in the absence of hydrogen, it was decided to carry out reactions at various temperatures without the use of hydrogen. The atmosphere within the reactor was kept inert with the use of 50 psig nitrogen pressure. As before, the catalyst loading was 10 percent by weight and the reaction time was 15 minutes. The results which are plotted in figure 13 indicate a decrease in ash content with increase in temperature.

Table 5 depicts the results of hydrogenation of waste $0 i 1$ batch four at $400{ }^{\circ} \mathrm{C}$ and 600 psig hydrogen pressure using three different catalysts. Catalyst 1 and Catalyst 2 are both high hydrogenation activity catalysts. Catalyst 3 is inert. In all three cases the ash content was reduced to 0 percent for a reaction time of 15 minutes.

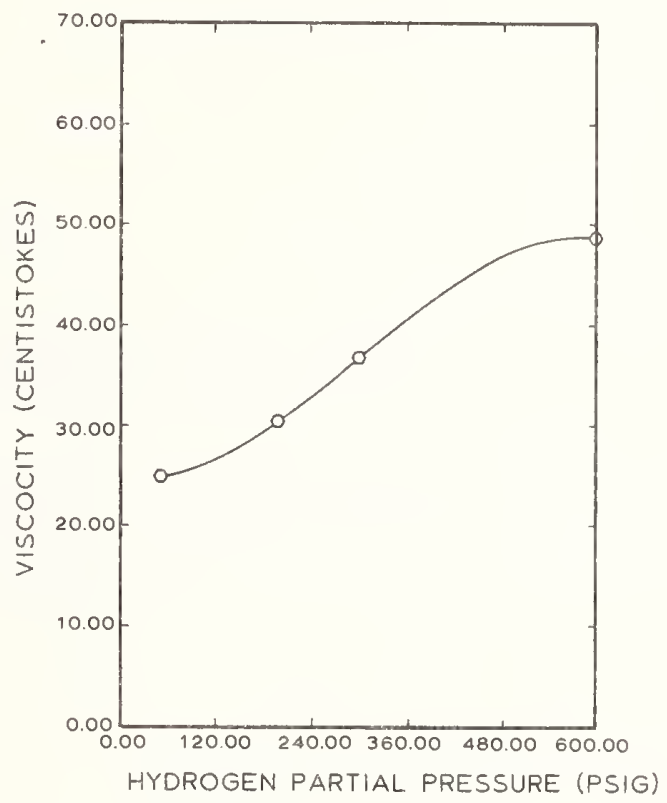

Figure 12. Viscosity versus hydrogen partial pressure. Reaction conditions: reaction temperature $=400$ (C), $850 \mathrm{rpm}, 15 \mathrm{~min} ., 10$ wt. \% catalysts loading. Original ash content $=0.88 \%$ by weight.

\subsection{Thermal Demetalitization}

The results of the hydrogen studies alluded to the possibility of removing metals from waste oil by simply heating the oil. This led to the brief investigation of the effect of heat on demetalization. The results presented in table 6 show that at $400{ }^{\circ} \mathrm{C}$ it is possible to demetallize waste oils completely without the use of any catalyst. However, this presents the problem of coking which is known to occur above $650^{\circ} \mathrm{F}$ $\left(344^{\circ} \mathrm{C}\right)(13)$.

It can be seen from table 6 that at lower temperatures partial demetallization can be achieved. Future studies will incorporate a systematic study of the effect of temperature on demetallization. An investigation into the mechanism of thermal demetallization will also be carried out.

Table 5. Weight percent ash versus catalyst type for reaction at $400{ }^{\circ} \mathrm{C}, 600 \mathrm{psig}_{2}$ partial pressure and 15 minutes of reaction time

$\begin{array}{lc}\text { Catalyst } & \% \text { Ash } \\ \text { Cat. } 1 & 0 \\ \text { Cat. } 2 & 0 \\ \text { Cat. } 3 & 0\end{array}$




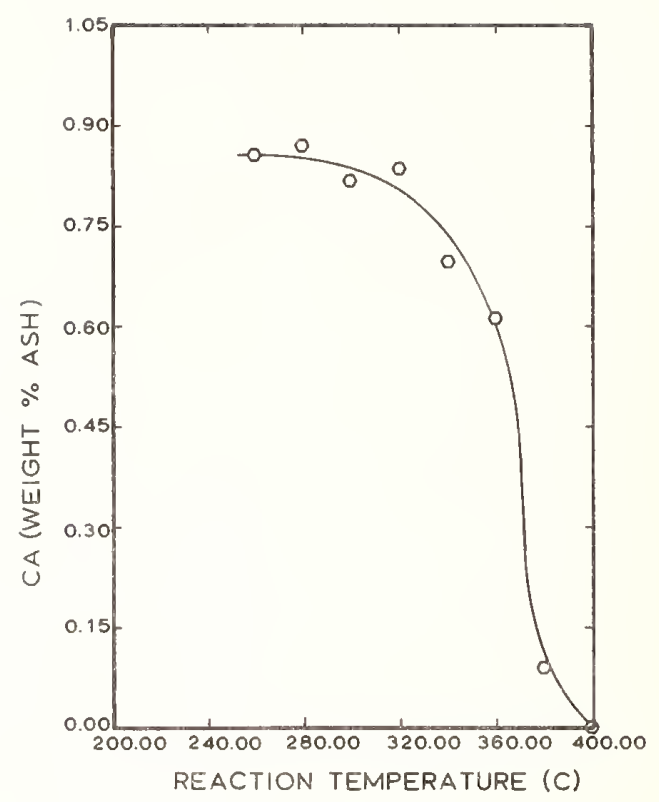

Figure 13. Weight $\%$ ash versus reaction temperature. Reaction conditions: 50 psig N2 partial pressure, 15 minutes, 10 Wt. \% catalyst loading, 850 rpm original ash content $=0.88 \%$ by weight.

Table 6. Results for thermal demetallization studies

A. $T=\left(166^{\circ} \mathrm{C}\right) 330^{\circ} \mathrm{F}, \mathrm{t}=15 \mathrm{~min}$.

\section{Batch of \\ Waste 0 il}

1

5
Original

Ash (wt. \%)

1.192

0.450
Final

Ash (wt. \%)

1.110

0.266

B. $T=\left(183^{\circ} \mathrm{C}\right) 360^{\circ} \mathrm{F}, t=15 \mathrm{~min}$.

\section{Batch of \\ Waste 0 il}

1

5
Original

Ash (wt. \%)
1.192
0.450

Final Ash (wt. \%)
0.801
0.156

c. $T=400^{\circ} \mathrm{C}\left(752^{\circ} \mathrm{F}\right), t=15$ min., 50 psig $N_{2}$ pressure

Batch of

Waste 0 il

1
Origina 1

Ash (wt. \%)

1.192
Final

Ash (wt. \%) 


\section{Conclusions}

1) It is possible to characterize certain waste oils and predict operating parameters for their treatment based on kinetic behavior. The major problem associated with this is that different oils exhibit varying kinetic behavior. Further studies should be conducted in this area.

2) The possibility of hydrogenation accompanied by demetallization in one step may be economically beneficial and should be investigated.

3) Although the sole use of thermal demetallization is not practical, the coupling of this method with some other effective means of demetallization may reduce operating costs considerably.

\section{References}

[1] Levenspie1, 0 . Chemical reaction engineering. 2nd edition. New York: John Wiley and Sons; 19.

[2] Georgi, C. W. Motor oils and engine lubrication. 1st edition. New York: Reinhold Publishing Corporation; 1951.

[3] Hsu, S. M.; Becker, D. A. Status report on the characterization of re-refined lubricating base oils. SAE Technical Paper number, 801382; Society of Automotive Engineers; Warrendale, Pennsylvania; 1980.

[4] Comeford, J. J. Test procedures for recycled oil used as burner fuel. Proceedings of measurements and standards for recycled oil-II; 1977 November 29-30. Nat. Bur. Stand. (U.S.) Spec. Pub1. 556; 1979 September; 87-92.

[5] Linnard, R. E.; Phillips recycled oil program. Proceedings of measurements and standards for recycled oil-II; 1977 November 29-30. Nat. Bur. Stand. (U.S.) Spec. Pub1. 556; 1979 September; $133-137$.

[6] Hess, L. Y. Reprocessing and disposal of waste petroleum oils. New Jersey: Noyes Data Corporation; 1979.

[7] Becker, D. A.; Comeford, J. J. Recycled oil program: Phase I - Test Procedures for Recycled 0 il Used as Burner Fue1. Nat. Bur. Stand. (U.S.) Tech. Note 1130; 1980, Washington.

[8] Whisman, M. L.; Cotton, F. 0.; Geotzinger, J. W.; Reynolds, J. W. Waste 1ubricating oil research: characterization of basestocks from used lubricating oils, part 1. ERDA BERC/RI-75/3; 1975.

[9] Whisman, M. L.; Cotton, F. 0.; Goetzinger, J. W. Waste lubricating oil research: goegraphical and seasonal variations in used lubricating oil basestock composition, part 2. ERDA BERC/RI-75/11, 1975.

[10] Whisman, M. L.; Cotton, F. 0.; Goetzinger, J. W.; Reynolds, J. W. Waste lubricating oil research: characterization of basestocks from used lubricating oils, part 3. ERDA BERC/RI-76/3; 1975.

[11] Whisman, M. L.; Cotton, F. 0.; Goetzinger, J. W. ; Reynolds, J. W. Waste lubricating oil research: a summary of composition variations among 30 used lubricating oils selected for seasonal and geographical significance. ERDA BERC/RI-76/4, 1976.

[12] Cotton, F. 0.; Whisman, M. L. ; Goetzinger, J. W. ; Reynolds, J. W. Waste lubricating oil research: a comprehensive characterization of five typical re-refinary feedstocks, part 5. ERDA BERC/RI-77/3; 1977.

[13] Steele, G. L.; Brinkman, D. W.; Whisman, M. L. Predictive test method for coking and fouling tendency of used lubricating oil. ERDA BERC/RI-79/7; 1979. 

National Bureau of Standards Special Publication 674. Proceedings, Conference on Measurements and Standards for Recycled 0il - IV, held at NBS, Gaithersburg, MD, September 14-16, 1982. (Issued July 1984).

\title{
RE-REFINED LUBRICATING BASE OIL CHARACTERIZATION USING LIQUID CHROMATOGRAPHIC TECHNIQUES
}

\author{
P. Pei and S. M. Hsu \\ Tribochemistry Group \\ Materials Chemistry Division \\ National Bureau of Standards \\ Washington, D.C. 20234
}

A separation scheme to characterize lubricating base oils in terms of molecular compound classes has been developed with the purpose of isolating and analyzing impurities in a re-refined base oil. The lubricating base oil is first separated into three major fractions--saturates, aromatics, and polars--using clay-gel 1iquid chromatography.

The polars fraction is separated further into chemical compound classes having different polarities and functional structures. Analytical methods such as infrared and mass spectroscopy were used to elucidate the functional structures of the major fractions and compound classes in the polars subfractions.

The saturate fraction consists mainly of paraffinic and cyclic paraffinic compounds. The aromatic fraction is composed of mono-, di-, and tri-aromatic compounds. Both poly-nuclear aromatic compounds and hydrocarbons with heteroatoms such as sulfur, halogen, and oxygen are present in the polar fraction.

The effects on performance of different molecular compound classes in each major fraction of a typical re-refined base oil are evaluated with respect to oxidation stability and wear. Among the three major fractions--saturates, aromatics and polars--the polar fraction has the largest effects on both of these two performance aspects. Of the compound classes in the polar subfractions, the amine and phenol types of compounds have the highest antioxidant capacity values, in comparison to other classes.

\section{Introduction}

A re-refined lubricating base oil can be defined as the base oil derived from used oil via a re-refining process which is designed to remove all or most of the contaminants in the used oil, such as oxidized products, additives, sludge, water, wear metals, etc.

One of the most important concerns with respect to the quality of a re-refined base oil is the amount and the chemical forms of contaminants/impurities remaining in the base oil after the re-refining process. Theoretically possible contaminants such as sulfur compounds (from sulfurized cutting oils), fatty acids or esters (from greases), polychlorinated biphenyls (PCB's) (from electrical transformer oils), or oxidized resins (from previous use) all suggest possible impact on oil performance.

To ensure consistency and good quality, it is important to devise a method to separate, isolate, and concentrate these contaminants. Having done so, the effects of these "contaminants/ impurities" on the performance of a lubricating base oil can then be measured and assessed.

Before the start of any isolation of the contaminants in a re-refined base oil, the composition of the oil itself needs to be understood. A lubricating base oil is a complex hydrocarbon mixture of C18 to C40. One general method used to characterize such mixtures is "Hydrocarbon Type Analysis"[1] ${ }^{1}$. In a hydrocarbon type analysis, the mixture is separated into paraffins, cycloparaffins, aromatics and hetroatom compounds. The general method available for such a hydrocarbon type analysis is chromatography [1].

${ }^{1}$ Figures in brackets indicate the literature references at the end of this paper. 
A clay-gel chromatographic method has been found to be a good method for hydrocarbon type analysis of lubricating base oils [2]. In the method, which is a modification of ASTM D2007, the base $0 i 1$ is separated into three fractions. They are: (1) the saturate fraction (paraffins and cycloparaffins), eluted with a non-polar solvent (pentane); (2) the aromatic fraction, recovered from the adsorbent by elution with an aromatic solvent such as toluene; and (3) the polar fraction, which contains the compounds that have the strongest surface affinity. Since these latter compounds have the strongest adsorption characteristics, a polar solvent such as an acetone/toluene mixture is needed to remove them from the column.

A set of seventeen virgin and re-refined base oils was analysed [2], which includes ten re-refined and seven virgin base oils. Table 1 lists the crude source and processing technologies of the seventeen base oils. The composite average results of the modified ASTM D2007 procedure are listed in table 2. These results show that there is no significant difference in the weight percentage range of saturates $(62.9-85.2$ vs $72.5-78.0)$ and aromatics $(14.5-35.4$ vs 20.0.24.1) between virgin and re-refined oils in this set. There is a significant difference in the weight percent of polar compounds between re-refined and virgin base oils. In re-refined base oils, the amount of polar compounds is significantly higher than that of virgin base oils. Based on these results, it is believed that most of the remaining contaminants in a re-refined base oil are probably concentrate in the polar fraction. Therefore, not only is it important to have a method to isolate the polar fraction, but also it is important to have a method to further separate and characterize the polar fraction itself.

Table 1. Crude source and processing technologies of the seventeen base oil set

\begin{tabular}{|c|c|c|}
\hline 0i1 ID & Viscosity Grade & Processing Technology \\
\hline VA & $150 N$ & Solvent extraction \\
\hline VB & $600 N$ & Solvent extraction \\
\hline VC & $\begin{array}{c}50: 50 \\
150 \mathrm{~N} / 600 \mathrm{~N}\end{array}$ & Solvent extraction \\
\hline VD & $210 \mathrm{~N}$ & Solvent extraction \\
\hline VE & $270 N$ & Solvent extraction \\
\hline VF & $210 N$ & Solvent extraction \\
\hline VG & $110 \mathrm{~N}$ & Solvent extraction \\
\hline RA & $200 N$ & $\begin{array}{l}\text { Pretreat/Vac. dist./ } \\
\text { Clay finish }\end{array}$ \\
\hline RB & $250 N$ & Clay treat \\
\hline $\mathrm{RC}$ & $350 N$ & Acid/Clay \\
\hline RD & $300 N$ & Acid/Clay \\
\hline RE & $400 N$ & $\begin{array}{l}\text { Caustic Pretreat/ } \\
\text { Vac. dist. }\end{array}$ \\
\hline RF & $350 \mathrm{~N}$ & Acid/Clay \\
\hline RG & $300 N$ & Acid/Clay \\
\hline RH & $250 \mathrm{~N}$ & Acid/Clay \\
\hline RI & $350 N$ & Acid/Clay \\
\hline RJ & $200 N$ & Acid/Clay \\
\hline
\end{tabular}

Crude Source Geographical Area

Mid-East

Mid-East

Canada

Mid-continent

Mid-East

Mid-continent

Mid-continent

Mid-West (US)

Southwest

Southeast

West Coast

Northeast

South

Northwest

Canada

West Coast

Northeast

$R=$ re-refined oils 
Table 2. Hydrocarbon type analysis of the seventeen base oils by ASTM D2007 (percent)

$\frac{7 \text { Virgin Base 0ils }}{\text { Range }}$

$62.9-85.2$

$14.5-35.4$

$0.3-1.7$

Polars

\begin{abstract}
Saturates
Aromatics
\end{abstract}

As shown by the hydrocarbon type separation, the polar compounds in a lubricating base oil are present at a relatively low concentration level. The major difficulty encountered with the use of the ASTM D2007 method is the limitation on sample-loading capactities, which has a maximum of approximately $10 \mathrm{gm}$ [3]. This means that only milligram quantities of the polar compounds can be obtained with each run, an amount that is not sufficient for further separations or performance testing.

Furthermore, the ASTM D2007 method, as given, does not provide for the separation of the polars fraction into compound classes. Therefore, a new separation scheme was needed to: (1) produce multigram quantities of the polar fraction; and (2) to separate the polar fraction into compound classes.

\title{
2. Experimental
}

\subsection{Re-refined Lubricating Base 0il Sample}

One re-refined base oil sample, RC, was chosen for a more detailed study. Its chemical properties are close to mid-range of the properties of the composite average of a set of $10 \mathrm{re}^{-}$ refined base oils, a set which represents the output of a cross-section of re-refining processes available at the time of sampling [4]. Table 3 lists the properties of RC in comparison to the range of re-refined base oils in the set.

\subsection{Chemicals and Instrumentation}

All solvents were glass-distilled solvents of HPLC grade, and were used as received. The attapulgus clay adsorbent conforms to the ATM D2007 clay specifications. The silica gel used was Davidson's silica gel 621 (60/200 mesh). Both neutral and basic alumina adsorbents was obtained from the Fisher Scientific Corp. (Brockman Activity 1, 80/200 mesh).

The preparative high performance liquid chromatographic unit used was a Waters' Associates Prep 500A with dual, radially-compressed polyethylene columns [5]. Columns were packed at NBS.

A glass column was used for the separation of the polar fraction into subfractions, as described below.

\subsection{Column Packing and Chromatograpinic Procedures}

\subsubsection{Preparative HPLC Column}

Columns were dry packed using a "fill and tap" procedure described earlier [6]. The chromatographic procedure described in reference 6 was used to produce the three major fractions: saturates, aromatics and polars.

\subsubsection{Glass columns for Polar Fraction}

A $45 \mathrm{~cm}$ long by $1 \mathrm{~cm}$ i.d. glass column having a $100 \mathrm{ml}$ reservoir was used for the separation of the polar fraction. The column has a tapered-end tip. The other end of the column is fitted with a $100 \mathrm{ml}$ reservoir, on top of which is a ground-glass socket so that $0.13 \mathrm{MPa}$ (4 psig) of back pressure can be supplied to the column. A glass wool plug is placed at the bottom of the column. Another glass plug is placed on the top of the packed adsorbent to protect it from disturbances when eluting solvents are added. Twenty-five grams of neutral alumina adsorbent are added to the column in small increments, and the column is packed uniformly with the aid of a vibrator. 
Table 3. Comparison of chemical properties of re-refined base oil $\mathrm{RC}$ with the re-refined base oil set ${ }^{\mathrm{a}}$ (percent)

\begin{tabular}{|c|c|c|c|c|}
\hline \multirow[b]{2}{*}{ Moisture (ppm) } & \multicolumn{2}{|c|}{$\underline{\text { Range }}$} & \multirow{2}{*}{$\frac{\text { Composite Average }}{92}$} & \multirow{2}{*}{$-\frac{R C}{87}$} \\
\hline & 40 & -219 & & \\
\hline $\begin{array}{l}\text { Total Acid Number } \\
(\mathrm{mgKOH} / \mathrm{g})\end{array}$ & 0.076 & -1.69 & 0.367 & 0.18 \\
\hline $\begin{array}{l}\text { Total Base Number } \\
(\mathrm{mgKOH} / \mathrm{g})\end{array}$ & 0.001 & -0.04 & 0.009 & 0.006 \\
\hline $\begin{array}{l}\text { Saponification } \\
\text { Number }\end{array}$ & 0 & -0.7 & 0.817 & 0.65 \\
\hline Chlorine (ppm) & 6.6 & -1140 & 231 & 190 \\
\hline Bromine (ppm) & 0.15 & -13.9 & 5.8 & 1.2 \\
\hline Sulfur (wt\%) & 0.12 & -0.25 & 0.18 & 0.18 \\
\hline $\begin{array}{l}\text { Sulfated Ash } \\
\text { (wt\%) }\end{array}$ & 0.0005 & -0.0144 & 0.0043 & 0.0067 \\
\hline $\begin{array}{l}\text { Carbon Residue } \\
\text { (wt\%) }\end{array}$ & 0.12 & -0.27 & 0.2 & 0.26 \\
\hline $\begin{array}{l}\text { Total Nitrogen } \\
\text { (ppm) }\end{array}$ & 9 & -47 & 21 & 18 \\
\hline $\begin{array}{l}\text { Basic Nitrogen } \\
\quad(\mathrm{ppm})\end{array}$ & 0.4 & -14.7 & 3 & 1.1 \\
\hline $\begin{array}{c}\text { Elemental Analysis } \\
\text { (wt\%) }\end{array}$ & & & & \\
\hline$C$ & 85.2 & -86.6 & 86.3 & 86.3 \\
\hline$H$ & 13.1 & -13.8 & 13.4 & 13.4 \\
\hline
\end{tabular}

a A set of 10 re-refined base oils from different locations and processing technologies.

Approximately 1 gram of the polar fraction was dissolved in $50 \mathrm{~m} 1 \mathrm{n}$-hexane. The solution was then charged onto the alumina in the glass column. The following step-gradient elution scheme was used to elute the polar subfractions according to their polarities: $125 \mathrm{ml} \mathrm{n}$-hexane, $100 \mathrm{ml}$ toluene, $200 \mathrm{ml}$ chloroform with 0.75 percent ethanol, $200 \mathrm{ml}$ of 10 percent ethanol in tetrahydrofuran, and $200 \mathrm{ml}$ methanol. Five subfractions were obtained. However, the first subfraction contains only a negligible amount of saturates, and the last two subfractions were combined. As a result, three subfractions in total were collected and studied.

\section{Results and Discussion}

\subsection{Separation Scheme}

After considerable work, the final separation obtained is shown in figure 1 . The process has three steps: the base oils are first separated on a clay column, generating a saturate/aromatic hydrocarbon fraction and a polar fraction. The saturate/aromatic hydrocarbon fraction is then separated into a saturate fraction and an aromatic fraction on a dual packed, alumina/silica gel column. The polar fraction is separated further on a neutral alumina adsorbent to obtain subfractions containing polynuclear aromatic compounds, nitrogen containing compounds, and oxygenated compounds. The three steps provided the flexibility necessary to optimize the separation of the base oils and the isolation of the contaminants. 


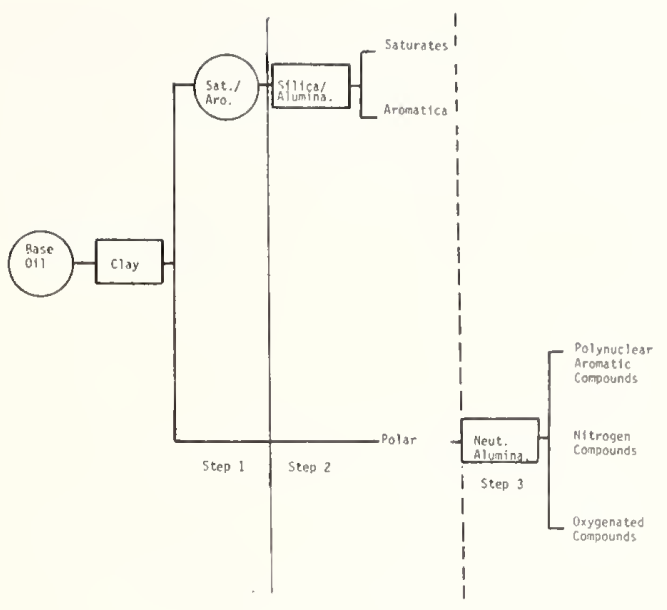

Figure 1. Separation scheme of the re-refined lubricating base oil.

Each major fraction and compound class is characterized chemically by analytical methods such as IR, mass spectroscopy, gel permeation chromatography, and C13 NMR. Besides analytical method characterization, performance evaluation tests were performed on these fractions and compound classes. They included antioxidant capacity titration and differential scanning calorimetry to determine oxidation stability of the fractions, and micro-sample step loading seizure wear tests to determine the wear characteristics under boundary lubricating conditions.

\subsection{Chemical Characterization of Major Fractions}

The mass balance and precision achieved with the preparative HPLC method is good. For oil RC, the mass balance is better than 99 percent by weight, for duplicate runs on the clay column separation, and 98 percent for the dual, alumina/silica gel column separation. Results obtained from the preparative LC method for the three major structural types agree well with those obtained with the ASTM 02007 method. For oil RC, the agreement is as follows: saturates, 76.4 percent vs 75.3 percent; aromatics, 21.5 percent vs 22.5 percent; and polars, 2.0 percent vs 2.2 percent.

Several analytical tests were performed to characterize these fractions. The techniques included refractive index, infrared spectrascopy, carbon 13 nuclear magnetic resonance spectrometry ( $C^{13}$ NMR), mass spectroscopy (both high and low resolution), gas chromatography, boiling point distribution, and ge 1 permeation chromatography.

\subsubsection{Refractive Index}

The refractive index values of the saturate and aromatic fractions of oil RC were measured; however, the dark color of the polar fraction and subfractions prevented the accurate determination of refractive index for these samples. The refractive indices of the saturate fraction is 1.4738 , distinctly lower than the value of 1.5209 for the aromatic fraction. Since the refractive index reflects the aromaticity of oils, the saturate fraction appears to be relatively free of aromatic hydrocarbons.

\subsubsection{Infrared Spectroscopy}

The IR spectra of the fractions of oil RC are shown in figure 2. Figure $2 a$ shows the spectrogram for the saturate fraction. The aliphatic band at $720 \mathrm{~cm}^{-1}$ is present but the aromatics band at $1600 \mathrm{~cm}^{-1}$ is absent. In figure 2b, the spectrogram for the aromatic fraction, the aromatic band at $1600 \mathrm{~cm}^{-1}$ is present. These spectra support our conclusion that the saturate and aromatic fractions are reasonably well separated from the other. The $\mathrm{C}=0$ band at $1700 \mathrm{~cm}^{-1}$ and the $0 \mathrm{H}-\mathrm{b}$ and at 3200 $\mathrm{cm}^{-1}$ are missing in both the saturate and aromatic spectra (fig. $2 \mathrm{a}$ and $2 \mathrm{~b}$ ), but are present in the polar fraction spectrogram (fig. 2c). Thus, the IR spectra indicate that most of the oxygenated compounds--such as esters, acids, ketones--are concentrated in the polar fraction, as would be expected. 


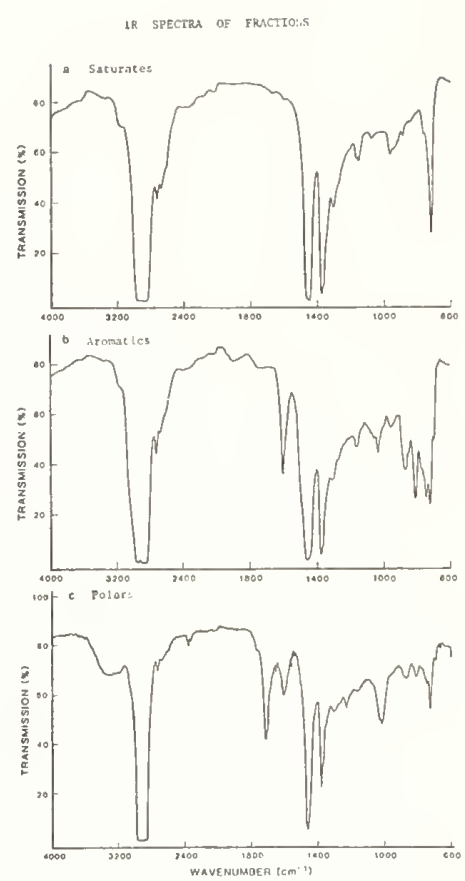

Figure 2. IR spectra of the re-refined base oil RC fractions: a) saturates b) aromatics c) polars.

\subsection{3. $C^{13}$ NMR}

$C^{13}$ NMR results of the RC fractions are shown in figure 3 . The absence of an aromatic $C^{13}$ signal in the saturate fraction is a good indication of its purity. The integral ratio of 1 inear carbon to the total carbon is 0.23 in the saturate fraction. A majority of the saturate fraction thus appears to be cycloparaffin. The ratio of aromatic carbon to aliphatic carbon is 0.27 in the aromatic fraction, an indication that large numbers of paraffin and cycloparaffin side chains are attached to the aromatic ring compounds. The ratio of aromatic carbon to aliphatic carbon in the polar fraction is 0.18 . The extra peak at $59 \mathrm{ppm}$ in the aromatic and polar fractions is probably due to the presence of a viscosity index improver, polysobutylene, which was not removed completely during the re-refining process. It is of interest to note that the preparative HPLC separation of the base oil concentrated most of the polyisobutylene in the polar fraction, so that its presence-albeit low--was easily detected.

\subsubsection{Mass Spectroscopy}

The saturate fraction was examined by low resolution mass spectroscopy to determine its aromatic content. The values found are listed in table 4 . The values found--approximately 2 percent--are considered normal for a saturate fraction.

High resolution mass spectroscopy was also performed on the polar fraction of sample RC in order to determine its major components. The fraction was found to be a very complex mixture consisting primarily of hydrocarbons, with possibly some alkylated phenols. At a probe temperature of $100{ }^{\circ} \mathrm{C}$, considerable residue remained, so that identification of components is likely incomplete.

\subsubsection{Gel Permeation Chromatography}

Gel permeation chromatography (GPC) was used to determine the molecular weight profiles of the fractions collected from the separations. The molecular weight calibration was done with polystyrene 
standards. The distributions obtained for the fractions are shown in figure 4 . The profile of the aromatic fraction shows the presence of compounds having lower molecular weight than the compounds in the saturate fraction. Moreover, the profile of the polar fraction is very broad, suggested that the polar compounds contain both high and low molecular weight compounds from the base oit.

Table 4. Composition of the saturate fraction of RC re-refined base oiT as measured by low resolution mass spectrometry

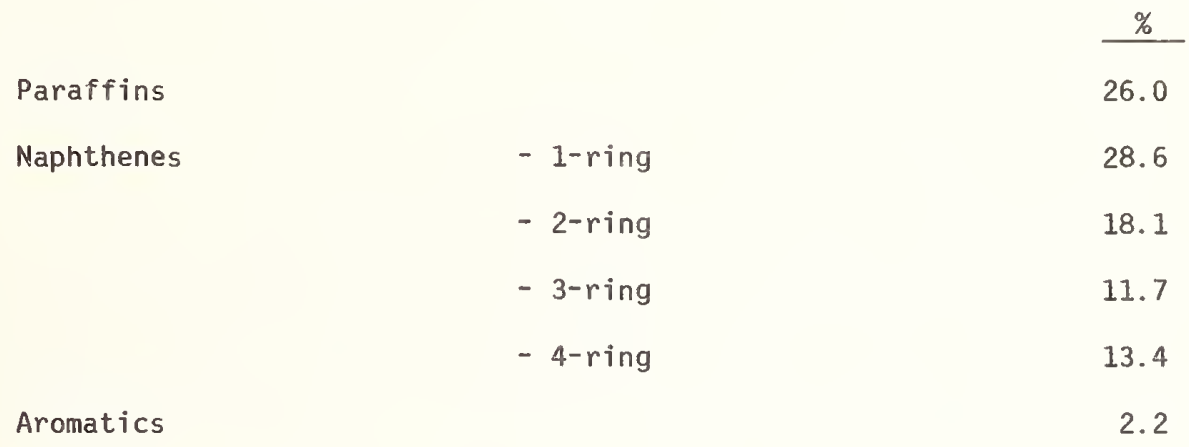

3.2.6. Simulated Boiling Point Distribution of the Aromatic and Saturate Fractions

The boiling point distillation values (ASTM D2887, modified) of the saturate and aromatic fractions are listed in table 5, and are compared to the boiling point distillation of oil RC itself.

The initial boiling point of the aromatic fraction is much lower than that of the saturate, indicating good agreement with the Gel Permeation Chromatographic (GPC) profile which showed the lower molecular weight compounds to be in the aromatic fraction.
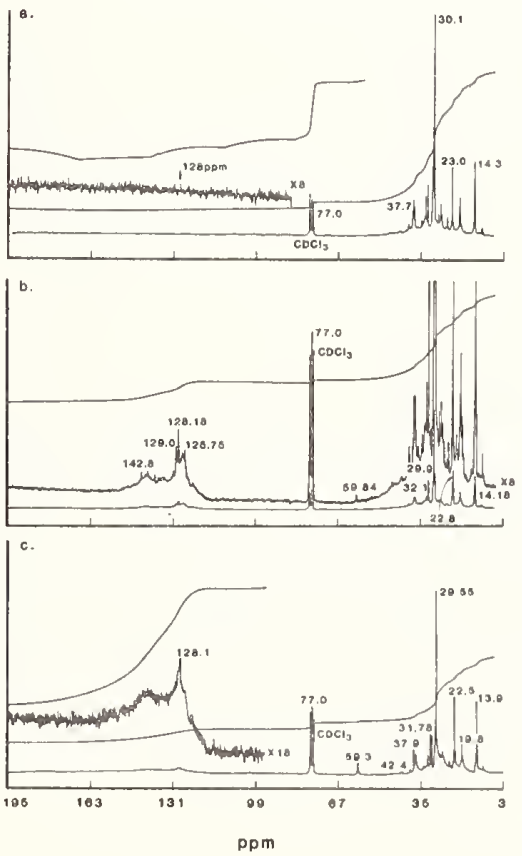

Figure 3. C 13 NMR of the Re-refined Base $0 i 1$ RC Fractions: a) Saturates b) Aromatics c) Polars 


\subsection{Chemical Characterization of the Polar Subfractions}

Three major polar compound classes resulted from the polar fraction separation of sample RC. They are the compound classes eluted from the neutral alumina column by: (1) toluene; (2) methylene chloride with 0.75 percent ethanol; and (3) a combined elution of tetrahydrofuran with 10 percent ethanol, and methanol. These three compound-classes (or subfractions) are lableled: (1) polynuclear aromatic (PNA) compounds; (2) nitrogen containing compounds; and (3) oxygenated compounds.

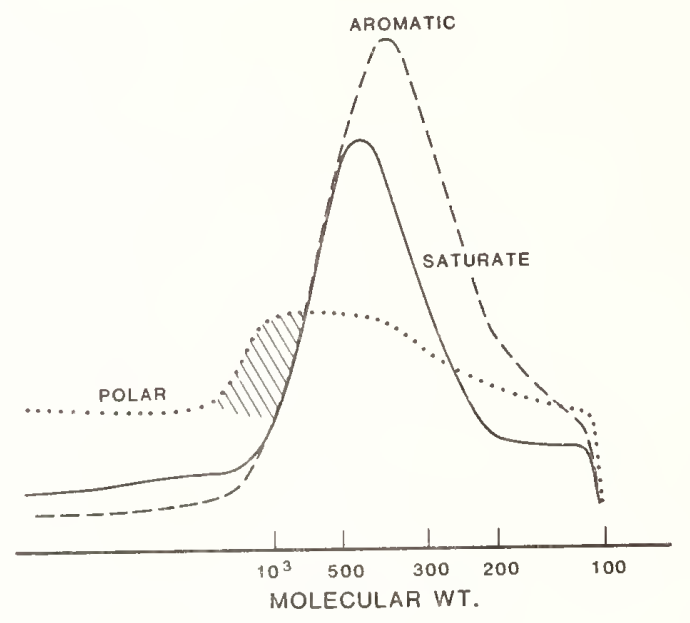

Figure 4. GPC of the Re-refined Base $0 i 1$ RC Fractions

Table 5. Boiling point distillation (D2887) of oil RC vs. its fractions $\left({ }^{\circ} \mathrm{C}\right.$ )

\begin{tabular}{|c|c|c|c|}
\hline & & \multicolumn{2}{|c|}{ RC Fractions } \\
\hline & 0i1 RC & Saturates & Aromatics \\
\hline Initial Boiling Point & 307 & 313.2 & 278.5 \\
\hline $10 \%$ & 383 & 383.7 & 375.1 \\
\hline $50 \%$ & 455 & 454.8 & 457 \\
\hline $90 \%$ & 537 & 541.1 & 546.2 \\
\hline
\end{tabular}

The normalized weight percent recovery for these three compound classes are listed in tabie 6. Sample RC has approximately the same weight fraction in the polynuclear aromatic and nitrogen subfractions ( $\sim 40$ percent each) but less in the oxygenated subfraction ( 20 percent). The elemental analyses for oxygen and nitrogen in each compound class are listed in table 7 . The amount of oxygen present in the oxygenated compound class is as high as twenty-five percent, about twelve times higher than the oxygen content in any of the other two compound classes. However, the nitrogen content is lower in the nitrogen-compound class than in PNA compound class, indicating possibly more polynuclear aromatic compounds containing nitrogen than other nitrogen compound types.

Table 6. Normalized weight percentage of polar subfractions from RC polar fraction

wt. \%

Polynuclear Aromatic Subfraction

Nitrogen Containing Compound Subfraction

Oxygenated Compound Subfraction 
Table 7. Elemental analyses of the polar subfractions for oil RC

$\begin{array}{lcc}\text { Compound Subfraction } & \text { Oxygen (\%) } & \text { Nitrogen } \\ \text { Polynuclear Aromatic } & 2.19 & 0.11 \\ \text { Nitrogen Compounds } & 3.61 & 0.070 \\ \text { Oxygen Compounds } & 25.43 & 0.033\end{array}$

3.3.1. Infrared and High Resolution Mass Spectrometry

IR spectra of the RC polar compound classes are shown in figure 5 . The $\mathrm{OH} / \mathrm{NH}$ band at 3400 $\mathrm{cm}^{-1}$ appears in the nitrogen and oxygenated compound classes (fig. $5 \mathrm{~b}$ and $5 \mathrm{c}$ ) but the $\mathrm{c}=0$ band $\left(1700 \mathrm{~cm}^{-1}\right)$ is clearly the strongest in the PNA class (fig. 5a), and relatively weak in the other two compound classes. But by elemental analysis, the oxygen content is the highest in the oxygenated compounds class. This indicates clearly that two types of oxygen compounds are present in polar fraction of oil RC. In the PNA and nitrogen compound subfractions, the oxygenated compounds are possibly esters. The oxygenated compounds in the oxygen compound class appear to be phenols, since the $\mathrm{OH}$-band at $3200 \mathrm{~cm}^{-1}$ (fig. $5 \mathrm{c}$ ) is not broad.

By high resolution mass spectrometry (HRMS), the presence of alkylated phenols in the oxygenated compound class is verified. Table 8 lists the chemical compound structure type detected by HRMS in each of the polar subfractions. Possible structures in the polynuclear aromatics subfraction include esters and amides. In the nitrogen compound subfraction, amines and amides may be present in addition to esters. However, in the oxygenated compound subfraction, alkylated phenols appear to be dominent.

\section{3,3.2. Molecular Weight Profiles of the Polar Subfractions}

Gel permeation chromatography profiles on the polar subfractions are shown in figure 6 . Both the polynuclear aromatic and nitrogen containing compound subfractions have a similar molecular weight distribution--in the 400 to 5000 molecular weight unit range. For the oxygenated compound subfraction, there are two distinct molecular weight peaks: one at 120 to 3000 units, and the other at less than 120 molecular weight units. The GPC results for the oxygenated compound subfraction indicate two major types of compounds are present in the subfraction. Further characterization of this subfraction is needed.

Table 8. Possible chemical functional structures in the RC polar subfractions as determined by high resolution mass spectrometry

\section{Compound Classes Subfraction}

Polynuclear Aromatics

Polynclear Aromatics

thes

Nitrogen Compound Class

Possible Frunctional Groups

Presence of

Ester

Phthalates

Amides

Esters

Amides

Amines

Oxygen Compound Class
Alkylated Phenols 


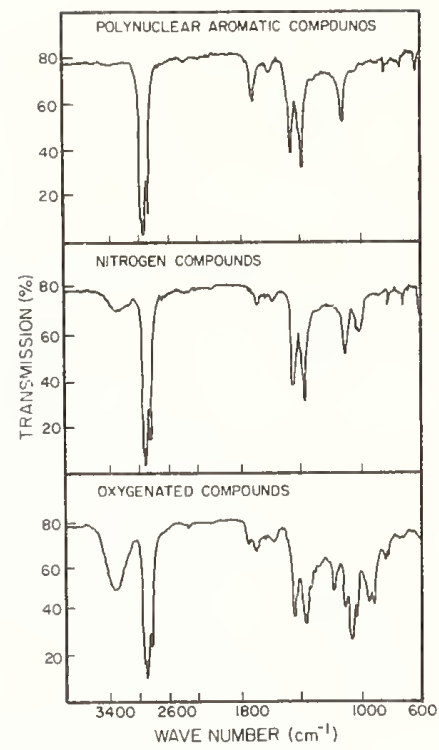

Figure 5. IR Spectra of the Polar Subfractions of the Re-refined Base 0il RC.

GPC OF THE POLAR SUBFRACTION OF THE RE-REFINED BASE OIL

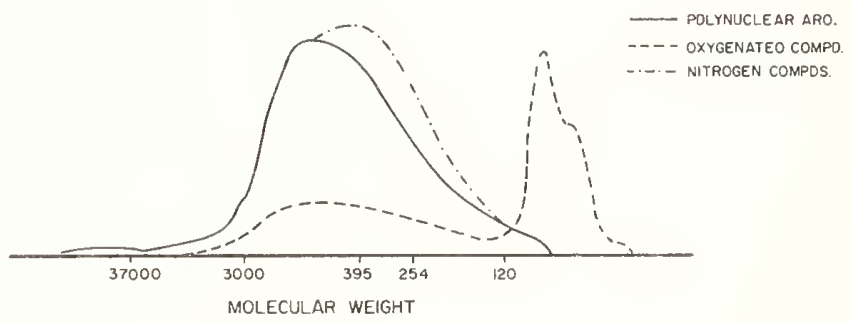

Figure 6. GPC of the Polar Subfractions of the Re-refined Base 0 il RC.

\subsection{Performance Testing of the Fractions}

Performance testing of the oil RC and its fractions was made to gain insight regarding the effects of the compounds present in each fraction on oil performance. The performance tests studied here are anti-oxidant titration [7], differential scanning calorimetry [8-11], and four-bal] wear tests [14]. 


\subsubsection{Anti-oxidant Titration}

The anti-oxidant titration method used was developed by Mahoney and Korcek [7]. This method determines the total effective concentration of free radical chain-stopping species present in a lubricating base oil. A virgin base oil's antioxidant capacity range is 1 to $10 \times 10^{-6}$ mole/g: for re-refined base oil, the range is 5 to $13.2 \times 10^{-6} \mathrm{~mole} / \mathrm{g}[4,8]$. The anti-oxident values for the fractions and polar subfractions of oil RC are 1isted in table 9. The unseparated re-refined oil has an anti-oxidant capacity of $8.3 \times 10^{-6} \mathrm{~mole} / \mathrm{g}$. The polar fraction has a value of $305 \times 10^{-6} \mathrm{~mole} / \mathrm{g}$. Thus, most of the chain-stopping (antioxidant) species are concentrated in the polars.

Table 9. Anti-oxidant titration values of the RC fractions

$$
\left(10^{-6} \mathrm{~mole} / \mathrm{g}\right)
$$

\begin{tabular}{|c|c|c|}
\hline Whole $0 i 1$ & & 8.3 \\
\hline Saturated & & 2 \\
\hline Aromatic & & 24 \\
\hline Polar & & 305 \\
\hline & $P N A^{a}$ & 140 \\
\hline Polar Subfractions & Nitrogen & 350 \\
\hline & Oxygen & 250 \\
\hline
\end{tabular}

$\overline{a_{\text {Polynuclear }}}$ Aromatic (PNA)

Among the polar subfractions, the nitrogen-containing compound subfraction has the highest antioxidant capacity value, at $350 \times 10^{-6} \mathrm{~mole} / \mathrm{g}$.

\subsubsection{Differential Scanning Calorimetry}

Thermal analysis is a method for the characterization of complex organic systems such as lubricating base oils $[9,10]$. Noel and Cranton were the first to use differential scanning calorimetry to measure the oxidation stability of the saturate and aromatic fractions of a lubricating base oil [11]. They reported that saturates are much less stable than the aromatic fractions. Walker and Tsang performed a similar study on all three fractions: saturates, aromatics and polars [12]. They also studied the interactions of each fraction with an additive package (which included an anti-oxidant additive) to illustrate possible interactions between them, reporting oxidation onset temperatures of each fraction with and without the additive package.

Oxidation onset temperatures are the temperatures at which oxidation occurs during a scanning temperature programmed experiment on DSC. Table 101 ists the onset temperatures and figures 7-9 show the DSC curves of the RC fractions with and without the additive package.

Table 10. DSC Onset temperature of the fractions of oil RC with and without $7 \%$ SE/CC additive package (by weight)

\section{Without Additive With Additive}

$\begin{array}{llr}\text { Saturate } & 202{ }^{\circ} \mathrm{C} & 245^{\circ} \mathrm{C} \\ \text { Aromatic } & 283^{\circ} \mathrm{C} & 294^{\circ} \mathrm{C} \\ \text { Polar } & 265^{\circ} \mathrm{C} & 265^{\circ} \mathrm{C}\end{array}$


The onset temperature of the saturate fraction without the additive package is $202{ }^{\circ} \mathrm{C}$, which is equivalent to the onset temperature of a mineral oil (204 ${ }^{\circ} \mathrm{C}$ ). However, with the presence of 7 percent SE/CC additive package (by weight), the onset temperature is raised to $245^{\circ} \mathrm{C}$, suggesting improved oxidation stability. This illustrates how effective an additive package can be to increase the oxidative stability of a petroleum lubricating oil.

However, the aromatics fraction is much more stable than the saturates, and its onset temperature is $283^{\circ} \mathrm{C}$ without the additive package. With the same additive package ( 7 percent by weight), the onset temperature is raised to $294{ }^{\circ} \mathrm{C}$ for the aromatics. This indicates the relative effectiveness of the additive package is less for the aromatic fraction as it only raises the onset temperature by $10^{\circ} \mathrm{C}$ instead by $43^{\circ} \mathrm{C}$, as in the case of the saturates.

The onset temperature of the polar fraction is $265{ }^{\circ} \mathrm{C}$ without the additive package, but the onset temperature remains the same when the additive package is added. However, in this case, the decomposition of the additive package is not observed. This may indicate that the polar fraction(s) have reacted with components of the additive package rendering it ineffective.

Another DSC experiment was performed to illustrate the interaction between the polar compounds and the additive components. Polars were added in various weight percentages--zero, one and five percent--to samples of the saturate fraction containing 0.5 percent of the anti-oxidant zinc dialkyl dithiophosphate (ZDDP). The oxidation induction time was then measured by isothermal DSC, the induction time being the period required for oxidation to occur at a certain temperature. Table 11 lists the induction times of the three samples, along with their composition. When the polar componerits are absent in a sample, the induction time is 17.5 minutes. With the polars present at one percent and five percent, the induction time decreases to 10.3 minutes and 6.5 minutes, respectively.

If the polars possess any anti-oxidative property, the induction time should increase as the concentration of the polar fraction increases. To the contrary, the induction time decreases. Therefore, it is very likely that the polar fraction reduced the effectiveness of the anti-oxidant ZDDP by reacting with it. These results are in agreement with a similar study reported by Hsu, et. a1. [13].

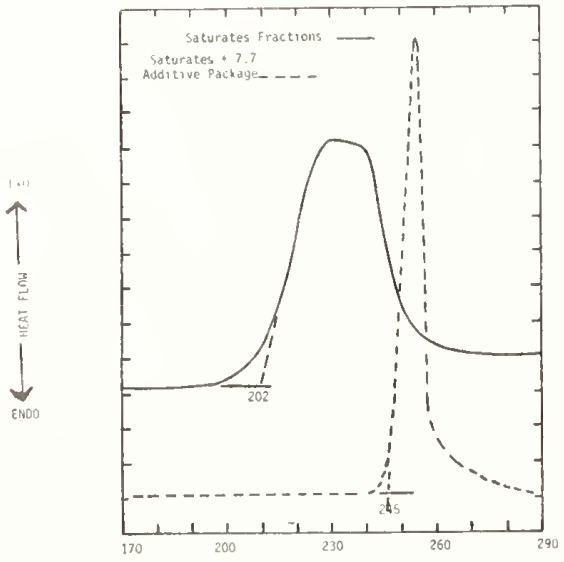

TEMPERATURE OC

Figure 7. Differential Scanning Calorimetric Thermogram of the Saturate Fraction of the Rerefined Base 0 il RC With and Without Additive Package. (Reproduced from Reference 12). 


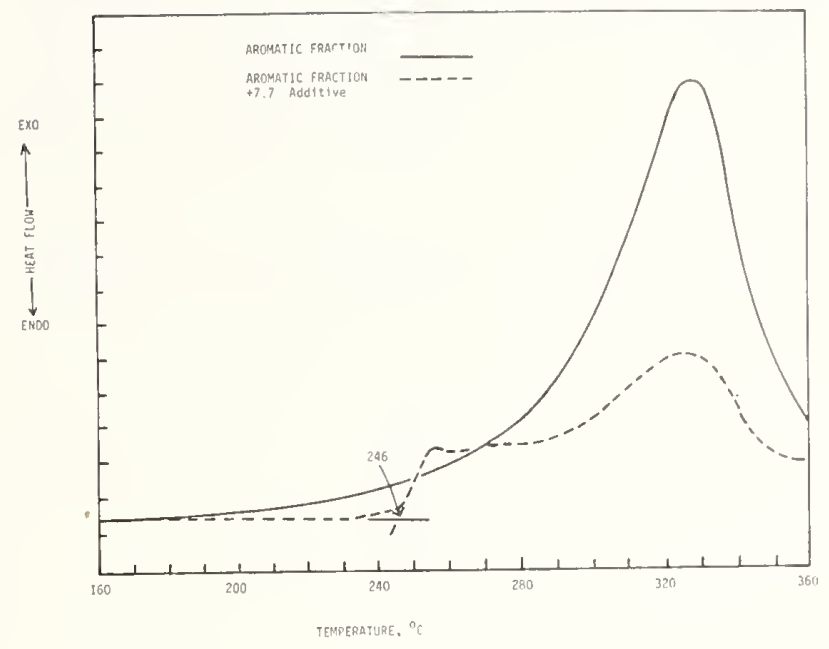

Figure 8. The Differential Scanning Calorimetric Thermogram of the Aromatic Fraction of the Re-refined Base $0 i 1$ RC With and Without Additive Package. (Reproduced from Reference 12).

Table 11. Oxidation stabilities of fractions measured by differential scanning calorimetry

Base $0 i 1$ RC

Saturate Fraction $+0.5 \%$ ZDDP

Saturate Fraction $+0.5 \%$ 2DDP $+1.0 \%$ Polars

Saturate Fraction $+0.5 \%$ ZDDP $+5.0 \%$ Polars
DSC Oxidation

Induction Time, min

17.5

10.3

6.5

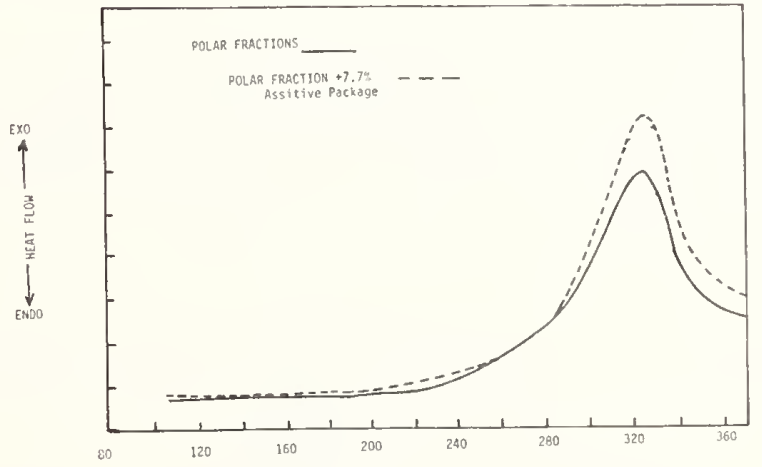

TEMPERATURE. ${ }^{\circ} \mathrm{C}$

Figure 9. The Differential Scanning Calorimetric Thermogram of the Polar Fraction of the Re-refined Base $0 i 1$ RC With and Withoug Additive Package (Reproduced from Reference 12). 


\subsubsection{Four-Ball Wear Test}

Gates and Hsu developed several four-ball wear test procedures to evaluate lubricating base oils [14]. One of the four-ball wear test procedures is the micro-sample step-loading seizure (SLST) test, which evaluates the load-carrying capability of a lubricant. The load is increased in increments during a run conducted under constant speed. When seizure occurs, the load capacity of the lubricant has been exceeded, and an accelerated wear condition exists. The micro-sample SLST test has been applied to both the fractions and subfractions of oil RC. Table 12 lists the seizure loads for each fraction.

Table 12. Micro sample step loading seizure test results on the fractions and polar subfractions of RC re-refined

Base $0 i 1$

\section{Fractions}

Saturates

Aromatics

Polar

Polynuclear

Aromatic subfraction

Nitrogen Subfraction

Oxygenated Subfraction
Seizure Load, $\mathrm{kg}$

105

210

210

120

165

The polar and aromatic fractions have th highest seizure loads, while the saturates has the lowest. Among the polar subfractions, polynuclear aromatic compounds demonstrate a high seizure load value, while the other nitrogen and oxygen compound classes have seizure loads as low as the saturate fraction. By these data, it appears reasonable to conclude that aromatic and polynuclear aromatic compounds isolated from this re-refined base oil posses anti-wear characteristics.

\section{Conclusion}

A liquid chromatographic separation scheme has been developed to characterize petroleum lubricating base oil in terms of its constituent molecular compound classes. The separation scheme consists of two-stages: The base oil is first separated into saturate, aromatic, and polar fractions; the polar fraction is then separated into polynuclear aromatic, nitrogen containing, and oxygen containing compound classes. These isolated constituents can then be tested in various performance tests.

The separation scheme developed in this study provides insight into the molecular structural effects of the base oil constituents on oxidation stability and wear characteristics. For re-refined base oil, the separation method provides a unique methodology to isolate and identify potential contaminants/impurities that may remain after the re-refining process. Thus, the method is a powerful diagnostic tool for process research.

The author wishes to thank Mr. Richard Gates, Dr. W. Tsang, Mr. Janes Walker, and Dr. Y.C. Wu of NBS for their contributions to the performance testing of the separated fractions.

\section{References}

[1] Manual on Hydrocarbon Analyses, 3rd Edition, sponsored by ASTM Committe D-2 on Petroleum Products and Lubricants, ASTM (03-332030-12), Philadelphia, PA (1977).

[2] Ku, C. S.; Pei, P.; Hsu, S. M. Evaluation of ASTM D2007 method for determination of lube base oil composition. Proceedings, Measurements and Standards for Recycled 0il-IV; Nat. Bur. Stand. (U.S.) Spec Publ. 674; 1983. 
[3] ASTM Standards, D2007, Characteristic Groups in Rubber Extender and Processing 0ils by C1ayGe] Adsorption Chromatographic Method, Part 24, 169 (1981).

[4] Hsu, S. M.; Ku, C. S.; Becker, D. A. Re-refined base oil characterization and consistency monitoring: SAE Reprint \#821240 from "Base $0 i 1$ for Automotive Lubricants." SP526, Toronto, Ontario, Canada (0ct. 1982).

[5] Certain commercial equipment, instruments, or materials are identified in this paper in order to adequately specify the experimental procedure. Such identification does not imply recommendation or endorsement by the National Bureau of Standards nor does it imply that the materials or equipment identified are necessarily the best available for the purpose.

[6] Pei, P.; Britton, Jr., J.; Hsu, S. M. Hydrocarbon type separation of lubricating base oil in multigram quantity by preparative HPLC. J. Liquid Chromatography 6(4): 627-645; 1983.

[7] Mahoney, L. E.; Korcek, S.; Hoffman, S.; Willermet, P. The determination of the anitoxidant capacity of new and used lubricants* method and applications Ind. Eng. Chem. Product Research and Development 17: 250; 1978.

[8] Rebbert, R. Application of the anti-oxident capacity test to re-refined and virgin stock base oils, Nat. Bur. Stand. (U.S.) Spec. Pub1. 584; 1979 October 237 p.

[9] Walker, J.; Tsang, W. Characterization of lubricating oils by differential scanning calorimetry SAE Reprint 落801383; Fuels \& Lubricants; Oct. 20-23, 1980; Baltimore, MD.

[10] Walker, J.; Tsang W. Application of differential scanning calorimetry to the characterization of lube oils, Nat. Bur. Stand. (U.S.), Spec. Publ. 584; 1979 October 271 p.

[11] Noel, F; Cranton, G. G. Analytical Calorimetry, Vol. 3. R. S. Porter and J. F. Johnson, ed. New York: Plenum Publishing Company; 1974. 305.

[12] Walker, J.; Tsang, W. Comparative response of re-refined and virgin lube oils to additives by DSC. Proceedings, Measurements and Standards for Recycled 0il-IV; Nat. Bur. Stand. (U.S.) Spec. Pub1. 674; 1983.

[13] Hsu, S. M.; Ku, S. C.; Lin, R. S. Relationship between lubricating basestock composition and the effects of additive on oxidation stability; SAE Paper \#821237 from Base $0 i 1$ for Automotive Lubricants, SP 526, Toronto, Ontario, Canada (Oct. 1982).

[14] Gates, R. S.; Hsu, S. M. Development of a four-ball wear test procedure to evaluate automotive lubricating oils, Reprint \#82-AM-6A-4, 37th ASLE Annual Meeting, Cincinnati, Ohio (May $10-13,1982$ ). 
National Bureau of Standards Special Publication 674. Proceedings, Conference on Measurements and Standards for Recycled 0i1 - IV, held at NBS, Gaithersburg, MD, September 14-16, 1982. (Issued July 1984).

\title{
EVALUATION OF ASTM D2007 METHOD FOR THE DETERMINATION OF LUBRICATING OIL COMPOSITION
}

\author{
C. S. Ku, P. Pei, and S. M. Hsu
}

\author{
Chemical Stability and Tribology Group \\ Inorganic Materials Division \\ National Bureau of Standards \\ Washington, DC 20234
}

\begin{abstract}
ASTM D2007, "Characteristic Groups in Rubber Extender and Processing 0ils by the Clay-Gel Adsorption Chromatographic Method," and its variations are evaluated for lubricating base oils, both virgin and re-refined. The results are compared with the $\mathrm{n}$-d-M method (refractive index, density, and molecular weight) and low resolution mass spectroscopy. ASTM 02007 is found to be acceptable for use with lubricating base oils, offering a rapid analytical procedure for classifying both virgin and re-refined base oils of various viscosity grades. Hydrocarbon types such as polar compounds, aromatics, and saturates are separated and characterized.
\end{abstract}

\section{Introduction}

Lubricating base oils are derived from petroleum fractions (C14 to C40) having an average molecular weight between 300 and $500[1]^{1}$. There are numerous theoretically possible molecular structural arrangements for hydrocarbon molecules with eighteen or more carbon atoms. Therefore, it is difficult to characterize molecular components in a complex mixture like a lubricating base oil. After twenty years of extensive research under American Petroleum Institute (API) Project 6 , it was concluded that the preparation and identification of even a uniform fraction (a fraction containing exclusively molecules of the same size and hydrocarbon type) is time-consuming and difficult [2].

The Energy Policy and Conservation Act of 1976 (Public Law 94-163, Section 383) requires the National Bureau of Standards to develop test procedures for the determination of the substantial equivalency of re-refined or otherwise processed used oils with new oils. One of the concerns with a re-refined base $0 i l$ is the presence of contaminants. Some of the contaminants can be harmful to engines, and may cause environmental hazards. They include contaminants such as sulfur from sulfurized cutting oils, polychlorinated biphenyls (PCBs) from electrical transformer oils, oxidized products from the previous use of the lubricating oils, and possibly other additives remaining after the re-refining process. In order to study such contaminants, it is necessary to isolate and identify them. Previous work [3] suggested that most of the contaminants were polar in nature and could be separated as a polar fraction.

One method for studying complex mixtures (like base oils) is by Hydrocarbon-Type Analysis, by clay gel chromatography, ASTM D2007, which yields an estimate of the various molecular structural groupings present in a mixture. The three basic types of structural molecules present in a petroleum oil are: 1) paraffins (normal or branched straight-chain hydrocarbons and cycloparaffins), 2) aromatics (one or multiple aromatic ring compounds), and 3) polar compounds (containing sulfur, oxygen, nitrogen, and/or halogens). Such an analysis provides compositional information for correlation with performance attributes such as oxidation stability and lubricity. The hydrocarbontype analysis can also indicate the extent of the severity of the refining process, thus serving as a quality control indicator.

\section{Methods Examined}

Under API Project 6, a variety of chromatographic methods were developed to separate petroleum fractions into hydrocarbon-type compounds [4]. One of the chromatographic methods investigated was adsorption chromatography, using solid adsorbents and a gradient solvent elution scheme. This method was extended and used to separate petroleum fractions into basic hydrocarbon-type fractions according to polarity [1]. However, this method has not been applied to lubricating base oils.

TFigures in brackets indicate the literature references at the end of this paper. 
ASTM Method 02007 was developed for the hydrocarbon-type analysis of rubber-extender and processing oils. The method uses a dual column (silica gel and clay adsorbents) to separate oils into three fractions: 1) saturated compounds, which do not adsorb on either the silica gel or clay column; 2) aromatic compounds, which adsorb on the silica gel column; and 3) polar compounds, which adsorb on a clay column of specified activity.

There are other ASTM methods which may be related and are currently being used. They include ASTM D1319, "Hydrocarbon Types in Liquid Petroleum Products by Fluorescent Indicator Adsorption" [5]; and ASTM D2549, "Separation of Representative Aromatics and Non-aromatics Fractions of High Boiling 0 ils by Elution Chromatography" [5]. The fluorescent indicator adsorption method (ASTM D1319) is applicable only to low-boiling petroleum products such as fuels and gasolines [7]. For high-boiling petroleum fractions, the aromatic dye used to mark the aromatics zone on the silica gel column is more strongly adsorbed on silica gel than the highly alkylated monoaromatics found in base oils. The method is limited to fuels, and therefore was not investigated further. The elution chromatographic method (ASTM D2549)[5], is designed to separate high-boiling oils into two major hydrocarbon types: aromatics and non-aromatics. Because of the limited scope of the separation, this method was not evaluated further.

In addition to these methods, Sautoni reported in 1970 an HPLC method for hydrocarbon-type analyses $[8,9]$. The method is rapid for molecular-type analysis, and can determine saturates and aromatics fractions quantitatively. The concentration of the polar compounds is determined by mass difference. Because they are strongly adsorbed onto the silica column and are thus not eluted, no polar compounds can be recovered by this method.

Hence, of the chromatographic methods surveyed, the clay/gel method--ASTM D2007--appeared to be the most promising one for detailed experimental investigations of its suitability for hydrocarbontype analysis of lubricating base oils as well as for isolation and recovery of polar impurities.

\section{Experimental}

The ASTM D2007 method [10] and a modification [11] were examined for their ability to separate different base lubricating oils into three hydrocarbon-type fractions: saturates, polars, and aromatics.

\subsection{0 i T Samples}

Seventeen base oils, used commercially in the manufacturing of formulated lubricating oils, were utilized in this study. Ten of the oils were re-refined base oils, and the other seven were virgin base oils. An extensive listing of their physical and chemical properties is given in references $[12,13]$. The re-refined base oils were selected to represent most of the different re-refining technologies available in the U.S. at that time, and the virgin base oils were selected based on the viscosities and crude sources as shown in table 1.

\subsection{Chromatographic Procedure}

ASTM D2007, as outlined in reference [10], was used. The reference should be consulted for specific procedures and chemicals. Briefly stated, the sample is diluted with n-pentane and charged to a glass percolation column containing clay in the upper section and silica gel ( $p l u s$ clay) in the lower section. The n-pentane containing the sample is then charged to the double column until a definite quantity of effluent has been collected. The upper (clay) section is removed from the lower section and washed further with n-pentane which is discarded. A toluene-acetone mixture 1:1 by volume is then charged to the clay section and a specified volume of effluent collected. The solvents are completely removed from the recovered pentane and toluene-acetone fractions and the residues are weighed and calculated as saturate and polar compounds contents. Aromatics are calculated by difference. When the sample contains more than one weight percent of $n$-pentane insolubles, the insoluble matter must be removed from the sample prior to charging to the column.

The modified 02007 procedure [11], differs in one important way from 02007 : instead of determining the aromatics fraction by mass difference after weighing the saturates and polars fractions, it is measured experimentally. The silica gel column, to which the aromatics fraction is bound, is extracted with $100 \mathrm{ml}$ of hot toluene. After the solvent is evaporated, the material remaining is weighed as the amount of the aromatic fraction. 
Table 1. Crude source and processing technologies of the seventeen base oil set

${\underline{0 i 1 I^{a}}}^{a}$

VA

VB

VC

VD

VE

VF

VG

RA

RB

$\mathrm{RC}$

RD

RE

RF

RG

RH

RI

RJ

\section{Viscosity Grade}

$150 \mathrm{~N}$

$600 \mathrm{~N}$

$50: 50$

$150 \mathrm{~N} / 600 \mathrm{~N}$

$210 \mathrm{~N}$

$270 \mathrm{~N}$

$210 N$

$110 \mathrm{~N}$

$200 N$

$250 \mathrm{~N}$

$350 \mathrm{~N}$

$300 \mathrm{~N}$

$400 \mathrm{~N}$

$350 N$

$300 \mathrm{~N}$

$250 N$

$350 \mathrm{~N}$

$200 \mathrm{~N}$
Processing Technology

Solvent extraction

Solvent extraction

Solvent extraction

Solvent extraction

Solvent extraction

Solvent extraction

Solvent extraction

Pretreat/Vac. dist./

Clay finish

Clay treat

Acid/Clay

Acid/Clay

Caustic Pretreat/

Vac. dist.

Acid/Clay

Acid/Clay

Acid/Clay

Acid/Clay

Acid/Clay
Crude Source Geographical Area

Mid-East

Mid-East

Canada

Mid-continent

Mid-East

Mid-continent

Mid-continent

Mid-West (US)

Southwest

Southeast

West Coast

Northeast

South

Northwest

Canada

West Coast

Northeast

$\overline{\mathrm{R}=\text { re-refined oils }}$

$a_{v}=$ virgin oils

4. Results and Discussion

In a chromatographic separation method evaluation, the important aspects to be considered are the validity of the method, as well as the recovery, precision, and the cleanness of the separations. The validity of the method can be shown by comparing the results to another independent analytical method, such as low resolution mass spectrometry [14].

\subsection{Validity of ASTM D2007}

Low resolution mass spectrometry [14] is a method of determining aromatics and saturates in gas oil samples, and can be used for hydrocarbon-type analyses of various petroleum fractions. However, in the mass spectrographic method, the weight percentage of polar compounds is not determined.

Table 2 gives a comparison of the hydrocarbon-type analysis data from the ASTM D2007 method with the low-resolution, mass spectroscopic method. The agreement between two sets of data indicates that 
the modified D2007 method is consistent with the mass spectroscopy method. There appears to be no significant difference in the results between the two methods for the levels of saturates, aromatics, and polars commonly found in lubricating base oils.

Table 2. Hydrocarbon type determination by clay gel method (ASTM D2007) and mass spectrometric method

RK
Sat
Aro
Polar

$\mathrm{RL}$

Sat
Aro
Polar

RM

Sat

Aro

Polar

RN

Sat

Aro

Polar

vo

Sat

Aro

Polar

VP

\section{ASTM D2007}

73.9
23.5
2.6

77.6

20.0

2.4

75.3

22.5

2.2

77.6

20.7

1.7

85.9

12.8

1. 3

79.9

18.5

1.6
MS

74.3

25.7

(NA)

79.6

20.4

(NA)

79.0

21.0

(NA)

79.1

20.9

(NA)

86.6

13.4

(NA)

82.8

17.2

(NA)

\subsection{Recovery of Base 0ils}

Since one of the objectives of the separation is to monitor the amount of potential polar contaminants, complete recovery of the adsorbed materials is desired. The recovery of the base oils is shown in table 3, where the percent recovery for each base oil is given. The overall recovery from the modified D2007 method--where the aromatics fraction is determined directly--is excellent, averaging more than 99 percent.

For a comparison of recovery between the virgin and the re-refined base oils, there is no apparent difference in the recovery levels. The average loss (loss $=100$ - recovery) for the re-refined base oils, taken as a group, is 0.6 to 0.8 percent, and the average loss for the virgin base $0 i 1 \mathrm{~s}$, taken as a group, is 0.2 to 0.7 percent.

A comparison between the 02007 method--where the aromatics fraction is determined by difference-and the modified D2007 method--where the aromatics fraction is measured directly--is shown in table 4. The data are averages of two and three separate determinations. The agreement between the two methods on aromatics determinations is excellent with the D2007 method generally has higher aromatic values than the direct determination. The difference may be attributed to the materials irreversibly adsorbed on the column. Therefore, it appears to be valid to use mass balance as an alternate to calculate the aromatic fraction as used in the 02007 method. 
Table 3. Sample recovery for base oils modified ASTM D2007 method (D2007M)

\begin{tabular}{c} 
Sample \\
\hline RM \\
RN \\
RO \\
$R P$ \\
$R Q$ \\
$R R$ \\
$R R$ \\
$R S$ \\
$R T$ \\
VJ \\
VK \\
VL \\
VZ \\
VM \\
VN \\
VO \\
VP \\
RK \\
RL \\
VH
\end{tabular}

\begin{tabular}{rrr}
\multicolumn{3}{c}{ Recovery, \% } \\
\hline 99.4 & 98.8 & \\
99.6 & 98.5 & \\
97.6 & 99.5 & \\
99.4 & 100.1 & \\
99.4 & 99.3 & \\
99.5 & 98.6 & \\
98.9 & 99.7 & \\
99.7 & 99.5 & \\
99.7 & 99.2 & \\
99.2 & 99.2 & \\
99.6 & 99.8 & \\
99.2 & 98.1 & \\
99.8 & 99.8 & \\
99.9 & 99.9 & \\
100.7 & 100.1 & \\
101.1 & 100.6 & \\
99.4 & 99.3 & 98.4 \\
99.9 & 98.6 & 99.3 \\
99.3 & 99.7 & 99.5
\end{tabular}

Table 4. Hydrocarbon-type composition for base lubricating oils by two methods

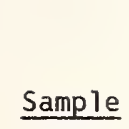

RK

$R L$

RM

RN

RO

$\mathrm{RP}$

$\mathrm{RQ}$

RR

RS

RT

VJ

VK

VL

VH

$V Z$

VM

VN

VO
VP
ASTM D2007

\begin{tabular}{ll} 
ASTM D2007 & \\
\hline Saturates & $\underline{\text { Polars }} \quad \underline{\text { romatics }}$
\end{tabular}

73.9

77.6

75.3

77.6

75.9

77.5

75.3

76.9

72.5

78.0

80.5

80.7

73.4

71.5

62.9

83.4

85.2

85.9

79.9
2. 6

2.4

2.2

1.7

1. 7

1. 4

2.2

2.2

3. 4

1. 8

0.6

0.3

0.3

0.4

1. 7

0.4

0.3

1.3

1.6
23.5

20.0

22.5

20.7

22.4

21.1

22.6

20.9

24.1

20.2

18.9

19.0

26.3

28. 1

35.4

16.2

14.5

12.8

18.5
Modified

ASTM D2007

Aromatics

22.5

19.3

21.7

19.9

21.1

20.8

22.0

20.0

22.9

19.9

18. 3

18.2

26.0

27.6

34.2

16.0

14.3

13.3

19.4

${ }^{a}$ Value by difference: $100-$ (Saturates) - (Polars) 


\subsection{Precision}

The repeatabilities for both methods for each of the nineteen oils have been determined. According to the ASTM D2007 procedure [10], the following repeatabilities are anticipated (95 percent confidence) when the method is used for rubber extender oils:
Saturates
0.8 percent;
Polars
0.7 times the square root of the percentage polars;
Aromatics
0.2 times the square root of the percentage aromatics.

For petroleum lubricating base oils, we find that the average repeatabilities for the fractions, expressed in the same terms, as shown in table 5 are:
Saturates
0.5 percent;
Polars
0.1 times the square root of the percentage polars;
Aromatics
0.1 times the square root of the percentage aromatics;
0.2 times the square root of the percentage aromatics (D2007M).

The above precision statements for lubricating base oils are well within the stated precision of ASTM D2007.

Table 5. D2007 and D2007 modified test method precision

$$
\text { Repeatability }
$$

\begin{tabular}{|c|c|c|c|c|}
\hline \multirow[b]{2}{*}{ Sample } & \multicolumn{3}{|c|}{ ASTM D2007 } & \multirow{2}{*}{$\begin{array}{c}\text { Modified } \\
\text { ASTM D2007 } \\
\text { Aromatics }\end{array}$} \\
\hline & Saturates $^{a}$ & Polar ${ }^{b}$ & Aromatics $^{b}$ & \\
\hline RK & 0.5 & 0.15 & 0.7 & 0.16 \\
\hline$R L$ & 0.75 & 0.16 & 0.17 & 0.25 \\
\hline RM & 0.0 & 0.07 & 0.02 & 0.11 \\
\hline $\mathrm{RN}$ & 1.0 & 0.08 & 0.20 & 0.02 \\
\hline RO & 1.1 & 0.08 & 0.21 & 0.65 \\
\hline RP & 0.6 & 0.27 & 0.07 & 0.09 \\
\hline $\mathrm{RQ}$ & 0.1 & 0.00 & 0.00 & 0.02 \\
\hline $\mathrm{RR}$ & 0.0 & 0.14 & 0.04 & 0.25 \\
\hline RS & 0.0 & 0.00 & 0.00 & 0.42 \\
\hline RT & 0.25 & 0.20 & 0.11 & 0.18 \\
\hline VJ & 0.5 & 0.00 & 0.11 & 0.24 \\
\hline VK & 0.4 & 0.00 & 0.09 & 0.09 \\
\hline VL & 0.8 & 0.00 & 0.16 & 0.12 \\
\hline VH & 0.4 & 0.00 & 0.08 & 0.00 \\
\hline$V Z$ & 0.7 & 0.08 & 0.10 & 0.30 \\
\hline VM & 0.5 & 0.00 & 0.13 & 0.13 \\
\hline VN & 0.1 & 0.00 & 0.03 & 0.00 \\
\hline Vo & 0.1 & 0.00 & 0.03 & 0.14 \\
\hline VP & 0.4 & 0.00 & 0.09 & 0.02 \\
\hline & $0.45 \%$ & $0.08 \%$ & $0.1 \%$ & $0.17 \%$ \\
\hline
\end{tabular}

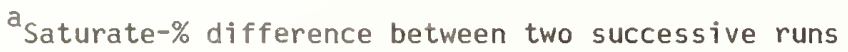




\subsection{Characterization of the Separated Fractions}

The separated fractions from the modified 02007 method were further characterized using the $n-d-M$ method, infrared spectroscopy, total acid number, and sulfur analysis. These data can then be used for consistency monitoring.

\subsubsection{Refractive Index, Density and Molecular Weight (n-d-M)}

One qualitative compositional evaluation of the hydrocarbon fractions was through use of the ASTM 03238 method ( $n-d-M$ method) [15]. The $n-d-M$ method determines the proportional percentage of carbons in ring (\%CR) and paraffinic compounds (\%CP). The carbon in ring compounds is expressed in terms of carbons in aromatic (\%CA) and naphthenic compounds (\%CN). Table 6 lists the relative percentage of carbon in the three hydrocarbon fractions of six oils.

From the $n-d-M$ data given in table 6 , the saturates fraction of the oils contain very little aromatic carbon (less than 1 percent), and the percentage of paraffinic carbon is high (61 percent to 70 percent). This indicates that the saturates fraction obtained from the ASTM D2007 method consists primarily of long-chain paraffinic and napthenic compounds. The n-d-M analyses also show that the aromatics fraction contains a high percentage of aromatic carbons (in the range of 22 to 28 percent), but it also has a relatively high percentage of paraffinic (\%CP) carbon (in the range of 50 to 65 percent). The high \%CP indicates a possible long-chain paraffinic carbon attached to one or more aromatic ring. On the basis of this $n-d-M$ analysis, it can be concluded that the saturates fraction from the ASTM D2007 separation contains a very low concentration of aromatic compounds, and the fraction is "clean."

\subsubsection{Infrared Measurements}

The fractions were also examined by infrared spectoscopic techniques. The infrared spectra of the saturates fraction (fig. $1 \mathrm{a}$ and 2a) of a typical virgin and re-refined base oil are free of aromatic and carbonyl absorption bands (1600 and $1700 \mathrm{~cm}{ }^{1}$ ). The aromatics fraction spectra (fig. 1b and 2b) show no carbonyl adsorption bands but they have aromatic absorption bands. Hydroxy1, carbony 1 , and aromatic bands are present in the polars fraction, suggesting that the polars fraction consists primarily of oxygenated compounds, as shown in figures $1 c$ and $2 c$.

Table 6. $n-d-M$ data of the ASTM 02007 fractions (ASTM D3238)

RK

RL

RM

RN

vo

VP
Sat

Aro

Sat

Aro

Sat

Aro

Sat

Aro

Sat

Aro

0.7

22.0

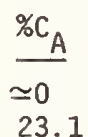

$\simeq 0$

24.5

$\simeq 0$

21.7

$\simeq 0$

23.3

Sat

Aro
0.2

23.7

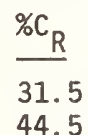

44.5

30.0

41.0

29.8

42.1

30.2

41.7

38.6

51.8

38.6

52.0
$\% \mathrm{C}_{\mathrm{N}}$

31.5

21.4

30.0

16.5

29.8

20.4

30.2

18.4

37.9

29.8

38.2

27.6

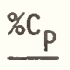

68.5

65.5

70.0

59.0

70.2

57.9

69.8

58.3

61.4

48.2

61.4

48.7 

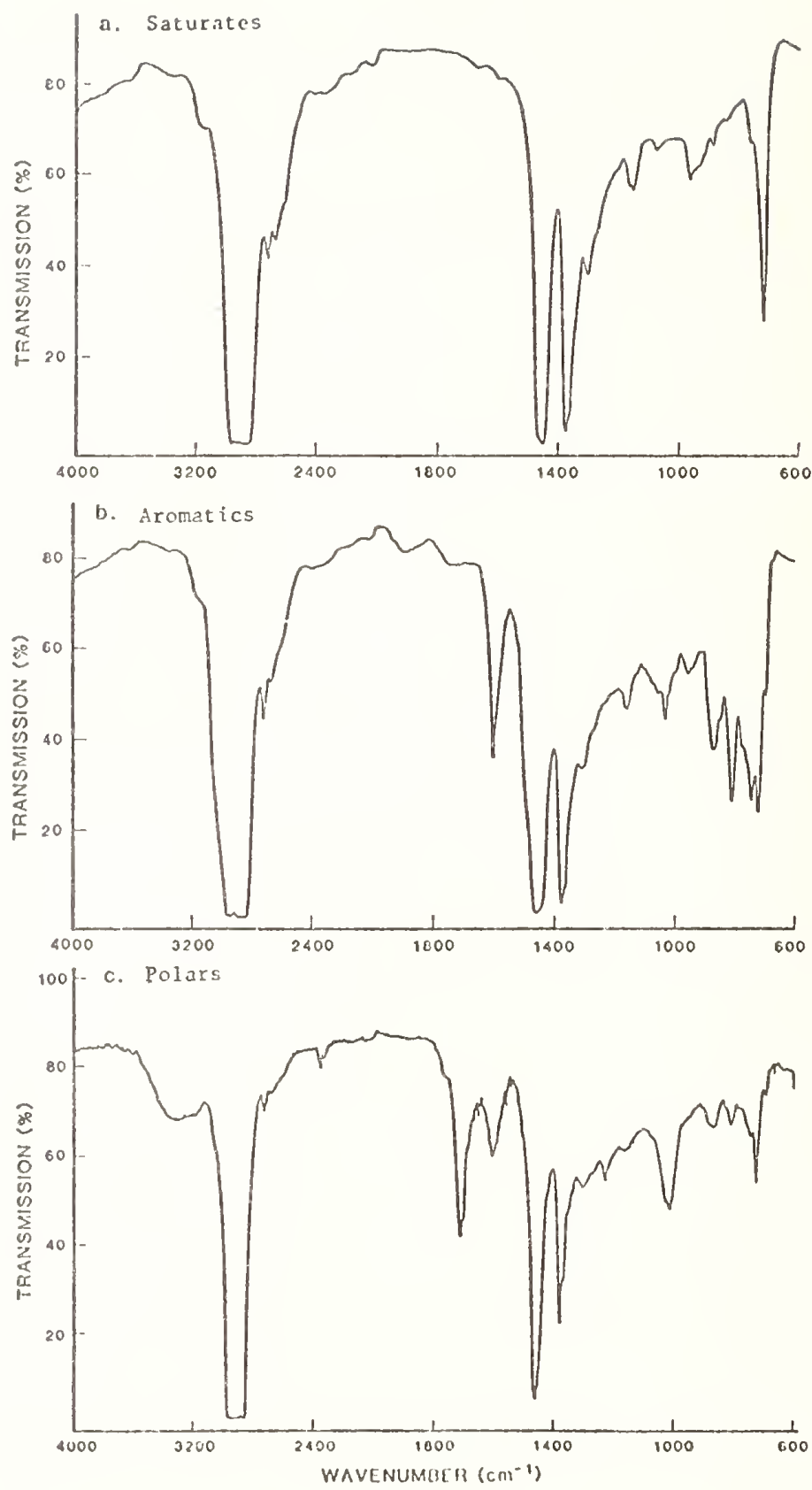

Figure 1. IR spectra of VM fractions (a) saturate, (b) aromatic and (c) polar. 


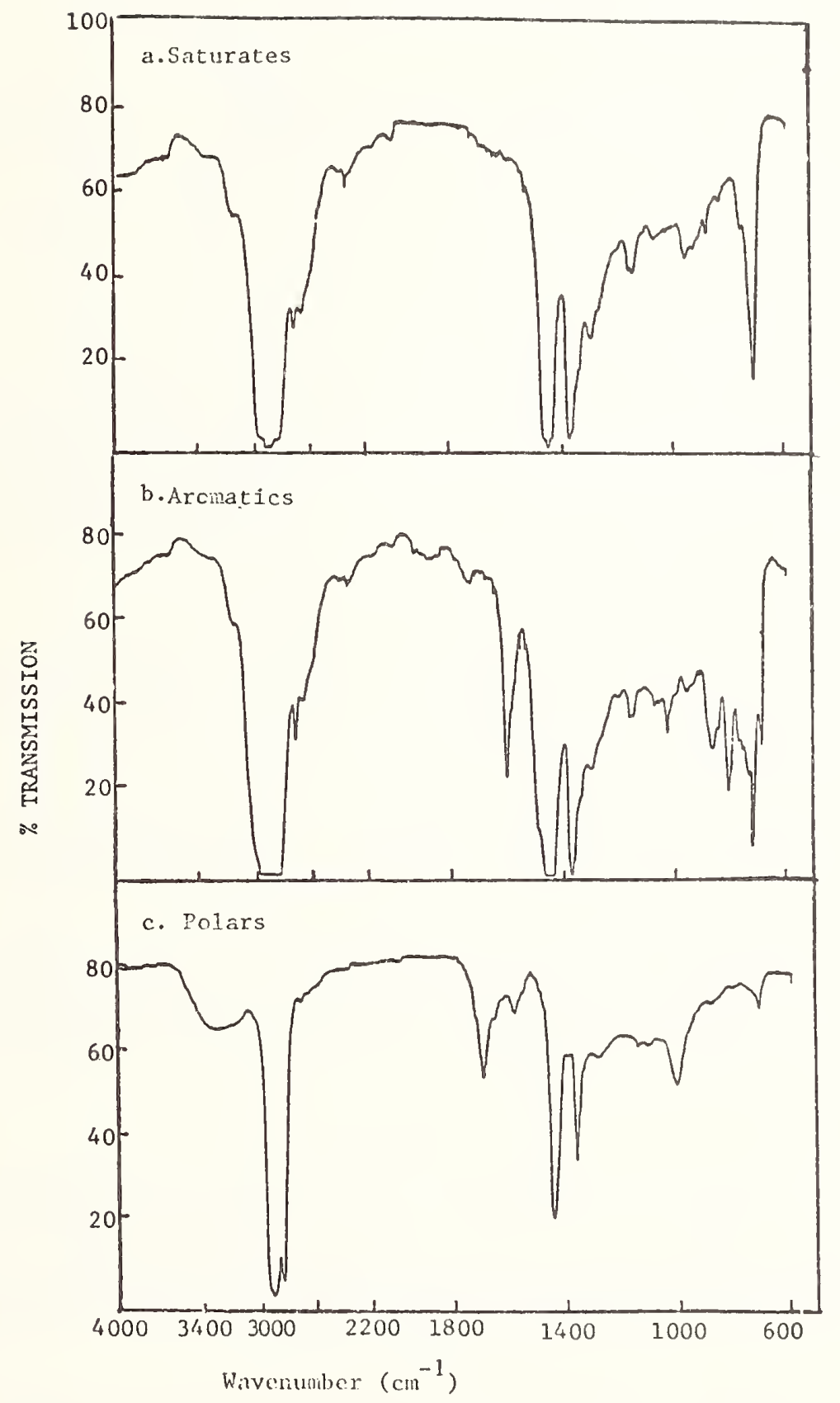

Figure 2. IR spectra of RM fractions (a) saturate, (b) aromatic, and (c) polar. 


\subsubsection{Compositional Comparison of Virgin and Re-Refined Base 0ils}

From the modified D2007 compositional data of the set of 7 virgin and 10 re-refined base oils (table 4), the range and the average weight percentage of the two types of oils are calculated and listed in table 7. It is interesting to note that the range of saturates, aromatics and polars is wider for the virgin base oil than for the re-refined base oils. The narrower range of the re-refined base oils may be due to the statistical averaging of a large number of virgin base oils in the collection of the used oils for re-refining.

Table 7. Composition distribution of base oils

Weight $\%$

\begin{tabular}{|c|c|c|c|c|c|c|}
\hline & \multicolumn{2}{|c|}{ Saturates } & \multicolumn{2}{|c|}{ Aromatics } & \multicolumn{2}{|c|}{ Polars } \\
\hline & Range & Avg. & Range & Avg. & Range & Avg. \\
\hline Re-refined Base 0ils & $72-78 \%$ & $76.1 \%$ & $20-24 \%$ & $21.8 \%$ & $1.4-3.4 \%$ & $2.16 \%$ \\
\hline Virgin Base 0ils & $63-86 \%$ & $78.2 \%$ & $13-34 \%$ & $21.1 \%$ & $0.3-1.7 \%$ & $0.77 \%$ \\
\hline
\end{tabular}

In both re-refined and virgin base oils, the average weight percentages of the saturates and aromatics are approximately equivalent, but there is a substanital difference for the average weight percentages of the polars fraction. All virgin base oils have a polars fraction of less than 0.6 percent except VZ, Vo, and VP, but all re-refined base oils have a weight percentage above 1 percent--and as high as 3.4 percent. Hence, the re-refined base oils have approximately three times more polar compounds than the virgin base oils. These additional polar compounds are likely to be oxidized hydrocarbons and additives which were not completely removed by the re-refining process used.

\subsubsection{Sulfur and Total Acid Number (TAN)}

In previous work [3], it was found that in several instances the polars fraction had a significant impact on the performance of the base oils. It is thus appropriate to study some important chemical properties of the fractions obtained from the D2007 separations. The sulfur content and total acid (TAN) were determined [16-18] on these fractions.

Table 8 lists the sulfur content in each fraction vs its content in the base oil. The saturates fractions are relatively free of sulfur compounds. Sulfur compounds are distributed in the aromatics and polars fractions. The sulfur compounds in the aromatics fraction are reported mostly as thiophenes [19], but the more polar sulfur compounds may be in the polars fraction.

Table 9 lists the total acid number of the base oils and their fractions. The high TAN values for the polars fractions indicate that most of the acidic compounds are concentrated in the polars fraction, and these acidic compounds are mostly the oxygenated compounds, as shown by the infrared spectra of the polars fraction (fig. 1c and 2c). The re-refined base oil sample RS has the highest weight percentage of polars compounds ( 3.4 percent) in the set of re-refined and virgin base oils as given in table 4 .

\section{Conclusions}

The test procedures ASTM D2007 and a modified version of that test (ASTM D2007M) were evaluated for use in characterizing the hydrocarbon types in re-refined base oils. From our study of a set of re-refined and virgin base lubricating oils, it is concluded that both tests are acceptable for the hydrocarbon type analysis of base oils. The advantages of modified ASTM D2007 are its simplicity and the excellent recovery of all three hydrocarbon-type fractions: saturates, aromatics, and polars. These fractions can be used in subsequent compositional evaluation of lubricating base oils.

Further, various evaluations of the fractions produced by this procedure show that the fractions are we11-separated. The saturates fraction is free of aromatic compounds; however, the aromatics fraction contains paraffinic carbon as well as aromatic carbon, indicating the possible presence of paraffinic chains attached to the ring compounds. 
In both re-refined and virgin base oils, the weight percentage of saturates and aromatics fractions are very similar; but, there is a large difference for the weight percent of polars fractions. 0n the average the polars fraction of the re-refined base oil is three times more than that of the virgin base oils. Two important chemical properties--sulfur and TAN--were determined for each fraction.

Table 8. Sulfur of base oils and fractions

$$
\frac{\text { Sulfur }}{\text { (wt. \%) }}
$$

VO

0 i 1

Sat

Aro

Polar

VP

0 i 1

Sat

Aro

Polar

RK

$0 i 1$

Sat

Aro

Polar

RL

$0 i 1$

Sat

Aro

Polar

$0 i 1$

Sat

Aro

Polar

RN
0.04

$\simeq 0$

0.14

0.24

0.054

$\simeq 0$

0.24

0.19

0.24

$\simeq 0$

0.84

1.9

0.12

$\simeq 0$

0.52

1. 1

0.18

$\simeq 0$

0.75

1. 2

0 i 1

Sat

Aro

Polar
0.19

$\simeq 0$

0.7

2.7 
RK

$\begin{array}{lc}0 i 1 & 0.17 \\ \text { Sat } & <0.001 \\ \text { Aro } & <0.01 \\ \text { Polar } & 0.79\end{array}$

RR

$\begin{array}{ll}0 i 1 & 0.81 \\ \text { Sat } & 0.049 \\ \text { Aro } & 0.056 \\ \text { Polar } & 8.86\end{array}$

RT

$\begin{array}{ll}\text { 0i1 } & 0.14 \\ \text { Sat } & 0.016 \\ \text { Aro } & 0.15 \\ \text { Polar } & 3.10\end{array}$

RS

$\begin{array}{lc}0 i 1 & 1.69 \\ \text { Sat } & 0.025 \\ \text { Aro } & 0.068 \\ \text { Polar } & 13.31\end{array}$

VH

$\begin{array}{lc}0 i 1 & 0.012 \\ \text { Sat } & <0.01 \\ \text { Aro } & 0.022 \\ \text { Polar } & 4.25\end{array}$

\section{References}

[1] Manual on Hydrocarbon Analysis, 3rd Ed., sponsored by ASTM Committee D-2 on Petroleum Products and Lubricants. ASTM (03-332030-12); Philadelphia, PA; 1977.

[2] Van Ness, K.; Van Western, H. A. Aspects of the constitution of mineral oils. Elsevier Publishing Corp., Inc; 1951.

[3] Gates, R.; Hsu, S. M. Development of a step loading seizure test for engine oil additive response. Proceedings, Measurements and Standards for Recycled 0i1-IV; Nat. Bur. Stand. (U.S.) Spec. Publ. 674; 1983.

[4] Mair, B. J. Proc. Seventh World Petrol Conference; 1967. 9, 39.

[5] ASTM Standards, D1319 Hydrocarbon types in liquid petroleum products by fluorescent indicator adsorption, Part 23; 1981. 708.

[6] ASTM Standards, D2549, Separation of representative aromatics and nonaromatics fractions of high boiling oils by elution chromatography; Part 24; 1981. 472.

[7] Knight, H. S.; Groennings, S. Ana1. Chem. 1956. 9.

[8] Suatoni, J. C.; Garber, H. R. J. Chromatogr. Sci. 1976. 546; 14.

[9] Suatoni, J. C. ; Swab, R. E. J. Chromatogr. Sci. 1976, 14; 535.

[10] ASTM Standards, D2007. Characteristic groups in rubber extender and processing oils by the clay-gel adsorption chromatographic method; Part 24; 1981; 169. 
[11] Corman, B. G. Exxon-Baytown, Private Communication.

[12] Weeks, S.; Hsu, S. Evaluation of physical property test methods for re-refined base oils. Proceedings, Measurements and Standards for Recycled 0i1-IV; Nat. Bur. Stand. (U.S.) Spec. Pub1. 674; 1983.

[13] Cummings A.; Pei, P.; Hsu, S. Evaluation of chemical property test methods for re-refined base oils. Proceedings, Measurements and Standards for Recycled 0il-IV; Nat. Bur. Stand. (U.S.) Spec. Pub1. 674; 1983.

[14] Robinson, C. J. Ana1. Chem. 43; 1425, 1971.

[15] ASTM Standard 03238. Calculation of carbon distribution and structural group analysis of petroleum oils by $n-d-M$ method; Part 25; 1981, 119 .

[16] Denison, Jr.; G. H., Ind. and Eng. Chem. 1944; 477, 36.

[17] Denison, Jr., G. H.; Condit, P. C. Ind. and Eng. Chem. 37; 477, 1945.

[18] Cartwright, S. J.; Carey, L. R. Control of engine oil acidity; SAE/SP-80/473, paper \#801366.

[19] Synder, L. R.; Suander, D. L. Chromatography in petroleum analysis K. H. Altgelt; and T. H. Gouw, eds. New York, NY: Marcel Dekker; 1979. 

National Bureau of Standards Special Publication 674. Proceedings, Conference on Measurements and Standards for Recycled 0i1 - IV, held at NBS, Gaithersburg, MD, September 14-16, 1982, (Issued Juty 1984).

\title{
TEST METHODS FOR TOTAL CHLORINE IN LUBRICATING BASE OILS
}

\author{
P. Pei, R. Fleming ${ }^{1}$, and S. M. Hsu \\ Chemical Stability \& Tribology Group \\ Inorganic Materials Division \\ National Bureau of Standards \\ Washington, DC 20234
}

\begin{abstract}
Chlorine in trace quantities usually can be found in re-refined lubricating base oils. While the effects of chlorine on performance is not clear at this time, a method to measure chlorine accurately as a means of quality control is needed.
\end{abstract}

Five analytical methods for the determination of chlorine in lubricating base oils were studied. They are: ASTM D-808, an oxygen bomb method; ASTM D-1317, a sodium alcoholate method; the Microcoulometric Titration method (MCT); X-ray Fluorescence (XRF); and Neutron Activation Analysis (NAA). The first three method (ASTM D808, D1317, and MCT) are not specific for chlorine but are generally used for chlorine measurement assuming that halogens other than chlorine are absent. The last two methods (XRF and NAA) are chlorine specific.

The NAA method was found to be the most accurate, interference free method. However, NAA is not widely available. Using the results from NAA as the primary reference data, the XRF method was found to be acceptable for the determination of specific values for concentration levels above $5 \mathrm{ppm}$. However, the modified 01317 (sodium alcoholate) and the micro-coulometric titration methods were also found to be acceptable methods for the determination of total chlorine in petroleum base oils, assuming halogens other than chlorine are not present at significant levels. The quantity of halogens other than chlorine in base oils has been found to be generally low and the results from these methods suggest reasonable agreement with chlorine content.

\section{Introduction}

Chlorine is normally present only at very low levels in virgin lubricating base oils. In re-refined base oils, various chlorine concentrations ranging from a few parts per million to 0.1 percent by weight have been found $[1]^{2}$. This is due to a variety of sources: 1ead scanvenger (ethylene dichloride) from leaded gasoline; chlorinated industrial oils; chlorinated electrical transformer oils; and chlorine containing additives in lubricants. These chlorine-containing compounds and/or fluids find their way into the used oil collection stream which is the feed-stock for re-refining. Most re-refining processes are reasonably effective in removing the chlorine as evidenced by the low average chlorine levels (34 ppm) for eight re-refined base oils [2]. The effects of this trace amount of chlorine on base oil performance are not clear at this time. However, the persistent presence of chlorine in re-refined base oils requires an accurate analytical method for its determination in the range of about $1 \mathrm{ppm}$ to approximately 0.1 percent by weight.

\section{Methods Discussion}

Five analytical methods currently used.for the determination of chlorine in petroleum oils are listed in table 1. Two of the methods are American Society for Testing Materials (ASTM) standard methods [3]. The other three methods are $x$-ray fluorescence (XRF), neutror activation analysis (NAA), and microcoulometric titration (MCT).

Both ASTM methods and the MCT method require sample preparation to convert organic chlorinecontaining compounds to chloride ions by oxidation in a closed system or by refluxing in sodium alcoholate. The chloride ions are, in turn, determined by a variety of methods. The total

\footnotetext{
1Neutron Activation Analysis Group, Inorganic Analytical Research Division, Center for Analytical Chemistry.

${ }^{2}$ Figures in brackets indicate the literature references at the end of this paper.
} 

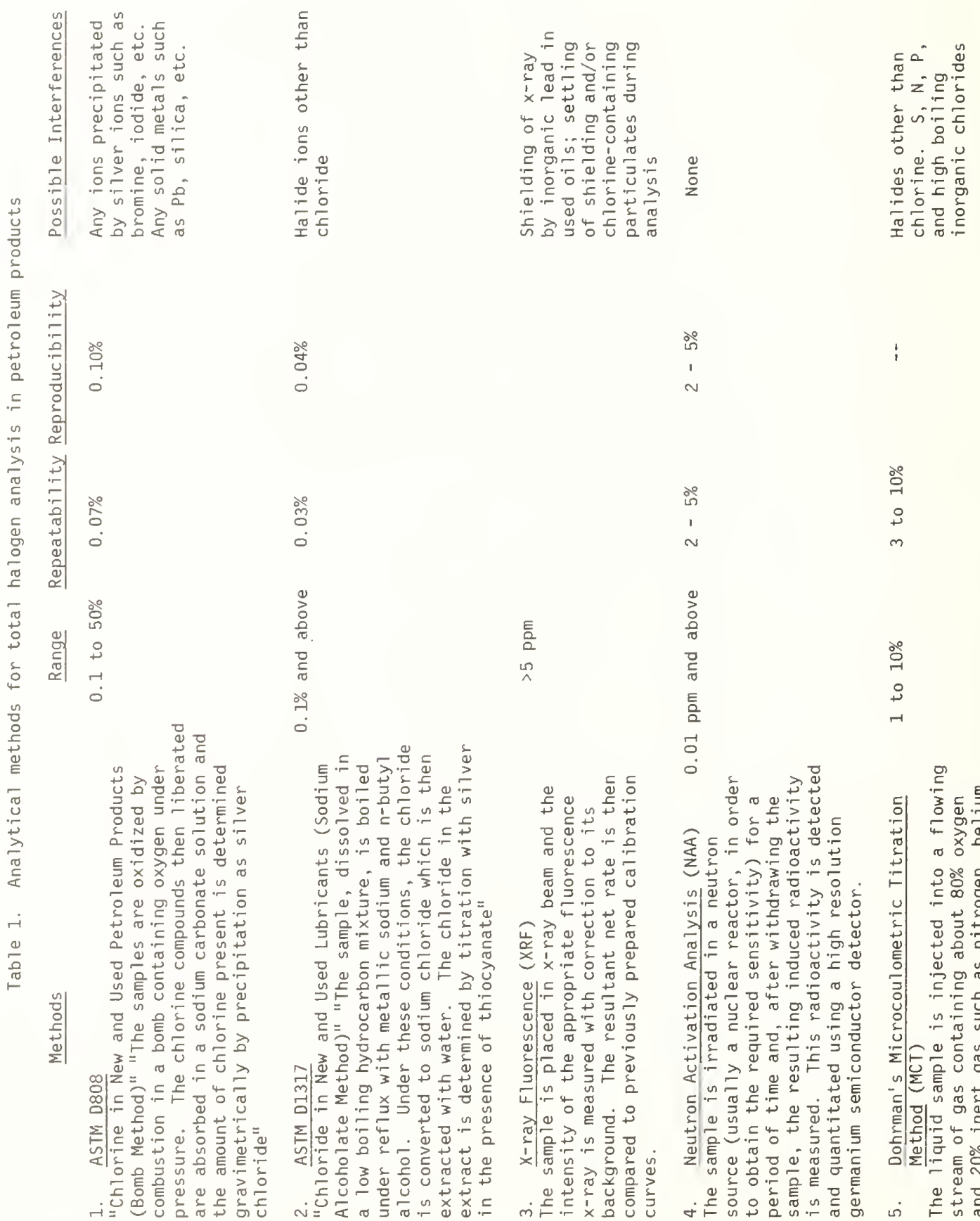

ஓें

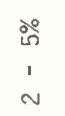

음
0
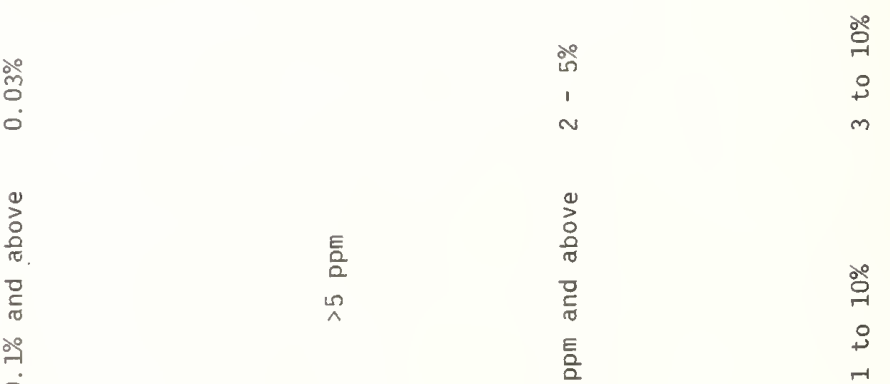

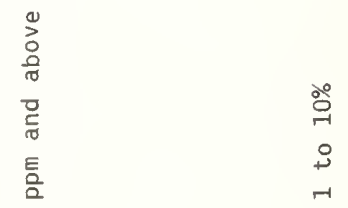

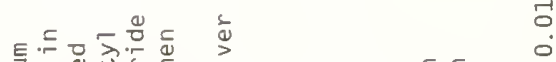

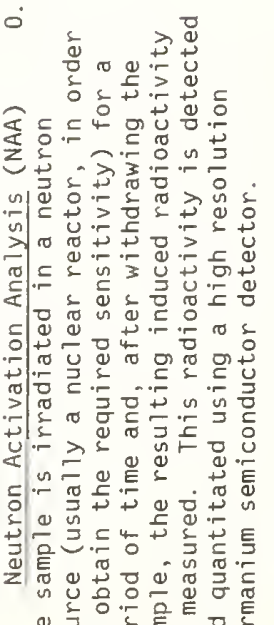

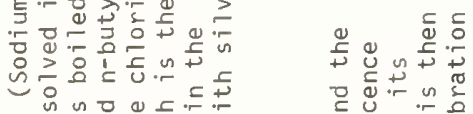
in

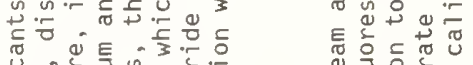

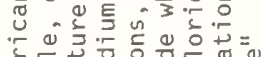

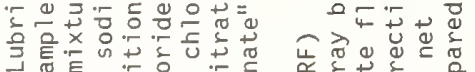

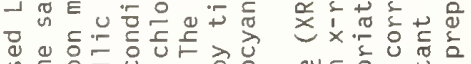
为品和

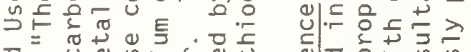

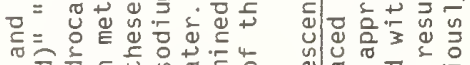

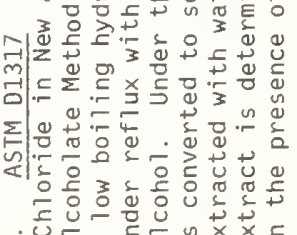

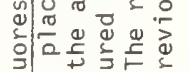

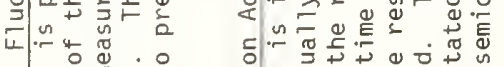

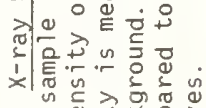

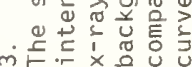

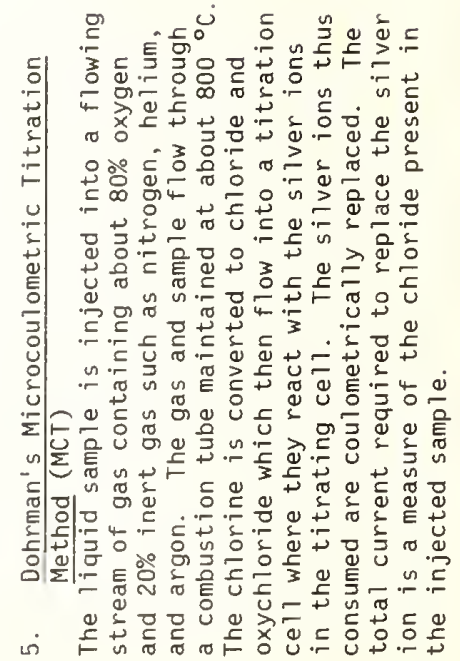


chlorine concentration as determined by the above three methods are based on the assumption that halogens other than chlorine are absent. X-ray fluorescence and neutron activation analysis are chlorine specific methods which do not require sample destruction, and the total chlorine concentration is measured directly.

A short summary of each method is listed in table 1, including limits of applicability and estimated uncertainties. Also listed in table 1 are possible interferences involved in each method. Seventeen Tubricating base oils were selected for chlorine determination in these studies, ten re-refined and seven virgin base oils. These base oils represent a cross-isection of avaitable processing technologies, crude sources and viscosity grades as listed in table 2.

Each method is described individualiy below.

Table 2. Crude source and processing technologies of the seventeen base oil set

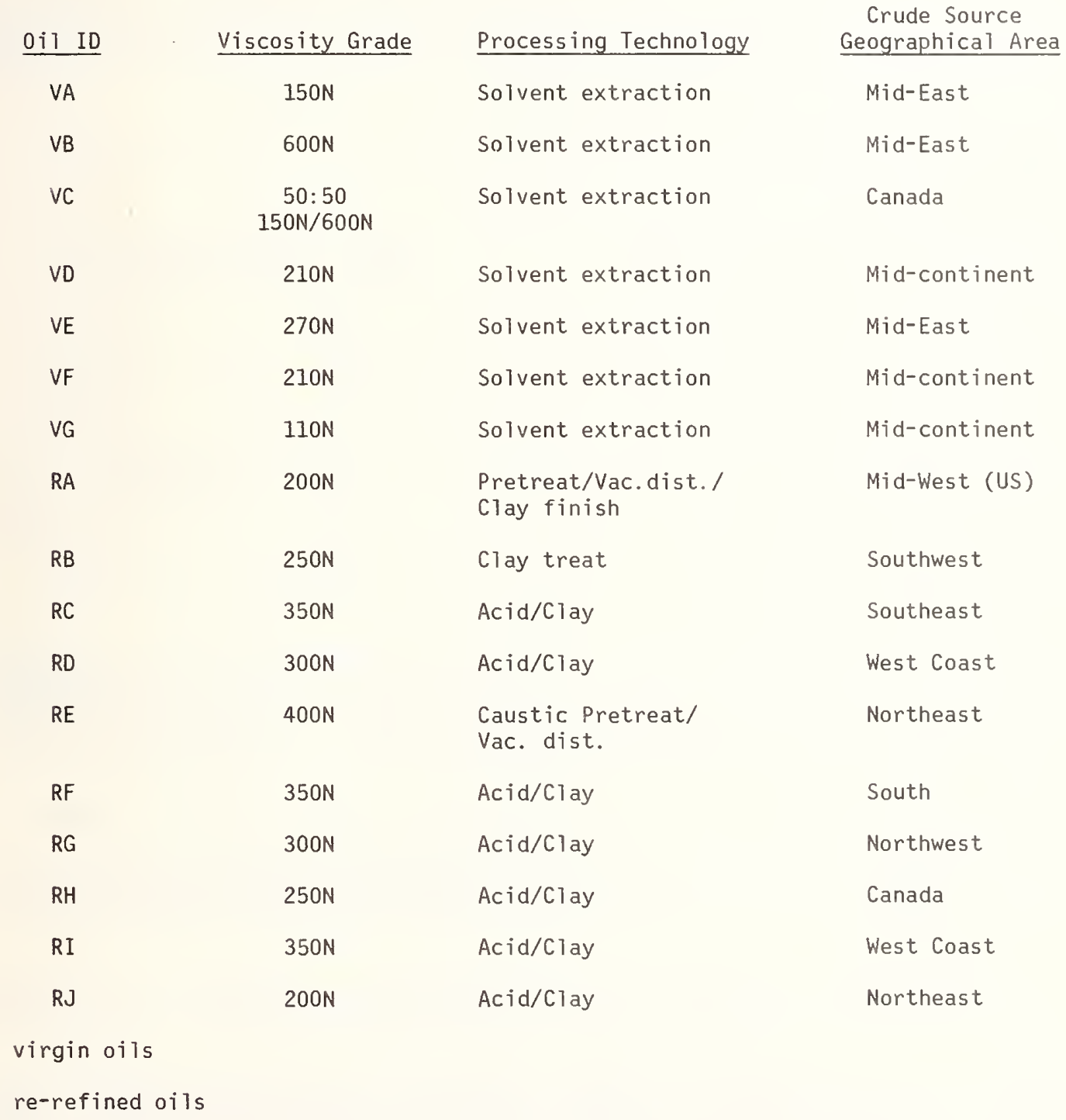

$R=$ re-refined oils 


\section{1. ASTM D808 Method, "Chlorine in New and Used Petroleum Products (Bomb Method)"}

In the 0808 method, the samples are introduced into a bomb and combusted in oxygen under pressure. The three halogen compounds present are then determined gravimetricaliy by precipitation with silver.

Because the ASTM D808 method was originally developed for industrial oils which contain a high chlorine content, its applicability range was designed to be $1000 \mathrm{ppm}$ to 50 percent chlorine and also with the assumption that halides other than chlorine are absent. The chlorine concentration in lubricating base oils are usually in the range of $1 \mathrm{ppm}$ to $100 \mathrm{ppm}$, which is below the applicability range of ASTM 0808 .

Modifications to this method were attempted in order to build-up the chloride concentration sufficiently to permit accurate silver chloride determination gravimetrically. For example, repeated burnings of samples in the same bomb were attempted to increase the apparent sample size. However, these attempts were not successful. Analytical results of the modified ASTM D808 method are shown in table 3 , including two sets of results obtained by two different operators. The discrepancy between the two sets of analytical results is more than 100 percent for samples having a chlorine content of less than 100 ppm (e.g., sample RM). This indicates that the modified ASTM D808 method may be operator-dependent and difficult to control at low chlorine concentrations. Hence, at concentration levels less than 100 ppm, the ASTM D808 method is not recommended.

Table 3. Analytical results of ASTM 0808 (modified) method for chlorine analyses $(\mu \mathrm{g} / \mathrm{g})$ by two operators

\section{Description Sample \#}

Re-refined Base 0 il

Re-refined Base $0 i 1$
RL

RM

Operator "A" Operator "B"

$\begin{array}{ll}68 & 27 \\ 70 & 26 \\ 68 & 28 \\ 68.6 \pm 1 & 27 \pm 1 \\ 219 & 201 \\ 320 & 221 \\ 251 & \\ 263 \pm 6 & 211 \pm 10\end{array}$

A further modification to the ASTM 0808 method was attempted, based on a technique used in the literature [4]. After digestion of the oil sample in the bomb, a chloride-specific ion-electrode detector was used for the chlorine determinations. Results for these oils show poor comparability with standards, apparently due to significant interferences by other ionic species present in the oils.

\subsection{ASTM DI317 Method, "Chlorine in New and Used Lubricants (Sodium Alcoholate Method)"}

In the sodium alcoholate method, the sample is boiled under reflux with sodium metal and n-butyl alcohol. Under these conditions, the halogens are converted to halide and extracted into water. The halides are determined as total chlorine by titration with silver in the presence of thiocyanate.

ASTM DI3I7 is a method developed originally for chlorine-containing industrial oils in which it is assumed that chlorine is the only halogen present. The lower limit of detection is 0.1 percent, similar to ASTM D-808.

In an attempt to improve this method, two modifications were evaluated. First, the oil sample size was increased in the sodium alcoholate treatment in order to lower the detection limit to the ppm level. However, the result was influenced by the chlorine blank found in the sodium metal used (10 to $15 \mathrm{ppm}$ ). Different batches of sodium metal from several manufacturers contained variable amounts of chlorine above $10 \mathrm{ppm}$. Since the desired analytical range included 1 to $20 \mathrm{ppm}$, the blank lue was often higher than the sample concentration causing large errors at concentrations 
below about $15 \mathrm{ppm}$. With larger sample sizes, the extraction of chloride into the aqueous phase becomes more difficult. Using fluoride as an internal standard with the individual halogens measured by ion chromatography, a chloride recovery rate as low as 38 percent has been observed.

All these difficulties, however, can be overcome if: (1) precautions are taken to use only sodium metal with low and constant chlorine content and with blank correction properly applied; and (2) the extraction procedure is adequately controlled with vigorous mixing to ensure constant extraction efficiency of chloride ions. Table 4 presents the precision data of the modified sodium alcoholate method on one sample. Table 5 presents the chlorine analysis of the seventeen base oils using sodium alcoholate method.

The detection limit for the modified sodium alcoholate method is approximately $1 \mathrm{ppm}$. This method may be used for samples above $1 \mathrm{ppm}$, if suitable precautions are taken as described above. The precision for six analyses on the same sample was \pm 30 percent at a chlorine content of 5.3 ppm. The detailed modifications developed for ASTM 1317 are listed in Appendix 1.

Table 4. The precision data of the modified sodium alcoholate method (ASTM 01317 modified)

Re-refined 0 il Sample
RO

$3.5 \mathrm{ppm}$

$4.0 \mathrm{ppm}$

$6.0 \mathrm{ppm}$

5. $1 \mathrm{ppm}$

$8.0 \mathrm{ppm}$

$5.0 \mathrm{ppm}$

Average $=5.3$

Standard deviation $=1.6$

Table 5. Analytical research for chlorine analyses by modified sodium alcoholate method (ASTM D1317, modified)

\begin{tabular}{|c|c|c|}
\hline Description & 0il Sample & Chlorine Analyses (ppm) \\
\hline \multirow[t]{7}{*}{ Virgin $0 i 1$} & VH & 1.0 \\
\hline & VZ & 2.0 \\
\hline & VJ & 1.0 \\
\hline & VK & 1.0 \\
\hline & VL & 1.0 \\
\hline & VM & 1.0 \\
\hline & VN & 1.0 \\
\hline \multirow[t]{10}{*}{ Re-refined 0 il } & RK & 5.0 \\
\hline & $\mathrm{RL}$ & 12.4 \\
\hline & $\mathrm{RM}$ & 186 \\
\hline & RN & 5.0 \\
\hline & RO & 5.3 \\
\hline & $\mathrm{RP}$ & 3.0 \\
\hline & $\mathrm{RQ}$ & 12.2 \\
\hline & RR & 19.2 \\
\hline & RS & 1029 \\
\hline & RT & 895 \\
\hline
\end{tabular}

\subsection{X-ray Fluorescence Method}

X-ray fluorescence (XRF) is a well-known analytical method which can be used for the determination of chlorine and bromine in petroleum products. This method is described briefly in table 1. The chief limitation of this method is the detection limit of approximately $5 \mathrm{ppm} c \mathrm{chlorine}$. Interference from inorganic lead in samples such as used automotive lubricating oils is also possible, due to shielding of the radiation. Another potential interference is from sulfur, since sulfur fluoresces at an energy level which is very close to that of chlorine. 
XRF results for the seventeen base oil set are listed in table 6 . The XRF results for the virgin base oils show that the concentration of chlorine is below the XRF detection limit. For re-refined base oils, all but two of the results are within the range of the detection.

This method is particularly suitable for fast scanning of total chloride in order to detect samples with high chlorine content, i.e., greater than $100 \mathrm{ppm}$. The XRF system used did not provide accurate total chloride determinations in base oil samples containing less than about 10 ppm.

\subsection{Neutron Activation Analys is}

The neutron activation analysis (NAA) method was also considered for chlorine analysis, since the high sensitivity and freedom from interferences were known. This method is described in table 1 and Appendix II. Primarily, this method was used as a reference method, since previous work at this laboratory had established its capabilities for high accuracy chlorine and bromine analyses. The precision and accuracy of the method was shown to be $\pm 1-3$ percent, when suitable care is given during the analyses. The results of NAA analysis on the 17 base oils are 1 isted in table 6.

In considering the advantages and disadvantages of the method, NAA appears to be the most accurate method available in the concentration range being investigated. However, there are only a 1 imited number of laboratories in the U.S. that are equipped to perform NAA, and the cost per analysis is usually considerably higher than for the other methods. Because of these limitations, the analyst may wish to consider alternate methods for routine chlorine analyses.

\subsection{Microcoulometric Titration (MCT) Method}

In 1960, Coulson and Cavanagh developed the MCT method for the analysis of organic chlorine compounds [5]. The microcoulometric method involves two steps: the sample is first burned in a combustion chamber in oxygen to convert the chlorine to chloride and oxychloride, and then the chloride is reacted with silver ions in a titrating cell, where the silver ions are replaced coulometrically. This method has the advantages of easy operation and good sensitivity (ca. 1 ppm). However, nitrogen, phosphorus, and sulfur compounds from contaminants or lubricant additives has been reported to cause interferences [6]. This method also failed to analyze properly some highboiling, inorganic chloride compounds $[7,8]$. A complete description of the MCT method can be found as Appendix III.

A modification of the MCT method by Matsuzaki and Koyano [6] entails the use of a copper oxide scrubber at the end of the combustion process to eliminate interference by nitrogen, phosphorus, and sulfur compounds. Matsuzaki and Koyano reported that their modification eliminates the interference of nitrogen-, sulfur-, and phosphorus-containing compounds at levels as high as 10 percent in finished lubricants containing additives. In re-refined base oils, potential contamination by residual additives is possible, but the levels of nitrogen, sulfur, and phosphorus compounds are very low compared with the study in reference [6].

The microcoulometric titration results on the 17 base oils are listed in two columns in table 6: using the copper oxide scrubber, and without using the scrubber. The use of the scrubber does not appear to consistently affect the results, however, analysis of the data show that use of the scrubber appears to slightly improve the results in comparison with NAA.

\section{Discussion of Results on Chlorine Analysis by Four Methods}

A set of seventeen base oils was analyzed by the sodium alcoholate (D1317, modified), XRF, NAA, and MCT methods. These results are shown in table 6 . Of the seventeen base oils, seven are virgin base oils and ten are re-refined base oils. The chlorine content of the seven virgin base oils is below $1 \mathrm{ppm}$, with the exception of the $V Z$ sample. The chlorine content of the ten re-refined base oils ranges from about $6 \mathrm{ppm}$ to over 0.1 percent by weight.

For the seven virgin base oils, the analytical results from the Modified D1317, XRF, and MCT methods are either higher than those from NAA, or below the method's detection limit. These results confirm the limitation of these methods for low levels of chlorine. The Modified D1317 and MCT methods also likely are suffering from interferences due to small amounts of halides other than chlorine in the re-refined oils, and/or from nitrogen, phosphorus and sulfur compounds present in the virgin base oils. 


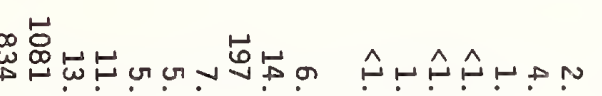

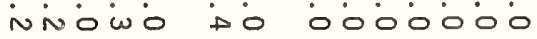


For seven of the ten re-refined base oils, the range of the chlorine concentration is from 6 to $20 \mathrm{ppm}$. The remaining three have a chlorine content well above $100 \mathrm{ppm}$ (RM, RS, and RT). The relative precision of multiple analyses of samples by NAA is \pm 1 percent; for the MCT method is \pm 6 percent; and for the Modified D1317 method is \pm 30 percent.

As was described earlier, both the Modified D1317 and MCT methods are for total halogen content in a base oil. Table 6 also lists the total bromine content of each base oil as determined by NAA. Presumably, the values reported by Modified D1317 and MCT should be the sum of the chlorine and bromine values determined by NAA. However, this is not observed. For example, let us examine values reported by the Modified 01317 and the MCT methods for re-refined oil sample RR. The total halide value reported by MCT is $18.4 \mathrm{ppm}$ (with scrubber), in comparison to the total halide (chlorine + bromine) value determined by NAA of $34.1 \mathrm{ppm}$. In general, it was observed that the halogen values determined by MCT appear to be substantially lower than the total halogen values (chlorine + bromine) as reported by NAA.

One possible reason for MCT's total halide measurements being low is as follows. During pyrolysis of the oil sample, halides and oxyhalides are produced. However, only halides and oxychloride are 100 percent titratable by the silver titrant ions, and the other oxyhalides, such as oxybromides and oxyiodides, are not titratable with the silver titrant ions [9]. Therefore, the recovery of chlorine is 100 percent, but only approximately 50 percent for bromide and iodides. Fluorides and oxyfluorides are not titratable at all in this system since no reaction will occur when they encounter silver ions.

The detection system used in MCT is a microcoulometric titration cell which measures all substances which will complex or precipitate with silver ions in a 70 percent acetic acid solution. When the silver ion concentration in the titration cell is lowered, the sensor electrode potential changes which in turn produces an input signal to the microcoulometer amplifier. The amplifier output voltage is placed across the generator electrodes and the following reaction occurs at the generator anode:

$$
\mathrm{Ag} \rightarrow \mathrm{Ag}^{+}+\mathrm{e}^{-}
$$

The silver ion generated in this way replaces the silver ion consumed in the silver halide reaction and also restores the electrode potential to the original state. The current flow in reaction ( 1 ) is measured and Faraday's Law is used to calculate the number of microequivalents of silver ion generated which are equivalent to the silver ions consumed by halides and oxychlorides entering the titration cell. Since the measurements are usually reported as a weight percentage of chlorides, the atomic weight of chlorine is used in the calculation. For correction factors for the presence of other halides, a conversion factor based on the ratio of atomic weights of chlorine and bromine or iodine has to be applied, assuming the concentration ratios are known. For example, in the case of bromides, the ratio is

$$
\frac{\text { At.wt. Br }}{\text { At.wt.C1 }}=\frac{79.90}{35.45}=2.25
$$

and for iodine, the ratio is

$$
\frac{\text { At.wt. I }}{\text { At.wt. } \mathrm{Cl}}=\frac{126 \cdot 90}{35 \cdot 45}=3.58
$$

With the above two considerations, the total chloride values determined by MCT are seen to be less affected by the presence of other halides, than originally expected.

The results of data analysis as shown in table 6 indicate that the MCT method, when used for samples above several ppm, provides results which agree reasonably well with the NAA results although the method seems to have about a 10 percent bias on the low side.

\section{Conclusions}

In this study, five analytical methods for determining the chlorine content of re-refined base oils have been evaluated. NAA was found to be the most accurate and reliable method. of the other methods, three (D1317M, XRF, and MCT) are found basically satisfactory for routine analysis when high accuracy is not required. Two methods (XRF and NAA) are chlorine specific and the remaining two (Modified ASTM D1317 and MCT) are not chlorine specific, but can be used if halogens other than 
chlorine are absent or present at relatively low levels. The ASTM D-808 (bomb method) has been found to be less than satisfactory due to the low chlorine levels usually found in base oils and the substantial possibility of interferences being present in re-refined oils.

If available, NAA should be the method of choice. Since it is independent of the chemical forms of the chlorine compounds, pretreatment is not required. It has the best accuracy and precision of all the methods evaluated. As stated previously, though, NAA may not be readily available for routine analyses, since relatively few commercial facilities in the U.S. can provide NAA analytical services. However, NAA should be used as the reference method in case of a dispute between other methods.

One of the three alternate methods is the MCT method. It has been automated for easy operation, and the instrument is readily available commercially. Its applicability range is stated to be $1 \mathrm{ppm}$ to 10 percent with proper dilution. However, the microcoulometric titration method is not chlorine specific and may not be interference-free. The possible interferences by nitrogen, sulfur, and phosphorus compounds in the base oil samples apparently can be eliminated by the use of the copper oxide scrubber. Concern regarding interferences due to high-boiling inorganic chloride compounds is low, because of the limited solubility of the inorganic chloride in base oil. The data obtained on re-refined base oils by the MCT method are in reasonably good agreement with chlorine values given by NAA analyses above the $3 \mathrm{ppm}$ level.

The other two methods are XRF and the modified sodium alcoholate methods. XRF method is very useful for fast sample scanning, but as with the MCT method it has limited use for oils with chlorine levels below $5 \mathrm{ppm}$, such as the virgin base oils. For the modified sodium alcoholate method, precautions must be taken in order to make this method applicable to base oils containing chlorine content of less than $100 \mathrm{ppm}$. Assuming that halogens other than chlorine are absent, the precautions are:
1) Sufficient reflux time to allow complete extraction of the chlorine from the sample;
2) Use of sodium metal with a low chlorine blank, which is homogeneously distributed throughout the sodium metal (to enable accurate blank corrections); and
3) Subtraction of the well-characterized blank value from the analyses results.

The authors wish to express their appreciation to Dr. William Koch, Dr. George Marinenko, and Dr. Yung Chi Wu, of NBS, Dr. John Houston of Suntech and Dr. Arthur Krawetz of Phoenix Lab for their cooperation in the preparation of this manuscript.

\section{References}

[1] Frame, E. A.; Bowen, T. C., Jr. U.S. Army/Environmental Protection Agency Re-Refined Engine 0 il Program. AFLRL Report No. 98. U.S. Army Mobility Equipment Research and Development Demand; 1978 May.

[2] Hsu, S. M.; Ku, C. S.; Becker, D. A. Re-Refined base oil characterization and consistency monitoring, SAE paper 82140; SAE SP 526; Society of Automotive Engineers; Warrendale, PA; 1982.

[3] 1981 Annual Book of ASTM Standards. Parts 23 and 24; ASTM Philadelphia, PA; 1981.

[4] Nadkarni, R. A. Multitechnique multielemental analysis of coal and fly ash. Anal. Chem. 52: $929 ; 1980$.

[5] Coulson, D. M; Cavanagh, L. A. Automatic chloride analyses. Anal. Chem. 32: 1245-1247; 1960.

[6] Matsuzake, A; Koyano, K. Estimation of nitrogen sulfur and phosphorus interferences in determination of chlorine in petroleum products by combustion and microcoulometric titration. Anal. Chem. 52: 146-149; 1980. 
[7] Ladrach, N.; Cvatas, V. D.; Gonverneur, P. Determination of traces of chlorine in organic liquids, a combustion-microcoulometric method. Anal. Chem. Acta 50: 219-228; 1970.

[8] Solomon, J.; Uthe, J. F. The determination of chlorine in organic materials by combustion and microcoulometry. Anal. Chem. Acta 73: 149-155; 1974.

[9] Burchfield, H. P.; Wheeler, R. J. Analysis by microcoulometric gas chromatography. J. of the Association of Official Analy. Chemists 49: 651-661; 1966. 
The full D1317 procedure is followed with the following modifications:

\section{Reagent}

4. 11 Sodium Metal - Reagent grade with low chlorine content such as the sodium sphere under naphtha which is available from MCB, catalog \#0240 (certain commercial materials are identified in order to adequately specify the experimental procedure. Such identification does not imply recommendation or endorsement by the National Bureau of Standards nor does it imply that the materials identified are necessarily the best available for the purpose.)

5. Procedure

5.1 The proper sample weight taken for analysis is:

$$
\begin{array}{ll}
\text { (ppm) C1 } & \text { Sample wt. } \\
1-10 \mathrm{ppm} & \sim 40 \mathrm{gm} \\
10-0.1 \% & \sim 4 \mathrm{gm}
\end{array}
$$

5.2 Reaction and Extraction

Sufficient time as much as 3 hours reflux may be needed to complete the reaction. Extraction procedure should be repeated three times to ensure efficient extraction.

\subsection{Blank Determination}

Al1 efforts must be taken to reduce the reagent blank to as low a level as possible. Repeated blank determinations are necessary in case the reagent blank changes with time.

\section{Calculation}

Reagent blank value should be subtracted from the total chlorine content of the sample. 
Appendix II. Procedure Description of Chlorine Determination by Neutron Activation Analys is

Activity determined: $\quad{ }^{37} \mathrm{Cl}(\mathrm{n}, \gamma){ }^{38} \mathrm{Cl}$

Equipment

$$
\begin{aligned}
& T \frac{1}{2}=37.21 \mathrm{~min} \\
& E_{\gamma 1}=1642 \mathrm{KeV} \\
& E_{\gamma 2}=2168 \mathrm{KeV}
\end{aligned}
$$

2. A thermal neuiro. irradiation facility with a flux of from $10^{12}-10^{13} \mathrm{n} / \mathrm{cm}^{2} / \mathrm{s}$.

b. A multichannel gamma spectrometry system (Ge or Ge-Li) with an energy resolution of 2 KeV 0 I332 $\mathrm{KeV}$, or better.

c. Pre-cleaned polyethylene, screw-top irradiation containers. (clean by soaking in high purity $\mathrm{HHO}_{3}+\mathrm{H}_{2} \mathrm{O}$ ).

d. Pre-weighed, glass counting vials.

Standards and Blank:

a. Standards can be prepared as aqueous solutions of high-purity KCl or $\mathrm{NaCl}$ (e.g. SRM-975 or 999). At least two concentration levels in the range of interest should be used.

b. Blank can be any oil with a low chlorine level, e.g., paraffin oil (Fisher 0-119) is about 70 ppb C1.

\section{Procedure}

a. Prepare oils, standards, and blank by transferring to irradiation container and sealing. A clean pipette should be used for each sample.

b. Irradiate each sample for a sufficient time (severa? minutes) to produce the desired activity. (A longer irradiation in a lower flux is preferable to the reverse.) Use flux monitors if necessary.

c. Transfer sample into pre-weighed counting vial filled to a fixed level. Weigh to determine net sample weight.

d. Wait at least ten minutes after end of irradiation to begin counting so that any short-lived activity (e.g. $\left.{ }^{\mathrm{S} 2 \mathrm{~V}},{ }^{28} \mathrm{Al},{ }^{37} \mathrm{~S}\right)$ may decay away.

e. Count samples at a fixed distance from the detector, recording the net peak area of the two lines. Two sequential counts of 15 minutes each is adequate.

\section{Data Reduction}

a. For each gamma line of each count compute

$$
A_{0}=\frac{\gamma N e^{\lambda t} 1}{\left(1-e^{-\lambda \tau}\right)\left(1-e^{-\lambda \Delta}\right)} \cdot \frac{e^{\lambda \delta}-1}{\lambda \delta}
$$

$\lambda=\ln 2 / T \frac{1}{2}=$ decay constant

$\tau=$ irradiation time

$t_{1}=$ time from end of irradiation to start of count

$\Delta=$ live time of count

$\hat{o}=$ dead time of count

$\mathbb{N}=$ net counts in the gamilia ray peak 
b. Compute the chlorine concentration as

$$
[C 1]_{x}=\frac{(A o / W) x}{(A o / W) s t d}[C l] s t d
$$

$W_{x}=$ weight of sample

$W_{\text {Std }}=$ weiaht of standard

$[\mathrm{Ci}]_{\text {std }}=$ chiorine concentration in standard

c. Propagate the Poisson counting uncertainty to determine an uncertainty for each measurement $[1]$.

d. Determine a best value for each sample by computing a weighted average.

\section{References}

[1] Stevenson, P. C., Processing of counting data. NAS-NS 3109; 1966.

[2] De Soete, D.; et al. Neutron activation analysis. Wiley-Interscience; 1972. 
I. Scope:

This method is designed for the determination of total chlorine in lubricating base oils in the concentration range of 1 to $200 \mathrm{ppm}$ and assuming that no other halogens are present. A single boat inlet (SBI) system is used. By proper dilution, chlorine concentrations as high as 10 percent can be accurately determined.

II. Summary of the Method:

A $5 \mu \mathrm{L}$ sample is injected into a quartz boat using a microsyringe. Argon is first allowed to flow for about 10 seconds over the boat and carry volatile compounds into combustion zone. Then the boat is advanced into the hot inlet zone $\left(900^{\circ} \mathrm{C}\right)$. The vaporizing compounds are burned in oxygen to yield among other things chloride and oxychloride, which pass into the coulometric titration cell where they precipitate as silver chloride. The silver is coulometrically generated to return the concentration of silver in the cell to the original state. From Faraday's law the amount of chloride equivalent to the amount of generated silver is calculated, and its weight fraction in the injected sample is expressed in parts per million.

Boat injections are repeated until two successive results agree within the pre-established limits.

II A Apparatus:

1. Pyrolysis Furnace: It should have three separate and independently controlled hot zones. The inlet zone is kept hot enough to volatilize or decompose all compounds in the sample. The center zone is maintained at a temperature chosen to optimize the scrubber efficiency.

Matszuki and Koyano [6] reported the following zone temperature for optimizing the 100 percent recovery of chloride in both organic and inorganic chlorides.

Inlet zone
Pyrolysis zone
outlet zone

\author{
$900{ }^{\circ} \mathrm{C}$ \\ $850{ }^{\circ} \mathrm{C}$ \\ $700{ }^{\circ} \mathrm{C}$ (with cupric oxide)
}

Note: The above temperature settings are for boat inlet system. If direct microsyringe injection are used, the high inlet temperature may foul the microsyringe needle.

2. Pyrolysis tube: The tube is made of quartz with the inlet end connected to the single boat inlet accessory. The tube has two side arms; one for the entry of argon carrier gas into the inlet zone and the other for the introduction of oxygen into the combustion zone.

3. Titration cel1: The titration cell contains: a sensor-reference electrode pair to detect changes in silver ion concentrations; a generator anode-cathode electrode pair to maintain constant silver ion concentrations; and a heated inlet for gaseous products from the pyrolysis tube. The sensor electrode is silver-plated platinum with a thin layer of silver chloride and the reference electrode is a silver-plated platinum wire in a silver acetate saturated half-cell. The generator anode is silver plated platinum and the cathode is platinum. The solution in the titration cell is stirred with a magnetic stirrer.

4. Microcoulometer: The microcoulometer has variable attenuation and gain controls, and is capable of measuring the potential of the sensing-reference electrode pair, compare this potential with a bias potential, amplify the potential difference, and applying the amplified voltage difference to the working-auxiliary electrode pair so as to generate the titrant. The total chlorine content of the injected material is read directly in nanograms from the interpreting digital coulometer. Knowing the volume of the injected sample and the density of sample, the concentration of chlorine in ppm can be easily computed.

Note: All the above equipment is commercially available from Dohrmann Envirotech Corporation as their system METS-20.

(Certain commercial equipment, instruments or materials are identified in this paper in order to adequately specify the experimental procedure. Such identification does not imply recommendation or endorsement by the National Bureau of Standards nor does it imply that the materials or equipment identified are necessarily the best available for the purpose.) 
IV. Sampling

Dilution with a suitable solvent may be necessary depending on the viscosity and chlorine level in the sample. If the viscosity of the sample prevents the use of microsyringe, proper dilution is needed to correct this problem or by weighing. the sample into the boat. If the chlorine concentration is above $200 \mathrm{ppm}$, dilution is needed to reduce the chlorine concentration down to 100-200 ppm.

V. Precision

The precision expected for various concentration levels, as reported in Dohrmann's Application Note MC-201 is:

$\begin{array}{cr}\text { ppm C1- } & \begin{array}{r}95 \% \text { Confide } \\ \text { \#\% Re }\end{array} \\ 1-10 & 10 \\ 10-100 & 5 \\ >100 & 3\end{array}$

VI. Safety

The samples analyzed may be toxic and may cause skin or eye irritation. Adequate ventilation should be used at all times and proper care should be exercised. The concentrated acetic acid electrolyte should be treated as any strong acid. The coulometer cabinet should be ventilated in a hood. 

National Bureau of Standards Special Publication 674. Proceedings, Conference on Measurements and Standards for Recycled 0i1 - IV, held at NBS, Gaithersburg, MD, September 14-16, 1982. (Issued July 1984).

\section{A THIN-FILM OXYGEN UPTAKE TEST FOR THE EVALUATION OF AUTOMOTIVE LUBRICANTS}

C. S. Ku and S. M. Hsu

Tribochemistry Group

Materials Chemistry Division

National Bureau of Standards

Washington, D.C. 20234

\section{ABSTRACT}

A thin-film, oxygen absorption test has been developed for the evaluation of automotive lubricants using a standard Rotary Bomb Oxidation Test apparatus (RBOT) with simple modifications. The test measures the induction time of the lubricant under test conditions which simulate high temperature oxidation process in automotive engines. Effects of oxidized fuel components and metal catalyses as well as the effect of hydrolysis on oil oxidation were considered. Test results on the ASTM engine sequence IIID reference oils suggested qualitative correlation with engine viscosity increase data. Additional commercial oils were also tested and the results fell within the reference oil ranges. The paper has been published elsewhere ${ }^{1}$ and a copy of the paper is included as an appendix to this abstract.

${ }^{1}$ C.S. Ku, S.M. Hsu, A thin film oxygen uptake test for the evaluation of automotive crankcase lubricants. Lubrication Engineering 40, 2; pp. 75-83; 1984. 


\section{A Thin-Film Oxygen Uptake Test for the Evaluation of Automotive Crankcase Lubricants}

\author{
CHIA-SOON KU (Member, ASLE) \\ and \\ STEPHEN M. HSU (Member, ASLE) \\ Natlonal Bureau of Standards \\ Washington, DC 20234
}

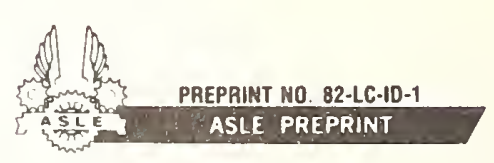

A thin-film oxygen absomption test has been developed for the evaluation of automotze crankcase lubrcants using a standard rotary bomls oxidation test (RBOT) apparatus with modifications. The test measures the oxulation induction tume of the lubricant under condtions which smulate the high-temperature oxidation procesies in automotive engines. Effects of oxidized fuel components and metal catalysts on oul oxidation were studied. Test results on the ASTM ingzne sequence $I I I D$ reference oils suggested qualitatize correlatum with engune azscosty increase data. Additumal commercial onls were also tested and the revults foll winth the range of reference ouls.

\section{INTAODUCTION}

Automotive crankcase oils dre fornulated to meet the modern engine service requirements. Such requirements are currently defined by a set of engine dynamoneter tests and field testing. One of the tests used to measure hightemperature oxidation stability is the ASTM sequence IIII) engine dynamometer test. T his test simulates high-temperature, high-load, highway operating conditions, and measures the oil viscosity increase, sludge and lacquer formation, and cam and lifter wear characteristics of crankcase oils. There are performance limits associated with each of the above parameters in IIID test. To maintain test precision, the ASTM test monitoring board has set up an engine test stand reference qualihication system. A coded reference oil is periodically sent to each testing laboratory and the results are checked for accuracy and precision compared with the known performance of that reference oil.

Due to the high cost involved in engine testing, many laboratory bench oxidation tests have been developed to assess oil quality prior to engine testing. Common tests such as the Rotary Bomb Oxidation Test (1). (RBOT, ASTM D2272) and the I urbine Oil Stability Test (2) (TOST, ASTM D943) were developed for steam turbine oils but sometimes were used for other oils also. Other tests such as the

Presentod as an American Society of Lubrication Engineers paper at the ASME/ASLE Lubricstion Confarence in Washington, D. C., October 5-7, 1882

Publication of the National Bureau of

Standards. Not subject to Copyriaht.
Penn State microoxidation test (3), oxygen absorption circulatory test (4), and Ford modihed oxidation test (5) have also been used. A detailed review of oxidation tests is presented in Ret. (6). However, correlation between these tests and the engine tests is not well established.

In this study, the development of a thin-film oxygen uptake test which correlates with engine sequence $111 \mathrm{D}$ viscosity increase test results is described.

\section{OIL DEGRADATION MECHANISM IN GASOLINE ENGINES}

Since a bench test is used to simulate an engine test, it is iniportant to understand how oil degrades in an engine.

There are a limited number of studies on oil degradation mechanisms based on engine sequence $I I I C$ engines or single-cylinder engines in the literature $(7)-(16)$. Although the basic mechanisms of oil oxidation and deposit formation are not well understood, these studies reveal some important parameters in oil oxidation and degradation processes in engines.

The engine can be viewed as a system consiscing of two chemical reactors in series. The first reactor is at the piston ring, cylinder-liner area where a thin film of oil is subjected to high temperature, high shear stress, and combustion gases. The second reactor is located in the oil sump with temperatures ranging from ambient to $100^{\circ} \mathrm{C}$.

Significant oil degradation occurs in the piston ring zone and the cylinder liner areas. Oil is pumped to various parts of the engine such as rocker arms, valve trains, and cams and lifters reaching temperatures between 80 and $100^{\circ} \mathrm{C}$, but it is subjected to far more severe conditions at the piston and cylinder liners. In these areas, oil can encounter the following conditions: (I) Some oil is left on the cylinder liner to face the combustion flame front at a temperature of 370 to $425^{\circ} \mathrm{C}$. At these temperatures, the light ends of the oil are vaporized. Heavier fractions are oxidized and are mixed with the high-molecular-weight fuel components such as fuel additives, lead salts and lead scavengers from leaded fuels, and partially oxidized gasoline fraction. This oil mixture is then scraped by the piston ring and returned 
to the oil sump. (2) Some oil is circulated ahough the pistom rings al tempetatures of 200 to $260^{\circ} \mathrm{C}$, clepending on operating conditions and engine ispe. Ihis oil in in comtact

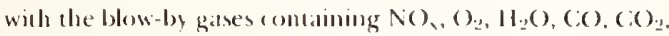
and soot, anel is olten oxidied and $/$ on mituated. At these temperatures, the oil may also be dehidrogenated because the polished iron of the piston rings can serse as a cottalyos for that process

Blow-by gases are appatently the mam anse of deposil formation. The blow-by gases ate mate up of combustion product and partially oxidized luel components a described above. Anderion (17) reponted ahat, in a labotator engine, out of the 1000 to $3000 \mathrm{ppon} \mathrm{NO}$, measured in exhaust gases (ithounts vally with ain/luel rittio. complession ratio, speed, etc.), only about 40 percent is lelt when the blow-by gases reath the crankease. I his suggests thall ap) proxinately 60 percent of the NO, reats with tuel components and oil in the ring zone areas. I he nimro and nitrate products appatently then react with oxidized hvel rocatoms to form sludge and varnish. Spindt (14) operated an engine in a nitrogen-liree atmosphere and obtained essentially clean pistons.

The olefins and aromatics in the luel have been identitied as the primary active hydrocarbon conponents. Several studies (7)-(10), (12) have indicated that sone $\mathrm{C}_{2 y}-\mathrm{C}_{1 ;}$ olefins in the fuel react with $N \mathrm{O}_{\mathrm{x}}$ to form $\alpha, \beta$ nitro-nitrates which

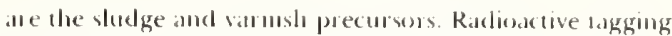
experiments with benene as luel demomstrate that 95 per(ent of the sludge callbon (omes lom the luel. Alhil-atromanc components in the luel ( $C_{4}-C_{11}$ alhyl bensenes and alhyl indanes) have aloo been shown to ellea banish lormanton in engines. I he chemical composinon ol several upes ol engine deposits is given in I ables 1 and?. As shown. whe ellects ol tirel componems are evidemt.

Certain additives may also play a role in engine varnish and sludge deposil lommation. For example, sulfomates ante ured as rust inhibions and detergents. Some sullondtes condd reace with water and oil oxiclation prosluch to lorm potsmers and gel the lubricant. Rine dialkyl dithophosplate (/1)1) $)^{2}$ ), while inhibiting oxidation and preventing we all and ecrome, maty acompose in hot acidic envirommens to give oil insoluble products. Viscosity index (V'l) inposers ant hugh-moleculats-weight polvmers thatl uncoil at high tentperallutes to increase oil viscosits. At the same time, l'l improvers are ver susceptible to oxidation and clatin scission via liee radical oxidation. Ihus, in oil lomulation. these additives most be properly balanced to maximise their desired benelos and to minimize their contribution in deposit lormation.

In summary, sludge and vamish precursors had been suggested to be lormed in the lirst reactor I rom lubricant blow-by gas interactions. The blow-by gaves comained par-

\begin{tabular}{|c|c|c|c|}
\hline$\underline{V \text { IR:M(T) }}$ & PMION VAR:MMI: & \multicolumn{2}{|c|}{ 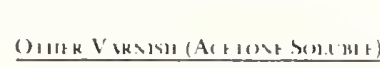 } \\
\hline c: & $20-7.5 \% W_{1}$ & (: & $67-76 \% \mathrm{~W}_{1}$ \\
\hline $\mathrm{H}$ & $2-10$ & H & $8-10$ \\
\hline $\mathrm{N}$ & $1-3$ & $\mathrm{~N}$ & $1-3$ \\
\hline S & $1.5-11$ & $\mathrm{~s}$ & $1-2$ \\
\hline $\mathrm{Br}$ & $1-5$ & Bir & $2-5$ \\
\hline (.) & $1-4$ & $(: 1$ & $1-4$ \\
\hline $\mathrm{Pb}$ & $5-11 i$ & Pll) & $5-6$ \\
\hline 0 & $11-16$ & 0 & $2-6$ \\
\hline MW & $300-350$ & $\mathrm{MW}$ & $600-650$ \\
\hline
\end{tabular}

*Elements listed by their chenical svmbol, $M W=$ drerage moleculdr weight.

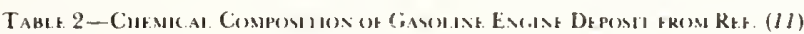

$\underline{\text { SI.t1). }}$

Solids $16-32 \%$ Wt

Liquid $64-80 \%$

Others $4 \%$

\begin{tabular}{|c|c|c|c|}
\hline \multicolumn{2}{|c|}{ Solns. } & \multicolumn{2}{|c|}{ Lielio } \\
\hline Lead halides & $30-40 \% W_{t}$ & Water & $0-2 \% W_{t}$ \\
\hline Zinc & $4-9$ & Oil & $60-80$ \\
\hline Phosphorus & $0.3-0.6$ & Fuel & $4-6$ \\
\hline Sulfur & $2-4$ & & \\
\hline Iron & $1-2$ & & \\
\hline Silicon & $0.1-1$ & & \\
\hline Oil insoluble & & & \\
\hline $\begin{array}{l}\text { oxidation } \\
\text { product* }\end{array}$ & $40-60$ & & \\
\hline
\end{tabular}

*oxygen $=13-15 \%$, Hydrogen $=8-10 \%$

Carbon $=60-70 \%$, Nisrogen $=1.5 \%$ 
tially oxidized fuel components, and these components were mixed with water and onler deposit precursors in the second reactor. Further reations then led to the formation ol sludge and varnish in engines. The postulated oil clegradation medanisms are sunnarized in Fig. I. 'To develop a bench rest for engine simulation, the following chemical rean tions need to be comsidered: (1) oxidation at high tenperature: (2) hydrolysis; (3) catalysis by luel components (uitrated olefun and aromatic components); (4) catalysis by metals (lead salts and iron and wear metals); as well as (5) thermal decomposition, and (h) alsorption, adsorption, and subsequent polymerization.

\section{OXIDATION TEST DESIGN}

Based on the oil degradation mechanisms discussed above. a thin-film oxidation test appears to be ideal to simulate the piston ring zone/cylinder liner conditions. A high-pressure, thin-film design should eliminate oxygen mass transfer limitations since the oxygen diffusion rate is much slower than the oxidation reaction rate. With a thin-film test, the amount of the oil tested necessarily has to be small. Therefore, fre- quent and periodic sampling of test oil for viscosity measurement is dulficult. Removing a large percentage of the test oil as samples during the procedue will also increase the test severity and affect the test precision. However, since the system discussed in this paper is under pressure, oxygen absorption by oil can be easily measured. This will provide an oxygen uptake value as a measure of oxidation stability. The next question is how to keep d uniformly thin oil film. Systems with oil spraying on rotating cylinders, inclined planes, or concentric cylinders were considered. However. these systems tend to be complex and dilficult to control. It was finally decided to use the existing Rotary Bomb Oxidation Test apparatus (ASTM D2272 oxidation apparatus) with some key modifications. The modifications were (A) to reduce the bomb volume and $(B)$ to reduce the oil sample size to ensure a uniformly thin oil $\mathrm{hlm}$. The existing rotary bomb apparatus (ASTM D2272) consists of a glass beaker loosely fited in the bomb which is located in an oil bath about $30^{\circ}$ Irom horizontal plane. The glass beaker holds about $50 \mathrm{~g}$ of oil and an oil film is formed on the glass wall when the bomb rotates. To increase the proportion of oil in the thin film while reducing that which remains in the

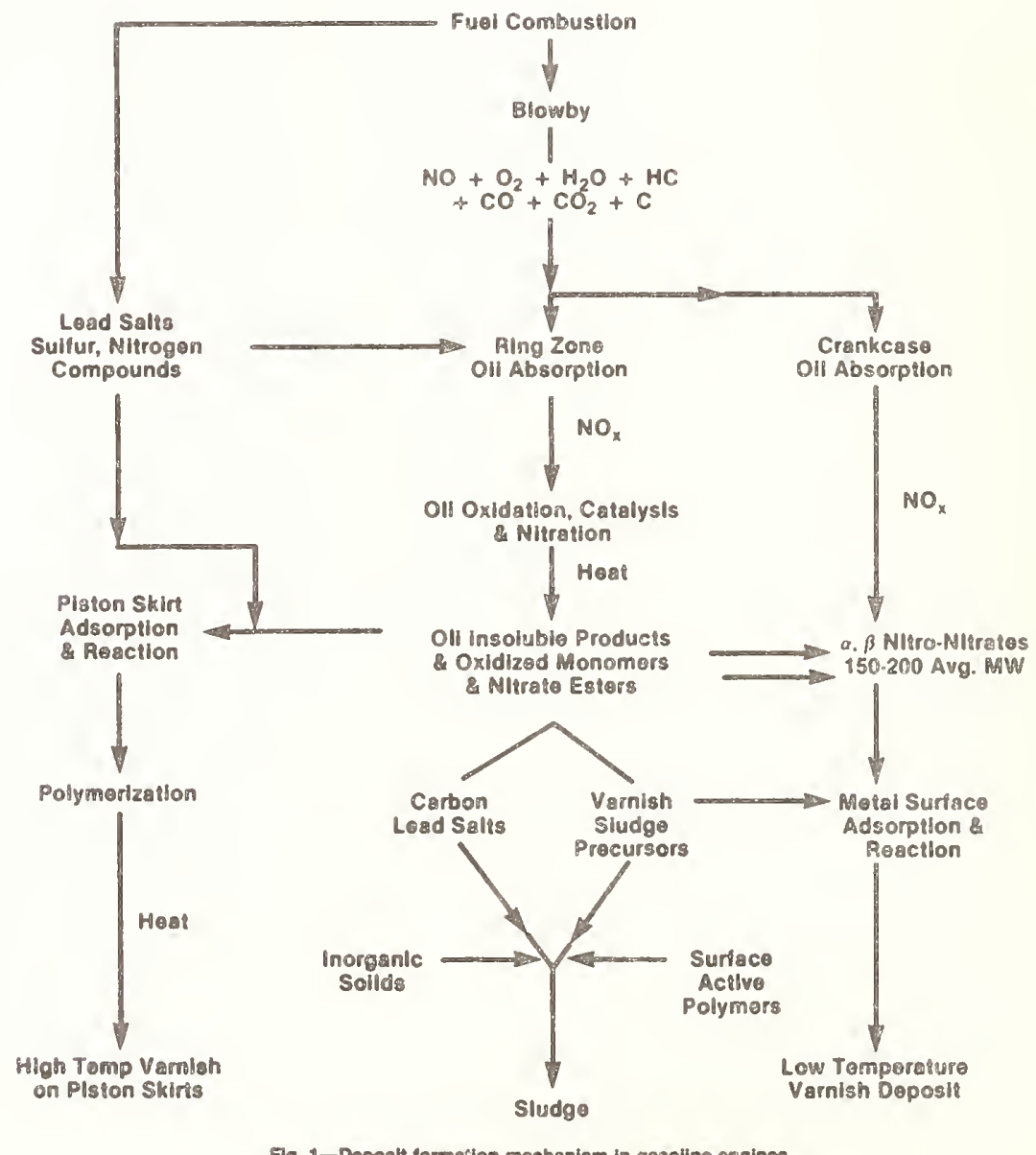

Fig. 1-Dopoalt formetion mochenism in gasoline engines 
bottom of the beaker, it was necessary to shorten the glass beaker and to use a smatler oit sampte. The glass beakel was made to have a closer fit with the bomb in order (1) avoid the use of a heat transfer Huid between the beaker and the bomb, and the retention tip of the beaker was extended to avoid oil spillage during the test (Fig. 2).

\section{EXPERIMENTAL APPARATUS AND PROCEDURES}

The ASTM RBOT (D2272) apparatus was modified for this study as shown in Fig. 2. An aluminum insert was put into the bomb to reduce the volume by 80 percent. As shown in the diagram, the beaker has a minimum of $0.64-\mathrm{cm}$ fong lip curved in approximately $30^{\circ}$ from the horizontat plane. This lip is designed to contain the oil since the bomb is positioned at an angle in the oil bath during the experinent.

The operating procedures are described below: $1.5 \mathrm{~g}$ of the oil sample was weighed into the beaker. Water and catalyst package were weighted and mixed with the oil. The beaker containing the sample was then placed in the bonb as shown in Fig. 2. The bomb was purged with pure oxygen at $620 \mathrm{KPa}$ successivefy to remove the air originafly present, and the bomb was charged with pure oxygen to 620 $\mathrm{KPa}$ at about $21^{\circ} \mathrm{C}$. (The oxygen feed pressure was controlled within $1 \mathrm{KPa}$ with an in-line precision pressure gauge. For each $3^{\circ} \mathrm{C}$ above or below this temperature, $7 \mathrm{KPa}(f \mathrm{psi}$ ) was added or subtracted to attain the required initial pressure.) The bomb was placed in a constant temperature bath at $160^{\circ} \mathrm{C}$ and rotated axially at $t 00 \mathrm{rpm}$ at an angle of $30^{\circ}$ from the horizontat (I). A typical pressure vs time trace during the test is shown in Fig. 3. As shown, the period from the start of the test (point A) to the point when the pressure of the bomb starts to drop (point $B$, determined by the interception of the pressure ptateau and the tangent of the pressure decrease line) is recorded. This time period is defined as the oxidation induction time of the oil.
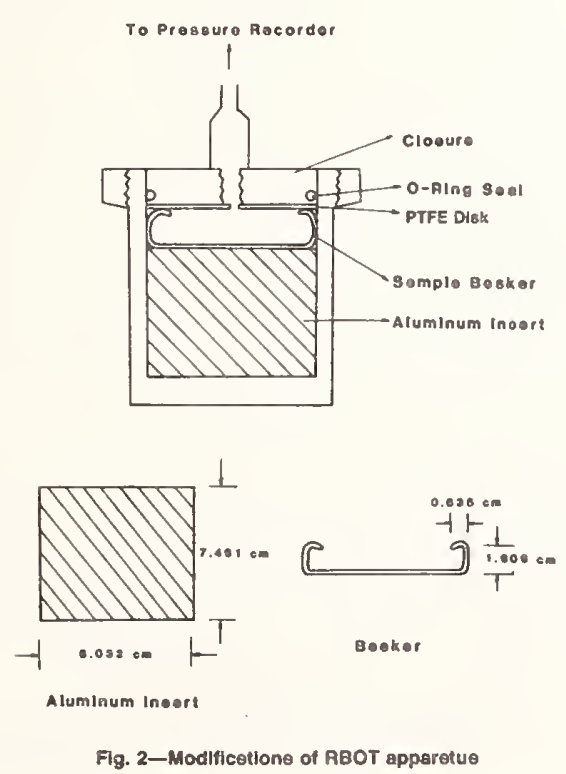

\section{TEST PROCEDURE DEVELOPMENT}

As discussed earfier, an ideal oxidation test lor the crank. case lubricating oils should simutate some of the key chenical reaction paths that exist in an engine. In IIID enginc test, the key chemical reactions may be the ligh-tentperature oxidation reactions caldyzed by metals and fuel conponents.

The temperature and pressure of the test are, to a large extent, finited by the rotary bomb oxidation apparatus design. Our initial starting point was to conduct the experiment at $150^{\circ} \mathrm{C}$ and $620 \mathrm{KPa}$ initial oxygen charge as specinted by ASTM D-2272. At $150^{\circ} \mathrm{C}$, the oxidation induction time for fully lormulated uncatafyzed oits was too fong and the pressure drop curves were sometimes indistinct. The temperature was then raised to $160^{\circ} \mathrm{C}$.

I wo forms of netat catalysts can be usect: sotid metal catafysts and oil-soluble metal catalysts. I.iterature (18), (19) indicated many oxidation tests use copper and iron as metat catalysts. From used oil analysis, mixed metals such as lead, iron, copper, manganese, and in had been found (20). Therefore, the effects of these metal catalysts and their forms need to be examined.

In addition, earlier discussions and hypotheses on the effects of oxidized/nitrated fuef components on engine oil degradation suggest the use of a "synthetic fuel btow-by" for the test. Verley (2l) and Forbes (22) devetoped a synthetic fuel bfow-by from oxidation of high-boiling gasoline fraction. Effects of synthetic luet blow-by on lubricant oxidation stability appear to be significant and should be evatuated.

The ultimate significance of the various catalytic effects on the test results were then studied using a set of ASTM sequence $I 11 \mathrm{D}$ engine test stand reterence oils. These oifs have a large body ol repeated engine test data. Through the oil viscosity break point hours (the time it takes for the oil viscosity increase to reach 375 percent in IIID engine tests), the oxidation stabitity of these reference oifs can be ranked. Therefore, various combinations of the catalyst systems were systematically examined using the ASTM reference oits.

\section{EFFECTS OF SOLID METAL CATALYSTS}

Solid metats have been used in many oxidation tests as catatysts. For example, Cecil (I8) used iron and copper wires and Kuhn (19) used iron and copper strips to study the oxidation stabifity of automotive crankcase oits. Using iron and copper wires, Cecil developed an oxidation test which

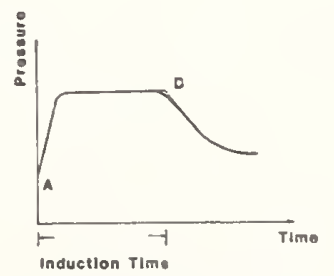

Fig. 3-Typlcal Induction time determination in the oxygen upteke test 


\begin{tabular}{|c|c|c|c|c|c|c|}
\hline \multicolumn{7}{|c|}{$\begin{array}{l}\text { Table 3-Induction Times of III-D Reference OIIS USint. Siffl and Copper Wires as } \\
\text { MeTal. Caralysts }\end{array}$} \\
\hline & CONDITIONS & \multicolumn{4}{|c|}{$\begin{array}{l}1.5 \mathrm{~g} \text { Oil } \\
2 \% \text { Warer } \\
12 \mathrm{~cm} \text { Steel and Copper Wires Each } \\
160^{\circ} \mathrm{C} \\
620.6 \mathrm{KPa} \text { Oxygen (90 psig) }\end{array}$} & \\
\hline \multirow[b]{2}{*}{$\mathrm{O}_{12}$} & \multirow{2}{*}{$\begin{array}{l}1110 \text { VISCOSITY } \\
\text { INCREASE } \\
\text { BREAKHOURS* }\end{array}$} & \multicolumn{5}{|c|}{ INDUCTION TIME (Min) } \\
\hline & & & & Avg. & \% Sid. dev & RANK \\
\hline $76 \mathrm{~A}-1$ & 64 (Pass) & $>590$ & $>590$ & $>590$ & - & 1 \\
\hline $75 B-1$ & 56 (Pass) & 395 & 487 & 441 & 15 & 2 \\
\hline $79 A$ & 40 (Pass) & 250 & 258 & 254 & 1 & 3 \\
\hline $77 \mathrm{~B}-1$ & 24 (Fail) & 240 & 250 & 245 & 3 & 3 \\
\hline $77 \mathrm{C}$ & 16 (Fail) & 193 & 168 & 181 & 10 & 4 \\
\hline $72 A-1$ & 16 (Fail) & 198 & 176 & 188 & 8 & 4 \\
\hline
\end{tabular}

*These hours indicate the average hours of the reference oil reaching $375 \%$ viscosity increase in the $11 \mathrm{D}$ engine lesi.

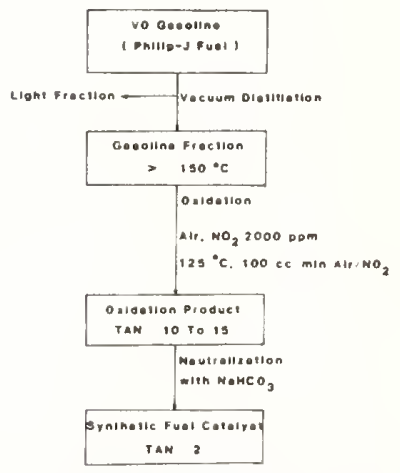

Fig. 4-Dlagrem for the synthesis of fuel catalyst for oxygen upteke test

correlated qualitatively with $11 \mathrm{IC}$ viscosity increases datcs using several formulated oils. He oxidized the oil, in the preseme of iron and copper wires, by bubbling oxygen into the oil for a fixed period. The viscosity increase of the oil was measured periodically. The criterion lor a pass was a viscosity increase of less than 400 pertent alter 400 hours.

Effects of iron and copper wire catalysts on oxidation were examined using the thin-thlm oxygen uptake apparatus. $12 \mathrm{~cm}$ each of low-metalloid steel wire and electrolytic copper wire (used in ASTM D943) were used. Immediately before use, the wires were polished with silicon carbide abrasive cloth, and wound into a $48-\mathrm{mm}$ o.d. coil. The coils were cleaned with $n$-pentane and acetone ultrasonically, dried by air, and inserted immediately inside the sample glass beaker by a turning motion.

Duplicate test results of the oxygen uptake test using iron and copper wires on six IIID reference oils are shown in Table 3 . There is a qualitative ranking of the reference oils. The range of the oxidation induction time is wide, from $181 \mathrm{~min}$ to $>590 \mathrm{~min}$. The most stable oil $76 \mathrm{~A}-1$, has an oxidation induction time greater than $590 \mathrm{~min}$. This corresponds to the IIID engine test results. However, oil $79 \mathrm{~A}$ (a pass oil) and oil 77B-1 (a fail oil) have the same oxidation induction time within the test repeatability. Separation of these two oils should be more pronounced. The test precision based on duplicate test results suggests some problems with the solid metal catalysts. Oil 75B-1 and oil 77C have 10 to 15 percent standard deviations. This problem may be inherent with the cleanliness of the metal surfaces and oil chemistry.

\section{EFFECTS OF FUEL CATALYST}

Earlier discussions indicated that the ef fects of fuel blowby on lubricant oxidation may be significant. Thus, a synthetic tuel "blow-by" catalyst was prepared to simulate the engine conditions. Since blow-by analysis indicates the presence of oxidized and nitrated high-boiling fuel components, the tuel catalyst was made by oxidizing, in the presence of nitrogen oxides, a high-boiling fraction of VD engine test luel. I his fuel catalyst was prepared according to the procedures shown in Fig. 4. The fuel was hrst distilled to obtain the high-boiling fraction $\left(>150^{\circ} \mathrm{C}\right)$. This material was then oxidized in the presence of 2000 ppm nitrogen dioxide at $125^{\circ} \mathrm{C}$ for 72 hours. The oxidation was carried out in a 3.8 $\mathrm{cm}$ dismeter open glass tube with $100 \mathrm{cc} / \mathrm{min}$ air flow rate. During oxidation, volatile oxidation products generated from gasoline oxidation were allowed to escape. The high-boiling oxidized/nitrated fuel components' were collected in the oxidation glass tube. Periodic samples were taken for the total acid number (TAN) analyses. The oxidation process was terminated when the $T A N$ of the reaction products reached between 10 to 15 . The reaction product was then neutralized with saturated sodium bicarbonate solution to a TAN of 2. This neutralization step removed most of the strong acidic oxidation products which, as suggested by Forbes (20), might react with overbased detergent additives in the oil, producing anomalous results. The neutralized reaction product was used as the synthetic fuel catalyst.

Experiments were conducted using 10 percent of this fuel catalyst together with $\mathrm{Fe}$ and $\mathrm{Cu}$ wires in the oxygen uptake 


\begin{tabular}{|c|c|c|c|c|c|c|c|c|c|}
\hline \multicolumn{10}{|c|}{ TABle 4-The Effects of Flel Catal yst on Test Results } \\
\hline \multicolumn{10}{|c|}{$\begin{array}{l}1.5 \mathrm{~g} \mathrm{Oil} \\
2 \% \text { Water } \\
12 \mathrm{~cm} \text { Steel and Copper Wires Each } \\
10 \% \text { Fuel Catalyst } \\
160^{\circ} \mathrm{C} \\
620.6 \mathrm{KPa} \text { Oxygen }(90 \mathrm{psig})\end{array}$} \\
\hline \multirow[b]{2}{*}{ OIL } & \multirow{2}{*}{$\begin{array}{l}\text { IID VISCOSITY } \\
\text { INCREASE } \\
\text { BREAKHOURS* }\end{array}$} & \multicolumn{8}{|c|}{ INDUCHION TIME (Min) } \\
\hline & & & & & & & Avg. & $\%$ Std. dev & RANK \\
\hline $76 \mathrm{~A}-1$ & 64 (Pass) & 120 & 112 & 113 & \multirow{6}{*}{79} & \multirow{6}{*}{82} & 115 & 4 & 2 \\
\hline $75 \mathrm{~B}-1$ & 56 (Pass) & 138 & 115 & 123 & & & 125 & 9 & 1 \\
\hline $79 \mathrm{~A}$ & 40 (Pass) & 97 & 95 & 100 & & & 97 & 3 & 3 \\
\hline $77 \mathrm{~B}-1$ & 24 (Fail) & 81 & 85 & 84 & & & 82 & 3 & 4 \\
\hline $77 \mathrm{C}$ & 16 (Fail) & 56 & 54 & 54 & & & 55 & 2 & 6 \\
\hline $72 \mathrm{~A}-1$ & 16 (Fail) & 63 & 60 & 65 & & & 63 & 4 & 5 \\
\hline
\end{tabular}

*These hours indicate the average hours of the reference oil reaching $375 \%$ viscosity increase in the IIID engine test.

\begin{tabular}{|l|c|c|}
\hline \multicolumn{2}{|c|}{ Table. 5-Composition of Soldibie Metal. Catalyst Package (20) } \\
\hline Metal & Weigiet Ratio & WEight Percent \\
\hline Lead Napthenate & 8.00 & 81.5 \\
Cupric Napthenate & 0.69 & 7.0 \\
Ferric Naphthenate & 0.41 & 4.2 \\
Manganese Naphthenate & 0.35 & 3.6 \\
Stannous Naphthenate & 0.36 & 3.7 \\
\hline
\end{tabular}

test. The triplicate test results are shown in Table 4 . The oxidation induction time ranges from 55 to 125 minutes, considerably shorter than the results with iron and copper wires alone. The correlation with engine test data was not achieved as could be seen from the oil ranking. However, the three "pass" oils have higher induction times than the three "fail" oils. The induction times of the three pass oils range from 97 to $125 \mathrm{~min}$, while those of the three fail oils range from 55 to $82 \mathrm{~min}$. Within each category, the test does not rank the oils correctly. For example, the $64 \mathrm{~h}$ pass oil $(76 \mathrm{~A}-1)$ is ranked lower than the $56 \mathrm{~h}$ pass oil ( $75 \mathrm{~B}-1)$.

The separation between the "pass" and the "fail" oils appears to be improved when the fuel catalyst is used. The repeatability of the test seems also to be improved slightly. Oil 75B-1 still has a standard deviation of 9 percent.

The results, so far, suggest that the fuel catalyst increases the separation between the "pass" and "fail" oils. The effects of the various metal catalysts will be examined next.

\section{EFFECTS OF SOLUBLE METAL CATALYSTS}

Various metals are found in used motor oils: iron, copper, manganese, tin, chromium, lead, etc. Some of these metals come from wear. Lead comes from the leaded gasoline and the scavenged lead. Wear metals and lead compounds can cause significant catalytic effects on oil degradation. To study the catalytic effects of these metals, a soluble metal catalyst package was prepared according to Hotten (20). The concentrations of the various metals are presented in Table 5 . This mixed soluble-metal catalyst package was used to re- place the solid-metal catalysts. The results of the oxygen uptake test are shown in Table 6. The oxidation induction time ranges from 40 to 106 minutes. The separation between the "pass" oils and "fail" oils is improved significantly from 15 minutes to 38 ininutes. The oxidation induction times of individual oils within each group, however, are not significantly different. One possible explanation is that the test conditions may be too severe and the concentrations of the catalyst packages need to be optinized.

\section{CONCENTRATIONS OF SOLUBLE METAL CATALYST AND FUEL CATALYST}

The oxidation induction time results shown in Tables 4 and 6 suggest that the soluble metal catalyst and the synthetic-fuel catalyst significantly affect the oxidation stability of automotive engine oils. In the presence of the two catalyst packages, the oxygen uptake test is able to clearly distinguish good reference oils from poor reference oils. However, in these experiments, the concentrations of the catalyst packages may not represent the optimum. Therefore, the effects of the concentrations of the two catalyst packages on the oxidation stability of reference oils were studied.

Two reference oils, one "pass" oil (79A) and one "fail" oil (77B-1), were tested at several catalyst package concentration combinations. Concentrations of the total catalyst packages were varied as well as the ratio of the two catalyst packages. Results of the test are shown in Table 7 . The best separation of the oxidation induction times between the two 


\begin{tabular}{|c|c|c|c|c|}
\hline \multicolumn{5}{|c|}{ 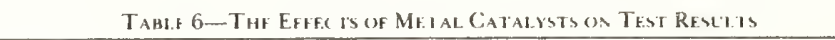 } \\
\hline \multicolumn{2}{|r|}{ CoNDITIONS: } & \multicolumn{3}{|c|}{$\begin{array}{l}1.5 \mathrm{~g} \text { Oil } \\
2 \% \text { Water } \\
10 \% \text { Fuel Catalyst } \\
5 \% \text { Soluble Metal Catalyst Package } \\
\quad(\mathrm{Pb} / \mathrm{Fe} / \mathrm{Cu} / \mathrm{Mn} / \mathrm{Sn}) \\
160^{\circ} \mathrm{C} \\
620.6 \mathrm{KPa} \text { Oxygen }(90 \mathrm{psig})\end{array}$} \\
\hline \multirow[b]{2}{*}{ Ori. } & \multirow{2}{*}{\multicolumn{2}{|c|}{$\begin{array}{l}\text { IIID VISL OSIIY } \\
\text { INCREASt. } \\
\text { BREAKILUL'R" }\end{array}$}} & \multicolumn{2}{|c|}{ INDTCION TIME (Min) } \\
\hline & & & & ANK \\
\hline $76 A-1$ & \multicolumn{2}{|c|}{64 (Pass) } & 93 & 2 \\
\hline $75 \mathrm{~B}-\mathrm{l}$ & \multicolumn{2}{|c|}{56 (Pass) } & 106 & 1 \\
\hline $79 \mathrm{~A}$ & \multicolumn{2}{|c|}{40 (Pass) } & 95 & 2 \\
\hline $77 \mathrm{~B}-1$ & \multicolumn{2}{|c|}{24 (Fail) } & 57 & 3 \\
\hline $77 \mathrm{C}$ & \multicolumn{2}{|c|}{16 (Fail) } & 40 & 5 \\
\hline $72 \mathrm{~A}-1$ & \multicolumn{2}{|c|}{16 (Fail) } & 47 & 4 \\
\hline
\end{tabular}

"These hours induate the average hours ol the reference oil reaching $375 \%$ viscosity increase in the IIID engtne test

$01 \mathrm{l}$ ( 100 minutes) was achieved at 5 percent each of the fuel and soluble-metal catalyst package.

The total amount of catalyst packages appear to have a significant impact on test severity but not the separation (comparing cases $\mathrm{A}$ and $\mathrm{D}$ as shown in Table 7). Too large a dosage of the catalyst packages seems to suppress the separation (comparing $\mathrm{A}$ and $\mathrm{D}, \mathrm{B}$ and $\mathrm{E}$ ). The ratio between the fuel catalyst package and the soluble-metal package also appears to be important. Results in the cases of $\mathrm{A}$, $B$, and $C$ suggested the ratio of 2:I having the best separation, yet case $\mathrm{E}$ at lower total catalyst concentration did not confirm this hypothesis. There could be a minimum concentration of the soluble-metal catalyst package below which the effects are not signihcant. For the purpose of this study, the case of 5 percent each appears to be adequate.

\section{RESULTS AND DISCUSSIONS}

The final test conditions, therefore are set as follows:

$$
\begin{aligned}
& \text { Sample size: } \quad 1.5 \mathrm{~g} \\
& \text { Temperature: } \quad 160^{\circ} \mathrm{C} \\
& \text { Catalyst Package: } \quad 5 \text { percent oxidized fuel } \\
& \text { components } \\
& 5 \text { percent soluble metal } \\
& \text { catalysts } \\
& 2 \text { percent water } \\
& \text { Initial oxygen pressure: } 620.6 \mathrm{KPa} \text { (90 psi). }
\end{aligned}
$$

Test results of six ASTM engine sequence IIID reference oils using the above test conditions are summarized in Table 8. As shown, the results correlate well with the engine test results. The "pass" oils have much higher oxidation induction times ( 155 to $273 \mathrm{~min}$ ) than the "fail" oils ( 39 to 60 min). The separation between the "pass" and "fail" oils is more than $90 \mathrm{~min}$. Further, the ranking of the oil is correct for all the oils, and the repeatability of the test is within 5 percent for alt the reference oils.

Eighteen commercial oils selected at random (I3 API SF and 6 API SE classifications) were also tested with the new procedure. Different SAE viscosity grades from different oil manufacturers were selected. The oxidation induction times of those oils are summarized in Table 9. The induction time of the $6 \mathrm{SE}$ oils ranges from 87 to $138 \mathrm{~min}$, and of the $13 \mathrm{SF}$ oils, the range is 87 to $210 \mathrm{~min}$. These oxidation induction times fall within the range of the IIID reference oils ( $39 \mathrm{~min}$ to $273 \mathrm{~min}$ ).

\section{CONCLUSIONS}

A high-pressure, thin-hilm, oxygen absorption test has been developed using an existing commercial oxidation apparatus. The results of the test correlate with the ASTM sequence IIID engine test data as demonstrated by the ASTM engine test stand reference oils. The study shows that it is important to understand the oil degradation mechanisms in engines so that bench test simulation can be achieved by providing a similar chemical environ ment for the key chemical reaction pathway. The study also shows that mixed metals and the fuel blow-by have significant impact on engine oil degradation. The optimization studies on the catalyst combination and concentration suggest that it is necessary to have the proper catalyst combinations and concentrations. The simulation is successful only when both requirements are met.

\section{ACKNOWLEDGMENT}

The authors wish to express their thanks to the Recycled Oil Program, Office of Recycled Materials for their generous support of this work.

\section{REFERENCES}

(I) ASTM D2272, 1981 Annual Book of ASTM Standards, Part 24, "Oxidation Stability of Steam Turbine Oils by Rotating Bomb," ASTM, Philadelphia (1981). pp 289-298.

(2) ASTM D943, 1981 Annual Book of ASTM Standards, Part 23, "Oxidation Characteristics of Inhibited Mineral Oils." ASTM, Philadelphia (1981). PP 437-450. 


\begin{tabular}{|c|c|c|c|c|c|}
\hline \multicolumn{6}{|c|}{$\begin{aligned} \text { Conditions: } & 160^{\circ} \mathrm{C} \\
& 620.6 \mathrm{KPa} \text { Oxygen } \\
& 2 \% \text { Water } \\
& 1.5 \mathrm{~g} \text { of Oil Sample }\end{aligned}$} \\
\hline & \multicolumn{2}{|c|}{ CONCENTRA TION, \% (Wi) } & \multirow{2}{*}{$\begin{array}{c}\text { TOMAL Catalyst } \\
\text { Concentration } \\
\% W_{L}\end{array}$} & \multicolumn{2}{|c|}{ OXIDAIION INDUCIION: TIMF (MII) } \\
\hline & $\begin{array}{c}\text { Fuel Catalyst } \\
\text { Package }\end{array}$ & $\begin{array}{c}\text { Soluble Metal } \\
\text { Packace }\end{array}$ & & $77 \mathrm{~B}-1$ & $79 \mathrm{~A}$ \\
\hline A & 10 & 10 & 20 & 38 & 45 \\
\hline B & 10 & 5 & 15 & 57 & 95 \\
\hline $\mathrm{C}$ & 10 & 2 & 12 & 100 & 95 \\
\hline D & 5 & 5 & 10 & 58 & 158 \\
\hline $\mathrm{E}$ & 5 & 2 & 7 & 125 & 210 \\
\hline
\end{tabular}

\begin{tabular}{|c|c|c|c|c|c|c|c|c|c|}
\hline \multicolumn{10}{|c|}{$\begin{array}{l}\text { Table 8-Comparison of the New Oxycen Uptake Test Results } \\
\text { With IIID Engine Tesi Results }\end{array}$} \\
\hline & \multicolumn{8}{|c|}{$\begin{array}{l}1.5 \mathrm{~g} \text { Oil } \\
2 \% \text { Water } \\
5 \% \text { Fuel Catalyst } \\
5 \% \text { Soluble Metal Catalyst Package } \\
160^{\circ} \mathrm{C} \\
620.6 \mathrm{KPa} \text { Oxygen }(90 \mathrm{psig})\end{array}$} & \\
\hline \multirow[b]{2}{*}{ OIL. } & \multirow{2}{*}{$\begin{array}{l}\text { IIID VISCOSITY } \\
\text { INCREASE } \\
\text { BREAKHOURS* }\end{array}$} & \multicolumn{8}{|c|}{ INDUCTION TIME (Min) } \\
\hline & & & & & & & Avg & $\%$ Sid. dev & RANK \\
\hline $76 \mathrm{~A}-1$ & 64 (Pass) & 268 & 278 & \multirow{6}{*}{$\begin{array}{r}158 \\
69\end{array}$} & \multirow{6}{*}{$\begin{array}{r}157 \\
61\end{array}$} & \multirow{6}{*}{$\begin{array}{r}154 \\
61\end{array}$} & 273 & 3 & 1 \\
\hline $75 \mathrm{~B}-1$ & 56 (Pass) & 200 & 186 & & & & 193 & 5 & 2 \\
\hline $79 \mathrm{~A}$ & 40 (Pass) & 154 & 150 & & & & 155 & 2 & 3 \\
\hline $77 \mathrm{~B}-1$ & 24 (Fail) & 58 & 60 & & & & 60 & 2 & 4 \\
\hline $77 \mathrm{C}$ & 16 (Fail) & 43 & 45 & & & & 44 & 3 & 5 \\
\hline $72 \mathrm{~A}-1$ & 16 (Fail) & 40 & 38 & & & & 39 & 4 & 5 \\
\hline
\end{tabular}

*These hours indicate the average hours of the reference oil reaching $375 \%$ viscosity increase in the 1110 engine tesi.

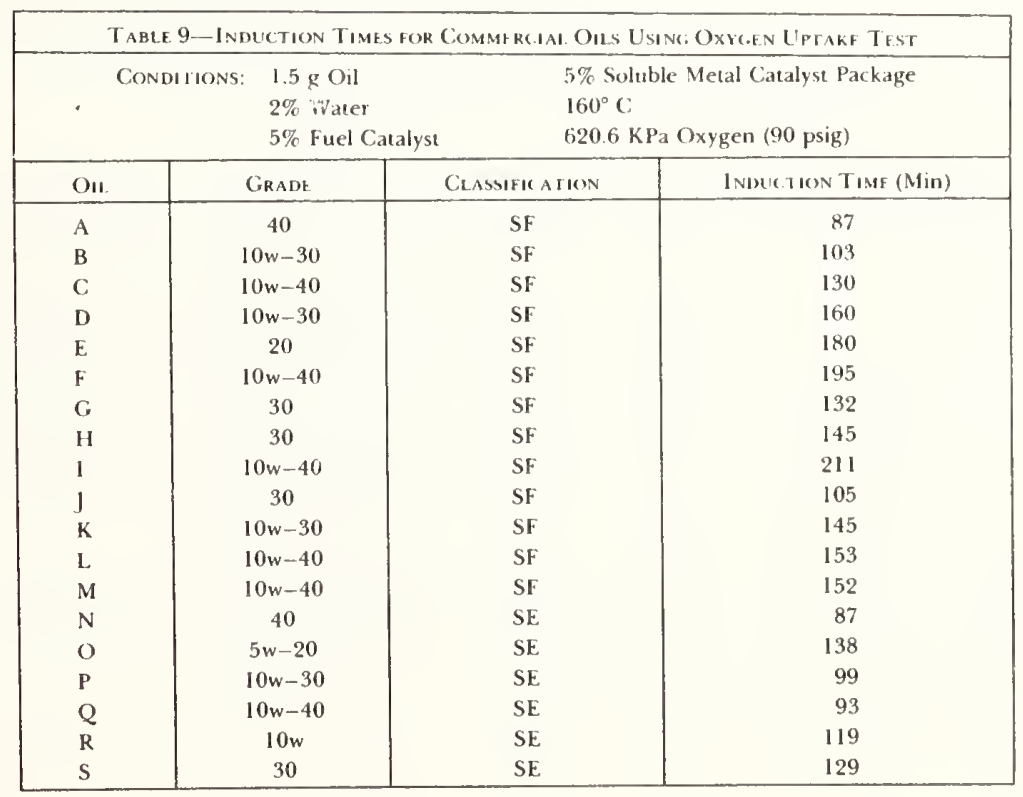




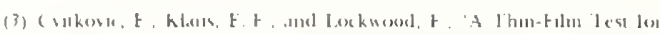

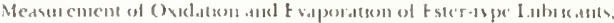

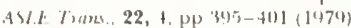

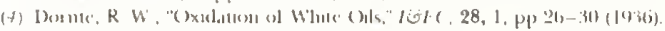

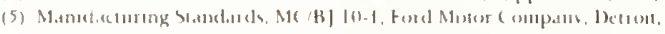
MI

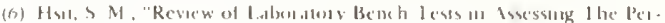

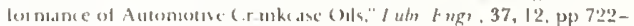
$731(1981)$.

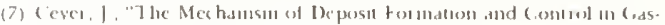

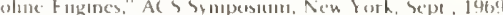

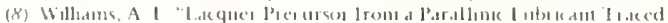

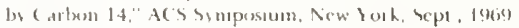

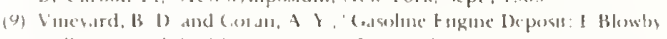

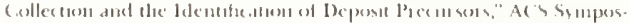
11111, New Youk, Sept, 1969

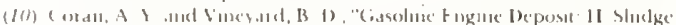

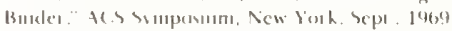

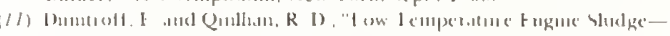

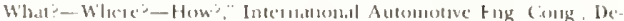

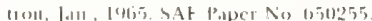

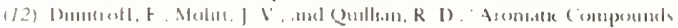

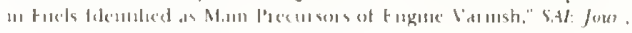

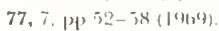

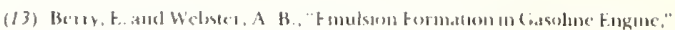
Jour low lepol. 55, 54t, pp 245-272 (I969)

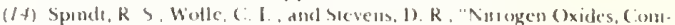
biston dund fingule De posils," SAf I rans, 64, pp 747-811 (1956)

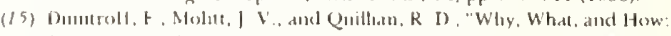

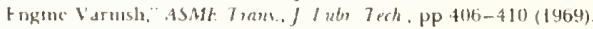

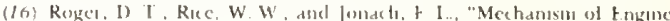
sludge Formatum and Adsluse Artion," SAl: 7rans, 64, pp 783-811 (1956)

(17) Anderson, 1) 1. "Mcrladuism ol $\mathrm{k}$ ngme Depost and Weal A Progless

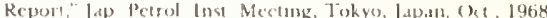

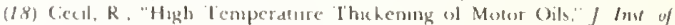
P'rtrol, 59, 569, pp 201-210 (1973).

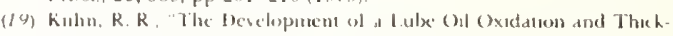
enurg Bench 7 est wo bumlate the ASI M Sequenee IIIC Fngme Test."

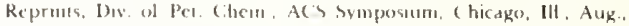
1973.

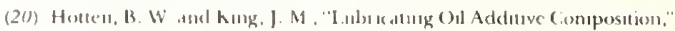
tis fittent No, 4, 1932,4ti2 (June 28, 1977)

(21) Vealev. (, M. "I.uhrkatmig (Mal Detergeney Testing." US P'atent No.

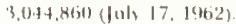

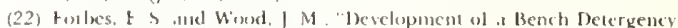

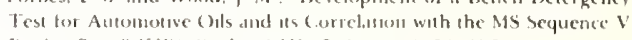

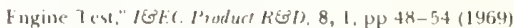


National Bureau of Standards Special Publication 674. Proceedings, Conference on Measurements and Standards for Recycled 0i1 - IV, held at NBS, Gaithersburg, MD, September 14-16, 1982.

(Issued July 1984).

\title{
THIN-FILM OXIDATION TEST: RELATIONSHIP BETWEEN COMPOSITION AND ADDITIVE RESPONSE FOR RE-REFINED OILS
}

C. S. Ku and S. M. Hsu

\author{
Chemical Stability and Tribology Group \\ Inorganic Materials Division \\ National Bureau of Standards \\ Washington, DC 20234
}

\begin{abstract}
Sixteen re-refined lubricating base oils from various manufacturing processes were examined for oxidation stability using a NBS thin film oxygen uptake test. The oils were tested with a commercial SE/CC detergent-inhibitor additive package. Correlations among oxidation stability and chemical composition parameters such as saturates, aromatics, polars, sulfur, chlorine, and total nitrogen content were investigated. The key components that appear to affect oxidation stability of re-refined base oils were found to be sulfur, total polar constituents and percent of saturated hydrocarbons.
\end{abstract}

\section{Introduction}

In modern lubricants, chemical additives are added to base oils to enhance lubricant performance. The extent of improvement in performance due to the additive package is called additive response. Recently, interest in chemical composition as a function of oxidation stability has increased due to the use of mixed crudes in oil refining.

The use of recycled lubricating base oils presents similar problems because of the difficulty encountered in defining the crude source for re-refined oils. Present Federal lubricant specifications (e.g., MIL-L-46152 and MIL-L-2104) require constancy of crude source, processing technology, and additive package. Any change in these items requires the lubricant manufacturer to re-qualify the lubricant including actual engine testing. It is clear that a better understanding of the relationship between the chemical composition of base oils and their additive response is needed as a basis for any future changes and improvements in base oil specifications and standards.

Sixteen re-refined base oils from various manufacturing processes were selected for this study. The relationship between oil composition and oxidation stability was examined. The oils were blended with a commercial, SE/CC detergent/inhibitor package. The oxidation stabilities of the oils were then measured with the NBS-developed, thin-film oxygen uptake test, which has shown a correlation with IIID engine test on ASTM reference oils [1] ${ }^{1}$.

\section{1. Oxidation Stability of Virgin Base 0ils}

Base oils for automotive lubricants are complex mixtures of paraffins, naphthenes, aromatics, and small amounts of oxygen, sulfur, and nitrogen containing compounds.

The molecules containing $S, N$, and 0 in addition to $C$ and $H$ are generally referred to as polar compounds. Some of these complex polar compounds are referred to as "natural inhibitors." When all of the polar compounds are removed from the mineral oil fraction, the remaining hydrocarbons generally are less resistant to oxidation, but are more responsive to synthetic oxidation inhibitors These synthetic inhibitors include many compounds containing carbon, hydrogen and oxygen; carbon, hydrogen and nitrogen; carbon, hydrogen and sulfur as well as other combinations where two of the three elements ( $S, N$, and 0 ) are combined with $C$ and $H$.

\footnotetext{
${ }^{1}$ Figures in brackets indicate the literature references at the end of this paper.
} 
The effect of these polar impurities on the oxidation of the hydrocarbon molecules ranges from oxidation promotion to oxidation inhibition. The relatively small quantities of the polar impurities, the complexity of the molecular structures, and the variation in molecular size make separation and identification of a specific polar compound very difficult.

More success has been achieved in the separation or synthesis of the various classes of simple hydrocarbons. Extensive studies of simple hydrocarbon oxidation are in general agreement that oxidation proceeds by a free radical mechanism involving initiation, propagation, branching, and termination steps [2].

The effects of hydrocarbon structure on oil oxidation stability have been studied by many investigators [3-10]. These studies have been conducted with both simple model compounds and fractions isolated from crude oils with various separation techniques. Many of the studies using crude oil fractions cannot separate the effects due to the small amount of impurities and those of the major hydrocarbon types. Some of the hydrocarbon oxidation data were determined in systems that were limited by oxygen diffusion and therefore, may not provide the true relative rates of oxidation as the hydrocarbon type varies.

The temperature range used in most of the oxidation studies reviewed was between 100 and $200{ }^{\circ} \mathrm{C}$. In this range, it appears that there are no major changes in the oxidation mechanism and that oxidation rates can be related by the Arrhenius Law. Based on these considerations, some fundamental trends in the oxidation of various types of hydrocarbons can be obtained from the literature.

Cranton [3] studied the effects of various types of aromatics on paraffin-naphthene mixtures using Differential Scanning Calorimetry (DSC) at $170{ }^{\circ} \mathrm{C}$ and $190{ }^{\circ} \mathrm{C}$. A solvent extracted mineral oil fraction from mid-continent crude was separated into saturated and aromatic fractions by silica gel separation and thermal diffusion. Through DSC analyses, Cranton found that alkylbenzene and naphthenobenzene decreased the stability of a saturate fraction containing isoparaffins. These same compounds had either no effect or even increased the stability of highly condensed naphthenes. Polynuclear aromatics were found to inhibit the oxidation of all saturate fractions.

Fenske [4] studied the oxidation of various fractions from a Pennsylvania neutra 1 cut at $140{ }^{\circ} \mathrm{C}$ to $180^{\circ} \mathrm{C}$ in a bulk oil oxidation system. He found that an optimum aromatic content of 15 to 25 percent in base oils gave the best oxidation stability. Larsen [5] studied a large number of pure hydrocarbon model compounds at three temperatures (110 ${ }^{\circ} \mathrm{C}, 130{ }^{\circ} \mathrm{C}$ ), and $150{ }^{\circ} \mathrm{C}$ ) using an oxygen absorption apparatus in a bulk oil system. He found that saturated hydrocarbons (paraffins or cyclic paraffins) oxidized easily producing similar oxidation products. Aromatics containing a benzene ring attached to a saturated side chain or ring structure were very active and also oxidized easily. He suggested that the hydrogen (of the saturate chain) alpha to the aromatic ring provided an active site for oxidation. Naphthalene and other polynuclear aromatics were very stable to oxidation. Larsen indicated that the formation of these inhibitors explained the autoretardation phenomena found during his oxygen uptake experiments.

Denison $[6,7]$ demonstrated in a bulk oil system that the natural sulfur compounds present in oil affected the oil's oxidation stability. He found that, after removing natural sulfur compounds, the oil had little resistance to oxidation. Using model compounds, he concluded that compounds such as monosulfides (except diaryl compounds), mercaptans, disulfides, and thiophene reduced oxidation. Tierney [8] in a bulk oil oxidation study found that lubricating oils from mid-continent crudes had high oxidation stability (low oxygen absorption rate) if 0.15 to 0.2 percent sulfur was retained through the oil refining process. Below this concentration level, the oils became increasingly unstable oxidatively. Higher level of sulfur compounds than 0.15 to 0.2 percent in oils again decreased the oxidation stability due to the formation of deleterious sulfur oxidation products. Therefore, the sulfur level should be kept at an optimum level depending on the crude source.

Korcek [9], using a bulk oxidation system, studied the behavior of base oils (used for automotive transmission fluids) at $180^{\circ} \mathrm{C}$. He found that the relative oxidation stability of base oils depended on the sulfur and aromatic contents at a low level of oxidation ( 0.1 moles of oxygen absorbed per liter of oil). This relative value is based on the inhibitor effect of the sulfur and aromatics. However, at a high degree of oxidation ( 0.4 moles of oxygen per 1 iter of oil), the aliphatic content of the base oil became significant. At this point the oxidative behavior of the bulk fluid becomes more important. . Correlation was obtained only after including a paraffinic/naphthenic ratio as a composition parameter. 
Very little work has been published on the effects of the naturally occurring oxygen and nitrogen compounds on the oil's oxidation stability [10]. In general, oxygen and nitrogen content is lower than the sulfur content and more difficult to measure precisely.

In summary, some aromatics and sulfur compounds in virgin base oils as produced appear to inhibit oxidation of oil. Sulfur compounds and polynuclear aromatics, while inhibiting oxidation, tend to form oil insoluble products when oxidation occurs. Saturated chains attached to an aromatic ring provide a point of vulnerability for oxidation at the hydrogen alpha to the aromatic ring. The role of naturally occurring oxygen and nitrogen compounds appears to be that of promoting oxidation, but very little work has been reported.

\subsection{Characteristics of Re-Refined Base 0ils}

Basestocks for re-refined lubricating oils are derived from the reprocessing of used lubricants to remove contaminants, oxidized products, and residual additives. A recent study [11] at NBS has indicated that, in several properties that are considered to influence oil quality, the re-refined base oils show higher values than the virgin base oils. These properties include total acid number, chlorine content, saponification number, bromine content, ash, and carbon residue. The saturated hydrocarbon and aromatic contents of re-refined base oils are comparable to those of virgin base oils. However, the polar content of re-refined oils is higher than that of the virgin base oils $[11]$.

The changes noted in re-refined base oils must be explained by the events that occur in the engine during the use cycle and in the re-refining processing steps. In the first case, the engine provides an environment where oxidation may occur, but the thermal environment is mild enough to preclude extensive hydrocarbon molecular structure changes from thermal or catalytic reactions. If a particular type of hydrocarbon is preferentially oxidized, that type of hydrocarbon would decrease and the more stable hydrocarbon types would increase. The re-refining processes are primarily separation techniques to remove undesirable products acquired through contamination or degradation reactions in the engine. Therefore, during refining, there should be no increase in a hydrocarbon type by addition or formation. The early studies [12] generally confirm that the basic hydrocarbon structures are not altered in the use and/or re-refining processes. The re-rcfined oils have a measurably higher content of polar material [11]. The four sources for additional polar materials over those in the virgin base oil are the use of additive package in the lubricant; the oxidative degradation of the lubricant in the engine; the lubricant-metal interaction to produce corrosion products; and the addition of contaminants from the combustion chamber. The polar content of the used lubricant is much higher than the polar content of the charge stocks from which the base oil is refined. This makes the removal of the polar compounds in the re-refining process more difficult than it is in the refining of the virgin base oil. All of the increases in non-hydrocarbon constituents of the re-refined base oils over those of the virgin base oils are directly related to this increase of polar constituents in used oils.

The basic hydrocarbon types in the re-refined basestocks appear to be the same as those in the virgin stocks. There appear to be no unexpected shifts in concentrations of the major hydrocarbon type constituents.

Sixteen re-refined automotive base oils representing various manufacturing processes and geographic areas were selected for this study. The chemical and physical properties of the oils are summarized in table 1 . As shown, these re-refined base oils have relatively uniform composition with regard to saturates $(72.5-78.4$ percent), and aromatics $(20.6-24.4$ percent). The viscosities of the oils vary from $130 \mathrm{~N}$ to $430 \mathrm{~N}$.

High chlorine content $(0.49-1140 \mathrm{ppm})$ in re-refined oils relative to virgin base oils appears to be a major chemical characteristic of the re-refined base oils. The presence of chlorine may be traced to the lead scavenger used in gasoline, ethylene dichloride, which finds its way into the used oil through fuel dilution and blow-by. Another potential source for chlorine is through used oil contamination by chlorinated solvents, electrical transformer oil (containing polychlorinated biphenyls), and cutting oils (containing chlorinated additives). It should be noted that the two highest chlorine levels in the re-refined oils shown in table 1 were not from currently existing re-refiners, but were included to evaluate the highest range of chlorine in this study.

The saponification numbers and acid numbers shown in table 1 for the re-refined base oils are indicative of the oxygen content in these products. 
Table 1. Analyses of re-refined oils

\begin{tabular}{|c|c|c|c|c|c|c|c|c|c|c|}
\hline \multirow[t]{2}{*}{0 i1 } & \multicolumn{2}{|c|}{ Viscosity } & \multirow{2}{*}{$\begin{array}{l}\text { Avg } \\
\text { Molecular } \\
\text { Weight } \\
\text { g/mole }\end{array}$} & \multicolumn{3}{|c|}{$\begin{array}{c}\text { Hydrocarbon } \\
\text { Type } \\
\text { Analyses }\end{array}$} & \multirow{2}{*}{$\begin{array}{l}\text { Sulfur } \\
\text { Content }\end{array}$} & \multirow{2}{*}{$\begin{array}{c}\text { Total } \\
\text { Acid } \\
\text { Number } \\
\mathrm{mgKOH} / \mathrm{g} \\
\end{array}$} & \multirow{2}{*}{$\begin{array}{c}\begin{array}{c}\text { Total } \\
\text { Nitrogen }\end{array} \\
\text { ppm }\end{array}$} & \multirow{2}{*}{$\begin{array}{r}\begin{array}{r}\text { Chlorine } \\
\text { Content }\end{array} \\
\text { NAA } \\
\text { ppm }\end{array}$} \\
\hline & $\begin{array}{c}c S t \\
\left(40^{\circ} \mathrm{C}\right)\end{array}$ & $\begin{array}{c}\text { SUS } \\
\left(100^{\circ} \mathrm{F}\right)\end{array}$ & & Sat & Aro & Polar & & & & \\
\hline$A$ & 81.9 & 430 & 480 & 73.9 & 23.5 & 2.6 & 0.23 & 0.17 & 47 & 9.2 \\
\hline B & 57.7 & 300 & 482 & 77.6 & 20.0 & 2.4 & 0.12 & 0.076 & 9 & 13 \\
\hline c & 73.5 & 380 & 501 & 75.3 & 22.5 & 2.2 & 0.20 & 0.18 & 18 & 190 \\
\hline 0 & 60.3 & 310 & 488 & 77.6 & 20.7 & 1.7 & 0.19 & 0.14 & 17 & 8.0 \\
\hline$E$ & 48.2 & 250 & 432 & 75.9 & 22.4 & 1.7 & 0.18 & 0.09 & 21 & 6.6 \\
\hline $\mathrm{F}$ & 78.7 & 410 & 516 & 77.5 & 21.1 & 1.4 & 0.14 & 0.102 & 9 & 8.3 \\
\hline G & 66.6 & 340 & 495 & 75.3 & 22.6 & 2.1 & 0.19 & 0.18 & 20 & 13.6 \\
\hline$H$ & 52.7 & 270 & 454 & 78.0 & 20.6 & 1.8 & 0.18 & 0.14 & 13 & 19.4 \\
\hline I & 79.5 & 410 & 515 & 76.9 & 20.9 & 2.2 & 0.17 & 0.27 & 28 & 1140 \\
\hline J & 41.5 & 210 & 433 & 72.5 & 24.1 & 3.4 & 0.25 & 1.69 & 24 & 906 \\
\hline$k$ & 26.6 & 140 & 384 & 78.0 & 20.6 & 1.4 & 0.24 & 0.05 & 64 & 37.8 \\
\hline $\mathrm{L}$ & 62.1 & 320 & 499 & 78.4 & 20.5 & 1.1 & 0.14 & 0.02 & 14 & 29.0 \\
\hline$M$ & 28.8 & 150 & 390 & 75.0 & 22.7 & 2.2 & 0.28 & 0.45 & 74 & 102 \\
\hline$N$ & 66.3 & 340 & 494 & 75.3 & 22.8 & 1.9 & 0.23 & 0.01 & 46 & 7.7 \\
\hline 0 & 37.6 & 190 & 409 & 74.4 & 24.4 & 1.2 & 0.23 & 0.00 & 21 & 4.9 \\
\hline$P$ & 61.3 & 320 & 494 & 75.7 & 23.8 & 0.5 & 0.05 & 0.02 & 20 & 0.49 \\
\hline $\begin{array}{r}\text { min } \\
\text { Range }\end{array}$ & 28.8 & 130 & 409 & 72.5 & 20.6 & 1.1 & 0.05 & 0.00 & 9 & 0.49 \\
\hline $\max$ & 81.9 & 430 & 501 & 78.4 & 24.4 & 3.4 & 0.28 & 0.81 & 64 & 1140 \\
\hline
\end{tabular}

Nitrogen is added to lubricants as oxidation inhibitors and dispersants in the additive package. NO enters the crankcase as part of the blow-by gas and may react with the oil. The nitrogen found in re-refined oils is less than that in the virgin basestocks. The analytical data indicate that the re-refining process is effective in removing nitrogen containing materials from the oil and suggest that the nitrogen left in the re-refined base oil is different from that originally in the virgin stocks.

Large amounts of sulfur are added to the virgin base oil as a part of the additive package. Sulfur also enters the crankcase as blow-by gases from the combustion process with fuels containing sulfur. The sulfur level of the re-refined base oils is slightly higher than that of the virgin stocks. These data indicate that the re-refining process is successful in removing a portion of the sulfur found in the used lubricants. The sulfur present in the virgin stocks and the sulfur present in the re-refined stock show opposite effects on the additive response of the respective virgin and re-refined base oils. This finding, which will be discussed in the following section, indicates clearly that the sulfur-type compounds left in by the two refining processes are quite different. 
Since the contaminant elements of $S, N$, and 0 are the same in virgin and re-refined stocks and many of the simple test methods for measuring the problems caused by these contaminants are the same, more work needs to be done to develop tests to predict significant performance differences if they do in fact exist. This study is designed to provide oxidation data which can then be compared with the amounts of non-hydrocarbon constituents and other simple analytical test data.

\section{Experimental}

A thin-film oxygen uptake test (TFOUT) is used for the oxidation studies of the base oils. The test has been found to correlate with ASTM sequence IIID engine test on IIID reference oils [1,13]. Re-refined base oils are blended with 7 weight percent of a commercial SE/CC additive package that contains antioxidant, antiwear agent, and detergent-dispersant agents. The formulated oils are then mixed with 3 percent of a soluble-metal-catalyst package, 3 percent of a fuel catalyst, and 2 percent of water. The metals, fuel catalyst, and water are used to simulate key chemical environments in an engine. The oxidation test is performed at $160{ }^{\circ} \mathrm{C}$ with $620 \mathrm{KPa}$ of initial oxygen charged.

The oxidation stability of an oil is indicated by the induction time of the oil. The induction time is defined as the time period, in minutes, from the beginning of the test to the time when the bomb pressure begins to decrease due to oxygen absorption by the oil sample.

\section{Results and Discussions}

Oxidation induction times of the 16 re-refined base oi1s, blended with 7 weight percent of a commercial SE/CC additive package, are given in table 2. The induction times of the oils range from 110 to 199 minutes. Since the thin-film oxygen uptake test simulates the chemical environment in the engine, these results should reflect the oxidation stabilities of these oils under engine conditions. Typical data for some re-refined base oils without any additives are shown in table 3 . The induction times of the base oils tested all fall in a narrow range from 12 to 18 minutes. Therefore, the oxidation stability of the re-refined base oils containing the commercial additive package is due primarily to the additive package. A similar study on virgin oil basestocks before and after compounding has also been published [13].

Table 2. Oxidation induction times of re-refined base oils with a $\mathrm{SE} / \mathrm{CC}$ additive package

$$
\begin{array}{ll}
\text { Conditions: } & 1.5 \mathrm{~g} 0 \mathrm{il} \\
& 3 \% \text { Fuel Catalyst } \\
& 3 \% \text { Metal Catalyst } \\
& 160{ }^{\circ} \mathrm{C} \\
& 620.6 \mathrm{KPa} \text { Oxygen ( } 90 \mathrm{psig})
\end{array}
$$

7 wt\% Additive Package

$\underline{0 i 1}$

$A$
$B$
$C$
$D$
$E$
$F$
$G$
$H$
$I$
$J$
$K$
$L$
$M$
$N$
$O$
$P$

\begin{tabular}{c} 
Viscosity \\
SUS $\left(37.78^{\circ} \mathrm{C}\right)$ \\
\hline
\end{tabular}

Oxidation Induction Time, min 
Table 3. Oxidation induction times of typeical re-refined oils without additive package min 18 12 E 14 15 17 15

The relationships between the oxidation times of the formulated re-refined base oils and the concentrations of sulfur, nitrogen, chlorine, polar compounds, aromatics, and paraffins were examined. Since acid number change is associated with oxidation [14], the oxidation of the compounded re-refined basestocks were also compared with the acid number.

Figures 1 through 7 show plots of individual compositional parameters as a function of TFOUT induction time. Included on each plot is the cross correlation coefficient indicating the degree to which the variables are linearly related. Also included on the plots is the $F$ statistic indicating the significance of the regression coefficient. A summary of the linear correlations between oxidation induction times and individual compositional parameter is given in table 4.

The component showing the best correlation with oxidation will be discussed first. The effect of sulfur content on oxidation stability is shown on figure 1 . These data cover a reasonable range of sulfur concentration and show the highest correlation coefficient with TFOUT oxidation induction time. Four of the points on figure 1 that fall well off the curve at $0.25,0.25,0.23$, and 0.17 percent sulfur also show a high value of acid number/and or nitrogen concentration. Both of these factors could contribute to the oxidative behavior. It should be emphasized that the correlation coefficient in this case is negative, indicating that more sulfur results in a reduction of oxidation stability. This information may be compared with comparable data obtained for the virgin base oils in a previous publication [13]. With the virgin basestocks and the same additive package, the sulfur content results in a low correlation coefficient of 0.08 but with a positive slope. These data agree in general with the idea that the sulfur compounds present in many virgin basestocks act as oxidation inhibitors. The primary reason for the low coefficient is probably related to the interaction between the sulfur as a natural inhibitor and the additive package used. It is clear that the sulfur compounds left in the re-refined base oil are different from those in the virgin stocks. Much of the original sulfur in virgin oils would have been chemically reacted in the engine. This sulfur containing reaction products together with sulfur from the additive package, and the blow-by from the combustion products form the total sulfur pool in used oils fed to the re-refiner. It is clear that sulfur in the re-refined base oil should be kept low because it adversely effects oxidation stability. The sulfur content in virgin base oils does not have a significant adverse effect on the oxidation stability [13].

The effect of polar compounds on oxidation stability is shown on figure 2. The polar compounds consist of compounds containing oxygen and nitrogen as well as sulfur. The correlation coefficient of the effect of polar compounds on oxidation stable life is -0.71 indicating a reduction in oxidation stablility with increasing concentration of polar materials. The polar fraction includes the oxygen, sulfur, and nitrogen containing molecules left in the re-refined base oil. The nitrogen and oxygen containing material would also be expected to cause reduced oxidation stability since they represent residual materials from the degraded and contaminated oil. The data on the effect of polar materials on oxidation stable life with the virgin base oils shows a -0.20 correlation coefficient [13]. In the virgin stocks, the change between the effect of sulfur and the polar materials would indicate that the oxygen and nitrogen containing materials have a significant deleterious effect on oxidation which dominates the positive effect of sulfur. In the re-refined base oils, the negative effect of the sulfur on the oxidation is the dominant effect while the oxygen and nitrogen containing materials appear to have a somewhat less negative effect than sulfur. Again, there is some indication that the oxygen and nitrogen containing compounds present in the re-refined base oils are different in structure and effect from those present in the virgin base oil. 


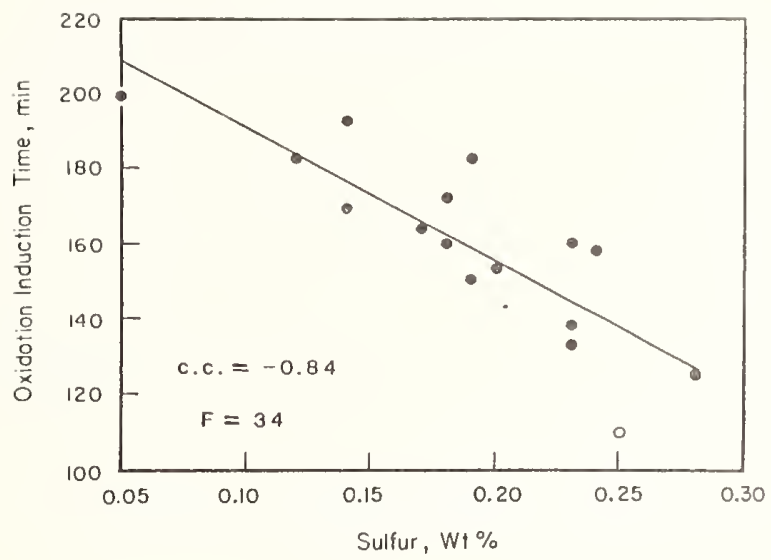

Figure 1. Effect of sulfur compounds on oxidation induction time ( 7 wt\% additives).

Table 4. Summary of correlation between re-refined base oil composition and oxidation induction times

\begin{tabular}{|c|c|c|c|}
\hline Parameter & Correlation Coefficient & $\underline{F}^{a}$ & Tail Significance \\
\hline Saturate & 0.71 & 18 & 0.002 \\
\hline Aromatic & -0.49 & 4 & 0.057 \\
\hline Sulfur & -0.84 & 34 & 0.000 \\
\hline Polars & -0.71 & 14 & 0.002 \\
\hline Total Nitrogen & -0.58 & 7 & 0.018 \\
\hline TAN & -0.63 & 9 & 0.009 \\
\hline Chlorine & -0.34 & 2 & 0.194 \\
\hline Sap. No. & -0.71 & 14 & 0.002 \\
\hline
\end{tabular}

$a_{F}$ statistics.

${ }^{b_{T a i l}}$ Significance $=$ Probability that the correlation is due to pure chance.

The effect of the saturated hydrocarbon portion of the re-refined base oils is shown on figure 3. These data show a 0.71 correlation coefficient indicating that the higher the portion of saturated hydrocarbons in the re-refined base oil, the better the resultant oxidation stability. This result agrees with the previous study [13] on virgin base oils. The correlation coefficient of 0.67 with the virgin base oils is about the same as the 0.71 value determined for the re-refined base oils. The concentration range of percent saturates for the virgin base oils was about 30 percent ( 57 to 87 percent) while the range for the refined stocks was on $7 y$ about 6 percent (72.5 to 78.5 percent). 


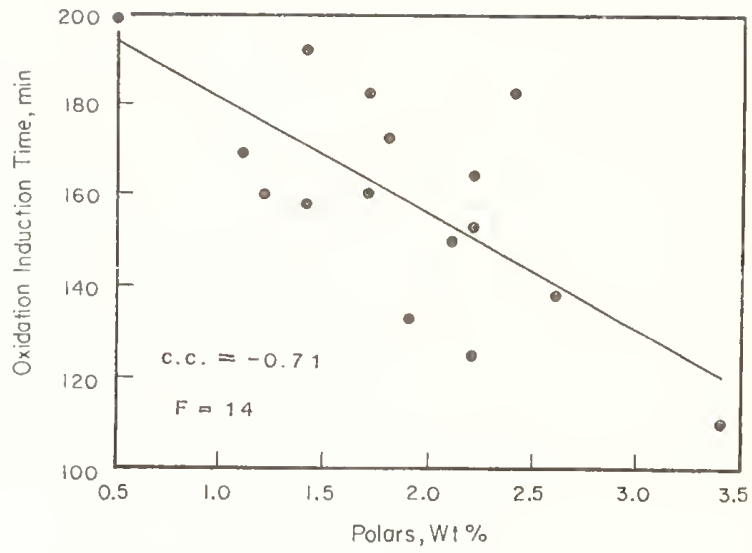

Figure 2. Effect of polar compounds on oxidation induction time (7 wt\% additives).

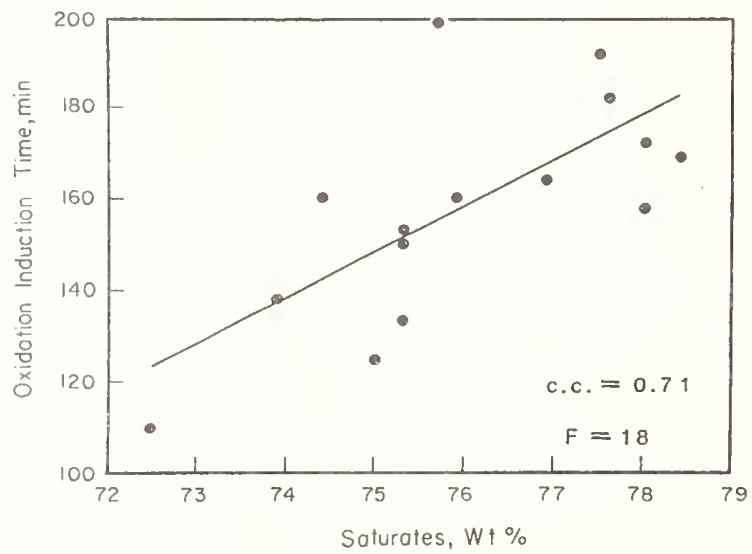

Figure 3. Effect of saturates on oxidation induction time ( 7 wt\% additives).

The effect of aromatic hydrocarbon concentration on the oxidation stable life is shown on figure 4 with a correlation coefficient of -0.49 . With a F statistic of 4 , the correlation is not significant. This compares with a correlation coefficient of -0.65 for the aromatic hydrocarbon concentration as a function of oxidation stable life for the virgin base oils [13]. As was the case with the percent saturates, there is a problem with the 1 imited concentration range of 4.5 percent for the re-refined base oils compared with a range of about 26 percent for the virgin base oils. The general overall trend of oxidation stable life appears to decrease with increasing aromatic content. From the literature result [11] discussed in a previous section of this report, it appears that the polynuclear aromatic concentration is higher in the re-refined base oils than in the virgin stocks. It appears that improved correlation with aromatic content of the oil might depend on better definition of the various types of aromatic compounds present, i.e., mononuclear, binuclear, or polynuclear. 


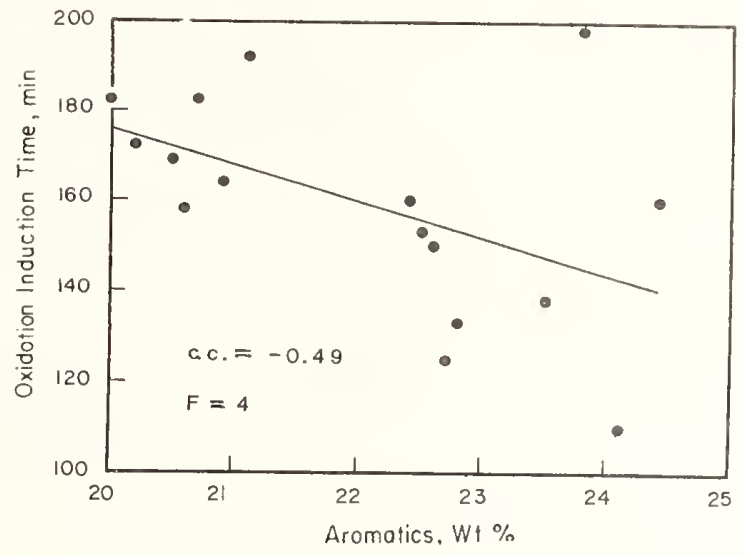

Figure 4. Effect of aromatics on oxidation induction time ( 7 wt\% additives).

The effect of total acid number on oxidation stable 1 ife is shown on figure 5 with a correlation coefficient of -0.63 . Again, with a F statistic of 9 , the correlation is not statisticaliy significant. Overal1, high acid number values appear to cause some loss in stable life. Acidity increase is a commonly used measure of oxidation and a large increase in acid number is indicative of the end of the stable life. Overbasing with additives is an effective way of controlling both oxidation and acidity increase.

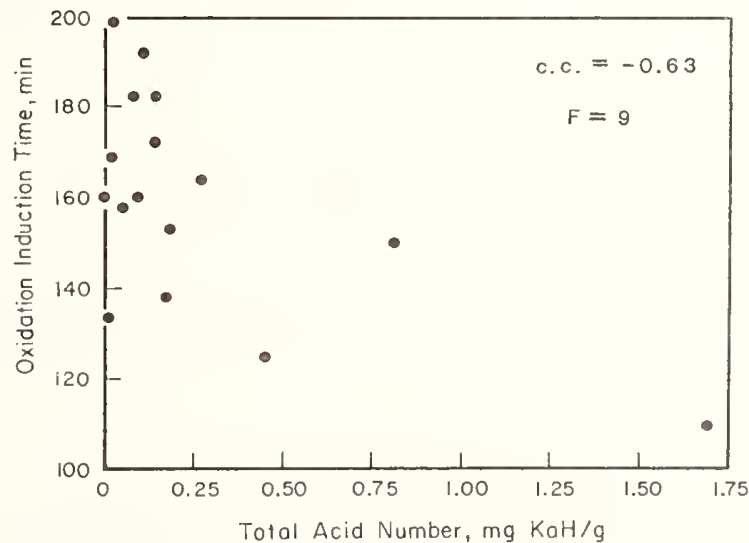

Figure 5. Effect of total acid number on oxidation induction time (7 wt\% additives).

The effect of nitrogen concentration on oxygen stable life is shown on figure 6 with a correlation coefficient of $-\mathbf{0 . 5 8}$. Again, the correlation is not statistically significant. The behavior of sulfur and nitrogen in the re-refined base oils appear to be similar. The nitrogen levels in the re-refined base oils are lower than those in the virgin basestocks. The nitrogen compounds in virgin oils, as well as nitrogen containing oxidation inhibitors added to the oil, tend to become a part of an insoluble reaction product in the early stages of oxidation. The nitrogen content of the re-refined base oils is probably derived from the nitrogen residues either from the additives used for stability and dispersancy or from NO "blow-by" contaminants that reacted with the lubricant. 


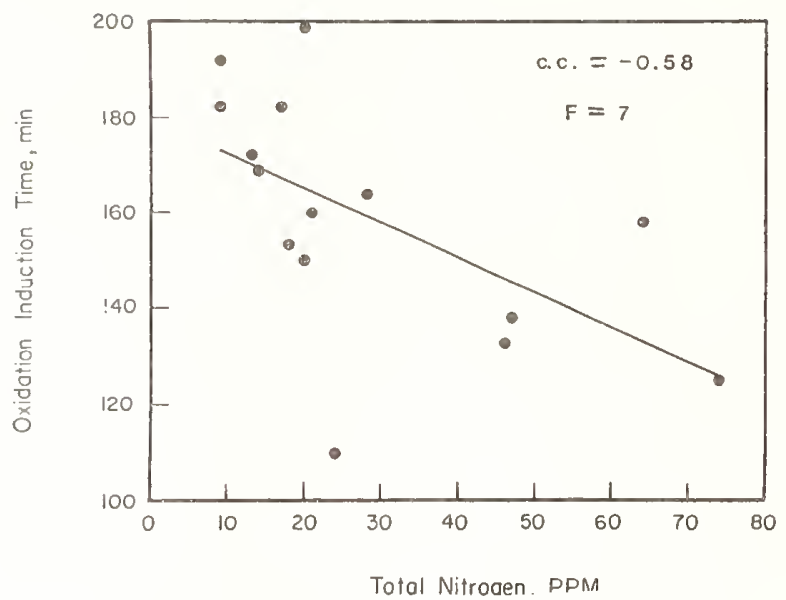

Figure 6. Effect of total nitrogen content on oxidation induction time ( 7 wt\% additives).

The effect of chlorine content on oxidation stability is shown on figure 7 with a correlation coefficient of -0.19 . There is no statistically significant correlation between chlorine and the oxidation stability. The sources of chlorine in re-refined base oils include: the residue from the ethylene dichloride used as a fuel additive; degreasing agents (chlorinated hydrocarbons); and contaminated lubricants containing polychlorinated biphenyl. The chlorine containing contaminants mentioned show a wide range of stability. The wide scatter shown here suggests a wide range in the stability of the chlorine containing compounds.

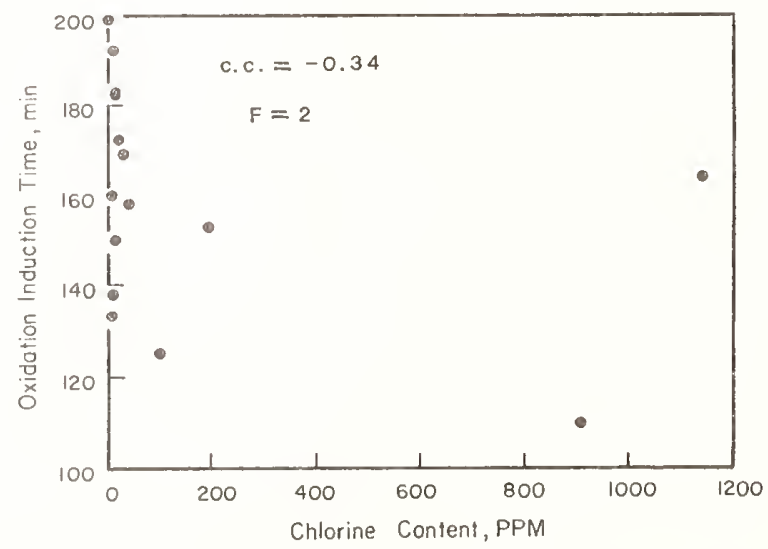

Figure 7. Effect of chlorine content on oxidation induction time (7 wt\% additives).

\subsection{Multi-Parameter Correlation}

An al1 Possible Subsets Regression (PSR) computer statistical program [15] was used to select the best linear regression equation for oxidation stability. The independent variables selected 
were saturate content, sulfur content, total nitrogen number, total acid number, and chlorine content. Aromatic content was not included in the regressor set because of its strong negative correlation with saturate content. Similarly, polar fraction was found to be relatively dependent on the sulfur content.

The program uses the Mallows' C Criterion to choose the "best" among the many possible linear relationships. The $C_{p}$ statistic use ${ }^{f}$ a total squared error choice criterion, incorporating consideration of bias ${ }^{p}$ or offset from the true equation as well as the random error in the response variable [16]. It also ascribes a penalty for adding independent variables into the regression equation. A t-test is applied to check that the coefficients of the prediction equation chosen are significantly different from zero.

The analyses of these data indicate that the induction times linearly correlate best with a two variable regression equation as shown in figure 8 :

Induction Time TFOUT $=A *$ Saturates $-B *$ Sulfur Content $+C$ where $A=5.8, B=277$, and $C=$ intercept as shown in figure 8.

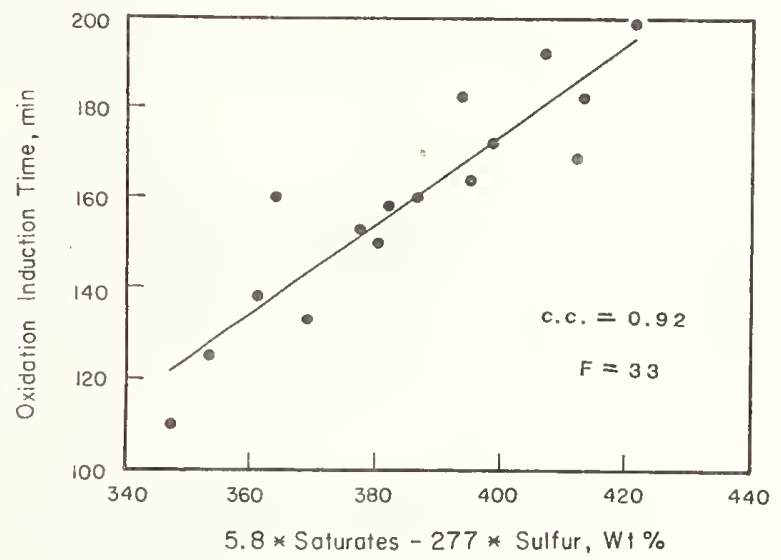

Figure 8. Effect of saturate and sulfur content on oxidation induction time ( 7 wt\% additives).

\section{Conclusions}

The effects of the same "contaminants" on oxidation can be different in virgin and re-refined base oils [13]. The hydrocarbon types show similar effects on oxidation stability in both virgin and re-refined base oils [13].

The oxidation stable life in the thin film oxidation uptake test for re-refined base oils decreases with increasing concentrations of sulfur, polar compounds, aromatic hydrocarbons, total acid number, nitrogen, and chlorine. The oxidation stable life in the TFOUT test for re-refined base oils appears to increase with the concentration of saturated hydrocarbons. The best correlation of oxidation stability with re-refined base oil constituents is obtained with sulfur, and the amount of saturated hydrocarbons. The correlation of oxidation stability with a combination of sulfur content and percent of saturated hydrocarbons shows a significant enhancement over the correlation with either component alone (table 8 ). 
The authors wish to express their thanks to the Recycled 0il Program, Office of Recycled Materials, National Bureau of Standards, for their support of the study. The authors would also like to thank Dr. Stephan Weeks, Inorganic Materials Division and Dr. Stefan Leigh, Statistical Engineering Division, for their comments and discussions.

\section{References}

[1] Ku, C. S.; Hsu, S. M. A thin-film oxygen uptake test for evaluating automotive lube oils. Lubrication Engineering 40, No. 2, 175-83; 1984.

[2] Mayo, F. R. Free-radical autoxidation of hydrocarbons. Acc. Chem. Res. 1, 193-201; 1968.

[3] Cranton, G. E. Composition and oxidation of petroleum fractions. Thermochimica Acta 14, 201-208; 1976

[4] Fenske, M. R.; et al. Dxidation of lubricating oils factors controlling oxidation stability. I\&EC 33, 516-524; 1941.

[5] Larsen, R. G.; Thorpe, R. E; Armfield, F. A. Oxidation characteristics of pure hydrocarbons. I\&EC, 34, 183-193; 1942 .

[6] Denison, G. H. Oxidation of lubricating oils-effect of natural sulfur compounds and of peroxides. I\&EC $36,447-481 ; 1944$.

[7] Denison, G. H; Condit, P. C. Oxidation of Iubricating oils-mechanism of sulfur inhibition. I\&EC $37,1102-1108 ; 1945$.

[8] Tierney, J. W.; Taylor, R. E. Process for maintaining high oxidation stability in refining of lubricating oils. U.S. Patent No. 2,793,982. Assigned to Pure 0 il Company; May 1975.

[9] Korcek, S.; Jensen, R. K. Relation between base oil composition and oxidation stability at increased temperatures. ASLE Transactions 19, 83-94; 1976.

[10] Zuidema, H. H. The performance of lubricating oils. Reinhold Publishing Co., N.Y.; 1959.

[11] Hsu, S. M.; Ku, C.S.; Becker, D. A. Re-refined base oil characterization and consistency monitoring. SAE Paper No. 821240, SP-526, Society of Automotive Engineering 86-105; 1982.

[12] Whisman, M. L.; et al. A summary of composition variations among 30 used lubricating oils selected for seasonal and geo-graphical significance. ERDA-BERC Research Report 7614 ; 1976.

[13] Hsu, S. M.; Ku, C. S.; Lin, R. S. Relationship between lubricating basestock composition and the effects of additives on oxidation stability. SAE Paper 821237, SP-526, Society of Automotive Engineering, 29-56; 1982.

[14] Cartwright, S. J. C.; Carey, L. R. Control of Engine 0 il Acidity. SAE Paper No. 801366, SP-473, Society of Automotive Engineering, 23-34; 1980.

[15] BMDP Statistical Software, Dept. of Biomathematics, University of California, Los Angeles, University of California Press, 1981 edition.

[16] Danie1, C.; Wood, F. Fitting equations to data. John Wiley and Sons, N.Y.; 1971. 
National Bureau of Standards Special Publication 674. Proceedings, Conference on Measurements and Standards for Recycled 0il - IV, held at NBS, Gaithersburg, MD, September 14-16, 1982. (Issued July 1984).

NBS PROVISIONAL TESTS FOR RE-REFINED ENGINE OIL

Donald A. Becker

Stephen Hsu

Recycled 0il Program

National Bureau of Standards

Washington, DC 20234

In Section 383(c) of the Energy Policy and Conservation Act of 1975 (42 U.S.C. 6363(c)), the Congress of the United States stated the following: "As soon as practicable after the date of enactment of this Act, the National Bureau of Standards shall develop test procedures for the determination of substantial equivalency of re-refined or otherwise processed used oil or blend of oil, consisting of such re-refined or otherwise processed used $0 i 1$ and new oil or additives, with new oil for a particular end use." The National Bureau of Standards (NBS) completed test procedures for recycled oil used as burner fuel in 1978 [1] $]^{1}$. This present paper, together with other papers delivered at this conference and in other publications, summarizes NBS efforts to provide a coherent methodology for establishing the substantial equivalency between re-refined and virgin engine crankcase oils. Further, this paper describes a set of proposed provisional test procedures which can be used to establish the consistency of re-refined engine crankcase oil.

There has been sufficient engine and field testing of re-refined engine oils to establish that: (a) a high quality re-refined engine crankcase lubricating oil formulated with an appropriate engine oil additive package can be substantially equivalent to a virgin oil similarly formulated, and (b) that both of these oils will provide adequate performance in most types of automotive service [2-15]. The strategy that NBS has adopted in providing a methodology for establishing this substantial equivalency of re-refined engine oils on a routine basis, first calls for the formulated oil quality to be determined by means of all current industry required performance tests. At present, these tests are primarily engine tests, and include the IID, IIID, VD and L-38 tests for API (American Petroleum Institute) Service Classification SF, with addition of the single cylinder 1-H2 test for the SF/CC classification and the MIL-L-46152B military specification (see section 1.I of this paper and also table 1 ).

Further, after the quality of the formulated re-refined oil has been established through engine testing, the consistency of the re-refined basestock can then be monitored as a function of time through use of the consistency tests described in section 1.2 of this paper. The concept of engine testing for quality, combined with consistency monitoring by means of chemical, physical and bench tests (if needed) has been discussed previously [16-18] and is included in the current military specification for administrative vehicle engine crankcase oil (MIL-L-46152B).

This basic stategy is shown schematically in figures 1 and 2 . Figure 1 is the proposed re-refined oil engine testing procedure. Figure 2 is the proposed re-refined oil consistency monitoring procedure, which can be used to monitor the re-refined oil once quality has been established through appropriate engine testing (and other tests, if required by the desired specification). These procedures will be described in more detail later in this paper.

\section{Proposed Test Procedures For Re-refined $0 i 1$}

\section{1:1. Performance Tests (Qualification Procedure)}

The performance tests as proposed for the use with re-refined oil are identical to those necessary for the various API engine service classifications and the military specifications for engine oil, and are listed in table 1 [19]. The primary performance criteria for these tests are also found in reference [19], and details about the tests can be found in references [20-23].

TFigures in brackets indicate the literature references at the end of this paper. 


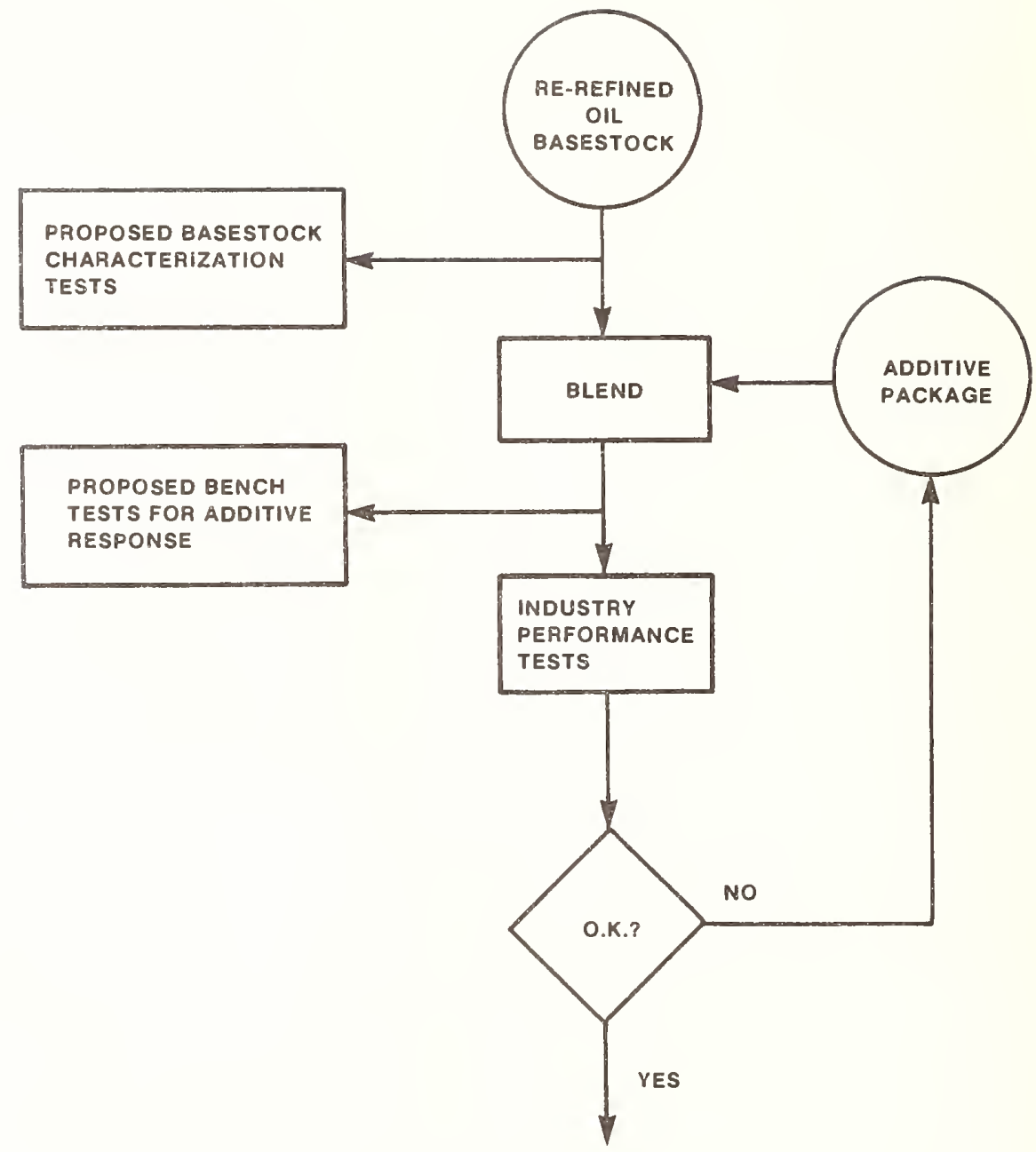

"SUBSTANTIAL EQUIVALENCY"

(Qualified Re-refined Oil)

Figure 1. Proposed re-refined engine oil qualification procedure. 


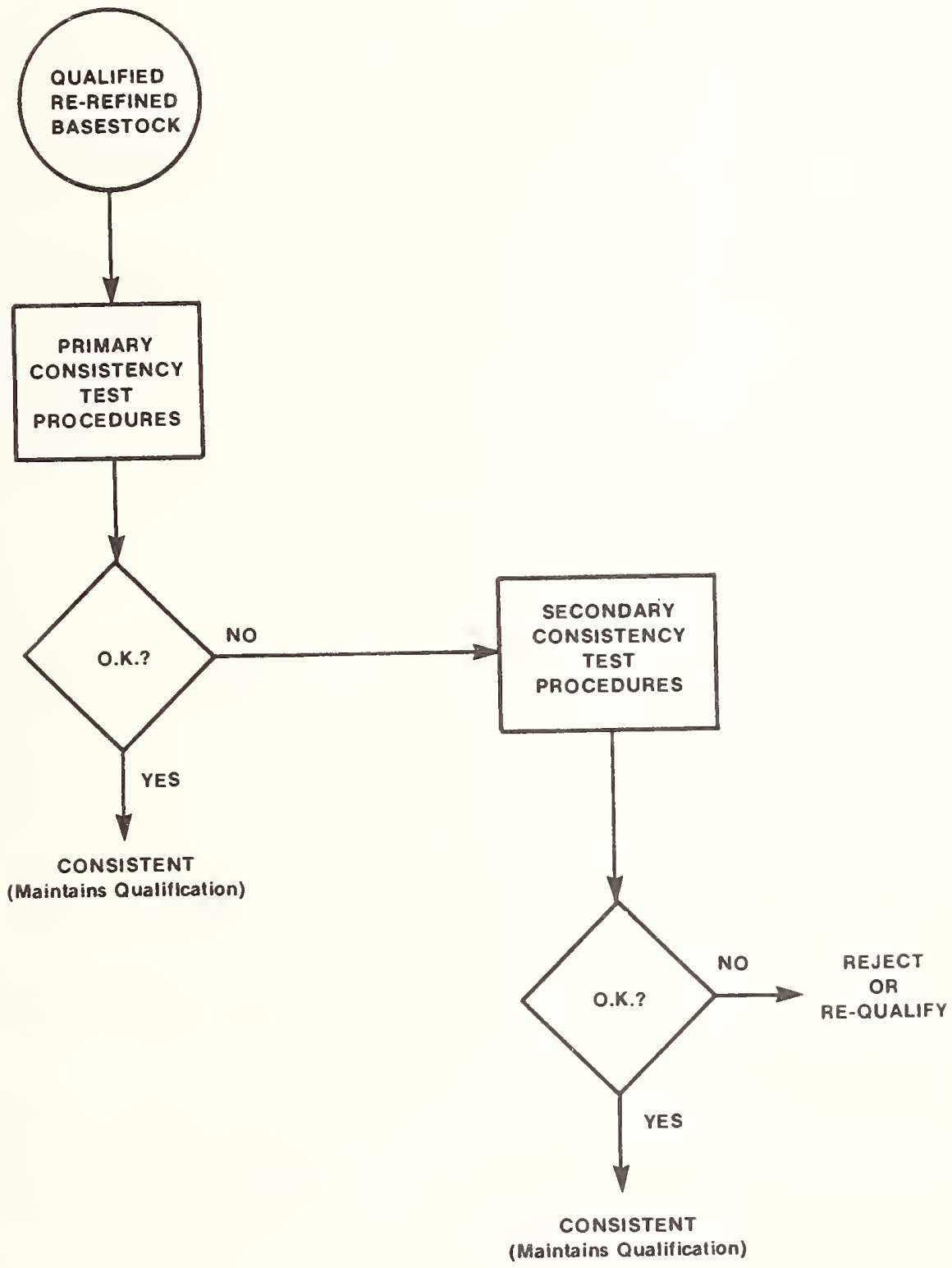

Figure 2. Proposed re-refined engine oil consistency monitoring procedure. 
Table 1. General requirements for API engine service classifications and U.S. military specifications

\begin{tabular}{|c|c|c|}
\hline API Engine Ser & Use & rent Engine Test Requirements ${ }^{a}$ \\
\hline$S A^{b}$ & $\begin{array}{l}\text { Utility Gasoline or } \\
\text { Diesel Engines }\end{array}$ & none \\
\hline$S B^{b}$ & $\begin{array}{l}\text { Minimum Duty } \\
\text { Gasoline Engines }\end{array}$ & $\begin{aligned} & \text { Sequence } \text { IV (obsolete); } \\
& L-38\end{aligned}$ \\
\hline SC & $\begin{array}{l}\text { 1964-1967-Gasoline } \\
\text { Engine Warranty } \\
\text { Service }\end{array}$ & $\begin{array}{c}\text { Sequences IIA, IIIA, IV, } V \text { and } L-1 \\
\text { (a)1 obsolete); } L-38\end{array}$ \\
\hline SD & $\begin{array}{l}\text { 1968-1970 (some 1971) } \\
\text { Gasoline Engine } \\
\text { Warranty Service }\end{array}$ & $\begin{array}{l}\text { Sequences IIB, IIIB, IV, VB, } L-1 \\
\text { or } 1-H, \text { Falcon (all obsolete); } L-38\end{array}$ \\
\hline SE & $\begin{array}{l}1971 \text { (some 1971)- } \\
\text { 1979-Gasoline Engine } \\
\text { Warranty Service }\end{array}$ & Sequences IID, IIID, VD; L-38 \\
\hline SF & $\begin{array}{l}1980 \text { and newer- } \\
\text { Gasoline Engine } \\
\text { Warranty Service }\end{array}$ & Sequences IID, IIID, VD; ${ }^{\mathrm{C}} \mathrm{L}-38$ \\
\hline$C A$ & $\begin{array}{l}\text { Light Duty Diesel } \\
\text { Engine Service }\end{array}$ & $L-1$ (obsolete); L-38 \\
\hline $\mathrm{CB}$ & $\begin{array}{l}\text { Moderate Duty Diesel } \\
\text { Engine Service }\end{array}$ & $L-1$ (obsolete); L-38 \\
\hline $\mathrm{CC}$ & $\begin{array}{l}\text { Moderate Duty Diesel } \\
\text { and Gasol ine Engine } \\
\text { Service; (includes } \\
\text { some current automotive } \\
\text { requirements }\end{array}$ & LTD (obsolete); L-38, IID, 1-H2 \\
\hline $\mathrm{CD}$ & $\begin{array}{l}\text { Severe Duty Diesel } \\
\text { Engine Service }\end{array}$ & $1-G 2, L-38$ \\
\hline MIL-L-46152B ${ }^{d}$ & $\begin{array}{l}\text { Military specifica- } \\
\text { tion for crankcase } \\
\text { lubricants for admin- } \\
\text { istrative vehicles } \\
\text { (approximately equivalent } \\
\text { to a SF/CC lubricant) }\end{array}$ & IID, IIID, IVD, L-38, $1-\mathrm{H} 2$ \\
\hline MIL-L-2104C ${ }^{d}$ & $\begin{array}{l}\text { Military specifi- } \\
\text { cation for crankcase } \\
\text { lubricants for heavy } \\
\text { duty diesel engines } \\
\text { (approximately equiv- } \\
\text { alent to a } S C / C D \text { lubrican }\end{array}$ & IID, IIID, VD, L-38, $1-G 2$ \\
\hline
\end{tabular}

a Obtained from the 1981 SAE Handbook, reference 19.

b old engine service classifications; should not be used in any engine

unless specifically recommended by manufacturer.

C Sequence tests for SF have different performance criteria than for the SE classification.

d Not an API service classification, but a separate military specification. 
Table 2. Proposed provisional test procedures

\begin{tabular}{|c|c|c|c|}
\hline \multirow[b]{2}{*}{ Characterization Tests } & \multirow[b]{2}{*}{ Reference } & \multicolumn{2}{|c|}{ Consistency Tests } \\
\hline & & Primary & Secondary \\
\hline API Gravity (Density) & ASTM D 287 & $x$ & \\
\hline Viscosity Index & ASTM D 2270 & $x$ & \\
\hline Pour Point & ASTM D 97 & $x$ & \\
\hline Flash Point & ASTM D 92 & K & \\
\hline Sulfated Ash & ASTM D $874(M)^{\mathrm{a}}$ & $x$ & \\
\hline Total Acid No. (TAN) & ASTM D 664 & $x$ & \\
\hline Saponification No. (SAP. NO.) & ASTM D 94 & $x$ & \\
\hline Clay-gel Chromatography & ASTM D 2007 & & $x$ \\
\hline Chlorine Analysis & $(37)$ & & $X$ \\
\hline Boiling Point Dist. by GC & ASTM D 2887 & & $x$ \\
\hline Infrared Spectroscopy & b & & $x$ \\
\hline Metals Analysis & $A A, E S$ & & K \\
\hline $\begin{array}{l}\text { Thin Film oxygen Uptake } \\
\text { Test (TFOUT) }\end{array}$ & $(35)$ & $x$ & \\
\hline $\begin{array}{l}\text { Four ball Step Loading } \\
\text { Seizure Test (SLST) }\end{array}$ & $(38)$ & & $x$ \\
\hline Bearing Corrosion Test & $(40)^{C}$ & & $x$ \\
\hline
\end{tabular}

\footnotetext{
as modified; see reference 39 .

b See manufacturers literature for determination of relative carbonyl absorption.

c NBS research on this test is not complete; reference 40 appears to provide a test with appropriate correlation to the $L-38$ engine test.
}

Re-refined oils to be engine tested and monitored for consistency under the proposed system described in sections 1.1 and 1.2 of this paper usually will have been fully formulated with an engine oil crankcase additive package. Initially, it is necessary that the oil be found to provide acceptable performance with that specific additive package and at that specific treat level. The actual engine testing may be obtained through various means (e.g., purchased at commercial test facilities, run by additive supplier as a customer service).

Concurrent with the engine testing, in order to implement the proposed system discussed in this paper, a complete set of base oil characterization tests (as described in section 1.2) must be performed using that same re-refined base oil (and formulated oil, to be used with the bench test for additive response). These steps are necessary in order to determine the baseline data required to monitor the basestock consistency (section 1.2).

Any proposed system of tests, such as that proposed here should be applicable to the complete spectrum of oils available in the marketplace. Thus, the API service classifications include, in additon to the SF category, oils classified as SA, SB, SC, SD, SE, CA, CB, CC and CD. These are described in table 1, along with their current engine test requirements as taken from reference [19]. Where such classifications are accepted by the lubricant industry, it could be expected that re-refined oil would need to meet the same testing requirements as the virgin engine crankcase oils. 
However, for some of the API service classifications, the engine tests are obsolete or no engine tests are required. While these oils may represent only 20 or 30 percent of the engine oil market, nevertheless some oils in these classifications are actively produced and marketed, and are at least tolerated by the lubricant and automotive industries. For example, in the API Service

Classification SA, no engine tests or other tests are currently required for either virgin or re-refined oils. Therefore, in the system proposed in figure 1 as well as in current industry requirements, a re-refined $0 i 1$ would meet the requirements for substantial equivalency to an SA virgin oil with no testing. This situation would exist until such time as testing requirements are instituted by the API for their Service Classification SA.

\subsection{Provisional Tests for Re-Refined Basestock Consistency}

For the past four years, the NBS Recycled 0 il Program has maintained an extensive research effort on lubricating base oil characterization and testing. That research has culminated in a series of publications detailing the evaluation of existing test procedures for use with re-refined oils, the development of new tests where existing tests were not adequate, and the determination of which characteristics of re-refined oil should be tested in order to monitor consistency in a re-refined oil already shown to be capable of producing a high quality crankcase oil.

These publications include many of the papers presented in this conference, as well as a number of additional papers already, published or in the process of publication [24-39]. In particular, the paper entitled, "Re-refined Base $0 i 1$ Characterization and Consistency Monitoring", summarizes the data and findings of this research effort [24]. Subjects covered in reference [24] include: Lubricating base oil quality; re-refined base oil characterization; comparison between re-refined and virgin base oils; physical properties; chemical properties; hydrocarbon structures; effect of viscosity grades on properties; contaminant isolation and analysis; bench performance characterization of oxidation and wear; base oil composition-oxidation performance correlation; and consistency of re-refined base oils.

The data and results presented in these publications are far too extensive to discuss in detail here. But, in summary, the results thus far show that some re-refined base oils, when compared to a set of typical medium to low sulfur crude derived virgin base oils in approximately the same viscosity grades, showed measureable and real differences in some characteristics (e.g., oxyacids, VI improvers, chlorine, additive/wear metals) and in some test results (e.g., total acid number (TAN), saponification number (SAP. NO.). Since the effect of all such variations on performance is still not well understood, a two level testing system is being proposed for the measurement of re-refined oil consistency, as shown in figure 2 and table 2 . Initially, the re-refined base oil undergoing engine testing would be characterized using the following physical/chemical tests: API gravity, viscosity index, pour point, flash point, sulfated ash, TAN, SAP NO., clay-gel chromatography, chlorine, boiling point distribution by gas chromatography, infrared spectroscopy, and metals analysis (e.g., by atomic absorption (AA) or emission spectroscopy (ES)). Further, after formulation with the additive package, the following bench tests would be made: NBS thin film oxygen uptake test (TFOUT), NBS four-ball step loading seizure test (SLST), and a bearing corrosion test.

The resulting data would then be used to establish a set of limits for each of the above tests. Consideration would also be given to the repeatability and reproducibility of these tests as established by ASTM or other means. The actual procedure to be used in obtaining these test limits probably should be developed by joint government/industry/ASTM groups. Once appropriate limits have been established, subsequent production samples of re-refined oils can be tested without additives in seven tests: API gravity, viscosity index, pour point, flash point, suifated ash, TAN and SAP. NO. If the base oil falls within the preset limits, the oil is then blended with the same additive package used to pass the engine tests, and tested in the TFOUT test. If the TFOUT test result meets the preset limits, the re-refined base oil could then be declared consistent.

However, if the re-refined base oil fails to meet the limit(s) in one or more parameters, then one or more additional tests are indicated. The additional tests needed to further evaluate the characteristics for each of the primary tests are listed in table 3 . Results from the additional tests should be compared with the baseline characterization test results of the initial sample. If the results deviate significantly from the preset limit(s), the sample under test should be rejected as inconsistent. The overall characterization scheme is shown in figure 1 and table 2 , and the consistency monitoring scheme in figure 2 and table 2. 
Table 3. Provisional tests for consistency monitoring

\section{Primary Test}

API Gravity ${ }^{a}$

Viscosity index

Pour point

Flash point

Sulfated ash

TAN

Saponification number

NBS TFOUT test
Secondary Test (if the 0il Fails to Meet the Limits of the Primary Test

ASTM D-2007 (saturates)

ASTM D-2007 (polars)

ASTM D-2007 (aromatics and saturates)

Boiling Point Distribution by GC

Metal analysis by AA/ES

Chlorine + bearing corrosion test

+4 ball wear test (SLST)

Chlorine + carbonyl by IR +4 ball wear test (SLST)

Reject

$\overline{\text { a Equivalent }}$ to density/specific gravity.

The success of this proposed consistency monitoring system relies heavily on the reasonableness and technical soundness of the limits derived from the initial characterization testing. One method to obtain data to support development of the test limits would be to use the ASTM/NBS Basestock Consistency Study [29] samples in the various proposed tests. Final results can then be verified by subsequent engine testing.

\section{Conclusion}

The engine oil testing system as proposed in this paper should be capable of providing an adequate methodology for establishing and monitoring the substantial equivalency of re-refined lubricating oil basestocks to be used as engine crankcase oil. Performance tests, including particularly the engine tests, part one of the testing system, are fully fully accepted throughout the lubricant industry as indicators of engine oil quality. Part two of the testing system, the set of provisional physical/chemical/additive response tests to monitor consistency in the re-refined oil basestock, provides a mechnaism to reduce the required level of costly engine testing while maintaining oil quality.

With respect to the set of provisional tests for consistency described in this paper, a period of verification of these tests would appear to be necessary before full implementation should be attempted. That is, a controlled application of these tests to re-refined oils over a period of time is needed to insure that the tests are completely capable of fulfilling the requirements of consistency monitoring. Upon successful completion of such a verification process, the provisional re-refined engine oil testing system as described should be an acceptable procedure for establishing that a re-refined engine oil product is substantially equivalent to a virgin engine oil.

\section{References}

[1] Becker, D. A. and Comeford, J. J. Recycled oil program: phase I-test procedures for recycled oil used as burner fuel. Nat. Bur. Stand. (U.S.) Tech. Note 1130; 1980.

[2] Sam, F. Chevron research's experiences with re-refined oils. Nat. Bur. Stand. (U.S.) Spec. Pub1. 488; 1977. 69 p.

[3] Bowen, T. C. The EPA/DOD investigation of re-refined engine oil. Nat. Bur. Stand. (U.S.) Spec. Publ. 556; 1979. 117 p. 
[4] Utrichson, D. L.; Yake, D. E. Iowa re-refined oil fleet test. Nat. Bur. Stand. (U.S.) Spec. Pub1. 556; 1979. 123 p.

[5] Linnard, R. E. Phillips recycled oil program. Nat. Bur. Stand. (U.S.) Spec. Pub1. 556; 1979. $133 \mathrm{p}$.

[6] Becker, D. A. Testing and use of re-refined engine oils in Europe. Nat. Bur. Stand. (U.S.) Spec. Pub1. 556; 1979. 141 p.

[7] Pedal1, R. F. Field experiences with re-refined motor oil. Nat. Bur. Stand. (U.S.) Spec. Pub1. 556; 1979. $171 \mathrm{p}$.

[8] Armstrong, J. Field test of re-refined automotive engine oil in RCMP vehicles. Nat. Bur. Stand. (U.S.) Spec. Publ. 584; 1980. 55 p.

[9] Linnard, R. E. PROP re-refined oil engine test performance. Nat. Bur. Stand. (U.S.) Spec. Publ. 584; 1980. 69 p.

[10] Reynolds, J. W. ; Whisman, M. L.; Thompson, C. J. Engine sequence testing of re-refined lubricating oils, S.A.E. paper no. 770431; Society of Automotive Engineers; Warrendale, PA; 1977. (Also published as Report No. BERC/OP-76/29).

[11] Anon., private communication (Caterpillar 1-G engine test run on a re-refined oil purchased on open market, provided to D.A. Becker) 1977.

[12] Frame, E. A.; Bowen, Jr., T. C. U.S. Army/Environmental Protection Agency re-refined engine oil program; Standard Engine Dynamometer Tests/Field Evaluation; AFLRL Report No. 98, U.S. Army Mobility Equipment Research and Development Command, Ft. Belvoir, VA 1978.

[13] UTrichson, D. L. and Yake, D. E. Iowa re-refined oil fleet test. Report No. ISU-ERI-AMES-7810. Iowa State University, Ames, Iowa. 1978.

[14] Reynolds, J. W.; Goetzinger, J. W. ; Cotton, F. 0.; Brinkman, D. W. ; Whisman, M. L. A closed-1oop study of the effects of multicycle re-refining of automotive lubricating oil. Report No. DOE/BETC/RI-81/9. Bartlesville Energy Technology Center, Bartlesville, $0 \mathrm{~K} .1982$.

[15] Enslin, C. Quality assurance of re-refined oil: the SABS certification mark scheme. Proceedings of the third international conference on waste $0 i 1$ recovery and reuse; Association of Petroleum Re-refiners; Washington, DC; 1978. 45 p.

[16] Bowen, T. C. An approach to qualification of re-refined engine oil under military specifications. Nat. Bur. Stand. (U.S.) Spec. Pub1. 556; 1979. 175 p.

[17] Winstead, R. L. Monitoring base oil quality and approval procedures. Proceedings of the third international conference on waste $0 i T$ recovery and reuse; Association of Petroleum Re-refiners; Washington, DC. 1978. 73 p.

[18] Bowen, T. C. Status of the MIL-L-46152A engine oil specification. Nat. Bur. Stand. (U.S.) Spec. Pub1. 584; 51 p.

[19] Society of Automotive Engineers (SAE), recommended Practice SAE J 183 (Feb. 1980). Fuel and Lubricants Technical Committee, Society of Automotive Engineers, Warrendale, PA. 1981.

[20] SAE, Recommended Practice SAE J 304. Fuel and Lubricants Technical Committee, SAE, Warrendale, PA. 1981.

[21] American Society for Testing and Materials (ASTM), Standard Technical Publication (STP) 315. ASTM, Philadelphia, PA. 1981.

[22] American Society for Testing and Materials, Standard Technical Publication (STP) 509, ASTM, Philadelphia, PA. 1981.

[23] Federal Test Method Standard 791. U.S. Army MERADCOM, Ft. Belvoir, VA. 1981. 
[24] Hsu, S. M.; Ku, C. S.; and Becker, D. A. Re-refined base oil characterization and consistency monitoring. SAE Paper No. 82-1240. SAE International Fuel and Lubricants Meeting. October 18-21, 1982. Toronto, Ontario, Canada.

[25] Hsu, S. M.; Becker, D. A. Status report on the characterization of re-refined lubricating base oi1. SAE paper 801382.1980.

[26] Hsu, S. M.; et. al Physical and chemical test methods for re-refined base oils, Nat. Bur. Stand. (U.S.) Spec. Pub1., will be issued in 1983.

[27] Hsu, S. M.; Ku, C. S.; and Lin, R. S. Relationship between lubricating basestock composition and the effects of additives on oxidation stability, SAE International Fuels and Lubricants Meeting. Oct. 18-21, 1982. Toronto, Canada, SAE paper 821237.

[28] Hsu, S. M.; Ku, C. S.; and Lin, R. S. Effects of base oil composition on additive response in oxidation stability. Proceedings, Measurement and Standards for Recycled 0i1-IV; Nat. Bur. Stand. (U.S.) Spec. Pub1., 674; 1983.

[29] Becker, D. A. ASTM/NBS basetock consistency study: preliminary compilation of data and results. Recycled $0 i 1$ Program, National Bureau of Standards. Washington, DC. June 1982.

[30] Ku, C. S.; Pei, P.; and Hsu, S. M. Evaluation of ASTM D2007 method for the determination of lubricating oil composition. Proceedings, Measurements and Standards for Recycled 0i1-IV; Nat. Bur. Stand. (U.S.) Spec. Publ. 674; 1983.

[31] Pei, P.; Britton, Jr., J.; and Hsu, S. M. Hydrocarbon type separation of 1ubricating base oil in multigram quantity by preparative HPLC; accepted for publication in J. of Chromatographic Science.

[32] Pei, P.; Hsu, S. M. Re-refined base oil characterization using liquid chromatographic techniques. Proceedings, Measurements and Standards for Recycled 0i1-IV; Nat. Bur. Stand. (U.S.) Spec. Publ. 674; 1983

[33] Hsu, S. M. Review of laboratory bench tests in assessing the performance of automotive crankcase oils. Lubrication Engineering 37 (12) 722; 1981.

[34] Gates, R. S. and Hsu, S. M. Development of a four-ball wear test procedure to evaluate automotive lubricating oi1s. ASLE preprint 82-AM-6A-4; 1982, May 10-13; Cincinnati, 0hio.

[35] Ku, C. S. and Hsu, S. M. A thin-film oxygen uptake test for the evaluation of automotive crankcase lubricants. ASLE preprint 82-LC-1D-1; 1982, 0ct. 5-7; Washington, DC.

[36] Ku, C. S.; Weeks, S. J.; and Hsu, S. M. Thin-film oxidation test: relationship between chemical composition and additive response for re-refined oils. Proceedings, Measurements and Standards for Recycled 0i1-IV; Nat. Bur. Stand. (U.S.) Spec. Pub1. 674; 1983.

[37] Pei, P; Fleming, R.; Hsu, S. M. Test methods for total chlorine in lubricating base oils. Proceedings, Measurements and Standards for Recycled 0i1-IV; Nat. Bur. Stand., (U.S.) Spec. Publ. 674; 1983.

[38] Gates, R. and Hsu, S. M. Development of a step-loading seizure test for engine oil additive response. Proceedings, Measurements and Standards for Recycled 0i1-IV; Nat. Bur. Stand. (U.S.) Spec. Publ. 674; 1983.

[39] Comeford, J. J. and Hsu, S. M. Evaluation of ashing methods for determination of total metal content of lubricating oil base stocks. Proceedings, Measurements and Standards for Recycled 0il-IV; Nat. Bur. Stand. (U.S.) Spec. Pub1. 674; 1983.

[40] Bowden, J. N. and Lestz, S. J. Historical perspective of lubricant deposit evaluations at southwest research institute, Proceedings of the joint conference on measurements and standards for recycled oil/systems performance and durability; Washington, DC. Nat. Bur. Stand. (U.S.) Spec. Pub1. 584; 1980. 80-83. 
NBS.114A (REV. 2-8C)

U.S. DEPT. OF COMM.

BIBLIOGRAPHIC DATA

1. PUBLICATION OR REPORT NO.

SHEET (See instructions)

NBS SP 674

2. Performing Organ. Report Nod 3. Publication Date

4. TITLE AND SUBTITLE

Measurements and Standards for Recycled Oil-IV

Proceedings of a conference held at NBS Sept. 14-16, 1982

5. AUTHOR(S)

Donald A. Becker, Editor

6. PERFORMING ORGANIZATION (If joint or other than NBS, see instructions)

7. Contract/Grant No.

PATIONAL BUREAU OF STANDARDS

DEPARTHEMT OF COMMERCE

WASHIMGTON, D.C. 20234

8. Type of Report \& Period Covered Final

9. SPONSORING ORGANIZATION NAME AND COMPLETE ADDRESS (Street, City, State, ZIP)

The conference was sponsored by NBS, ASTM Technical Division P on Recycled

Petroleum Products, and the Association of Petroleum Re-refiners.

10. SUPPLEMENTARY NOTES

Iibrary of Congress Catalog Card Number: 84-601070

Document describes a computer program; SF-185, FIPS Software Summary, is attached.

11. ABSTRACT (A 200-word or less factual summary of most significant information. If document includes a significant tibliography or literoture survey, mention it here)

This publication is a formal report of the fourth and last Conference on Measurements and Standards for Recycled $0 i 1$, held at the National Bureau of Standards on september 14 to 16, 1982. There were five sessions on specific subject areas, with a total of 28 presentations.

This conference was designed to bring together a11 of the work by NBS and NBS cooperators on the development of test procedures for re-refined lubricating oil. This proceedings contains the entire texts of the various presentations, including figures and tables.

12. KEY WORDS (Six to twelve entries; alphabetical order: capitalize only proper names; and separate key words ty semicolons) engine oil; hydraulic oil; industrial oil; lubricating oil; $0 i 1$ specifications; petroleurn staridards; petroleum test methods; recycled oil, re-refined oil; used oil; waste oi .

13. AVAILABILITY

X] Unlimited

T For Official Distribution. Do Not Release to NTIS

[X] Ordel rom Superintendent of Documents, U.S. Government Printing Office, Washington, D.C. 20402

14. NO. OF

PRINTED PAGES

314

15. Price

Order From National Technical Information Service (NTIS), Springfield, VA, 2216 


\section{NBS TECHNICAL PUBLICATIONS}

\section{PERIODICALS}

JOURNAL OF RESEARCH-The Journal of Research of the National Bureau of Standards reports NBS research and development in those disciplines of the physical and engineering sciences in which the Bureau is active. These include physics, chemistry, engineering, mathematics, and computer sciences. Papers cover a broad range of subjects, with major emphasis on measurement methodology and the basic technology underlying standardization Also included from time to time are survey articles on topics closely related to the Bureau's technical and scientific programs. As a special service to subscribers each issue contains complete citations to all recent Bureau publications in both NBS and nonNBS media. Issued six times a year. Annual subscription: domestic $\$ 18$; foreign $\$ 22.50$. Single copy, $\$ 5.50$ domestic; $\$ 6.90$ foreign.

\section{NONPERIODICALS}

Monographs-Major contributions to the technical literature on various subjects related to the Bureau's scientific and technical activities.

Handbooks-Recommended codes of engineering and industrial practice (including safety codes) developed in cosperation with interested industries, professional organizations, and regulatory bodies.

Special Publications-Include proceedings of conferences sponsored by NBS, NBS annual reports, and other special publications appropriate to this grouping such as wall charts, pocket cards, and bibliographies.

Applied Mathematics Series-Mathematical tables, manuals, and studies of special interest to physicists, engineers, chemists, biologists, mathematicians, computer programmers, and others engaged in scientific and technical work

National Standard Reference Data Series-Provides quantitative data on the physical and chemical properties of materials, compiled from the world's literature and critically evaluated Developed under a worldwide program coordinated by NBS under the authority of the National Standard Data Act (Public Law 90-396).

NOTE: The principal publication outlet for the foregoing data is the Journal of Physical and Chemical Reference Data (JPCRD) published quarterly for NBS by the American Chemical Society (ACS) and the American Institute of Physics (AIP). Subscriptions, reprints, and supplements available from ACS, 1155 Sixteenth St., NW, Washington, DC 20056.
Building Science Series-Disseminates technical information developed at the Bureau on building materials, components, systems, and whole structures. The series presents research results, test methods, and performance criteria related to the structural and environmental functions and the durability and safety characteristics of building elements and systems.

Technical Notes-Studies or reports which are complete in themselves but restrictive in their treatment of a subject. Analogous to monographs but not so comprehensive in scope or definitive in treatment of the subject area. Often serve as a vehicle for final reports of work performed at NBS under the sponsorship of other government agencies.

Voluntary Product Standards-Developed under procedures published by the Department of Commerce in Part 10. Title 15, of the Code of Federal Regulations. The standards establish nationally recognized requirements for products, and provide all concerned interests with a basis for common understanding of the characteristics of the products. NBS administers this program as a supplement to the activities of the private sector standardizing organizations.

Consumer Information Series-Practical information, based on NBS research and experience, covering areas of interest to the consumer. Easily understandable language and illustrations provide useful background knowledge for shopping in today's technological marketplace

Order the above NBS publications from: Superintendent of Documents. Government Printing Office, Washinglon. DC 20402

Order the following NBS publications-FIPS and NBSIR's-from the National Technical Information Service, Springfield, VA 22161.

Federal Information Processing Standards Publications (FIPS PUB)-Publications in this series collectively constitute the Federal Information Processing Standards Register. The Register serves as the official source of information in the Federal Government regarding standards issued by NBS pursuant to the Federal Property and Administrative Services Act of 1949 as amended. Public Law 89-306 (79 Stat. 1127), and as implemented by Ex. ecutive Order II717 (38 FR 12315, dated May 11, 1973) and Part 6 of Title 15 CFR (Code of Federal Regulations).

NBS Interagency Reports (NBSIR)-A special series of interim or final reports on work performed by NBS for outside sponsors (both government and non-government). In general, initial distribution is handled by the sponsor; public distribution is by the National Technical Information Service, Springfield, VA 22161. in paper copy or microfiche form 
U.S. Department of Commerce

National Bureau of Standards

Washington, D.C. 20234

Official Business

Penaliy for Private Use $\$ 300$ 